\title{
Total Synthesis and Biological Evaluation of Tiancimycins A and B, Yangpumicin A, and Related Anthraquinone-Fused Enediyne Antitumor Antibiotics
}

K. C. Nicolaou, ${ }^{*}{ }^{\dagger}$ Dipendu Das, ${ }^{\dagger}, \|$ Yong Lu, ${ }^{\dagger, \|}$ Subhrajit Rout, ${ }^{\dagger, \|}$ Emmanuel N. Pitsinos, ${ }^{\dagger, \S}$ Joseph

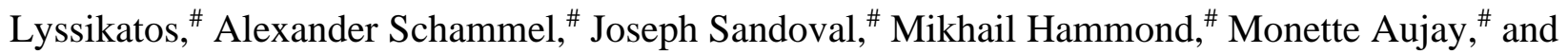
Julia Gavrilyuk ${ }^{\#}$

$\dagger$ Department of Chemistry, BioScience Research Collaborative, Rice University, 6100 Main Street, Houston, Texas 77005, United States of America

${ }^{\diamond}$ Laboratory of Natural Products Synthesis \& Bioorganic Chemistry, Institute of Nanoscience and Nanotechnology, National Centre for Scientific Research "Demokritos", 15310 Agia Paraskevi, Greece

\# AbbVie Stemcentrx, LLC, 450 East Jamie Court, South San Francisco, California 94080, United States of America

E-mail: kcn@ rice.edu

\section{Table of Contents}

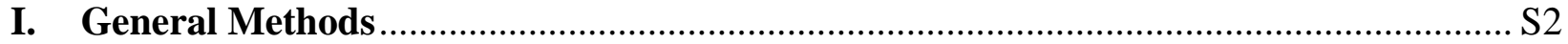

II. Experimental Procedures and Physical Data of Compounds ....................................... S3

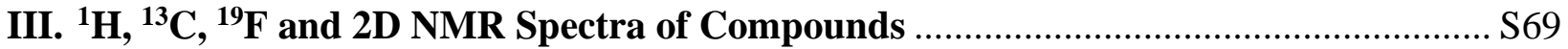

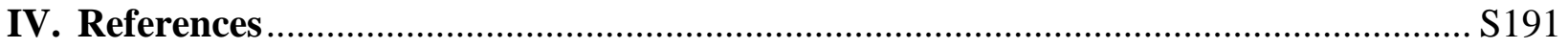




\section{General Methods}

All reactions were carried out under an argon atmosphere with dry solvents under anhydrous conditions, unless otherwise noted. Dry tetrahydrofuran (THF), toluene, benzene, methanol $(\mathrm{MeOH})$, diethyl ether $\left(\mathrm{Et}_{2} \mathrm{O}\right), N, N^{\prime}$-dimethylformamide (DMF), and methylene chloride $\left(\mathrm{CH}_{2} \mathrm{Cl}_{2}\right)$ were obtained by passing commercially available pre-dried, oxygen-free formulations through activated alumina columns. Reagents were purchased at the highest commercial quality and used without further purification, unless otherwise stated.

Reactions were monitored by thin-layer chromatography (TLC) carried out on $0.25 \mathrm{~mm}$ E. Merck silica gel plates (60F-254) and visualized under UV light and/or by appropriate staining method (an ethanolic solution of phosphomolybdic acid or cerium sulphate). Flash column chromatography was performed using E. Merck silica gel (60, particle size $0.04-0.063 \mathrm{~mm}$ ). When stated, silica gel was deactivated by suspending in eluent with $5 \%$ added $\mathrm{H}_{2} \mathrm{O}$ for $12 \mathrm{~h}$ prior to chromatographic purification.

Yields refer to chromatographically and spectroscopically ( ${ }^{1} \mathrm{H}$ NMR) homogeneous materials, unless otherwise stated. NMR spectra were recorded on a Bruker 500 UltraShield and a Bruker DRX-600 instrument and calibrated using residual not perdeuterated solvent $\left(\mathrm{CDCl}_{3}\right.$ : $\delta_{\mathrm{H}}=7.26 \mathrm{ppm}, \delta_{\mathrm{C}}=77.16 \mathrm{ppm} ; \mathrm{CD}_{3} \mathrm{CN}: \delta_{\mathrm{H}}=1.94 \mathrm{ppm}, \delta_{\mathrm{C}}=118.26 \mathrm{ppm} ;$ acetone- $d_{6}: \delta_{\mathrm{H}}=2.05$ ppm, $\delta_{\mathrm{C}}=206.26 \mathrm{ppm} ;$ DMSO- $d_{6}: \delta_{\mathrm{H}}=2.50 \mathrm{ppm}, \delta_{\mathrm{C}}=39.52 \mathrm{ppm} ;$ THF $-d_{8}: \delta_{\mathrm{H}}=3.58 \mathrm{ppm}$, $\delta_{\mathrm{C}}=67.57 \mathrm{ppm} ; \mathrm{CD}_{3} \mathrm{OD}: \delta_{\mathrm{H}}=4.87 \mathrm{ppm}, \delta_{\mathrm{C}}=49.0 \mathrm{ppm}$ ) as an internal reference or using an external reference for ${ }^{19} \mathrm{~F}$ NMR $\left[\delta_{\mathrm{F}}=0\left(\mathrm{CCl}_{3} \mathrm{~F}\right) \mathrm{ppm}\right]$ at $298 \mathrm{~K}$. All ${ }^{13} \mathrm{C}$ NMR spectra were broadband ${ }^{1} \mathrm{H}$ decoupled. The chemical shifts of the peaks of the major rotamer are reported and coupling constants are given in $\mathrm{Hz}$ only for the major rotamer. The following abbreviations were used to designate multiplicities: $\mathrm{s}=$ singlet, $\mathrm{d}=$ doublet, $\mathrm{t}=$ triplet, $\mathrm{q}=$ quartet, $\mathrm{m}=$ multiplet, $\mathrm{br}=$ broad. Infrared (IR) spectra were recorded on a Perkin-Elmer 100 FT-IR spectrometer. High-resolution mass spectra (HRMS) were obtained on an Agilent ESI-TOF (time of flight) mass spectrometer using ESI (electrospray ionization). Optical rotations were recorded on a Schmidt+Haensch Polartronic M100 polarimeter at $589 \mathrm{~nm}$, and are reported in units of $10^{-2}\left(\mathrm{deg} \mathrm{cm}^{2} \mathrm{~g}^{-1}\right)$. 


\section{Experimental Procedures and Physical Data of Compounds}

\section{Total Synthesis of Yangpumicin A (6)}

$N, N$-Diethyl-3-(methoxymethoxy)benzamide (43a): To a stirred solution of amide derivative<smiles>CCNC(=O)c1cccc(OCOC)c1</smiles>
42a ${ }^{1}$ (1.3 g, $6.7 \mathrm{mmol}, 1.0$ equiv) in $\mathrm{CH}_{2} \mathrm{Cl}_{2}(15 \mathrm{~mL})$ was added dropwise $N, N$-diisopropylethylamine $(3.5 \mathrm{~mL}, 20 \mathrm{mmol}, 3.0$ equiv). The reaction mixture was stirred at $23{ }^{\circ} \mathrm{C}$ for $0.5 \mathrm{~h}$. Then, methoxymethyl chloride $(1.5 \mathrm{~mL}, 20 \mathrm{mmol}$, 3.0 equiv) was added dropwise and the resulting mixture was stirred at $23^{\circ} \mathrm{C}$ for $5 \mathrm{~h}$. Subsequently, the reaction mixture was quenched by addition of saturated aq. $\mathrm{NH}_{4} \mathrm{Cl}$ solution $(15 \mathrm{~mL})$ and extracted with $\mathrm{CH}_{2} \mathrm{Cl}_{2}(2 \times 30 \mathrm{~mL})$. The combined organic layers were washed with brine $(25 \mathrm{~mL})$, dried over anhydrous $\mathrm{Na}_{2} \mathrm{SO}_{4}$, and concentrated under reduced pressure. Flash column chromatographic purification (silica gel, hexanes/EtOAc 4:1, v/v to 1:1, $v / v)$ of the crude mixture furnished protected benzamide $43 \mathbf{a}(1.48 \mathrm{~g}, 6.24 \mathrm{mmol}, 93 \%$ yield $)$ as a colorless viscous oil.

43a: $R_{f}=0.48$ (silica gel, 50\% EtOAc in hexanes); FT-IR (film) $v_{\max }$ :2971, 2936, 1626, 1579, 1456, 1437, 1381, 1315, 1289, 1237, 1219, 1150, 1077, 1014, 987, 922, 824, 793, 751, $688 \mathrm{~cm}^{-1}$. ${ }^{1} \mathrm{H} \mathrm{NMR}\left(\mathrm{CDCl}_{3}, 600 \mathrm{MHz}\right): \delta 7.23-7.20(\mathrm{~m}, 1 \mathrm{H}), 6.98-6.96(\mathrm{~m}, 2 \mathrm{H}), 6.91(\mathrm{~d}, J=7.5 \mathrm{~Hz}, 1 \mathrm{H})$, 5.10 (s, 2H), 3.45 (brs, 2 H), 3.39 (s, 3 H), 3.17 (brs, 2H), 1.16 (bs, 3H), 1.03 (brs, $3 \mathrm{H}$ ) ppm;

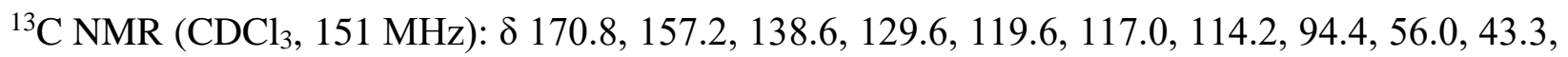
39.2, 14.2, 12.9 ppm; HRMS (ESI-TOF): calcd for $\mathrm{C}_{13} \mathrm{H}_{19} \mathrm{NO}_{3} \mathrm{Na}^{+}[\mathrm{M}+\mathrm{Na}]^{+} 260.1263$, found 260.1262 .

$N, N$-Diethyl-2-formyl-3-(methoxymethoxy)benzamide (44a). To a stirred solution of protected<smiles>CCNC(=O)c1c(C=O)cccc1OCOC</smiles>
benzamide 43a (1.0 g, $4.3 \mathrm{mmol}, 1.0$ equiv) in THF $(13 \mathrm{~mL})$ was added $N, N, N^{\prime}, N^{\prime}$-tetramethylethylenediamine $\left(710 \mu \mathrm{L}, 4.7 \mathrm{mmol}, 1.1\right.$ equiv) at $-78^{\circ} \mathrm{C}$. After $20 \mathrm{~min}, n$-BuLi (2.5 M in hexane, $1.9 \mathrm{~mL}, 4.7 \mathrm{mmol}, 1.1$ equiv) was added dropwise, and the resulting solution was stirred for $40 \mathrm{~min}$ at $-78^{\circ} \mathrm{C}$. Then DMF $(400 \mu \mathrm{L}, 5.2 \mathrm{mmol}, 1.2$ equiv) was added dropwise and the resulting reaction mixture was stirred for $1 \mathrm{~h}$ at $-78^{\circ} \mathrm{C}$. It was then quenched by addition of saturated aqueous $\mathrm{NH}_{4} \mathrm{Cl}$ solution $(10 \mathrm{~mL})$ and extracted with EtOAc $(3 \times 25 \mathrm{~mL})$. The combined organic layers were washed 
with brine $(20 \mathrm{~mL})$, dried over anhydrous $\mathrm{Na}_{2} \mathrm{SO}_{4}$ and concentrated under reduced pressure. The crude product was purified by flash column chromatography (silica gel, hexanes/EtOAc 4:1, $v / v$ to $1: 1, v / v)$ to afford formylated benzamide $44 \mathbf{a}(930 \mathrm{mg}, 3.5 \mathrm{mmol}, 81 \%$ yield) as colorless viscous oil.

44a: $R_{\mathrm{f}}=0.25$ (silica gel, 50\% EtOAc in hexanes); FT-IR (film) v $v_{\max }$ : 2974, 2935, 1691, 1628, 1577, 1482, 1445, 1395, 1288, 1254, 1153, 1086, 1024, 984, 944, 913, 798, $747 \mathrm{~cm}^{-1}$; ${ }^{1} \mathrm{H} \mathrm{NMR}$ $\left(\mathrm{CDCl}_{3}, 600 \mathrm{MHz}\right): \delta 10.49(\mathrm{~s}, 1 \mathrm{H}), 7.50(\mathrm{t}, J=8.0,1 \mathrm{H}), 7.22(\mathrm{~d}, J=8.5 \mathrm{~Hz}, 1 \mathrm{H}), 6.88(\mathrm{~d}$, $J=7.4 \mathrm{~Hz}, 1 \mathrm{H}), 5.29$ (s, 2 H), 3.57 (q, $J=7.1 \mathrm{~Hz}, 2 \mathrm{H}), 3.51(\mathrm{~s}, 3 \mathrm{H}), 3.06(\mathrm{q}, J=7.1 \mathrm{~Hz}, 2 \mathrm{H}), 1.31$ $(\mathrm{t}, J=7.1 \mathrm{~Hz}, 3 \mathrm{H}), 1.00(\mathrm{t}, J=7.1 \mathrm{~Hz}, 3 \mathrm{H}) \mathrm{ppm} ;{ }^{13} \mathrm{C} \mathrm{NMR}\left(\mathrm{CDCl}_{3}, 151 \mathrm{MHz}\right): \delta 189.3,169.8$, 160.1, 139.4, 135.5, 122.0, 120.3, 115.2, 94.9, 57.0, 42.6, 38.8, 13.6, 12.2 ppm; HRMS (ESI-TOF): calcd for $\mathrm{C}_{14} \mathrm{H}_{19} \mathrm{NO}_{4} \mathrm{Na}^{+}[\mathrm{M}+\mathrm{Na}]^{+}$288.1212, found 288.1214 .

7-(Methoxymethoxy)-3-oxo-1,3-dihydro-2-benzofuran-1-carbonitrile (45a): To a stirred solution of formylbenzamide $44 \mathrm{a}\left(610 \mathrm{mg}, 2.3 \mathrm{mmol}, 1.0\right.$ equiv) in $\mathrm{CH}_{2} \mathrm{Cl}_{2}(12 \mathrm{~mL})$
was added $\mathrm{KCN}(30 \mathrm{mg}, 0.46 \mathrm{mmol}, 0.2$ equiv) followed by 18 -crown-6 (120 mg, trap) and the residue was dissolved in glacial AcOH $(4.5 \mathrm{~mL})$ in a well-ventilated fume hood. The mixture was stirred for $13 \mathrm{~h}$ at $23^{\circ} \mathrm{C}$. Then, saturated aqueous $\mathrm{NH}_{4} \mathrm{Cl}$ solution $(80 \mathrm{~mL})$ was added and the mixture was extracted with $\mathrm{CH}_{2} \mathrm{Cl}_{2}(3 \times 100 \mathrm{~mL})$. The combined organic layers were washed with brine $(60 \mathrm{~mL})$, dried over anhydrous $\mathrm{Na}_{2} \mathrm{SO}_{4}$ and concentrated under reduced pressure. Flash column chromatographic purification (silica gel, hexanes/EtOAc 3:1, v/v to 1:1, $v / v$ ) of the crude mixture furnished cyanophthalide $45 \mathbf{a}(470 \mathrm{mg}, 2.2 \mathrm{mmol}, 93 \%$ yield) as white solid.

45a: $\mathrm{R}_{\mathrm{f}}=0.69$ (silica gel, 50\% EtOAc in hexanes); $\mathrm{mp} 123-124{ }^{\circ} \mathrm{C}$ (EtOAc/hexanes); FT-IR (film) $v_{\max }: 2938,2296,1789,1618,1490,1266,1157,1075,1022,992,894,745 \mathrm{~cm}^{-1} ;{ }^{1} \mathrm{H} \mathrm{NMR}\left(\mathrm{CDCl}_{3}\right.$, $600 \mathrm{MHz}): \delta 7.63(\mathrm{t}, J=7.8 \mathrm{~Hz}, 1 \mathrm{H}), 7.59$ (d, $J=7.4 \mathrm{~Hz}, 1 \mathrm{H}), 7.49(\mathrm{dd}, J=8.0,1.0 \mathrm{~Hz}, 1 \mathrm{H}), 6.02$ $(\mathrm{s}, 1 \mathrm{H}), 5.40(\mathrm{~d}, J=7.0 \mathrm{~Hz}, 1 \mathrm{H}), 5.32(\mathrm{~d}, J=7.0 \mathrm{~Hz}, 1 \mathrm{H}), 3.54(\mathrm{~s}, 3 \mathrm{H}) \mathrm{ppm} ;{ }^{13} \mathrm{C} \mathrm{NMR}\left(\mathrm{CDCl}_{3}\right.$, $151 \mathrm{MHz}): \delta 167.6,152.2,133.5,129.9,126.3,120.0,119.1,113.3,94.6,64.3,56.9$ ppm; HRMS (ESI-TOF): calcd for $\mathrm{C}_{11} \mathrm{H}_{9} \mathrm{NO}_{4} \mathrm{Na}^{+}[\mathrm{M}+\mathrm{Na}]^{+} 242.0429$, found 242.0429 . 
(1aS,11S,11aR,18R)-3,18-Dihydroxy-8-(methoxymethoxy)-11a-\{(1R)-1-[(triethylsilyl)oxy]ethyl\}-11,11a-dihydro-4H-11,1a-hept[3] ene[1,5]diynonaphtho[2,3- $h]$ oxireno[c]quinoline4,9(10H)-dione (47a): To a stirred solution of cyanophthalide $45 \mathbf{a}(12 \mathrm{mg}, 54 \mu \mathrm{mol}, 3.0$ equiv;

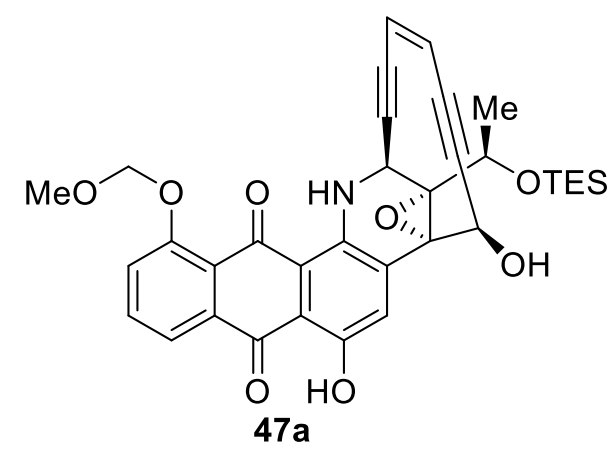

previously dried azeotropically with benzene) in degassed THF $(0.2 \mathrm{~mL})$ was added dropwise at $-78^{\circ} \mathrm{C}$ KHMDS $(1 \mathrm{M}$ in THF, $72 \mu \mathrm{L}, 72 \mu \mathrm{mol}, 4.0$ equiv). The resulting reaction mixture was stirred for $20 \mathrm{~min}$ at the same temperature. A solution of semiquinone aminal (+)-39 ${ }^{1}(10 \mathrm{mg}, 18 \mu \mathrm{mol}$, 1.0 equiv; previously dried azeotropically with benzene) in degassed THF $(0.2 \mathrm{~mL})$ was added dropwise and the mixture was stirred for $5 \mathrm{~min}$ at $-78^{\circ} \mathrm{C}$. Then, the reaction mixture was brought to $0{ }^{\circ} \mathrm{C}$ and stirred for $1.5 \mathrm{~h}$. Then the resulting mixture was stirred at $23^{\circ} \mathrm{C}$ for $2.5 \mathrm{~h}$. The reaction mixture was quenched by addition of $\mathrm{pH} 6.8$ buffer $(5 \mathrm{~mL})$ and extracted with EtOAc $(3 \times 15 \mathrm{~mL})$. The combined organic extracts were dried over anhydrous $\mathrm{Na}_{2} \mathrm{SO}_{4}$ and concentrated under reduced pressure to furnish the impure Alloc-protected anthraquinone as a red solid, which was then dissolved in degassed THF $(0.4 \mathrm{~mL})$ under argon at $0{ }^{\circ} \mathrm{C}$. To this solution was added $\mathrm{Pd}\left(\mathrm{PPh}_{3}\right)_{4}$ ( $1.5 \mathrm{mg}, 13 \mu \mathrm{mol}, 0.07$ equiv) followed by slow addition of morpholine $(4.0 \mu \mathrm{L}, 47 \mu \mathrm{mol}$, 2.6 equiv). The reaction flask was wrapped with aluminium foil, and allowed to stir for $2 \mathrm{~h}$. The cooling bath was removed and the reaction mixture was stirred at $23^{\circ} \mathrm{C}$ for $0.5 \mathrm{~h}$. It was then quenched by addition of $\mathrm{pH} 6.8$ buffer $(5 \mathrm{~mL})$ and extracted with EtOAc $(3 \times 10 \mathrm{~mL})$. The combined organic extracts were washed with saturated aq. $\mathrm{NaHCO}_{3}$ solution $(7 \mathrm{~mL})$, brine $(6 \mathrm{~mL})$, dried over anhydrous $\mathrm{Na}_{2} \mathrm{SO}_{4}$, and concentrated under reduced pressure. The crude residue was purified by preparative thin layer chromatography (hexanes/EtOAc 2:1, v/v) to afford bis-protected anthraquinone 47a (5.4 mg, $9.0 \mu \mathrm{mol}, 49 \%$ yield) as purple solid.

47a: $\mathrm{R}_{\mathrm{f}}=0.24$ (silica gel, $25 \%$ EtOAc in hexanes); $[\alpha]_{\mathrm{D}}^{23}=+7.0(c=0.40$, EtOAc); FT-IR (film) $v_{\max }: 3398,2927,1618,1590,1577,1483,1356,1274,1204,1115,1061,1007,933,784,740$ $\mathrm{cm}^{-1} ;{ }^{1} \mathrm{H}$ NMR $\left(\mathrm{CD}_{3} \mathrm{CN}, 600 \mathrm{MHz}\right): \delta 13.00(\mathrm{~d}, J=1.2 \mathrm{~Hz}, 1 \mathrm{H}), 9.89(\mathrm{~d}, J=4.6 \mathrm{~Hz}, 1 \mathrm{H}), 8.43(\mathrm{~s}$, $1 \mathrm{H}), 8.00-7.98(\mathrm{~m}, 1 \mathrm{H}), 7.71(\mathrm{dt}, J=8.1,3.6 \mathrm{~Hz}, 1 \mathrm{H}), 7.56(\mathrm{ddd}, J=8.4,3.1,1.2 \mathrm{~Hz}), 5.94(\mathrm{~d}$, $J=9.9 \mathrm{~Hz}, 1 \mathrm{H}), 5.87(\mathrm{~d}, J=9.9 \mathrm{~Hz}, 1 \mathrm{H}), 5.32(\mathrm{~s}, 2 \mathrm{H}), 5.11(\mathrm{~d}, J=5.1 \mathrm{~Hz}, 1 \mathrm{H}), 4.96(\mathrm{dd}, J=4.6$, $1.6 \mathrm{~Hz}, 1 \mathrm{H}), 4.55(\mathrm{q}, J=6.3 \mathrm{~Hz}, 1 \mathrm{H}), 4.38(\mathrm{~d}, J=4.9 \mathrm{~Hz}, 1 \mathrm{H}), 3.51(\mathrm{~s}, 3 \mathrm{H}), 1.39(\mathrm{~d}, J=6.3 \mathrm{~Hz}$, $3 \mathrm{H}), 0.99(\mathrm{t}, J=8.0 \mathrm{~Hz}, 9 \mathrm{H}), 0.67(\mathrm{q}, J=7.8 \mathrm{~Hz}, 6 \mathrm{H}) \mathrm{ppm} ;{ }^{13} \mathrm{C} \mathrm{NMR}\left(\mathrm{CD}_{3} \mathrm{CN}, 151 \mathrm{MHz}\right): \delta 188.6$, 
184.7, 158.9, 155.9, 143.9, 136.5, 135.9, 135.2, 129.7, 124.9, 124.8, 124.8, 123.8, 121.2, 114.2, 100.9, 100.4, 100.1, 96.7, 91.5, 88.5, 77.6, 66.9, 65.2, 64.9, 57.0, 44.4, 22.7, 7.3, 5.7 ppm; HRMS (ESI-TOF): calcd for $\mathrm{C}_{34} \mathrm{H}_{35} \mathrm{NO}_{8} \mathrm{SiNa}^{+}[\mathrm{M}+\mathrm{Na}]^{+} 636.2030$, found 636.2022 .

$(1 \mathrm{a} S, 11 S, 11 \mathrm{a} R, 18 R)-3,8,18$-Trihydroxy-11a- $\{(1 R)-1-[($ triethylsilyl)oxy]ethyl $\}-11,11 \mathrm{a}-\mathrm{di}-$ hydro-4H-11,1a-hept[3] ene[1,5]diynonaphtho[2,3-h]oxireno[c]quinoline-4,9(10H)-dione

(48a): To a stirred solution of bis-protected anthraquinone $47 \mathbf{a}(3.9 \mathrm{mg}, 6.4 \mu \mathrm{mol}, 1.0$ equiv) in

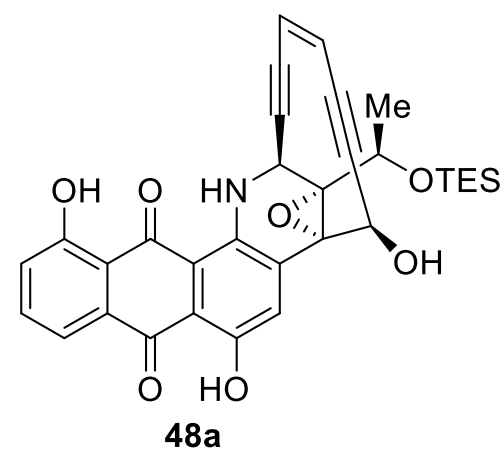
degassed THF $(0.35 \mathrm{~mL})$ was added at $0{ }^{\circ} \mathrm{C}$ and in one portion $\mathrm{MgBr}_{2} \cdot \mathrm{Et}_{2} \mathrm{O}$ (4.6mg, $18 \mu \mathrm{mol}, 3.0$ equiv). The resulting solution was stirred for $3 \mathrm{~h}$ at the same temperature and $15 \mathrm{~min}$ at $23^{\circ} \mathrm{C}$. Then, the reaction mixture was quenched by addition of $\mathrm{pH} 6.8$ buffer $(5 \mathrm{~mL})$ and extracted with EtOAc $(2 \times 10 \mathrm{~mL})$. The combined organic layers were washed with brine $(5 \mathrm{~mL})$, dried over anhydrous $\mathrm{Na}_{2} \mathrm{SO}_{4}$ and concentrated under reduces pressure.

Purification of the so-obtained residue by preparative thin layer chromatography (hexanes/EtOAc $3: 1, v / v)$ afforded TES-protected anthraquinone 48a $(3.2 \mathrm{mg}, 5.6 \mu \mathrm{mol}, 89 \%$ yield) as purple powder.

48a: $\mathrm{R}_{\mathrm{f}}=0.62$ (silica gel, 25\% EtOAc in hexanes); $[\alpha]_{\mathrm{D}}^{23}=+23.7(c=0.30$, EtOAc); FT-IR (film) $v_{\max }: 3442,2952,2925,1598,1490,1466,1368,1288,1222,1204,1175,1118,925,779,737$ $\mathrm{cm}^{-1}$; ${ }^{1} \mathrm{H}$ NMR $\left(\mathrm{CD}_{3} \mathrm{CN}, 600 \mathrm{MHz}\right): \delta 13.36(\mathrm{~s}, 1 \mathrm{H}), 13.01$ (s, $\left.1 \mathrm{H}\right), 9.77$ (brd, $\left.J=4.7 \mathrm{~Hz}, 1 \mathrm{H}\right)$, $8.50(\mathrm{~s}, 1 \mathrm{H}), 7.80-7.77(\mathrm{~m}, 1 \mathrm{H}), 7.68(\mathrm{td}, J=8.0,4.6 \mathrm{~Hz}, 1 \mathrm{H}), 7.29-7.27(\mathrm{~m}, 1 \mathrm{H}), 5.97(\mathrm{~d}$, $J=9.9 \mathrm{~Hz}, 1 \mathrm{H}), 5.91(\mathrm{~d}, J=10.1 \mathrm{~Hz}, 1 \mathrm{H}), 5.12(\mathrm{~d}, J=5.0 \mathrm{~Hz}, 1 \mathrm{H}), 5.00(\mathrm{dd}, J=4.7,1.6 \mathrm{~Hz}, 1 \mathrm{H})$, $4.56(\mathrm{q}, J=6.3 \mathrm{~Hz}, 1 \mathrm{H}), 4.43(\mathrm{~d}, J=4.8 \mathrm{~Hz}, 1 \mathrm{H}), 1.40(\mathrm{~d}, J=6.3 \mathrm{~Hz}, 3 \mathrm{H}), 1.00(\mathrm{t}, J=8.0 \mathrm{~Hz}, 9 \mathrm{H})$, 0.67 (q, $J=7.8 \mathrm{~Hz}, 6 \mathrm{H}) \mathrm{ppm} ;{ }^{13} \mathrm{C} \mathrm{NMR}\left(\mathrm{CD}_{3} \mathrm{CN}, 151 \mathrm{MHz}\right): \delta 189.4,187.8,163.4,157.4,145.5$, 136.9, 136.5, 134.2, 131.9, 125.1, 124.9, 124.1, 119.2, 113.9, 111.8, 100.3, 99.6, 91.5, 88.6, 77.3, 66.8, 65.0, 64.8, 44.5, 22.7, 7.3, $5.7 \mathrm{ppm}$; HRMS (ESI-TOF): calcd for $\mathrm{C}_{32} \mathrm{H}_{31} \mathrm{NO}_{7} \mathrm{SiNa}^{+}[\mathrm{M}+\mathrm{Na}]^{+}$ 592.1767 , found 592.1759 . 
$(1 \mathrm{a} S, 11 S, 11 \mathrm{a} R, 18 R)-3,8,18$-Trihydroxy-11a-[(1R)-1-hydroxyethyl]-11,11a-dihydro-4H11,1a-hept[3]ene[1,5]diynonaphtho[2,3-h] oxireno[c]quinoline-4,9(10H)-dione (Yangpumicin A, 6): To a stirred solution of TES-protected anthraquinone $48 \mathbf{a}(2.9 \mathrm{mg}, 5.0 \mu \mathrm{mmol}$,

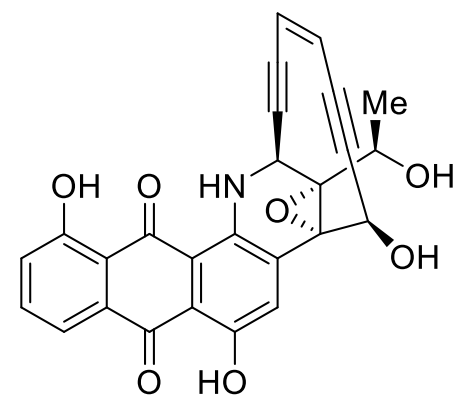

Yangpumicin A (6) 1.0 equiv $)$ in degassed THF $(0.6 \mathrm{~mL})$ at $0{ }^{\circ} \mathrm{C}$ was added a solution of $3 \mathrm{HF} \cdot \mathrm{Et}_{3} \mathrm{~N} / \mathrm{THF}(210 \mu \mathrm{L}, 1: 1, v / v)$. The sealed reaction flask was removed from the cooling bath, wrapped with aluminium foil, and stirred at ambient temperature for $1 \mathrm{~h}$. The reaction mixture was partitioned between EtOAc $(10 \mathrm{~mL})$ and saturated aq. $\mathrm{NaHCO}_{3}$ solution $(4 \mathrm{~mL})$. The organic layer was washed with brine $(5 \mathrm{~mL})$, dried over anhydrous $\mathrm{Na}_{2} \mathrm{SO}_{4}$, and concentrated under reduced pressure. Purification of the so-obtained residue by preparative thin layer chromatography (hexanes/EtOAc 1:1, v/v) provided yangpumicin A $(6 ; 2.0 \mathrm{mg}, 4.4 \mu \mathrm{mol}, 6 \%$ yield) as purple powder.

6: $\mathrm{R}_{\mathrm{f}}=0.26$ (silica gel, $50 \%$ EtOAc in hexanes); $[\alpha]_{\mathrm{D}}^{23}=+2800\left(c=0.001, \mathrm{CH}_{3} \mathrm{OH}\right)$; FT-IR (film) $v_{\max }: 3393,2923,2852,1598,1560,1489,1368,1287,1264,1222,1202,1176,1106,906,793$, $749 \mathrm{~cm}^{-1}$; HRMS (ESI-TOF): calcd for $\mathrm{C}_{26} \mathrm{H}_{17} \mathrm{NO}_{7} \mathrm{Na}^{+}[\mathrm{M}+\mathrm{Na}]^{+} 478.0903$, found 478.0895 .

The following table presents ${ }^{1} \mathrm{H}$ and ${ }^{13} \mathrm{C}$ NMR data recorded for synthetic yangpumicin $\mathrm{A}[(+)-6]$ in acetone- $d_{6}$ (at $600 \mathrm{MHz}$ for ${ }^{1} \mathrm{H}$ and $151 \mathrm{MHz}$ for ${ }^{13} \mathrm{C}$ nuclei, respectively) alongside the corresponding data that have been reported for the isolated natural product in acetone- $d_{6}$ (at 700 $\mathrm{MHz}$ for ${ }^{1} \mathrm{H}$ and $175 \mathrm{MHz}$ for ${ }^{13} \mathrm{C}$ nuclei, respectively). ${ }^{2}$ 
Table S1. Comparison of ${ }^{1} \mathrm{H}$ and ${ }^{13} \mathrm{C}$ NMR of natural and synthetic yangpumicin A (6).

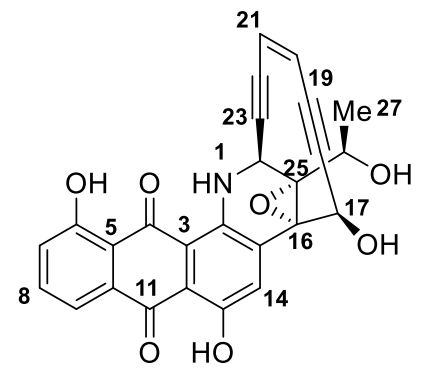

\begin{tabular}{|c|c|c|c|c|}
\hline \multirow{2}{*}{ Position } & \multicolumn{2}{|l|}{ Natural } & \multicolumn{2}{|c|}{ Synthetic (this work) } \\
\hline & $\delta{ }^{1} \mathrm{H}$ (mult., $J$ in $\mathrm{Hz}$ ) & $\delta^{13} \mathrm{C}$ & $\delta{ }^{1} \mathrm{H}$ (mult., $J$ in $\mathrm{Hz}$ ) & $\delta^{13} \mathrm{C}$ \\
\hline 1 & 10.28 (brs) & & 9.98 (brs) & \\
\hline 2 & & 144.6 & & 144.9 \\
\hline 3 & & 112.8 & & 112.5 \\
\hline 4 & & 191.4 & & 188.0 \\
\hline 5 & & $\mid 116.1$ & & 117.3 \\
\hline 6 & & 162.2 & & 162.5 \\
\hline 7 & $7.30(\mathrm{dd}, 7.7,1.4)$ & 122.5 & $7.31(\mathrm{~d}, J=8.0)$ & 123.2 \\
\hline 8 & $7.83(\mathrm{t}, 7.7)$ & 137.1 & $7.76(\mathrm{t}, J=7.9)$ & 136.0 \\
\hline 9 & $7.85(\mathrm{dd}, 7.7,1.4)$ & 118.7 & $7.83(\mathrm{~d}, J=7.2)$ & 118.1 \\
\hline 10 & & 135.3 & & 133.2 \\
\hline 11 & & 182.2 & & 186.6 \\
\hline 12 & & 112.8 & & 112.5 \\
\hline 13 & & 156.0 & & 156.7 \\
\hline 14 & $8.73(\mathrm{~s})$ & 130.6 & $8.74(\mathrm{~s})$ & 131.5 \\
\hline 15 & & 136.5 & & 135.7 \\
\hline 16 & & 64.3 & & 64.3 \\
\hline 17 & $5.46(\mathrm{~d}, 4.9)$ & 63.9 & $5.44(\mathrm{~s})$ & 63.9 \\
\hline 18 & & 99.9 & & 99.9 \\
\hline 19 & & 90.1 & & 90.1 \\
\hline 20 & $6.04(\mathrm{dd}, 9.8,0.7)$ & 123.1 & $6.04(\mathrm{~d}, J=10.0)$ & 123.5 \\
\hline 21 & $5.96(\mathrm{dt}, 9.8,1.4)$ & 123.5 & $5.95(\mathrm{~d}, J=10.0)$ & 124.0 \\
\hline 22 & & 87.8 & & 87.8 \\
\hline 23 & & 98.4 & & 98.2 \\
\hline 24 & $5.14(\mathrm{dd}, 4.2,1.4)$ & 43.5 & $5.17(\mathrm{~d}, J=3.9)$ & 43.7 \\
\hline 25 & & 76.0 & & 75.9 \\
\hline 26 & $4.55(\mathrm{qd}, 6.3,4.9)$ & 64.9 & $4.57-4.50(\mathrm{~m})$ & 64.8 \\
\hline 27 & $1.46(\mathrm{~d}, 6.3)$ & 20.8 & $1.44(\mathrm{~d}, J=6.4)$ & 20.8 \\
\hline $6-\mathrm{OH}$ & 12.19 (brs) & & $13.08(\mathrm{~s})$ & \\
\hline $13-\mathrm{OH}$ & 12.59 (brs) & & $13.52(\mathrm{~s})$ & \\
\hline $17-\mathrm{OH}$ & & & $5.81(\mathrm{~s})$ & \\
\hline $26-\mathrm{OH}$ & & & $4.31(\mathrm{~d}, J=4.1)$ & \\
\hline
\end{tabular}




\section{Total Synthesis of Tiancimycin A (7)}

$\boldsymbol{N}, \boldsymbol{N}$-Diethyl-3-hydroxy-4-methoxybenzamide (42b). To acid 41b (3.0 g, 18 mmol, 1.0 equiv) in<smiles>CCNC(=O)c1ccc(OC)c(O)c1</smiles>
$\mathrm{CH}_{2} \mathrm{Cl}_{2}(55 \mathrm{~mL})$ was added DMF $(70 \mathrm{~mL})$ and the mixture was cooled to $0^{\circ} \mathrm{C}$. Oxalyl chloride $(3.9 \mathrm{~mL}, 46 \mathrm{mmol}, 2.6$ equiv) was then added dropwise. The solution was allowed to warm to $23^{\circ} \mathrm{C}$ and stirred for $12 \mathrm{~h}$. $\mathrm{CH}_{2} \mathrm{Cl}_{2}$ was evaporated and toluene $(40 \mathrm{~mL})$ was added and the mixture was evaporated to dryness. This process was repeated twice for complete removal of excess oxalyl chloride. The resulting residue was re-dissolved in THF $(30 \mathrm{~mL})$ and cooled to $0{ }^{\circ} \mathrm{C}$. Diethylamine $(8.6 \mathrm{~mL}, 83 \mathrm{mmol}, 4.6$ equiv) was added dropwise and the resulting mixture was allowed to warm to $23^{\circ} \mathrm{C}$ and stirred a further $12 \mathrm{~h}$. Then, the resulting mixture was quenched by addition of aqueous $\mathrm{HCl}$ solution $(1 \mathrm{M})$ to adjust the $\mathrm{pH}$ to lower than 3 . The mixture was extracted with $\mathrm{CH}_{2} \mathrm{Cl}_{2}$ $(3 \times 150 \mathrm{~mL})$. The combined organic layers were washed with brine $(130 \mathrm{~mL})$, dried over anhydrous $\mathrm{Na}_{2} \mathrm{SO}_{4}$, and concentrated under reduced pressure. The resulting crude product was purified by flash column chromatography (silica gel, hexanes/EtOAc 4:1, v/v to 1:1, v/v) to afford benzamide 42b (3.7 g, $17 \mathrm{mmol}, 93 \%$ yield) as colorless crystals.

42b: $R_{\mathrm{f}}=0.35$ (silica gel, 60\% EtOAc in hexanes); mp 91-93 ${ }^{\circ} \mathrm{C}$ (EtOAc/hexanes); FT-IR (film) $v_{\max }=2974,2938,2841,1610,1582,1426,1381,1242,1216,1168,1130,1097,1025,953,879$, 844, $753 \mathrm{~cm}^{-1} ;{ }^{1} \mathrm{H} \mathrm{NMR}\left(\mathrm{CDCl}_{3}, 600 \mathrm{MHz}\right): \delta 6.95(\mathrm{~d}, J=1.9 \mathrm{~Hz}, 1 \mathrm{H}), 6.88(\mathrm{dd}, J=8.2,1.7 \mathrm{~Hz}$, $1 \mathrm{H}), 6.82(\mathrm{~d}, J=8.2 \mathrm{~Hz}, 1 \mathrm{H}), 3.88(\mathrm{~s}, 3 \mathrm{H}), 3.60-3.19(\mathrm{~m}, 4 \mathrm{H}), 1.16(\mathrm{bs}, 6 \mathrm{H}) \mathrm{ppm} ;{ }^{13} \mathrm{C}$ NMR $\left(\mathrm{CDCl}_{3}, 151 \mathrm{MHz}\right): \delta 171.2,147.7,145.7,130.3,118.8,113.4,110.6,56.1,43.6,39.5,14.1,13.0$ ppm; HRMS (ESI-TOF): calcd for $\mathrm{C}_{12} \mathrm{H}_{17} \mathrm{NO}_{3} \mathrm{Na}^{+}[\mathrm{M}+\mathrm{Na}]^{+} 246.1106$, found 246.1110.

$N, N$-Diethyl-4-methoxy-3-(methoxymethoxy)benzamide (43b). To a stirred solution of<smiles>CCNC(=O)c1ccc(OC)c(OCOC)c1</smiles>
benzamide derivative $\mathbf{4 2 b}\left(2.0 \mathrm{~g}, 9.0 \mathrm{mmol}, 1.0\right.$ equiv) in $\mathrm{CH}_{2} \mathrm{Cl}_{2}(30 \mathrm{~mL})$ was added dropwise $N, N$-diisopropylethylamine $(4.7 \mathrm{~mL}, 27 \mathrm{mmol}$, 3.0 equiv). The reaction mixture was stirred at $23^{\circ} \mathrm{C}$ for $0.5 \mathrm{~h}$. Then, methoxymethyl chloride $(2.0 \mathrm{~mL}, 27 \mathrm{mmol}, 3.0$ equiv) was added dropwise and the resulting mixture was stirred at $23^{\circ} \mathrm{C}$ for $2 \mathrm{~h}$. Then, it was quenched by addition of saturated aq. $\mathrm{NaHSO}_{4}$ solution $(23 \mathrm{~mL})$ and extracted with $\mathrm{CH}_{2} \mathrm{Cl}_{2}(2 \times 75 \mathrm{~mL})$. The combined organic layers were washed with brine $(40 \mathrm{~mL})$, dried over anhydrous $\mathrm{Na}_{2} \mathrm{SO}_{4}$, and 
concentrated under reduced pressure. Flash column chromatographic purification (silica gel, hexanes/EtOAc 7:3, $v / v$ to 2:3, v/v) of the crude mixture provided protected benzamide $43 \mathbf{b}$ ( $2.3 \mathrm{~g}$, $8.8 \mathrm{mmol}, 98 \%$ yield) as a colorless viscous oil.

43b: $R_{\mathrm{f}}=0.30$ (silica gel, 60\% EtOAc in hexanes); FT-IR (film) $v_{\max }$ : 2972, 2936, 2839, 1625, 1582, 1514, 1456, 1429, 1381, 1291, 1254, 1153, 1133, 1075, 986, 922, 816, $750 \mathrm{~cm}^{-1} ;{ }^{1} \mathrm{H}$ NMR $\left(\mathrm{CDCl}_{3}, 600 \mathrm{MHz}\right): \delta 7.22(\mathrm{~s}, 1 \mathrm{H}), 7.05(\mathrm{~d}, J=8.2 \mathrm{~Hz}, 1 \mathrm{H}), 6.89(\mathrm{~d}, J=8.2 \mathrm{~Hz}, 1 \mathrm{H}), 5.23(\mathrm{~s}, 2 \mathrm{H})$, 3.89 (s, 3H), 3.50-3.27(m, 7 H), 1.18 (s, 6H) ppm; ${ }^{13} \mathrm{C}$ NMR (151 MHz, $\left.\mathrm{CDCl}_{3}\right): \delta 170.9,150.6$, 146.2, 129.9, 121.1, 115.2, 111.5, 95.6, 56.2, 56.0, 43.5, 39.6, 14.1, 13.0 ppm; HRMS (ESI-TOF): calcd for $\mathrm{C}_{14} \mathrm{H}_{21} \mathrm{NO}_{4} \mathrm{Na}^{+}[\mathrm{M}+\mathrm{Na}]^{+} 290.1368$, found 290.1370 .

$N, N$-Diethyl-2-formyl-4-methoxy-3-(methoxymethoxy)benzamide (44b). To a stirred solution (4bb) of benzamide $43 \mathrm{~b}$ ( $1.77 \mathrm{~g}, 6.62 \mathrm{mmol}, 1.0$ equiv) in THF $(25 \mathrm{~mL})$ was added $N, N, N^{\prime}, N^{\prime}$-tetramethylethylenediamine $(1.09 \mathrm{~mL}, 7.28 \mathrm{mmol}, 1.1$ equiv) at $-78^{\circ} \mathrm{C}$. After $20 \mathrm{~min}, n$-BuLi $(2.5 \mathrm{M}$ in hexane, $2.91 \mathrm{~mL}, 7.28 \mathrm{mmol}$, 1.1 equiv) was added dropwise and the resulting solution was stirred for $40 \mathrm{~min}$ at $-78^{\circ} \mathrm{C}$. Then DMF $(614 \mu \mathrm{L}, 7.94 \mathrm{mmol}, 1.2$ equiv) was added dropwise and the resulting reaction mixture was stirred for $40 \mathrm{~min}$ at $-78^{\circ} \mathrm{C}$. The reaction mixture was then quenched by addition of saturated aqueous $\mathrm{NH}_{4} \mathrm{Cl}$ solution $(35 \mathrm{~mL})$ and extracted with EtOAc $(3 \times 60 \mathrm{~mL})$. The combined organic layers were washed with brine $(40 \mathrm{~mL})$, dried over anhydrous $\mathrm{Na}_{2} \mathrm{SO}_{4}$ and concentrated under reduced pressure. The crude product was purified by flash column chromatography (silica gel, hexanes/EtOAc 9:1, v/v to 2:3, v/v) to afford the formylated benzamide $\mathbf{4 4 b}$ (1.66 g, $5.62 \mathrm{mmol}, 85 \%$ yield) as a light-yellow viscous oil.

44b: $R_{\mathrm{f}}=0.26$ (silica gel, 60\% EtOAc in hexanes); FT-IR (film) $v_{\max }$ : 2973, 2936, 1692, 1626, 1571, 1457, 1432, 1378, 1285, 1263, 1234, 1157, 1064, 1022, 976, 931, 876, 821, $792 \mathrm{~cm}^{-1}$; ${ }^{1} \mathrm{H} \mathrm{NMR}\left(\mathrm{CDCl}_{3}, 600 \mathrm{MHz},\right): \delta 10.47(\mathrm{~s}, 1 \mathrm{H}), 7.11(\mathrm{~d}, J=8.3 \mathrm{~Hz}, 1 \mathrm{H}), 6.98(\mathrm{~d}, J=8.3 \mathrm{~Hz}, 1 \mathrm{H})$, $5.22(\mathrm{~s}, 2 \mathrm{H}), 3.89$ (s, 3H), 3.56 (q, J=7.2 Hz, 2 H), 3.55 (s, 3 H), 3.06 (q, J=7.1 Hz, 2 H), 1.30 (t, $J=7.1 \mathrm{~Hz}, 3 \mathrm{H}), 1.00$ (t, $J=7.1 \mathrm{~Hz}, 3 \mathrm{H}) \mathrm{ppm} ;{ }^{13} \mathrm{C} \mathrm{NMR}\left(\mathrm{CDCl}_{3}, 151 \mathrm{MHz}\right): \delta 190.1,169.7,152.6$, 149.6, 130.5, 127.5, 122.9, 117.2, 99.7, 58.1, 56.3, 42.7, 38.9, 13.7, 12.3 ppm; HRMS (ESI-TOF): calcd for $\mathrm{C}_{15} \mathrm{H}_{21} \mathrm{NO}_{5} \mathrm{Na}^{+}[\mathrm{M}+\mathrm{Na}]^{+} 318.1317$, found 318.1317 . 
6-Methoxy-7-(methoxymethoxy)-3-oxo-1,3-dihydro-2-benzofuran-1-carbonitrile (45b): To a<smiles>COCOc1c(OC)ccc2c1C(C#N)OC2=O</smiles>
stirred solution of formylbenzamide $44 \mathrm{~b}(402 \mathrm{mg}, 1.36 \mathrm{mmol}, 1.0$ equiv) in $\mathrm{CH}_{2} \mathrm{Cl}_{2}(7.0 \mathrm{~mL})$ was added $\mathrm{KCN}(17.6 \mathrm{mg}, 0.272 \mathrm{mmol}, 0.2$ equiv) followed by 18 -crown-6 (71.4 mg, $0.272 \mathrm{mmol}, 0.2$ equiv). After $15 \mathrm{~min}$, TMSCN $(221 \mu \mathrm{L}, 1.77 \mathrm{mmol}, 1.3$ equiv) was added dropwise and the solution was stirred for $5 \mathrm{~h}$ at $0{ }^{\circ} \mathrm{C}$. The solvent and excess TMSCN were removed under reduced pressure (CAUTION: use efficient cooling trap) and the residue was dissolved in glacial $\mathrm{AcOH}(2.5 \mathrm{~mL})$ in a well-ventilated fume hood. The mixture was stirred for $16 \mathrm{~h}$ at $23^{\circ} \mathrm{C}$. Then, aqueous saturated $\mathrm{NH}_{4} \mathrm{Cl}$ solution $(40 \mathrm{~mL})$ was added and the mixture was extracted with $\mathrm{CH}_{2} \mathrm{Cl}_{2}$ $(3 \times 60 \mathrm{~mL})$. The combined organic layers were washed with brine $(40 \mathrm{~mL})$, dried over anhydrous $\mathrm{Na}_{2} \mathrm{SO}_{4}$, and concentrated under reduced pressure. Flash column chromatographic purification ( silica gel, hexanes/EtOAc 3:2, $v / v$ to $2: 3, v / v$ ) of the crude mixture furnished cyanophthalide $\mathbf{4 5 b}$ (331 mg, $1.33 \mathrm{mmol}, 97 \%$ yield) as white solid.

45b: $\mathrm{R}_{\mathrm{f}}=0.55$ (silica gel, 60\% EtOAc in hexanes); $\mathrm{mp} 134-135^{\circ} \mathrm{C}$ (EtOAc/hexanes); FT-IR (film) $v_{\max }: 2942,2296,1791,1611,1502,1343,1272,1255,1161,1061,1021,987,911,873,759 \mathrm{~cm}^{-1}$; ${ }^{1} \mathrm{H}$ NMR $\left(\mathrm{CDCl}_{3}, 600 \mathrm{MHz}\right): \delta 7.70(\mathrm{~d}, J=8.3 \mathrm{~Hz}, 1 \mathrm{H}), 7.20(\mathrm{~d}, J=8.3 \mathrm{~Hz}, 1 \mathrm{H}), 6.08(\mathrm{~s}, 1 \mathrm{H}), 5.28$ $(\mathrm{d}, J=6.2 \mathrm{~Hz}, 1 \mathrm{H}), 5.23(\mathrm{~d}, J=6.2 \mathrm{~Hz}, 1 \mathrm{H}), 3.99(\mathrm{~s}, 3 \mathrm{H}), 3.64(\mathrm{~s}, 3 \mathrm{H}) \mathrm{ppm} ;{ }^{13} \mathrm{C} \mathrm{NMR}\left(\mathrm{CDCl}_{3}\right.$, $151 \mathrm{MHz}): \delta 167.3,157.6,141.1,134.8,123.2,117.3,115.9,113.8,99.0,64.1,58.0,56.9$ ppm; HRMS (ESI-TOF): calcd for $\mathrm{C}_{12} \mathrm{H}_{11} \mathrm{NO}_{5} \mathrm{Na}^{+}[\mathrm{M}+\mathrm{Na}]^{+} 272.0535$, found 272.0536.

$(1 \mathrm{a} S, 11 S, 11 \mathrm{a} R, 18 R)-3,18-D i h y d r o x y-7-m e t h o x y-8-($ methoxymethoxy $)-11 \mathrm{a}-\{(1 R)-1-[($ triethylsilyl)oxy]ethyl \}-11,11a-dihydro-4H-11,1a-hept[3]ene[1,5]diynonaphtho[2,3$\boldsymbol{h}]$ oxireno[ $[c]$ quinoline-4,9(10H)-dione $(\mathbf{4 7 b})$ : To a stirred solution of cyanophthalide $\mathbf{4 5 b}$

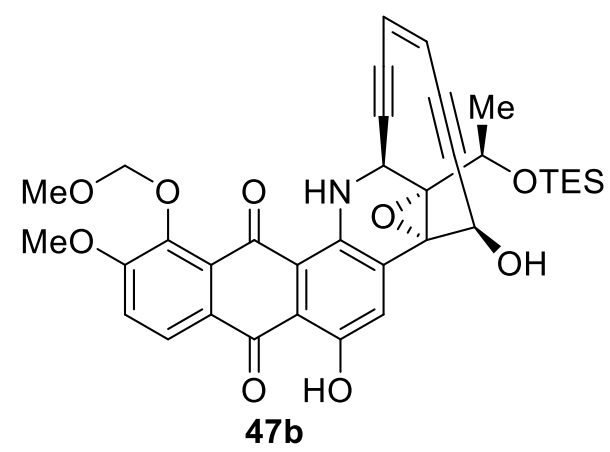

added dropwise and the mixture was stirred for $15 \mathrm{~min}$ at $-78^{\circ} \mathrm{C}$. Then, the reaction mixture was 
brought to $0{ }^{\circ} \mathrm{C}$ and stirred for additional $2 \mathrm{~h}$. The reaction mixture was quenched by addition of pH 6.8 buffer $(7 \mathrm{~mL})$ and extracted with EtOAc $(3 \times 20 \mathrm{~mL})$. The combined organic extracts were dried over anhydrous $\mathrm{Na}_{2} \mathrm{SO}_{4}$ and concentrated under reduced pressure to furnish the impure Alloc-protected anthraquinone as a red solid, which was then dissolved in degassed THF $(0.8 \mathrm{~mL})$ under argon at $0{ }^{\circ} \mathrm{C}$. To this solution was added $\mathrm{Pd}\left(\mathrm{PPh}_{3}\right)_{4}(2.2 \mathrm{mg}, 1.9 \mu \mathrm{mol}, 0.07$ equiv) followed by slow addition of morpholine $(6.0 \mu \mathrm{L}, 73 \mu \mathrm{mol}, 3.0$ equiv). The reaction flask was wrapped with aluminium foil, and the mixture was allowed to stir for $2 \mathrm{~h}$. Then the cooling bath was removed and the resulting mixture was stirred at $23^{\circ} \mathrm{C}$ for $20 \mathrm{~min}$. It was then quenched by addition of $\mathrm{pH}$ 6.8 buffer $(7 \mathrm{~mL})$ and extracted with EtOAc $(3 \times 10 \mathrm{~mL})$. The organic extracts were washed with saturated aq. $\mathrm{NaHCO}_{3}$ solution $(8 \mathrm{~mL})$, brine $(8 \mathrm{~mL})$, dried over anhydrous $\mathrm{Na}_{2} \mathrm{SO}_{4}$, and concentrated under reduced pressure. The crude residue was purified by preparative thin layer chromatography (hexanes/EtOAc 3:2, v/v) to afford bis-protected anthraquinone $47 \mathbf{b}(11 \mathrm{mg}$, $17 \mu \mathrm{mol}, 59 \%$ yield) as purple solid.

47b: $R_{\mathrm{f}}=0.42$ (silica gel, 35\% EtOAc in hexanes); $[\alpha]_{\mathrm{D}}^{23}=+227.5(c=0.08$, EtOAc); FT-IR (film) $v_{\max }: 3415,2922,2297,1716,1622,1570,1465,1367,1270,1233,1053,936,749 \mathrm{~cm}^{-1}$; ${ }^{1} \mathrm{H}$ NMR $\left(\mathrm{CD}_{3} \mathrm{CN}, 600 \mathrm{MHz}\right): \delta 13.15(\mathrm{~s}, 1 \mathrm{H}), 9.83(\mathrm{~d}, J=4.5 \mathrm{~Hz}, 1 \mathrm{H}), 8.41(\mathrm{~s}, 1 \mathrm{H}), 8.11(\mathrm{~d}, J=8.7 \mathrm{~Hz}$, $1 \mathrm{H}), 7.37(\mathrm{~d}, J=8.7 \mathrm{~Hz}, 1 \mathrm{H}), 5.94(\mathrm{~d}, J=9.9 \mathrm{~Hz}, 1 \mathrm{H}), 5.88(\mathrm{~d}, J=10.0 \mathrm{~Hz}, 1 \mathrm{H}), 5.14(\mathrm{~d}, J=5.8 \mathrm{~Hz}$, $1 \mathrm{H}), 5.11-5.10(\mathrm{~m}, 2 \mathrm{H}), 4.94(\mathrm{dd}, J=4.5,1.6 \mathrm{~Hz}, 1 \mathrm{H}), 4.54(\mathrm{q}, J=6.3 \mathrm{~Hz}, 1 \mathrm{H}), 4.38(\mathrm{~d}, J=4.9 \mathrm{~Hz}$, $1 \mathrm{H}), 3.96$ (s, $3 \mathrm{H}), 3.58$ (s, $3 \mathrm{H}), 1.38(\mathrm{~d}, J=6.3 \mathrm{~Hz}, 3 \mathrm{H}), 0.99$ (t, $J=8.0 \mathrm{~Hz}, 9 \mathrm{H}), 0.66$ (q, $J=7.8 \mathrm{~Hz}$, $6 \mathrm{H}) \mathrm{ppm} ;{ }^{13} \mathrm{C} \mathrm{NMR}\left(\mathrm{CD}_{3} \mathrm{CN}, 151 \mathrm{MHz}\right): \delta 187.7,184.8,160.6,155.7,147.5,144.1,135.7,130.1$, 128.7, 127.4, 125.5, 124.9, 123.8, 117.2, 114.3, 114.0, 100.9, 100.4, 100.0, 91.4, 88.5, 77.6, 66.9, 65.1, 64.9, 58.0, 57.2, 44.4, 22.7, 7.3, 5.7 ppm; HRMS (ESI-TOF): calcd for $\mathrm{C}_{35} \mathrm{H}_{37} \mathrm{NO}_{9} \mathrm{SiNa}^{+}$ $[\mathrm{M}+\mathrm{Na}]^{+}$666.2135, found 666.2123 .

\section{$(1 \mathrm{a} S, 11 S, 11 \mathrm{a} R, 18 R)-3,8,18$-Trihydroxy-7-methoxy-11a-\{(1R)-1-[(triethylsilyl)oxy]ethyl $\}$ -} 11,11a-dihydro-4H-11,1a-hept[3] ene[1,5]diynonaphtho[2,3-h] oxireno[c]quinoline-4,9(10H)dione (48b): To a stirred solution of bis-protected anthraquinone 47b (7.8 mg, $12 \mu \mathrm{mol}, 1.0$ equiv) in degassed THF $(0.7 \mathrm{~mL})$ was added at $0^{\circ} \mathrm{C}$ and in one portion $\mathrm{MgBr}_{2} \cdot \mathrm{Et}_{2} \mathrm{O}(9.3 \mathrm{mg}, 36 \mu \mathrm{mol}$, 3.0 equiv). The resulting mixture was stirred for $1.5 \mathrm{~h}$ at the same temperature and $15 \mathrm{~min}$ at $23^{\circ} \mathrm{C}$. Then, the reaction mixture was quenched by addition of $\mathrm{pH} 6.8$ buffer $(6 \mathrm{~mL})$ and extracted with 


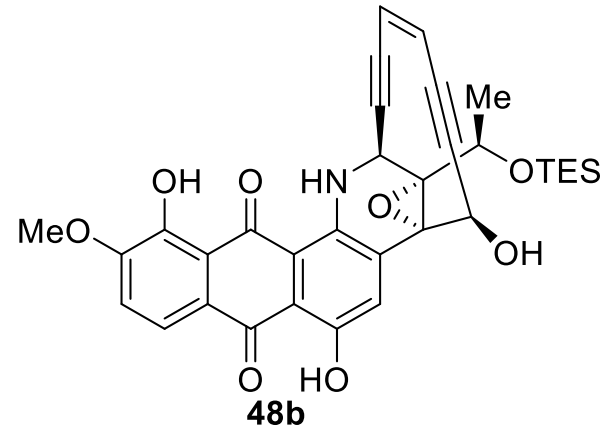

EtOAc $(3 \times 10 \mathrm{~mL})$. The combined organic layers were washed with brine $(8 \mathrm{~mL})$, dried over anhydrous $\mathrm{Na}_{2} \mathrm{SO}_{4}$ and concentrated under reduces pressure. Purification of the soobtained residue by preparative thin layer chromatography (hexanes/EtOAc 3:2) afforded TES-protected anthraquinone $48 \mathrm{~b}(6.3 \mathrm{mg}, 10 \mu \mathrm{mol}, 88 \%$ yield $)$ as purple solid.

48b: $\mathrm{R}_{\mathrm{f}}=0.62$ (silica gel, 35\% EtOAc in hexanes); $[\alpha]_{\mathrm{D}}^{23}=+113.3\left(c=0.09\right.$, EtOAc); FT-IR (film) $v_{\max }: 3477,2924,2299$, 1598, 1455, 1373, 1270, 1234, 1203, 1114, 1062, 1032, 783, $739 \mathrm{~cm}^{-1}$; ${ }^{1} \mathrm{H}$ NMR (CD $\left.{ }_{3} \mathrm{CN}, 600 \mathrm{MHz}\right): \delta 13.48$ (s, $\left.1 \mathrm{H}\right)$, $13.30(\mathrm{~s}, 1 \mathrm{H}), 9.70(\mathrm{~d}, J=4.6 \mathrm{~Hz}, 1 \mathrm{H}), 8.46(\mathrm{~s}, 1 \mathrm{H}), 7.74(\mathrm{~d}, J=8.5 \mathrm{~Hz}, 1 \mathrm{H}), 7.22(\mathrm{~d}, J=8.5 \mathrm{~Hz}$, $1 \mathrm{H}), 5.97(\mathrm{~d}, J=10.0 \mathrm{~Hz}, 1 \mathrm{H}), 5.91(\mathrm{~d}, J=9.9 \mathrm{~Hz}, 1 \mathrm{H}), 5.11(\mathrm{~d}, J=4.6 \mathrm{~Hz}, 1 \mathrm{H}), 4.99(\mathrm{dd}, J=4.7$, $1.7 \mathrm{~Hz}, 1 \mathrm{H}), 4.56(\mathrm{q}, J=6.3 \mathrm{~Hz}, 1 \mathrm{H}), 4.42$ (d, $J=4.8 \mathrm{~Hz}, 1 \mathrm{H}), 3.94$ (s, 3 H), 1.39 (d, $J=6.3 \mathrm{~Hz}$, $3 \mathrm{H}), 0.99(\mathrm{t}, J=8.0 \mathrm{~Hz}, 9 \mathrm{H}), 0.67(\mathrm{q}, J=7.9 \mathrm{~Hz}, 6 \mathrm{H}) \mathrm{ppm} ;{ }^{13} \mathrm{C} \mathrm{NMR}\left(\mathrm{CD}_{3} \mathrm{CN}, 151 \mathrm{MHz}\right): \delta 189.7$, 186.9, 157.0, 155.3, 153.5, 145.4, 135.6, 132.0, 125.6, 124.9, 124.0, 120.7, 116.7, 113.9, 112.3, 100.3, 99.6, 91.4, 88.6, 77.4, 66.8, 65.0, 64.8, 57.0, 44.5, 22.7, 7.3, 5.7 ppm; HRMS (ESI-TOF): calcd for $\mathrm{C}_{33} \mathrm{H}_{33} \mathrm{NO}_{8} \mathrm{SiNa}^{+}[\mathrm{M}+\mathrm{Na}]^{+}$622.1873, found 622.1863 .

$(1 \mathrm{a} S, 11 S, 11 \mathrm{a} R, 18 R)-3,8,18$-Trihydroxy-11a-[(1R)-1-hydroxyethyl]-7-methoxy-11,11a-dihydro-4H-11,1a-hept[3]ene[1,5]diynonaphtho[2,3-h]oxireno[c]quinoline-4,9(10H)-dione

(Tiancimycin A, 7): To a stirred solution of TES-protected anthraquinone $\mathbf{4 8 b}(5.0 \mathrm{mg}, 8.3 \mu \mathrm{mol}$,

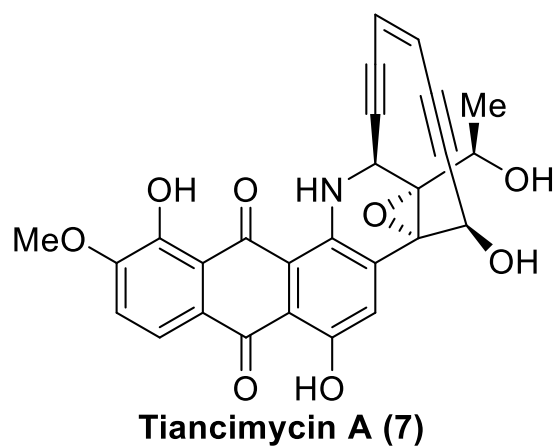
1.0 equiv) in degassed THF $(1 \mathrm{~mL})$ at $0{ }^{\circ} \mathrm{C}$ was added a solution of $3 \mathrm{HF} \cdot \mathrm{Et}_{3} \mathrm{~N} / \mathrm{THF}(400 \mu \mathrm{L}, 1: 1, v / v)$. The sealed reaction flask was removed from the cooling bath, wrapped with aluminium foil, and the mixture was stirred at $23{ }^{\circ} \mathrm{C}$ for $1 \mathrm{~h}$. The reaction mixture was partitioned between EtOAc $(12 \mathrm{~mL})$ and saturated aq. $\mathrm{NaHCO}_{3}$ solution $(5 \mathrm{~mL})$. The organic layer was washed with brine $(6 \mathrm{~mL})$, dried over anhydrous $\mathrm{Na}_{2} \mathrm{SO}_{4}$, and concentrated under reduced pressure. Purification of the so-obtained residue by preparative thin layer chromatography (hexanes/EtOAc 2:3, v/v) provided tiancimycin A (7, $3.9 \mathrm{mg}, 8.0 \mu \mathrm{mol}, 97 \%$ yield) as purple powder. 
7: $\mathrm{R}_{\mathrm{f}}=0.26$ (silica gel, 50\% EtOAc in hexanes); $[\alpha]_{\mathrm{D}}^{23}=+2700\left(c=0.001, \mathrm{CH}_{3} \mathrm{OH}\right)$; FT-IR (film) $v_{\max }: 3265,2923,2851,2103,1726,1598,1453,1374,1270,1237,1200,1132,1060,813 \mathrm{~cm}^{-1}$; HRMS (ESI-TOF): calcd for $\mathrm{C}_{27} \mathrm{H}_{19} \mathrm{NO}_{8} \mathrm{Na}^{+}[\mathrm{M}+\mathrm{Na}]^{+}$508.1008, found 508.1003.

The following table presents ${ }^{1} \mathrm{H}$ and ${ }^{13} \mathrm{C}$ NMR data recorded for synthetic tiancimycin $\mathrm{A}$ [(+)-7] in acetone- $d_{6}$ (at $600 \mathrm{MHz}$ for ${ }^{1} \mathrm{H}$ and $151 \mathrm{MHz}$ for ${ }^{13} \mathrm{C}$ nuclei, respectively) alongside the corresponding data that have been reported for the isolated natural product in acetone- $d_{6}$ (at 700 $\mathrm{MHz}$ for ${ }^{1} \mathrm{H}$ and $175 \mathrm{MHz}$ for ${ }^{13} \mathrm{C}$ nuclei, respectively). ${ }^{4}$

Table S2. Comparison of ${ }^{1} \mathrm{H}$ and ${ }^{13} \mathrm{C}$ NMR of natural and synthetic tiancimycin A.

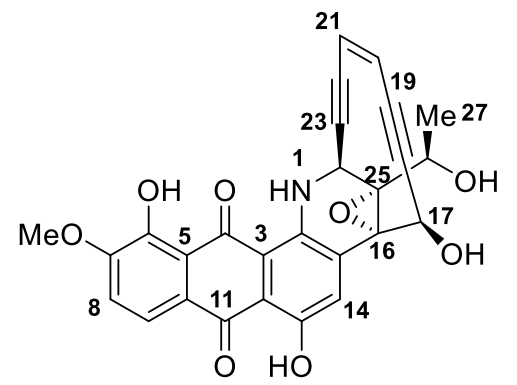

\begin{tabular}{|c|c|c|c|c|}
\hline \multirow{2}{*}{ Position } & \multicolumn{2}{|l|}{ Natural } & \multicolumn{2}{|l|}{ Synthetic (this work) } \\
\hline & $\delta{ }^{1} \mathrm{H}$ (mult., $J$ in $\mathrm{Hz}$ ) & $\delta^{13} \mathrm{C}$ & $\delta^{1} \mathrm{H}$ (mult., $J$ in $\left.\mathrm{Hz}\right)$ & $\delta^{13} \mathrm{C}$ \\
\hline 1 & 9.97 (brs) & & 9.93(br d, 5.0) & \\
\hline 2 & & 144.8 & & 144.8 \\
\hline 3 & & 110.8 & & 110.8 \\
\hline 4 & & 188.5 & & 188.6 \\
\hline 5 & & 116.9 & & 117.0 \\
\hline 6 & & 152.8 & & 152.8 \\
\hline 7 & & 154.5 & & 154.5 \\
\hline 8 & $7.41(\mathrm{~d}, 8.4)$ & 115.8 & $7.40(\mathrm{~d}, 8.5)$ & 115.9 \\
\hline 9 & $7.86(\mathrm{~d}, 8.4)$ & 119.7 & $7.84(\mathrm{~d}, 8.4)$ & 119.8 \\
\hline 10 & & 124.6 & & 124.7 \\
\hline 11 & & 185.5 & & 185.9 \\
\hline 12 & & 112.6 & & 112.7 \\
\hline 13 & & 156.4 & & 156.4 \\
\hline 14 & $8.74(\mathrm{~s})$ & 131.6 & $8.72(\mathrm{~s})$ & 131.6 \\
\hline 15 & & 135.1 & & 135.2 \\
\hline 16 & & 64.3 & & 64.4 \\
\hline 17 & 5.43 (brs) & 63.9 & $5.42(\mathrm{~d}, 5.7)$ & 64.1 \\
\hline 18 & & 99.9 & & 100.0 \\
\hline 19 & & 90.0 & & 90.1 \\
\hline 20 & $6.04(\mathrm{~d}, 9.9)$ & 123.2 & $6.03(\mathrm{~d}, 9.9)$ & 123.2 \\
\hline 21 & $5.96(\mathrm{~d}, 9.9)$ & 123.5 & $5.95(\mathrm{~d}, 9.9)$ & 123.6 \\
\hline
\end{tabular}




\begin{tabular}{|l|l|l|l|l|}
\hline 22 & & 87.7 & & 87.9 \\
\hline 23 & & 98.2 & & 98.3 \\
\hline 24 & $5.19(\mathrm{~d}, 4.4)$ & 43.7 & $5.16(\mathrm{~d}, 4.5)$ & 43.7 \\
\hline 25 & & 75.9 & & 76.0 \\
\hline 26 & $4.54(\mathrm{q}, 6.5)$ & 64.7 & $4.53(\mathrm{q}, 6.3)$ & 64.9 \\
\hline 27 & $1.44(\mathrm{~d}, 6.5)$ & 20.8 & $1.44(\mathrm{~d}, 6.5)$ & 20.8 \\
\hline $6-\mathrm{OH}$ & $13.42(\mathrm{brs})$ & & $13.39(\mathrm{brs})$ & \\
\hline $7-\mathrm{OMe}$ & $4.01(\mathrm{~s})$ & 55.9 & $4.01(\mathrm{~s})$ & 55.9 \\
\hline $13-\mathrm{OH}$ & 13.69 (brs) & & $13.66(\mathrm{brs})$ & \\
\hline $17-\mathrm{OH}$ & & & $5.83(\mathrm{~d}, 5.0)$ & \\
\hline $26-\mathrm{OH}$ & & & $4.32(\mathrm{~d}, 5.0)$ & \\
\hline
\end{tabular}

Total Synthesis of Tiancimycin B (8)

$(1 \mathrm{a} S, 11 S, 11 \mathrm{a} R, 18 R)-3-H y d r o x y-4,9-d i o x o-11 a-\{(1 R)-1-[($ triethylsilyl)oxy]ethyl\}-9,10,11,11atetrahydro-4H-11,1a-hept[3] ene[1,5]diynonaphtho[2,3- $h]$ oxireno[c]quinolin-18-yl acetate (50): To a stirred solution of protected anthraquinone 49 (34 mg, $61 \mu$ mol, 1.0 equiv) in $\mathrm{CH}_{2} \mathrm{Cl}_{2}$

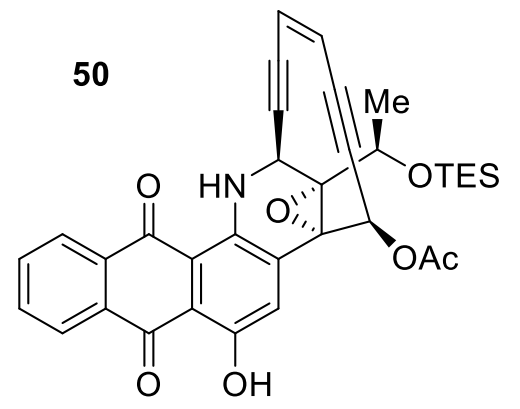
$(2.0 \mathrm{~mL})$ was sequentially added $i-\operatorname{Pr}_{2} \mathrm{NEt}(22 \mu \mathrm{L}, 120 \mu \mathrm{mol}$, 2.0 equiv), DMAP $\left(0.70 \mathrm{mg}, 6.1 \mu \mathrm{mol}, 0.1\right.$ equiv) and $\mathrm{Ac}_{2} \mathrm{O}$ $\left(12 \mu \mathrm{L}, 120 \mu \mathrm{mol}, 2.0\right.$ equiv) at $0^{\circ} \mathrm{C}$ and the resulting mixture was stirred for $10 \mathrm{~min}$ at the same temperature. Then, the reaction mixture was quenched by addition of $\mathrm{pH} 6.8$ buffer $(6 \mathrm{~mL})$ and extracted with EtOAc $(3 \times 10 \mathrm{~mL})$. The combined organic layers were washed with brine $(8 \mathrm{~mL})$, dried over anhydrous $\mathrm{Na}_{2} \mathrm{SO}_{4}$ and concentrated under reduce pressure. Purification of the so-obtained residue by preparative thin layer chromatography (hexanes/EtOAc 3:2, v/v) afforded acetyl-protected anthraquinone $50(36 \mathrm{mg}, 61 \mu \mathrm{mol}$, quant. yield) as orange foam.

50: $\mathrm{R}_{\mathrm{f}}=0.38$ (silica gel, 20\% EtOAc in hexanes); $[\alpha]_{\mathrm{D}}^{23}=-136.9(c=0.36$, EtOAc); FT-IR (film) $v_{\max }: 3248,2955,1758,1623,1589,1485,1370,1352,1208,1118,1065,1020,929,780,728$ $\mathrm{cm}^{-1} ;{ }^{1} \mathrm{H}$ NMR $\left(\mathrm{CD}_{3} \mathrm{CN}, 600 \mathrm{MHz}\right): \delta 13.13(\mathrm{~s}, 1 \mathrm{H}), 9.97(\mathrm{~d}, J=4.2 \mathrm{~Hz}, 1 \mathrm{H}), 8.24-8.19(\mathrm{~m}, 2 \mathrm{H})$, $8.13(\mathrm{~s}, 1 \mathrm{H}), 7.83-7.74(\mathrm{~m}, 2 \mathrm{H}), 6.17(\mathrm{~s}, 1 \mathrm{H}), 5.98(\mathrm{~d}, J=10.1 \mathrm{~Hz}, 1 \mathrm{H}), 5.93(\mathrm{dt}, J=10.0,1.3 \mathrm{~Hz}$, $1 \mathrm{H}), 4.96(\mathrm{dd}, J=4.4,1.4 \mathrm{~Hz}, 1 \mathrm{H}), 4.62(\mathrm{q}, J=12.8,6.4 \mathrm{~Hz}, 1 \mathrm{H}), 2.2(\mathrm{~s}, 3 \mathrm{H}), 1.45(\mathrm{~d}, J=6.4 \mathrm{~Hz}$, $3 \mathrm{H}), 0.98(\mathrm{t}, J=8.0 \mathrm{~Hz}, 9 \mathrm{H}), 0.67(\mathrm{q}, J=7.9 \mathrm{~Hz}, 6 \mathrm{H}) \mathrm{ppm} ;{ }^{13} \mathrm{C} \mathrm{NMR}\left(\mathrm{CD}_{3} \mathrm{CN}, 151 \mathrm{MHz}\right): \delta 188.6$, 184.4, 170.5, 156.6, 144.5, 135.8, 135.7, 135.3, 134.5, 133.6, 130.2, 127.8, 127.1, 125.7, 123.5, 
114.6, 112.9, 99.7, 96.9, 93.7, 88.8, 78.0, 67.5, 65.3, 64.1, 44.6, 22.7, 21.2, 7.3, 5.6 ppm; HRMS (ESI-TOF): calcd for $\mathrm{C}_{34} \mathrm{H}_{33} \mathrm{NO}_{7} \mathrm{SiNa}^{+}[\mathrm{M}+\mathrm{Na}]^{+} 618.1919$, found 618.1920.

$(1 \mathrm{a}, 11 S, 11 \mathrm{a} R, 18 R)-3-H y d r o x y-11 \mathrm{a}-[(1 R)-1$-hydroxyethyl]-4,9-dioxo-9,10,11,11a-tetrahydro-4H-11,1a-hept[3]ene[1,5]diynonaphtho[2,3-h]oxireno[c]quinolin-18-yl acetate (26): To a stirred solution of $\mathbf{5 0}\left(35 \mathrm{mg}, 59 \mu \mathrm{mol}, 1.0\right.$ equiv) in degassed THF $(3 \mathrm{~mL})$ at $0{ }^{\circ} \mathrm{C}$ was added<smiles>CC(=O)OC1C2C#CC=CCC(C(C)(C)O)C1c1cc(O)c3c(c1N2)C(=O)c1ccccc1C3=O</smiles>
a solution of $3 \mathrm{HF} \cdot \mathrm{Et}_{3} \mathrm{~N} / \mathrm{THF}$ (1.4 mL, 1:1, v/v, $8.8 \mathrm{mmol}, 150$ equiv). The sealed reaction flask was removed from the cooling bath, wrapped with aluminium foil, and the mixture was stirred at $23^{\circ} \mathrm{C}$ for $2 \mathrm{~h}$. The reaction mixture was partitioned between EtOAc $(12 \mathrm{~mL})$ and saturated aq. $\mathrm{NaHCO}_{3}$ solution $(5 \mathrm{~mL})$. The organic layer was washed with brine $(6 \mathrm{~mL})$, dried over anhydrous $\mathrm{Na}_{2} \mathrm{SO}_{4}$,

and concentrated under reduced pressure. Purification of the so-obtained residue by preparative thin layer chromatography (hexanes/EtOAc 3:7, $v / v)$ provided $26(25 \mathrm{mg}, 51 \mu \mathrm{mol}, 85 \%$ yield) as yellow foam.

26: $\mathrm{R}_{\mathrm{f}}=0.25$ (silica gel, $40 \%$ EtOAc in hexanes); $[\alpha]_{\mathrm{D}}^{23}=-265.5(c=0.18$, EtOAc); FT-IR (film) $v_{\max }$ : 3500, 2925, 1757, 1623, 1589, 1484, 1354, 1209, 1092, 1054, 1027, 964, 927, 796, $730 \mathrm{~cm}^{-1}$; ${ }^{1} \mathrm{H}$ NMR (CD $\left.3 \mathrm{CN}, 600 \mathrm{MHz}\right): \delta 13.13$ (s, $\left.1 \mathrm{H}\right), 9.98$ (d, $\left.J=4.0 \mathrm{~Hz}, 1 \mathrm{H}\right), 8.25-8.19$ (m, $\left.2 \mathrm{H}\right), 8.15$ (s, $1 \mathrm{H}), 7.83-7.76$ (m, 2 H), 6.24 (s, 1 H), 5.99 (d, $J=10.0 \mathrm{~Hz}, 1 \mathrm{H}), 5.94$ (dt, $J=10.0,1.3 \mathrm{~Hz}, 1 \mathrm{H})$, 4.93 (dd, $J=4.4,1.3 \mathrm{~Hz}, 1 \mathrm{H}), 4.50-4.44(\mathrm{~m}, 1 \mathrm{H}), 3.45$ (d, $J=4.9 \mathrm{~Hz}, 1 \mathrm{H}), 2.2$ (s, $3 \mathrm{H}), 1.44$ (d, $J=6.6 \mathrm{~Hz}, 3 \mathrm{H}) \mathrm{ppm} ;{ }^{13} \mathrm{C} \mathrm{NMR}\left(\mathrm{CD}_{3} \mathrm{CN}, 151 \mathrm{MHz}\right): \delta 188.7,184.4,170.5,156.6,144.4,135.8$, 135.7, 135.1, 134.5, 133.6, 130.2, 127.8, 127.1, 125.5, 123.7, 114.7, 112.9, 99.2, 96.9, 93.6, 89.0, 77.8, 66.3, 65.4, 64.4, 44.5, 21.3, 21.2 ppm; HRMS (ESI-TOF): calcd for $\mathrm{C}_{28} \mathrm{H}_{19} \mathrm{NO}_{7} \mathrm{Na}^{+}[\mathrm{M}+\mathrm{Na}]^{+}$ 504.1054 , found 504.1057 . 
$(1 \mathrm{a} S, 11 S, 11 \mathrm{a} S, 18 R)-11 \mathrm{a}-\mathrm{Acetyl}-3-h y d \operatorname{roxy}-4,9-\operatorname{dioxo}-9,10,11,11 \mathrm{a}-t$ trahydro-4H-11,1ahept[3] ene[1,5]diynonaphtho[2,3-h]oxireno[c]quinolin-18-yl acetate (51): To a solution of 26

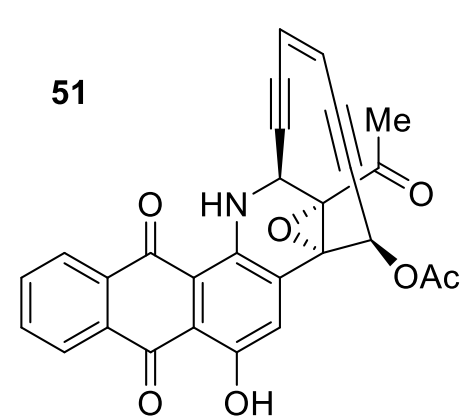
(23 mg, $48 \mu \mathrm{mol}, 1.0$ equiv) in $\mathrm{CH}_{2} \mathrm{Cl}_{2}(2 \mathrm{~mL})$ was added DMP $\left(50 \mathrm{mg}, 120 \mu \mathrm{mol}, 2.5\right.$ equiv) portion-wise at $0^{\circ} \mathrm{C}$. Stirring was continued for $3 \mathrm{~h}$ at $0^{\circ} \mathrm{C}$ and then the reaction mixture was quenched by addition of saturated aqueous $\mathrm{Na}_{2} \mathrm{~S}_{2} \mathrm{O}_{3}$ and the reaction mixture was partitioned between EtOAc $(12 \mathrm{~mL})$ and saturated aq. $\mathrm{NaHCO}_{3}$ solution $(5 \mathrm{~mL})$. The organic layer was washed with brine $(6 \mathrm{~mL})$, dried over anhydrous $\mathrm{Na}_{2} \mathrm{SO}_{4}$, and concentrated under reduced pressure. Purification of the soobtained residue by preparative thin layer chromatography (hexanes/EtOAc 2:3, v/v) provided 51 (20 mg, $42 \mu \mathrm{mol}, 89 \%$ yield) as yellow foam.

51: $\mathrm{R}_{\mathrm{f}}=0.38$ (silica gel, 40\% EtOAc in hexanes); $[\alpha]_{\mathrm{D}}^{23}=-266.7(c=0.18$, EtOAc); FT-IR (film) $\nu_{\max }: 2923,1762,1716,1625,1589,1483,1354,1208,1078,1025,927,797,728 \mathrm{~cm}^{-1}$; ${ }^{1} \mathrm{H}$ NMR $\left(\mathrm{CD}_{3} \mathrm{CN}, 600 \mathrm{MHz}\right): \delta 13.06(\mathrm{~s}, 1 \mathrm{H}), 9.93(\mathrm{~d}, J=3.9 \mathrm{~Hz}, 1 \mathrm{H}), 8.24-8.20(\mathrm{~m}, 2 \mathrm{H}), 8.18(\mathrm{~s}, 1 \mathrm{H})$, 7.85-7.77 (m, 2 H), $6.01(\mathrm{~d}, J=10.1 \mathrm{~Hz}, 1 \mathrm{H}), 5.98$ (dt, $J=10.0,1.2 \mathrm{~Hz}, 1 \mathrm{H}), 5.93(\mathrm{~s}, 1 \mathrm{H}), 5.03$ $(\mathrm{dd}, J=4.3,1.3 \mathrm{~Hz}, 1 \mathrm{H}), 2.51(\mathrm{~s}, 3 \mathrm{H}), 2.22(\mathrm{~s}, 3 \mathrm{H}) \mathrm{ppm} ;{ }^{13} \mathrm{C} \mathrm{NMR}\left(\mathrm{CD}_{3} \mathrm{CN}, 151 \mathrm{MHz}\right): \delta 200.7$, $188.8,184.7,170.4,156.5,143.4,135.8,135.6,134.7,133.6,133.4,130.3,127.8,127.2,125.4$, 124.2, 115.1, 113.6, 98.3, 95.9, 93.5, 90.1, 76.9, 65.5, 65.2, 45.5, 29.8, 21.2 ppm; HRMS (ESITOF): calcd for $\mathrm{C}_{28} \mathrm{H}_{17} \mathrm{NO}_{7} \mathrm{Na}^{+}[\mathrm{M}+\mathrm{Na}]^{+}$502.0897, found 502.0905.

(1aS,11S,11aS,18R)-11a-Acetyl-3,18-dihydroxy-11,11a-dihydro-4H-11,1a-hept[3]ene[1,5]diynonaphtho[2,3-h]oxireno[c]quinoline-4,9(10H)-dione (27): To a stirred solution of 51 (17 mg,

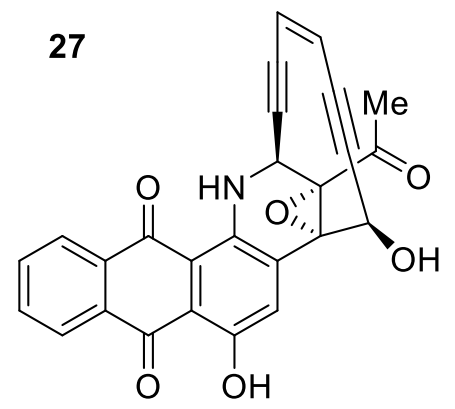
$35 \mu \mathrm{mol}, 1.0$ equiv) in $\mathrm{MeOH}(2 \mathrm{~mL})$ was added anhydrous $\mathrm{K}_{2} \mathrm{CO}_{3}$ $\left(5.0 \mathrm{mg}, 35 \mu \mathrm{mol}, 1.0\right.$ equiv) portion-wise at $0^{\circ} \mathrm{C}$. Stirring was continued for $1.5 \mathrm{~h}$ at $0{ }^{\circ} \mathrm{C}$ and the resulting mixture was then quenched by addition of $\mathrm{pH} 6.8$ buffer $(7 \mathrm{~mL})$ and extracted with EtOAc $(3 \times 10 \mathrm{~mL})$. The organic extracts were washed with saturated brine $(8 \mathrm{~mL})$, dried over anhydrous $\mathrm{Na}_{2} \mathrm{SO}_{4}$, and concentrated under reduced pressure. The crude residue was purified by preparative thin layer chromatography (hexanes/EtOAc 2:3, v/v) to afford hydroxyl-ketone $27(15 \mathrm{mg}, 34 \mu \mathrm{mol}, 96 \%$ yield) as yellow foam. 
27: $\mathrm{R}_{\mathrm{f}}=0.35$ (silica gel, 40\% EtOAc in hexanes); $[\alpha]_{\mathrm{D}}^{23}=-190.0(c=0.24$, EtOAc); FT-IR (film) $v_{\max }: 3490,2926,2851,1710,1621,1587,1567,1485,1356,1231,1206,1102,1079,1028,967$, 945, 899, 796, $763 \mathrm{~cm}^{-1}$; ${ }^{1} \mathrm{H}$ NMR (CD $\left.3 \mathrm{CN}, 600 \mathrm{MHz}\right): \delta 13.10(\mathrm{~s}, 1 \mathrm{H}), 9.99(\mathrm{~d}, J=3.5 \mathrm{~Hz}, 1 \mathrm{H})$, $8.61(\mathrm{~s}, 1 \mathrm{H}), 8.22-8.16(\mathrm{~m}, 2 \mathrm{H}), 7.84-7.74(\mathrm{~m}, 2 \mathrm{H}), 5.96(\mathrm{~d}, J=9.9 \mathrm{~Hz}, 1 \mathrm{H}), 5.93-5.82(\mathrm{~m}, 2 \mathrm{H})$, $5.12(\mathrm{dd}, J=4.3,1.4 \mathrm{~Hz}, 1 \mathrm{H}), 5.02(\mathrm{~s}, 1 \mathrm{H}), 2.39$ (s, $3 \mathrm{H}) \mathrm{ppm} ;{ }^{13} \mathrm{C} \mathrm{NMR}\left(\mathrm{CD}_{3} \mathrm{CN}, 151 \mathrm{MHz}\right): \delta$ 200.8, 188.9, 184.7, 156.6, 144.3, 135.8, 135.7, 134.7, 134.6, 133.7, 131.1, 127.9, 127.2, 124.6, 124.5, 114.9, 113.3, 99.6, 98.3, 91.3, 90.1, 76.8, 66.4, 65.5, 45.5, 29.9 ppm; HRMS (ESI-TOF): calcd for $\mathrm{C}_{26} \mathrm{H}_{15} \mathrm{NO}_{6} \mathrm{Na}^{+}[\mathrm{M}+\mathrm{Na}]^{+} 460.0792$, found 460.0792 .

Methyl (2E)-3-[(1aS,11S,11aS,18R)-3,18-dihydroxy-4,9-dioxo-4,9,10,11-tetrahydro-11a $H$ 11,1a-hept[3] ene[1,5]diynonaphtho[2,3- $h]$ oxireno[ $c$ ]quinolin-11a-yl]but-2-enoate

(Tiancimycin B, 8): A mixture of methyl diethylphosphonoacetate $(30 \mu \mathrm{L}, 160 \mu \mathrm{mol}, 6.0$ equiv)

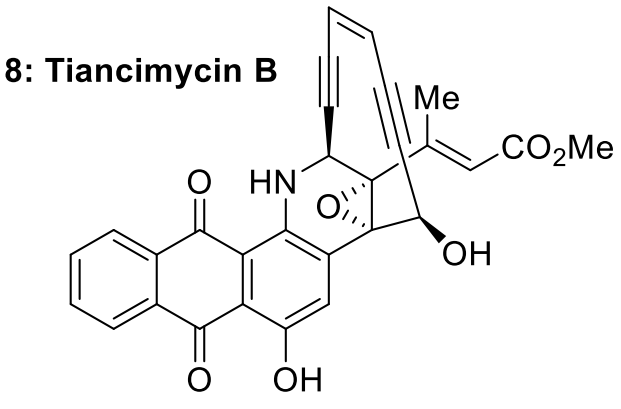
and $\mathrm{NaH}(95 \%, 3.4 \mathrm{mg}, 140 \mu \mathrm{mol}, 5.0$ equiv) in $\mathrm{THF}$ $(2 \mathrm{~mL})$ was stirred at $0^{\circ} \mathrm{C}$ for $1 \mathrm{~h}$. Then a solution of compound 27 (12 mg, $27 \mu \mathrm{mol}, 1.0$ equiv) in THF $(2 \mathrm{~mL})$ was cannulated to the former mixture at $-78^{\circ} \mathrm{C}$. After stirring for $15 \mathrm{~min}$, the resulting mixture was brought to $0{ }^{\circ} \mathrm{C}$ and stirred for another $5 \mathrm{~h}$. The reaction mixture was then quenched by addition of $\mathrm{pH} 6.8$ buffer $(4 \mathrm{~mL})$ and extracted with EtOAc $(3 \times 10 \mathrm{~mL})$. The organic extracts were washed with saturated brine $(8 \mathrm{~mL})$, dried over anhydrous $\mathrm{Na}_{2} \mathrm{SO}_{4}$, and concentrated under reduced pressure. The residue was then purified by preparative thin layer chromatography (hexanes/EtOAc 1:1, v/v) to afford tiancimycin B [8, $11 \mathrm{mg}, 23 \mu \mathrm{mol}, 84 \%$ yield, $(E):(Z)=8: 1]$ as red powder and its $(Z)$-isomer $(\mathbf{1 6}, 1.3 \mathrm{mg}, 2.7 \mu \mathrm{mol}, 10 \%$ yield $)$ as red powder.

8: $\mathrm{R}_{\mathrm{f}}=0.62$ (silica gel, 50\% EtOAc in hexanes); $[\alpha]_{\mathrm{D}}^{23}=+895.8(c=0.12, \mathrm{MeOH})$; FT-IR (film) $v_{\max }: 3444,2952,2854,2329,2115,1994,1719,1622,1587,1481,1350,1230,1018 \mathrm{~cm}^{-1}$; ${ }^{1} \mathrm{H}$ NMR (acetone- $\left.d_{6}, 600 \mathrm{MHz}\right): \delta 13.24$ (brs, $\left.1 \mathrm{H}\right), 10.13(\mathrm{~d}, J=4.4 \mathrm{~Hz}, 1 \mathrm{H}), 8.63$ (s, $\left.1 \mathrm{H}\right), 8.31$ $(\mathrm{dt}, J=7.5,1.7 \mathrm{~Hz}, 2 \mathrm{H}), 7.93(\mathrm{td}, J=7.5,1.3 \mathrm{~Hz}, 1 \mathrm{H}), 7.89$ (td, $J=7.5,1.3 \mathrm{~Hz}, 1 \mathrm{H}), 6.54$ (brs, $1 \mathrm{H}$ ), $6.13(\mathrm{~d}, J=10.0 \mathrm{~Hz}, 1 \mathrm{H}), 6.01$ (dt, $J=10.0,1.3 \mathrm{~Hz}, 1 \mathrm{H}), 5.81$ (brs, $1 \mathrm{H}), 5.05$ (brs, $1 \mathrm{H}), 4.98$ (dd, $J=4.6,1.6 \mathrm{~Hz}, 1 \mathrm{H}), 3.71(\mathrm{~s}, 3 \mathrm{H}), 2.42(\mathrm{~d}, J=1.4 \mathrm{~Hz}, 3 \mathrm{H}) \mathrm{ppm} ;{ }^{13} \mathrm{C}$ NMR (acetone- $\left.d_{6}, 151 \mathrm{MHz}\right)$ : $\delta 187.6,183.3,165.8,156.0,148.3,143.7,134.8,134.7,133.5,132.8,130.3,126.8,126.3,123.8$, 
123.3, 121.2, 113.4, 111.8, 100.1, 97.8, 91.0, 89.0, 75.8, 66.9, 65.7, 50.7, 46.3, 16.4 ppm; HRMS (ESI-TOF): calcd for $\mathrm{C}_{29} \mathrm{H}_{19} \mathrm{NO}_{7} \mathrm{Na}^{+}[\mathrm{M}+\mathrm{Na}]^{+} 516.1054$, found 516.1055 .

Methyl (2Z)-3-[(1aS,11S,11aS,18R)-3,18-dihydroxy-4,9-dioxo-4,9,10,11-tetrahydro-11a $H$ 11,1a-hept[3]ene[1,5] diynonaphtho[2,3- $h]$ oxireno[c]quinolin-11a-yl]but-2-enoate (16):

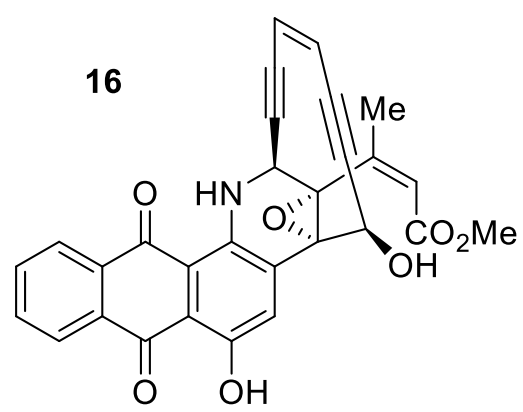

$\mathrm{R}_{\mathrm{f}}=0.58$ (silica gel, 50\% EtOAc in hexanes); $[\alpha]_{\mathrm{D}}^{23}=+55.8$ $(c=0.43, \mathrm{MeOH})$; FT-IR (film) $v_{\max }: 3421,2952,2925,2853$, $1720,1621,1586,1568,1482,1353,1260,1228,1205,1097$, 1042, 1016, 954, 912, 902, 794, $728 \mathrm{~cm}^{-1} ;{ }^{1} \mathrm{H}$ NMR $\left(\mathrm{CD}_{3} \mathrm{CN}\right.$, $600 \mathrm{MHz}): \delta 13.14$ (s, $1 \mathrm{H}), 10.02$ (d, $J=3.8 \mathrm{~Hz}, 1 \mathrm{H}), 8.40$ (s, $1 \mathrm{H}), 8.31-8.26(\mathrm{~m}, 2 \mathrm{H})$, ), 7.87 (td, $J=7.5,1.0 \mathrm{~Hz}, 1 \mathrm{H}), 7.83$ (td, $J=7.5,1.0 \mathrm{~Hz}, 1 \mathrm{H}), 6.11-6.08(\mathrm{~m}, 1 \mathrm{H}), 6.01(\mathrm{~d}, J=10.1 \mathrm{~Hz} 1 \mathrm{H}), 5.95-5.89(\mathrm{~m}, 1 \mathrm{H}), 4.87(\mathrm{~d}$, $4.6 \mathrm{~Hz}, 1 \mathrm{H}), 4.79(\mathrm{dd}, J=4.4,1.4 \mathrm{~Hz}, 1 \mathrm{H}), 4.44(\mathrm{~d}, J=4.6 \mathrm{~Hz}, 1 \mathrm{H}), 3.68(\mathrm{~s}, 3 \mathrm{H}), 2.19$ (d, $J=0.9 \mathrm{~Hz}$, $3 \mathrm{H}) \mathrm{ppm} ;{ }^{13} \mathrm{C}$ NMR $\left(\mathrm{CD}_{3} \mathrm{CN}, 151 \mathrm{MHz}\right): \delta 188.8,184.6,167.6,156.7,144.2,143.9,135.8,135.7$, 135.5, 134.5, 133.7, 130.9, 127.8, 127.2, 127.1, 124.7, 124.3, 114.6, 113.0, 101.4, 93.4, 93.1, 90.6, 75.9, 66.5, 66.4, 52.3, 47.8, 24.4 ppm; HRMS (ESI-TOF): calcd for $\mathrm{C}_{29} \mathrm{H}_{19} \mathrm{NO}_{7}{ }^{+}[\mathrm{M}+\mathrm{H}]^{+}$ 494.1234, found 494.1237 .

The following table presents ${ }^{1} \mathrm{H}$ and ${ }^{13} \mathrm{C}$ NMR data recorded for synthetic tiancimycin $\mathrm{B}(\mathbf{8})$ in acetone- $d_{6}$ (at $600 \mathrm{MHz}$ for ${ }^{1} \mathrm{H}$ and $151 \mathrm{MHz}$ for ${ }^{13} \mathrm{C}$ nuclei, respectively) alongside the corresponding data that have been reported for the isolated natural product in acetone- $d_{6}$ (at 700 $\mathrm{MHz}$ for ${ }^{1} \mathrm{H}$ and $175 \mathrm{MHz}$ for ${ }^{13} \mathrm{C}$ nuclei, respectively). ${ }^{5}$ 
Table S3. Comparison of ${ }^{1} \mathrm{H}$ and ${ }^{13} \mathrm{C}$ NMR of natural and synthetic tiancimycin B (8).

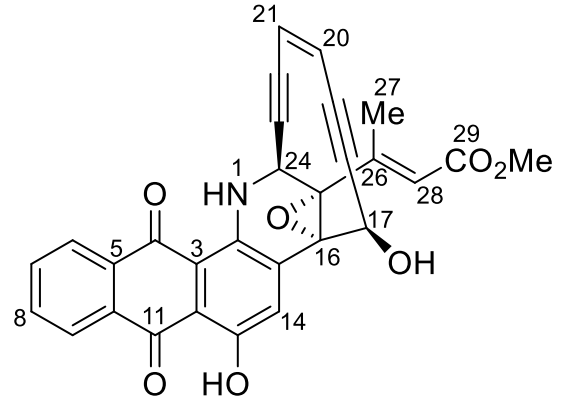

\begin{tabular}{|c|c|c|c|c|}
\hline \multirow{2}{*}{ Position } & \multicolumn{2}{|l|}{ Natural } & \multicolumn{2}{|l|}{ Synthetic (this work) } \\
\hline & $\delta{ }^{1} \mathrm{H}$ (mult., $J$ in $\mathrm{Hz}$ ) & $\delta{ }^{13} \mathrm{C}$ & $\delta{ }^{1} \mathrm{H}$ (mult., $J$ in $\mathrm{Hz}$ ) & $\delta^{13} \mathrm{C}$ \\
\hline 1 & 10.14 (brs) & & $10.13(\mathrm{~d}, 4.4)$ & \\
\hline 2 & & 143.7 & & 143.7 \\
\hline 3 & & 111.7 & & 111.8 \\
\hline 4 & & 187.6 & & 187.6 \\
\hline 5 & & 132.8 & & 132.8 \\
\hline 6 & $8.34(\mathrm{~d}, 1.3)$ & 126.9 & $8.31(\mathrm{dt}, 7.5,1.7)$ & 126.8 \\
\hline 7 & $7.92(\mathrm{td}, 7.6,1.4)$ & 133.6 & $7.89(\mathrm{td}, 7.5,1.3)$ & 133.5 \\
\hline 8 & $7.96(\mathrm{td}, 7.6,1.4)$ & 134.8 & $7.93(\mathrm{td}, 7.5,1.3)$ & 134.7 \\
\hline 9 & $8.33(\mathrm{~d}, 8.4)$ & 126.3 & $8.31(\mathrm{dt}, 7.5,1.7)$ & 126.3 \\
\hline 10 & & 130.2 & & 130.3 \\
\hline 11 & & 183.2 & & 183.3 \\
\hline 12 & & 113.3 & & 113.4 \\
\hline 13 & & 156.0 & & 156.0 \\
\hline 14 & $8.65(\mathrm{~s})$ & 130.3 & $8.63(\mathrm{~s})$ & 130.3 \\
\hline 15 & & 134.8 & & 134.8 \\
\hline 16 & & 66.9 & & 66.9 \\
\hline 17 & 5.06 (brs) & 65.6 & 5.05 (brs) & 65.7 \\
\hline 18 & & 100.1 & & 100.1 \\
\hline 19 & & 91.0 & & 91.0 \\
\hline 20 & $6.14(\mathrm{~d}, 10.0)$ & 123.8 & $6.13(\mathrm{~d}, 10.0)$ & 123.8 \\
\hline 21 & $6.00(\mathrm{~d}, 10.0)$ & 123.3 & $6.01(\mathrm{dt}, 10.0,1.3)$ & 123.3 \\
\hline 22 & & 89.0 & & 89.0 \\
\hline 23 & & 97.8 & & 97.8 \\
\hline 24 & $4.99(\mathrm{~d}, 4.4)$ & 46.3 & $4.98(\mathrm{dd}, 4.4,1.6)$ & 46.3 \\
\hline 25 & & 75.8 & & 75.8 \\
\hline 26 & & 148.3 & & 148.3 \\
\hline 27 & $2.43(\mathrm{~d}, 1.4)$ & 16.4 & $2.42(\mathrm{~d}, 1.4)$ & 16.4 \\
\hline 28 & $6.55(\mathrm{~d}, 1.4)$ & 121.2 & 6.54 (brs) & 121.2 \\
\hline 29 & & 165.8 & & 165.8 \\
\hline $13-\mathrm{OH}$ & 13.26 (brs) & & 13.24 (brs) & \\
\hline $17-\mathrm{OH}$ & & & 5.81 (brs) & \\
\hline $29-\mathrm{OMe}$ & $3.72(\mathrm{~s})$ & 50.7 & $3.71(\mathrm{~s})$ & 50.7 \\
\hline
\end{tabular}


$(1 \mathrm{a} R, 11 S, 11 \mathrm{a} S)$-11a-Acetyl-3-hydroxy-11,11a-dihydro-4H-11,1a-hept[3]ene[1,5]diynonaphtho[2,3- $h]$ oxireno[ $[c]$ quinoline-4,9,18(10H)-trione (28): To a stirred solution of hydroxy

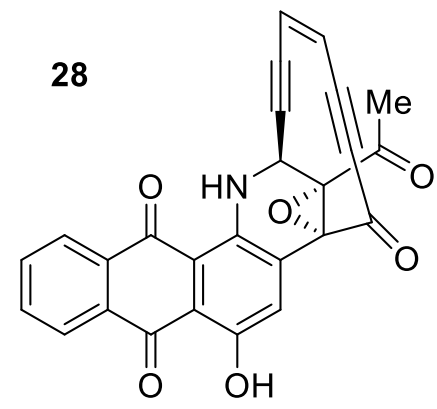
ketone 27 (5.0 mg, $12 \mu \mathrm{mol}, 1.0$ equiv) in $\mathrm{CH}_{2} \mathrm{Cl}_{2}(2 \mathrm{~mL})$ was added DMP $\left(12 \mathrm{mg}, 29 \mu \mathrm{mol}, 2.5\right.$ equiv) portion-wise at $0{ }^{\circ} \mathrm{C}$. Stirring was continued for $3 \mathrm{~h}$ at $0^{\circ} \mathrm{C}$ and then the reaction mixture was quenched by addition of saturated aqueous $\mathrm{Na}_{2} \mathrm{~S}_{2} \mathrm{O}_{3}$ and the reaction mixture was partitioned between EtOAc $(12 \mathrm{~mL})$ and saturated aq. $\mathrm{NaHCO}_{3}$ solution $(5 \mathrm{~mL})$. The organic layer was washed with brine $(6 \mathrm{~mL})$, dried over anhydrous $\mathrm{Na}_{2} \mathrm{SO}_{4}$, and concentrated under reduced pressure. Purification of the soobtained residue by preparative thin layer chromatography (hexanes/EtOAc 1:1, v/v) provided 28 ( $4.5 \mathrm{mg}, 10 \mu \mathrm{mol}, 89 \%$ yield) as purple powder.

28: $\mathrm{R}_{\mathrm{f}}=0.58$ (silica gel, $40 \%$ EtOAc in hexanes); $[\alpha]_{\mathrm{D}}^{23}=-252.9(c=0.17$, EtOAc); FT-IR (film) $v_{\max }$ : 2922, 2851, 2148, 1709, 1697, 1627, 1589, 1485, 1353, 1242, 1211, 1194, 1075, 761, 749, $728,704 \mathrm{~cm}^{-1} ;{ }^{1} \mathrm{H}$ NMR (THF- $\left.d_{8}, 600 \mathrm{MHz}\right): \delta 13.10(\mathrm{~s}, 1 \mathrm{H}), 10.06(\mathrm{~d}, J=3.4 \mathrm{~Hz}, 1 \mathrm{H}), 8.32-8.29$ (m, 2H), 7.89-7.77 (m, 2 H), 7.37 (s, $1 \mathrm{H}), 6.34(\mathrm{dd}, J=9.9,1.6 \mathrm{~Hz}, 1 \mathrm{H}), 6.20$ (d, J=9.9Hz, $1 \mathrm{H})$, $5.23(\mathrm{dd}, J=4.1,1.5 \mathrm{~Hz}, 1 \mathrm{H}), 2.21$ (s, $3 \mathrm{H}) \mathrm{ppm} ;{ }^{13} \mathrm{C}$ NMR (THF- $\left.d_{8}, 151 \mathrm{MHz}\right): \delta 199.9,188.7$, 184.6, 175.9, 156.8, 141.3, 135.7, 135.4, 134.3, 133.7, 133.1, 130.6, 128.8, 127.6, 127.2, 121.7, 116.1, 113.8, 106.9, 101.8, 95.9, 89.3, 76.6, 67.5, 45.0, 27.0 ppm; HRMS (ESI-TOF): calcd for $\mathrm{C}_{26} \mathrm{H}_{13} \mathrm{NO}_{6} \mathrm{Na}^{+}[\mathrm{M}+\mathrm{Na}]^{+} 458.0635$, found 458.0637 .

\section{Synthesis of Analogues 29 and 17-22}

Allyl (1aS,11S,11aR,18R)-18-acetoxy-3-(methoxymethoxy)-4,9-dioxo-11a-\{(1R)-1-[(triethylsilyl)oxy]ethyl $\}-4,9,11,11$ a-tetrahydro-10H-11,1a-hept[3]ene[1,5]diynonaphtho[2,3$\boldsymbol{h}$ ]oxireno[c]quinoline-10-carboxylate (54): To a stirred solution of $\mathbf{5 3}^{3}$ (93 $\mu \mathrm{mol}$,

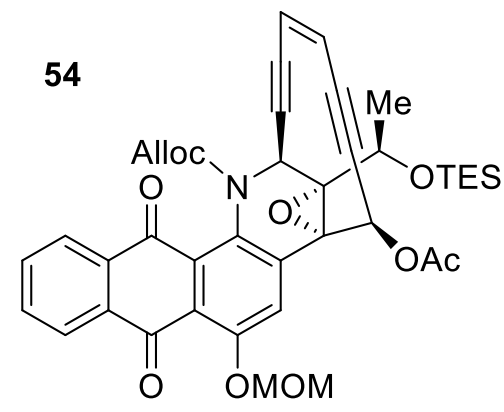
1.0 equiv) in $\mathrm{CH}_{2} \mathrm{Cl}_{2}(2.0 \mathrm{~mL})$ were sequentially added $i-\mathrm{Pr}_{2} \mathrm{NEt}$ $(49 \mu \mathrm{L}, 280 \mu \mathrm{mol}, 3.0$ equiv) and $\mathrm{MOMCl}(22 \mu \mathrm{L}, 280 \mu \mathrm{mol}$, 3.0 equiv) at $23^{\circ} \mathrm{C}$ and the resulting mixture was stirred for $12 \mathrm{~h}$ at the same temperature. Then, the reaction mixture was quenched by addition of $\mathrm{pH} 6.8$ buffer $(6 \mathrm{~mL})$ and extracted with EtOAc $(3 \times 10 \mathrm{~mL})$. The combined organic extracts were dried over 
anhydrous $\mathrm{Na}_{2} \mathrm{SO}_{4}$ and concentrated under reduced pressure to furnish the crude MOM-protected anthraquinone. The latter was then dissolved in $\mathrm{CH}_{2} \mathrm{Cl}_{2}(2.0 \mathrm{~mL})$ and to this stirred solution were sequentially added $i$ - $\operatorname{Pr}_{2} \mathrm{NEt}(32 \mu \mathrm{L}, 190 \mu \mathrm{mol}, 2.0$ equiv), DMAP $(1.2 \mathrm{mg}, 9.3 \mu \mathrm{mol}, 0.1$ equiv) and $\mathrm{Ac}_{2} \mathrm{O}\left(18 \mu \mathrm{L}, 190 \mu \mathrm{mol}, 2.0\right.$ equiv) at $0{ }^{\circ} \mathrm{C}$ and the resulting mixture was stirred for $0.5 \mathrm{~h}$ at the same temperature. Then, the reaction mixture was quenched by addition of $\mathrm{pH} 6.8$ buffer $(6 \mathrm{~mL})$ and extracted with EtOAc $(3 \times 10 \mathrm{~mL})$. The combined organic layers were washed with brine $(8 \mathrm{~mL})$, dried over anhydrous $\mathrm{Na}_{2} \mathrm{SO}_{4}$ and concentrated under reduce pressure. Purification of the so-obtained residue by preparative thin layer chromatography (hexanes/EtOAc 3:7, v/v) provided $54(50 \mathrm{mg}, 70 \mu \mathrm{mol}, 75 \%$ yield) as yellow foam.

54: $\mathrm{R}_{\mathrm{f}}=0.55$ (silica gel, 50\% EtOAc in hexanes); $[\alpha]_{\mathrm{D}}^{23}=+198.2(c=1.2$, EtOAc); FT-IR (film) $v_{\max }$ : 2955, 2877, 1759, 1718, 1674, 1594, 1464, 1391, 1375, 1325, 1279, 1264, 1217, 1153, 1119 , 1100, 1080, 1049, 1030, 971, 921, 777, $729 \mathrm{~cm}^{-1} ;{ }^{1} \mathrm{H}$ NMR (CD $\left.\mathrm{CDN}_{3}, 600 \mathrm{MHz}\right): \delta 8.51(\mathrm{~s}, 1 \mathrm{H})$, 8.11-8.04 (m, 2 H), 7.82-7.75 (m, 2 H), $6.17(\mathrm{~s}, 1 \mathrm{H}), 5.96-5.93(\mathrm{~m}, 1 \mathrm{H}), 5.92-5.88(\mathrm{~m}, 1 \mathrm{H}), 5.83-$ $5.80(\mathrm{~m}, 1 \mathrm{H}), 5.64-5.55(\mathrm{~m}, 1 \mathrm{H}), 5.37(\mathrm{~d}, J=7.0 \mathrm{~Hz}, 1 \mathrm{H}), 5.33(\mathrm{~d}, J=7.0 \mathrm{~Hz}, 1 \mathrm{H}), 5.00-4.95(\mathrm{~m}$, $1 \mathrm{H}), 4.93-4.89$ (m, $1 \mathrm{H}), 4.68$ (d, J=6.3 Hz, $1 \mathrm{H}), 4.49-4.44$ (m, $1 \mathrm{H}), 4.39-4.33$ (m, $1 \mathrm{H}), 3.53$ (s, $3 \mathrm{H}), 2.19$ (s, $3 \mathrm{H}), 1.48$ (d, $J=6.4 \mathrm{~Hz}, 3 \mathrm{H}), 0.99$ (t, $J=8.0 \mathrm{~Hz}, 9 \mathrm{H}), 0.67$ (q, $J=7.9 \mathrm{~Hz}, 6 \mathrm{H}) \mathrm{ppm}$; ${ }^{13} \mathrm{C}$ NMR $\left(\mathrm{CD}_{3} \mathrm{CN}, 151 \mathrm{MHz}\right): \delta 184.5,182.9,170.4,155.4,155.2,136.3,135.2,134.9,134.6$, 133.1, 131.9, 130.9, 127.4, 127.1, 127.0, 126.7, 124.9, 124.5, 124.3, 97.1, 96.5, 96.2, 94.4, 91.4, 78.1, 67.9, 67.4, 65.4, 64.9, 56.9, 47.9, 22.5, 20.9, 7.2, 5.6 ppm; HRMS (ESI-TOF): calcd for $\mathrm{C}_{40} \mathrm{H}_{41} \mathrm{NO}_{10} \mathrm{SiNa}^{+}[\mathrm{M}+\mathrm{Na}]^{+}$746.2392, found 746.2403.

\section{Allyl (1aS,11S,11aR,18R)-11a-[(1R)-1-(carbamoyloxy)ethyl]-18-hydroxy-3-(methoxy-} methoxy)-4,9-dioxo-4,9,11,11a-tetrahydro-10H-11,1a-hept[3]ene[1,5]diynonaphtho[2,3$\boldsymbol{h}$ ]oxireno[c]quinoline-10-carboxylate (55): To a solution of $54(50 \mathrm{mg}, 69 \mu \mathrm{mol}, 1.0$ equiv) in

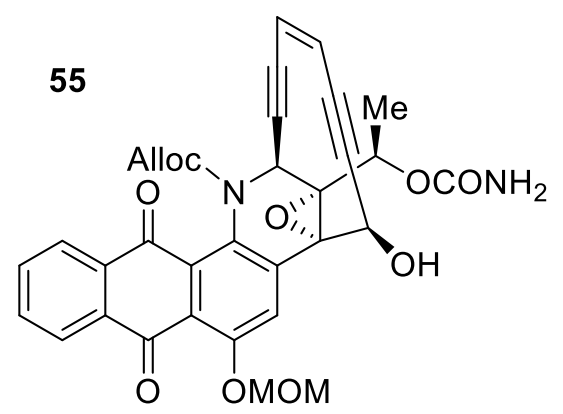
degassed THF $(3 \mathrm{~mL})$ at $0^{\circ} \mathrm{C}$ was added a solution of 3 HF. Et ${ }_{3} \mathrm{~N} / \mathrm{THF}(1.7 \mathrm{~mL}, 1: 1, v / v, 10 \mathrm{mmol}, 150$ equiv). The sealed reaction flask was removed from the cooling bath, wrapped with aluminium foil, and the mixture was stirred at $23^{\circ} \mathrm{C}$ for $2 \mathrm{~h}$. The reaction mixture was partitioned between EtOAc $(12 \mathrm{~mL})$ and saturated aq. $\mathrm{NaHCO}_{3}$ solution $(5 \mathrm{~mL})$. The organic layer was washed with brine $(6 \mathrm{~mL})$, dried over anhydrous $\mathrm{Na}_{2} \mathrm{SO}_{4}$, and concentrated under 
reduced pressure. The crude intermediate was then dissolved in 1,2-dichloroethane $(3 \mathrm{~mL})$ at $0{ }^{\circ} \mathrm{C}$ was added tri-chloroacetylisocyanate $(21 \mu \mathrm{L}, 170 \mu \mathrm{mol}, 2.5$ equiv). The reaction mixture was stirred at the same temperature for $5 \mathrm{~h}$. Then anhydrous $\mathrm{K}_{2} \mathrm{CO}_{3}(12 \mathrm{mg}, 90 \mu \mathrm{mol}, 1.3$ equiv) was added portion-wise at $0{ }^{\circ} \mathrm{C}$ and stirring was continued for $10 \mathrm{~min}$ at $0{ }^{\circ} \mathrm{C}$. Then $\mathrm{MeOH}(1.0 \mathrm{~mL})$ was added slowly to the reaction mixture with vigorous stirring. After the reaction mixture was stirred for $16 \mathrm{~h}$ at $23^{\circ} \mathrm{C}$, it was quenched by addition of $\mathrm{pH} 6.8$ buffer $(7 \mathrm{~mL})$ and extracted with EtOAc $(3 \times 10 \mathrm{~mL})$. The organic extracts were washed with saturated brine $(8 \mathrm{~mL})$, dried over anhydrous $\mathrm{Na}_{2} \mathrm{SO}_{4}$, and concentrated under reduced pressure. Purification of the so-obtained residue by preparative thin layer chromatography (hexanes/EtOAc 3:7, v/v) provided 55 (30 mg, $50 \mu \mathrm{mol}, 72 \%$ yield) as yellow foam.

55: $\mathrm{R}_{\mathrm{f}}=0.25$ (silica gel, 50\% EtOAc in hexanes); $[\alpha]_{\mathrm{D}}^{23}=+254.2(c=1.6$, EtOAc); FT-IR (film) $v_{\max }: 3450,3363,2927,1700,1671,1591,1552,1453,1378,1328,1296,1280,1268,1243,1205$, 1153, 1101, 1080, 1050, 1029, 961, 925, $730 \mathrm{~cm}^{-1} ;{ }^{1} \mathrm{H}$ NMR (CD $\left.{ }_{3} \mathrm{CN}, 600 \mathrm{MHz}\right): \delta 8.79(\mathrm{~s}, 1 \mathrm{H})$, 8.11-8.03 (m, 2 H), 7.81-7.74 (m, 2 H), 5.98 (d, J=1.5 Hz, 1 H), 5.91-5.88 (m, $1 \mathrm{H}), 5.74-5.71$ (m, $1 \mathrm{H}), 5.64-5.56(\mathrm{~m}, 1 \mathrm{H}), 5.31(\mathrm{~d}, J=6.7 \mathrm{~Hz}, 1 \mathrm{H}), 5.28(\mathrm{~d}, J=6.7 \mathrm{~Hz}, 1 \mathrm{H}), 5.15(\mathrm{~d}, J=4.9 \mathrm{~Hz}, 1 \mathrm{H})$, 5.00-4.95 (m, $1 \mathrm{H}), 4.93-4.90(\mathrm{~m}, 1 \mathrm{H}), 4.53(\mathrm{~d}, J=4.9 \mathrm{~Hz}, 1 \mathrm{H}), 4.49-4.44(\mathrm{~m}, 1 \mathrm{H}), 4.41-4.36(\mathrm{~m}$, $1 \mathrm{H}), 3.51(\mathrm{~s}, 3 \mathrm{H}), 2.16(\mathrm{~s}, 3 \mathrm{H}), 1.44(\mathrm{~d}, J=6.4 \mathrm{~Hz}, 3 \mathrm{H}) \mathrm{ppm} ;{ }^{13} \mathrm{C} \mathrm{NMR}\left(\mathrm{CD}_{3} \mathrm{CN}, 151 \mathrm{MHz}\right): \delta$ 184.6, 183.0, 156.1, 155.3, 155.1, 136.6, 135.2, 134.9, 134.6, 133.0, 132.0, 130.8, 128.3, 127.4, 127.0, 125.1, 123.6, 99.4, 97.2, 94.8, 92.2, 91.3, 75.7, 67.8, 66.9, 66.4, 65.3, 57.0, 47.2, 18.6 ppm; HRMS (ESI-TOF): calcd for $\mathrm{C}_{33} \mathrm{H}_{26} \mathrm{~N}_{2} \mathrm{O}_{10} \mathrm{Na}^{+}[\mathrm{M}+\mathrm{Na}]^{+}$633.1480, found 633.1484.

\section{(1R)-1-[(1aS,11S,11aR,18R)-3,18-Dihydroxy-4,9-dioxo-4,9,10,11-tetrahydro-11aH-11,1a-} hept[3]ene[1,5]diynonaphtho[2,3-h]oxireno[c]quinolin-11a-yl]ethyl carbamate (29): To a

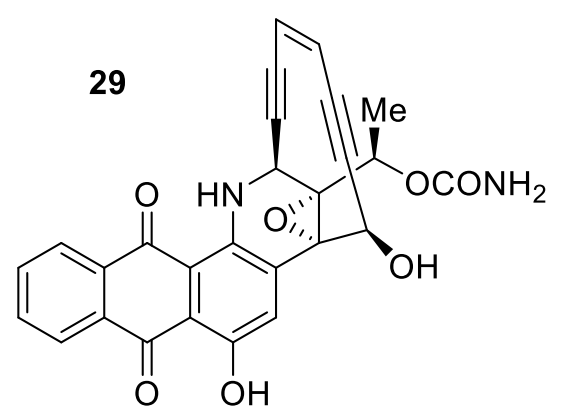
solution of $\mathbf{5 5}\left(25 \mathrm{mg}, 41 \mu \mathrm{mol}, 1.0\right.$ equiv) in $\mathrm{THF}(2 \mathrm{~mL})$ at $0{ }^{\circ} \mathrm{C}$ was added $\mathrm{Pd}\left(\mathrm{PPh}_{3}\right)_{4}(3.3 \mathrm{mg}, 2.9 \mu \mathrm{mol}, 0.07$ equiv) followed by the slow addition of morpholine $(10 \mu \mathrm{L}, 110 \mu \mathrm{mol}, 2.6$ equiv) and allowed to stir for $2 \mathrm{~h}$. The cooling bath was removed, and the reaction mixture was stirred at $23{ }^{\circ} \mathrm{C}$ for $12 \mathrm{~h}$. It was then quenched by addition of $\mathrm{pH} 6.8$ buffer $(7 \mathrm{~mL})$ and extracted with EtOAc $(3 \times 10 \mathrm{~mL})$. The organic extracts were washed with saturated aq. $\mathrm{NaHCO}_{3}$ solution $(8 \mathrm{~mL})$, brine $(8 \mathrm{~mL})$, dried over anhydrous $\mathrm{Na}_{2} \mathrm{SO}_{4}$, and concentrated under reduced pressure. The 
crude residue was purified by preparative thin layer chromatography hexanes/EtOAc 1:4, $v / v$ ) to afford the Alloc-deprotected derivative $(21 \mathrm{mg}, 39 \mu \mathrm{mol}, 96 \%$ yield) as orange solid.

Alloc-deprotected derivative: $\mathrm{R}_{\mathrm{f}}=0.25$ (silica gel, 50\% EtOAc in hexanes); $[\alpha]_{\mathrm{D}}^{23}=-15.3(c=1.5$, EtOAc); FT-IR (film) v $v_{\max }$ : 3495, 3387, 1731, 1671, 1643, 1591, 1466, 1371, 1344, 1281, 1241, 1197, 1151, 1095, 1034, 967, 952, 937, 802, 772, $727 \mathrm{~cm}^{-1} ;{ }^{1} \mathrm{H}$ NMR (CD $\left.{ }_{3} \mathrm{CN}, 600 \mathrm{MHz}\right): \delta 9.89$ (d, $J=4.1 \mathrm{~Hz}, 1 \mathrm{H}), 8.75$ (s, $1 \mathrm{H}), 8.22-8.18$ (m, $1 \mathrm{H}), 8.15-8.05$ (m, $1 \mathrm{H}), 7.81-7.76$ (m, 2 H), 5.93$5.91(\mathrm{~m}, 1 \mathrm{H}), 5.86-5.83(\mathrm{~m}, 1 \mathrm{H}), 5.34$ (q, J=6.6 Hz, $1 \mathrm{H}), 5.21-5.18(\mathrm{~m}, 1 \mathrm{H}), 5.18-5.14(\mathrm{~m}, 3 \mathrm{H})$, $4.96(\mathrm{dd}, J=4.4,1.6 \mathrm{~Hz}, 1 \mathrm{H}), 4.42(\mathrm{~d}, J=4.9 \mathrm{~Hz}, 1 \mathrm{H}), 3.51(\mathrm{~s}, 3 \mathrm{H}), 1.43(\mathrm{~d}, J=6.6 \mathrm{~Hz}, 3 \mathrm{H}) \mathrm{ppm}$; ${ }^{13} \mathrm{C}$ NMR $\left(\mathrm{CD}_{3} \mathrm{CN}, 151 \mathrm{MHz}\right): 186.5,183.2,156.0,149.5,145.5,135.3,134.8,134.6,134.5$, 133.6, 131.2, 127.2, 127.1, 124.4, 124.2, 123.9, 116.2, 100.2, 98.5, 97.9, 91.5, 76.4, 67.6, 65.9, 65.2, 57.0, 44.1 ppm; HRMS (ESI-TOF): calcd for $\mathrm{C}_{29} \mathrm{H}_{22} \mathrm{~N}_{2} \mathrm{O}_{8} \mathrm{Na}^{+}[\mathrm{M}+\mathrm{Na}]^{+}$549.1268, found 549.1267.

The so-obtained Alloc-deprotected derivative ( $15 \mathrm{mg}, 28 \mu \mathrm{mol}, 1.0$ equiv) was dissolved in degassed THF (2.0 mL) and $\mathrm{MgBr}_{2} \cdot \mathrm{Et}_{2} \mathrm{O}(36 \mathrm{mg}, 142 \mu \mathrm{mol}, 5.0$ equiv) was added in one portion at $0^{\circ} \mathrm{C}$. The resulting mixture was stirred for $1.5 \mathrm{~h}$ at the same temperature. Then, the reaction mixture was quenched by addition of $\mathrm{pH} 6.8$ buffer $(6 \mathrm{~mL})$ and extracted with EtOAc $(3 \times 10 \mathrm{~mL})$. The combined organic layers were washed with brine $(8 \mathrm{~mL})$, dried over anhydrous $\mathrm{Na}_{2} \mathrm{SO}_{4}$ and concentrated under reduces pressure. Purification of the so-obtained residue by preparative thin layer chromatography (hexanes/EtOAc 1:4, v/v) afforded the required carbamate 29 (12 mg, $24 \mu \mathrm{mol}, 87 \%$ yield) as purple solid.

29: $R_{\mathrm{f}}=0.50$ (silica gel, $80 \%$ EtOAc in hexanes); $[\alpha]_{\mathrm{D}}^{23}=-83.5\left(c=1.6\right.$, EtOAc); FT-IR (film) $v_{\max }$ : 3499, 3368, 1714, 1632, 1588, 1475, 1460, 1379, 1313, 1268, 1219, 1201, 1097, 1068, 1038, 957, 933, 906, 794, $727 \mathrm{~cm}^{-1}$; ${ }^{1} \mathrm{H}$ NMR (THF- $\left.d_{8}, 600 \mathrm{MHz}\right): \delta 13.23$ (s, $\left.1 \mathrm{H}\right), 10.20$ (d, J=4.2 Hz, $1 \mathrm{H}$ ), $8.69(\mathrm{~s}, 1 \mathrm{H}), 8.32-8.25(\mathrm{~m}, 2 \mathrm{H}), 7.83-7.73(\mathrm{~m}, 2 \mathrm{H}), 5.87(\mathrm{~d}, J=9.9 \mathrm{~Hz}, 1 \mathrm{H}), 5.78-5.71(\mathrm{~m}, 3 \mathrm{H})$, $5.38(\mathrm{q}, J=6.6 \mathrm{~Hz}, 1 \mathrm{H}), 5.28-5.26(\mathrm{~m}, 1 \mathrm{H}), 4.98-4.95(\mathrm{~m}, 1 \mathrm{H}), 2.53(\mathrm{bs}, 1 \mathrm{H}), 1.44(\mathrm{~d}, J=6.6 \mathrm{~Hz}$, $3 \mathrm{H}) \mathrm{ppm} ;{ }^{13} \mathrm{C}$ NMR (THF- $\left.d_{8}, 151 \mathrm{MHz}\right): \delta 188.1,183.7,157.3,155.9,144.8,136.2,136.1,134.9$, 133.9, 133.7, 131.8, 127.5, 126.9, 124.0, 123.4, 114.0, 112.1, 100.9, 98.1, 91.1, 88.8, 79.4, 75.1, 66.2, 65.5, 43.8, 18.4 ppm; HRMS (ESI-TOF): calcd for $\mathrm{C}_{27} \mathrm{H}_{18} \mathrm{~N}_{2} \mathrm{O}_{7} \mathrm{Na}^{+}[\mathrm{M}+\mathrm{Na}]^{+}$505.1006, found 505.1004. 
(1aS,11S,11aR,18R)-3-(Methoxymethoxy)-4,9-dioxo-11a-\{(1R)-1-[(triethylsilyl)oxy]ethyl\}9,10,11,11a-tetrahydro-4H-11,1a-hept[3]ene[1,5]diynonaphtho[2,3-h] oxireno[c]quinolin-18yl acetate (56): To a solution of $\mathbf{5 3}\left(65 \mathrm{mg}, 90 \mu \mathrm{mol}, 1.0\right.$ equiv) in THF $(2 \mathrm{~mL})$ at $0{ }^{\circ} \mathrm{C}$ was

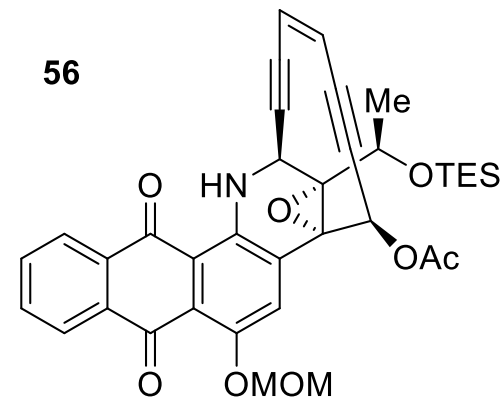
added $\mathrm{Pd}\left(\mathrm{PPh}_{3}\right)_{4}(8.6 \mathrm{mg}, 7.4 \mu \mathrm{mol}, 0.08$ equiv) followed by slow addition of morpholine ( $21 \mu \mathrm{L}, 240 \mu \mathrm{mol}, 2.6$ equiv) and allowed to stir for $2 \mathrm{~h}$. The cooling bath was removed, and the reaction mixture was stirred at $23^{\circ} \mathrm{C}$ for $20 \mathrm{~min}$. It was then quenched by addition of $\mathrm{pH} 6.8$ buffer $(7 \mathrm{~mL})$ and extracted with EtOAc $(3 \times 10 \mathrm{~mL})$. The organic extracts were washed with saturated aq. $\mathrm{NaHCO}_{3}$ solution $(8 \mathrm{~mL})$, brine $(8 \mathrm{~mL})$, dried over anhydrous $\mathrm{Na}_{2} \mathrm{SO}_{4}$, and concentrated under reduced pressure. The crude residue was purified by preparative thin layer chromatography (hexanes/EtOAc 1:1, $v / v$ ) to afford $\mathbf{5 6}(43 \mathrm{mg}, 67 \mu \mathrm{mol}, 74 \%$ yield) as orange foam.

56: $\mathrm{R}_{\mathrm{f}}=0.55$ (silica gel, $40 \%$ EtOAc in hexanes); $[\alpha]_{\mathrm{D}}^{23}=+77.9(c=0.63$, EtOAc); FT-IR (film) $v_{\max }: 3262,2954,2877,1756,1725,1666,1635,1593,1488,1357,1324,1284,1218,1197,1151$, 1120, 1094, 1059, 1030, 976, 925, 826, 780, $730 \mathrm{~cm}^{-1} ;{ }^{1} \mathrm{H}$ NMR (CD $\left.\mathrm{CDN}_{3}, 600 \mathrm{MHz}\right): \delta 9.86$ (d, $J=3.7 \mathrm{~Hz}, 1 \mathrm{H}), 8.44(\mathrm{~s}, 1 \mathrm{H}), 8.21-8.17(\mathrm{~m}, 1 \mathrm{H}), 8.15-8.09(\mathrm{~m}, 1 \mathrm{H}), 7.81-7.76(\mathrm{~m}, 2 \mathrm{H}), 6.14(\mathrm{~s}$, $1 \mathrm{H}), 5.96(\mathrm{~d}, J=10.0 \mathrm{~Hz}, 1 \mathrm{H}), 5.93(\mathrm{~d}, J=10.0 \mathrm{~Hz}, 1 \mathrm{H}), 5.25(\mathrm{~d}, J=7.0 \mathrm{~Hz}, 1 \mathrm{H}), 5.19$ (d, $J=7.0 \mathrm{~Hz}, 1 \mathrm{H}), 4.98-4.94(\mathrm{~m}, 1 \mathrm{H}), 4.62(\mathrm{q}, J=6.3 \mathrm{~Hz}, 1 \mathrm{H}), 3.54(\mathrm{~s}, 1 \mathrm{H}), 2.19(\mathrm{~s}, 3 \mathrm{H}), 1.45(\mathrm{~d}$, $J=6.3 \mathrm{~Hz}, 3 \mathrm{H}), 0.98(\mathrm{t}, J=7.9 \mathrm{~Hz}, 9 \mathrm{H}), 0.67(\mathrm{q}, J=7.9 \mathrm{~Hz}, 1 \mathrm{H}) \mathrm{ppm} ;{ }^{13} \mathrm{C} \mathrm{NMR}\left(\mathrm{CD}_{3} \mathrm{CN}\right.$, $151 \mathrm{MHz}$ ): $\delta$ 186.5, 183.2, 170.5, 149.7, 145.3, 134.7, 134.5, 131.5, 127.2, 127.1, 125.8, 123.5, 116.4, 99.4, 98.3, 96.9, 93.6, 88.8, 78.9, 67.5, 65.5, 64.1, 56.9, 44.7, 22.7, 21.0, 7.3, 5.6 ppm; HRMS (ESI-TOF): calcd for $\mathrm{C}_{36} \mathrm{H}_{37} \mathrm{NO}_{8} \mathrm{SiNa}^{+}[\mathrm{M}+\mathrm{Na}]^{+}$662.2181, found 662.2171.

(1aS,11S,11aS,18R)-11a-Acetyl-3-(methoxymethoxy)-4,9-dioxo-9,10,11,11a-tetrahydro-4H11,1a-hept[3]ene[1,5]diynonaphtho[2,3- $\boldsymbol{h}]$ oxireno[ $[\boldsymbol{c}]$ quinolin-18-yl acetate (57): To a stirred

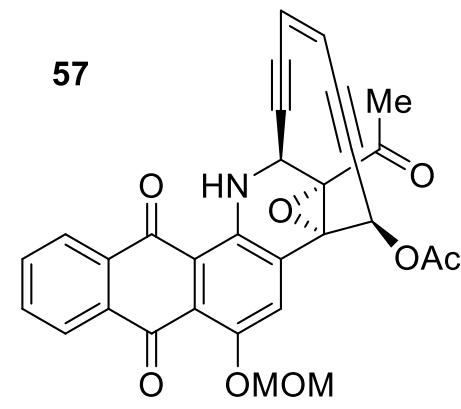
solution of $\mathbf{5 6}$ ( $46 \mathrm{mg}, 72 \mu \mathrm{mol}, 1.0$ equiv) in degassed THF $(3 \mathrm{~mL})$ at $0{ }^{\circ} \mathrm{C}$ was added a solution of $3 \mathrm{HF} \cdot \mathrm{Et}_{3} \mathrm{~N} / \mathrm{THF}(1.8 \mathrm{~mL}, 1: 1 \mathrm{v} / \mathrm{v}$, $10.8 \mathrm{mmol}, 150$ equiv). The sealed reaction flask was removed from the cooling bath, wrapped with aluminium foil, and the mixture was stirred at $23^{\circ} \mathrm{C}$ for $2 \mathrm{~h}$. The reaction mixture was partitioned between EtOAc $(12 \mathrm{~mL})$ and saturated aq. $\mathrm{NaHCO}_{3}$ solution $(5 \mathrm{~mL})$. The 
organic layer was washed with brine $(6 \mathrm{~mL})$, dried over anhydrous $\mathrm{Na}_{2} \mathrm{SO}_{4}$, and concentrated under reduced pressure. Purification of the so-obtained residue by preparative thin layer chromatography (hexanes/EtOAc 3:7, v/v) provided the intermediate hydroxyl-ketone compound (36 mg, $67.7 \mu \mathrm{mol}, 94 \%$ yield) as red foam.

hydroxyl-ketone intermediate: $\mathrm{R}_{\mathrm{f}}=0.25$ (silica gel, $40 \%$ EtOAc in hexanes); $[\alpha]_{\mathrm{D}}^{23}=-21.3(c=0.9$, EtOAc); FT-IR (film) v $v_{\max }$ : 3466, 3267, 3056, 2933, 1754, 1664, 1634, 1592, 1487, 1437, 1358, 1283, 1218, 1196, 1150, 1093, 1054, 1030, 971, 922, 903, 822, 800, 730, $700 \mathrm{~cm}^{-1} ;{ }^{1} \mathrm{H}$ NMR $\left(\mathrm{CD}_{3} \mathrm{CN}, 600 \mathrm{MHz}\right): \delta 9.88(\mathrm{~d}, J=4.0 \mathrm{~Hz}, 1 \mathrm{H}), 8.46(\mathrm{~s}, 1 \mathrm{H}), 8.22-8.17(\mathrm{~m}, 1 \mathrm{H}), 8.15-8.10(\mathrm{~m}$, $1 \mathrm{H}), 7.81-7.76(\mathrm{~m}, 2 \mathrm{H}), 6.21(\mathrm{~s}, 1 \mathrm{H}), 5.99-5.96(\mathrm{~m}, 1 \mathrm{H}), 5.96-5.91(\mathrm{~m}, 1 \mathrm{H}), 5.25(\mathrm{~d}, J=7.0 \mathrm{~Hz}$, $1 \mathrm{H}), 5.20(\mathrm{~d}, J=7.0 \mathrm{~Hz}, 1 \mathrm{H}), 4.92(\mathrm{dd}, J=4.4,1.4 \mathrm{~Hz}, 1 \mathrm{H}), 4.49-4.43$ (m, $1 \mathrm{H}), 3.54$ (s, $1 \mathrm{H}), 3.41$ $(\mathrm{d}, J=4.9 \mathrm{~Hz}, 1 \mathrm{H}), 2.19(\mathrm{~s}, 3 \mathrm{H}), 1.43(\mathrm{~d}, J=6.5 \mathrm{~Hz}, 3 \mathrm{H}) \mathrm{ppm} ;{ }^{13} \mathrm{C} \mathrm{NMR}\left(\mathrm{CD}_{3} \mathrm{CN}, 151 \mathrm{MHz}\right): \delta$ $186.5,183.2$, 170.5, 149.8, 145.2, 135.3, 134.8, 134.7, 134.5, 131.6, 130.8, 127.2, 127.1, 125.5, 123.7, 123.6, 116.5, 98.9, 98.3, 96.9, 93.6, 89.0, 78.7, 66.3, 65.5, 64.5, 56.9, 44.6, 21.3, 21.0 ppm; HRMS (ESI-TOF): calcd for $\mathrm{C}_{30} \mathrm{H}_{23} \mathrm{NO}_{8} \mathrm{Na}^{+}[\mathrm{M}+\mathrm{Na}]^{+}$548.1316, found 548.1303.

The hydroxyl-ketone compound was dissolved in $\mathrm{CH}_{2} \mathrm{Cl}_{2}(2 \mathrm{~mL})$ was sequentially added $\mathrm{NaHCO}_{3}\left(29 \mathrm{mg}, 340 \mu \mathrm{mol}, 5.0\right.$ equiv) and DMP ( $73 \mathrm{mg}, 170 \mu \mathrm{mol}, 2.5$ equiv) at $0{ }^{\circ} \mathrm{C}$. Stirring was continued for $3 \mathrm{~h}$ at $0{ }^{\circ} \mathrm{C}$ and then the reaction mixture was quenched by addition of saturated aqueous $\mathrm{Na}_{2} \mathrm{~S}_{2} \mathrm{O}_{3}$ and the reaction mixture was partitioned between EtOAc (12 mL) and saturated aq. $\mathrm{NaHCO}_{3}$ solution $(5 \mathrm{~mL})$. The organic layer was washed with brine $(6 \mathrm{~mL})$, dried over anhydrous $\mathrm{Na}_{2} \mathrm{SO}_{4}$, and concentrated under reduced pressure. Purification of the so-obtained residue by preparative thin layer chromatography (hexanes/EtOAc 2:3, v/v) provided 57 (30 mg, $58 \mu \mathrm{mol}, 86 \%$ yield) as orange foam.

57: $\mathrm{R}_{\mathrm{f}}=0.35$ (silica gel, 40\% EtOAc in hexanes); $[\alpha]_{\mathrm{D}}^{23}=+803.9(c=0.18$, EtOAc); FT-IR (film) $v_{\max }: 3257,3068,2925,2299,1759,1719,1667,1636,1592,1486,1434,1359,1283,1241,1217$, 1152, 1092, 1049, 1031, 981, 924, $736 \mathrm{~cm}^{-1} ;{ }^{1} \mathrm{H}$ NMR $\left(\mathrm{CD}_{3} \mathrm{CN}, 600 \mathrm{MHz}\right): \delta 9.86(\mathrm{~d}, J=3.8 \mathrm{~Hz}$, $1 \mathrm{H}), 8.50(\mathrm{~s}, 1 \mathrm{H}), 8.22-8.18(\mathrm{~m}, 1 \mathrm{H}), 8.16-8.11(\mathrm{~m}, 1 \mathrm{H}), 7.83-7.78(\mathrm{~m}, 2 \mathrm{H}), 6.02-5.96(\mathrm{~m}, 2 \mathrm{H})$, $5.92(\mathrm{~s}, 1 \mathrm{H}), 5.26(\mathrm{~d}, J=7.0 \mathrm{~Hz}, 1 \mathrm{H}), 5.21(\mathrm{~d}, J=7.0 \mathrm{~Hz}, 1 \mathrm{H}), 5.04(\mathrm{dd}, J=4.3,1.1 \mathrm{~Hz}, 1 \mathrm{H}), 3.54$ $(\mathrm{s}, 3 \mathrm{H}), 2.51(\mathrm{~s}, 3 \mathrm{H}), 2.21$ (s, $3 \mathrm{H}) \mathrm{ppm} ;{ }^{13} \mathrm{C} \mathrm{NMR}\left(\mathrm{CD}_{3} \mathrm{CN}, 151 \mathrm{MHz}\right): \delta 200.7,186.7,183.1$, 170.4 , 149.9, 144.9, 135.3, 134.9, 134.7, 134.6, 131.4, 129.3, 127.3, 127.2, 125.4, 124.2, 124.1, 117.2, 98.2, 98.0, 95.9, 93.4, 90.1, 77.8, 65.6, 65.3, 56.9, 45.5, 29.8, 21.0 ppm; HRMS (ESI-TOF): calcd for $\mathrm{C}_{30} \mathrm{H}_{21} \mathrm{NO}_{8} \mathrm{Na}^{+}[\mathrm{M}+\mathrm{Na}]^{+}$546.1159, found 546.1147. 
Methyl (2E)-3-[(1aS,11S,11aS,18R)-18-acetoxy-3-(methoxymethoxy)-4,9-dioxo-4,9,10,11tetrahydro-11aH-11,1a-hept[3] ene[1,5]diynonaphtho[2,3-h]oxireno[c]quinolin-11a-yl]but-

2-enoate (17): A mixture of methyl diethylphosphonoacetate $(28 \mu \mathrm{L}, 320 \mu \mathrm{mol}, 6.0$ equiv) and

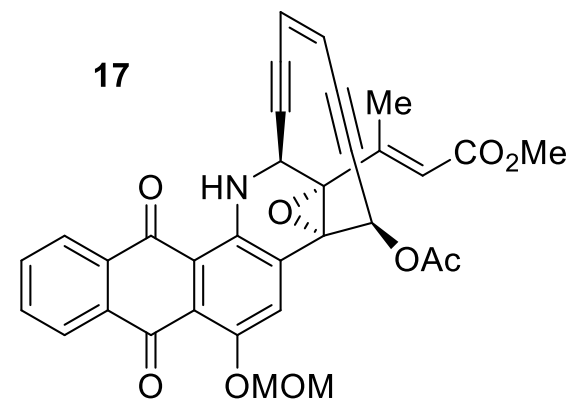
$\mathrm{NaH}(60 \%, 47 \mathrm{mg}, 1.2 \mathrm{mmol}, 5.0$ equiv) in THF $(2 \mathrm{~mL})$ was stirred at $0{ }^{\circ} \mathrm{C}$ for $1 \mathrm{~h}$. Then the solution of compound $\mathbf{5 7}$ ( $28 \mathrm{mg}, 54 \mu \mathrm{mol}, 1.0$ equiv) in THF $(2 \mathrm{~mL})$ was cannulated to the mixture at $-78^{\circ} \mathrm{C}$. After stirring for $15 \mathrm{~min}$, the reaction mixture was brought to $0^{\circ} \mathrm{C}$ and stirred for another $5 \mathrm{~h}$. The reaction mixture was then quenched by addition of $\mathrm{pH} 6.8$ buffer $(4 \mathrm{~mL})$ and extracted with EtOAc $(3 \times 10 \mathrm{~mL})$. The organic extracts were washed with saturated brine $(8 \mathrm{~mL})$, dried over anhydrous $\mathrm{Na}_{2} \mathrm{SO}_{4}$, and concentrated under reduced pressure. The crude residue was purified by preparative thin layer chromatography (hexanes/EtOAc 1:1, v/v) to afford 17 ( $25 \mathrm{mg}, 43 \mu \mathrm{mol}, 81 \%$ yield) an orange solid.

17: $\mathrm{R}_{\mathrm{f}}=0.62$ (silica gel, 50\% EtOAc in hexanes); $[\alpha]_{\mathrm{D}}^{23}=+829.4(c=0.5$, EtOAc); FT-IR (film) $v_{\max }: 2950,1760,1722,1666,1637,1593,1485,1435,1353,1285,1218,1197,1154,1090,1031$, 969, 803, $730 \mathrm{~cm}^{-1}$; ${ }^{1} \mathrm{H}$ NMR (CD $\left.3 \mathrm{CN}, 600 \mathrm{MHz}\right): \delta 9.86$ (d, J=3.8 Hz, $\left.1 \mathrm{H}\right), 8.42(\mathrm{~s}, 1 \mathrm{H}), 8.22-$ $8.17(\mathrm{~m}, 1 \mathrm{H}), 8.17-8.11(\mathrm{~m}, 1 \mathrm{H}), 7.83-7.77(\mathrm{~m}, 2 \mathrm{H}), 6.52(\mathrm{~s}, 1 \mathrm{H}), 6.07-6.02(\mathrm{~m}, 1 \mathrm{H}), 6.01-5.96$ $(\mathrm{m}, 1 \mathrm{H}), 5.72(\mathrm{~s}, 1 \mathrm{H}), 5.26(\mathrm{~d}, J=7.0 \mathrm{~Hz}, 1 \mathrm{H}), 5.21(\mathrm{~d}, J=7.0 \mathrm{~Hz}, 1 \mathrm{H}), 4.78(\mathrm{dd}, J=4.3,1.3 \mathrm{~Hz}$, $1 \mathrm{H}), 3.71(\mathrm{~S}, 3 \mathrm{H}), 3.54(\mathrm{~s}, 3 \mathrm{H}), 2.38(\mathrm{~d}, J=1.0 \mathrm{~Hz}, 3 \mathrm{H}), 2.18(\mathrm{~s}, 3 \mathrm{H}) \mathrm{ppm} ;{ }^{13} \mathrm{C} \mathrm{NMR}\left(\mathrm{CD}_{3} \mathrm{CN}\right.$, $151 \mathrm{MHz}): \delta 186.7,183.2,170.3,166.9,149.9,148.3,144.9,135.4,134.8,134.7,134.6,131.3$, 129.9, 127.3, 127.2, 125.3, 124.3, 123.9, 122.6, 177.1, 98.5, 98.2, 96.9, 94.2, 89.9, 78.2, 66.9, 66.6, 56.9, 52.1, 47.3, 21.0, 17.4 ppm; HRMS (ESI-TOF): calcd for $\mathrm{C}_{33} \mathrm{H}_{25} \mathrm{NO}_{9} \mathrm{Na}^{+}[\mathrm{M}+\mathrm{Na}]^{+} 602.1422$, found 602.1412 .

(2E)-3-[(1aS,11S,11aS,18R)-18-Hydroxy-3-(methoxymethoxy)-4,9-dioxo-4,9,10,11-tetrahydro-11a $H$-11,1a-hept[3] ene[1,5]diynonaphtho[2,3-h]oxireno[c]quinolin-11a-yl]but-2enoic acid (18): To a solution of compound 17 (40 mg, $69 \mu \mathrm{mol}, 1.0$ equiv) in $\mathrm{THF} / \mathrm{H}_{2} \mathrm{O}(3: 1$, 


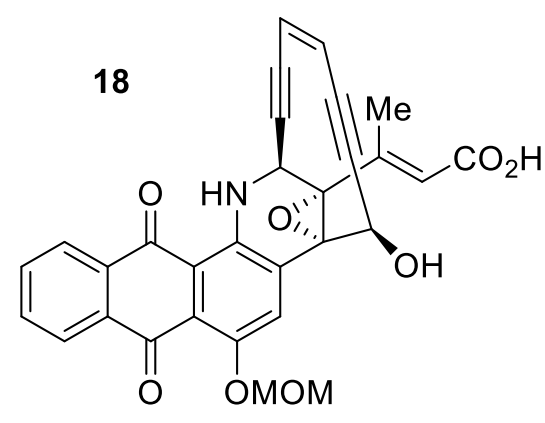

$v / v, 10 \mathrm{~mL} / \mathrm{mmol})$ at $0{ }^{\circ} \mathrm{C}$ was added $\mathrm{LiOH}(16 \mathrm{mg}, 690 \mu \mathrm{mol}$, 10 equiv) and the mixture was stirred at $23^{\circ} \mathrm{C}$ for $12 \mathrm{~h}$. The reaction mixture was then quenched by addition of $\mathrm{pH} 6.8$ buffer $(4 \mathrm{~mL})$, brine $(2 \mathrm{~mL})$ and extracted with EtOAc $(3 \times 10 \mathrm{~mL})$. The organic extracts were washed with saturated brine $(8 \mathrm{~mL})$, dried over anhydrous $\mathrm{Na}_{2} \mathrm{SO}_{4}$, and concentrated under reduced pressure. The crude residue was purified by preparative thin layer chromatography (EtOAc/MeOH $4: 1, v / v)$ to afford $18(31 \mathrm{mg}, 60 \mu \mathrm{mol}, 87 \%$ yield $)$ as orange solid.

18: $\mathrm{R}_{\mathrm{f}}=0.58$ (silica gel, $20 \% \mathrm{MeOH}$ in EtOAc); $[\alpha]_{\mathrm{D}}^{23}=-80.0\left(c=0.36\right.$, EtOAc); FT-IR (film) $v_{\max }$ : 3264, 2924, 2853, 1698, 1659, 1591, 1484, 1435, 1362, 1281, 1249, 1234, 1194, 1153, 1095, 1070, 1053, 1018, 971, 891, 799, $731 \mathrm{~cm}^{-1} ;{ }^{1} \mathrm{H}$ NMR $\left(\mathrm{CD}_{3} \mathrm{CN}, 600 \mathrm{MHz}\right): \delta 9.86(\mathrm{~d}, J=4.1 \mathrm{~Hz}, 1 \mathrm{H})$, 8.67 (s, $1 \mathrm{H}), 8.22-8.17$ (m, $1 \mathrm{H}), 8.15-8.11(\mathrm{~m}, 1 \mathrm{H}), 7.81-7.76$ (m, 2 H), 6.46 (s, 1 H), 6.04-5.99 (m, $1 \mathrm{H}), 5.94-5.89(\mathrm{~m}, 1 \mathrm{H}), 5.18(\mathrm{~d}, J=6.8 \mathrm{~Hz}, 1 \mathrm{H}), 5.17(\mathrm{~d}, J=6.8 \mathrm{~Hz}, 1 \mathrm{H}), 4.93(\mathrm{~s}, 1 \mathrm{H}), 4.72$ $(\mathrm{dd}, J=4.3,1.4 \mathrm{~Hz}, 1 \mathrm{H}), 3.51(\mathrm{~S}, 3 \mathrm{H}), 2.34(\mathrm{~d}, J=1.0 \mathrm{~Hz}, 3 \mathrm{H}) \mathrm{ppm} ;{ }^{13} \mathrm{C} \mathrm{NMR}\left(\mathrm{CD}_{3} \mathrm{CN}\right.$, $151 \mathrm{MHz}): \delta 186.6,183.2,167.1,149.6,149.3,145.4,135.3,134.7,134.5,133.1,131.1,127.2$, 127.1, 124.8, 124.3, 123.9, 122.1, 116.7, 100.9, 98.5, 98.4, 92.0, 89.9, 77.8, 67.8, 66.4, 57.0, 47.4, 17.4 ppm; HRMS (ESI-TOF): calcd for $\mathrm{C}_{30} \mathrm{H}_{21} \mathrm{NO}_{8} \mathrm{Na}^{+}[\mathrm{M}+\mathrm{Na}]^{+} 546.1159$, found 546.1142 .

(2E)-3-[(1aS,11S,11aS,18R)-3,18-Dihydroxy-4,9-dioxo-4,9,10,11-tetrahydro-11a $H$-11,1ahept[3] ene[1,5]diynonaphtho[2,3- $h]$ oxireno[c]quinolin-11a-yl]but-2-enoic acid (19): To a

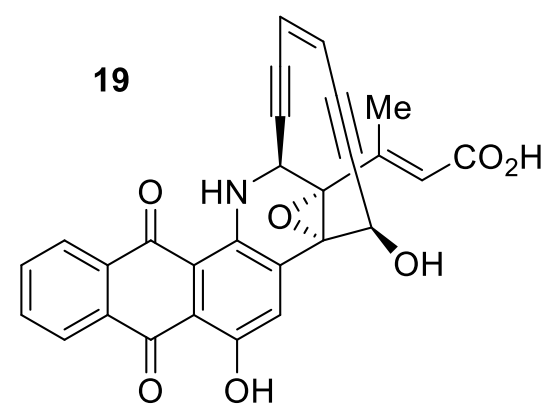

stirred solution of hydroxy-acid 19 ( $25 \mathrm{mg}, 48 \mu \mathrm{mol}, 1.0$ equiv) in degassed THF $(2.0 \mathrm{~mL})$ was added at $0{ }^{\circ} \mathrm{C}$ and in one portion $\mathrm{MgBr}_{2} \cdot \mathrm{Et}_{2} \mathrm{O}$ (62 mg, $240 \mu \mathrm{mol}$, 5.0 equiv). The resulting mixture was stirred for $12 \mathrm{~h}$ at $23^{\circ} \mathrm{C}$. Then, the reaction mixture was quenched by addition of $\mathrm{pH} 6.8$ buffer $(6 \mathrm{~mL})$ and extracted with EtOAc $(3 \times 10 \mathrm{~mL})$. The combined organic layers were washed with brine $(8 \mathrm{~mL})$, dried over anhydrous $\mathrm{Na}_{2} \mathrm{SO}_{4}$ and concentrated under reduces pressure. Purification of the so-obtained residue by preparative thin layer chromatography (EtOAc/MeOH 4:1, v/v) afforded acid 19 (23 mg, $48 \mu \mathrm{mol}$, quant. yield) as purple solid.

19: $\mathrm{R}_{\mathrm{f}}=0.68$ (silica gel, $20 \% \mathrm{MeOH}$ in EtOAc). $[\alpha]_{\mathrm{D}}^{23}=-71.1\left(c=0.81\right.$, EtOAc); FT-IR (film) $v_{\max }$ : $3408,2924,2853,2298,1697,1623,1587,1464,1377,1354,1230,1131,996,795,730 \mathrm{~cm}^{-1}$; 
${ }^{1} \mathrm{H}$ NMR $\left(\mathrm{CD}_{3} \mathrm{CN}, 600 \mathrm{MHz}\right): \delta 13.13(\mathrm{~s}, 1 \mathrm{H}), 9.95(\mathrm{~d}, J=3.9 \mathrm{~Hz}, 1 \mathrm{H}), 8.42(\mathrm{~s}, 1 \mathrm{H}), 8.30-8.26$ (m, 2 H), 7.89-7.81 (m, 2 H), $6.47(\mathrm{~s}, 1 \mathrm{H}), 6.05-5.99(\mathrm{~m}, 1 \mathrm{H}), 5.94-5.90(\mathrm{~m}, 1 \mathrm{H}), 4.99(\mathrm{~s}, 1 \mathrm{H})$, $4.72(\mathrm{dd}, J=4.3,1.4 \mathrm{~Hz}, 1 \mathrm{H}), 2.33(\mathrm{~d}, J=1.0 \mathrm{~Hz}, 3 \mathrm{H}) \mathrm{ppm} ;{ }^{13} \mathrm{C} \mathrm{NMR}\left(\mathrm{CD}_{3} \mathrm{CN}, 151 \mathrm{MHz}\right): \delta 188.8$, 184.7, 167.7, 156.7, 147.8, 144.4, 135.8, 135.7, 135.5, 134.6, 133.7, 130.8, 127.8, 127.2, 124.8, 124.2, 123.1, 114.6, 113.2, 100.9, 98.7, 92.0, 89.9, 76.9, 67.8, 66.2, 47.3,17.5 ppm; HRMS (ESITOF): calcd for $\mathrm{C}_{28} \mathrm{H}_{18} \mathrm{NO}_{7}{ }^{+}[\mathrm{M}+\mathrm{H}]^{+} 480.1078$, found 480.1062 .

(2E)-3-[(1aS,11S,11aS,18R)-3,18-Dihydroxy-4,9-dioxo-4,9,10,11-tetrahydro-11aH-11,1ahept[3] ene[1,5]diynonaphtho[2,3-h]oxireno[c]quinolin-11a-yl]but-2-enamide (20): To a

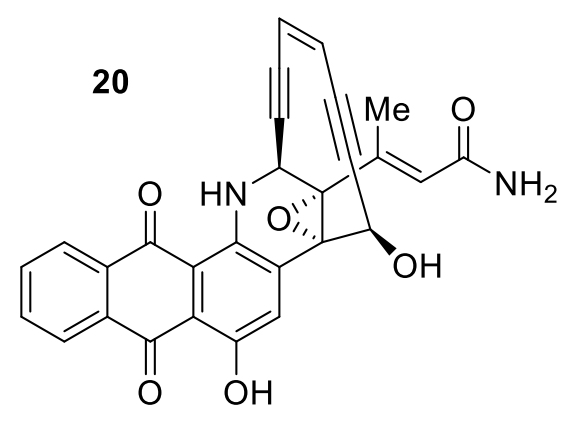

stirred solution of the acid $\mathbf{1 9}(8.0 \mathrm{mg}, 17 \mu \mathrm{mol}, 1.0$ equiv) in $\mathrm{CH}_{2} \mathrm{Cl}_{2}$ at $0{ }^{\circ} \mathrm{C}$ were sequentially added 1-hydroxy-7azabenztriazole (HOAt, $3.5 \mathrm{mg}, 26 \mu \mathrm{mol}, 1.5$ equiv) and 1 ethyl-3-[3-(dimethylamino)propyl]carbodimide hydrochloride (EDCI, $4.9 \mathrm{mg}, 25.5 \mathrm{mmol}, 1.5$ equiv). After $10 \mathrm{~min}, \mathrm{NH}_{3}$ in THF ( $0.4 \mathrm{M}, 55 \mu \mathrm{L}, 22 \mu \mathrm{mol}, 1.3$ equiv) was added into the reaction mixture followed by addition of DIPEA $(15 \mu \mathrm{L}, 85 \mu \mathrm{mol}, 5.0$ equiv). The reaction mixture was brought to $23^{\circ} \mathrm{C}$ and stirred for $12 \mathrm{~h}$. Then, the reaction mixture was quenched by addition of pH 6.8 buffer $(6 \mathrm{~mL})$ and extracted with EtOAc $(3 \times 10 \mathrm{~mL})$. The combined organic layers were washed with brine $(8 \mathrm{~mL})$, dried over anhydrous $\mathrm{Na}_{2} \mathrm{SO}_{4}$ and concentrated under reduces pressure. Purification of the so-obtained residue by preparative thin layer chromatography (EtOAc/MeOH 19:1, v/v) afforded the required amide 20 (17 $\mathrm{mg}, 23 \mu \mathrm{mol}, 74 \%$ yield $)$ as purple solid.

20: $\mathrm{R}_{\mathrm{f}}=0.70$ (silica gel, $10 \% \mathrm{MeOH}$ in EtOAc); $[\alpha]_{\mathrm{D}}^{23}=-53.2\left(c=0.44\right.$, EtOAc); FT-IR (film) $v_{\max }$ : 3344, 2922, 2853, 2308, 1663, 1619, 1587, 1482, 1374, 1353, 1287, 1270, 1231, 1205, 1144, 1098, 1076, 1043, 1018, 961, 903, 815, 794, $729 \mathrm{~cm}^{-1}$; ${ }^{1} \mathrm{H}$ NMR (CD $\left.{ }_{3} \mathrm{CN}, 600 \mathrm{MHz}\right): \delta 13.14$ (s, $\left.1 \mathrm{H}\right)$, $9.95(\mathrm{~d}, J=3.8 \mathrm{~Hz}, 1 \mathrm{H}), 8.41(\mathrm{~s}, 1 \mathrm{H}), 8.30-8.26(\mathrm{~m}, 2 \mathrm{H}), 7.89-7.80(\mathrm{~m}, 2 \mathrm{H}), 6.45(\mathrm{~s}, 1 \mathrm{H}), 6.27$ (bs, 1 H), 6.04-6.00 (m, 1 H), 5.94-5.90 (m, 1 H), 5.80 (bs, 1 H), 4.98 (bs, $1 \mathrm{H}), 4.71$ (dd, $J=4.3$, $1.3 \mathrm{~Hz}, 1 \mathrm{H}), 4.44$ (bs, $1 \mathrm{H}), 2.30$ (bs, $3 \mathrm{H}) \mathrm{ppm} ;{ }^{13} \mathrm{C} \mathrm{NMR}\left(\mathrm{CD}_{3} \mathrm{CN}, 151 \mathrm{MHz}\right): \delta 188.8,184.6$, 168.5, 156.7, 144.5, 143.0, 135.8, 135.7, 135.6, 134.6, 133.7, 130.8, 127.8, 127.2, 125.7, 124.7, 124.2, 114.6, 113.2, 100.9, 98.8, 92.1, 90.1, 76.8, 67.8, 66.0, 47.4, 17.3 ppm; HRMS (ESI-TOF): calcd for $\mathrm{C}_{28} \mathrm{H}_{18} \mathrm{~N}_{2} \mathrm{O}_{6} \mathrm{Na}^{+}[\mathrm{M}+\mathrm{Na}]^{+}$501.1057, found 501.1047. 
9H-Fluoren-9-ylmethyl [2-(\{(2E)-3-[(1aS,11S,11aS,18R)-3,18-dihydroxy-4,9-dioxo4,9,10,11-tetrahydro-11a $H-11,1 \mathrm{a}-h e p t[3]$ ene[1,5]diynonaphtho[2,3- $h]$ oxireno[c]quinolin11a-yl]but-2-enoyl \}amino)ethyl]carbamate (21): To a stirred solution of the acid $\mathbf{1 9}$ (15 mg,

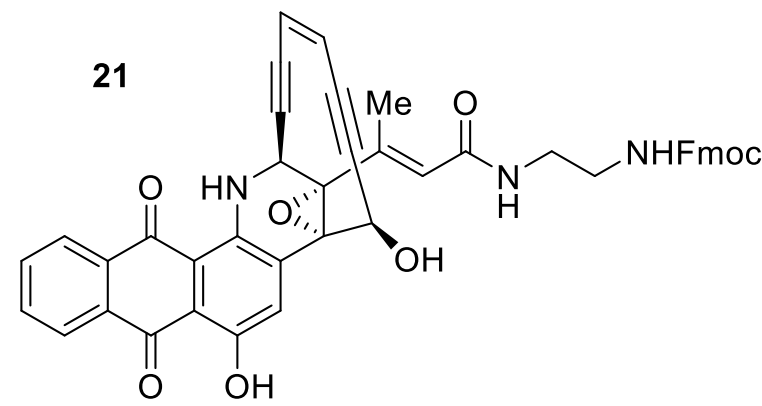
$31 \mu \mathrm{mol}$, 1.0 equiv) in $\mathrm{CH}_{2} \mathrm{Cl}_{2}$ at $0^{\circ} \mathrm{C}$ were sequentially added 1-hydroxy-7-azabenztriazole (HOAt, $6.4 \mathrm{mg}, 46.9 \mu \mathrm{mol}, 1.5$ equiv) and 1-ethyl3-[3-(dimethylamino)propyl]carbodimide hydrochloride (EDCI, $9.0 \mathrm{mg}, 47 \mathrm{mmol}, 1.5$ equiv). After 10 min, $\mathrm{NH}_{2} \mathrm{CH}_{2} \mathrm{CH}_{2} \mathrm{NHFmoc} \quad(\mathbf{5 8}, 12 \mathrm{mg}$, $41 \mu \mathrm{mol}, 1.3$ equiv) was added into the reaction mixture followed by addition of DIPEA ( $27 \mu \mathrm{L}$, $160 \mu \mathrm{mol}, 5.0$ equiv). The reaction mixture was brought to $23^{\circ} \mathrm{C}$ and stirred for $1 \mathrm{~h}$. Then, the reaction mixture was quenched by addition of $\mathrm{pH} 6.8$ buffer $(6 \mathrm{~mL})$ and extracted with EtOAc $(3 \times 10 \mathrm{~mL})$. The combined organic layers were washed with brine $(8 \mathrm{~mL})$, dried over anhydrous $\mathrm{Na}_{2} \mathrm{SO}_{4}$ and concentrated under reduces pressure. Purification of the so-obtained residue by preparative thin layer chromatography (EtOAc) afforded the required amide 21 (17 mg, $23 \mu \mathrm{mol}$, $74 \%$ yield) as red foam.

21: $\mathrm{R}_{\mathrm{f}}=0.75$ (silica gel, 5\% MeOH in EtOAc); $[\alpha]_{\mathrm{D}}^{23}=-163.7$ ( $c=0.24$, EtOAc); FT-IR (film) $v_{\max }$ : 3374, 1923, 2855, 2304, 1694, 1624, 1587, 1550, 1476, 1449, 1353, 1269, 1228, 1079, 907, 806, 759, $726 \mathrm{~cm}^{-1}$; ${ }^{1} \mathrm{H}$ NMR $\left(\mathrm{CD}_{3} \mathrm{CN}, 600 \mathrm{MHz}\right): \delta 13.13(\mathrm{~s}, 1 \mathrm{H}), 9.93(\mathrm{~d}, J=4.1 \mathrm{~Hz}, 1 \mathrm{H}), 8.41(\mathrm{~s}$, $1 \mathrm{H}), 8.30-8.26$ (m, 2H), 7.89-7.81 (m, 4H), 7.67-7.64 (m, 2 H), 7.44-7.40 (m, 2 H), 7.36-7.32 (m, 2H), $6.70(\mathrm{t}, J=6.0 \mathrm{~Hz}, 1 \mathrm{H}), 6.40-6.38(\mathrm{~m}, 1 \mathrm{H}), 6.00-5.96(\mathrm{~m}, 1 \mathrm{H}), 5.91-5.83(\mathrm{~m}, 2 \mathrm{H}), 4.96$ $(\mathrm{d}, J=4.4 \mathrm{~Hz}, 1 \mathrm{H}), 4.64(\mathrm{~d}, J=3.0 \mathrm{~Hz}, 1 \mathrm{H}), 4.42(\mathrm{~d}, J=4.6 \mathrm{~Hz}, 1 \mathrm{H}), 4.34(\mathrm{~d}, J=6.9 \mathrm{~Hz}, 2 \mathrm{H}), 4.23$ $(\mathrm{t}, J=6.9 \mathrm{~Hz}, 1 \mathrm{H}), 3.34-3.19(\mathrm{~m}, 4 \mathrm{H}), 2.28(\mathrm{~d}, J=1.0 \mathrm{~Hz}, 3 \mathrm{H}) \mathrm{ppm} ;{ }^{13} \mathrm{C} \mathrm{NMR}\left(\mathrm{CD}_{3} \mathrm{CN}\right.$, $151 \mathrm{MHz}$ ): $\delta$ 188.8, 184.6, 167.2, 157.7, 156.7, 145.3, 145.2, 144.4, 142.4, 142.2, 135.8, 135.7, 135.6, 134.6, 133.7, 130.7, 128.7, 128.1, 127.8, 127.2, 126.2, 126.1, 124.8, 124.2, 121.0, 114.6, 113.1, 100.9, 98.7, 92.2, 90.1 , 76.8, 67.7, 67.0, 66.1, 48.2 , 47.4, 41.5, 40.1, 17.4 ppm; HRMS (ESITOF): calcd for $\mathrm{C}_{45} \mathrm{H}_{33} \mathrm{~N}_{3} \mathrm{O}_{8} \mathrm{Na}^{+}[\mathrm{M}+\mathrm{Na}]^{+}$766.2160, found 766.2137. 
(2E)- $N$-(2-Aminoethyl)-3-[(1aS,11S,11aS,18R)-3,18-dihydroxy-4,9-dioxo-4,9,10,11-tetrahydro-11aH-11,1a-hept[3] ene[1,5]diynonaphtho[2,3-h]oxireno[c]quinolin-11a-yl]but-2enamide (22): To a stirred solution of the amide 21 (9.0 mg, $12 \mu \mathrm{mol}, 1.0$ equiv) in DMSO

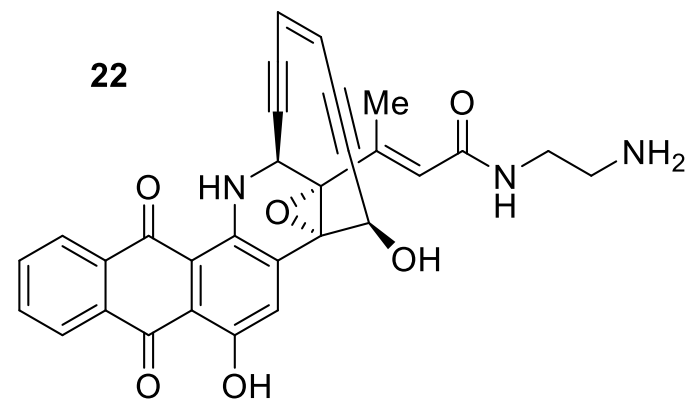
$(1 \mathrm{~mL})$ at $23^{\circ} \mathrm{C}$ was added diethylamine $(25 \mu \mathrm{L}$, $240 \mu \mathrm{mol}, 20$ equiv). The reaction mixture was stirred for $15 \mathrm{~min}$. Then, the reaction mixture was quenched by addition of $\mathrm{pH} 6.8$ buffer $(6 \mathrm{~mL})$ and extracted with EtOAc $(3 \times 10 \mathrm{~mL})$. The combined organic layers were washed with brine $(8 \mathrm{~mL})$, dried over anhydrous $\mathrm{Na}_{2} \mathrm{SO}_{4}$ and concentrated under reduces pressure. Purification of the so-obtained residue by preparative thin layer chromatography $(\mathrm{MeOH} /$ acetone 3:2, v/v) afforded primary amine 22 (6.3 mg, $12 \mu \mathrm{mol}$, quant. yield) as purple solid.

22: $\mathrm{R}_{\mathrm{f}}=0.25$ (silica gel, $60 \% \mathrm{MeOH}$ in acetone); $[\alpha]_{\mathrm{D}}^{23}=-382.3(c=0.17, \mathrm{MeOH})$; FT-IR (film) $v_{\max }: 3265,2924,2853,1725,1622,1587,1558,1482,1468,1378,1353,1269,1248,1233,1100$, 1077, 1019, 971, 901, 794, $730 \mathrm{~cm}^{-1} ;{ }^{1} \mathrm{H}$ NMR (THF-d8, $\left.600 \mathrm{MHz}\right): \delta 13.24$ (brs, $\left.1 \mathrm{H}\right), 10.13$ (d, $J=4.1 \mathrm{~Hz}, 1 \mathrm{H}), 8.57(\mathrm{~s}, 1 \mathrm{H}), 8.31(\mathrm{dd}, J=3.8,1.1 \mathrm{~Hz}, 1 \mathrm{H}), 8.30(\mathrm{dd}, J=4.1,1.5 \mathrm{~Hz}, 1 \mathrm{H}), 7.82(\mathrm{dt}$, $J=7.5,1.3 \mathrm{~Hz}, 1 \mathrm{H}), 7.79$ (dt, $J=7.5,1.5 \mathrm{~Hz}, 1 \mathrm{H}), 7.26$ (brs, $1 \mathrm{H}), 6.37$ (brs, $1 \mathrm{H}$ ), 5.98 (d, $J=9.9 \mathrm{~Hz}$, $1 \mathrm{H}), 5.88-5.85$ (m, $1 \mathrm{H}), 5.75$ (brs, $1 \mathrm{H}), 4.94$ (brs, $1 \mathrm{H}), 4.72$ (dd, $J=4.4,1.4 \mathrm{~Hz}, 1 \mathrm{H}), 3.32-3.22$ $(\mathrm{m}, 2 \mathrm{H}), 2.90-2.83(\mathrm{~m}, 1 \mathrm{H}), 2.78-2.70(\mathrm{~m}, 1 \mathrm{H}), 2.44$ (brs, $3 \mathrm{H}) \mathrm{ppm} ;{ }^{13} \mathrm{C} \mathrm{NMR}\left(\mathrm{THF}-d_{8}\right.$, $151 \mathrm{MHz}): \delta 188.1,183.7,165.7,160.8,144.6,143.2,135.8,134.8,133.7,133.6,131.1,127.4$, 126.8, 125.9, 124.2, 123.4, 113.9, 112.4, 101.5, 98.8, 91.4, 89.9, 76.5, 65.9, 47.1, 46.6, 40.6, 30.4, 30.2, 17.2 ppm; HRMS (ESI-TOF): calcd for $\mathrm{C}_{30} \mathrm{H}_{24} \mathrm{~N}_{3} \mathrm{O}_{6}{ }^{+}[\mathrm{M}+\mathrm{H}]^{+}$522.1660, found 522.1655. 


\section{Synthesis of Analogues 23, 24 and 30}

Allyl $(1 \mathrm{a} S, 11 S, 11 \mathrm{a} R, 18 R)-18$-acetoxy-6-(\{[(allyloxy)carbonyl $]$ (methyl)amino\}methyl)-3hydroxy-4,9-dioxo-11a- $\{(1 R)-1-[($ triethylsilyl)oxy $]$ ethyl $\}-4,9,11,11 a-t e t r a h y d r o-10 H-11,1 a-$ hept[3]ene[1,5]diynonaphtho[2,3-h] oxireno[c] quinoline-10-carboxylate (60): To a stirred

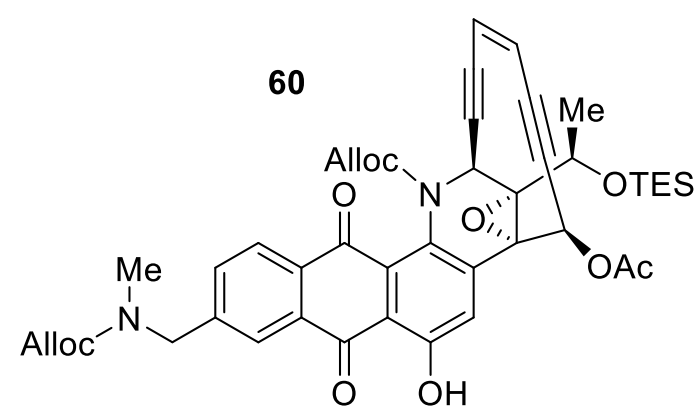

solution of cyanophthalide $\mathbf{5 9}(80 \mathrm{mg}, 280 \mu \mathrm{mol}$, 3.0 equiv; previously dried azeotropically with benzene) in degassed THF $(1.0 \mathrm{~mL})$ was added dropwise at $-78^{\circ} \mathrm{C}$ LiHMDS solution $(1 \mathrm{M}$ in THF, $370 \mu \mathrm{L}, 370 \mu \mathrm{mol}, 4.0$ equiv). The resulting mixture was stirred for $0.5 \mathrm{~h}$ at the same temperature. A

solution of semiquinone aminal $39(50 \mathrm{mg}, 93 \mu \mathrm{mol}, 1.0$ equiv; previously dried azeotropically with benzene) in degassed THF $(1.0 \mathrm{~mL})$ was added dropwise and the mixture was stirred for $20 \mathrm{~min}$ at $-78^{\circ} \mathrm{C}$. Then, the reaction mixture was brought to $23^{\circ} \mathrm{C}$ and stirred for additional $2 \mathrm{~h}$. The reaction mixture was quenched by addition of $\mathrm{pH} 6.8$ buffer $(7 \mathrm{~mL})$ and extracted with EtOAc $(3 \times 20 \mathrm{~mL})$. The combined organic extracts were dried over anhydrous $\mathrm{Na}_{2} \mathrm{SO}_{4}$ and concentrated under reduced pressure to furnish the impure Alloc-protected anthraquinone as a red solid, which was then dissolved in $\mathrm{CH}_{2} \mathrm{Cl}_{2}(2.0 \mathrm{~mL})$ was sequentially added $i-\mathrm{Pr}_{2} \mathrm{NEt}(32 \mu \mathrm{L}, 190 \mu \mathrm{mol}$, 2.0 equiv), DMAP (1.1 mg, $9.3 \mu \mathrm{mol}, 0.1$ equiv) and $\mathrm{Ac}_{2} \mathrm{O}\left(18 \mu \mathrm{L}, 186 \mu \mathrm{mol}, 2.0\right.$ equiv) at $0{ }^{\circ} \mathrm{C}$ and the resulting mixture was stirred for $10 \mathrm{~min}$ at the same temperature. Then, the reaction mixture was quenched by addition of $\mathrm{pH} 6.8$ buffer $(6 \mathrm{~mL})$ and extracted with EtOAc $(3 \times 10 \mathrm{~mL})$. The combined organic layers were washed with brine $(8 \mathrm{~mL})$, dried over anhydrous $\mathrm{Na}_{2} \mathrm{SO}_{4}$ and concentrated under reduce pressure. Purification of the so-obtained residue by preparative thin layer chromatography (hexanes/EtOAc 3:2, v/v) afforded the protected anthraquinone $\mathbf{6 0}(49 \mathrm{mg}$, $61.4 \mu \mathrm{mol}, 66 \%$ yield over two steps) as yellow foam.

60: $\mathrm{R}_{\mathrm{f}}=0.50$ (silica gel, $35 \%$ EtOAc in hexanes); $[\alpha]_{\mathrm{D}}^{23}=-302.8(c=0.7$, EtOAc); FT-IR (film) $v_{\max }: 2955,2930,2875,1759,1710,1673,1640,1602,1459,1436,1400,1370,1282,1216,1154$, 1053, 1022, 943, 777, $731 \mathrm{~cm}^{-1}$; ${ }^{1} \mathrm{H}$ NMR (CD $\left.{ }_{3} \mathrm{CN}, 600 \mathrm{MHz}\right): \delta 12.89$ (s, $\left.1 \mathrm{H}\right), 8.16$ (s, $\left.1 \mathrm{H}\right), 8.14$ $(\mathrm{d}, J=8.1 \mathrm{~Hz}, 1 \mathrm{H}), 8.07(\mathrm{~s}, 1 \mathrm{H}), 7.73(\mathrm{~d}, J=7.1 \mathrm{~Hz}, 1 \mathrm{H}), 6.21(\mathrm{~s}, 1 \mathrm{H}), 5.96(\mathrm{~d}, J=5.8 \mathrm{~Hz}, 1 \mathrm{H})$, $5.89(\mathrm{~d}, J=1.6 \mathrm{~Hz}, 1 \mathrm{H}), 5.84-5.81(\mathrm{~m}, 1 \mathrm{H}), 5.65-5.57(\mathrm{~m}, 1 \mathrm{H}), 4.99(\mathrm{dq}, J=17.3,1.5 \mathrm{~Hz}, 1 \mathrm{H})$, 4.94-4.90 (m, 1 H), 4.71-4.55 (m, 9H), 4.46-4.37 (m, 2H), 2.93 (s, 3H), 2.19 (s, $3 \mathrm{H}), 1.47$ (d, 
$J=6.4 \mathrm{~Hz}, 3 \mathrm{H}), 0.98(\mathrm{t}, J=7.9 \mathrm{~Hz}, 9 \mathrm{H}), 0.67(\mathrm{q}, J=7.9 \mathrm{~Hz}, 6 \mathrm{H}) \mathrm{ppm} ;{ }^{13} \mathrm{C} \mathrm{NMR}\left(\mathrm{CD}_{3} \mathrm{CN}\right.$, $151 \mathrm{MHz}): \delta 189.8,183.0,170.5,160.5,155.3,146.3,139.3,134.7,133.5,133.4,133.1,130.9$, 128.9, 127.9, 127.5, 127.2, 125.0, 124.5, 116.9, 96.7, 96.2, 94.3, 91.5, 77.6, 67.8, 67.4, 66.8, 65.3, 65.0, 47.9, 22.5, 21.1, 7.2, 5.6 ppm; HRMS (ESI-TOF): calcd for $\mathrm{C}_{44} \mathrm{H}_{46} \mathrm{~N}_{2} \mathrm{O}_{11} \mathrm{SiNa}^{+}[\mathrm{M}+\mathrm{Na}]^{+}$ 829.2763 , found 829.2756 .

Allyl (1aS,11S,11aR,18R)-18-acetoxy-6-(\{[(allyloxy)carbonyl](methyl)amino\}methyl)-3hydroxy -11a-[(1R)-1-hydroxyethyl]-4,9-dioxo-4,9,11,11a-tetrahydro-10H-11,1ahept[3]ene[1,5]diynonaphtho[2,3-h] oxireno[c]quinoline-10-carboxylate (61): To a stirred

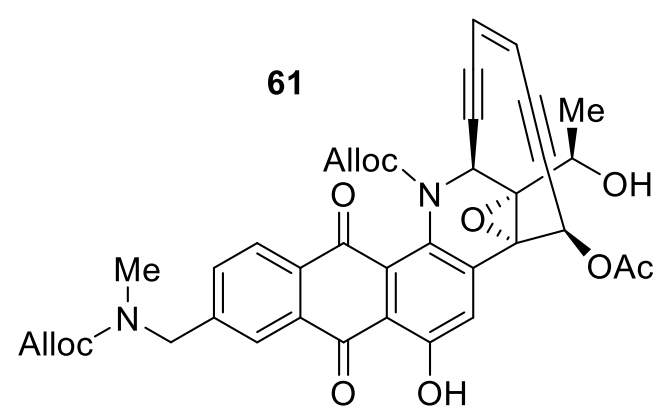
solution of 60 ( $47 \mathrm{mg}, 58 \mu \mathrm{mol}, 1.0$ equiv) in degassed THF $(3 \mathrm{~mL})$ at $0^{\circ} \mathrm{C}$ was added a solution of $3 \mathrm{HF} \cdot \mathrm{Et}_{3} \mathrm{~N} / \mathrm{THF}(1.42 \mathrm{~mL}, 1: 1, v / v, 8.7 \mathrm{mmol}, 150$ equiv $)$. The sealed reaction flask was removed from the cooling bath, wrapped with aluminium foil, and stirred at $23^{\circ} \mathrm{C}$ for $2 \mathrm{~h}$. The reaction mixture was partitioned between EtOAc $(12 \mathrm{~mL})$ and saturated aq. $\mathrm{NaHCO}_{3}$ solution $(5 \mathrm{~mL})$. The organic layer was washed with brine $(6 \mathrm{~mL})$, dried over anhydrous $\mathrm{Na}_{2} \mathrm{SO}_{4}$, and concentrated under reduced pressure. Purification of the so-obtained residue by preparative thin layer chromatography (hexanes/EtOAc 2:3, v/v) provided $\mathbf{6 1}$ (33 mg, $48 \mu \mathrm{mol}, 83 \%$ yield) as yellow foam.

61: $\mathrm{R}_{\mathrm{f}}=0.30$ (silica gel, $50 \%$ EtOAc in hexanes); $[\alpha]_{\mathrm{D}}^{23}=-34.6(c=0.65$, EtOAc); FT-IR (film) $v_{\max }: 3439,2926,2854,1758,1709,1640,1602,1459,1438,1400,1369,1281,1216,1153,1103$, 1049, 1027, 994, 896, 780, $735 \mathrm{~cm}^{-1}$; ${ }^{1} \mathrm{H}$ NMR (CD $\left.3 \mathrm{CN}, 600 \mathrm{MHz}\right): \delta 12.89$ (s, $\left.1 \mathrm{H}\right), 8.18(\mathrm{~s}, 1 \mathrm{H})$, $8.14(\mathrm{~d}, J=7.9 \mathrm{~Hz}, 1 \mathrm{H}), 8.07(\mathrm{~s}, 1 \mathrm{H}), 7.73(\mathrm{~d}, J=5.4 \mathrm{~Hz}, 1 \mathrm{H}), 6.27$ (s, $1 \mathrm{H}), 5.96$ (d, J=10.0 Hz, $1 \mathrm{H}), 5.88(\mathrm{~s}, 1 \mathrm{H}), 5.82(\mathrm{~d}, J=9.9 \mathrm{~Hz}, 1 \mathrm{H}), 5.65-5.56(\mathrm{~m}, 1 \mathrm{H}), 5.01-4.89(\mathrm{~m}, 2 \mathrm{H}), 4.73-4.37$ (m, $10 \mathrm{H}), 3.57-3.53(\mathrm{~m}, 1 \mathrm{H}), 2.93(\mathrm{~s}, 3 \mathrm{H}), 2.20(\mathrm{~s}, 3 \mathrm{H}), 1.45(\mathrm{~d}, J=6.4 \mathrm{~Hz}, 3 \mathrm{H}) \mathrm{ppm} ;{ }^{13} \mathrm{C} \mathrm{NMR}$ $\left(\mathrm{CD}_{3} \mathrm{CN}, 151 \mathrm{MHz}\right): \delta 189.8,183.0,170.5,160.5,155.3,146.3,139.2,134.7,133.6,133.3,133.1$, 130.9, 128.9, 127.9, 127.5, 127.2, 124.8, 124.6, 116.9, 96.5, 95.9, 94.3, 91.6, 77.5, 67.8, 66.8, 66.0, 65.4, 65.3, 60.9, 47.6, 21.2, 21.0 ppm; HRMS (ESI-TOF): calcd for $\mathrm{C}_{38} \mathrm{H}_{32} \mathrm{~N}_{2} \mathrm{O}_{11} \mathrm{Na}^{+}[\mathrm{M}+\mathrm{Na}]^{+}$ 715.1898 , found 715.1887 . 
Allyl (1aS,11S,11aS,18R)-18-acetoxy-11a-acetyl-6-(\{[(allyloxy)carbonyl](methyl)amino\}methyl)-3-hydroxy-4,9-dioxo-4,9,11,11a-tetrahydro-10H-11,1a-hept[3]ene[1,5]diynonaphtho[2,3-h]oxireno[c]quinoline-10-carboxylate (62): To a stirred solution of 61 (30 mg,

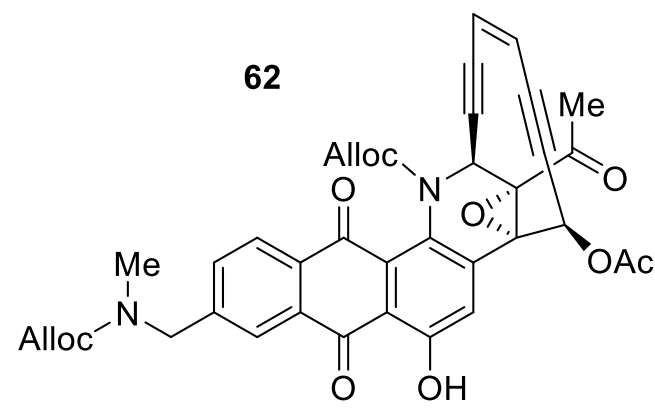
$43 \mu \mathrm{mol}, 1.0$ equiv) in $\mathrm{CH}_{2} \mathrm{Cl}_{2}(2 \mathrm{~mL})$ was added DMP (46 mg, $110 \mathrm{mmol}, 2.5$ equiv) portion-wise at $0^{\circ} \mathrm{C}$. Stirring was continued for $3 \mathrm{~h}$ at $0^{\circ} \mathrm{C}$ and then the reaction mixture was quenched by addition of saturated aqueous $\mathrm{Na}_{2} \mathrm{~S}_{2} \mathrm{O}_{3}$ and the reaction mixture was partitioned between EtOAc $(12 \mathrm{~mL})$ and saturated aq.

$\mathrm{NaHCO}_{3}$ solution $(5 \mathrm{~mL})$. The organic layer was washed with brine $(6 \mathrm{~mL})$, dried over anhydrous $\mathrm{Na}_{2} \mathrm{SO}_{4}$, and concentrated under reduced pressure. Purification of the so-obtained residue by preparative thin layer chromatography (hexanes/EtOAc 1:1, v/v) provided $62(26 \mathrm{mg}, 37 \mu \mathrm{mol}$, $86 \%$ yield) as yellow foam.

62: $\mathrm{R}_{\mathrm{f}}=0.45$ (silica gel, 50\% EtOAc in hexanes); $[\alpha]_{\mathrm{D}}^{23}=+216.7(c=0.45$, EtOAc); FT-IR (film) $v_{\max }$ : 2948, 2926, 2854, 2384, 1760, 1716, 1642, 1601, 1459, 1432, 1363, 1286, 1215, 1151, 1027, 992, 940, 895, $813 \mathrm{~cm}^{-1}$; ${ }^{1} \mathrm{H}$ NMR $\left(\mathrm{CD}_{3} \mathrm{CN}, 600 \mathrm{MHz}\right): \delta 12.90(\mathrm{~s}, 1 \mathrm{H}), 8.22(\mathrm{~s}, 1 \mathrm{H}), 8.15(\mathrm{~d}$, $J=7.9 \mathrm{~Hz}, 1 \mathrm{H}), 8.08(\mathrm{~s}, 1 \mathrm{H}), 7.75(\mathrm{~d}, J=7.2 \mathrm{~Hz}, 1 \mathrm{H}), 6.06(\mathrm{~s}, 1 \mathrm{H}), 6.01(\mathrm{~d}, J=10.0 \mathrm{~Hz}, 1 \mathrm{H}), 5.88$ (d, $J=10.2 \mathrm{~Hz}, 1 \mathrm{H}), 5.81(\mathrm{~s}, 1 \mathrm{H}), 5.65-5.57(\mathrm{~m}, 1 \mathrm{H}), 5.02-4.91(\mathrm{~m}, 2 \mathrm{H}), 4.70-4.37(\mathrm{~m}, 10 \mathrm{H})$, 2.94 (s, $3 \mathrm{H}$ ), 2.54 (s, $3 \mathrm{H}), 2.22$ (s, $3 \mathrm{H}) \mathrm{ppm} ;{ }^{13} \mathrm{C} \mathrm{NMR}\left(\mathrm{CD}_{3} \mathrm{CN}, 151 \mathrm{MHz}\right)$ : $\delta$ 199.9, 189.8, 183.0, 170.4, 160.7, 155.1, 146.5, 136.9, 134.6, 133.6, 133.3, 132.9, 130.4, 128.9, 128.3, 127.6, 125.3, 124.7, 117.5, 95.5, 94.7, 94.0, 92.7, 76.2, 68.1, 66.8, 65.7, 65.6, 48.2, 30.2, 21.1 ppm; HRMS (ESITOF): calcd for $\mathrm{C}_{38} \mathrm{H}_{30} \mathrm{~N}_{2} \mathrm{O}_{11} \mathrm{Na}^{+}[\mathrm{M}+\mathrm{Na}]^{+}$713.1742, found 713.1732.

Allyl (1aS,11S,11aS,18R)-11a-acetyl-6-(\{[(allyloxy)carbonyl](methyl)amino\}methyl)-3,18dihydroxy-4,9-dioxo-4,9,11,11a-tetrahydro-10H-11,1a-hept[3] ene[1,5]diynonaphtho[2,3$\boldsymbol{h}$ ]oxireno[c]quinoline-10-carboxylate (63): To a solution of $\mathbf{6 2}(24 \mathrm{mg}, 35 \mu \mathrm{mol}, 1.0$ equiv) in

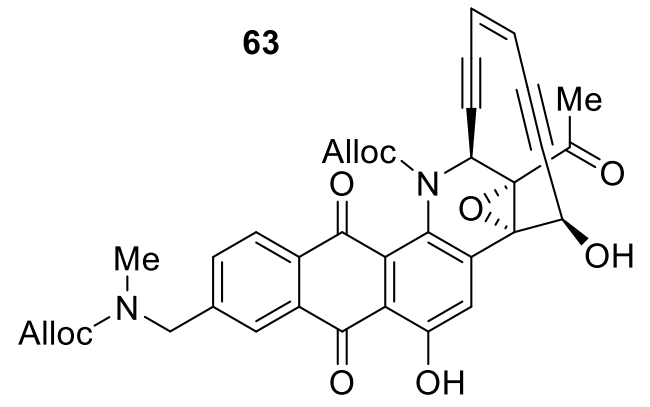
$\mathrm{MeOH}(2 \mathrm{~mL})$ was added anh. $\mathrm{K}_{2} \mathrm{CO}_{3}(4.8 \mathrm{mg}, 35 \mathrm{mmol}$, 1.0 equiv) portion-wise at $0^{\circ} \mathrm{C}$. Stirring was continued for $1.5 \mathrm{~h}$ at $0^{\circ} \mathrm{C}$ and It was then quenched by addition of $\mathrm{pH}$ 6.8 buffer $(7 \mathrm{~mL})$ and extracted with EtOAc $(3 \times 10 \mathrm{~mL})$. The organic extracts were washed with saturated brine 
$(8 \mathrm{~mL})$, dried over anhydrous $\mathrm{Na}_{2} \mathrm{SO}_{4}$, and concentrated under reduced pressure. The crude residue was purified by preparative thin layer chromatography (hexanes/EtOAc 1:1, v/v) to afford bisprotected anthraquinone $\mathbf{6 3}(18 \mathrm{mg}, 28 \mu \mathrm{mol}, 81 \%$ yield) as yellow foam.

63: $\mathrm{R}_{\mathrm{f}}=0.45$ (silica gel, 50\% EtOAc in hexanes); $[\alpha]_{\mathrm{D}}^{23}=+219.0(c=0.41$, EtOAc); FT-IR (film) $v_{\max }: 3383,2951,2924,2854,1714,1679,1641,1602,1460,1435,1362,1283,1244,1233,1209$, 1151, 1110, 946, 898, 777, 734, $707 \mathrm{~cm}^{-1} ;{ }^{1} \mathrm{H}$ NMR (CD $\left.{ }_{3} \mathrm{CN}, 600 \mathrm{MHz}\right): \delta 12.84(\mathrm{~s}, 1 \mathrm{H}), 8.52$ (s, $1 \mathrm{H}), 8.14(\mathrm{~d}, J=7.9 \mathrm{~Hz}, 1 \mathrm{H}), 8.07$ (s, $1 \mathrm{H}), 7.73$ (d, J=7.3 Hz, 1 H), 6.00-5.97 (m, $2 \mathrm{H}), 5.82$ (d, $J=10.1 \mathrm{~Hz}, 1 \mathrm{H}), 5.65-5.58(\mathrm{~m}, 1 \mathrm{H}), 5.05-4.86(\mathrm{~m}, 1 \mathrm{H}), 4.71-4.38(\mathrm{~m}, 1 \mathrm{H}), 2.93$ (s, $3 \mathrm{H}), 2.48$ (s, $3 \mathrm{H}) \mathrm{ppm} ;{ }^{13} \mathrm{C} \mathrm{NMR}\left(\mathrm{CD}_{3} \mathrm{CN}, 151 \mathrm{MHz}\right): \delta 200.1,189.8,183.1,160.5,155.2,146.4,138.0$, 134.6, 133.6, 133.4, 133.0, 128.9, 128.3, 128.0, 125.8, 123.8, 117.2, 99.2, 94.7, 92.7, 91.9, 76.2, 67.9, 67.1, 66.8, 65.7, 48.3, 30.3, 21.1 ppm; HRMS (ESI-TOF): calcd for $\mathrm{C}_{36} \mathrm{H}_{28} \mathrm{~N}_{2} \mathrm{O}_{10} \mathrm{Na}^{+}$ $[\mathrm{M}+\mathrm{Na}]^{+}$671.1636, found 671.1623 .

(1aS,11S,11aS,18R)-11a-Acetyl-3,18-dihydroxy-6-[(methylamino)methyl]-11,11a-dihydro$4 H$-11,1a-hept[3]ene[1,5]diynonaphtho[2,3- $h]$ oxireno[c]quinoline-4,9(10H)-dione (30): To a

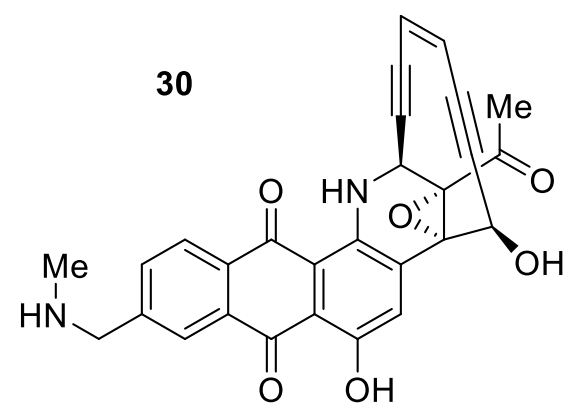
solution of $\mathbf{6 3}(15 \mathrm{mg}, 23 \mu \mathrm{mol}, 1.0$ equiv) in $\mathrm{DMF}(2 \mathrm{~mL})$ at $0{ }^{\circ} \mathrm{C}$ was added $\mathrm{Pd}\left(\mathrm{PPh}_{3}\right)_{4}(5.3 \mathrm{mg}, 4.6 \mu \mathrm{mol}, 0.2$ equiv $)$ followed by slow addition of morpholine $(10 \mu \mathrm{L}, 120 \mu \mathrm{mol}$, 5.2 equiv) and allowed to stir for $2 \mathrm{~h}$. The cooling bath was removed, and the reaction mixture was stirred at $23^{\circ} \mathrm{C}$ for 12 h. It was then quenched by addition of $\mathrm{pH} 6.8$ buffer $(7 \mathrm{~mL})$ and extracted with EtOAc $(3 \times 10 \mathrm{~mL})$. The organic extracts were washed with saturated aq. $\mathrm{NaHCO}_{3}$ solution $(8 \mathrm{~mL})$, brine $(8 \mathrm{~mL})$, dried over anhydrous $\mathrm{Na}_{2} \mathrm{SO}_{4}$, and concentrated under reduced pressure. The crude residue was purified by preparative thin layer chromatography (EtOAc/MeOH 4:1, v/v) to afford 30 (7.8 mg, $16 \mu \mathrm{mol}, 71 \%$ yield) as purple solid.

30: $\mathrm{R}_{\mathrm{f}}=0.14$ (silica gel, $20 \% \mathrm{MeOH}$ in EtOAc); $[\alpha]_{\mathrm{D}}^{23}=-255.0(c=0.41$, EtOAc); FT-IR (film) $v_{\max }: 2924,2853,1714,1628,1598,1564,1483,1465,1414,1377,1287,1239,1205,1145,1102$, 1079, 1037, 973, 949, 904, 796, $700 \mathrm{~cm}^{-1} ;{ }^{1} \mathrm{H} \mathrm{NMR}\left(\mathrm{CD}_{3} \mathrm{CN}, 600 \mathrm{MHz}\right): \delta 9.91$ (d, J=4.1 Hz, $1 \mathrm{H}), 8.48$ (s, $1 \mathrm{H}), 8.23-8.20$ (m, 2 H), 7.83-7.80 (m, 1 H), 5.99-5.89 (m, 2H), 4.97-4.92 (m, $2 \mathrm{H})$, 3.89 (s, $3 \mathrm{H}), 2.44$ (s, $3 \mathrm{H}), 2.40$ (s, $3 \mathrm{H}) \mathrm{ppm} ;{ }^{13} \mathrm{C} \mathrm{NMR}\left(\mathrm{CD}_{3} \mathrm{CN}, 151 \mathrm{MHz}\right): \delta 200.9,188.9,184.6$, $156.6,148.1,144.2$, 135.4, 134.5, 133.6, 130.9, 128.0, 126.4, 124.6, 124.5, 114.9, 113.3, 99.6, 
98.3, 91.2, 90.1, 76.8, 66.4, 65.5, 55.5, 45.5, 36.1, 29.9 ppm; HRMS (ESI-TOF): calcd for $\mathrm{C}_{28} \mathrm{H}_{21} \mathrm{~N}_{2} \mathrm{O}_{6}{ }^{+}[\mathrm{M}+\mathrm{H}]^{+} 481.1394$, found 481.1390 .

Allyl (1aS,11S,11aS,18R)-18-acetoxy-6-(\{[(allyloxy)carbonyl](methyl)amino\}methyl)-3hydroxy-11a-[(2E)-4-methoxy-4-oxobut-2-en-2-yl]-4,9-dioxo-4,9,11,11a-tetrahydro-10H11,1a-hept[3]ene[1,5] diynonaphtho[2,3-h]oxireno[ $c]$ quinoline-10-carboxylate (64): A

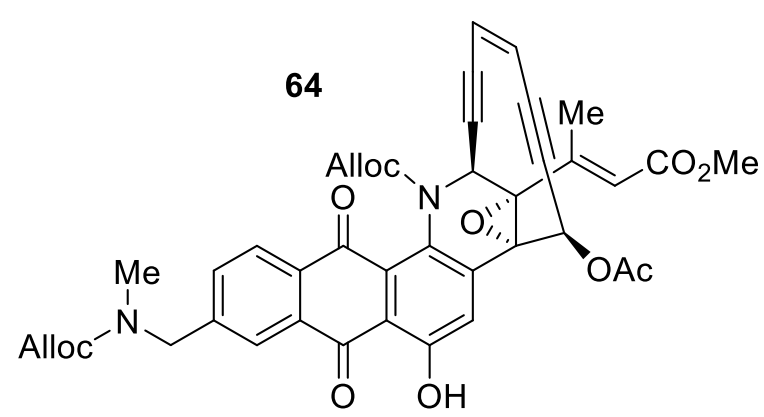

mixture of methyl diethylphosphonoacetate $(32 \mu \mathrm{L}, 170 \mu \mathrm{mol}, 6.0$ equiv) and $\mathrm{NaH}(95 \%$, $3.7 \mathrm{mg}, 150 \mu \mathrm{mol}, 5.0$ equiv) in THF $(2 \mathrm{~mL})$ was stirred at $0{ }^{\circ} \mathrm{C}$ for $1 \mathrm{~h}$. Then the solution of compound 62 (20 mg, $29 \mu \mathrm{mol}, 1.0$ equiv) in THF $(2 \mathrm{~mL})$ was cannulated to the former mixture at $-78^{\circ} \mathrm{C}$. After stirring for $15 \mathrm{~min}$, the reaction mixture was brought to $0{ }^{\circ} \mathrm{C}$ and stirred for another $5 \mathrm{~h}$. The reaction mixture was then quenched by addition of $\mathrm{pH} 6.8$ buffer $(4 \mathrm{~mL})$ and extracted with EtOAc $(3 \times 10 \mathrm{~mL})$. The organic extracts were washed with saturated brine $(8 \mathrm{~mL})$, dried over anhydrous $\mathrm{Na}_{2} \mathrm{SO}_{4}$, and concentrated under reduced pressure. The crude residue was purified by preparative thin layer chromatography (hexanes/EtOAc 1:1, v/v) to afford $64(18 \mathrm{mg}, 23.8 \mu \mathrm{mol}$, $82 \%$ yield) as yellow foam.

64: $\mathrm{R}_{\mathrm{f}}=0.62$ (silica gel, 50\% EtOAc in hexanes); $[\alpha]_{\mathrm{D}}^{23}=+153.7(c=0.49$, EtOAc); FT-IR (film) $v_{\max }: 3059,2950,2927,2855,2325,2192,1761,1706,1674,1640,1601,1537,1457,1434,1363$, 1270, 1212, 1198, 1158, 1101, 1025, 996, 933, 884, 769, 735, $704 \mathrm{~cm}^{-1} ;{ }^{1} \mathrm{H} \mathrm{NMR}\left(\mathrm{CD}_{3} \mathrm{CN}\right.$, $600 \mathrm{MHz}): \delta 12.91(\mathrm{~s}, 1 \mathrm{H}), 8.16-8.12(\mathrm{~m}, 2 \mathrm{H}), 8.09-8.06(\mathrm{~m}, 1 \mathrm{H}), 7.74(\mathrm{~d}, J=7.1 \mathrm{~Hz}, 1 \mathrm{H}), 6.48$ (s, $1 \mathrm{H}), 6.05-6.03(\mathrm{~m}, 1 \mathrm{H}), 5.91-5.86(\mathrm{~m}, 1 \mathrm{H}), 5.79(\mathrm{~d}, J=1.3 \mathrm{~Hz}, 1 \mathrm{H}), 5.74(\mathrm{bs}, 1 \mathrm{H}), 5.67-5.58$ (m, 1 H), 5.03-4.91 (m, 2H), 4.73-4.40 (m, 9H), $3.72(\mathrm{~s}, 3 \mathrm{H}), 2.94$ (s, 3 H), 2.40 (s, 3 H), 2.19 (s, $3 \mathrm{H}) \mathrm{ppm} ;{ }^{13} \mathrm{C} \mathrm{NMR}\left(\mathrm{CD}_{3} \mathrm{CN}, 151 \mathrm{MHz}\right): \delta 189.9,182.9,170.4,166.8,160.7,155.3,147.9,146.4$, 137.9, 134.6, 133.5, 133.4, 133.0, 130.6, 128.9, 128.3, 127.4, 125.3, 124.6, 122.5, 117.3, 96.6, 95.5, 94.8, 92.3, 79.7, 68.0, 67.3, 66.8, 66.5, 52.2, 50.0, 21.1, 17.2 ppm; HRMS (ESI-TOF): calcd for $\mathrm{C}_{41} \mathrm{H}_{35} \mathrm{~N}_{2} \mathrm{O}_{12}{ }^{+}[\mathrm{M}+\mathrm{H}]^{+}$747.2185, found 747.2182. 
(2E)-3-[(1aS,11S,11aS,18R)-10-[(Allyloxy)carbonyl]-6-(\{[(allyloxy)carbonyl](methyl)amino\}methyl)-3,18-dihydroxy-4,9-dioxo-4,9,10,11-tetrahydro-11a $H$-11,1a-hept[3]ene$[1,5]$ diynonaphtho[2,3-h]oxireno[c]quinolin-11a-yl]but-2-enoic acid (65): To a solution of

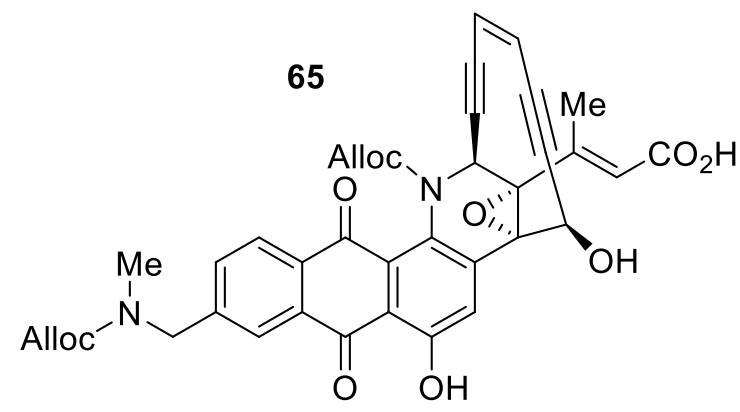

compound $64(15 \mathrm{mg}, 20 \mu \mathrm{mol}, 1.0$ equiv $)$ in $\mathrm{THF} / \mathrm{H}_{2} \mathrm{O}(3: 1, v / v, 10 \mathrm{~mL} / \mathrm{mmol})$ at $0{ }^{\circ} \mathrm{C}$ was added $\mathrm{LiOH}(4.8 \mathrm{mg}, 200 \mu \mathrm{mol}, 10$ equiv) and the mixture was stirred at $23^{\circ} \mathrm{C}$ for $12 \mathrm{~h}$. The reaction mixture was then quenched by addition of $\mathrm{pH} 6.8$ buffer $(4 \mathrm{~mL})$, brine $(2 \mathrm{~mL})$ and extracted with EtOAc $(3 \times 10 \mathrm{~mL})$. The organic extracts were washed with saturated brine $(8 \mathrm{~mL})$, dried over anhydrous $\mathrm{Na}_{2} \mathrm{SO}_{4}$, and concentrated under reduced pressure. The crude residue was purified by preparative thin layer chromatography (EtOAc/MeOH 4:1, v/v) to afford acid 65 (12 mg, $18 \mu \mathrm{mol}, 89 \%$ yield) as yellow foam.

65: $\mathrm{R}_{\mathrm{f}}=0.62$ (silica gel, $20 \% \mathrm{MeOH}$ in EtOAc); $[\alpha]_{\mathrm{D}}^{23}=+152.8(c=0.32$, EtOAc); FT-IR (film) $v_{\max }: 3396,3087,2926,2855,1699,1640,1601,1458,1435,1366,1342,1282,1244,1228,1203$, 1153, 1108, 1084, 1054, 990, 969, 941, 898, 774, 736, $704 \mathrm{~cm}^{-1} ;{ }^{1} \mathrm{H}$ NMR $\left(\mathrm{CD}_{3} \mathrm{CN}, 600 \mathrm{MHz}\right): \delta$ 12.86 (bs, $1 \mathrm{H}), 8.44$ (s, $1 \mathrm{H}), 8.14(\mathrm{~d}, J=8.0 \mathrm{~Hz}, 1 \mathrm{H}), 8.09-8.05(\mathrm{~m}, 1 \mathrm{H}), 7.73(\mathrm{~d}, J=6.8 \mathrm{~Hz}, 1 \mathrm{H})$, $6.42(\mathrm{~s}, 1 \mathrm{H}), 6.01-5.97(\mathrm{~m}, 1 \mathrm{H}), 5.82-5.77(\mathrm{~m}, 1 \mathrm{H}), 5.73(\mathrm{~d}, J=1.0 \mathrm{~Hz}, 1 \mathrm{H}), 5.67-5.57(\mathrm{~m}, 1 \mathrm{H})$, $5.08(\mathrm{~s}, 1 \mathrm{H}), 5.02-4.89(\mathrm{~m}, 2 \mathrm{H}), 4.74-4.38(\mathrm{~m}, 9 \mathrm{H}), 2.93(\mathrm{~s}, 3 \mathrm{H}), 2.31(\mathrm{~s}, 3 \mathrm{H}) \mathrm{ppm} ;{ }^{13} \mathrm{C} \mathrm{NMR}$ $\left(\mathrm{CD}_{3} \mathrm{CN}, 151 \mathrm{MHz}\right): \delta 189.8,183.1,160.5,155.4,146.2,139.5,134.7,134.5,133.6,133.4,133.1$, 130.9, 128.9, 128.6, 128.3, 127.9, 125.9, 123.4, 116.9, 100.9, 95.6, 92.5, 76.3, 68.7, 67.9, 66.8, 65.8, 60.9, 50.6, 50.2, 17.3 ppm; HRMS (ESI-TOF): calcd for $\mathrm{C}_{38} \mathrm{H}_{31} \mathrm{~N}_{2} \mathrm{O}_{11}{ }^{+}[\mathrm{M}+\mathrm{H}]^{+} 691.1922$, found 691.1918 . 
(2E)-3-\{(1aS,11S,11aS,18R)-3,18-Dihydroxy-6-[(methylamino)methyl]-4,9-dioxo-4,9,10,11tetrahydro-11a $H-11,1 a-h e p t[3]$ ene[1,5]diynonaphtho[2,3- $h]$ oxireno[ $c]$ quinolin-11a-yl\}but-

2-enoic acid (23): To a solution of $\mathbf{6 5}\left(5.6 \mathrm{mg}, 8.1 \mu \mathrm{mol}, 1.0\right.$ equiv) in DMF $(2 \mathrm{~mL})$ at $0{ }^{\circ} \mathrm{C}$ was

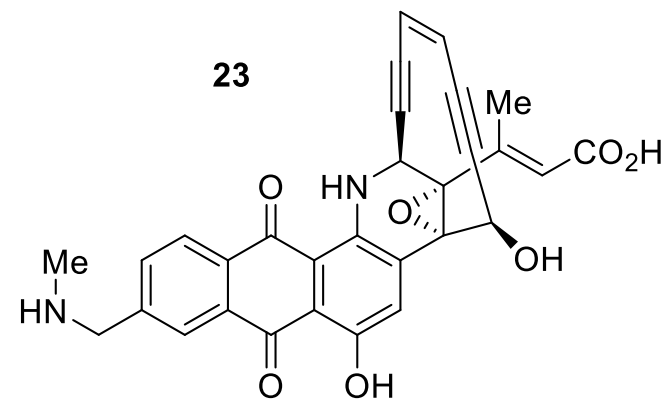
added $\mathrm{Pd}\left(\mathrm{PPh}_{3}\right)_{4}(1.9 \mathrm{mg}, 1.6 \mu \mathrm{mol}, 0.2$ equiv) followed by slow addition of morpholine $(3.6 \mu \mathrm{L}, 42 \mu \mathrm{mol}$, 5.2 equiv) and stirred for $2 \mathrm{~h}$ at the same temperature. The cooling bath was removed, and the reaction mixture was stirred at $23^{\circ} \mathrm{C}$ for $12 \mathrm{~h}$. It was then quenched by addition of $\mathrm{pH} 6.8$ buffer $(7 \mathrm{~mL})$ and extracted with EtOAc $(3 \times 10 \mathrm{~mL})$. The organic extracts were washed with saturated aq. $\mathrm{NaHCO}_{3}$ solution $(8 \mathrm{~mL})$, brine $(8 \mathrm{~mL})$, dried over anhydrous $\mathrm{Na}_{2} \mathrm{SO}_{4}$, and concentrated under reduced pressure. The crude residue was purified by preparative thin layer chromatography (EtOAc/MeOH 2:3, v/v) to afford $\mathbf{2 3}$ (3.2 $\mathrm{mg}, 6.3 \mu \mathrm{mol}, 78 \%$ yield) as purple solid.

23: $\mathrm{R}_{\mathrm{f}}=0.38$ (silica gel, $50 \% \mathrm{MeOH}$ in EtOAc); $[\alpha]_{\mathrm{D}}^{23}=-132.5(c=0.36, \mathrm{MeOH})$; FT-IR (film) $v_{\max }: 3423,2923,2853,2266,1682,1603,1438,1409,1377,1206,1185,1136,1028,907,842$, 802, $724 \mathrm{~cm}^{-1} ;{ }^{1} \mathrm{H}$ NMR (DMSO- $\left.d_{6}, 600 \mathrm{MHz}\right): \delta 9.96(\mathrm{~d}, J=4.5 \mathrm{~Hz}, 1 \mathrm{H}), 8.45(\mathrm{~s}, 1 \mathrm{H}), 8.30(\mathrm{~s}$, $1 \mathrm{H}), 8.24(\mathrm{~d}, J=7.9 \mathrm{~Hz}, 1 \mathrm{H}), 7.98-7.91(\mathrm{~m}, 1 \mathrm{H}), 6.36$ (s, 1 H), 6.19-6.15 (m, 1 H), 6.08-6.05 (m, $1 \mathrm{H}), 4.98(\mathrm{dd}, J=4.4,1.3 \mathrm{~Hz}, 1 \mathrm{H}), 4.81(\mathrm{~s}, 1 \mathrm{H}), 4.11(\mathrm{bs}, 1 \mathrm{H}), 2.89(\mathrm{~s}, 3 \mathrm{H}), 2.28(\mathrm{~s}, 3 \mathrm{H}) \mathrm{ppm}$; ${ }^{13} \mathrm{C}$ NMR (DMSO- $\left.d_{6}, 151 \mathrm{MHz}\right): \delta 186.9,182.4,167.1,162.3,154.8,143.1,135.2,134.5,133.7$, 132.2, 129.7, 126.9, 126.4, 124.2, 123.6, 118.3, 116.3, 113.1, 111.2, 100.5, 97.9, 90.7, 88.9, 75.5, 66.3, 64.6, 45.7, 35.7, 30.7, 16.6 ppm; HRMS (ESI-TOF): calcd for $\mathrm{C}_{30} \mathrm{H}_{23} \mathrm{~N}_{2} \mathrm{O}_{7}^{+}[\mathrm{M}+\mathrm{H}]^{+}$ 523.1500 , found 523.1500 .

Allyl (1aS,11S,11aS,18R)-6-(\{[(allyloxy)carbonyl](methyl)amino $\}$ methyl)-11a-\{(2E)-4-[(2$\{[(9 H$-fluoren-9-ylmethoxy) carbonyl $]$ amino\}ethyl)amino]-4-oxobut-2-en-2-yl\}-3,18dihydroxy-4,9-dioxo-4,9,11,11a-tetrahydro-10H-11,1a-hept[3]ene[1,5]diynonaphtho[2,3$\boldsymbol{h}$ ]oxireno[c]quinoline-10-carboxylate (24): To a stirred solution of the acid $\mathbf{6 5}(5.0 \mathrm{mg}$, $7.2 \mu \mathrm{mol}, 1$ equiv) in $\mathrm{CH}_{2} \mathrm{Cl}_{2}$ at $0^{\circ} \mathrm{C}$ were sequentially added 1-hydroxy-7-azabenztriazole (HOAt, $1.5 \mathrm{mg}, 11 \mu \mathrm{mol}, 1.5$ equiv) and 1-ethyl-3-[3-(dimethylamino)propyl]carbodimide hydrochloride (EDCI, $2.1 \mathrm{mg}, 11 \mu \mathrm{mol}, 1.5$ equiv). After $10 \mathrm{~min}, \mathrm{NH}_{2} \mathrm{CH}_{2} \mathrm{CH}_{2} \mathrm{NHFmoc}$ (58) $(2.7 \mathrm{mg}, 9.4 \mu \mathrm{mol}$, 


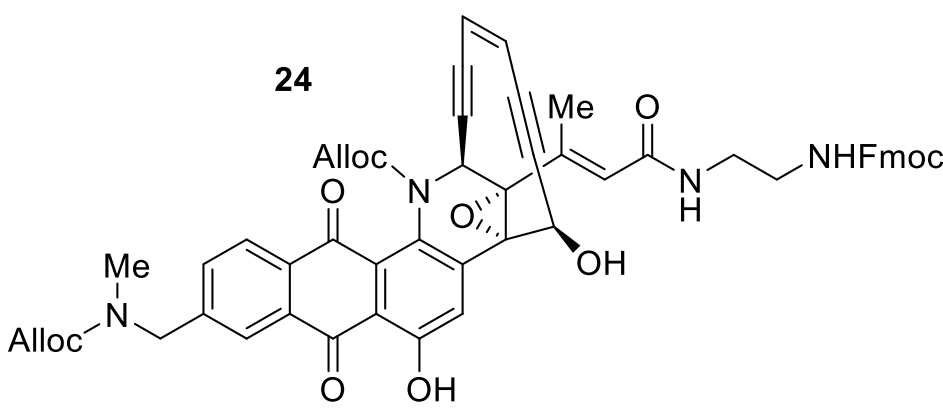

1.3 equiv) was added into the reaction mixture followed by addition of DIPEA $(6 \mu \mathrm{L}, 36 \mu \mathrm{mol}, 5.0$ equiv). The reaction mixture was brought to $23{ }^{\circ} \mathrm{C}$ and stirred for $1 \mathrm{~h}$. Then, the reaction mixture was quenched by addition of

pH 6.8 buffer $(6 \mathrm{~mL})$ and extracted with EtOAc $(3 \times 10 \mathrm{~mL})$. The combined organic layers were washed with brine $(8 \mathrm{~mL})$, dried over anhydrous $\mathrm{Na}_{2} \mathrm{SO}_{4}$ and concentrated under reduces pressure. Purification of the so-obtained residue by preparative thin layer chromatography (EtOAc) afforded amide 24 (5.5 mg, $5.8 \mu \mathrm{mol}, 80 \%$ yield) as yellow foam.

24: $\mathrm{R}_{\mathrm{f}}=0.50$ (silica gel, 50\% EtOAc in hexanes); $[\alpha]_{\mathrm{D}}^{23}=+85.7(c=0.35$, EtOAc); FT-IR (film) $v_{\max }: 3337,2924,2854,2301,1707,1676,1637,1602,1530,1458,1437,1379,1341,1261,1209$, 1102, 1084, 1020, 870, 799, $731 \mathrm{~cm}^{-1} ;{ }^{1} \mathrm{H}$ NMR $\left(\mathrm{CD}_{3} \mathrm{CN}, 600 \mathrm{MHz}\right): \delta 12.86(\mathrm{~s}, 1 \mathrm{H}), 8.42(\mathrm{~s}$, $1 \mathrm{H}), 8.14(\mathrm{~d}, J=8.0 \mathrm{~Hz}, 1 \mathrm{H}), 8.10-8.04(\mathrm{~m}, 1 \mathrm{H}), 7.85-7.82(\mathrm{~m}, 2 \mathrm{H}), 7.73(\mathrm{~d}, J=6.9 \mathrm{~Hz}, 1 \mathrm{H})$, 7.67-7.63 (m, 2H), $7.42(\mathrm{t}, J=7.4 \mathrm{~Hz}, 2 \mathrm{H}), 7.34(\mathrm{t}, J=7.4 \mathrm{~Hz}, 2 \mathrm{H}), 6.74-6.67(\mathrm{~m}, 1 \mathrm{H}), 6.34$ (s, $1 \mathrm{H}), 5.99-5.94(\mathrm{~m}, 1 \mathrm{H}), 5.88-5.82(\mathrm{~m}, 1 \mathrm{H}), 5.81-5.76(\mathrm{~m}, 1 \mathrm{H}), 5.71(\mathrm{~s}, 1 \mathrm{H}), 5.66-5.58(\mathrm{~m}, 1 \mathrm{H})$, 5.08-4.89 (m, 3 H), 4.72-4.53 (m, 6H), 4.49-4.19 (m, 7 H), 3.35-3.18 (m, 4 H, 2.93 (s, 3 H, 2.31 (s, $3 \mathrm{H}) \mathrm{ppm} ;{ }^{13} \mathrm{C}$ NMR $\left(\mathrm{CD}_{3} \mathrm{CN}, 151 \mathrm{MHz}\right): \delta 189.8,183.0,166.9,160.5,157.6,155.4,153.9$, 145.2, 142.2, 139.3, 134.7, 133.4, 133.1, 130.9, 128.7, 128.1, 126.2, 125.7, 123.5, 121.0, 116.9, 100.5, 95.5, 92.7, 92.5, 76.2, 68.5, 67.9, 67.0, 66.8, 65.9, 50.2, 48.2, 41.5, 40.1, 17.2 ppm; HRMS (ESI-TOF): calcd for $\mathrm{C}_{55} \mathrm{H}_{47} \mathrm{~N}_{4} \mathrm{O}_{12}{ }^{+}[\mathrm{M}+\mathrm{H}]^{+}$955.3185, found 955.3176 .

2-(4-Bromo-3-fluorophenyl)-1,3-dioxolane (S1): To a stirred solution of compound 66 (15g,<smiles>Fc1cc(C2OCCO2)ccc1Br</smiles>
$76 \mathrm{mmol}, 1.0$ equiv) in toluene $(250 \mathrm{~mL})$ was added ethylene glycol $(50 \mathrm{~mL})$ at $23^{\circ} \mathrm{C}$, followed by $p-\mathrm{TsOH}(7.2 \mathrm{~g}, 38 \mathrm{mmol}, 0.5$ equiv). The reaction mixture was heated to $111^{\circ} \mathrm{C}$ and the water was continuously removed with a DeanStark apparatus. After $12 \mathrm{~h}$, the reaction mixture was cooled to $23^{\circ} \mathrm{C}$ and $100 \mathrm{~mL}$ saturated aq. $\mathrm{NaHCO}_{3}$ solution was added. The resulting mixture was extracted with EtOAc $(2 \times 100 \mathrm{~mL})$. The combined organic layers were washed with brine $(50 \mathrm{~mL})$, dried over anhydrous $\mathrm{Na}_{2} \mathrm{SO}_{4}$ and concentrated under reduced pressure. The residue was purified by flash column chromatography (silica gel, hexanes:EtOAc $=8: 1, v / v$ ) to give acetal $\mathbf{S 1}$ as a colorless oil 
(19 g, $75 \mathrm{mmol}, 99 \%$ yield).

S1: $R_{\mathrm{f}}=0.51$ (silica gel, 20\% EtOAc in hexanes); FT-IR (film): $v_{\max }=2957,2889,1581,1484$, 1427, 1398, 1278, 1241, 1166, 1088, 1040, 969, 945, 876, 821, 782, 739, 724, 696, $668 \mathrm{~cm}^{-1}$; ${ }^{1} \mathrm{H}$ NMR $\left(600 \mathrm{MHz}, \mathrm{CDCl}_{3}\right) \delta 7.55(\mathrm{t}, J=7.5 \mathrm{~Hz}, 1 \mathrm{H}), 7.25(\mathrm{dd}, J=9.0,2.1 \mathrm{~Hz}, 1 \mathrm{H}), 7.14(\mathrm{dd}, J=8.2$, $1.9 \mathrm{~Hz}, 1 \mathrm{H}), 5.77(\mathrm{~s}, 1 \mathrm{H}), 4.15-3.96(\mathrm{~m}, 4 \mathrm{H}) \mathrm{ppm} ;{ }^{13} \mathrm{C} \mathrm{NMR}\left(151 \mathrm{MHz}, \mathrm{CDCl}_{3}\right) \delta 159.0(\mathrm{~d}$, $J=248.0 \mathrm{~Hz}), 140.0$ (d, $J=6.1 \mathrm{~Hz}), 133.5,123.3$ (d, $J=3.7 \mathrm{~Hz}), 114.6$ (d, $J=23.6 \mathrm{~Hz}), 109.7$ (d, $J=21.0 \mathrm{~Hz}), 102.2(\mathrm{~d}, J=1.7 \mathrm{~Hz}), 65.3 \mathrm{ppm} ;{ }^{19} \mathrm{~F} \mathrm{NMR}\left(565 \mathrm{MHz}, \mathrm{CDCl}_{3}\right) \delta-105.90(\mathrm{dd}, J=9.1$, $6.8 \mathrm{~Hz}, 1 \mathrm{~F}) \mathrm{ppm}$; HRMS (CI) calcd for $\mathrm{C}_{9} \mathrm{H}_{9} \mathrm{BrFO}_{2}{ }^{+}[\mathrm{M}+\mathrm{H}]^{+} 246.9770$, found 246.9774 .

Methyl 3-bromo-6-(1,3-dioxolan-2-yl)-2-fluorobenzoate (67): To a flame-dried flask were<smiles>COC(=O)c1c(C2OCCO2)ccc(Br)c1F</smiles>
added $i$ - $\operatorname{Pr}_{2} \mathrm{NH}(1.7 \mathrm{~mL}, 12 \mathrm{mmol}, 1.1$ equiv) and anhydrous THF $(25 \mathrm{~mL})$ at $23^{\circ} \mathrm{C}$ and under an atmosphere of nitrogen. $n$-BuLi $(2.5 \mathrm{M}, 4.8 \mathrm{~mL}, 12 \mathrm{mmol}$, 1.1 equiv) was added to the mixture at $-78^{\circ} \mathrm{C}$. The resulting mixture was stirred at the same temperature for $0.5 \mathrm{~h}$. Then the mixture was warmed to $0{ }^{\circ} \mathrm{C}$ and stirred for $15 \mathrm{~min}$.

The above LDA solution was cooled to $-78^{\circ} \mathrm{C}$, and acetal $\mathbf{S 1}(2.7 \mathrm{~g}, 11 \mathrm{mmol}, 1.0$ equiv) in anhydrous THF $(5 \mathrm{~mL})$ was added to the LDA solution dropwise. The reaction mixture was stirred at $-78^{\circ} \mathrm{C}$ for $1 \mathrm{~h}$, then $\mathrm{ClCO}_{2} \mathrm{Me}\left(0.90 \mathrm{~mL}, 12 \mathrm{mmol}, 1.1\right.$ equiv) was added at $-78^{\circ} \mathrm{C}$. The reaction mixture was stirred at $-78^{\circ} \mathrm{C}$ for $1 \mathrm{~h}$ before quenching by addition of saturated $\mathrm{NH}_{4} \mathrm{Cl}$ solution $(10 \mathrm{~mL})$. The resulting mixture was extracted with EtOAc $(2 \times 10 \mathrm{~mL})$. The combined organic layers were washed with brine $(10 \mathrm{~mL})$, dried over anhydrous $\mathrm{Na}_{2} \mathrm{SO}_{4}$, and concentrated under reduced pressure. The residue was purified by flash column chromatography (silica gel, hexanes:EtOAc, 6:1, v/v) to give compound 67 (2.6 g, $8.5 \mathrm{mmol}, 79 \%$ yield) as a light yellow oil. 67: $R_{\mathrm{f}}=0.22$ (silica gel, 20\% EtOAc in hexanes); FT-IR (film): $v_{\max }=2954,2893,1736,1603$, 1572, 1471, 1438, 1424, 1393, 1349, 1267, 1216, 1191, 1145, 1101, 1029, 1011, 964, 950, 846, 801, 780, 747, $719 \mathrm{~cm}^{-1} ;{ }^{1} \mathrm{H} \mathrm{NMR}\left(600 \mathrm{MHz} \mathrm{CDCl}_{3}\right) \delta 7.62(\mathrm{dd}, J=8.4,6.6 \mathrm{~Hz}, 1 \mathrm{H}), 7.28(\mathrm{dt}$, $J=8.4,0.9 \mathrm{~Hz}, 1 \mathrm{H}), 6.09(\mathrm{~s}, 1 \mathrm{H}), 4.02-3.95(\mathrm{~m}, 4 \mathrm{H}), 3.95(\mathrm{~s}, 3 \mathrm{H}) \mathrm{ppm} ;{ }^{13} \mathrm{C} \mathrm{NMR}(151 \mathrm{MHz}$, $\left.\mathrm{CDCl}_{3}\right) \delta 164.6,156.0(\mathrm{~d}, J=252.1 \mathrm{~Hz}), 138.3(\mathrm{~d}, J=1.2 \mathrm{~Hz}), 134.6,123.0(\mathrm{~d}, J=3.9 \mathrm{~Hz}), 121.8(\mathrm{~d}$, $J=18.4 \mathrm{~Hz}), 110.1(\mathrm{~d}, J=21.6 \mathrm{~Hz}), 100.6(\mathrm{~d}, J=2.3 \mathrm{~Hz}), 65.1,52.9 \mathrm{ppm} ;{ }^{19} \mathrm{~F}$ NMR $(565 \mathrm{MHz}$, $\left.\mathrm{CDCl}_{3}\right) \delta-107.23(\mathrm{dd}, J=6.6,1.1 \mathrm{~Hz}, 1 \mathrm{~F}) \mathrm{ppm}$; HRMS (ESI) calcd for $\mathrm{C}_{11} \mathrm{H}_{10} \mathrm{BrFO}_{4} \mathrm{Na}^{+}[\mathrm{M}+\mathrm{Na}]^{+}$ 326.9639 , found 326.9643 . 
Methyl 3-[(tert-butoxycarbonyl)amino]-6-(1,3-dioxolan-2-yl)-2-fluorobenzoate (S2): To a<smiles>CC(=O)OCc1ccccc1</smiles>
stirred solution of ester $\mathbf{6 7}(1.5 \mathrm{~g}, 4.9 \mathrm{mmol}, 1.0$ equiv) in 1,4-dioxane $(50 \mathrm{~mL})$ was added $\mathrm{BocNH}_{2}\left(690 \mathrm{mg}, 5.9 \mathrm{mmol}, 1.2\right.$ equiv) at $23^{\circ} \mathrm{C}$ and sequentially XPhos $(210 \mathrm{mg}, 0.44 \mathrm{mmol}, 9 \mathrm{~mol} \%), \mathrm{Cs}_{2} \mathrm{CO}_{3}(2.2 \mathrm{~g}$, $6.9 \mathrm{mmol}, 1.4$ equiv) and $\mathrm{Pd}(\mathrm{OAc})_{2}(33 \mathrm{mg}, 0.15 \mathrm{mmol}, 3 \mathrm{~mol} \%)$. The reaction mixture was degassed with nitrogen five times and then heated to $100^{\circ} \mathrm{C}$. After $8 \mathrm{~h}$, the reaction mixture was cooled to $23^{\circ} \mathrm{C}$, and filtered through a pad of Celite. The filtrate was washed with $\mathrm{H}_{2} \mathrm{O}(30 \mathrm{~mL})$ and extracted with EtOAc $(2 \times 30 \mathrm{~mL})$. The combined organic layers were washed with brine $(20 \mathrm{~mL})$, dried over anhydrous $\mathrm{Na}_{2} \mathrm{SO}_{4}$, and concentrated under reduced pressure. The residue was purified by flash column chromatography (silica gel, hexanes:EtOAc, $2: 1, v / v)$ to give compound $\mathbf{S 2}(1.6 \mathrm{~g}, 4.8 \mathrm{mmol}, 97 \%$ yield) as a light yellow oil.

S2: $R_{f}=0.45$ (silica gel, 33\% EtOAc in hexanes); FT-IR (film): $v_{\max }=3334,2979,2893,1729$, 1628, 1528, 1484, 1427, 1393, 1368, 1322, 1261, 1242, 1232, 1145, 1106, 1070, 1030, 999, 975, 948, 874, 841, 813, 771, 753, $730 \mathrm{~cm}^{-1}$; ${ }^{1} \mathrm{H}$ NMR $\left(600 \mathrm{MHz}, \mathrm{CD}_{3} \mathrm{CN}\right) \delta 8.05(\mathrm{t}, J=8.3 \mathrm{~Hz}, 1 \mathrm{H})$, 7.42 (s, $1 \mathrm{H}), 7.33$ (dd, $J=8.6,1.2 \mathrm{~Hz}, 1 \mathrm{H}), 5.92(\mathrm{~s}, 1 \mathrm{H}), 3.97-3.91(\mathrm{~m}, 4 \mathrm{H}), 3.87$ (s, $3 \mathrm{H}), 1.49$ (s, $9 \mathrm{H}) \mathrm{ppm} ;{ }^{13} \mathrm{C}$ NMR $\left(151 \mathrm{MHz}, \mathrm{CD}_{3} \mathrm{CN}\right) \delta 165.8,153.6,150.3(\mathrm{~d}, J=247.5 \mathrm{~Hz}), 132.4,128.9(\mathrm{~d}$, $J=11.1 \mathrm{~Hz}), 123.6$ (d, $J=3.4 \mathrm{~Hz}), 123.0,121.7$ (d, $J=16.5 \mathrm{~Hz}), 101.8,81.6,66.0,53.3,28.4 \mathrm{ppm}$; ${ }^{19} \mathrm{~F}$ NMR (565 MHz, CD 3 CN) $\delta-132.17$ (s, $1 \mathrm{~F}$ ) ppm; HRMS (ESI) calcd for $\mathrm{C}_{16} \mathrm{H}_{20} \mathrm{FNO}_{6} \mathrm{Na}^{+}$ $[\mathrm{M}+\mathrm{Na}]^{+}$364.1167, found 364.1166.

Methyl 3-[(tert-butoxycarbonyl)amino]-2-fluoro-6-formylbenzoate (68): To a stirred solution<smiles>COC(=O)c1c(C=O)ccc(NC(C)(C)C)c1F</smiles>
of Boc-amino ester $\mathbf{S} 2(1.5 \mathrm{~g}, 4.4 \mathrm{mmol}, 1.0$ equiv) in acetone $(15 \mathrm{~mL})$ was added $p$-toluenesulfonic acid ( $420 \mathrm{mg}, 2.2 \mathrm{mmol}, 0.5$ equiv) at $23^{\circ} \mathrm{C}$. The resulting mixture was stirred for $1 \mathrm{~h}$ at the same temperature before all volatiles were removed under reduced pressure. The residue was then re-dissolved in EtOAc $(10 \mathrm{~mL})$ and the resulting solution was washed with saturated $\mathrm{NaHCO}_{3}$ solution $(10 \mathrm{~mL})$. The organic layer was washed with brine $(10 \mathrm{~mL})$, dried over anhydrous $\mathrm{Na}_{2} \mathrm{SO}_{4}$ and concentrated under reduced pressure. The residue was purified by flash column chromatography (silica gel, hexanes:EtOAc $=4: 1, v / v)$ to give aldehyde $\mathbf{6 8}(1.0 \mathrm{~g}, 3.4 \mathrm{mmol}, 78 \%$ yield $)$ as a light yellow solid. 68: $\mathrm{R}_{\mathrm{f}}=0.56$ (silica gel, $33 \%$ EtOAc in hexanes); $\mathrm{mp} 85-86^{\circ} \mathrm{C}$ (EtOAc/hexanes); FT-IR (film): $v_{\max }=3443,3335,2980,1733,1694,1608,1527,1486,1431,1394,1369,1331,1300,1277,1235$, 
1149, 1071, 1038, 1025, 983, 910, 875, 833, 813, 800, 771, 755, $665 \mathrm{~cm}^{-1} ;{ }^{1} \mathrm{H}$ NMR (600 MHz, $\left.\mathrm{CDCl}_{3}\right) \delta 9.91(\mathrm{~d}, J=1.5 \mathrm{~Hz}, 1 \mathrm{H}), 8.41(\mathrm{t}, J=8.0 \mathrm{~Hz}, 1 \mathrm{H}), 7.67(\mathrm{~d}, J=8.5 \mathrm{~Hz}, 1 \mathrm{H}), 6.99(\mathrm{~s}, 1 \mathrm{H})$, $4.00(\mathrm{~s}, 3 \mathrm{H}), 1.55$ (s, 9H) ppm; ${ }^{13} \mathrm{C} \mathrm{NMR}\left(151 \mathrm{MHz}, \mathrm{CDCl}_{3}\right) \delta 188.5(\mathrm{~d}, J=2.7 \mathrm{~Hz}), 164.3,151.5$, $148.2(\mathrm{~d}, J=248.7 \mathrm{~Hz}), 132.9$ (d, $J=10.4 \mathrm{~Hz}), 128.4(\mathrm{~d}, J=3.1 \mathrm{~Hz}), 128.0,121.5$ (d, $J=16.3 \mathrm{~Hz})$, $119.6(\mathrm{~d}, J=1.9 \mathrm{~Hz}), 82.5,53.2,28.2 \mathrm{ppm} ;{ }^{19} \mathrm{~F}$ NMR $\left(565 \mathrm{MHz}, \mathrm{CDCl}_{3}\right) \delta-133.99$ (s, $\left.1 \mathrm{~F}\right) \mathrm{ppm}$; HRMS (ESI) calcd for $\mathrm{C}_{14} \mathrm{H}_{16} \mathrm{FNO}_{5} \mathrm{Na}^{+}[\mathrm{M}+\mathrm{Na}]^{+}$320.0905, found 320.0910 .

tert-Butyl (1-cyano-4-fluoro-3-oxo-1,3-dihydro-2-benzofuran-5-yl)carbamate (69): To a<smiles>CC(C)(C)ONc1ccc2c(c1F)C(=O)OC2C#N</smiles>
stirred solution of aldehyde $\mathbf{6 8}\left(500 \mathrm{mg}, 1.7 \mathrm{mmol}, 1.0\right.$ equiv) in $\mathrm{CH}_{2} \mathrm{Cl}_{2}$ $(15 \mathrm{~mL})$ was added 18 -crown-6 $(45 \mathrm{mg}, 0.17 \mathrm{mmol}, 0.1$ equiv) and $\mathrm{KCN}$ (11 mg, $0.17 \mathrm{mmol}, 0.1$ equiv) at $0^{\circ} \mathrm{C}$. After $15 \mathrm{~min}$, TMSCN $(0.40 \mathrm{~mL}$, $3.4 \mathrm{mmol}, 2.0$ equiv) was added. The resulting mixture was stirred at $23^{\circ} \mathrm{C}$

for $1 \mathrm{~h}$. The solvent was removed under reduced pressure, and the residue was co-evaporated with toluene $(2 \times 5 \mathrm{~mL})$ to remove all traces of TMSCN. The resulting residue was dissolved in $\mathrm{AcOH}$ $(15 \mathrm{~mL})$ and stirred for $24 \mathrm{~h}$ at $80^{\circ} \mathrm{C}$. Then, the mixture was allowed to cool to $23^{\circ} \mathrm{C}$ and saturated $\mathrm{NaHCO}_{3}$ solution $(20 \mathrm{~mL})$ was slowly added. The resulting mixture was extracted with EtOAc $(2 \times 20 \mathrm{~mL})$. The combined organic layers were washed with brine $(10 \mathrm{~mL})$, dried over anhydrous $\mathrm{Na}_{2} \mathrm{SO}_{4}$, and concentrated under reduced pressure. The residue was purified by flash column chromatography (silica gel, hexanes:EtOAc, 1:1, v/v) to give the titled compound (300mg, $1.0 \mathrm{mmol}, 60 \%$ yield) as a yellow solid.

69: $\mathrm{R}_{\mathrm{f}}=0.54$ (silica gel, 50\% EtOAc in hexanes); $\mathrm{mp} 172-174{ }^{\circ} \mathrm{C}($ EtOAc/hexanes); FT-IR (film): $v_{\max }=3343,2981,2936,1793,1728,1610,1537,1483,1449,1394,1369,1343,1275,1229,1208$, 1153, 1104, 1004, 916, 873, 842, 768, $728 \mathrm{~cm}^{-1} ;{ }^{1} \mathrm{H}$ NMR $\left(600 \mathrm{MHz}, \mathrm{CDCl}_{3}\right) \delta 8.70(\mathrm{t}, J=7.6 \mathrm{~Hz}$, $1 \mathrm{H}), 7.43(\mathrm{~d}, J=8.5 \mathrm{~Hz}, 1 \mathrm{H}), 6.95(\mathrm{~s}, 1 \mathrm{H}), 6.05(\mathrm{~d}, J=1.0 \mathrm{~Hz}, 1 \mathrm{H}), 1.54(\mathrm{~s}, 9 \mathrm{H}) \mathrm{ppm} ;{ }^{13} \mathrm{C} \mathrm{NMR}$ $\left(151 \mathrm{MHz}, \mathrm{CDCl}_{3}\right) \delta 163.3,151.8,148.0(\mathrm{~d}, J=263.1 \mathrm{~Hz}), 135.2,130.1(\mathrm{~d}, J=7.7 \mathrm{~Hz}), 127.9,118.9$ $(\mathrm{d}, J=4.6 \mathrm{~Hz}), 113.5,112.1(\mathrm{~d}, J=13.6 \mathrm{~Hz}), 82.4,65.2,28.1 \mathrm{ppm} ;{ }^{19} \mathrm{~F} \mathrm{NMR}\left(565 \mathrm{MHz}, \mathrm{CDCl}_{3}\right) \delta$ -131.73 (s, 1F) ppm; HRMS (ESI) calcd for $\mathrm{C}_{14} \mathrm{H}_{13} \mathrm{FN}_{2} \mathrm{O}_{4} \mathrm{Na}^{+}[\mathrm{M}+\mathrm{Na}]^{+} 315.0752$, found 315.0754 . 
5-Amino-4-fluoro-3-oxo-1,3-dihydro-2-benzofuran-1-carbonitrile (70): To a stirred solution of<smiles>N#CC1OC(=O)c2c1ccc(N)c2F</smiles>
compound 69 (100 mg, $0.34 \mathrm{mmol}, 1.0$ equiv) in 1,2-dichloroethane $(25 \mathrm{~mL})$ was added MK10 (20 mg, $20 \mathrm{wt} . \%)$ at $23^{\circ} \mathrm{C}$. The reaction mixture was heated to $84^{\circ} \mathrm{C}$ for $3 \mathrm{~h}$. After allowing the mixture to cool to $23^{\circ} \mathrm{C}$, it was filtered through a pad of Celite. The filtrate was concentrated under reduced pressure. The residue was purified by flash column chromatography (silica gel, hexanes:EtOAc, 1:1, v/v) to give amine $\mathbf{7 0}$ as a yellow solid (64 mg, $0.34 \mathrm{mmol}, 98 \%$ yield).

70: $\mathrm{R}_{\mathrm{f}}=0.29$ (silica gel, 50\% EtOAc in hexanes); mp 193-195 ${ }^{\circ} \mathrm{C}$ (EtOAc/hexanes); FT-IR (film): $v_{\max }=3485,3379,3226,1779,1642,1616,1601,1520,1462,1364,1331,1276,1257,1216,1170$, $1132,1067,1038,998,919,832,803,765,738,707,683 \mathrm{~cm}^{-1} ;{ }^{1} \mathrm{H}$ NMR $\left(600 \mathrm{MHz}, \mathrm{CD}_{3} \mathrm{CN}\right) \delta$ 7.32-7.24 (m, 2H), 6.17 (s, $1 \mathrm{H}), 4.71$ (s, $2 \mathrm{H}) \mathrm{ppm} ;{ }^{13} \mathrm{C}$ NMR $\left(151 \mathrm{MHz}, \mathrm{CD}_{3} \mathrm{CN}\right) \delta 165.7$ (d, $J=2.2 \mathrm{~Hz}), 147.4$ (d, $J=255.3 \mathrm{~Hz}), 139.4$ (d, $J=10.6 \mathrm{~Hz}), 131.5,125.5$ (d, $J=5.5 \mathrm{~Hz}), 120.0$ (d, $J=4.1 \mathrm{~Hz}), 116.0,113.4(\mathrm{~d}, J=12.4 \mathrm{~Hz}), 66.7 \mathrm{ppm} ;{ }^{19} \mathrm{~F}$ NMR $\left(565 \mathrm{MHz}, \mathrm{CD}_{3} \mathrm{CN}\right) \delta-140.01(\mathrm{~d}$, $J=7.2 \mathrm{~Hz}, 1 \mathrm{~F}$ ) ppm; HRMS (ESI) calcd for $\mathrm{C}_{9} \mathrm{H}_{5} \mathrm{FN}_{2} \mathrm{O}_{2} \mathrm{H}^{+}[\mathrm{M}+\mathrm{H}]^{+}$193.0408, found 193.0410.

Methyl 6-(1,3-dioxolan-2-yl)-2-fluoro-3-vinylbenzoate (72): To a stirred solution of ester 67<smiles>C=Cc1ccc(C2OCCO2)c(C(C)=O)c1F</smiles>
$(2.0 \mathrm{~g}, 6.6 \mathrm{mmol}, 1.0$ equiv) in 1,4-dioxane $(66 \mathrm{~mL})$ was added pinacol vinylboronate $\left(1.2 \mathrm{~g}, 7.2 \mathrm{mmol}, 1.1\right.$ equiv) at $23^{\circ} \mathrm{C}$. Then, $\mathrm{Cs}_{2} \mathrm{CO}_{3}(4.3 \mathrm{~g}$, $13 \mathrm{mmol}, 2.0$ equiv) and $\mathrm{PPh}_{3}(340 \mathrm{mg}, 1.3 \mathrm{mmol}, 0.2$ equiv) were added to the reaction mixture, followed by $\operatorname{Pd}(\mathrm{OAc})_{2}(74 \mathrm{mg}, 0.33 \mathrm{mmol}, 5 \mathrm{~mol} \%)$.

The reaction mixture was degassed with nitrogen five times and heated to $70^{\circ} \mathrm{C}$. After $12 \mathrm{~h}$, the resulting mixture was allowed to cool to $23^{\circ} \mathrm{C}$ and filtered through a pad of Celite. The filtrate was washed with $\mathrm{H}_{2} \mathrm{O}(30 \mathrm{~mL})$ and extracted with EtOAc $(2 \times 20 \mathrm{~mL})$. The combined organic layers were washed with brine $(20 \mathrm{~mL})$, dried over anhydrous $\mathrm{Na}_{2} \mathrm{SO}_{4}$, and concentrated under reduced pressure. The residue was purified by flash column chromatography (silica gel, hexanes:EtOAc, $5: 1, v / v)$ to give ester $\mathbf{7 2}(1.5 \mathrm{~g}, 6.0 \mathrm{mmol}, 91 \%$ yield $)$ as a light yellow oil.

72: $R_{\mathrm{f}}=0.54$ (silica gel, 33\% EtOAc in hexanes); FT-IR (film): $v_{\max }=2954,2893,1736,1633$, 1571, 1482, 1441, 1411, 1285, 1254, 1193, 1135, 1109, 1070, 1008, 977, 938, 876, 843, 811, 792, $745 \mathrm{~cm}^{-1} ;{ }^{1} \mathrm{H}$ NMR $\left(600 \mathrm{MHz}, \mathrm{CDCl}_{3}\right) \delta 7.55(\mathrm{t}, J=7.7 \mathrm{~Hz}, 1 \mathrm{H}), 7.34(\mathrm{~d}, J=8.1 \mathrm{~Hz}, 1 \mathrm{H}), 6.85$ $(\mathrm{dd}, J=17.7,11.2 \mathrm{~Hz}, 1 \mathrm{H}), 6.10(\mathrm{~s}, 1 \mathrm{H}), 5.85(\mathrm{dd}, J=17.7,1.0 \mathrm{~Hz}, 1 \mathrm{H}), 5.44(\mathrm{dd}, J=11.2,0.9 \mathrm{~Hz}$, 1H), 4.01-3.97 (m, 4H), 3.94 (s, 3H) ppm; $\left.{ }^{13} \mathrm{C} \mathrm{NMR} \mathrm{(151} \mathrm{MHz,} \mathrm{CDCl}_{3}\right) \delta 165.6,156.9(\mathrm{~d}$, 
$J=254.4 \mathrm{~Hz}), 137.8(\mathrm{~d}, J=2.6 \mathrm{~Hz}), 128.3(\mathrm{~d}, J=4.0 \mathrm{~Hz}), 128.2(\mathrm{~d}, J=4.4 \mathrm{~Hz}), 126.3(\mathrm{~d}, J=13.2 \mathrm{~Hz})$, $121.9(\mathrm{~d}, J=3.8 \mathrm{~Hz}), 121.0(\mathrm{~d}, J=18.2 \mathrm{~Hz}), 118.0(\mathrm{~d}, J=4.7 \mathrm{~Hz}), 101.0(\mathrm{~d}, J=2.4 \mathrm{~Hz}), 65.1$, $52.7 \mathrm{ppm} ;{ }^{19} \mathrm{~F}$ NMR $\left(565 \mathrm{MHz}, \mathrm{CDCl}_{3}\right) \delta-119.94(\mathrm{~d}, J=7.3 \mathrm{~Hz}, 1 \mathrm{~F}) \mathrm{ppm}$; HRMS (ESI) calcd for $\mathrm{C}_{13} \mathrm{H}_{13} \mathrm{FO}_{4} \mathrm{Na}^{+}[\mathrm{M}+\mathrm{Na}]^{+}$275.0690, found 275.0697 .

Methyl 6-(1,3-dioxolan-2-yl)-2-fluoro-3-formylbenzoate (73a): Through a stirred solution of<smiles>CC(=O)c1c(C2OCCO2)ccc(C=O)c1F</smiles>
compound 72 (710 mg, $2.8 \mathrm{mmol}, 1.0$ equiv) in $\mathrm{CH}_{2} \mathrm{Cl}_{2}(50 \mathrm{~mL})$ was bubbled $\mathrm{O}_{3}$ at $-78^{\circ} \mathrm{C}$ until the reaction mixture turned light blue. Then $\mathrm{Me}_{2} \mathrm{~S}\left(1.0 \mathrm{~mL}, 14 \mathrm{mmol}, 5.0\right.$ equiv) was added at $-78^{\circ} \mathrm{C}$, the cooling bath was removed and the reaction mixture was stirred at $23^{\circ} \mathrm{C}$ for $1 \mathrm{~h}$. The

resulting mixture was concentrated under reduced pressure to remove the solvent, and the residue was purified by flash column chromatography (silica gel, hexanes:EtOAc, 3:1, v/v) to give aldehyde 73a as a colorless oil (580 $\mathrm{mg}, 2.3 \mathrm{mmol}, 81 \%$ yield).

73a: $R_{f}=0.33$ (silica gel, 33\% EtOAc in hexanes); FT-IR (film): $v_{\max }=2955,2894,1737,1702$, 1619, 1575, 1478, 1442, 1429, 1399, 1283, 1244, 1194, 1171, 1136, 1111, 1015, 975, 950, 891, 848, 805, 735, 694; ${ }^{1} \mathrm{H}$ NMR $\left(600 \mathrm{MHz}, \mathrm{CDCl}_{3}\right) \delta 10.36(\mathrm{~d}, J=0.8 \mathrm{~Hz}, 1 \mathrm{H}), 7.94(\mathrm{dd}, J=8.1$, 6.7 Hz, 1 H), 7.55-7.50 (m, 1 H), $6.18(\mathrm{~s}, 1 \mathrm{H}), 4.06-3.95(\mathrm{~m}, 4 \mathrm{H}), 3.97(\mathrm{~s}, 3 \mathrm{H}) \mathrm{ppm} ;{ }^{13} \mathrm{C}$ NMR $\left(151 \mathrm{MHz}, \mathrm{CDCl}_{3}\right) \delta 186.0(\mathrm{~d}, J=7.0 \mathrm{~Hz}), 164.5,161.6(\mathrm{~d}, J=262.7 \mathrm{~Hz}), 145.5(\mathrm{~d}, J=2.8 \mathrm{~Hz})$, $129.8(\mathrm{~d}, J=2.5 \mathrm{~Hz}), 124.3$ (d, $J=9.0 \mathrm{~Hz}), 122.4$ (d, $J=3.9 \mathrm{~Hz}), 121.8$ (d, $J=16.7 \mathrm{~Hz}), 100.5$ (d, $J=2.4 \mathrm{~Hz}), 65.3,53.0 \mathrm{ppm} ;{ }^{19} \mathrm{~F} \mathrm{NMR}\left(565 \mathrm{MHz}, \mathrm{CDCl}_{3}\right) \delta-123.65(\mathrm{~d}, J=6.7 \mathrm{~Hz}, 1 \mathrm{~F}) \mathrm{ppm}$; HRMS (ESI) calcd for $\mathrm{C}_{12} \mathrm{H}_{11} \mathrm{FO}_{5} \mathrm{Na}^{+}[\mathrm{M}+\mathrm{Na}]^{+} 277.0483$, found 277.0487.

Methyl 3-(\{[(allyloxy)carbonyl $]($ methyl)amino $\}$ methyl)-6-(1,3-dioxolan-2-yl)-2-fluorobenzoate (S3): To a stirred solution of aldehyde 73a $(660 \mathrm{mg}, 2.6 \mathrm{mmol}, 1.0$ equiv) in trifluoro-<smiles>COC(=O)c1c(C2OCCO2)ccc(CN(C)[13CH3])c1F</smilesethanol $(6 \mathrm{~mL})$ was added methyl amine $(2.0 \mathrm{M}, 1.3 \mathrm{~mL}, 2.6 \mathrm{mmol}$, 1.0 equiv) at $23^{\circ} \mathrm{C}$. The resulting mixture was stirred for $5 \mathrm{~min}$ at the same temperature. Then, $\mathrm{NaBH}_{4}(120 \mathrm{mg}, 3.1 \mathrm{mmol}, 1.2$ equiv) was added. After $5 \mathrm{~min}$, the reaction mixture was quenched by addition of $\mathrm{H}_{2} \mathrm{O}(0.5 \mathrm{~mL})$. The organic solvent was removed under reduced pressure. The residue was dissolved in $\mathrm{THF} / \mathrm{H}_{2} \mathrm{O}(1: 1, v / v, 12 \mathrm{~mL})$. To the resulting mixture at ambient temperature was added $\mathrm{NaHCO}_{3}$ (440 mg, $5.2 \mathrm{mmol}, 2.0$ equiv), followed by AllocCl $(0.40 \mathrm{~mL}, 3.9 \mathrm{mmol}$, 
1.5 equiv). The reaction mixture was stirred at the same temperature for $40 \mathrm{~min}$. The resulting mixture was extracted with EtOAc $(2 \times 10 \mathrm{~mL})$, and the combined organic layers were washed with brine $(10 \mathrm{~mL})$, dried over $\mathrm{Na}_{2} \mathrm{SO}_{4}$, and concentrated under reduced pressure. The residue was purified by flash column chromatography (silica gel, hexanes:EtOAc, 2:1, v/v) to give Allocprotected amine $\mathbf{S 3}$ as a colorless oil (784.4 $\mathrm{mg}, 2.2 \mathrm{mmol}, 85 \%$ yield).

S3: $R_{\mathrm{f}}=0.27$ (silica gel, 33\% EtOAc in hexanes); FT-IR (film): $v_{\max }=2953,2895,1737,1703$, $1649,1623,1581,1480,1428,1400,1362,1281,1252,1134,1110,972,944,795,769 \mathrm{~cm}^{-1} ;{ }^{1} \mathrm{H}$ NMR (600 MHz, $\left.\mathrm{CDCl}_{3}\right) \delta$ 7.47-7.27 (m, 2H), 6.11 (s, 1 H), 5.93 (dddd, J=35.7, 15.8, 10.6, $5.6 \mathrm{~Hz}, 1 \mathrm{H}), 5.36-5.15(\mathrm{~m}, 2 \mathrm{H}), 4.62(\mathrm{~d}, J=5.4 \mathrm{~Hz}, 2 \mathrm{H}), 4.55(\mathrm{~s}, 2 \mathrm{H}), 3.99(\mathrm{t}, J=6.5 \mathrm{~Hz}, 4 \mathrm{H})$, $3.94(\mathrm{~s}, 3 \mathrm{H}), 2.92(\mathrm{~d}, J=13.2 \mathrm{~Hz}, 3 \mathrm{H}) \mathrm{ppm} ;{ }^{13} \mathrm{C} \mathrm{NMR}\left(151 \mathrm{MHz}, \mathrm{CDCl}_{3}\right) \delta 165.5(\mathrm{~d}, J=12.8 \mathrm{~Hz})$, $157.6(\mathrm{dd}, J=251.0,35.5 \mathrm{~Hz}), 156.3(\mathrm{~d}, J=63.0 \mathrm{~Hz}), 138.1(\mathrm{~d}, J=12.2 \mathrm{~Hz}), 132.9$ (d, $J=17.7 \mathrm{~Hz})$, $130.8(\mathrm{~d}, J=187.5 \mathrm{~Hz}), 125.7$ (d, $J=14.8 \mathrm{~Hz}), 122.1,120.6(\mathrm{~d}, J=18.1 \mathrm{~Hz}), 117.6(\mathrm{~d}, J=47.5 \mathrm{~Hz})$, $100.9(\mathrm{~d}, J=15.7 \mathrm{~Hz}), 66.3,65.1,52.7$ (d, $J=21.1 \mathrm{~Hz}), 46.0$ (d, $J=14.9 \mathrm{~Hz}), 34.5$ (dd, $J=99.8$, $15.4 \mathrm{~Hz}) \mathrm{ppm} ;{ }^{19} \mathrm{~F} \mathrm{NMR}\left(565 \mathrm{MHz}, \mathrm{CDCl}_{3}\right) \delta-119.73(\mathrm{dd}, J=174.7,7.1 \mathrm{~Hz}, 1 \mathrm{~F}) \mathrm{ppm}$; HRMS (ESI) calcd for $\mathrm{C}_{17} \mathrm{H}_{20} \mathrm{FNO}_{6} \mathrm{Na}^{+}[\mathrm{M}+\mathrm{Na}]^{+} 376.1167$, found 376.1173 .

\section{Methyl 3-(\{[(allyloxy)carbonyl](methyl)amino\}methyl)-2-fluoro-6-formylbenzoate (74a): To}

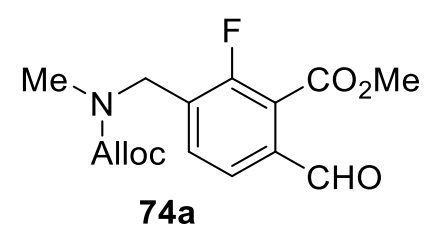
a stirred solution of compound $\mathbf{S 3}(1.2 \mathrm{~g}, 3.4 \mathrm{mmol}, 1.0$ equiv) in THF $(30 \mathrm{~mL})$ was added aq. $\mathrm{HCl}\left(4 \mathrm{~N}, 13 \mathrm{~mL}, 51 \mathrm{mmol}, 15\right.$ equiv) at $23^{\circ} \mathrm{C}$. The reaction mixture was stirred for $4 \mathrm{~h}$, then slowly poured into icecold saturated $\mathrm{NaHCO}_{3}$ solution. The resulting mixture was extracted

with EtOAc $(2 \times 20 \mathrm{~mL})$. The combined organic layers were washed with brine $(20 \mathrm{~mL})$, dried over anhydrous $\mathrm{Na}_{2} \mathrm{SO}_{4}$, and concentrated under reduced pressure. The residue was purified by flash column chromatography (silica gel, hexanes:EtOAc=2:1) to give aldehyde 74a (790 mg, $2.5 \mathrm{mmol}, 75 \%$ yield) as a colorless oil.

74a: $R_{\mathrm{f}}=0.27$ (silica gel, 33\% EtOAc in hexanes); FT-IR (film): $v_{\max }=2954,2849,1738,1694$, 1649, 1612, 1578, 1480, 1442, 1429, 1398, 1364, 1277, 1245, 1228, 1131, 1038, 973, 937, 888, 829, 792, 767, 756, 733, $661 \mathrm{~cm}^{-1} ;{ }^{1} \mathrm{H}$ NMR (600 MHz, $\left.\mathrm{CDCl}_{3}\right) \delta 10.03(\mathrm{~s}, 1 \mathrm{H}), 7.78-7.37(\mathrm{~m}$, 2 H), 6.03-5.81 (m, 1 H), 5.38-5.15 (m, 2 H), 4.66-4.58 (m, 2 H), 4.61 (s, 2 H), 4.01 (s, 3 H), 3.03$2.90(\mathrm{~m}, 3 \mathrm{H}) \mathrm{ppm} ;{ }^{13} \mathrm{C} \mathrm{NMR}\left(151 \mathrm{MHz}, \mathrm{CDCl}_{3}\right) \delta 189.1(\mathrm{~d}, J=11.4 \mathrm{~Hz}), 164.5(\mathrm{~d}, J=11.1 \mathrm{~Hz})$, $157.6(\mathrm{dd}, J=253.3,33.9 \mathrm{~Hz}), 156.2(\mathrm{~d}, J=84.9 \mathrm{~Hz}), 134.7,132.7(\mathrm{dd}, J=23.1,7.0 \mathrm{~Hz}), 131.9(\mathrm{t}$, 
$J=17.9 \mathrm{~Hz}), 130.9(\mathrm{~d}, J=186.4 \mathrm{~Hz}), 126.5(\mathrm{~d}, J=12.0 \mathrm{~Hz}), 122.0(\mathrm{dd}, J=18.4,10.8 \mathrm{~Hz}), 117.8(\mathrm{~d}$, $J=53.3 \mathrm{~Hz}), 66.5$ (d, $J=4.9 \mathrm{~Hz}), 53.2(\mathrm{~d}, J=22.1 \mathrm{~Hz}), 46.5(\mathrm{~d}, J=17.8 \mathrm{~Hz}), 34.9$ (dd, $J=91.2$, $15.4 \mathrm{~Hz}) \mathrm{ppm} ;{ }^{19} \mathrm{~F} \mathrm{NMR}\left(565 \mathrm{MHz}, \mathrm{CDCl}_{3}\right) \delta-118.66(\mathrm{dd}, J=165.6,6.7 \mathrm{~Hz}, 1 \mathrm{~F}) \mathrm{ppm}$; HRMS (ESI) calcd for $\mathrm{C}_{15} \mathrm{H}_{16} \mathrm{FNO}_{5} \mathrm{Na}^{+}[\mathrm{M}+\mathrm{Na}]^{+}$332.0905, found 332.0912.

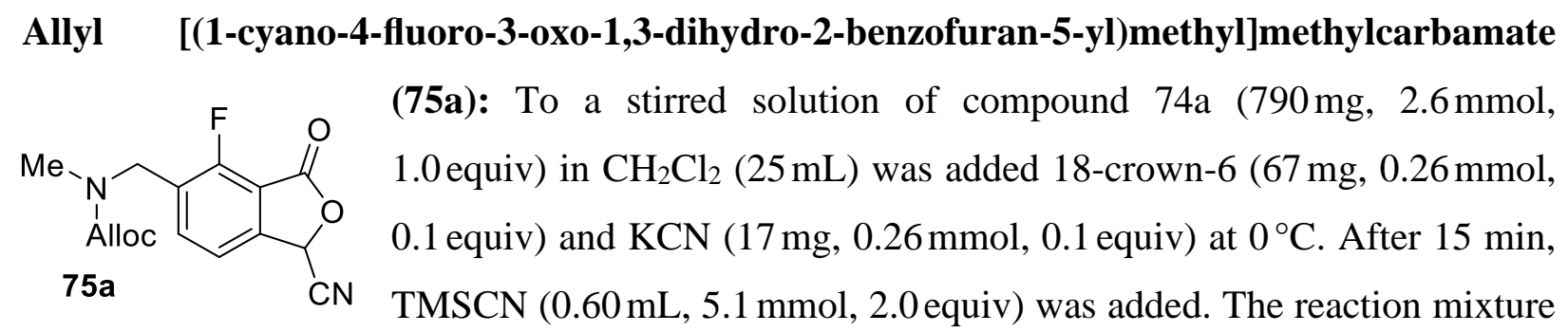

was stirred at $23^{\circ} \mathrm{C}$ for $4 \mathrm{~h}$. The solvent was removed under reduced pressure, and the residue was co-evaporated with toluene $(2 \times 5 \mathrm{~mL})$ to remove all traces of TMSCN. The resulting residue was dissolved in $\mathrm{AcOH}(25 \mathrm{~mL})$, and $p$-toluenesulfonic acid ( $240 \mathrm{mg}, 1.3 \mathrm{mmol}, 0.5$ equiv) was added. The resulting mixture was stirred for $12 \mathrm{~h}$ at $80^{\circ} \mathrm{C}$. After the mixture was allowed to cool to $23^{\circ} \mathrm{C}$, saturated $\mathrm{NaHCO}_{3}$ solution $(30 \mathrm{~mL})$ was added slowly. The resulting mixture was extracted with EtOAc $(2 \times 20 \mathrm{~mL})$. The combined organic layers were washed with brine $(10 \mathrm{~mL})$, dried over anhydrous $\mathrm{Na}_{2} \mathrm{SO}_{4}$, and concentrated under reduced pressure. The residue was purified by flash column chromatography (silica gel, hexanes:EtOAc, 2:1, v/v) to give compound 75a (430 mg, $1.4 \mathrm{mmol}, 56 \%$ yield) as a yellow oil.

75a: $R_{\mathrm{f}}=0.42$ (silica gel, 50\% EtOAc in hexanes); FT-IR (film): $v_{\max }=2946,1795,1698,1648$, 1633, 1603, 1490, 1448, 1402, 1371, 1330, 1283, 1256, 1207, 1147, 1080, 1012, 928, 896, 839, $768 \mathrm{~cm}^{-1} ;{ }^{1} \mathrm{H} \mathrm{NMR}\left(600 \mathrm{MHz}, \mathrm{CDCl}_{3}\right) \delta 7.99-7.67(\mathrm{~m}, 1 \mathrm{H}), 7.47(\mathrm{~d}, J=7.8 \mathrm{~Hz}, 1 \mathrm{H}), 6.06(\mathrm{~s}, 1 \mathrm{H})$, $5.94(\mathrm{t}, J=8.4 \mathrm{~Hz}, 1 \mathrm{H}), 5.37-5.18(\mathrm{~m}, 2 \mathrm{H}), 4.69-4.55(\mathrm{~m}, 4 \mathrm{H}), 2.99$ (s, $3 \mathrm{H}) \mathrm{ppm} ;{ }^{13} \mathrm{C}$ NMR $(151$ $\left.\mathrm{MHz}, \mathrm{CDCl}_{3}\right) \delta 163.1(\mathrm{~d}, J=17.1 \mathrm{~Hz}), 157.7$ (d, $\left.J=267.3 \mathrm{~Hz}\right), 156.2$ (d, $\left.J=114.3 \mathrm{~Hz}\right), 142.9,138.4$ (d, $J=223.7 \mathrm{~Hz}), 132.6$ (d, $J=14.7 \mathrm{~Hz}), 129.0$ (d, $J=12.8 \mathrm{~Hz}), 118.8$ (d, $J=4.9 \mathrm{~Hz}), 118.0$ (d, $J=75.2 \mathrm{~Hz}), 113.3,112.5$ (d, $J=16.5 \mathrm{~Hz}), 66.6$ (d, $J=10.4 \mathrm{~Hz}), 65.1,45.7$ (d, $J=44.2 \mathrm{~Hz}), 34.9$ (d, $J=63.7 \mathrm{~Hz}) \mathrm{ppm} ;{ }^{19} \mathrm{~F}$ NMR $\left(565 \mathrm{MHz}, \mathrm{CDCl}_{3}\right) \delta-116.41(\mathrm{dd}, J=366.6,6.1 \mathrm{~Hz}, 1 \mathrm{~F}) \mathrm{ppm}$; HRMS (ESI) calcd for $\mathrm{C}_{15} \mathrm{H}_{13} \mathrm{FN}_{2} \mathrm{O}_{4} \mathrm{H}^{+}[\mathrm{M}+\mathrm{H}]^{+}$305.0932, found 305.0937. 
Methyl 6-(1,3-dioxolan-2-yl)-2-fluoro-3-(3-oxopropyl)benzoate (73b): To a stirred solution of<smiles>CC(=O)c1c(C2OCCO2)ccc(CCC=O)c1F</smiles>
compound 67 (620 mg, $2.0 \mathrm{mmol}, 1.0$ equiv) in DMF $(10 \mathrm{~mL})$ was added 2-(di-tert-butylphosphino)-1-phenylindole ( $41 \mathrm{mg}, 0.1 \mathrm{mmol}, 6$ mol\%) at $23^{\circ} \mathrm{C}$, followed by $\mathrm{Pd}(\mathrm{dba})_{2}(23 \mathrm{mg}, 0.04 \mathrm{mmol}, 2 \mathrm{~mol} \%)$. The reaction mixture was degassed with nitrogen five times. Then, allyl alcohol ( $0.20 \mathrm{~mL}, 2.2 \mathrm{mmol}, 1.1$ equiv) was added, followed by $\mathrm{Cy}_{2} \mathrm{NMe}(0.50 \mathrm{~mL}, 2.2 \mathrm{mmol}$, 1.1 equiv). The resulting mixture was heated to $100^{\circ} \mathrm{C}$ and stirred at the same temperature for $1 \mathrm{~h}$. After allowing the mixture to cool to $23^{\circ} \mathrm{C}$, EtOAc $(10 \mathrm{~mL})$ and $\mathrm{H}_{2} \mathrm{O}(10 \mathrm{~mL})$ were added. The organic phase was separated and washed with $\mathrm{H}_{2} \mathrm{O}(2 \times 10 \mathrm{~mL})$. The combined organic layers were washed with brine $(10 \mathrm{~mL})$, dried over anhydrous $\mathrm{Na}_{2} \mathrm{SO}_{4}$, and concentrated under reduced pressure. The residue was purified by flash column chromatography (silica gel, hexanes:EtOAc, $2: 1, v / v)$ to give aldehyde $\mathbf{7 3 b}(450 \mathrm{mg}, 1.6 \mathrm{mmol}, 78 \%$ yield) as a light yellow oil.

73b: $R_{\mathrm{f}}=0.26$ (silica gel, 33\% EtOAc in hexanes); FT-IR (film): $v_{\max }=2954,2895,1725,1624$, 1578, 1484, 1441, 1428, 1389, 1351, 1278, 1253, 1193, 1136, 1103, 1055, 1010, 973, 948, 914 , 836, 802, $730 \mathrm{~cm}^{-1} ;{ }^{1} \mathrm{H}$ NMR $\left(600 \mathrm{MHz}, \mathrm{CDCl}_{3}\right) \delta 9.79(\mathrm{~d}, J=1.1 \mathrm{~Hz}, 1 \mathrm{H}), 7.32-7.27(\mathrm{~m}, 2 \mathrm{H})$, $6.07(\mathrm{~s}, 1 \mathrm{H}), 4.00-3.94(\mathrm{~m}, 4 \mathrm{H}), 3.92(\mathrm{~s}, 3 \mathrm{H}), 2.97(\mathrm{td}, J=7.5,1.2 \mathrm{~Hz}, 2 \mathrm{H}), 2.78(\mathrm{td}, J=7.4$, $1.0 \mathrm{~Hz}, 2 \mathrm{H}) \mathrm{ppm} ;{ }^{13} \mathrm{C} \mathrm{NMR}\left(151 \mathrm{MHz}, \mathrm{CDCl}_{3}\right) \delta 200.5,165.6,157.8(\mathrm{~d}, J=250.4 \mathrm{~Hz}), 137.1$ (d, $J=2.3 \mathrm{~Hz}), 132.0(\mathrm{~d}, J=5.5 \mathrm{~Hz}), 128.5(\mathrm{~d}, J=16.2 \mathrm{~Hz}), 122.0(\mathrm{~d}, J=3.8 \mathrm{~Hz}), 120.7$ (d, $J=18.3 \mathrm{~Hz})$, $101.0(\mathrm{~d}, J=2.5 \mathrm{~Hz}), 65.1,52.6,43.5,21.6(\mathrm{~d}, J=2.9 \mathrm{~Hz}) \mathrm{ppm} ;{ }^{19} \mathrm{~F}$ NMR $\left(565 \mathrm{MHz}, \mathrm{CDCl}_{3}\right) \delta$ $-119.40--119.46(\mathrm{~m}, 1 \mathrm{~F}) \mathrm{ppm}$; HRMS (ESI) calcd for $\mathrm{C}_{14} \mathrm{H}_{15} \mathrm{FO}_{5} \mathrm{Na}^{+}[\mathrm{M}+\mathrm{Na}]^{+} 305.0796$, found 305.0804 .

Methyl 3-(3-\{[(allyloxy)carbonyl](methyl)amino\}propyl)-6-(1,3-dioxolan-2-yl)-2-fluorobenzoate (S4): To a stirred solution of compound $\mathbf{7 3 b}(150 \mathrm{mg}, 0.50 \mathrm{mmol}, 1.0$ equiv) in<smiles>CC(=O)c1c(CCCN(C)C)ccc(C2OCCO2)c1F</smiles>
trifluoroethanol $(5 \mathrm{~mL})$ was added methyl amine $(2.0 \mathrm{M}, 0.30 \mathrm{~mL}$, $0.50 \mathrm{mmol}, 1.0$ equiv) at ambient temperature. The resulting mixture was stirred for $5 \mathrm{~min}$ at the same temperature. Then $\mathrm{NaBH}_{4}$ ( $24 \mathrm{mg}, 0.6 \mathrm{mmol}, 1.2$ equiv) was added. After $5 \mathrm{~min}$, the reaction mixture was quenched by addition of $\mathrm{H}_{2} \mathrm{O}(0.5 \mathrm{~mL})$. The organic solvent was removed under reduced pressure. The residue was dissolved in $\mathrm{THF} / \mathrm{H}_{2} \mathrm{O}(1: 1, v / v, 10 \mathrm{~mL})$. To the resulting mixture at $23^{\circ} \mathrm{C}$ was added $\mathrm{NaHCO}_{3}(89 \mathrm{mg}, 1.1 \mathrm{mmol}, 2.0$ equiv), followed by AllocCl $(85 \mu \mathrm{L}$, 
$0.80 \mathrm{mmol}, 1.5$ equiv). The reaction mixture was stirred at the same temperature for $40 \mathrm{~min}$. The resulting mixture was extracted with EtOAc $(2 \times 10 \mathrm{~mL})$, and the combined organic layers were washed with brine $(10 \mathrm{~mL})$, dried over $\mathrm{Na}_{2} \mathrm{SO}_{4}$ and concentrated under reduced pressure. The residue was purified by flash column chromatography (silica gel, hexanes:EtOAc, 1:1, v/v) to give compound $\mathbf{S 4}$ as a colorless oil (100 $\mathrm{mg}, 0.30 \mathrm{mmol}, 51 \%$ yield).

S4: $R_{\mathrm{f}}=0.50$ (silica gel, 50\% EtOAc in hexanes); FT-IR (film): $v_{\max }=2951,2892,1735,1696$, 1648, 1623, 1578, 1482, 1427, 1401, 1277, 1254, 1191, 1128, 1107, 1055, 974, 939, 837, 804, 769, 735, $671 \mathrm{~cm}^{-1} ;{ }^{1} \mathrm{H}$ NMR (600 MHz, $\left.\mathrm{CDCl}_{3}\right) \delta 7.32-7.22(\mathrm{~m}, 2 \mathrm{H}), 6.08(\mathrm{~s}, 1 \mathrm{H}), 5.93(\mathrm{~d}$, $J=16.5 \mathrm{~Hz}, 1 \mathrm{H}), 5.28(\mathrm{t}, J=16.4 \mathrm{~Hz}, 1 \mathrm{H}), 5.19(\mathrm{~d}, J=10.5 \mathrm{~Hz}, 1 \mathrm{H}), 4.58(\mathrm{~d}, J=5.4 \mathrm{~Hz}, 1 \mathrm{H}), 4.02-$ $3.95(\mathrm{~m}, 4 \mathrm{H}), 3.93(\mathrm{~s}, 3 \mathrm{H}), 3.38-3.27(\mathrm{~m}, 2 \mathrm{H}), 2.90(\mathrm{~s}, 3 \mathrm{H}), 2.64(\mathrm{t}, J=7.9 \mathrm{~Hz}, 2 \mathrm{H}), 1.87-1.81$ $(\mathrm{m}, 2 \mathrm{H}) \mathrm{ppm} ;{ }^{13} \mathrm{C} \mathrm{NMR}\left(151 \mathrm{MHz}, \mathrm{CDCl}_{3}\right) \delta 165.8,157.8(\mathrm{~d}, J=250.0 \mathrm{~Hz}), 156.2,136.5,133.1$, $131.7(\mathrm{~d}, J=26.6 \mathrm{~Hz}), 129.8$ (d, $J=24.9 \mathrm{~Hz}), 121.8$ (d, $J=3.6 \mathrm{~Hz}), 120.5$ (d, $J=17.1 \mathrm{~Hz}), 117.1$ (d, $J=17.6 \mathrm{~Hz}), 101.1(\mathrm{~d}, J=2.3 \mathrm{~Hz}), 65.9,65.1,52.6,48.4(\mathrm{~d}, J=63.4 \mathrm{~Hz}), 34.1$ (d, $J=105.5 \mathrm{~Hz}), 27.8$ $(\mathrm{d}, J=48.8 \mathrm{~Hz}), 26.1 \mathrm{ppm} ;{ }^{19} \mathrm{~F} \mathrm{NMR}\left(565 \mathrm{MHz}, \mathrm{CDCl}_{3}\right) \delta-119.66--119.91$ (m, $\left.1 \mathrm{~F}\right) \mathrm{ppm}$; HRMS (ESI) calcd for $\mathrm{C}_{19} \mathrm{H}_{24} \mathrm{FNO}_{6} \mathrm{Na}^{+}[\mathrm{M}+\mathrm{Na}]^{+} 404.1480$, found 404.1480.

\section{Methyl 3-(3-\{[(allyloxy)carbonyl](methyl)amino\}propyl)-2-fluoro-6-formylbenzoate (74b):}

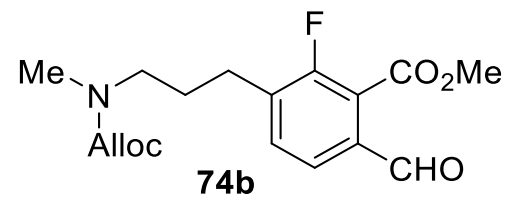

To a stirred solution of compound S4 (98 $\mathrm{mg}, 0.26 \mathrm{mmol}$, 1.0 equiv) in $\mathrm{THF}(3 \mathrm{~mL})$ was added aq. $\mathrm{HCl}(4 \mathrm{~N}, 1.0 \mathrm{~mL}$, $3.9 \mathrm{mmol}, 15$ equiv) at $23^{\circ} \mathrm{C}$. The reaction mixture was stirred for $4 \mathrm{~h}$, then slowly poured into an ice-cold saturated $\mathrm{NaHCO}_{3}$ solution. The resulting mixture was extracted with EtOAc $(2 \times 5 \mathrm{~mL})$. The combined organic layers were washed with brine $(10 \mathrm{~mL})$, dried over anhydrous $\mathrm{Na}_{2} \mathrm{SO}_{4}$, and concentrated under reduced pressure. The residue was purified by flash column chromatography (silica gel, hexanes:EtOAc, 2:1, v/v) to give compound $\mathbf{7 4 b}$ as a colorless oil ( $75 \mathrm{mg}, 0.20 \mathrm{mmol}, 86 \%$ yield).

74b: $R_{f}=0.50$ (silica gel, 50\% EtOAc in hexanes); FT-IR (film): $v_{\max }=2952,2870,1738,1693$, 1648, 1610, 1574, 1483, 1445, 1430, 1400, 1279, 1255, 1231, 1190, 1142, 1127, 1056, 1032, 977, 931, 864, 832, 802, 768, $756 \mathrm{~cm}^{-1} ;{ }^{1} \mathrm{H} \mathrm{NMR}\left(600 \mathrm{MHz}, \mathrm{CDCl}_{3}\right) \delta 9.99(\mathrm{~s}, 1 \mathrm{H}), 7.62(\mathrm{~d}, J=7.8 \mathrm{~Hz}$, $1 \mathrm{H}), 7.46(\mathrm{~d}, J=22.5 \mathrm{~Hz}, 1 \mathrm{H}), 5.93(\mathrm{~s}, 1 \mathrm{H}), 5.28(\mathrm{t}, J=17.1 \mathrm{~Hz}, 1 \mathrm{H}), 5.20(\mathrm{~d}, J=10.5 \mathrm{~Hz}, 1 \mathrm{H})$, $4.58(\mathrm{dt}, J=5.5,1.5 \mathrm{~Hz}, 2 \mathrm{H}), 3.99(\mathrm{~s}, 3 \mathrm{H}), 3.35(\mathrm{~d}, J=8.0 \mathrm{~Hz}, 2 \mathrm{H}), 2.91(\mathrm{~s}, 3 \mathrm{H}), 2.72(\mathrm{t}, J=7.9 \mathrm{~Hz}$, $2 \mathrm{H}), 1.88(\mathrm{td}, J=7.6,7.2,3.6 \mathrm{~Hz}, 2 \mathrm{H}) \mathrm{ppm} ;{ }^{13} \mathrm{C} \mathrm{NMR}\left(151 \mathrm{MHz}, \mathrm{CDCl}_{3}\right) \delta 189.1,164.8,157.8$ 
(d, $J=252.2 \mathrm{~Hz}), 156.1$ (d, $J=20.3 \mathrm{~Hz}), 136.2,133.7,133.1,132.1$ (d, $J=31.4 \mathrm{~Hz}), 126.4,121.9$, $117.3(\mathrm{~d}, J=23.9 \mathrm{~Hz}), 66.0,53.1,48.3(\mathrm{~d}, J=59.9 \mathrm{~Hz}), 34.2$ (d, $J=101.7 \mathrm{~Hz}), 27.5(\mathrm{~d}, J=53.1 \mathrm{~Hz})$, $26.6 \mathrm{ppm} ;{ }^{19} \mathrm{~F}$ NMR $\left(565 \mathrm{MHz}, \mathrm{CDCl}_{3}\right) \delta-118.84$ (dd, $\left.J=82.5,6.9 \mathrm{~Hz}, 1 \mathrm{~F}\right) \mathrm{ppm}$; HRMS (ESI) calcd for $\mathrm{C}_{17} \mathrm{H}_{21} \mathrm{FNO}_{5}{ }^{+}[\mathrm{M}+\mathrm{H}]^{+} 338.1398$, found 338.1404.

\section{Allyl [3-(1-cyano-4-fluoro-3-oxo-1,3-dihydro-2-benzofuran-5-yl)propyl]methylcarbamate}

(75b): To a stirred solution of compound $\mathbf{7 4 b}\left(54 \mathrm{mg}, 0.16 \mathrm{mmol}, 1.0\right.$ equiv) in $\mathrm{CH}_{2} \mathrm{Cl}_{2}(2 \mathrm{~mL})$ was<smiles>CN(C)CCCc1ccc2c(c1F)C(=O)OC2C#N</smiles>
added 18-crown-6 (4.3 mg, 0.016 mmol, 0.1 equiv) and $\mathrm{KCN}(1.0 \mathrm{mg}$, $0.016 \mathrm{mmol}, 0.1$ equiv) at $0^{\circ} \mathrm{C}$. After $15 \mathrm{~min}$, TMSCN $(40 \mu \mathrm{L}$, $0.32 \mathrm{mmol}, 2.0$ equiv) was added. The reaction mixture was stirred at $23^{\circ} \mathrm{C}$ for $4 \mathrm{~h}$. The solvent was removed under reduced pressure, and the residue was co-evaporated with toluene $(2 \times 1 \mathrm{~mL})$ to remove all traces of TMSCN. The resulting residue was dissolved in $\mathrm{AcOH}(2 \mathrm{~mL})$, and $p$-toluenesulfonic acid $(15 \mathrm{mg}, 0.080 \mathrm{mmol}, 0.5$ equiv) was added. The resulting mixture was stirred for $12 \mathrm{~h}$ at $80^{\circ} \mathrm{C}$. After cooled down to $23^{\circ} \mathrm{C}$, saturated $\mathrm{NaHCO}_{3}$ solution $(10 \mathrm{~mL})$ was added slowly to the reaction mixture. The resulting mixture was extracted with EtOAc $(2 \times 5 \mathrm{~mL})$. The combined organic layers were washed with brine $(10 \mathrm{~mL})$, dried over anhydrous $\mathrm{Na}_{2} \mathrm{SO}_{4}$ and concentrated under reduced pressure. The residue was purified by flash column chromatography (silica gel, hexanes:EtOAc, $1: 1, v / v)$ to give compound $\mathbf{7 5 b}(35 \mathrm{mg}, 0.11 \mathrm{mmol}$, $66 \%$ yield) as a yellow oil.

75b: $\mathrm{R}_{\mathrm{f}}=0.32$ (silica gel, 50\% EtOAc in hexanes); FT-IR (film): $v_{\max }=2938,1791,1693,1630$, 1601, 1491, 1449, 1404, 1309, 1281, 1210, 1192, 1135, 1085, 1049, 1005, 929, 908, 843, 768, 657 $\mathrm{cm}^{-1} ;{ }^{1} \mathrm{H}$ NMR $\left(600 \mathrm{MHz}, \mathrm{CDCl}_{3}\right) \delta 7.72(\mathrm{~d}, J=33.3 \mathrm{~Hz}, 1 \mathrm{H}), 7.41(\mathrm{~d}, J=7.8 \mathrm{~Hz}, 1 \mathrm{H}), 6.04(\mathrm{~s}$, $1 \mathrm{H}), 5.93(\mathrm{~s}, 1 \mathrm{H}), 5.35-5.23(\mathrm{~m}, 1 \mathrm{H}), 5.21(\mathrm{~d}, J=10.5 \mathrm{~Hz}, 1 \mathrm{H}), 4.59(\mathrm{dt}, J=5.5,1.5 \mathrm{~Hz}, 2 \mathrm{H})$, $3.36(\mathrm{t}, J=7.2 \mathrm{~Hz}, 2 \mathrm{H}), 2.93(\mathrm{~s}, 3 \mathrm{H}), 2.78(\mathrm{t}, J=7.9 \mathrm{~Hz}, 2 \mathrm{H}), 1.90(\mathrm{p}, J=7.5 \mathrm{~Hz}, 2 \mathrm{H}) \mathrm{ppm} ;{ }^{13} \mathrm{C}$ NMR (151 MHz, CDCl $) \delta 163.4,157.8(\mathrm{~d}, J=265.8 \mathrm{~Hz}), 156.2$ (d, $J=33.8 \mathrm{~Hz}), 141.5,139.0$ (d, $J=50.7 \mathrm{~Hz}), 133.1,132.8$ (d, $J=8.9 \mathrm{~Hz}), 118.4$ (d, $J=4.9 \mathrm{~Hz}), 117.2,113.5,112.4,66.0,65.0,48.1$ (d, $J=38.4 \mathrm{~Hz}), 34.2$ (d, $J=102.8 \mathrm{~Hz}), 27.8(\mathrm{~d}, J=69.4 \mathrm{~Hz}), 25.8 \mathrm{ppm} ;{ }^{19} \mathrm{~F} \mathrm{NMR}\left(565 \mathrm{MHz}, \mathrm{CDCl}_{3}\right)$ $\delta-116.36(\mathrm{dd}, J=70.9,6.2 \mathrm{~Hz}, 1 \mathrm{~F}) \mathrm{ppm}$; HRMS (ESI) calcd for $\mathrm{C}_{17} \mathrm{H}_{17} \mathrm{FN}_{2} \mathrm{O}_{4} \mathrm{Na}^{+}[\mathrm{M}+\mathrm{Na}]^{+}$ 355.1065 , found 355.1066 . 
Methyl 5-bromo-4-fluoro-2-iodobenzoate (78): To a stirred mixture of compound 77 (12 g,<smiles>COC(=O)c1cc(Br)c(F)cc1I</smiles>
$50 \mathrm{mmol}, 1.0$ equiv) in $\mathrm{HCl}$ (conc., $42 \mathrm{~mL}, 500 \mathrm{mmol}, 10$ equiv) and $\mathrm{H}_{2} \mathrm{O}$ $(80 \mathrm{~mL})$ was added $\mathrm{NaNO}_{2}\left(4.1 \mathrm{~g}, 60 \mathrm{mmol}, 1.2\right.$ equiv) in $\mathrm{H}_{2} \mathrm{O}(20 \mathrm{~mL})$ at $0{ }^{\circ} \mathrm{C}$ over $0.5 \mathrm{~h}$. Then, the reaction mixture was stirred at the same temperature for further $0.5 \mathrm{~h}$. Then an ice-cold solution of $\mathrm{KI}$ ( $13 \mathrm{~g}, 75 \mathrm{mmol}, 1.5$ equiv) in $\mathrm{H}_{2} \mathrm{O}(20 \mathrm{~mL})$ was added dropwise to the above mixture at $0{ }^{\circ} \mathrm{C}$ over $20 \mathrm{~min}$. The resulting mixture was stirred for further 1 $\mathrm{h}$ at the same temperature. The red mixture was heated to $90^{\circ} \mathrm{C}$ and stirred at this temperature for $0.5 \mathrm{~h}$. After cooling to $23^{\circ} \mathrm{C}$, saturated $\mathrm{Na}_{2} \mathrm{~S}_{2} \mathrm{O}_{3}$ solution $(50 \mathrm{~mL})$ was added. The mixture was extracted with EtOAc $(2 \times 150 \mathrm{~mL})$. The combined organic layers were washed with brine $(150 \mathrm{~mL})$, dried over anhydrous $\mathrm{Na}_{2} \mathrm{SO}_{4}$ and concentrated under reduced pressure. The residue was used to the next step directly without further purification.

To a stirred solution of the above residue in $\mathrm{MeOH}(150 \mathrm{~mL})$ was added $\mathrm{H}_{2} \mathrm{SO}_{4}$ (conc., $6.1 \mathrm{~mL}, 100 \mathrm{mmol}, 2.0$ equiv) slowly at $23^{\circ} \mathrm{C}$. The resulting mixture was heated to $65^{\circ} \mathrm{C}$ for $12 \mathrm{~h}$. After allowing the mixture to cool to $23^{\circ} \mathrm{C}$, the mixture was poured to an ice-cold saturated $\mathrm{NaHCO}_{3}$ solution $(100 \mathrm{~mL})$. The mixture was extracted with EtOAc $(2 \times 150 \mathrm{~mL})$. The combined organic layers were washed with brine $(150 \mathrm{~mL})$, dried over anhydrous $\mathrm{Na}_{2} \mathrm{SO}_{4}$, and concentrated under reduced pressure. The residue was purified by flash column chromatography (silica gel, hexanes:EtOAc, 5:1, v/v) to give compound $78(15 \mathrm{~g}, 41 \mathrm{mmol}, 82 \%$ yield for two steps) as a yellow solid.

78: $\mathrm{R}_{\mathrm{f}}=0.60$ (silica gel, 20\% EtOAc in hexanes); $\mathrm{mp} 57-58^{\circ} \mathrm{C}$ (EtOAc/hexanes); FT-IR (film): $v_{\max }=3092,3024,2952,2843,1734,1579,1556,1475,1434,1354,1341,1284,1259,1190,1111$, 1062, 972, 901, 863, 811, 775, 727, 696, $664 \mathrm{~cm}^{-1} ;{ }^{1} \mathrm{H}$ NMR (600 MHz, $\left.\mathrm{CDCl}_{3}\right) \delta 8.08$ (d, $J=7.0 \mathrm{~Hz}, 1 \mathrm{H}), 7.75(\mathrm{~d}, J=7.8 \mathrm{~Hz}, 1 \mathrm{H}), 3.93(\mathrm{~s}, 3 \mathrm{H}) \mathrm{ppm} ;{ }^{13} \mathrm{C} \mathrm{NMR}\left(151 \mathrm{MHz}, \mathrm{CDCl}_{3}\right) \delta 164.6$, 160.1 (d, $J=258.4 \mathrm{~Hz}), 135.9$ (d, $J=1.9 \mathrm{~Hz}), 131.7$ (d, $J=3.8 \mathrm{~Hz}), 129.3$ (d, $J=24.4 \mathrm{~Hz}), 109.1$ (d, $J=21.1 \mathrm{~Hz}), 92.7(\mathrm{~d}, J=7.4 \mathrm{~Hz}), 52.8 \mathrm{ppm} ;{ }^{19} \mathrm{~F} \mathrm{NMR}\left(565 \mathrm{MHz}, \mathrm{CDCl}_{3}\right) \delta-99.84(\mathrm{t}, J=7.4 \mathrm{~Hz}$, 1 F) ppm; HRMS (EI) calcd for $\mathrm{C}_{8} \mathrm{H}_{5} \mathrm{BrfiO}_{2}{ }^{+}[\mathrm{M}]^{+}$357.8502, found 357.8494 .

Methyl 5-bromo-4-fluoro-2-vinylbenzoate (79): To a stirred solution of compound 78 (2.0 g,<smiles>C=Cc1cc(F)c(Br)cc1C(=O)OC</smiles>
$5.6 \mathrm{mmol}, 1.0$ equiv) in 1,4-dioxane $(56 \mathrm{~mL})$ was added pinacol vinylboronate (940 mg, $6.1 \mathrm{mmol}, 1.1$ equiv) at $23^{\circ} \mathrm{C}$. Then $\mathrm{Cs}_{2} \mathrm{CO}_{3}(4.5 \mathrm{~g}, 14 \mathrm{mmol}$, 2.0 equiv) and $\mathrm{PPh}_{3}(290 \mathrm{mg}, 1.1 \mathrm{mmol}, 0.2$ equiv) were added to the reaction 
mixture, followed by $\mathrm{Pd}(\mathrm{OAc})_{2}(63 \mathrm{mg}, 0.28 \mathrm{mmol}, 5 \mathrm{~mol} \%)$. The reaction mixture was degassed with nitrogen five times and heated to $70^{\circ} \mathrm{C}$. After $12 \mathrm{~h}$, the reaction mixture was allowed to cool to ambient temperature and filtered through a pad of Celite. The filtrate was washed with $\mathrm{H}_{2} \mathrm{O}$ $(30 \mathrm{~mL})$ and extracted with EtOAc $(2 \times 20 \mathrm{~mL})$. The combined organic layers were washed with brine $(20 \mathrm{~mL})$, dried over anhydrous $\mathrm{Na}_{2} \mathrm{SO}_{4}$, and concentrated under reduced pressure. The residue was purified by flash column chromatography (silica gel, hexanes:EtOAc, 10:1, v/v) to give ester 79 (1.3 g, $5.1 \mathrm{mmol}, 92 \%$ yield) as a light yellow oil.

79: $\mathrm{R}_{\mathrm{f}}=0.66$ (silica gel, 11\% EtOAc in hexanes); FT-IR (film): $v_{\max }=3096,2953,1725,1597$, 1560, 1483, 1435, 1385, 1294, 1264, 1245, 1156, 1096, 988, 924, 905, 874, 791, 723, $670 \mathrm{~cm}^{-1}$; ${ }^{1} \mathrm{H}$ NMR $\left(600 \mathrm{MHz}, \mathrm{CDCl}_{3}\right) \delta 8.14(\mathrm{~d}, J=7.1 \mathrm{~Hz}, 1 \mathrm{H}), 7.45(\mathrm{ddd}, J=17.4,11.0,1.4 \mathrm{~Hz}, 1 \mathrm{H}), 7.31$ $(\mathrm{d}, J=9.6 \mathrm{~Hz}, 1 \mathrm{H}), 5.67(\mathrm{dd}, J=17.4,0.9 \mathrm{~Hz}, 1 \mathrm{H}), 5.43(\mathrm{dd}, J=10.9,1.0 \mathrm{~Hz}, 1 \mathrm{H}), 3.90(\mathrm{~s}, 3 \mathrm{H})$ ppm; ${ }^{13} \mathrm{C}$ NMR $\left(151 \mathrm{MHz}, \mathrm{CDCl}_{3}\right) \delta 165.6,161.2(\mathrm{~d}, J=253.6 \mathrm{~Hz}), 141.8(\mathrm{~d}, J=7.9 \mathrm{~Hz}), 136.2(\mathrm{~d}$, $J=2.1 \mathrm{~Hz}), 134.3(\mathrm{~d}, J=1.6 \mathrm{~Hz}), 125.5$ (d, $J=3.3 \mathrm{~Hz}), 118.1,114.8$ (d, $J=23.2 \mathrm{~Hz}), 107.8$ (d, $J=21.6 \mathrm{~Hz}), 52.4 \mathrm{ppm} ;{ }^{19} \mathrm{~F} \mathrm{NMR}\left(565 \mathrm{MHz}, \mathrm{CDCl}_{3}\right) \delta-100.73(\mathrm{ddd}, J=9.2,7.1,1.4 \mathrm{~Hz}, 1 \mathrm{~F}) \mathrm{ppm}$; HRMS (EI) calcd for $\mathrm{C}_{10} \mathrm{H}_{8} \mathrm{BrFO}_{2}^{+}[\mathrm{M}]^{+}$257.9692, found 257.9685.

Methyl 5-[(tert-butoxycarbonyl)amino]-4-fluoro-2-vinylbenzoate (80): To a stirred solution of<smiles>C=Cc1cc(F)c(NC(=O)OCc2ccccc2)cc1C(=O)OC</smiles>
compound 79 (1.1 g, $4.2 \mathrm{mmol}, 1.0$ equiv) in 1,4-dioxane $(40 \mathrm{~mL})$ was added $\mathrm{BocNH}_{2}\left(600 \mathrm{mg}, 5.1 \mathrm{mmol}, 1.2\right.$ equiv) at $23^{\circ} \mathrm{C}$, followed by XPhos (180 mg, $0.38 \mathrm{mmol}, 9 \mathrm{~mol} \%), \mathrm{Cs}_{2} \mathrm{CO}_{3}(1.9 \mathrm{~g}, 5.9 \mathrm{mmol}$, 1.4 equiv) and $\mathrm{Pd}(\mathrm{OAc})_{2}(29 \mathrm{mg}, 0.13 \mathrm{mmol}, 3 \mathrm{~mol} \%)$. The reaction mixture was degassed with nitrogen five times and heated to $100^{\circ} \mathrm{C}$. After $8 \mathrm{~h}$, the reaction mixture was allowed to cool to $23^{\circ} \mathrm{C}$, and filtered through a pad of Celite. The filtrate was washed with $\mathrm{H}_{2} \mathrm{O}(30 \mathrm{~mL})$ and extracted with EtOAc $(2 \times 30 \mathrm{~mL})$. The combined organic layers were washed with brine $(20 \mathrm{~mL})$, dried over anhydrous $\mathrm{Na}_{2} \mathrm{SO}_{4}$, and concentrated under reduced pressure. The residue was purified by flash column chromatography (silica gel, hexanes:EtOAc, 2:1, v/v) to give compound 80 as a light yellow oil (1.2 $\mathrm{g}, 4.0 \mathrm{mmol}, 95 \%$ yield).

80: $\mathrm{R}_{\mathrm{f}}=0.31$ (silica gel, 11\% EtOAc in hexanes); FT-IR (film): $v_{\max }=3336,2980,1721,1621$, 1587, 1482, 1437, 1368, 1335, 1256, 1228, 1157, 1144, 1078, 1057, 1009, 912, 844, 793, 748 $\mathrm{cm}^{-1} ;{ }^{1} \mathrm{H} \mathrm{NMR}\left(600 \mathrm{MHz}, \mathrm{CDCl}_{3}\right) \delta 8.63(\mathrm{~d}, J=8.3 \mathrm{~Hz}, 1 \mathrm{H}), 7.43$ (ddd, $J=17.4,11.0,1.6 \mathrm{~Hz}$, $1 \mathrm{H}), 7.28(\mathrm{~d}, J=12.3 \mathrm{~Hz}, 1 \mathrm{H}), 6.72(\mathrm{~s}, 1 \mathrm{H}), 5.58(\mathrm{dd}, J=17.4,1.0 \mathrm{~Hz}, 1 \mathrm{H}), 5.33(\mathrm{dd}, J=10.9$, 
$1.0 \mathrm{~Hz}, 1 \mathrm{H}), 3.89(\mathrm{~s}, 3 \mathrm{H}), 1.54(\mathrm{~s}, 9 \mathrm{H}) \mathrm{ppm} ;{ }^{13} \mathrm{C} \mathrm{NMR}\left(151 \mathrm{MHz}, \mathrm{CDCl}_{3}\right) \delta 166.8,153.7(\mathrm{~d}$, $J=248.5 \mathrm{~Hz}$ ), 152.0, 135.4 (d, $J=7.7 \mathrm{~Hz}), 134.4,126.1$ (d, $J=10.8 \mathrm{~Hz}), 125.1$ (d, $J=2.8 \mathrm{~Hz}), 121.8$, $116.2,113.0(\mathrm{~d}, J=20.5 \mathrm{~Hz}), 81.5,52.2,28.2 \mathrm{ppm} ;{ }^{19} \mathrm{~F} \mathrm{NMR}\left(565 \mathrm{MHz}, \mathrm{CDCl}_{3}\right) \delta-126.45(\mathrm{~s}, 1 \mathrm{~F})$ ppm; HRMS (ESI) calcd for $\mathrm{C}_{15} \mathrm{H}_{18} \mathrm{FNO}_{4} \mathrm{Na}^{+}[\mathrm{M}+\mathrm{Na}]^{+} 318.1112$, found 318.1118 .

Methyl 5-[(tert-butoxycarbonyl)amino]-4-fluoro-2-formylbenzoate (81): Through a stirred<smiles>COC(=O)c1cc(NC=O)c(F)cc1C=O</smiles>
solution of compound $80\left(500 \mathrm{mg}, 1.7 \mathrm{mmol}, 1.0\right.$ equiv) in $\mathrm{CH}_{2} \mathrm{Cl}_{2}$ $\left(20 \mathrm{~mL}\right.$ ) was bubbled $\mathrm{O}_{3}$ at $-78^{\circ} \mathrm{C}$ until the reaction mixture turned light blue. Then $\mathrm{Me}_{2} \mathrm{~S}\left(0.60 \mathrm{~mL}, 8.5 \mathrm{mmol}, 5.0\right.$ equiv) was added at $-78^{\circ} \mathrm{C}$ and the reaction mixture was allowed to warm to $23^{\circ} \mathrm{C}$ and stirrd at this temperature for $1 \mathrm{~h}$. The resulting mixture was concentrated to remove the solvent, and the residue was purified by flash column chromatography (silica gel, hexanes:EtOAc, 2:1, v/v) to give aldehyde $\mathbf{8 1}$ (400 mg, $1.3 \mathrm{mmol}, 79 \%$ yield) as a light yellow solid.

81: $\mathrm{R}_{\mathrm{f}}=0.35$ (silica gel, $20 \%$ EtOAc in hexanes); $\mathrm{mp} 114-115^{\circ} \mathrm{C}$ (EtOAc/hexanes); FT-IR (film): $v_{\max }=3340,2980,1720,1686,1610,1591,1525,1481,1439,1369,1341,1301,1257,1234,1154$, 1130, 1044, 1019, 959, 913, 770, $741 \mathrm{~cm}^{-1}$; ${ }^{1} \mathrm{H}$ NMR $\left(600 \mathrm{MHz}, \mathrm{CDCl}_{3}\right) \delta 10.55$ (d, $J=3.1 \mathrm{~Hz}$, $1 \mathrm{H}), 8.82(\mathrm{~d}, J=7.4 \mathrm{~Hz}, 1 \mathrm{H}), 7.71(\mathrm{~d}, J=11.3 \mathrm{~Hz}, 1 \mathrm{H}), 6.97(\mathrm{~s}, 1 \mathrm{H}), 3.97(\mathrm{~s}, 3 \mathrm{H}), 1.55(\mathrm{~s}, 9 \mathrm{H})$ ppm; ${ }^{13} \mathrm{C}$ NMR $\left(151 \mathrm{MHz}, \mathrm{CDCl}_{3}\right) \delta 189.8,165.8,153.0(\mathrm{~d}, J=250.6 \mathrm{~Hz}), 151.6,132.0(\mathrm{~d}$, $J=6.1 \mathrm{~Hz}), 131.6(\mathrm{~d}, J=10.5 \mathrm{~Hz}), 129.7$ (d, $J=3.3 \mathrm{~Hz}), 121.0,114.5$ (d, $J=21.1 \mathrm{~Hz}), 82.4,52.9$, $28.2 \mathrm{ppm} ;{ }^{19} \mathrm{~F}$ NMR $\left(565 \mathrm{MHz}, \mathrm{CDCl}_{3}\right) \delta-125.55$ (s, 1 F) ppm; HRMS (ESI) calcd for $\mathrm{C}_{14} \mathrm{H}_{16} \mathrm{FNO}_{5} \mathrm{Na}^{+}[\mathrm{M}+\mathrm{Na}]^{+} 320.0905$, found 320.0908 .

tert-Butyl (1-cyano-6-fluoro-3-oxo-1,3-dihydro-2-benzofuran-5-yl)carbamate (82): To a stirred solution of aldehyde $81\left(200 \mathrm{mg}, 0.67 \mathrm{mmol}, 1.0\right.$ equiv) in $\mathrm{CH}_{2} \mathrm{Cl}_{2}$
$(7 \mathrm{~mL})$ was added 18 -crown-6 $(18 \mathrm{mg}, 0.067 \mathrm{mmol}, 0.1$ equiv) and $\mathrm{KCN}$ $1.4 \mathrm{mmol}, 2.0$ equiv) was added. The reaction mixture was stirred at $23^{\circ} \mathrm{C}$ for $1 \mathrm{~h}$. The solvent was removed under reduced pressure, and the residue was co-evaporated with toluene $(2 \times 2 \mathrm{~mL})$ to remove all traces of TMSCN. The resulting residue was dissolved in $\mathrm{AcOH}(7 \mathrm{~mL})$ and stirred for $24 \mathrm{~h}$ at $80^{\circ} \mathrm{C}$. After the mixture was allowed to cool to $23^{\circ} \mathrm{C}$, saturated $\mathrm{NaHCO}_{3}$ solution $(10 \mathrm{~mL})$ was slowly added and the resulting mixture was extracted with EtOAc $(2 \times 10 \mathrm{~mL})$. The combined 
organic layers were washed with brine $(10 \mathrm{~mL})$, dried over anhydrous $\mathrm{Na}_{2} \mathrm{SO}_{4}$, and concentrated under reduced pressure. The residue was purified by flash column chromatography (silica gel, hexanes:EtOAc, $2: 1, v / v)$ to give compound $\mathbf{8 2}$ as a yellow oil (130 $\mathrm{mg}, 0.44 \mathrm{mmol}, 65 \%$ yield).

82: $R_{f}=0.48$ (silica gel, 33\% EtOAc in hexanes); FT-IR (film): $v_{\max }=3345,2981,1792,1726$, 1608, 1525, 1450, 1369, 1345, 1330, 1246, 1153, 1032, 1013, 944, 906, 838, 768, 754, $730 \mathrm{~cm}^{-1}$; ${ }^{1} \mathrm{H} \mathrm{NMR}\left(600 \mathrm{MHz}, \mathrm{CDCl}_{3}\right) \delta 8.80(\mathrm{~d}, J=6.8 \mathrm{~Hz}, 1 \mathrm{H}), 7.39(\mathrm{~d}, J=9.1 \mathrm{~Hz}, 1 \mathrm{H}), 6.94(\mathrm{~d}, J=3.9 \mathrm{~Hz}$, $1 \mathrm{H}), 6.00(\mathrm{~s}, 1 \mathrm{H}), 1.55(\mathrm{~s}, 9 \mathrm{H}) \mathrm{ppm} ;{ }^{13} \mathrm{C} \mathrm{NMR}\left(151 \mathrm{MHz}, \mathrm{CDCl}_{3}\right) \delta 166.3,155.8(\mathrm{~d}, J=255.9 \mathrm{~Hz})$, $151.6,135.5$ (d, $J=10.0 \mathrm{~Hz}), 131.2(\mathrm{~d}, J=11.2 \mathrm{~Hz}), 121.0$ (d, $J=2.6 \mathrm{~Hz}), 117.1(\mathrm{~d}, J=3.8 \mathrm{~Hz})$, 113.6, $109.4(\mathrm{~d}, J=24.3 \mathrm{~Hz}), 82.6,64.8(\mathrm{~d}, J=2.5 \mathrm{~Hz}), 28.2 \mathrm{ppm} ;{ }^{19} \mathrm{~F} \mathrm{NMR}\left(565 \mathrm{MHz}, \mathrm{CDCl}_{3}\right) \delta$ -117.46 (s, 1F) ppm; HRMS (ESI) calcd for $\mathrm{C}_{14} \mathrm{H}_{13} \mathrm{FN}_{2} \mathrm{O}_{4} \mathrm{Na}^{+}[\mathrm{M}+\mathrm{Na}]^{+} 315.0752$, found 315.0756 .

5-Amino-6-fluoro-3-oxo-1,3-dihydro-2-benzofuran-1-carbonitrile (83): To a stirred solution of<smiles>N#CC1OC(=O)c2cc(N)c(F)cc21</smiles>
compound $82(51 \mathrm{mg}, 0.17 \mathrm{mmol}, 1.0$ equiv) in 1,2-dichloroethane $(15 \mathrm{~mL})$ was added MK10 (10 mg, $20 \mathrm{wt} . \%)$ at $23^{\circ} \mathrm{C}$. The reaction mixture was heated to $84^{\circ} \mathrm{C}$ for $3 \mathrm{~h}$. After the mixture was allowed to cool to $23^{\circ} \mathrm{C}$, it was filtered through a pad of Celite and the filtrate was concentrated under reduced pressure. The residue was purified by flash column chromatography (silica gel, hexanes:EtOAc, 1:1, v/v) to give compound 83 (33 mg, $0.17 \mathrm{mmol}$, $98 \%$ yield) as a yellow solid.

83: $\mathrm{R}_{\mathrm{f}}=0.47$ (silica gel, 50\% EtOAc in hexanes); $\mathrm{mp} 234-235^{\circ} \mathrm{C}$ (EtOAc/hexanes); FT-IR (film): $v_{\max }=3470,3368,1778,1752,1635,1508,1345,1268,1213,1169,1117,1035,1021,945,878$, 838, 766, $737 \mathrm{~cm}^{-1} ;{ }^{1} \mathrm{H}$ NMR $\left(600 \mathrm{MHz}, \mathrm{CD}_{3} \mathrm{CN}\right) \delta 7.39(\mathrm{~d}, J=10.0 \mathrm{~Hz}, 1 \mathrm{H}), 7.21(\mathrm{~d}, J=7.8 \mathrm{~Hz}$, $1 \mathrm{H}), 6.15(\mathrm{~d}, J=1.0 \mathrm{~Hz}, 1 \mathrm{H}), 4.79(\mathrm{~s}, 2 \mathrm{H}) \mathrm{ppm} ;{ }^{13} \mathrm{C} \mathrm{NMR}\left(151 \mathrm{MHz}, \mathrm{CD}_{3} \mathrm{CN}\right) \delta 168.7,156.5(\mathrm{~d}$, $J=250.3 \mathrm{~Hz}), 140.6$ (d, $J=14.4 \mathrm{~Hz}), 132.3$ (d, $J=9.9 \mathrm{~Hz}), 121.9$ (d, $J=2.2 \mathrm{~Hz}), 115.9,111.7$ (d, $J=6.6 \mathrm{~Hz}), 110.7(\mathrm{~d}, J=23.8 \mathrm{~Hz}), 66.5(\mathrm{~d}, J=2.3 \mathrm{~Hz}) \mathrm{ppm} ;{ }^{19} \mathrm{~F} \mathrm{NMR}\left(565 \mathrm{MHz}, \mathrm{CD}_{3} \mathrm{CN}\right) \delta$ -122.93 (ddd, $J=9.1,8.0,1.0 \mathrm{~Hz}, 1 \mathrm{~F}$ ) ppm; HRMS (ESI) calcd for $\mathrm{C}_{9} \mathrm{H}_{6} \mathrm{FN}_{2} \mathrm{O}_{2}{ }^{+}[\mathrm{M}+\mathrm{H}]^{+}$ 193.0408, found 193.0409. 
Methyl 5-bromo-4-fluoro-2-formylbenzoate (84): Through a stirred solution of compound 79<smiles>COC(=O)c1cc(Br)c(F)cc1C=O</smiles>
(900 mg, $3.5 \mathrm{mmol}, 1.0$ equiv) in $\mathrm{CH}_{2} \mathrm{Cl}_{2}(35 \mathrm{~mL})$ was bubbled $\mathrm{O}_{3}$ at $-78^{\circ} \mathrm{C}$ until the reaction mixture turned light blue. Then $\mathrm{Me}_{2} \mathrm{~S}(1.3 \mathrm{~mL}, 17 \mathrm{mmol}$, 5.0 equiv) was added at $-78^{\circ} \mathrm{C}$ and the reaction mixture was stirred at $23{ }^{\circ} \mathrm{C}$ for $1 \mathrm{~h}$. The reaction mixture was concentrated under reduced pressure, and the residue was purified by flash column chromatography (silica gel, hexanes:EtOAc, 5:1, v/v) to give aldehyde 84 (710 mg, $2.7 \mathrm{mmol}, 78 \%$ yield) as a white solid.

84: $\mathrm{R}_{\mathrm{f}}=0.28$ (silica gel, $11 \%$ EtOAc in hexanes); $\mathrm{mp} 54-56^{\circ} \mathrm{C}$ (EtOAc/hexanes); FT-IR (film): $v_{\max }=3098,3048,2965,1735,1692,1593,1571,1484,1435,1383,1302,1278,1190,1139,1101$, 1009, 950, 908, 835, 779, 754, $693 \mathrm{~cm}^{-1} ;{ }^{1} \mathrm{H}$ NMR $\left(600 \mathrm{MHz}, \mathrm{CDCl}_{3}\right) \delta 10.63(\mathrm{~d}, J=2.7 \mathrm{~Hz}, 1 \mathrm{H})$, $8.27(\mathrm{~d}, J=6.4 \mathrm{~Hz}, 1 \mathrm{H}), 7.68(\mathrm{~d}, J=8.4 \mathrm{~Hz}, 1 \mathrm{H}), 3.99(\mathrm{~s}, 3 \mathrm{H}) \mathrm{ppm} ;{ }^{13} \mathrm{C} \mathrm{NMR}\left(151 \mathrm{MHz}, \mathrm{CDCl}_{3}\right)$ $\delta 189.9,164.5,161.6(\mathrm{~d}, J=257.0 \mathrm{~Hz}), 138.6$ (d, $J=6.1 \mathrm{~Hz}), 136.7,128.6$ (d, $J=3.9 \mathrm{~Hz}), 116.0$ (d, $J=23.9 \mathrm{~Hz}), 114.7$ (d, $J=21.8 \mathrm{~Hz}), 53.1 \mathrm{ppm} ;{ }^{19} \mathrm{~F} \mathrm{NMR}\left(565 \mathrm{MHz}, \mathrm{CDCl}_{3}\right) \delta-97.79$ (ddd, $J=8.8$, 6.3, $2.8 \mathrm{~Hz}, 1 \mathrm{~F}$ ) ppm; HRMS (EI) calcd for $\mathrm{C}_{9} \mathrm{H}_{6} \mathrm{BrFO}_{3}{ }^{+}[\mathrm{M}]^{+} 259.9484$, found 259.9486 .

Methyl 5-bromo-2-(1,3-dioxolan-2-yl)-4-fluorobenzoate (85): To a stirred solution of<smiles>COC(=O)c1cc(Br)c(F)cc1C1OCCO1</smiles>
compound 84 (600 mg, $2.3 \mathrm{mmol}, 1.0$ equiv) in $\mathrm{CH}_{2} \mathrm{Cl}_{2}(10 \mathrm{~mL})$ was added 1,2-bis(trimethylsilyloxy)ethane $\left(1.1 \mathrm{~mL}, 4.6 \mathrm{mmol}, 2.0\right.$ equiv) at $23^{\circ} \mathrm{C}$. After cooling to $0^{\circ} \mathrm{C}$, TMSOTf ( $41 \mu 1,0.2 \mathrm{mmol}, 0.1$ equiv) was added and the reaction mixture was stirred at the same temperature for $1 \mathrm{~h}$ and at $23^{\circ} \mathrm{C}$ for $3 \mathrm{~h}$. Then, saturated $\mathrm{NaHCO}_{3}$ solution $(10 \mathrm{~mL})$ was added. The mixture was extracted with $\mathrm{CH}_{2} \mathrm{Cl}_{2}$ $(2 \times 10 \mathrm{~mL})$. The combined organic layers were washed with brine $(10 \mathrm{~mL})$, dried over anhydrous $\mathrm{Na}_{2} \mathrm{SO}_{4}$, and concentrated under reduced pressure. The residue was purified by flash column chromatography (silica gel, hexanes:EtOAc, 5:1, v/v) to give compound $85(660 \mathrm{mg}, 2.2 \mathrm{mmol}$, $95 \%$ yield) as a white solid.

85: $\mathrm{R}_{\mathrm{f}}=0.34$ (silica gel, 20\% EtOAc in hexanes); mp 53-54 ${ }^{\circ} \mathrm{C}$ (EtOAc/hexanes); FT-IR (film): $v_{\max }=2954,2891,1731,1600,1576,1487,1435,1388,1289,1271,1244,1161,1109,1082,1030$, 943, 905, 836, 791, 773, $687 \mathrm{~cm}^{-1} ;{ }^{1} \mathrm{H}$ NMR $\left(600 \mathrm{MHz}, \mathrm{CDCl}_{3}\right) \delta 8.15(\mathrm{~d}, J=6.8 \mathrm{~Hz}, 1 \mathrm{H}), 7.52$ $(\mathrm{d}, J=9.5 \mathrm{~Hz}, 1 \mathrm{H}), 6.57(\mathrm{~d}, J=1.3 \mathrm{~Hz}, 1 \mathrm{H}), 4.05(\mathrm{~s}, 4 \mathrm{H}), 3.92$ (s, $3 \mathrm{H}) \mathrm{ppm} ;{ }^{13} \mathrm{C}$ NMR $(151 \mathrm{MHz}$, $\left.\mathrm{CDCl}_{3}\right) \delta 165.4,161.2(\mathrm{~d}, J=254.2 \mathrm{~Hz}), 141.9$ (d, $\left.J=6.9 \mathrm{~Hz}\right), 136.2,126.9$ (d, $\left.J=4.0 \mathrm{~Hz}\right), 115.0$ (dd, $J=24.7,4.5 \mathrm{~Hz}), 109.2(\mathrm{~d}, J=21.6 \mathrm{~Hz}), 99.6(\mathrm{~d}, J=8.1 \mathrm{~Hz}), 65.4(\mathrm{~d}, J=11.6 \mathrm{~Hz}), 52.6(\mathrm{~d}$, 
$J=11.9 \mathrm{~Hz}) \mathrm{ppm} ;{ }^{19} \mathrm{~F}$ NMR $\left(565 \mathrm{MHz}, \mathrm{CDCl}_{3}\right) \delta-99.61(\mathrm{ddd}, J=9.5,6.8,1.2 \mathrm{~Hz}, 1 \mathrm{~F}) \mathrm{ppm}$; HRMS (ESI) calcd for $\mathrm{C}_{11} \mathrm{H}_{10} \mathrm{BrFO}_{4} \mathrm{Na}^{+}[\mathrm{M}+\mathrm{Na}]^{+} 326.9639$, found 326.9647 .

Methyl 2-(1,3-dioxolan-2-yl)-4-fluoro-5-vinylbenzoate (S5): To a stirred solution of compound

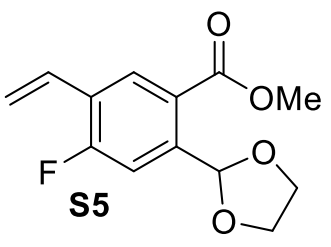
$85(1.5 \mathrm{~g}, 4.9 \mathrm{mmol}, 1.0$ equiv) in 1,4-dioxane $(50 \mathrm{~mL})$ was added pinacol vinylboronate $\left(830 \mathrm{mg}, 5.4 \mathrm{mmol}, 1.1\right.$ equiv) at $23^{\circ} \mathrm{C}$. Then $\mathrm{Cs}_{2} \mathrm{CO}_{3}(3.2 \mathrm{~g}$, $9.8 \mathrm{mmol}, 2.0$ equiv) and $\mathrm{PPh}_{3}(260 \mathrm{mg}, 1.0 \mathrm{mmol}, 0.2$ equiv) were added to the reaction mixture, followed by $\operatorname{Pd}(\mathrm{OAc})_{2}(55 \mathrm{mg}, 0.2 \mathrm{mmol}, 5 \mathrm{~mol} \%)$. The reaction mixture was degassed with nitrogen five times and heated to $80^{\circ} \mathrm{C}$. After $18 \mathrm{~h}$, the reaction mixture was allowed to cool to ambient temperature and filtered through a pad of Celite. The filtrate was washed with $\mathrm{H}_{2} \mathrm{O}(30 \mathrm{~mL})$ and extracted with EtOAc $(2 \times 20 \mathrm{~mL})$. The combined organic layers were washed with brine $(20 \mathrm{~mL})$, dried over anhydrous $\mathrm{Na}_{2} \mathrm{SO}_{4}$, and concentrated under reduced pressure. The residue was purified by flash column chromatography (silica gel, hexanes:EtOAc, 5:1, v/v) to give compound $\mathbf{S 5}(1.2 \mathrm{~g}, 4.6 \mathrm{mmol}, 94 \%$ yield) as a light yellow oil. S5: $R_{\mathrm{f}}=0.34$ (silica gel, 20\% EtOAc in hexanes); FT-IR (film): $v_{\max }=2954,2889,1727,1631$, 1619, 1570, 1495, 1436, 1405, 1377, 1282, 1250, 1226, 1198, 1170, 1132, 1102, 1062, 1028, 989 , 943, 916, 890, 793, $770 \mathrm{~cm}^{-1}$; ${ }^{1} \mathrm{H}$ NMR $\left(600 \mathrm{MHz}, \mathrm{CDCl}_{3}\right) \delta 8.07(\mathrm{~d}, J=7.5 \mathrm{~Hz}, 1 \mathrm{H}), 7.44(\mathrm{~d}$, $J=11.4 \mathrm{~Hz}, 1 \mathrm{H}), 6.83(\mathrm{dd}, J=17.7,11.2 \mathrm{~Hz}, 1 \mathrm{H}), 6.59$ (d, $J=1.1 \mathrm{~Hz}, 1 \mathrm{H}), 5.91$ (dd, $J=17.7$, $0.9 \mathrm{~Hz}, 1 \mathrm{H}), 5.46(\mathrm{dd}, J=11.2,0.9 \mathrm{~Hz}, 1 \mathrm{H}), 4.05(\mathrm{~s}, 4 \mathrm{H}), 3.92(\mathrm{~s}, 3 \mathrm{H}) \mathrm{ppm} ;{ }^{13} \mathrm{C}$ NMR $(151 \mathrm{MHz}$, $\left.\mathrm{CDCl}_{3}\right) \delta 166.6,162.0(\mathrm{~d}, J=256.4 \mathrm{~Hz}), 141.3(\mathrm{~d}, J=7.8 \mathrm{~Hz}), 130.3(\mathrm{~d}, J=5.4 \mathrm{~Hz}), 128.2(\mathrm{~d}$, $J=3.3 \mathrm{~Hz}), 125.8(\mathrm{~d}, J=3.3 \mathrm{~Hz}), 125.6(\mathrm{~d}, J=12.3 \mathrm{~Hz}), 118.3(\mathrm{~d}, J=4.5 \mathrm{~Hz}), 114.5(\mathrm{~d}, J=24.5 \mathrm{~Hz})$, 99.9, 65.3, $52.3 \mathrm{ppm} ;{ }^{19} \mathrm{~F}$ NMR $\left(565 \mathrm{MHz}, \mathrm{CDCl}_{3}\right) \delta-110.90$ (ddd, $\left.J=11.5,7.5,1.3 \mathrm{~Hz}, 1 \mathrm{~F}\right) \mathrm{ppm}$; HRMS (ESI) calcd for $\mathrm{C}_{13} \mathrm{H}_{14} \mathrm{FO}_{4}{ }^{+}[\mathrm{M}+\mathrm{H}]^{+}$253.0871, found 253.0878.

Methyl 2-(1,3-dioxolan-2-yl)-4-fluoro-5-formylbenzoate (86a): Through a stirred solution of<smiles>COC(=O)c1cc(C=O)c(F)cc1C1OCCO1</smiles>
compound $\mathbf{S 5}\left(1.0 \mathrm{~g}, 4.0 \mathrm{mmol}, 1.0\right.$ equiv) in $\mathrm{CH}_{2} \mathrm{Cl}_{2}(40 \mathrm{~mL})$ was bubbled $\mathrm{O}_{3}$ at $-78^{\circ} \mathrm{C}$ until the reaction mixture turned light blue. Then $\mathrm{Me}_{2} \mathrm{~S}$ $\left(1.5 \mathrm{~mL}, 20 \mathrm{mmol}, 5.0\right.$ equiv) was added at $-78^{\circ} \mathrm{C}$ and the reaction mixture was stirred at $23^{\circ} \mathrm{C}$ for $1 \mathrm{~h}$. The reaction mixture was concentrated under reduced pressure, and the residue was purified by flash column chromatography (silica gel, hexanes:EtOAc, $2: 1, v / v)$ to give compound $86 \mathbf{a}(830 \mathrm{mg}, 3.3 \mathrm{mmol}, 82 \%$ yield) as a light yellow 
oil.

86a: $R_{f}=0.23$ (silica gel, 20\% EtOAc in hexanes); FT-IR (film): $v_{\max }=2956,2891,1730,1698$, $1618,1579,1437,1403,1283,1238,1162,1137,1103,1050,944,894,810,790,770,735,660$ $\mathrm{cm}^{-1} ;{ }^{1} \mathrm{H}$ NMR $\left(600 \mathrm{MHz}, \mathrm{CDCl}_{3}\right) \delta 10.34(\mathrm{~s}, 1 \mathrm{H}), 8.43(\mathrm{~d}, J=6.9 \mathrm{~Hz}, 1 \mathrm{H}), 7.59$ (d, J=11.1 Hz, $1 \mathrm{H}), 6.62(\mathrm{~d}, J=1.1 \mathrm{~Hz}, 1 \mathrm{H}), 4.09-4.02(\mathrm{~m}, 4 \mathrm{H}), 3.93(\mathrm{~s}, 3 \mathrm{H}) \mathrm{ppm} ;{ }^{13} \mathrm{C} \mathrm{NMR}\left(151 \mathrm{MHz}, \mathrm{CDCl}_{3}\right)$ $\delta 185.8(\mathrm{~d}, J=5.5 \mathrm{~Hz}), 165.9(\mathrm{~d}, J=264.8 \mathrm{~Hz}), 165.7,148.57(\mathrm{~d}, J=8.5 \mathrm{~Hz}), 132.0(\mathrm{~d}, J=2.8 \mathrm{~Hz})$, $126.7(\mathrm{~d}, J=3.5 \mathrm{~Hz}), 123.7(\mathrm{~d}, J=9.3 \mathrm{~Hz}), 115.3(\mathrm{~d}, J=23.2 \mathrm{~Hz}), 99.5,65.5,52.6 \mathrm{ppm} ;{ }^{19} \mathrm{~F}$ NMR $\left(565 \mathrm{MHz} \mathrm{CDCl}_{3}\right) \delta-114.27(\mathrm{ddd}, J=11.2,6.9,1.2 \mathrm{~Hz}, 1 \mathrm{~F}) \mathrm{ppm}$; HRMS (ESI) calcd for $\mathrm{C}_{12} \mathrm{H}_{11} \mathrm{FO}_{5} \mathrm{Na}^{+}[\mathrm{M}+\mathrm{Na}]^{+}$277.0483, found 277.0489.

\section{Methyl 5-(\{[(allyloxy)carbonyl $]($ methyl)amino $\}$ methyl)-2-(1,3-dioxolan-2-yl)-4-fluoro-} benzoate (S6): To a stirred solution of compound $86 \mathrm{a}(1.0 \mathrm{~g}, 3.9 \mathrm{mmol}, 1.0$ equiv) in trifluoro-<smiles>COC(=O)c1cc(CN(C)[14CH3])c(F)cc1C1OCCO1</smiles>

ethanol $(40 \mathrm{~mL})$ was added methyl amine $(2.0 \mathrm{M}, 2.0 \mathrm{~mL}, 3.9 \mathrm{mmol}$, 1.0 equiv) at ambient temperature. The resulting mixture was stirred for $5 \mathrm{~min}$ at the same temperature. Then $\mathrm{NaBH}_{4}(180 \mathrm{mg}, 4.7 \mathrm{mmol}$, 1.2 equiv) was added. After $5 \mathrm{~min}$, the reaction mixture was quenched

by adding water $(5 \mathrm{~mL})$. The organic solvent was removed under reduced pressure. The residue was dissolved in $\mathrm{THF} / \mathrm{H}_{2} \mathrm{O}(1: 1, v / v, 40 \mathrm{~mL})$. To the resulting mixture at ambient temperature was added $\mathrm{NaHCO}_{3}$ (660 mg, $7.9 \mathrm{mmol}, 2.0$ equiv), followed by AllocCl $(0.60 \mathrm{~mL}, 5.9 \mathrm{mmol}$, 1.5 equiv). The reaction mixture was stirred at the same temperature for $40 \mathrm{~min}$. The reaction mixture was extracted with EtOAc $(2 \times 20 \mathrm{~mL})$, and the combined organic layers were washed with brine $(20 \mathrm{~mL})$, dried over $\mathrm{Na}_{2} \mathrm{SO}_{4}$ and concentrated under reduced pressure. The residue was purified by flash column chromatography (silica gel, hexanes:EtOAc, 1:1, v/v) to give compound S6 as a light yellow oil (1.2 g, $3.3 \mathrm{mmol}, 83 \%$ yield).

S6: $R_{\mathrm{f}}=0.44$ (silica gel, 50\% EtOAc in hexanes); FT-IR (film): $v_{\max }=2953,2890,1726,1704$, 1583, 1479, 1436, 1400, 1284, 1226, 1144, 1103, 1046, 983, 944, 789, $769 \mathrm{~cm}^{-1} ;{ }^{1} \mathrm{H}$ NMR (600 $\left.\mathrm{MHz}, \mathrm{CDCl}_{3}\right) \delta 7.85(\mathrm{dd}, J=36.7,7.3 \mathrm{~Hz}, 1 \mathrm{H}), 7.45(\mathrm{~d}, J=10.8 \mathrm{~Hz}, 1 \mathrm{H}), 6.58(\mathrm{~s}, 1 \mathrm{H}), 5.95(\mathrm{~d}$, $J=15.9 \mathrm{~Hz}, 1 \mathrm{H}), 5.30(\mathrm{t}, J=19.8 \mathrm{~Hz}, 1 \mathrm{H}), 5.24-5.17(\mathrm{~m}, 1 \mathrm{H}), 4.63(\mathrm{~d}, J=5.5 \mathrm{~Hz}, 2 \mathrm{H}), 4.55(\mathrm{~d}$, $J=9.1 \mathrm{~Hz}, 2 \mathrm{H}), 4.05(\mathrm{~s}, 4 \mathrm{H}), 3.90(\mathrm{~s}, 3 \mathrm{H}), 2.93(\mathrm{~d}, J=19.7 \mathrm{~Hz}, 3 \mathrm{H}) \mathrm{ppm} ;{ }^{13} \mathrm{C} \mathrm{NMR}(151 \mathrm{MHz}$, $\left.\mathrm{CDCl}_{3}\right) \delta 166.4(\mathrm{~d}, J=15.6 \mathrm{~Hz}), 162.7(\mathrm{dd}, J=253.0,27.6 \mathrm{~Hz}), 156.2(\mathrm{~d}, J=60.4 \mathrm{~Hz}), 141.8(\mathrm{~d}$, $J=6.4 \mathrm{~Hz}), 133.1-132.7(\mathrm{~m}), 132.3,126.0(\mathrm{~d}, J=10.3 \mathrm{~Hz}), 125.0(\mathrm{~d}, J=15.7 \mathrm{~Hz}), 117.4$ (d, 
$J=54.2 \mathrm{~Hz}), 114.1(\mathrm{~d}, J=24.4 \mathrm{~Hz}), 99.7,66.3(\mathrm{~d}, J=9.4 \mathrm{~Hz}), 65.3,52.3,45.8(\mathrm{~d}, J=23.2 \mathrm{~Hz}), 34.4$ $(\mathrm{d}, J=119.3 \mathrm{~Hz}) \mathrm{ppm} ;{ }^{19} \mathrm{~F}$ NMR $\left(565 \mathrm{MHz}, \mathrm{CDCl}_{3}\right) \delta-110.74(\mathrm{dd}, J=121.9,9.2 \mathrm{~Hz}, 1 \mathrm{~F}) \mathrm{ppm}$; HRMS (ESI) calcd for $\mathrm{C}_{17} \mathrm{H}_{20} \mathrm{FNO}_{6} \mathrm{Na}^{+}[\mathrm{M}+\mathrm{Na}]^{+} 376.1167$, found 376.1163 .

Methyl 5-(\{[(allyloxy)carbonyl](methyl)amino\}methyl)-4-fluoro-2-formylbenzoate (87a): To<smiles>COC(=O)c1cc(CN(C)C)c(F)cc1C=O</smiles>
a stirred solution of compound $\mathbf{S 6}$ ( $440 \mathrm{mg}, 1.2 \mathrm{mmol}, 1.0$ equiv) in THF $(9 \mathrm{~mL})$ was added aq. $\mathrm{HCl}\left(4 \mathrm{~N}, 4.6 \mathrm{~mL}, 19 \mathrm{mmol}, 15\right.$ equiv) at $23^{\circ} \mathrm{C}$. The reaction mixture was stirred for $4 \mathrm{~h}$, then slowly poured into icecold saturated $\mathrm{NaHCO}_{3}$ solution. The resulting mixture was extracted with EtOAc $(2 \times 10 \mathrm{~mL})$. The combined organic layers were washed with brine $(10 \mathrm{~mL})$, dried over anhydrous $\mathrm{Na}_{2} \mathrm{SO}_{4}$ and concentrated under reduced pressure. The residue was purified by flash column chromatography (silica gel, hexanes:EtOAc, 2:1, v/v) to give compound 87a $(370 \mathrm{mg}$, $1.2 \mathrm{mmol}, 98 \%$ yield) as a light yellow oil.

87a: $\mathrm{R}_{\mathrm{f}}=0.61$ (silica gel, 50\% EtOAc in hexanes); FT-IR (film): $v_{\max }=2955,1697,1616,1576$, 1481, 1437, 1400, 1364, 1286, 1229, 1168, 1129, 1051, 986, 954, 889, 859, 797, 770, $754 \mathrm{~cm}^{-1}$; ${ }^{1} \mathrm{H}$ NMR $\left(600 \mathrm{MHz}, \mathrm{CDCl}_{3}\right) \delta 10.62(\mathrm{~s}, 1 \mathrm{H}), 7.94(\mathrm{dd}, J=44.9,6.7 \mathrm{~Hz}, 1 \mathrm{H}), 7.63(\mathrm{~d}, J=9.8 \mathrm{~Hz}$, $1 \mathrm{H}), 5.95(\mathrm{dd}, J=28.6,16.8 \mathrm{~Hz}, 1 \mathrm{H}), 5.38-5.16(\mathrm{~m}, 2 \mathrm{H}), 4.65(\mathrm{~d}, J=5.2 \mathrm{~Hz}, 2 \mathrm{H}), 4.60(\mathrm{~s}, 2 \mathrm{H})$, $3.97(\mathrm{~s}, 3 \mathrm{H}), 2.98(\mathrm{~d}, J=11.7 \mathrm{~Hz}, 3 \mathrm{H}) \mathrm{ppm} ;{ }^{13} \mathrm{C} \mathrm{NMR}\left(151 \mathrm{MHz}, \mathrm{CDCl}_{3}\right) \delta 190.5,165.6(\mathrm{~d}$, $J=14.4 \mathrm{~Hz}), 162.9$ (dd, $J=256.3,34.7 \mathrm{~Hz}), 156.2$ (d, $J=81.2 \mathrm{~Hz}), 138.9$ (d, $J=7.0 \mathrm{~Hz}), 132.9$ (d, $J=30.7 \mathrm{~Hz}), 132.4$ (d, $J=80.9 \mathrm{~Hz}), 130.0(\mathrm{~d}, J=16.6 \mathrm{~Hz}), 128.1,117.7$ (d, $J=58.6 \mathrm{~Hz}), 115.3$ (d, $J=22.8 \mathrm{~Hz}), 66.5,52.9(\mathrm{~d}, J=14.1 \mathrm{~Hz}), 46.2(\mathrm{~d}, J=43.7 \mathrm{~Hz}), 34.8(\mathrm{dd}, J=99.9,10.0 \mathrm{~Hz}) \mathrm{ppm} ;{ }^{19} \mathrm{~F}$ NMR $\left(565 \mathrm{MHz}, \mathrm{CDCl}_{3}\right) \delta-109.33(\mathrm{dt}, J=84.9,8.5 \mathrm{~Hz}, 1 \mathrm{~F}) \mathrm{ppm}$; HRMS (ESI) calcd for $\mathrm{C}_{15} \mathrm{H}_{17} \mathrm{FNO}_{5}{ }^{+}[\mathrm{M}+\mathrm{H}]^{+}$310.1085, found 310.1095 .

\section{Allyl [(1-cyano-6-fluoro-3-oxo-1,3-dihydro-2-benzofuran-5-yl)methyl]methylcarbamate} (88a): To a stirred solution of compound 87a (450 mg, $1.4 \mathrm{mmol}$, 1.0 equiv) in $\mathrm{CH}_{2} \mathrm{Cl}_{2}(15 \mathrm{~mL})$<smiles>CN(C)Cc1cc2c(cc1F)C(C#N)OC2=O</smiles>
was added 18-crown-6 (38 mg, $0.14 \mathrm{mmol}, 0.1$ equiv) and $\mathrm{KCN}(9.4 \mathrm{mg}$, $0.14 \mathrm{mmol}, 0.1$ equiv) at $0^{\circ} \mathrm{C}$. After $15 \mathrm{~min}$, TMSCN $(0.40 \mathrm{~mL}, 2.9 \mathrm{mmol}$, 2.0 equiv) was added. The reaction mixture was stirred at $23^{\circ} \mathrm{C}$ for $4 \mathrm{~h}$. The solvent was removed under reduced pressure, and the residue was co-evaporated with toluene $(2 \times 5 \mathrm{~mL})$ to remove all traces of TMSCN. The resulting residue was dissolved in $\mathrm{AcOH}(15 \mathrm{~mL})$, 
and $p$-toluenesulfonic acid ( $140 \mathrm{mg}, 0.70 \mathrm{mmol}, 0.5$ equiv) was added. The resulting mixture was stirred for $12 \mathrm{~h}$ at $80^{\circ} \mathrm{C}$. After it was allowed to cool to $23^{\circ} \mathrm{C}$, saturated $\mathrm{NaHCO}_{3}$ solution ( $\left.30 \mathrm{~mL}\right)$ was slowly added to the reaction mixture. The resulting mixture was extracted with EtOAc $(2 \times 20 \mathrm{~mL})$. The combined organic layers were washed with brine $(10 \mathrm{~mL})$, dried over anhydrous $\mathrm{Na}_{2} \mathrm{SO}_{4}$, and concentrated under reduced pressure. The residue was purified by flash column chromatography (silica gel, hexanes:EtOAc, 2:1, v/v) to give compound 88a (320 mg, $1.0 \mathrm{mmol}$, $72 \%$ yield) as a yellow oil.

88a: $R_{f}=0.40$ (silica gel, 50\% EtOAc in hexanes); FT-IR (film): $v_{\max }=2940,1788,1692,1648$, 1632, 1604, 1479, 1444, 1400, 1299, 1246, 1221, 1189, 1145, 1097, 1029, 985, 938, 915, 834, 766, $733 \mathrm{~cm}^{-1} ;{ }^{1} \mathrm{H}$ NMR (600 MHz, $\left.\mathrm{CDCl}_{3}\right) \delta$ 7.95-7.85 (m, $\left.1 \mathrm{H}\right), 7.40(\mathrm{~d}, J=7.8 \mathrm{~Hz}, 1 \mathrm{H}), 6.05$ (s, 1 H), 6.02-5.83 (m, 1 H), $5.34(\mathrm{~d}, J=17.1 \mathrm{~Hz}, 1 \mathrm{H}), 5.30-5.17(\mathrm{~m}, 2 \mathrm{H}), 4.71-4.55(\mathrm{~m}, 4 \mathrm{H}), 3.01$ (s, $3 \mathrm{H}) \mathrm{ppm} ;{ }^{13} \mathrm{C} \mathrm{NMR}\left(151 \mathrm{MHz}, \mathrm{CDCl}_{3}\right) \delta 166.2,165.2(\mathrm{~d}, J=261.4 \mathrm{~Hz}), 156.1$ (d, J=102.9 Hz), 142.9 (d, $J=11.4 \mathrm{~Hz}), 132.5$ (d, $J=18.9 \mathrm{~Hz}), 130.4$ (d, $J=17.1 \mathrm{~Hz}), 127.7$ (d, $J=21.1 \mathrm{~Hz}), 120.7$, $118.1(\mathrm{~d}, J=67.2 \mathrm{~Hz}), 113.3,110.4(\mathrm{~d}, J=25.7 \mathrm{~Hz}), 66.7,64.9(\mathrm{~d}, J=2.6 \mathrm{~Hz}), 46.5(\mathrm{~d}, J=45.9 \mathrm{~Hz})$, $35.0(\mathrm{~d}, J=68.7 \mathrm{~Hz}) \mathrm{ppm} ;{ }^{19} \mathrm{~F}$ NMR $\left(565 \mathrm{MHz} \mathrm{CDCl}_{3}\right) \delta-102.52(\mathrm{dt}, J=126.2,7.2 \mathrm{~Hz}, 1 \mathrm{~F}) \mathrm{ppm}$; HRMS (ESI) calcd for $\mathrm{C}_{15} \mathrm{H}_{13} \mathrm{FN}_{2} \mathrm{O}_{4} \mathrm{Na}^{+}[\mathrm{M}+\mathrm{Na}]^{+}$327.0752, found 327.0750.

Methyl 2-(1,3-dioxolan-2-yl)-4-fluoro-5-(3-oxopropyl)benzoate (86b): To a stirred solution of<smiles>COC(=O)c1cc(CCC=O)c(F)cc1C1OCCO1</smiles>
compound 85 (400 mg, $1.3 \mathrm{mmol}$, 1.0equiv) in DMF (5mL) was added 2-(di-tert-butylphosphino)-1-phenylindole $\quad(28 \mathrm{mg}$ $0.078 \mathrm{mmol}, 6 \mathrm{~mol} \%$ ) at ambient temperature and under an atmosphere of nitrogen, followed by $\mathrm{Pd}(\mathrm{dba})_{2}(15 \mathrm{mg}, 0.026 \mathrm{mmol}, 2 \mathrm{~mol} \%)$. The reaction mixture was degassed with nitrogen five times. Then allyl alcohol $(0.10 \mathrm{~mL}, 1.4 \mathrm{mmol}, 1.1$ equiv) was added, followed by $\mathrm{Cy}_{2} \mathrm{NMe}(0.30 \mathrm{~mL}, 1.4 \mathrm{mmol}, 1.1$ equiv). The reaction mixture was heated to $100{ }^{\circ} \mathrm{C}$ and stirred at the same temperature for $1 \mathrm{~h}$. After cooling down to $23^{\circ} \mathrm{C}$, EtOAc $(5 \mathrm{~mL})$ and $\mathrm{H}_{2} \mathrm{O}(5 \mathrm{~mL})$ were added to the reaction mixture. The organic phase was washed with $\mathrm{H}_{2} \mathrm{O}$ $(2 \times 5 \mathrm{~mL})$. The combined organic layers were washed with brine $(5 \mathrm{~mL})$, dried over anhydrous $\mathrm{Na}_{2} \mathrm{SO}_{4}$ and concentrated under reduced pressure. The residue was purified by flash column chromatography (silica gel, hexanes:EtOAc, 2:1, v/v) to give compound $\mathbf{8 6 b}(310 \mathrm{mg}, 1.1 \mathrm{mmol}$, $84 \%$ yield) as a light yellow oil. 
86b: $R_{f}=0.26$ (silica gel, 33\% EtOAc in hexanes); FT-IR (film): $v_{\max }=2954,2891,1719,1579$, 1436, 1405, 1390, 1283, 1225, 1194, 1129, 1100, 1049, 1029, 958, 943, 891, $790 \mathrm{~cm}^{-1}$; ${ }^{1} \mathrm{H} \mathrm{NMR}$ $\left(600 \mathrm{MHz}, \mathrm{CDCl}_{3}\right) \delta 9.81(\mathrm{~d}, J=1.1 \mathrm{~Hz}, 1 \mathrm{H}), 7.81(\mathrm{~d}, J=7.5 \mathrm{~Hz}, 1 \mathrm{H}), 7.42(\mathrm{~d}, J=10.9 \mathrm{~Hz}, 1 \mathrm{H})$, $6.57(\mathrm{~d}, J=1.2 \mathrm{~Hz}, 1 \mathrm{H}), 4.04(\mathrm{~d}, J=1.2 \mathrm{~Hz}, 4 \mathrm{H}), 3.90(\mathrm{~s}, 3 \mathrm{H}), 2.99(\mathrm{t}, J=7.5 \mathrm{~Hz}, 2 \mathrm{H}), 2.79$ (td, $J=7.5,1.1 \mathrm{~Hz}, 2 \mathrm{H}) \mathrm{ppm} ;{ }^{13} \mathrm{C} \mathrm{NMR}\left(151 \mathrm{MHz}, \mathrm{CDCl}_{3}\right) \delta 200.4,166.5,163.0(\mathrm{~d}, J=252.6 \mathrm{~Hz})$, 140.9 (d, $J=7.7 \mathrm{~Hz}), 133.6$ (d, $J=6.0 \mathrm{~Hz}), 127.8$ (d, $J=16.5 \mathrm{~Hz}), 125.8$ (d, J=3.4 Hz), 114.1 (d, $J=24.8 \mathrm{~Hz}), 99.8,65.3,52.3,43.5,21.4(\mathrm{~d}, J=2.1 \mathrm{~Hz}) \mathrm{ppm} ;{ }^{19} \mathrm{~F} \mathrm{NMR}\left(565 \mathrm{MHz}, \mathrm{CDCl}_{3}\right) \delta$ $-110.35(\mathrm{dd}, J=10.9,7.6 \mathrm{~Hz}, 1 \mathrm{~F}) \mathrm{ppm}$; HRMS (ESI) calcd for $\mathrm{C}_{14} \mathrm{H}_{15} \mathrm{FO}_{5} \mathrm{Na}^{+}[\mathrm{M}+\mathrm{Na}]^{+} 305.0796$, found 305.0800 .

\section{Methyl 5-(3-\{[(allyloxy)carbonyl](methyl)amino\}propyl)-2-(1,3-dioxolan-2-yl)-4-fluoro-} benzoate (S7): To a stirred solution of compound 86b (260 mg, $0.90 \mathrm{mmol}, 1.0$ equiv) in<smiles>COC(=O)c1cc(CCCN(C)[Al])c(F)cc1C1OCCO1</smiles>
trifluoroethanol $(10 \mathrm{~mL})$ was added methyl amine $(2.0 \mathrm{M}, 0.45 \mathrm{~mL}$, $0.90 \mathrm{mmol}, 1.0$ equiv) at $23^{\circ} \mathrm{C}$. The resulting mixture was stirred for $5 \mathrm{~min}$ at the same temperature. Then $\mathrm{NaBH}_{4}(41 \mathrm{mg}, 1.1 \mathrm{mmol}$, 1.2 equiv) was added. After $5 \mathrm{~min}$, the reaction mixture was quenched by adding $\mathrm{H}_{2} \mathrm{O}(2 \mathrm{~mL})$. The organic solvent was removed under reduced pressure. The residue was dissolved in $\mathrm{THF} / \mathrm{H}_{2} \mathrm{O}(1: 1$, $v / v, 20 \mathrm{~mL})$. To the resulting mixture at ambient temperature was added $\mathrm{NaHCO}_{3}(150 \mathrm{mg}$, $1.8 \mathrm{mmol}, 2.0$ equiv), followed by AllocCl $(0.14 \mathrm{~mL}, 1.4 \mathrm{mmol}, 1.5$ equiv). The reaction mixture was stirred at the same temperature for $40 \mathrm{~min}$. The reaction mixture was extracted with EtOAc $(2 \times 10 \mathrm{~mL})$, and the combined organic layers were washed with brine $(10 \mathrm{~mL})$, dried over $\mathrm{Na}_{2} \mathrm{SO}_{4}$ and concentrated under reduced pressure. The residue was purified by flash column chromatography (silica gel, hexanes:EtOAc, 2:1, v/v) to give compound S7 (170 mg, $0.45 \mathrm{mmol}$, $50 \%$ yield) as a colorless oil.

S7: $R_{\mathrm{f}}=0.29$ (silica gel, 33\% EtOAc in hexanes); FT-IR (film): $v_{\max }=2951,2888,1725,1697$, $1579,1481,1435,1401,1282,1222,1192,1128,1100,1050,963,942,915,890,789,769,746$ $\mathrm{cm}^{-1} ;{ }^{1} \mathrm{H} \mathrm{NMR}\left(600 \mathrm{MHz}, \mathrm{CDCl}_{3}\right) \delta 7.78(\mathrm{~d}, J=6.9 \mathrm{~Hz}, 1 \mathrm{H}), 7.40(\mathrm{~d}, J=10.8 \mathrm{~Hz}, 1 \mathrm{H}), 6.56(\mathrm{~d}$, $J=1.1 \mathrm{~Hz}, 1 \mathrm{H}), 5.91(\mathrm{~s}, 1 \mathrm{H}), 5.33-5.21(\mathrm{~m}, 1 \mathrm{H}), 5.21-5.14(\mathrm{~m}, 1 \mathrm{H}), 4.57(\mathrm{dt}, J=5.5,1.5 \mathrm{~Hz}, 2 \mathrm{H})$, 4.08-3.98 (m, 4H), 3.89 (s, 3 H), 3.32 (p, J=7.2 Hz, 2H), 2.90 (s, 3 H), 2.64 (t, J=8.0 Hz, 2 H), $1.84(\mathrm{p}, J=7.7 \mathrm{~Hz}, 2 \mathrm{H}) \mathrm{ppm} ;{ }^{13} \mathrm{C} \mathrm{NMR}\left(151 \mathrm{MHz}, \mathrm{CDCl}_{3}\right) \delta 166.6,163.0$ (d, $\left.J=252.2 \mathrm{~Hz}\right), 156.1$, 140.3, 133.4, 133.1, 129.0, 125.5, 117.1 (d, $J=5.0 \mathrm{~Hz}), 113.9$ (d, $J=24.9 \mathrm{~Hz}), 99.9,65.9,65.2$, 
52.2, $48.4(\mathrm{~d}, J=84.2 \mathrm{~Hz}), 34.2(\mathrm{~d}, J=98.6 \mathrm{~Hz}), 27.8(\mathrm{~d}, J=40.0 \mathrm{~Hz}), 26.0 \mathrm{ppm} ;{ }^{19} \mathrm{~F}$ NMR $\left(565 \mathrm{MHz}, \mathrm{CDCl}_{3}\right) \delta-110.67(\mathrm{dt}, J=24.6,9.2 \mathrm{~Hz}, 1 \mathrm{~F}) \mathrm{ppm}$; HRMS (ESI) calcd for $\mathrm{C}_{19} \mathrm{H}_{24} \mathrm{FNO}_{6} \mathrm{Na}^{+}[\mathrm{M}+\mathrm{Na}]^{+}$404.1480, found 404.1479.

Methyl 5-(3-\{[(allyloxy)carbonyl](methyl)amino\}propyl)-4-fluoro-2-formylbenzoate (87b):<smiles>CC(=O)c1cc(CCCN(C)[18OH])c(F)cc1C=O</smiles>

To a stirred solution of compound $\mathbf{S 7}(140 \mathrm{mg}, 0.38 \mathrm{mmol}$, 1.0 equiv) in THF ( $3 \mathrm{~mL})$ was added aq. $\mathrm{HCl}(4 \mathrm{~N}, 1.4 \mathrm{~mL}$, $5.7 \mathrm{mmol}, 15$ equiv) at $23^{\circ} \mathrm{C}$. The reaction mixture was stirred for $4 \mathrm{~h}$, then slowly poured into an ice-cold saturated $\mathrm{NaHCO}_{3}$ solution. The resulting mixture was extracted with EtOAc $(2 \times 5 \mathrm{~mL})$. The combined organic layers were washed with brine $(10 \mathrm{~mL})$, dried over anhydrous $\mathrm{Na}_{2} \mathrm{SO}_{4}$, and concentrated under reduced pressure. The residue was purified by flash column chromatography (silica gel, hexanes:EtOAc, 2:1, v/v) to give compound 87b (120 $\mathrm{mg}, 0.35 \mathrm{mmol}, 91 \%$ yield) as a light yellow oil.

87b: $R_{f}=0.63$ (silica gel, 50\% EtOAc in hexanes); FT-IR (film): $v_{\max }=2953,1690,1649,1613$, 1572, 1484, 1436, 1400, 1283, 1227, 1191, 1171, 1126, 1053, 994, 960, 917, 848, 769, $751 \mathrm{~cm}^{-1}$; ${ }^{1} \mathrm{H} \mathrm{NMR}\left(600 \mathrm{MHz}, \mathrm{CDCl}_{3}\right) \delta 10.60(\mathrm{~d}, J=2.7 \mathrm{~Hz}, 1 \mathrm{H}), 7.89(\mathrm{~d}, J=7.1 \mathrm{~Hz}, 1 \mathrm{H}), 7.58(\mathrm{~d}, J=9.8 \mathrm{~Hz}$, $1 \mathrm{H}), 5.92(\mathrm{~d}, J=15.9 \mathrm{~Hz}, 1 \mathrm{H}), 5.27$ (t, $J=20.8 \mathrm{~Hz}, 1 \mathrm{H}), 5.19$ (d, $J=9.9 \mathrm{~Hz}, 1 \mathrm{H}), 4.57$ (dt, $J=5.6$, $1.5 \mathrm{~Hz}, 2 \mathrm{H}), 3.96$ (s, $3 \mathrm{H}), 3.42-3.29$ (m, $2 \mathrm{H}), 2.92$ (s, $3 \mathrm{H}), 2.72$ (t, J=8.0 Hz, $2 \mathrm{H}), 1.93-1.83$ (m, 2H) ppm; ${ }^{13} \mathrm{C}$ NMR $\left(151 \mathrm{MHz}, \mathrm{CDCl}_{3}\right) \delta 190.5,165.8,163.2(\mathrm{~d}, J=254.8 \mathrm{~Hz}), 156.1,137.7(\mathrm{~d}$, $J=7.1 \mathrm{~Hz}), 134.2,133.6$ (d, $J=12.3 \mathrm{~Hz}), 133.1,127.8$ (d, $J=3.6 \mathrm{~Hz}), 117.2,115.1$ (d, $J=24.4 \mathrm{~Hz})$, 65.9, 52.7, $48.4(\mathrm{~d}, J=80.7 \mathrm{~Hz}), 34.2(\mathrm{~d}, J=94.5 \mathrm{~Hz}), 27.6(\mathrm{~d}, J=45.0 \mathrm{~Hz}), 26.4 \mathrm{ppm} ;{ }^{19} \mathrm{~F}$ NMR $\left(565 \mathrm{MHz}, \mathrm{CDCl}_{3}\right) \delta-109.37$ (dt, $\left.J=46.5,8.4 \mathrm{~Hz}, 1 \mathrm{~F}\right) \mathrm{ppm}$; HRMS (ESI) calcd for $\mathrm{C}_{17} \mathrm{H}_{21} \mathrm{FNO}_{5}{ }^{+}$ $[\mathrm{M}+\mathrm{H}]^{+} 338.1398$, found 338.1403 .

\section{Allyl [3-(1-cyano-6-fluoro-3-oxo-1,3-dihydro-2-benzofuran-5-yl)propyl]methylcarbamate}

(88b): To a stirred solution of compound $\mathbf{8 7 b}$ ( $78 \mathrm{mg}, 0.23 \mathrm{mmol}, 1.0$ equiv) in $\mathrm{CH}_{2} \mathrm{Cl}_{2}(2 \mathrm{~mL})$ was<smiles>CN(C)CCCc1cc2c(cc1F)C(C#N)OC2=O</smiles>
added 18 -crown-6 (6.1 mg, $0.023 \mathrm{mmol}, 0.1$ equiv) and $\mathrm{KCN}(1.5 \mathrm{mg}$, $0.023 \mathrm{mmol}, 0.1$ equiv) at $0^{\circ} \mathrm{C}$. After $15 \mathrm{~min}$, TMSCN $(58 \mu \mathrm{L}$, $0.46 \mathrm{mmol}, 2.0$ equiv) was added. The reaction mixture was stirred at $23^{\circ} \mathrm{C}$ for $4 \mathrm{~h}$. The solvent was removed under reduced pressure, and the residue was co-evaporated with toluene $(2 \times 1 \mathrm{~mL})$ to remove all traces of TMSCN. The resulting residue was dissolved in 
$\mathrm{AcOH}(2 \mathrm{~mL})$, and $p$-toluenesulfonic acid ( $22 \mathrm{mg}, 0.12 \mathrm{mmol}, 0.5$ equiv) was added. The resulting mixture was stirred for $12 \mathrm{~h}$ at $80{ }^{\circ} \mathrm{C}$. After it was allowed to cool to $23^{\circ} \mathrm{C}$, saturated $\mathrm{NaHCO}_{3}$ solution $(10 \mathrm{~mL})$ was slowly added to the mixture. The resulting mixture was extracted with EtOAc $(2 \times 5 \mathrm{~mL})$. The combined organic layers were washed with brine $(10 \mathrm{~mL})$, dried over anhydrous $\mathrm{Na}_{2} \mathrm{SO}_{4}$, and concentrated under reduced pressure. The residue was purified by flash column chromatography (silica gel, hexanes:EtOAc, 2:1, v/v) to give compound $\mathbf{8 8 b}(57 \mathrm{mg}, 0.17 \mathrm{mmol}$, $74 \%$ yield) as a light yellow solid.

88b: $\mathrm{R}_{\mathrm{f}}=0.63$ (silica gel, 50\% EtOAc in hexanes); $\mathrm{mp} 105-107^{\circ} \mathrm{C}$ (EtOAc/hexanes); FT-IR (film): $v_{\max }=2938,1791,1693,1601,1482,1437,1404,1303,1251,1201,1184,1133,1101,1026,938$, 874, 829, 792, $768 \mathrm{~cm}^{-1} ;{ }^{1} \mathrm{H}$ NMR $\left(600 \mathrm{MHz} \mathrm{CDCl}_{3}\right) \delta 7.85(\mathrm{~d}, J=6.2 \mathrm{~Hz}, 1 \mathrm{H}), 7.36(\mathrm{~d}, J=8.0 \mathrm{~Hz}$, $1 \mathrm{H}), 6.04(\mathrm{~s}, 1 \mathrm{H}), 5.92(\mathrm{~d}, J=15.7 \mathrm{~Hz}, 1 \mathrm{H}), 5.27(\mathrm{t}, J=17.7 \mathrm{~Hz}, 1 \mathrm{H}), 5.19(\mathrm{~d}, J=10.5 \mathrm{~Hz}, 1 \mathrm{H})$, $4.58(\mathrm{dt}, J=5.5,1.5 \mathrm{~Hz}, 2 \mathrm{H}), 3.36(\mathrm{~d}, J=7.5 \mathrm{~Hz}, 2 \mathrm{H}), 2.92(\mathrm{~s}, 3 \mathrm{H}), 2.76(\mathrm{t}, J=7.9 \mathrm{~Hz}, 2 \mathrm{H}), 1.90$ $(\mathrm{p}, J=7.5 \mathrm{~Hz}, 2 \mathrm{H}) \mathrm{ppm} ;{ }^{13} \mathrm{C} \mathrm{NMR}\left(151 \mathrm{MHz}, \mathrm{CDCl}_{3}\right) \delta 166.4,165.5(\mathrm{~d}, J=258.9 \mathrm{~Hz}), 156.1(\mathrm{~d}$, $J=23.3 \mathrm{~Hz}), 141.9$ (d, $J=10.5 \mathrm{~Hz}), 134.0,133.0,128.6,120.3,117.3$ (d, $J=26.2 \mathrm{~Hz}), 113.5,110.1$ (d, $J=27.0 \mathrm{~Hz}), 66.0,64.9$ (d, J=2.7 Hz), 48.2 (d, J=65.8 Hz), $34.2(\mathrm{~d}, J=100.5 \mathrm{~Hz}), 27.4$ (d, $J=37.9 \mathrm{~Hz}), 26.3 \mathrm{ppm} ;{ }^{19} \mathrm{~F}$ NMR $\left(565 \mathrm{MHz}, \mathrm{CDCl}_{3}\right) \delta-102.36(\mathrm{dt}, J=27.8,7.1 \mathrm{~Hz}, 1 \mathrm{~F}) \mathrm{ppm}$; HRMS (ESI) calcd for $\mathrm{C}_{17} \mathrm{H}_{18} \mathrm{FN}_{2} \mathrm{O}_{4}{ }^{+}[\mathrm{M}+\mathrm{H}]^{+} 333.1245$, found 333.1246.

\section{Procedure a:}
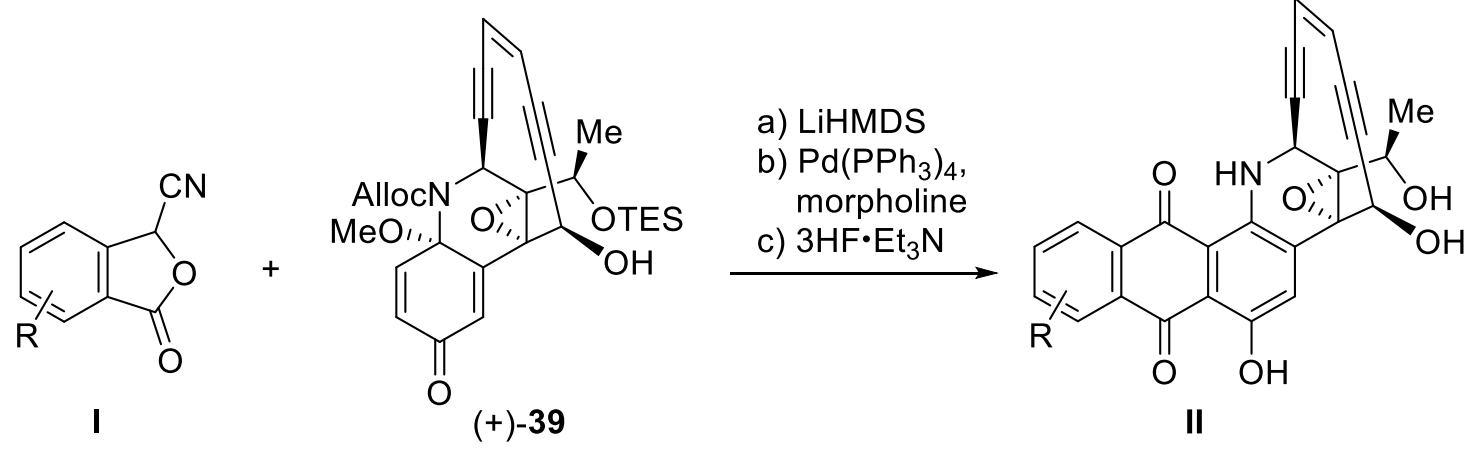

(a) To a stirred solution of cyanophthalide $\mathbf{I}$ (3.0 equiv) in THF $(0.2 \mathrm{M})$ at $-78{ }^{\circ} \mathrm{C}$ was added LiHMDS (1.0 $\mathrm{M}$ in THF, 4.0 equiv). The resulting mixture was stirred at the same temperature for $20 \mathrm{~min}$. Quinone aminal (+)-39 (1.0 equiv) was added at $-78^{\circ} \mathrm{C}$. After $5 \mathrm{~min}$, the resulting mixture was slowly warmed to $23^{\circ} \mathrm{C}$. The reaction was monitored by TLC until quinone aminal (+)-39 was completely consumed. The reaction mixture was quenched by addition of 
$\mathrm{pH} 6.8$ buffer $(2 \mathrm{~mL})$ and extracted with EtOAC $(3 \times 5 \mathrm{~mL})$. The combined organic layers were washed with brine $(20 \mathrm{~mL})$, dried over $\mathrm{Na}_{2} \mathrm{SO}_{4}$, filtered and concentrated under reduced pressure to give crude Alloc-anthraquinone as a dark red or dark yellow oil.

(b) To a stirred solution of Alloc-anthraquinone in $\operatorname{THF}(0.2 \mathrm{M})$ at $0{ }^{\circ} \mathrm{C}$ was added $\operatorname{Pd}\left(\mathrm{PPh}_{3}\right)_{4}$ ( 0.1 equiv), followed by morpholine ( 3.0 equiv). The resulting mixture, was protected from light with aluminium foil, was stirred for $2 \mathrm{~h}$ while the temperature was slowly rising from $0{ }^{\circ} \mathrm{C}$ to $23^{\circ} \mathrm{C}$. The reaction mixture was then quenched by addition of $\mathrm{pH} 6.8$ buffer $(2 \mathrm{~mL})$ and extracted with EtOAc $(3 \times 5 \mathrm{~mL})$. The combined organic layers were washed with brine $(20 \mathrm{~mL})$, dried over $\mathrm{Na}_{2} \mathrm{SO}_{4}$, filtered through a pad of silica gel and concentrated under reduced pressure to give the crude anthraquinone as a purple oil.

(c) To a stirred solution of the prepared anthraquinone in THF $(0.2 \mathrm{M})$ at $0^{\circ} \mathrm{C}$ was added slowly $3 \mathrm{HF} \cdot \mathrm{Et}_{3} \mathrm{~N}$ (30 equiv). The resulting mixture, protected from light with aluminium foil, was aloowed to warm to $23^{\circ} \mathrm{C}$ and stirred at the same temperature for $1.5 \mathrm{~h}$. The resulting mixture was quenched by addition of saturated aqueous $\mathrm{NaHCO}_{3}$ solution, and extracted with EtOAc $(3 \times 5 \mathrm{~mL})$. The combined organic layers were washed with brine $(20 \mathrm{~mL})$, dried over $\mathrm{Na}_{2} \mathrm{SO}_{4}$, filtered and concentrated under reduced pressure. The obtained residue was purified by flash column chromatography to afford pure uncialamycin analogues II.

tert-Butyl \{(1aS,11S,11aR,18R)-5-fluoro-3,18-dihydroxy-11a-[(1R)-1-hydroxyethyl]-4,9dioxo-9,10,11,11a-tetrahydro-4H-11,1a-hept[3] ene[1,5]diynonaphtho[2,3- $h]$ oxireno[c]quinolin-6-yl\}carbamate (31): Prepared according to Procedure a from cyanophthalide 69

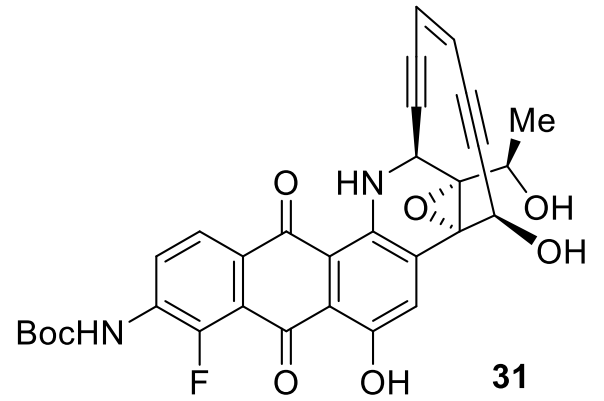

$(18.0 \mathrm{mg}, 61.6 \mu \mathrm{mol}, 3.0$ equiv) and quinone aminal (+)-39 (11.0 mg, $20.5 \mu \mathrm{mol}, 1.0$ equiv). Compound $31(6.3 \mathrm{mg}$, $11.1 \mu \mathrm{mol}, 54 \%$ for three steps) was obtained as a purple solid.

31: $\mathrm{R}_{\mathrm{f}}=0.29$ (silica gel, $50 \%$ EtOAc in hexanes); $[\alpha]_{\mathrm{D}}^{23}=-2267$ ( $c=0.015$, EtOAc); FT-IR (film): $v_{\max }=3443$, 2980, 2931, 1736, 1626, 1592, 1525, 1481, 1370, 1340, 1268, 1227, 1152, 1109, 1061, 993, 871, 815, 772, $663 \mathrm{~cm}^{-1} ;{ }^{1} \mathrm{H}$ NMR $\left(500 \mathrm{MHz}, \mathrm{CD}_{3} \mathrm{CN}\right) \delta 13.16(\mathrm{~s}, 1 \mathrm{H}), 9.96(\mathrm{~d}, J=4.5 \mathrm{~Hz}, 1 \mathrm{H}), 8.50$ $(\mathrm{dd}, J=8.8,7.0 \mathrm{~Hz}, 1 \mathrm{H}), 8.47$ (d, $J=0.6 \mathrm{~Hz}, 1 \mathrm{H}), 8.10(\mathrm{dd}, J=8.7,1.2 \mathrm{~Hz}, 1 \mathrm{H}), 7.84(\mathrm{~d}, J=3.1 \mathrm{~Hz}$, $1 \mathrm{H}), 5.97(\mathrm{dd}, J=9.9,0.9 \mathrm{~Hz}, 1 \mathrm{H}), 5.89(\mathrm{dt}, J=10.0,1.3 \mathrm{~Hz}, 1 \mathrm{H}), 5.24(\mathrm{~d}, J=4.9 \mathrm{~Hz}, 1 \mathrm{H}), 4.90$ 
$(\mathrm{dd}, J=4.4,1.7 \mathrm{~Hz}, 1 \mathrm{H}), 4.44(\mathrm{~d}, J=5.0 \mathrm{~Hz}, 1 \mathrm{H}), 4.38(\mathrm{qd}, J=6.5,5.0 \mathrm{~Hz}, 1 \mathrm{H}), 3.27(\mathrm{~d}, J=4.9 \mathrm{~Hz}$, $1 \mathrm{H}), 1.53(\mathrm{~s}, 9 \mathrm{H}), 1.38(\mathrm{~d}, J=6.5 \mathrm{~Hz}, 3 \mathrm{H}) \mathrm{ppm} ;{ }^{13} \mathrm{C} \mathrm{NMR}\left(126 \mathrm{MHz}, \mathrm{CD}_{3} \mathrm{CN}\right) \delta 187.4,182.8$, 156.6, 153.3, 151.0 (d, $J=266.4 \mathrm{~Hz}), 144.4,135.9,134.2$ (d, $J=10.2 \mathrm{~Hz}), 131.0,130.2,125.8$ (d, $J=3.8 \mathrm{~Hz}), 124.6$ (d, $J=3.5 \mathrm{~Hz}), 124.5,124.1,121.3,114.9,112.0,100.3,99.2,91.3,88.8,82.2$, 77.0, 65.9, 65.3, 64.7, 44.3, 28.3, $21.2 \mathrm{ppm} ;{ }^{19} \mathrm{~F}$ NMR (565 MHz, $\left.\mathrm{CD}_{3} \mathrm{CN}\right) \delta-128.84$ (s, $\left.1 \mathrm{~F}\right) \mathrm{ppm}$; HRMS (ESI) calcd for $\mathrm{C}_{31} \mathrm{H}_{26} \mathrm{FN}_{2} \mathrm{O}_{8}{ }^{+}[\mathrm{M}+\mathrm{H}]^{+} 573.1668$, found 573.1663 .

\section{(1aS,11S,11aR,18R)-6-Amino-5-fluoro-3,18-dihydroxy-11a-[(1R)-1-hydroxyethyl]-11,11a-} dihydro-4H-11,1a-hept[3] ene[1,5] diynonaphtho[2,3- $h]$ oxireno[c]quinoline-4,9(10H)-dione

(32): Prepared according to Procedure a from cyanophthalide 70 (15.0 mg, $78.1 \mu \mathrm{mol}, 3.0$ equiv)

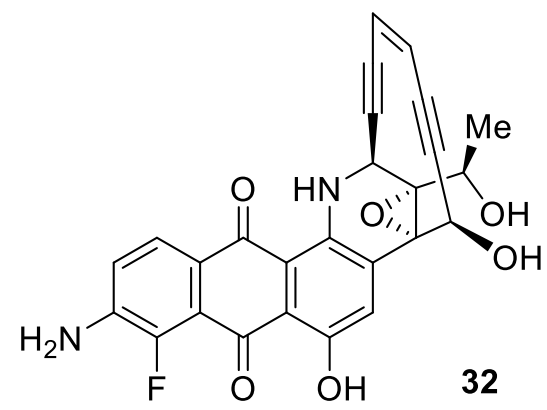
and quinone aminal (+)-39 (14.0 mg, $26.0 \mu \mathrm{mol}, 1.0$ equiv). Compound 32 (6.8 mg, $14.3 \mu \mathrm{mol}, 55 \%$ for three steps) was obtained as a purple solid.

32: $\mathrm{R}_{\mathrm{f}}=0.14$ (silica gel, $50 \%$ EtOAc in hexanes); $[\alpha]_{\mathrm{D}}^{23}=-2633$ ( $c=0.015$, EtOAc); FT-IR (film): $v_{\max }=3474,3367,3233,2931$, $2851,1720,1614,1583,1482,1374,1349,1264,1237,1210$, 1144, 1132, 1097, 1060, 1045, 1018, 994, 960, 939, 902, 869, 844, 803, 759, 709, $662 \mathrm{~cm}^{-1} ;{ }^{1} \mathrm{H}$ NMR (600 MHz, CD $\left.{ }_{3} \mathrm{CN}\right) \delta 13.17(\mathrm{~s}, 1 \mathrm{H}), 9.93(\mathrm{~d}, J=4.3 \mathrm{~Hz}, 1 \mathrm{H}), 8.43(\mathrm{~s}, 1 \mathrm{H}), 7.92$ (d, $J=8.5 \mathrm{~Hz}, 1 \mathrm{H}), 7.16(\mathrm{t}, J=8.5 \mathrm{~Hz}, 1 \mathrm{H}), 5.96(\mathrm{~d}, J=10.0 \mathrm{~Hz}, 1 \mathrm{H}), 5.88(\mathrm{dt}, J=10.0,1.3 \mathrm{~Hz}, 1 \mathrm{H})$, $5.24(\mathrm{~d}, J=4.8 \mathrm{~Hz}, 1 \mathrm{H}), 5.14(\mathrm{~s}, 2 \mathrm{H}), 4.87(\mathrm{dd}, J=4.3,1.3 \mathrm{~Hz}, 1 \mathrm{H}), 4.41(\mathrm{~d}, J=4.9 \mathrm{~Hz}, 1 \mathrm{H}), 4.37$ $(\mathrm{qd}, J=6.5,4.9 \mathrm{~Hz}, 1 \mathrm{H}), 3.21(\mathrm{~d}, J=4.8 \mathrm{~Hz}, 1 \mathrm{H}), 1.38(\mathrm{~d}, J=6.5 \mathrm{~Hz}, 3 \mathrm{H}) \mathrm{ppm} ;{ }^{13} \mathrm{C}$ NMR $(151$ $\left.\mathrm{MHz}, \mathrm{CD}_{3} \mathrm{CN}\right) \delta 188.4,183.3(\mathrm{~d}, J=3.4 \mathrm{~Hz}), 156.4,149.0(\mathrm{~d}, J=261.4 \mathrm{~Hz}), 143.9,143.3(\mathrm{~d}$, $J=12.3 \mathrm{~Hz}), 135.7,130.4,125.6(\mathrm{~d}, J=2.8 \mathrm{~Hz}), 125.1,124.5,124.1,121.5,121.3(\mathrm{~d}, J=6.6 \mathrm{~Hz})$, 115.2, 112.4, 100.5, 99.4, 91.3, 88.9, 77.1, 66.1, 65.5, 64.9, 44.3, 21.2 ppm; ${ }^{19} \mathrm{~F}$ NMR (565 MHz, $\left.\mathrm{CD}_{3} \mathrm{CN}\right) \delta-135.80(\mathrm{~d}, J=7.9 \mathrm{~Hz}, 1 \mathrm{~F}) \mathrm{ppm}$; HRMS (ESI) calcd for $\mathrm{C}_{26} \mathrm{H}_{17} \mathrm{FN}_{2} \mathrm{O}_{6} \mathrm{Na}^{+}[\mathrm{M}+\mathrm{Na}]^{+}$ 495.0963, found 495.0966. 
tert-Butyl \{(1aS,11S,11aR,18R)-7-fluoro-3,18-dihydroxy-11a-[(1R)-1-hydroxyethyl]-4,9dioxo-9,10,11,11a-tetrahydro-4H-11,1a-hept[3]ene[1,5]diynonaphtho[2,3-h]oxireno[c]quinolin-6-yl \}carbamate (33): Prepared according to Procedure a from cyanophthalide 82

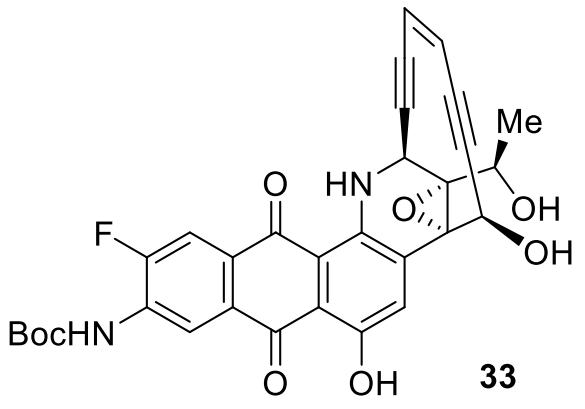

(20.0 mg, 68.4 $\mu \mathrm{mol}, 3.0$ equiv) and quinone aminal (+)-39 (12.3 mg, $22.8 \mu \mathrm{mol}, 1.0$ equiv). Compound 33 ( $8.1 \mathrm{mg}$, $14.1 \mu \mathrm{mol}, 62 \%$ for three steps) was obtained as a purple solid. 33: $\mathrm{R}_{\mathrm{f}}=0.32$ (silica gel, 50\% EtOAc in hexanes); $[\alpha]_{\mathrm{D}}^{23}=-3350\left(c=0.010\right.$, EtOAc); FT-IR (film): $v_{\max }=3445$, 2980, 2936, 1718, 1628, 1601, 1525, 1484, 1370, 1325, 1234, 1204, 1150, 1109, 1056, 910, 850, 794, 770, 743, $679 \mathrm{~cm}^{-1} ;{ }^{1} \mathrm{H}$ NMR (500 MHz, CD $\left.3 \mathrm{CN}\right) \delta 13.13$ $(\mathrm{d}, J=1.3 \mathrm{~Hz}, 1 \mathrm{H}), 9.94(\mathrm{~d}, J=4.3 \mathrm{~Hz}, 1 \mathrm{H}), 8.90$ (dd, $J=8.1,3.3 \mathrm{~Hz}, 1 \mathrm{H}), 8.48(\mathrm{~s}, 1 \mathrm{H}), 7.94-7.88$ $(\mathrm{m}, 1 \mathrm{H}), 7.83(\mathrm{~s}, 1 \mathrm{H}), 5.96(\mathrm{~d}, J=9.9 \mathrm{~Hz}, 1 \mathrm{H}), 5.88(\mathrm{dd}, J=10.1,1.4 \mathrm{~Hz}, 1 \mathrm{H}), 5.24(\mathrm{~d}, J=5.1 \mathrm{~Hz}$, $1 \mathrm{H}), 4.90(\mathrm{dd}, J=4.2,1.6 \mathrm{~Hz}, 1 \mathrm{H}), 4.44(\mathrm{~d}, J=5.0 \mathrm{~Hz}, 1 \mathrm{H}), 4.38(\mathrm{p}, J=6.3 \mathrm{~Hz}, 1 \mathrm{H}), 3.27(\mathrm{~d}$, $J=4.9 \mathrm{~Hz}, 1 \mathrm{H}), 1.54(\mathrm{~s}, 9 \mathrm{H}), 1.38(\mathrm{~d}, J=6.4 \mathrm{~Hz}, 3 \mathrm{H}) \mathrm{ppm} ;{ }^{13} \mathrm{C} \mathrm{NMR}\left(126 \mathrm{MHz}, \mathrm{CD}_{3} \mathrm{CN}\right) \delta 187.5$, 182.6, 156.9, 156.6 (d, $J=253.9 \mathrm{~Hz}), 153.3,144.7,136.2,133.5$ (d, $J=11.8 \mathrm{~Hz}), 131.7$ (d, $J=7.3 \mathrm{~Hz}), 131.01,130.98,124.5,124.1,114.2$, 114.1, 113.9, 112.3, 100.4, 99.2, 91.3, 88.9, 82.4, 76.9, 65.9, 65.4, 64.8, 44.3, 28.3, 21.2 ppm; ${ }^{19} \mathrm{~F}$ NMR (565 MHz, $\left.\mathrm{CD}_{3} \mathrm{CN}\right) \delta-120.12$ (s, $\left.1 \mathrm{~F}\right) \mathrm{ppm}$; HRMS (ESI) calcd for $\mathrm{C}_{31} \mathrm{H}_{26} \mathrm{FN}_{2} \mathrm{O}_{8}{ }^{+}[\mathrm{M}+\mathrm{H}]^{+}$573.1668, found 573.1664.

(1aS,11S,11aR,18R)-6-Amino-7-fluoro-3,18-dihydroxy-11a-[(1R)-1-hydroxyethyl]-11,11adihydro-4H-11,1a-hept[3] ene[1,5] diynonaphtho[2,3- $h]$ oxireno[c]quinoline-4,9(10H)-dione (34): Prepared according to Procedure a from cyanophthalide 83 (14.0 mg, $72.9 \mu \mathrm{mol}, 3.0$ equiv)

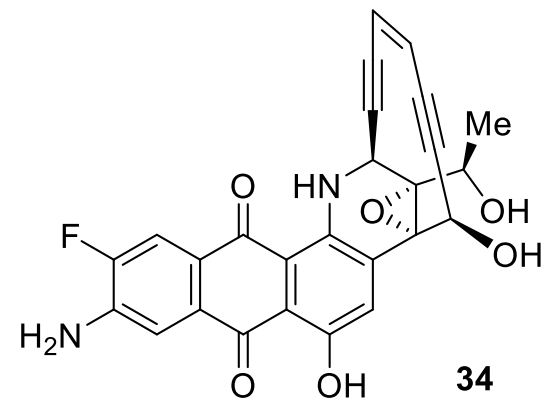
and quinone aminal (+)-39 (13.1 mg, $24.3 \mu \mathrm{mol}, 1.0$ equiv). Compound $34(6.7 \mathrm{mg}, 14.1 \mu \mathrm{mol}, 58 \%$ for three steps) was obtained as a purple solid.

34: $\mathrm{R}_{\mathrm{f}}=0.23$ (silica gel, 50\% EtOAc in hexanes); $[\alpha]_{\mathrm{D}}^{23}=-2586$ ( $c=0.014$, EtOAc); FT-IR (film): $v_{\max }=3451,3362,3222,2958$, 2924, 2853, 1658, 1633, 1611, 1591, 1481, 1469, 1377, 1347, $1260,1230,1202,1185,1096,1045,901,800,736,706,683 \mathrm{~cm}^{-1} ;{ }^{1} \mathrm{H} \mathrm{NMR}\left(600 \mathrm{MHz}, \mathrm{CD}_{3} \mathrm{CN}\right)$ $\delta 13.09(\mathrm{~s}, 1 \mathrm{H}), 9.92(\mathrm{~d}, J=4.3 \mathrm{~Hz}, 1 \mathrm{H}), 8.44(\mathrm{~s}, 1 \mathrm{H}), 7.80(\mathrm{~d}, J=11.8 \mathrm{~Hz}, 1 \mathrm{H}), 7.56(\mathrm{~d}, J=8.4 \mathrm{~Hz}$, $1 \mathrm{H}), 5.95(\mathrm{~d}, J=10.0 \mathrm{~Hz}, 1 \mathrm{H}), 5.88(\mathrm{dt}, J=10.0,1.6 \mathrm{~Hz}, 1 \mathrm{H}), 5.24(\mathrm{~d}, J=4.8 \mathrm{~Hz}, 1 \mathrm{H}), 5.18(\mathrm{~s}$, 
$2 \mathrm{H}), 4.88(\mathrm{dd}, J=4.3,1.6 \mathrm{~Hz}, 1 \mathrm{H}), 4.40(\mathrm{~d}, J=5.0 \mathrm{~Hz}, 1 \mathrm{H}), 4.37(\mathrm{td}, J=6.6,5.0 \mathrm{~Hz}, 1 \mathrm{H}), 3.22(\mathrm{~d}$, $J=4.8 \mathrm{~Hz}, 1 \mathrm{H}), 1.38(\mathrm{~d}, J=6.6 \mathrm{~Hz}, 3 \mathrm{H}) \mathrm{ppm} ;{ }^{13} \mathrm{C} \mathrm{NMR}\left(151 \mathrm{MHz}, \mathrm{CD}_{3} \mathrm{CN}\right) \delta 188.2,183.2,156.7$, $155.3(\mathrm{~d}, J=248.6 \mathrm{~Hz}), 144.2,142.6(\mathrm{~d}, J=14.0 \mathrm{~Hz}), 136.1,132.7$ (d, $J=9.7 \mathrm{~Hz}), 131.9,130.3$, 129.7, 126.8 (d, $J=6.5 \mathrm{~Hz}), 124.5,124.1,114.3,113.0$ (d, $J=6.2 \mathrm{~Hz}), 100.5,99.4,91.4,88.9,77.0$, 66.1, 65.5, 64.9, 44.3, $21.2 \mathrm{ppm} ;{ }^{19} \mathrm{~F}$ NMR (565 MHz, CD $\left.{ }_{3} \mathrm{CN}\right) \delta-126.96(\mathrm{dd}, J=11.9,8.6 \mathrm{~Hz}$, 1 F) ppm; HRMS (ESI) calcd for $\mathrm{C}_{26} \mathrm{H}_{17} \mathrm{FN}_{2} \mathrm{O}_{6} \mathrm{~K}^{+}[\mathrm{M}+\mathrm{K}]^{+}$511.0702, found 511.0685.

\section{Procedure b:}

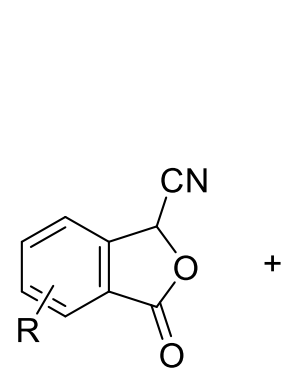

III

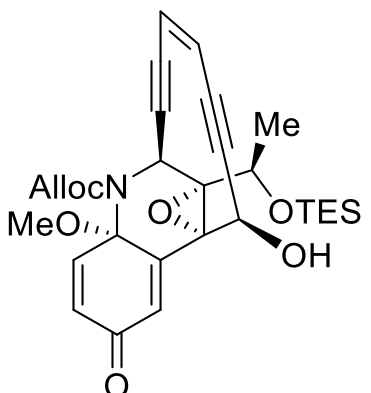

$(+)-39$ a) LiHMDS

b) $3 \mathrm{HF} \cdot \mathrm{Et}_{3} \mathrm{~N}$

c) $\mathrm{Pd}\left(\mathrm{PPh}_{3}\right)_{4}$ morpholine

(a) To a stirred solution of cyanophthalide I (3.0 equiv) in THF $(0.2 \mathrm{M})$ at $-78{ }^{\circ} \mathrm{C}$ was added LiHMDS (1.0 $\mathrm{M}$ in THF, 4.0 equiv). The resulting mixture was stirred at the same temperature for $20 \mathrm{~min}$. Quinone aminal (+)-39 (1.0 equiv) was added at $-78^{\circ} \mathrm{C}$. After $5 \mathrm{~min}$, the resulting mixture was allowed to slowly warm to $23^{\circ} \mathrm{C}$. The reaction was monitored by TLC until quinone aminal (+)-39 was completely consumed. The reaction mixture was quenched by addition of $\mathrm{pH} 6.8$ buffer $(2 \mathrm{~mL})$ and extracted with EtOAC $(3 \times 5 \mathrm{~mL})$. The combined organic layers were washed with brine $(20 \mathrm{~mL})$, dried over $\mathrm{Na}_{2} \mathrm{SO}_{4}$, filtered and concentrated under reduced pressure to give crude Alloc-anthraquinone as a dark red or dark yellow oil.

(b) To a stirred solution of Alloc-anthraquinone in $\operatorname{THF}(0.2 \mathrm{M})$ at $0{ }^{\circ} \mathrm{C}$ was added slowly $3 \mathrm{HF} \cdot \mathrm{Et}_{3} \mathrm{~N}$ (30 equiv). The resulting mixture, protected from light with aluminium foil, was allowed to warm to $23^{\circ} \mathrm{C}$ and stirred at the same temperature for $1.5 \mathrm{~h}$. The reaction mixture was quenched by addition of saturated aqueous $\mathrm{NaHCO}_{3}$, and extracted with EtOAc $(3 \times 5 \mathrm{~mL})$. The combined organic layers were washed with brine $(20 \mathrm{~mL})$, dried over $\mathrm{Na}_{2} \mathrm{SO}_{4}$, filtered and concentrated under reduced pressure to give the crude anthraquinone as a dark red or dark yellow oil. 
(c) To a stirred solution of the Alloc-anthraquinone in THF $(0.2 \mathrm{M})$ at $0{ }^{\circ} \mathrm{C}$ was added $\left.\mathrm{Pd}_{(\mathrm{PPh}}\right)_{4}$ (0.1 equiv), followed by morpholine (3.0 equiv). The resulting mixture, protected from light with aluminium foil, was stirred for $2 \mathrm{~h}$ while the temperature was slowly rising from $0{ }^{\circ} \mathrm{C}$ to $23^{\circ} \mathrm{C}$. The reaction mixture was quenched by addition of $\mathrm{pH} 6.8$ buffer $(2 \mathrm{~mL})$ and extracted with EtOAc $(3 \times 5 \mathrm{~mL})$. The combined organic layers were washed with brine $(20 \mathrm{~mL})$, dried over $\mathrm{Na}_{2} \mathrm{SO}_{4}$, filtered through a pad of silica gel and concentrated under reduced pressure. The obtained residue was purified by flash column chromatography to afford pure uncialamycin analogues IV.

(1aS,11S,11aR,18R)-5-Fluoro-3,18-dihydroxy-11a-[(1R)-1-hydroxyethyl]-6-[(methylamino)methyl]-11,11a-dihydro-4H-11,1a-hept[3] ene[1,5] diynonaphtho[2,3- $h]$ oxireno[c]quinoline4,9(10H)-dione (35): Prepared according to Procedure b from cyanophthalide 75a (35.0 mg,

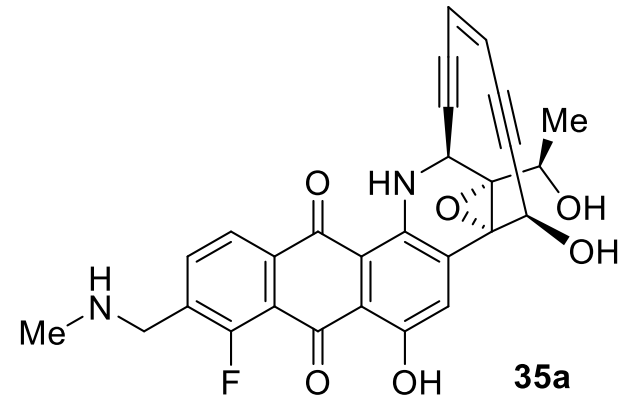
$0.12 \mathrm{mmol}, 3.0$ equiv) and quinone aminal (+)-39 (20.6 mg, $38.3 \mu \mathrm{mol}$, 1.0 equiv). Compound 35 (9.6 mg, $19.2 \mu \mathrm{mol}$, $50 \%$ for three steps) was obtained as a purple solid.

35: $\mathrm{R}_{\mathrm{f}}=0.25$ (silica gel, $20 \% \mathrm{MeOH}$ in EtOAc); $[\alpha]_{\mathrm{D}}^{23}=-3090 \quad(c=0.010, \quad$ EtOAc $) ; \quad$ FT-IR $\quad($ film $):$ $v_{\max }=3357,2961,2923,2853,1631,1594,1488,1374$,

1261, 1235, 1095, 1021, 872, 799, $700 \mathrm{~cm}^{-1} ;{ }^{1} \mathrm{H}$ NMR (600 MHz, CD $\left.{ }_{3} \mathrm{CN}\right) \delta 9.94(\mathrm{~d}, J=4.4 \mathrm{~Hz}$, $1 \mathrm{H}), 8.49$ (s, $1 \mathrm{H}), 8.09$ (d, $J=8.0 \mathrm{~Hz}, 1 \mathrm{H}), 7.87(\mathrm{t}, J=7.2 \mathrm{~Hz}, 1 \mathrm{H}), 5.96(\mathrm{~d}, J=10.0 \mathrm{~Hz}, 1 \mathrm{H}), 5.88$ $(\mathrm{d}, J=10.0 \mathrm{~Hz}, 1 \mathrm{H}), 5.23(\mathrm{~s}, 1 \mathrm{H}), 4.90(\mathrm{dd}, J=4.5,1.6 \mathrm{~Hz}, 1 \mathrm{H}), 4.37$ (q, $J=6.4 \mathrm{~Hz}, 1 \mathrm{H}), 3.88-$ $3.84(\mathrm{~m}, 2 \mathrm{H}), 2.38(\mathrm{~s}, 3 \mathrm{H}), 1.38(\mathrm{~d}, J=6.4 \mathrm{~Hz}, 3 \mathrm{H}) \mathrm{ppm} ;{ }^{13} \mathrm{C} \mathrm{NMR}\left(151 \mathrm{MHz}, \mathrm{CD}_{3} \mathrm{CN}\right) \delta 187.6$, 183.2, 160.4 (d, $J=267.5 \mathrm{~Hz}), 156.6,144.6,136.8$ (d, $J=6.9 \mathrm{~Hz}), 136.1,136.0$ (d, $J=15.0 \mathrm{~Hz})$, 135.8, 131.4, 124.5, 124.2, 123.7 (d, $J=3.7 \mathrm{~Hz}), 121.1$ (d, $J=4.3 \mathrm{~Hz}), 114.8,112.1,100.5,99.2$, 91.3, 88.9, 77.1, 66.0, 65.4, 64.8, 49.0 (d, J=4.9Hz), 44.4, 36.2, 21.3 ppm; ${ }^{19} \mathrm{~F}$ NMR (565 MHz, $\left.\mathrm{CD}_{3} \mathrm{CN}\right) \delta-116.91(\mathrm{~d}, J=6.5 \mathrm{~Hz}, 1 \mathrm{~F}) \mathrm{ppm}$; HRMS (ESI) calcd for $\mathrm{C}_{28} \mathrm{H}_{21} \mathrm{FN}_{2} \mathrm{O}_{6} \mathrm{H}^{+}[\mathrm{M}+\mathrm{H}]^{+}$ 501.1456 , found 501.1460 .

(1aS,11S,11aR,18R)-7-Fluoro-3,18-dihydroxy-11a-[(1R)-1-hydroxyethyl]-6-[(methylamino)methyl]-11,11a-dihydro-4H-11,1a-hept[3] ene[1,5]diynonaphtho[2,3- $h]$ oxireno[c]quinoline4,9(10H)-dione (36): Prepared according to Procedure b from cyanophthalide 88a (35.7 mg, 


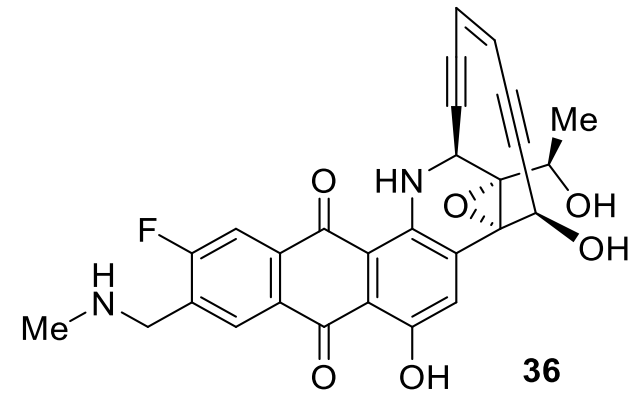

$0.12 \mathrm{mmol}, 3.0$ equiv) and quinone aminal (+)-39 $(21.0 \mathrm{mg}$, $39.1 \mu \mathrm{mol}, 1.0$ equiv). Compound 36 (11.7 mg, $23.4 \mu \mathrm{mol}$, $60 \%$ for three steps) was obtained as a purple solid.

36: $\mathrm{R}_{\mathrm{f}}=0.35$ (silica gel, $20 \% \mathrm{MeOH}$ in EtOAc); $[\alpha]_{\mathrm{D}}^{23}=-3720 \quad(c=0.010, \quad$ EtOAc $) ; \quad$ FT-IR $\quad($ film $):$ $v_{\max }=3368,2934,1736,1603,1434,1369,1234,1160$, 1046, 907, 850, 701, $676 \mathrm{~cm}^{-1} ;{ }^{1} \mathrm{H}$ NMR (600 MHz, CD $\left.{ }_{3} \mathrm{CN}\right) \delta 9.91$ (d, J=4.4 Hz, $\left.1 \mathrm{H}\right), 8.49$ (d, $J=0.7 \mathrm{~Hz}, 1 \mathrm{H}), 8.30(\mathrm{~d}, J=7.0 \mathrm{~Hz}, 1 \mathrm{H}), 7.85(\mathrm{~d}, J=10.3 \mathrm{~Hz}, 1 \mathrm{H}), 5.95(\mathrm{dd}, J=10.0,0.8 \mathrm{~Hz}, 1 \mathrm{H})$, $5.87(\mathrm{dt}, J=10.1,1.4 \mathrm{~Hz}, 1 \mathrm{H}), 5.21(\mathrm{~d}, J=1.1 \mathrm{~Hz}, 1 \mathrm{H}), 4.89(\mathrm{dd}, J=4.4,1.6 \mathrm{~Hz}, 1 \mathrm{H}), 4.37$ (q, $J=6.5 \mathrm{~Hz}, 1 \mathrm{H}), 3.88(\mathrm{~d}, J=6.9 \mathrm{~Hz}, 2 \mathrm{H}), 2.42(\mathrm{~s}, 3 \mathrm{H}), 1.37(\mathrm{~d}, J=6.5 \mathrm{~Hz}, 3 \mathrm{H}) \mathrm{ppm} ;{ }^{13} \mathrm{C} \mathrm{NMR}(151$ $\left.\mathrm{MHz}, \mathrm{CD}_{3} \mathrm{CN}\right) \delta 187.4,182.9,165.9(\mathrm{~d}, J=255.2 \mathrm{~Hz}), 156.8,144.9,137.3(\mathrm{~d}, J=8.6 \mathrm{~Hz}), 136.1$, $135.1(\mathrm{~d}, J=17.0 \mathrm{~Hz}), 131.3,130.1$ (d, $J=2.9 \mathrm{~Hz}), 129.7$ (d, $J=6.5 \mathrm{~Hz}), 124.5,124.1,113.9$ (d, $J=7.6 \mathrm{~Hz}), 113.7,112.3,100.4,99.1,91.2,88.9,76.9,65.8,65.3,64.7,49.0$ (d, $J=2.5 \mathrm{~Hz}), 44.3$, 36.1, $21.3 \mathrm{ppm} ;{ }^{19} \mathrm{~F}$ NMR (565 MHz, CD $\left.3 \mathrm{CN}\right) \delta-108.55--108.66$ (m, 1 F) ppm; HRMS (ESI): calcd for $\mathrm{C}_{28} \mathrm{H}_{21} \mathrm{FN}_{2} \mathrm{O}_{6} \mathrm{H}^{+}[\mathrm{M}+\mathrm{H}]^{+}$501.1456, found 501.1461.

$(1 \mathrm{a} S, 13 S, 13 \mathrm{a} R, 20 R)-3,20-D i h y d \operatorname{roxy}-13 \mathrm{a}-[(1 R)-1$-hydroxyethyl]-5-methyl-5,6,7,8,13,13ahexahydro-4H-13,1a-hept [3] ene[1,5]diynooxireno[c]benzo[1,2- $\left.h: 4,5-h^{\prime}\right]$ diquinoline-

4,11(12H)-dione (37'): Prepared according to Procedure b from cyanophthalide $\mathbf{7 5 b}(38.6 \mathrm{mg}$,

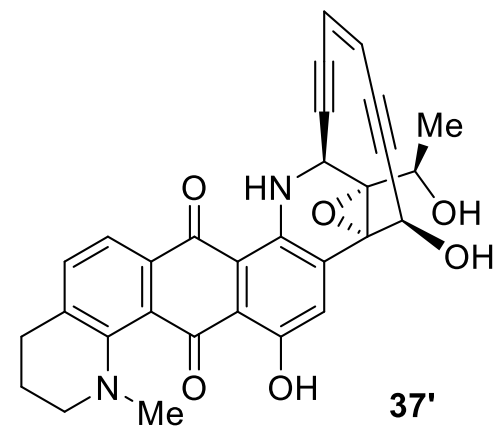
$0.116 \mathrm{mmol}, 3.0$ equiv) and quinone aminal (+)-39 (20.8 mg, $38.7 \mu \mathrm{mol}, 1.0$ equiv). Compound 37' (9.8 mg, $18.6 \mu \mathrm{mol}, 48 \%$ for three steps) was obtained as a violet solid.

37': $\mathrm{R}_{\mathrm{f}}=0.42$ (silica gel, $25 \%$ hexanes in EtOAc); $[\alpha]_{\mathrm{D}}^{23}=-2175$ ( $c=0.016$, EtOAc); FT-IR (film): $v_{\max }=3440,2927,2853,2369$, $1717,1652,1607,1588,1547,1514,1483,1402,1370,1310$, 1226, 1194, 1102, 1066, 886, 813, 769, $704 \mathrm{~cm}^{-1} ;{ }^{1} \mathrm{H}$ NMR (600 MHz, CD $\left.{ }_{3} \mathrm{CN}\right) \delta 13.51(\mathrm{~s}, 1 \mathrm{H})$, $9.71(\mathrm{~d}, J=4.2 \mathrm{~Hz}, 1 \mathrm{H}), 8.39(\mathrm{~s}, 1 \mathrm{H}), 7.46(\mathrm{~d}, J=7.4 \mathrm{~Hz}, 1 \mathrm{H}), 7.25(\mathrm{~d}, J=7.3 \mathrm{~Hz}, 1 \mathrm{H}), 5.95(\mathrm{~d}$, $J=9.9 \mathrm{~Hz}, 1 \mathrm{H}), 5.88(\mathrm{~d}, J=9.9 \mathrm{~Hz}, 1 \mathrm{H}), 5.23(\mathrm{~d}, J=4.4 \mathrm{~Hz}, 1 \mathrm{H}), 4.85(\mathrm{dd}, J=4.2,1.6 \mathrm{~Hz}, 1 \mathrm{H})$, $4.42-4.33(\mathrm{~m}, 2 \mathrm{H}), 3.52-3.39(\mathrm{~m}, 2 \mathrm{H}), 3.19(\mathrm{~d}, J=4.8 \mathrm{~Hz}, 1 \mathrm{H}), 2.88(\mathrm{~d}, J=1.2 \mathrm{~Hz}, 3 \mathrm{H}), 2.83(\mathrm{t}$, $J=6.3 \mathrm{~Hz}, 2 \mathrm{H}), 1.38(\mathrm{~d}, J=6.5 \mathrm{~Hz}, 3 \mathrm{H}) \mathrm{ppm} ;{ }^{13} \mathrm{C} \mathrm{NMR}\left(151 \mathrm{MHz}, \mathrm{CD}_{3} \mathrm{CN}\right) \delta 185.8,185.6,154.7$, $150.3,143.3$, 136.6, 135.7, 133.0, 132.9, 130.4, 124.6, 124.0, 116.7, 116.7, 116.4, 113.5, 100.7, 
99.5, 91.2, 88.9, 77.3, 66.2, 65.6, 65.0, 53.2, 46.1, 44.4, 29.6, 22.5, 21.2 ppm; HRMS (ESI) calcd for $\mathrm{C}_{30} \mathrm{H}_{25} \mathrm{~N}_{2} \mathrm{O}_{6}{ }^{+}[\mathrm{M}+\mathrm{H}]^{+}$509.1707, found 509.1705.

$(1 \mathrm{a} S, 13 S, 13 \mathrm{a} R, 20 R)-3,20-D i h y d \operatorname{roxy}-13 \mathrm{a}-[(1 R)-1-h y d r o x y e t h y l]-9-m e t h y l-6,7,8,9,13,13 a-$ hexahydro-4H-13,1a-hept[3]ene[1,5]diynooxireno[ $\left[c^{\prime}\right]$ benzo[1,2-g:5,4- $\left.h^{\prime}\right]$ diquinoline4,11(12H)-dione $\left(\mathbf{3 8}^{\prime}\right)$ : Prepared according to Procedure b from cyanophthalide $\mathbf{8 8 b}$ (34.9 mg,<smiles>CC(O)C1(O)C(=O)c2c(O)cc3c(c2N[C@@H]1c1ccccc1)C(=O)c1cc2c(cc1C3=O)N(C)CCC2</smiles>
$0.10 \mathrm{mmol}, 3.0$ equiv) and quinone aminal (+)-39 (18.8 $\mathrm{mg}$, $35.0 \mu \mathrm{mol}, 1.0$ equiv). Compound 38' (9.2 mg, $18.2 \mu \mathrm{mol}, 52 \%$ for 3 steps) was obtained as a purple solid.

38': $R_{\mathrm{f}}=0.49$ (silica gel, $25 \%$ hexanes in EtOAc); $[\alpha]_{\mathrm{D}}^{23}=-2506$ $\left(c=0.016\right.$, EtOAc); FT-IR (film): $v_{\max }=3375,2928,2850,2240$, $1623,1571,1525,1479,1451,1402,1349,1326,1308,1230$, 1203, 1097, 2050, 880, 811, 763, 742, $679 \mathrm{~cm}^{-1}$; ${ }^{1} \mathrm{H}$ NMR (600 MHz, THF- $\left.d_{8}\right) \delta 13.66(\mathrm{~s}, 1 \mathrm{H})$, $10.07(\mathrm{~d}, J=4.3 \mathrm{~Hz}, 1 \mathrm{H}), 8.59$ (s, $1 \mathrm{H}), 7.78(\mathrm{~s}, 1 \mathrm{H}), 7.33(\mathrm{~s}, 1 \mathrm{H}), 5.89$ (d, J=9.9 Hz, $1 \mathrm{H}), 5.81$ $(\mathrm{dt}, J=9.9,1.3 \mathrm{~Hz}, 1 \mathrm{H}), 5.68(\mathrm{dd}, J=4.9,2.1 \mathrm{~Hz}, 1 \mathrm{H}), 5.28(\mathrm{~d}, J=4.7 \mathrm{~Hz}, 1 \mathrm{H}), 4.87(\mathrm{dd}, J=4.3$, $1.6 \mathrm{~Hz}, 1 \mathrm{H}), 4.42(\mathrm{qd}, J=6.5,4.8 \mathrm{~Hz}, 1 \mathrm{H}), 4.23(\mathrm{~d}, J=4.9 \mathrm{~Hz}, 1 \mathrm{H}), 3.43(\mathrm{td}, J=5.9,2.1 \mathrm{~Hz}, 2 \mathrm{H})$, $3.10(\mathrm{~d}, J=2.1 \mathrm{~Hz}, 3 \mathrm{H}), 2.85(\mathrm{t}, J=6.2 \mathrm{~Hz}, 2 \mathrm{H}), 1.97(\mathrm{t}, J=6.2 \mathrm{~Hz}, 2 \mathrm{H}), 1.40(\mathrm{~d}, J=6.5 \mathrm{~Hz}, 3 \mathrm{H})$ ppm; ${ }^{13} \mathrm{C}$ NMR $\left(151 \mathrm{MHz}, \mathrm{THF}-d_{8}\right) \delta 186.8,184.9,156.7,152.1,144.7,136.8,134.8,131.7,128.1$, 127.8, 124.1, 123.8, 122.1, 114.3, 112.9, 107.3, 101.5, 99.8, 90.6, 88.7, 76.8, 66.2, 65.4, 65.4, 51.9, 44.9, 39.1, 28.8, 22.5, 22.1 ppm; HRMS (ESI) calcd for $\mathrm{C}_{30} \mathrm{H}_{25} \mathrm{~N}_{2} \mathrm{O}_{6}{ }^{+}[\mathrm{M}+\mathrm{H}]^{+}$509.1707, found 509.1712. 
III. ${ }^{1} \mathrm{H},{ }^{13} \mathrm{C},{ }^{19} \mathrm{~F}$ and 2D NMR Spectra of Compounds
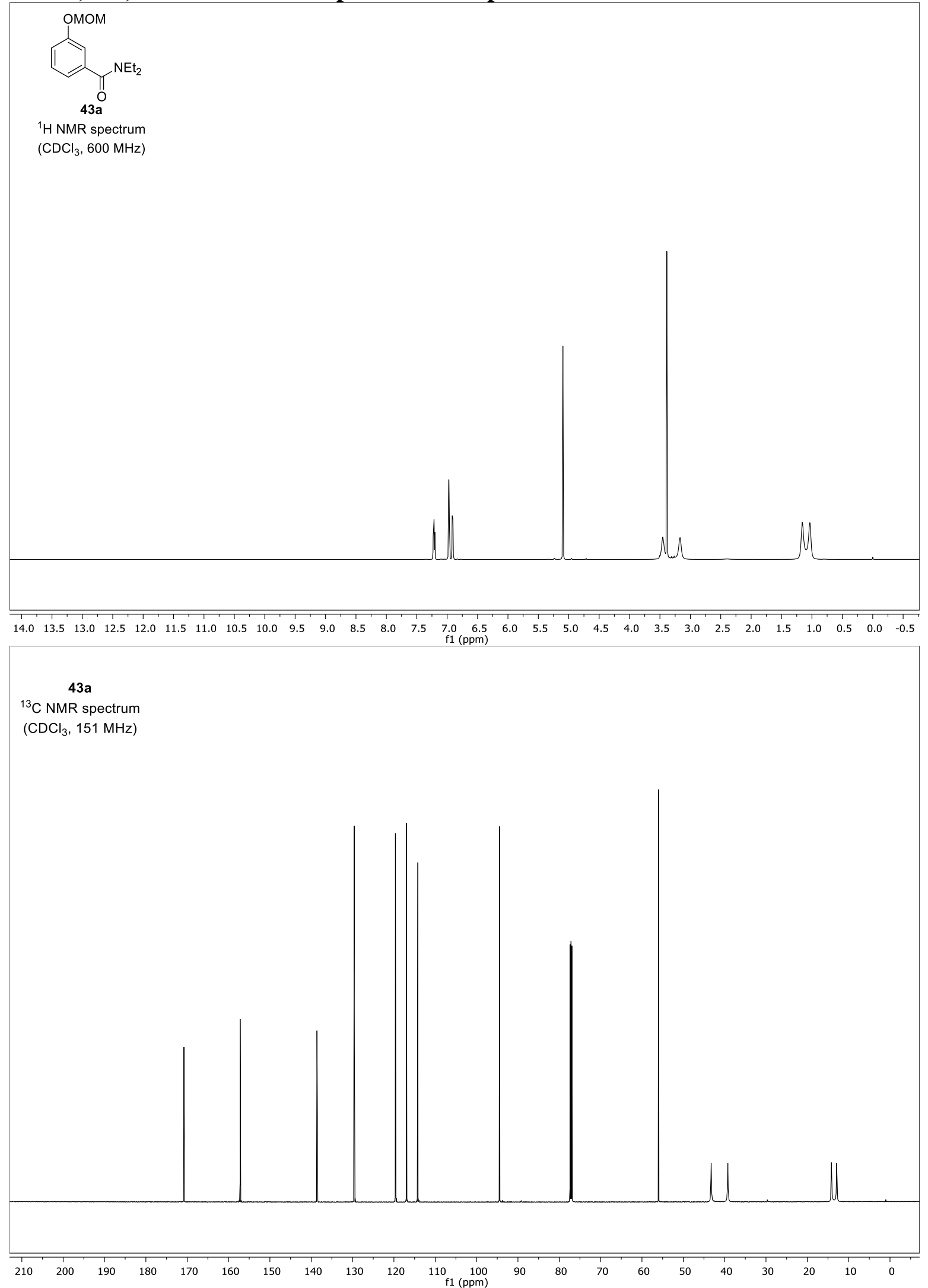


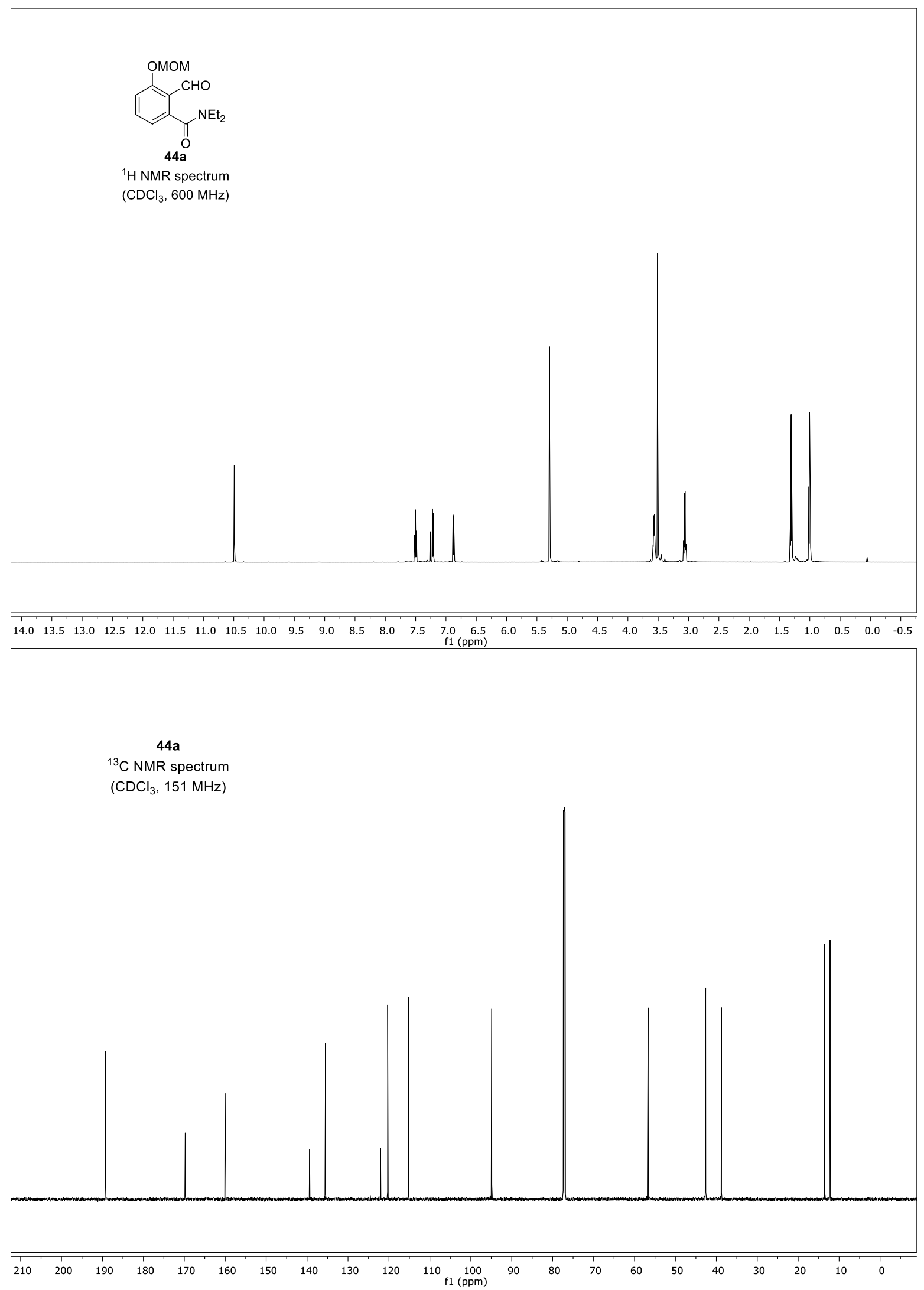




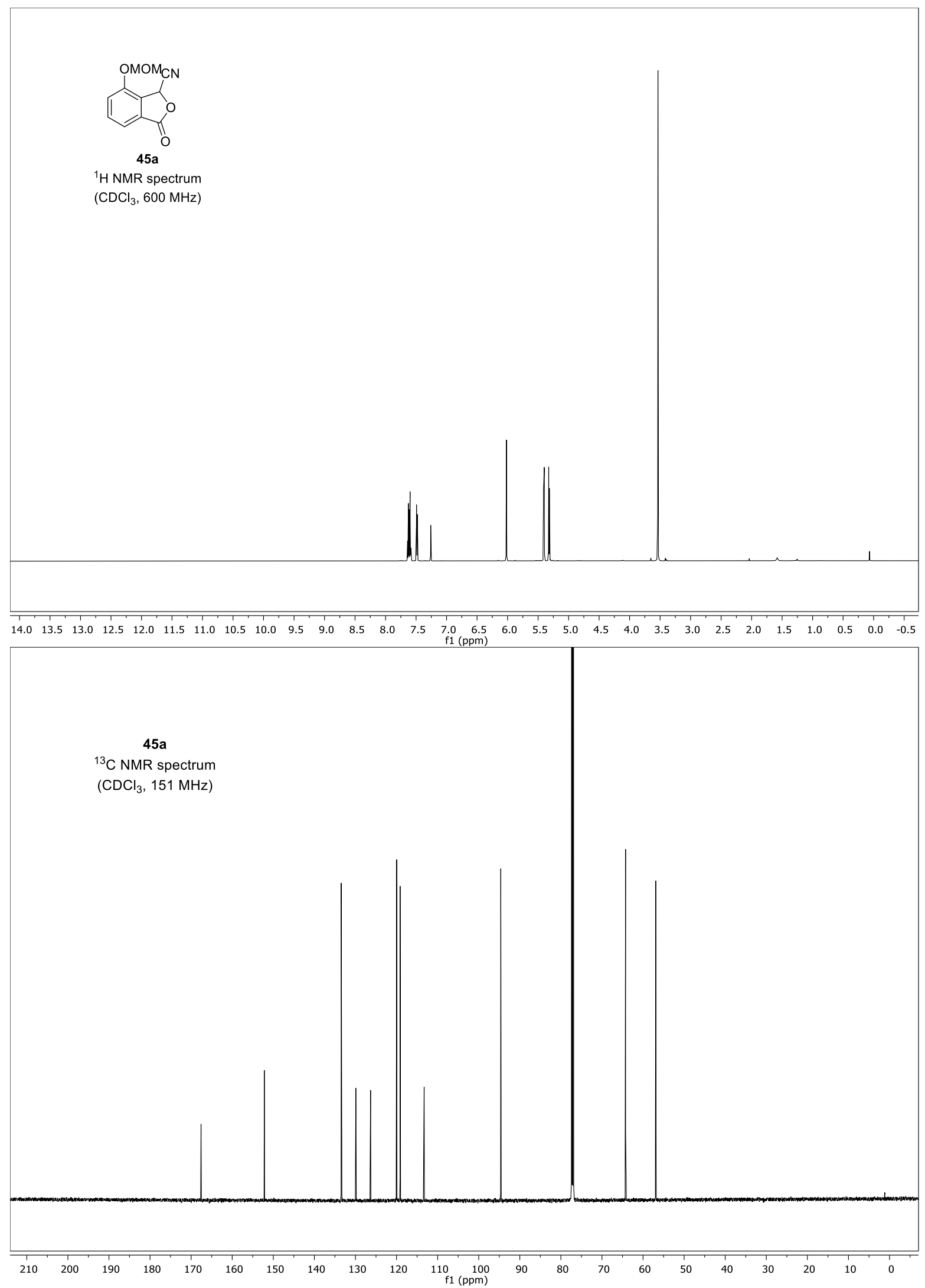




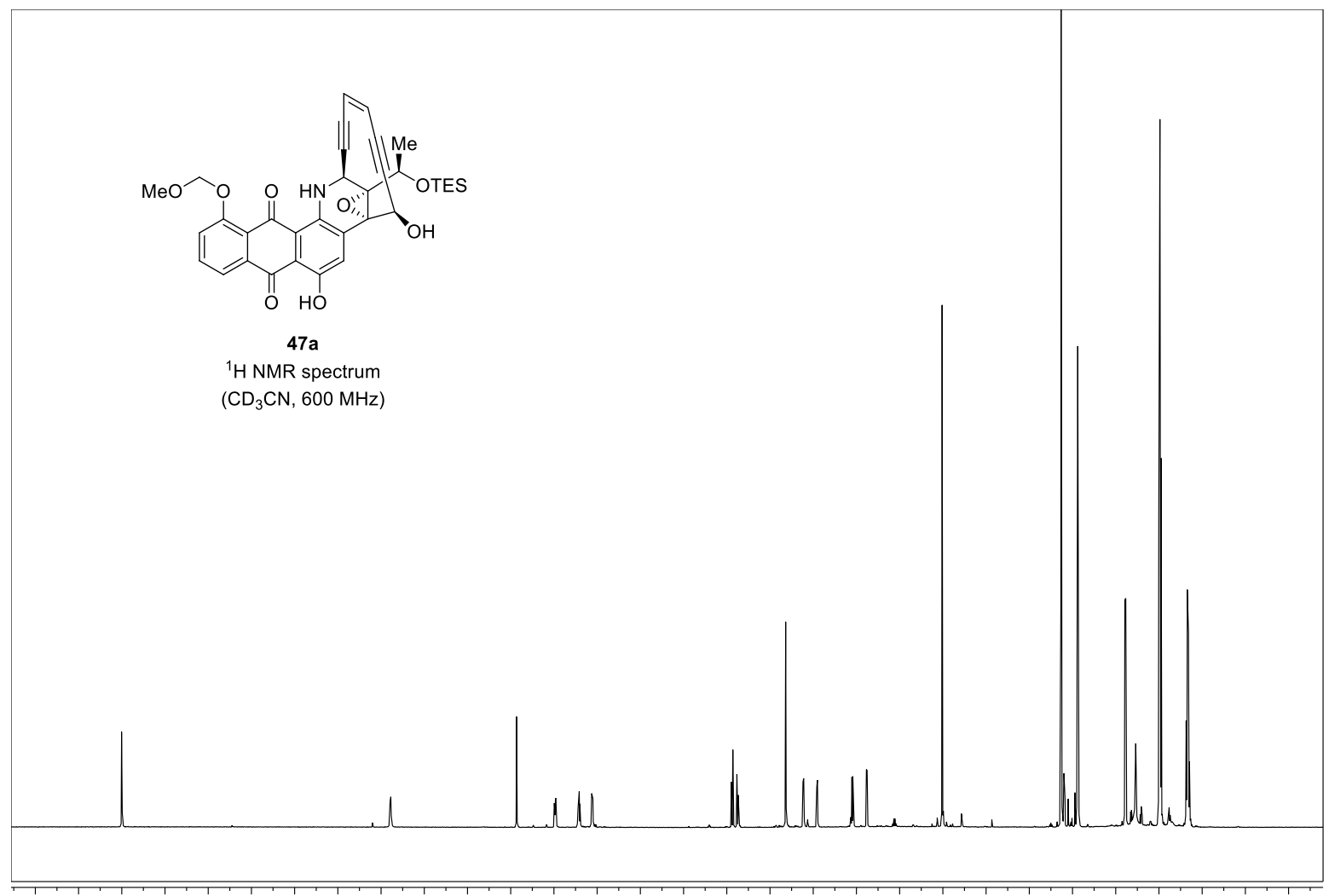

$\begin{array}{lllllllllllllllllllllllllllllllllllllllllllllllll}14.0 & 13.5 & 13.0 & 12.5 & 12.0 & 11.5 & 11.0 & 10.5 & 10.0 & 9.5 & 9.0 & 8.5 & 8.0 & 7.5 & 7.0 & 6.5 & 6.0 & 5.5 & 5.0 & 4.5 & 4.0 & 3.5 & 3.0 & 2.5 & 2.0 & 1.5 & 1.0 & 0.5 & 0.0 & -0.5\end{array}$

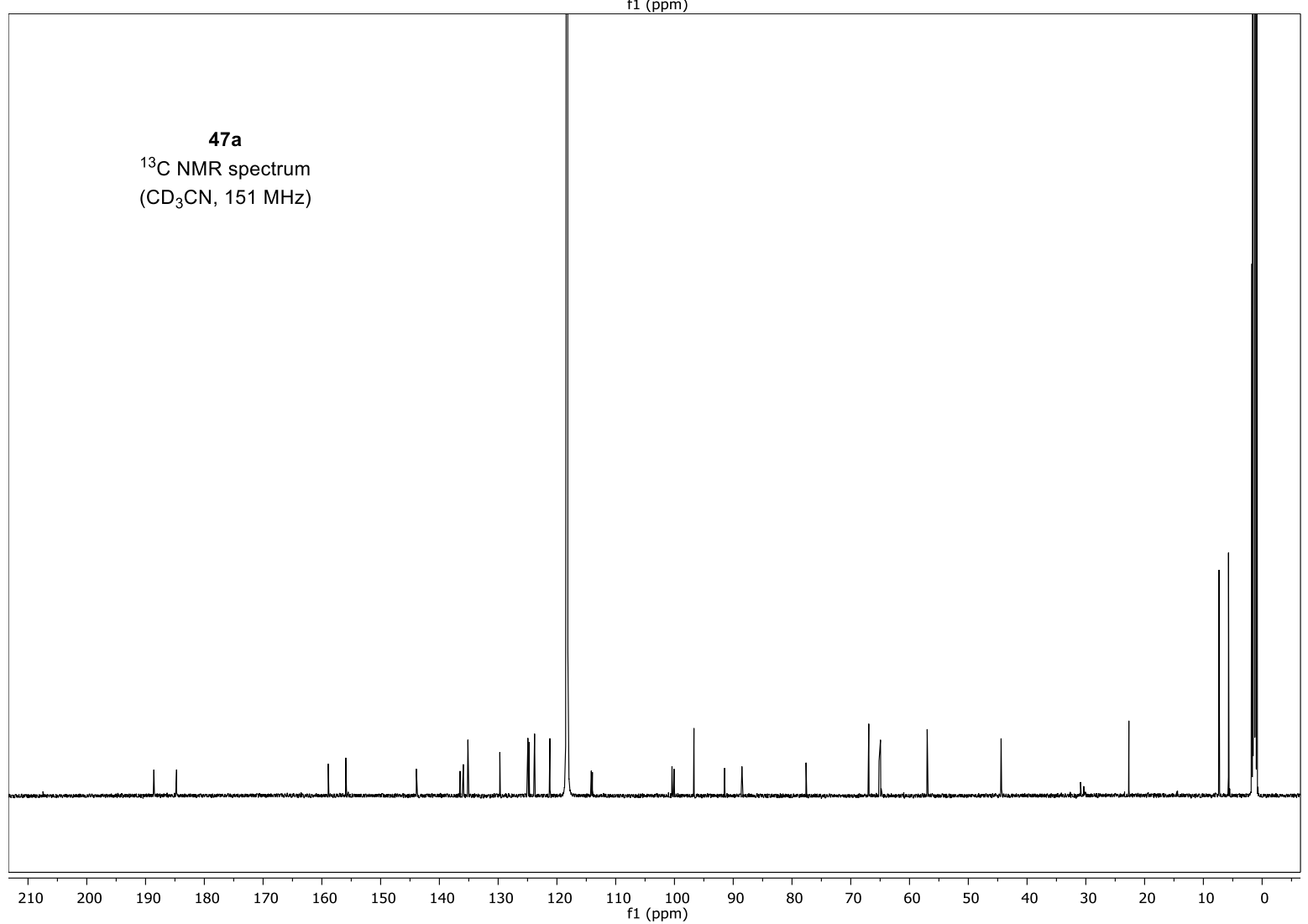



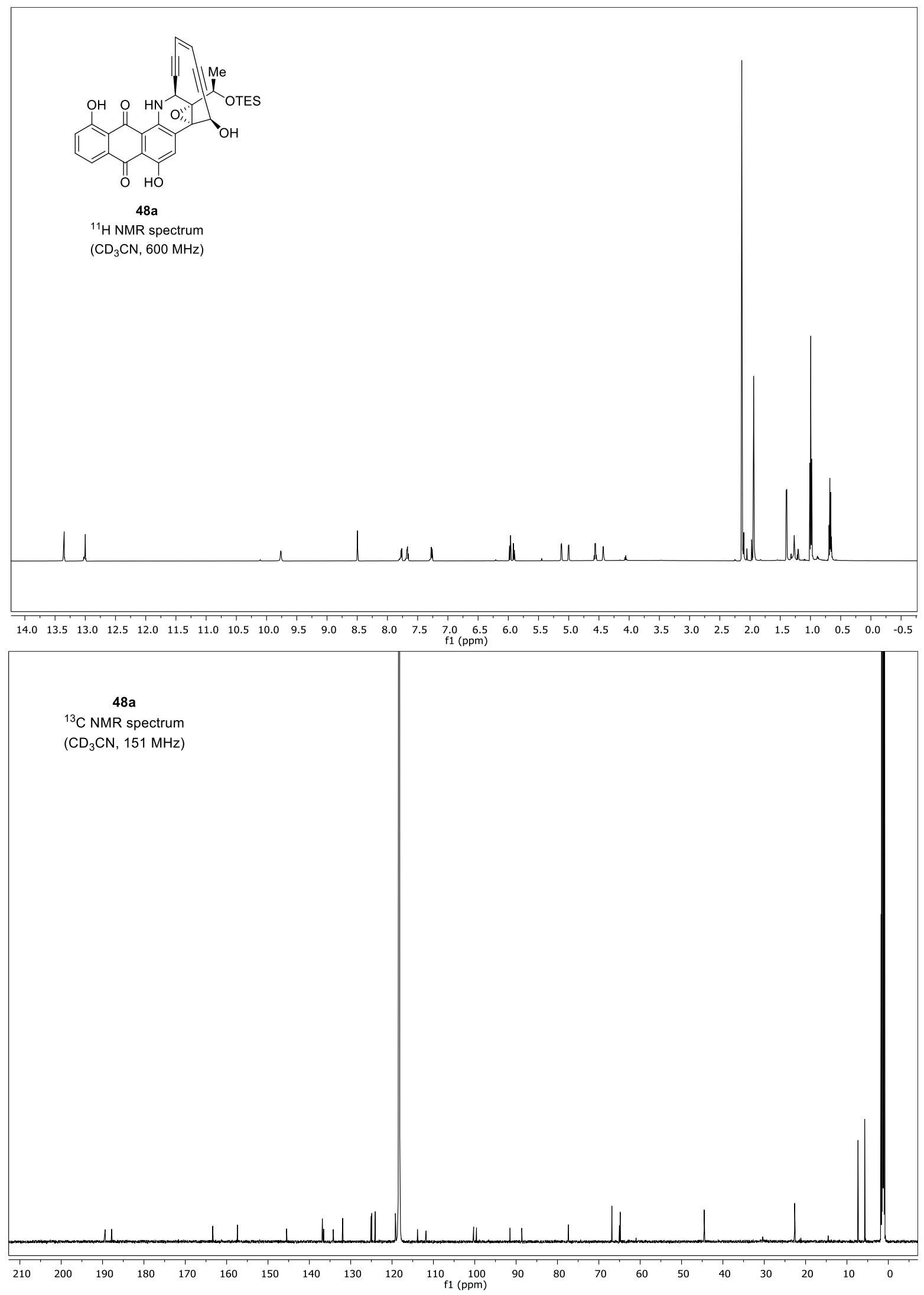

S73 


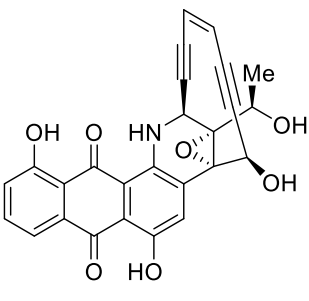

6

${ }^{1} \mathrm{H}$ NMR spectrum

(Acetone- $d_{6}, 600 \mathrm{MHz}$ )

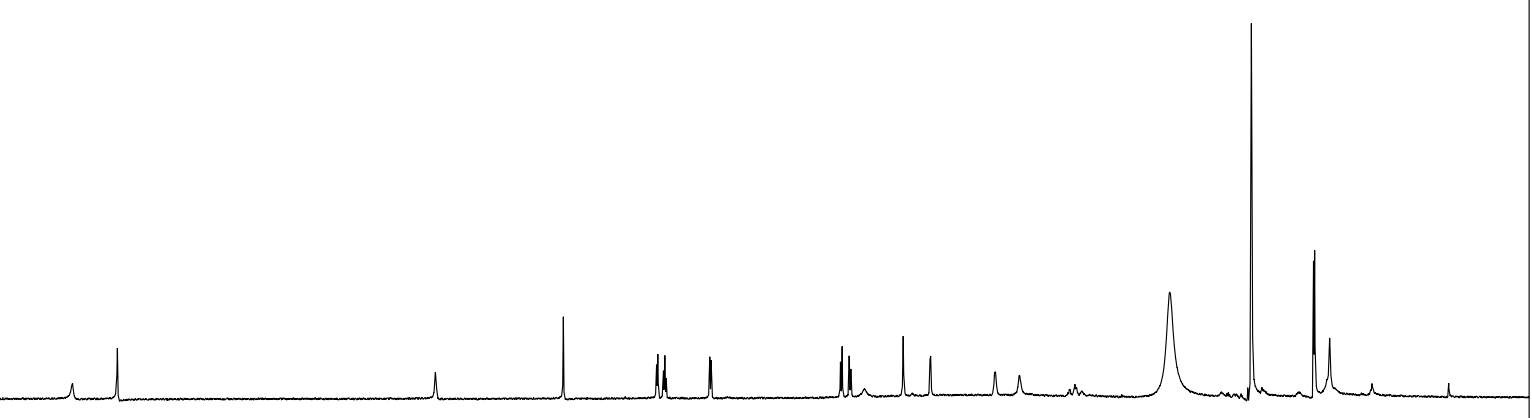

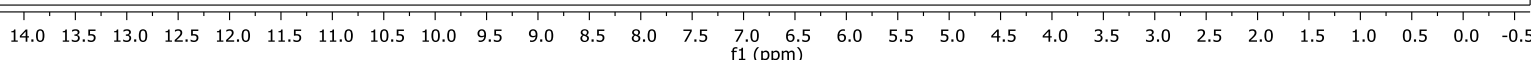

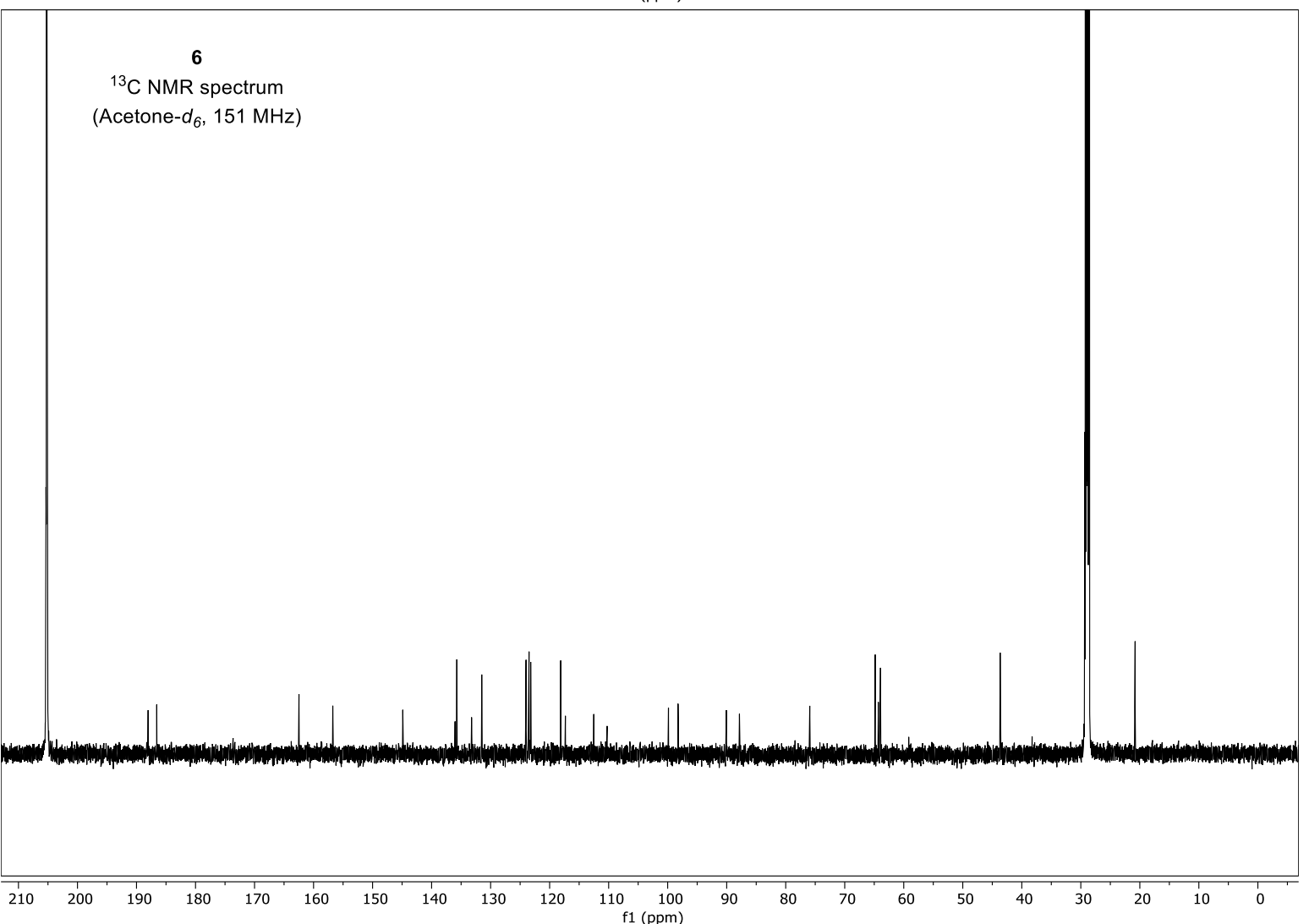



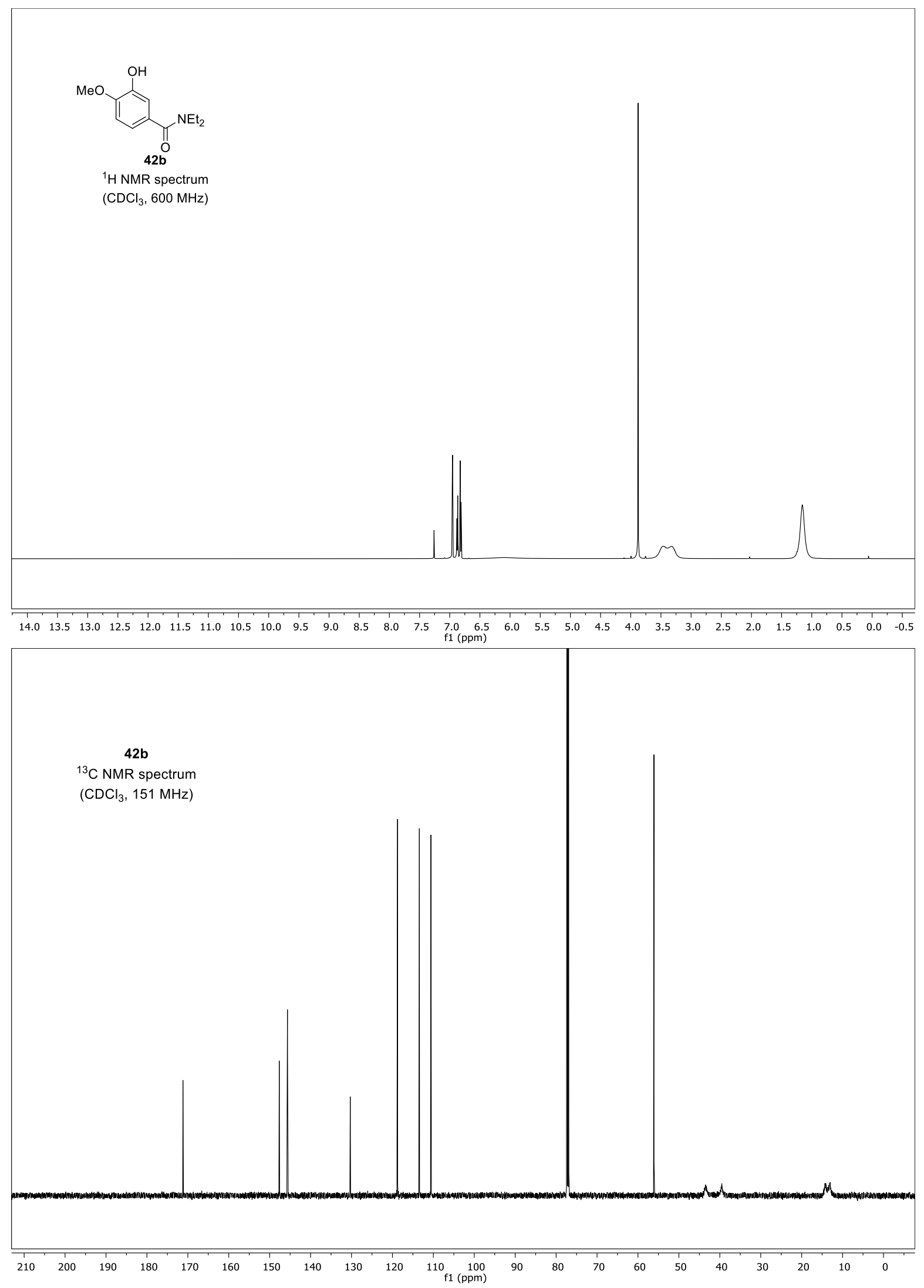


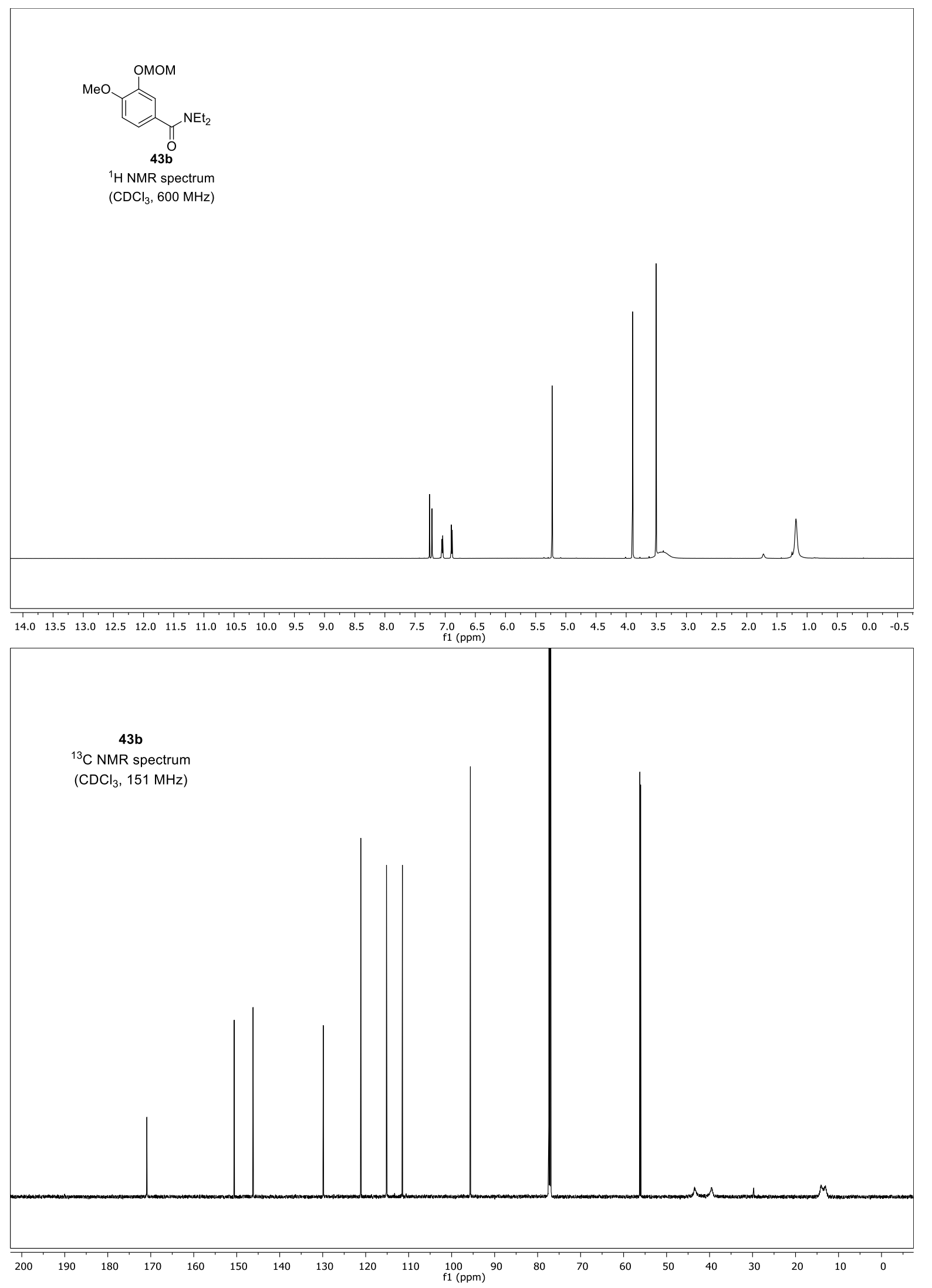



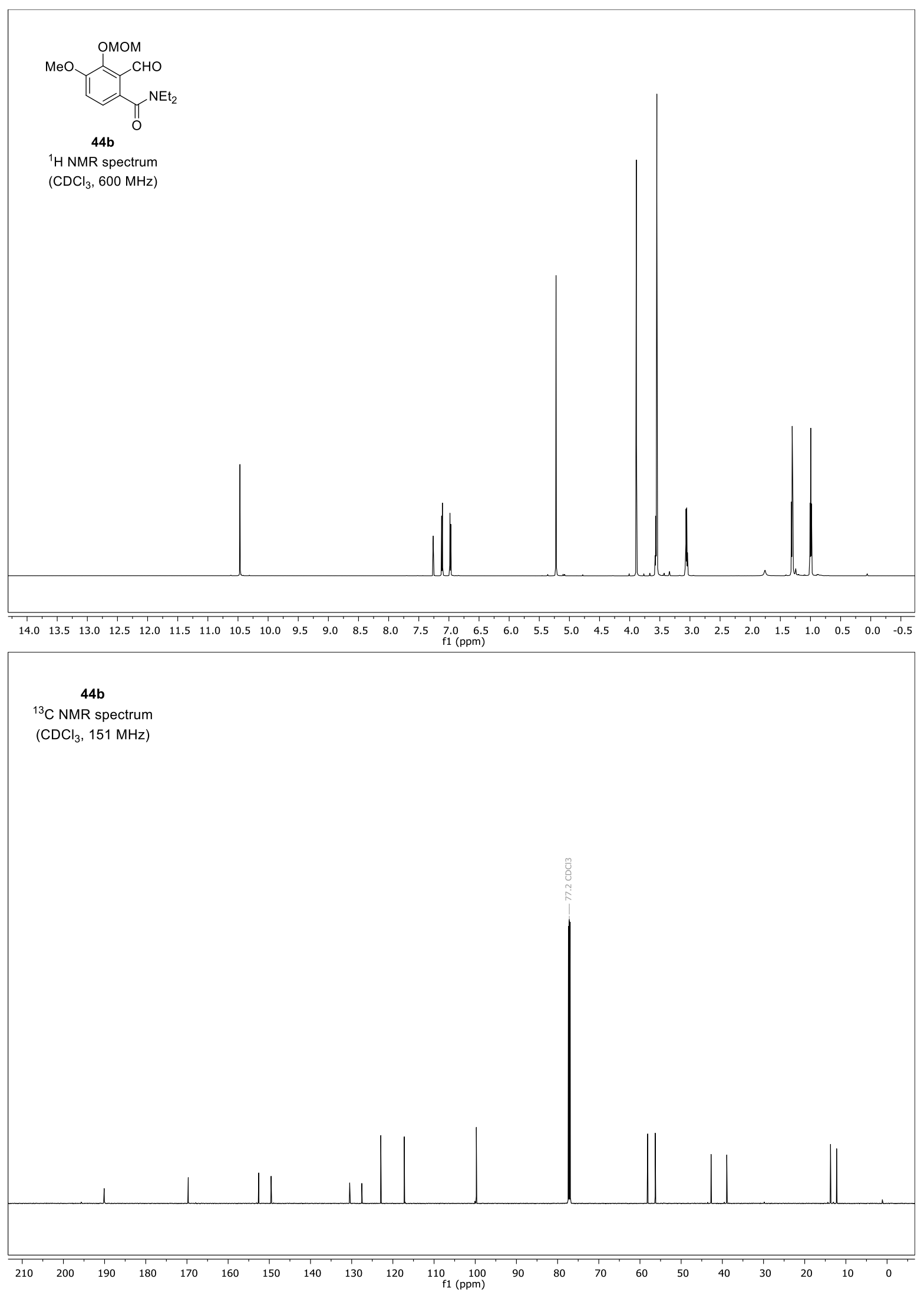


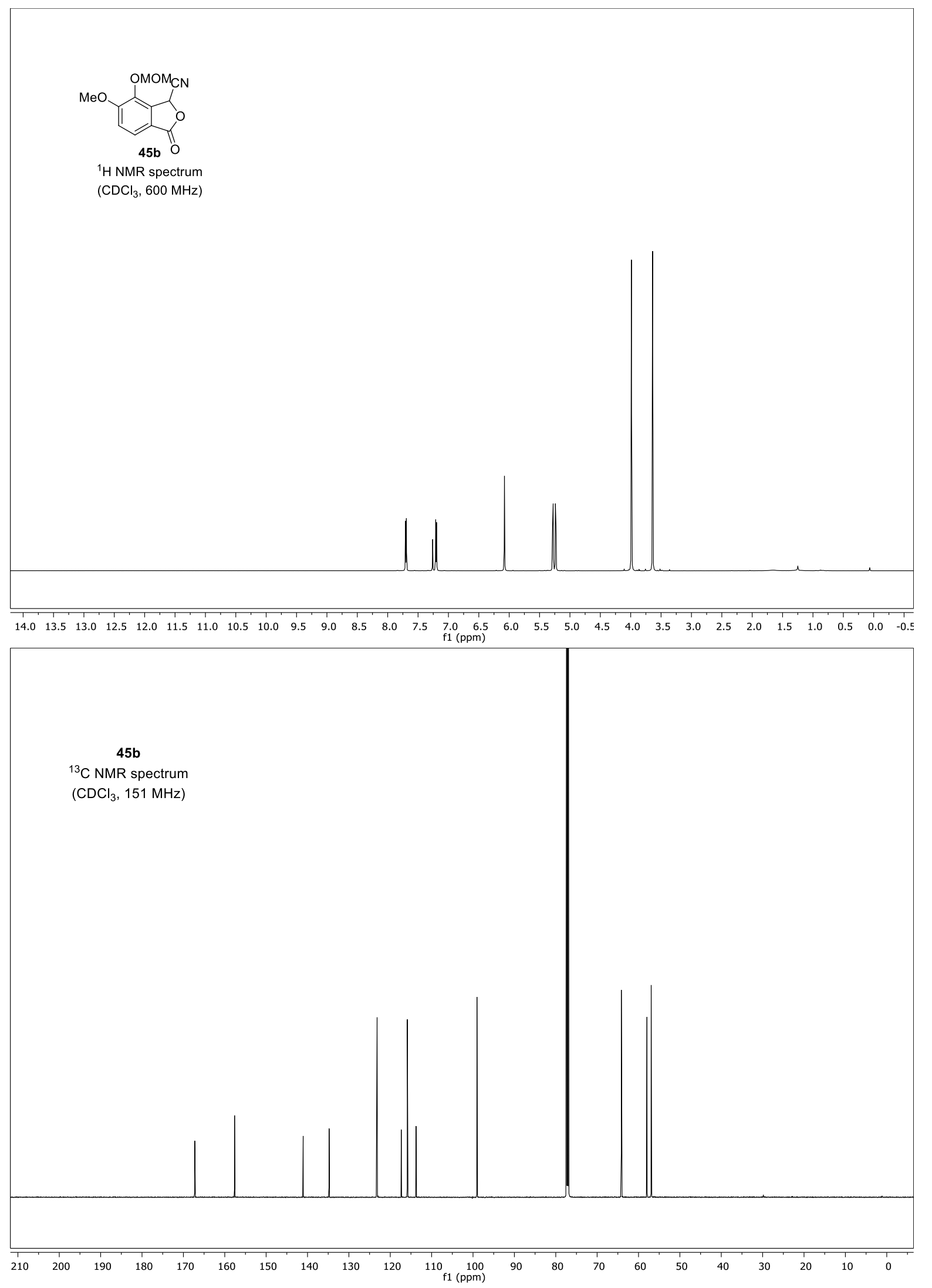




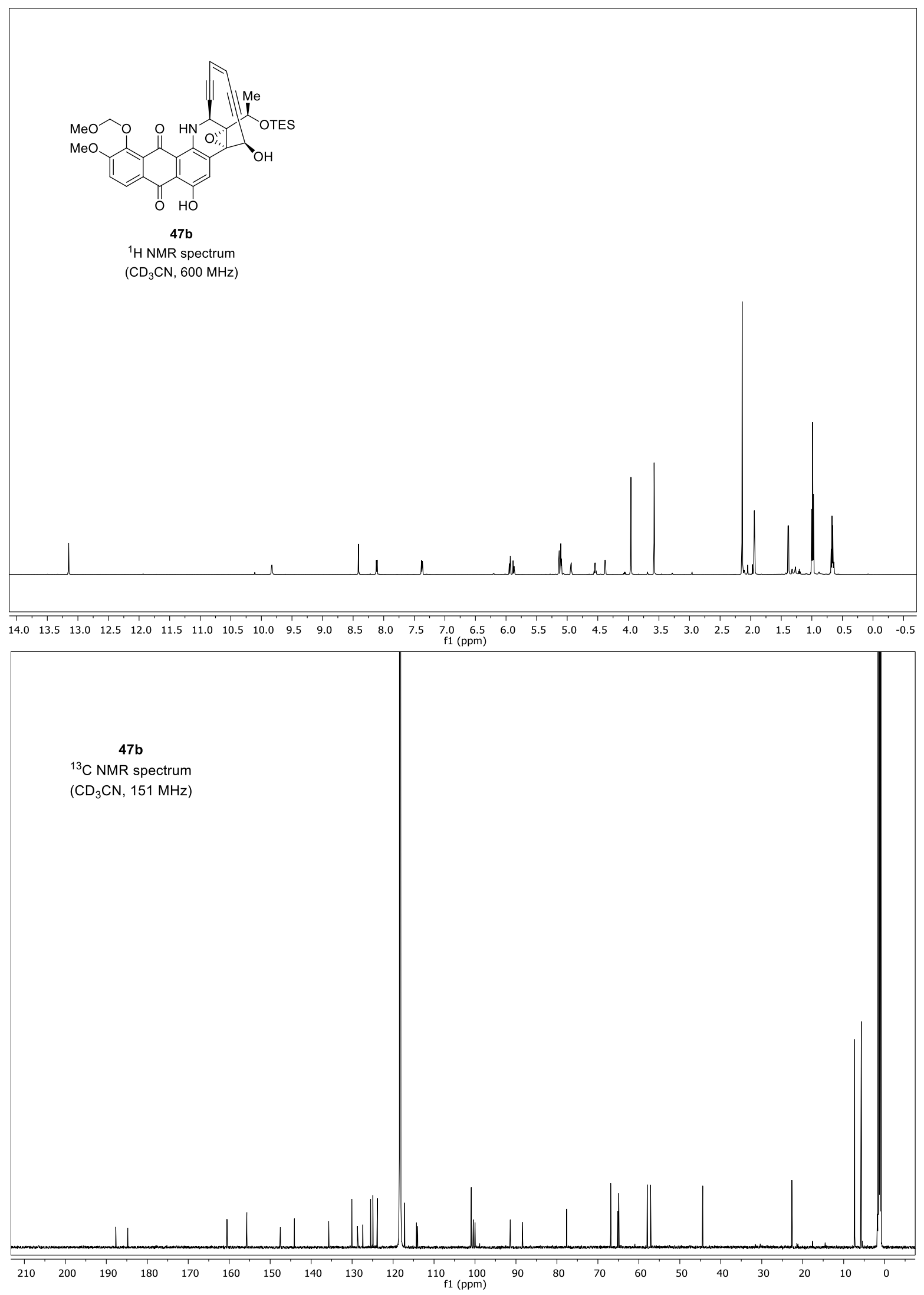



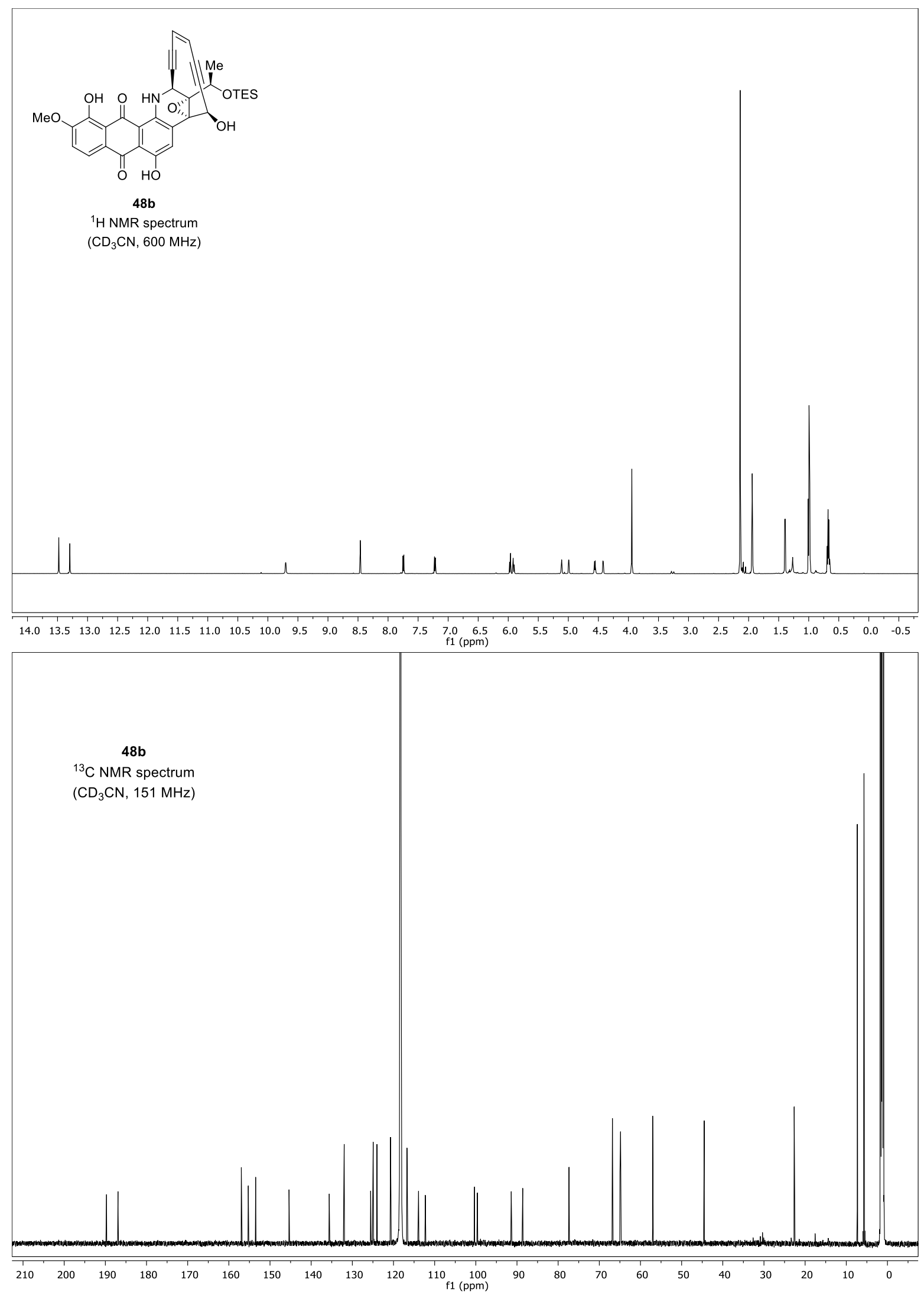

S80 

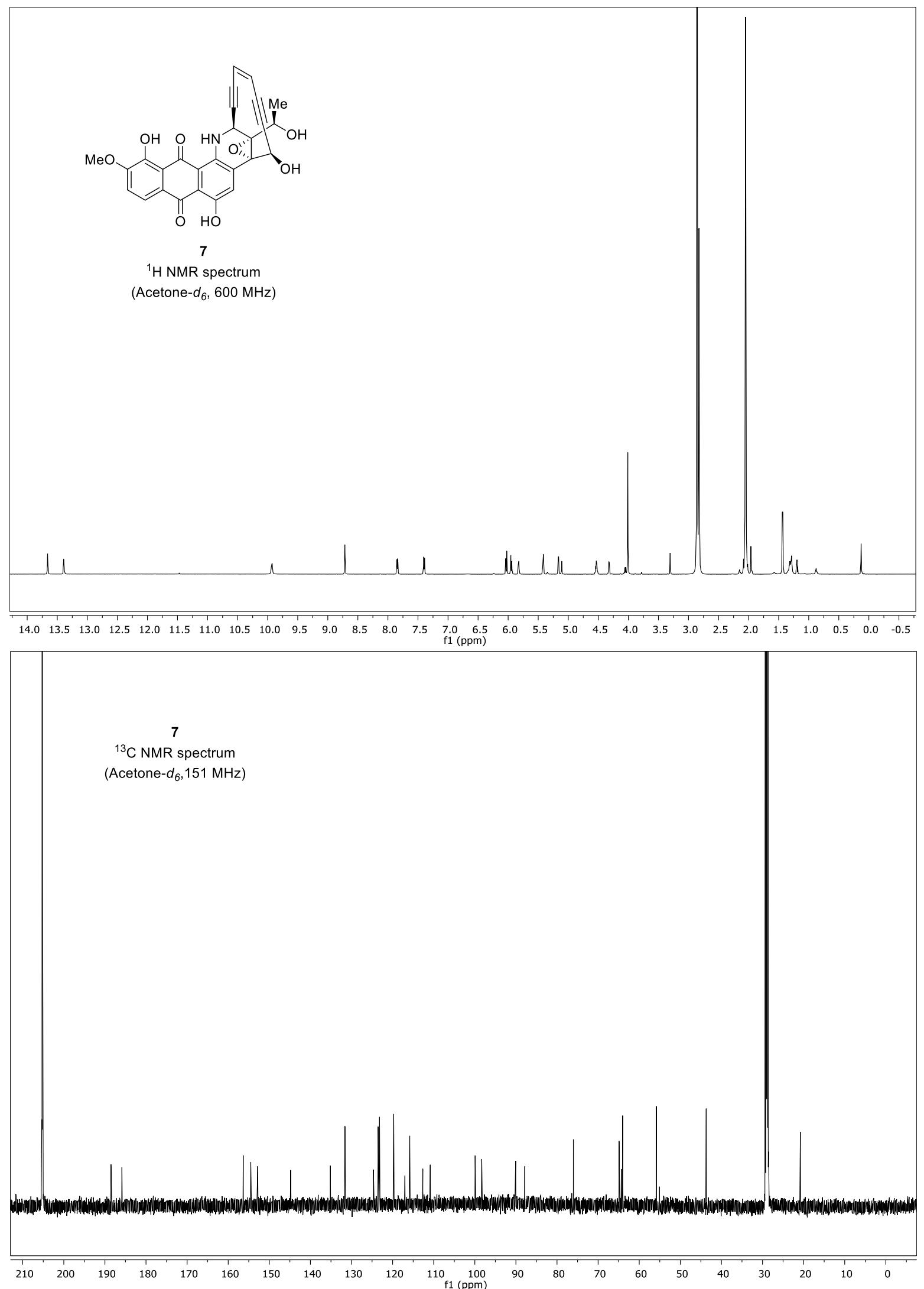


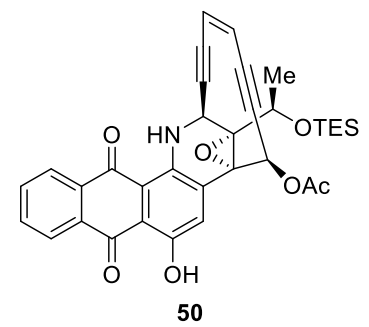

${ }^{1} \mathrm{H}$ NMR spectrum $\left(\mathrm{CD}_{3} \mathrm{CN}, 600 \mathrm{MHz}\right)$

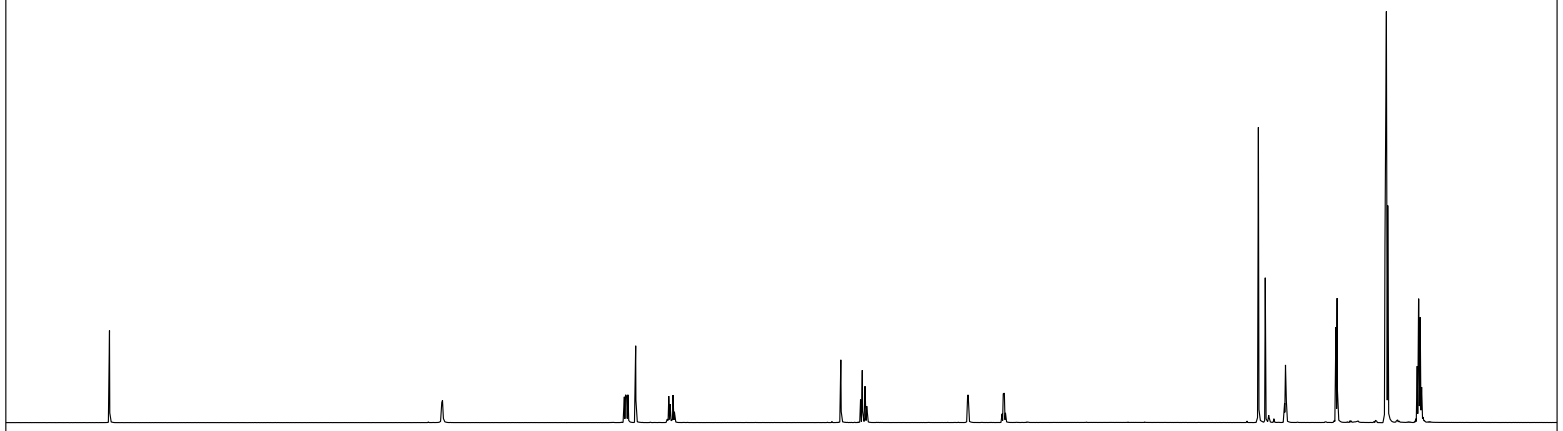

\begin{tabular}{|l|lllllllllllllllllllllllllllllllllll}
\hline 14.0 & 13.5 & 13.0 & 12.5 & 12.0 & 11.5 & 11.0 & 10.5 & 10.0 & 9.5 & 9.0 & 8.5 & 8.0 & 7.5 & 7.0 & 6.5 & 6.0 & 5.5 & 5.0 & 4.5 & 4.0 & 3.5 & 3.0 & 2.5 & 2.0 & 1.5 & 1.0 & 0.5 & 0.0 & -0.5
\end{tabular}

50

${ }^{13} \mathrm{C}$ NMR spectrum

$\left(\mathrm{CD}_{3} \mathrm{CN}, 151 \mathrm{MHz}\right)$

|

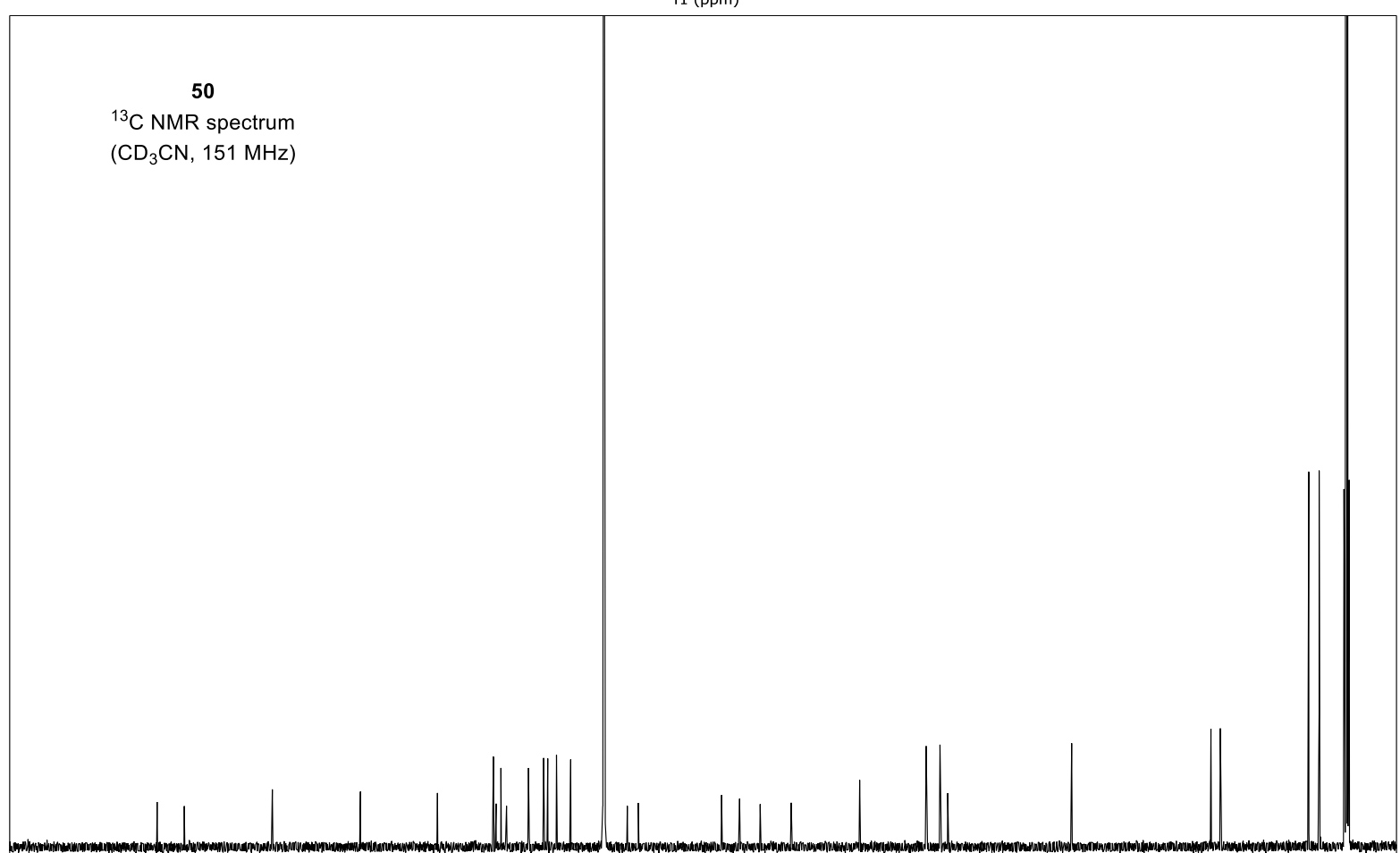

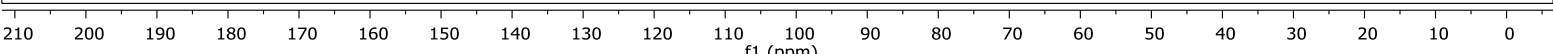




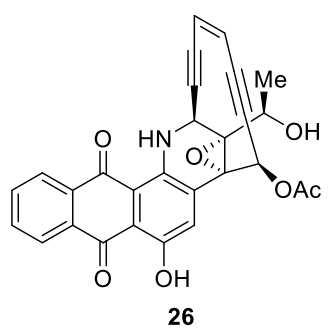

${ }^{1} \mathrm{H}$ NMR spectrum

$\left(\mathrm{CD}_{3} \mathrm{CN}, 600 \mathrm{MHz}\right)$

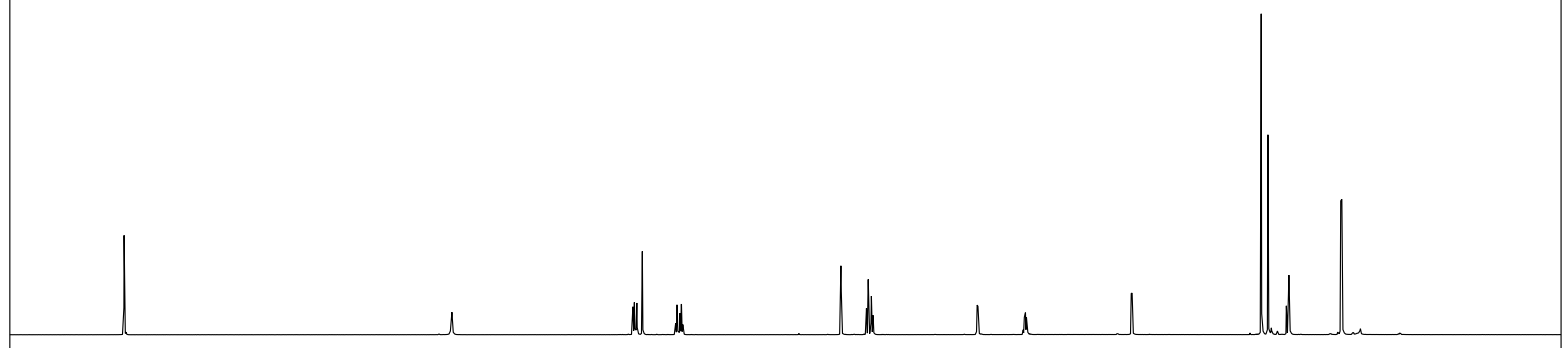

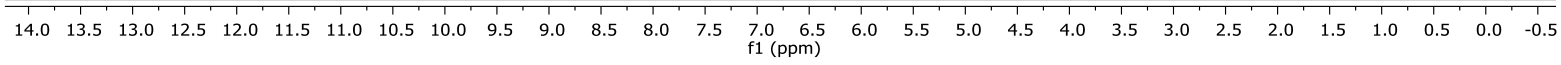

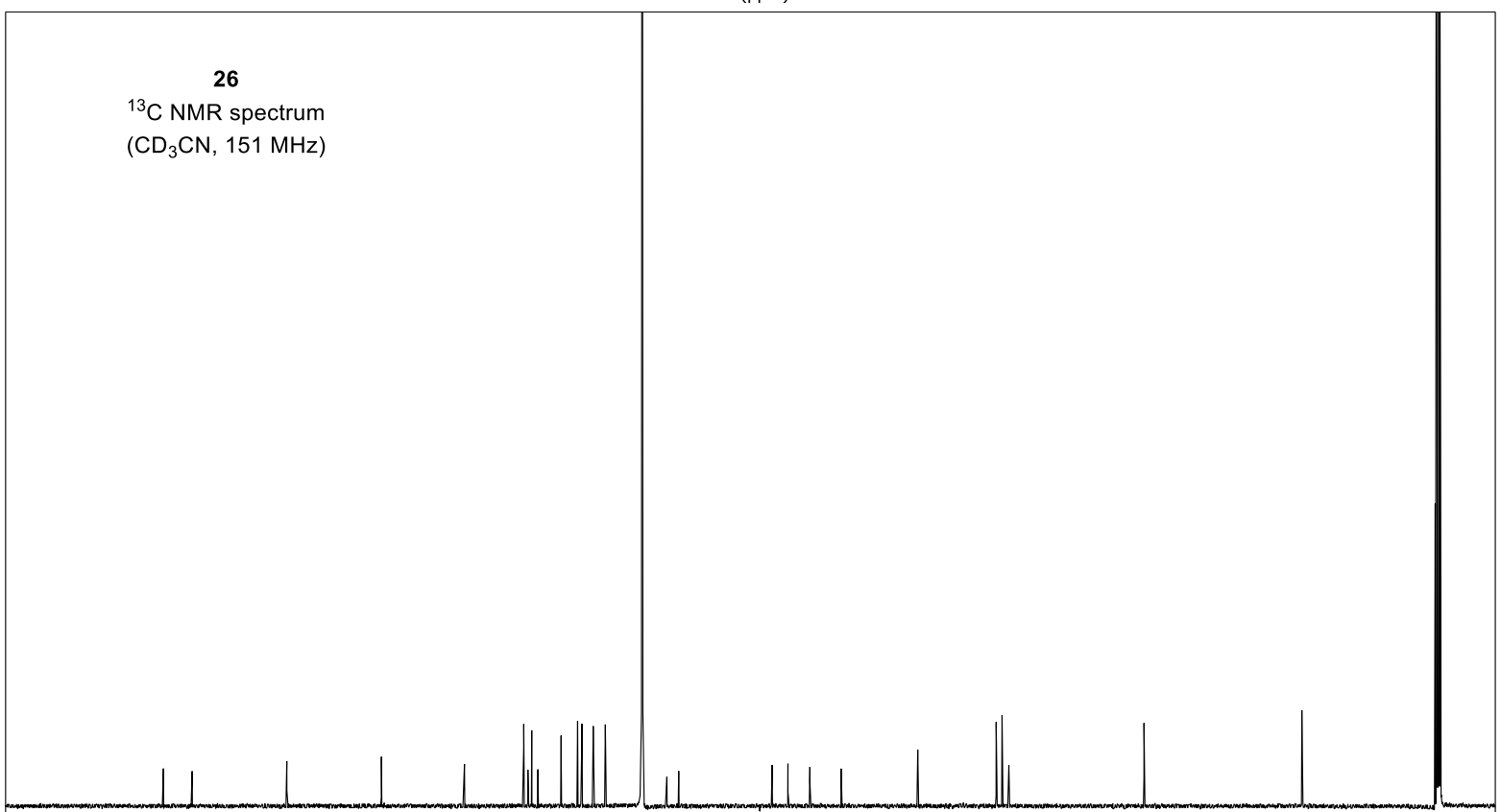

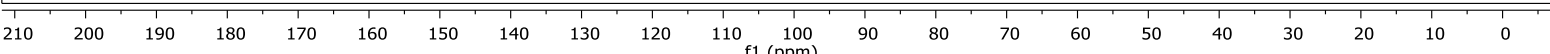



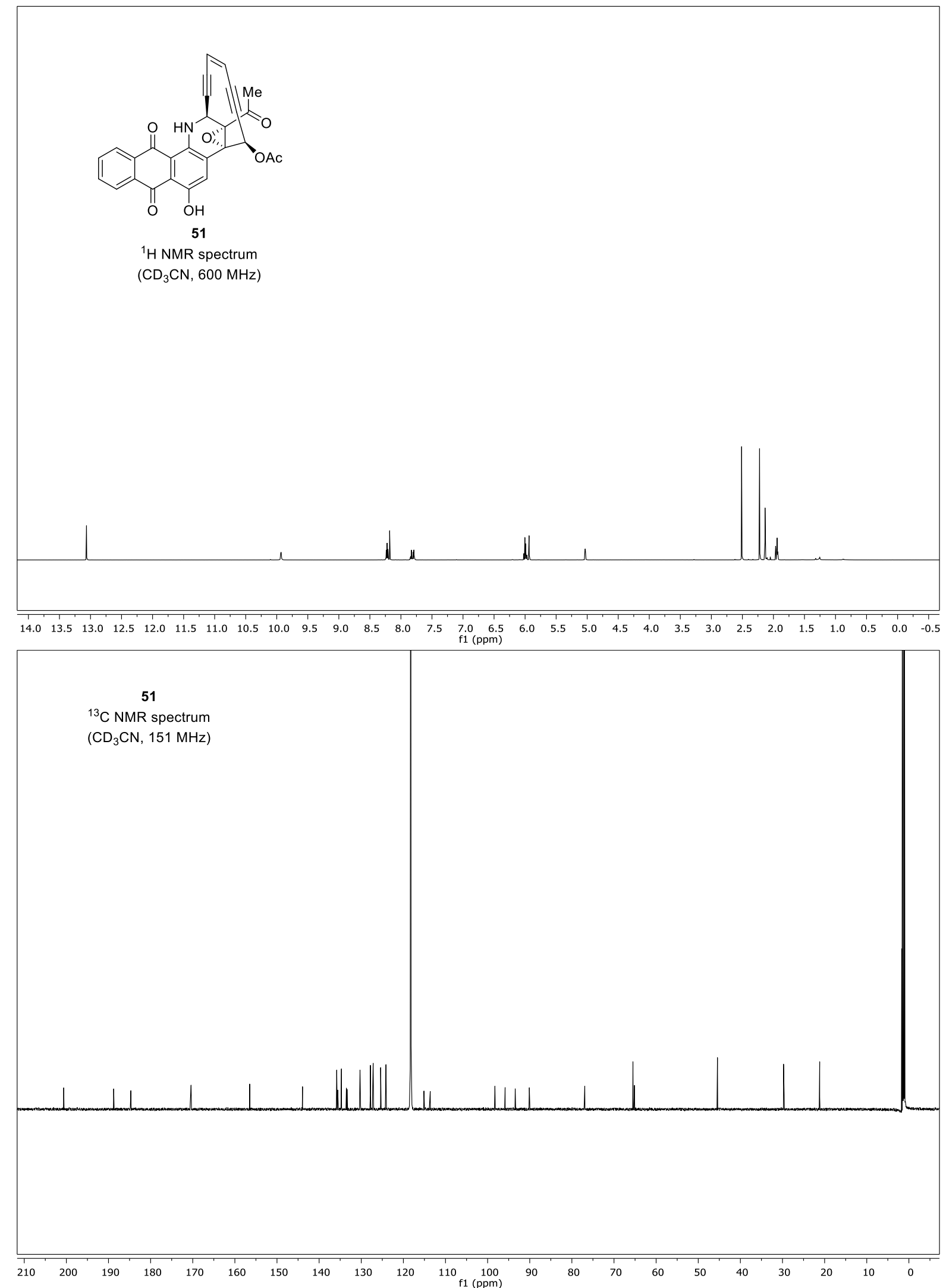


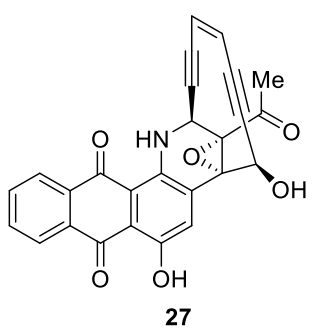

${ }^{1} \mathrm{H}$ NMR spectrum $\left(\mathrm{CD}_{3} \mathrm{CN}, 600 \mathrm{MHz}\right)$

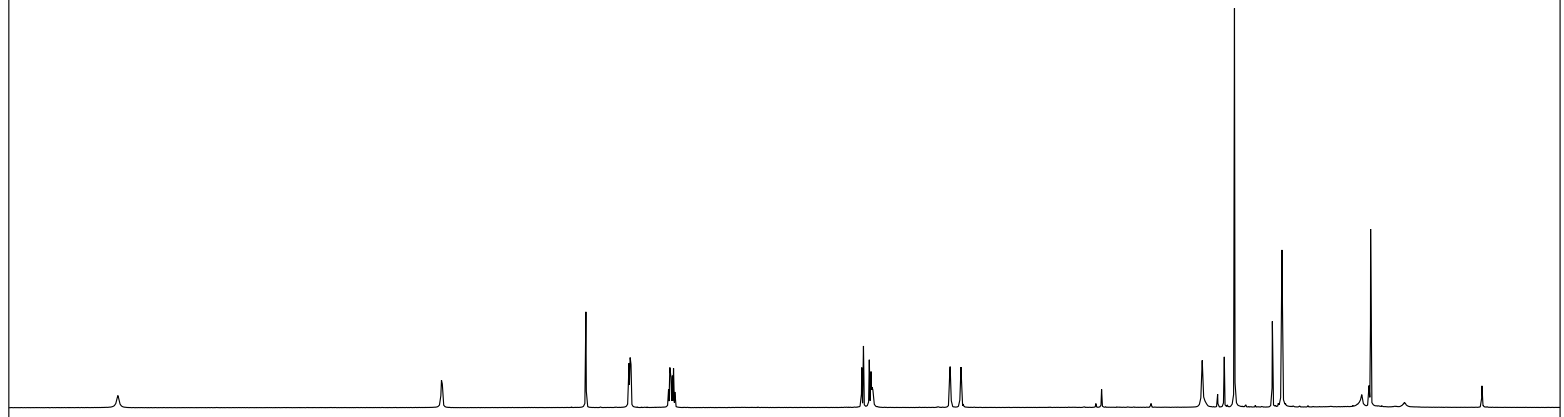

$\begin{array}{rrrrrrrrrrrrrrrrrrrrrrrrrrrrrrrrrrr}14.0 & 13.5 & 13.0 & 12.5 & 12.0 & 11.5 & 11.0 & 10.5 & 10.0 & 9.5 & 9.0 & 8.5 & 8.0 & 7.5 & 7.0 & 6.5 & 6.0 & 5.5 & 5.0 & 4.5 & 4.0 & 3.5 & 3.0 & 2.5 & 2.0 & 1.5 & 1.0 & 0.5 & 0.0 & -0.5\end{array}$

27

${ }^{13} \mathrm{C}$ NMR spectrum $\left(\mathrm{CD}_{3} \mathrm{CN}, 151 \mathrm{MHz}\right)$

\begin{tabular}{lllllllllll}
\hline 210 & 200 & 190 & 180 & 170 & 160 & 150 & 140 & 130 & 120 & 110 \\
\hline 10 & 100
\end{tabular} 

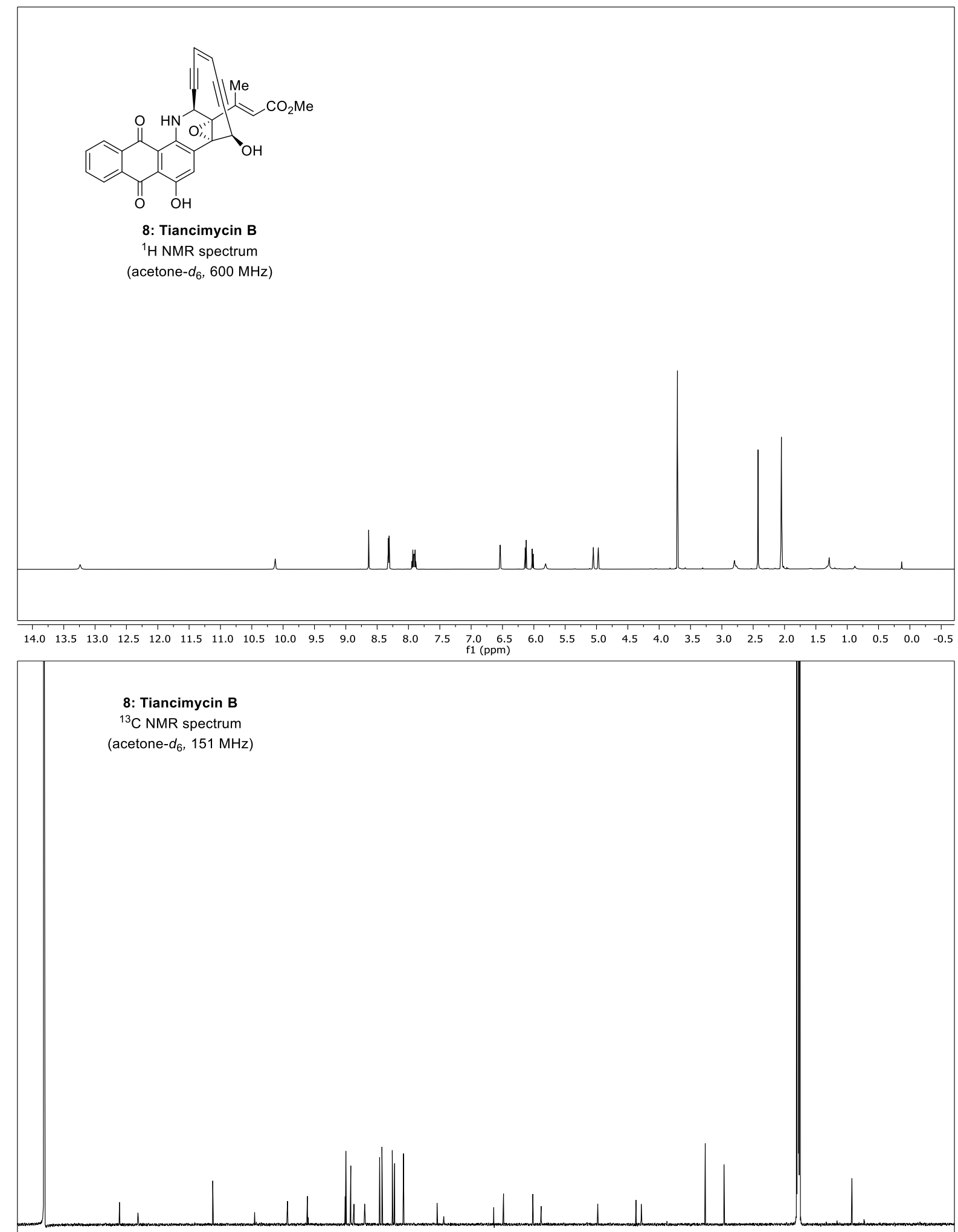

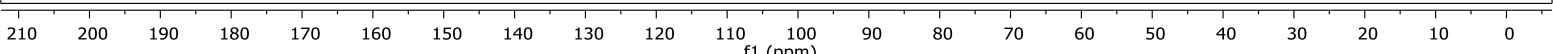




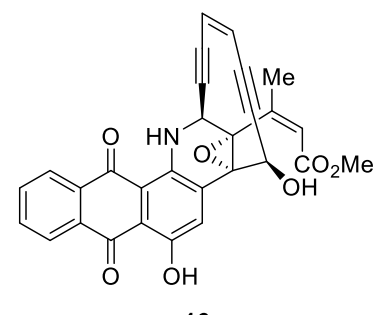

16

${ }^{1} \mathrm{H}$ NMR spectrum

$\left(\mathrm{CD}_{3} \mathrm{CN}, 600 \mathrm{MHz}\right)$

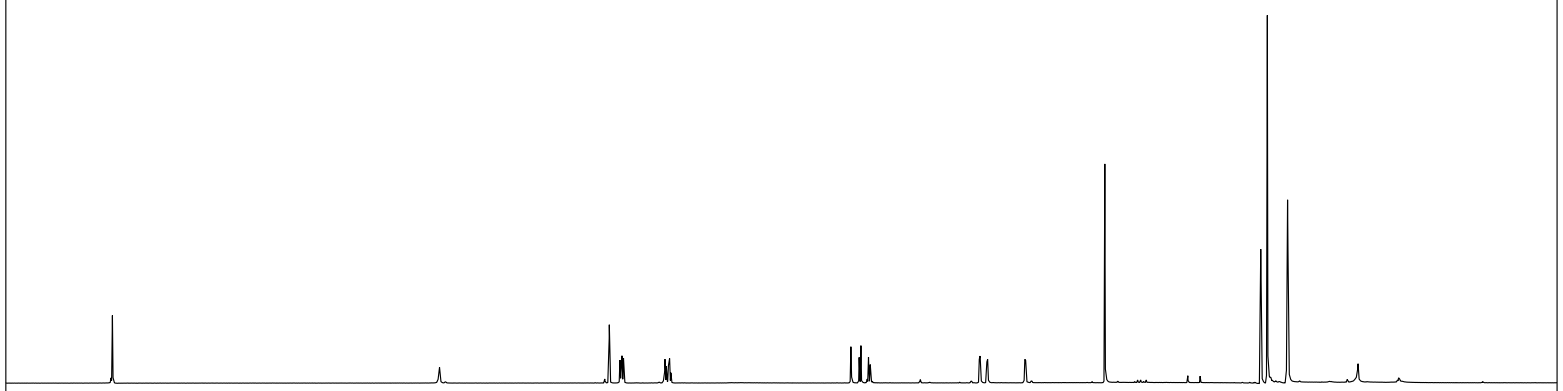

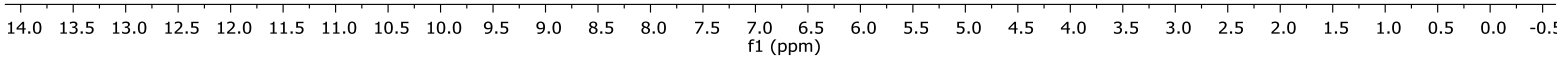

16

${ }^{13} \mathrm{C}$ NMR spectrum $\left(\mathrm{CD}_{3} \mathrm{CN}, 151 \mathrm{MHz}\right)$

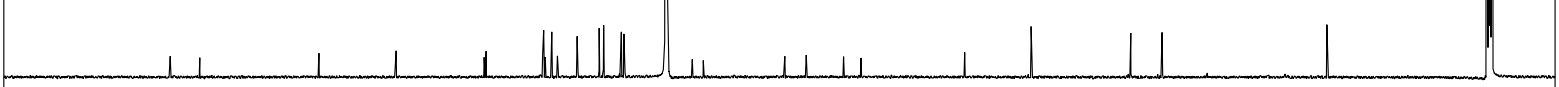

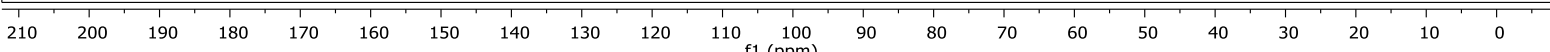



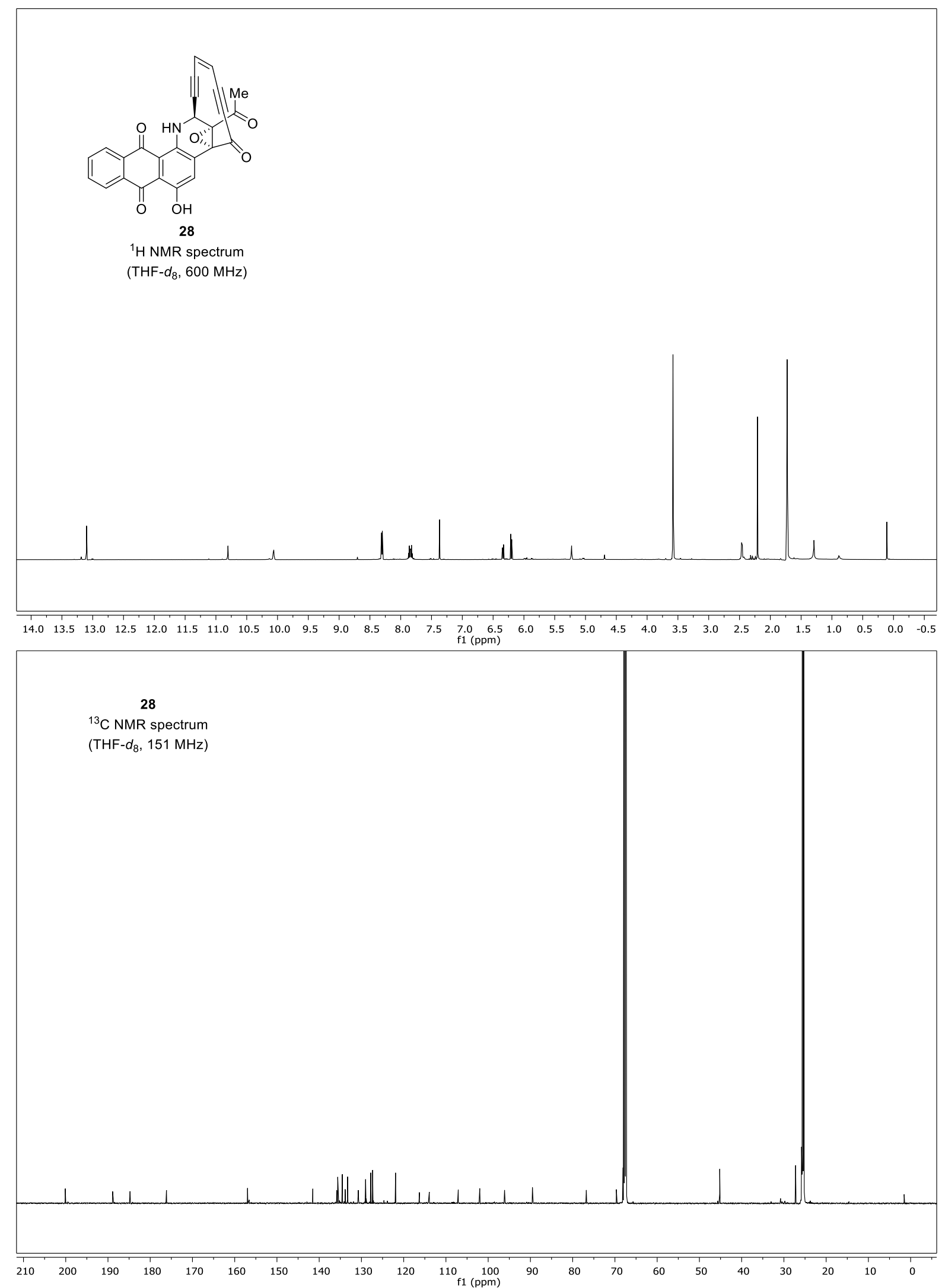


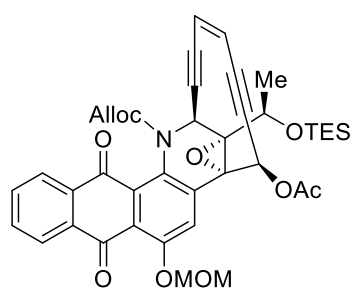

54

${ }^{1} \mathrm{H}$ NMR spectrum $\left(\mathrm{CD}_{3} \mathrm{CN}, 600 \mathrm{MHz}\right)$

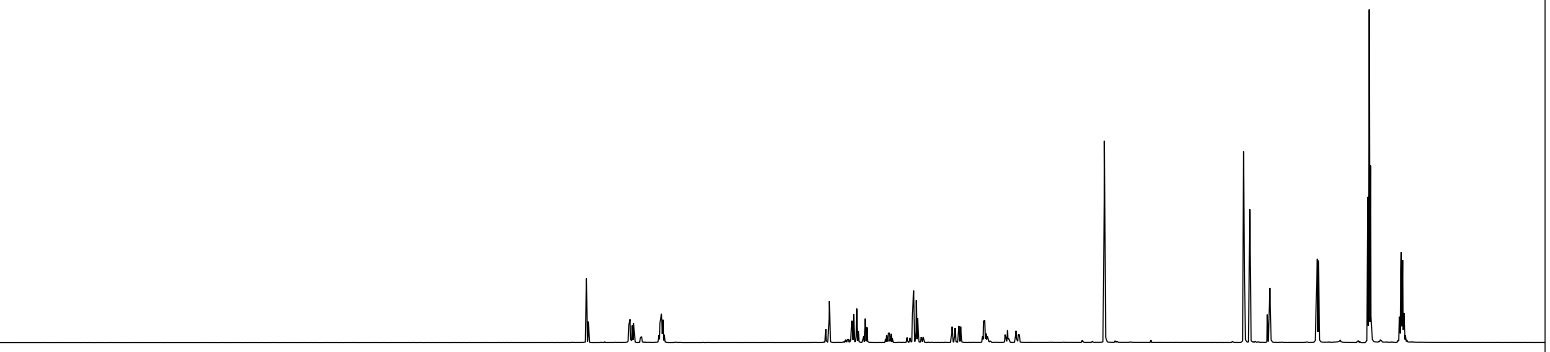

$\begin{array}{rrrrrrrrrrrrrrrrrrrrrrrrrrrrrrrrrr}14.0 & 13.5 & 13.0 & 12.5 & 12.0 & 11.5 & 11.0 & 10.5 & 10.0 & 9.5 & 9.0 & 8.5 & 8.0 & 7.5 & 7.0 & 6.5 & 6.0 & 5.5 & 5.0 & 4.5 & 4.0 & 3.5 & 3.0 & 2.5 & 2.0 & 1.5 & 1.0 & 0.5 & 0.0 & -0.5\end{array}$

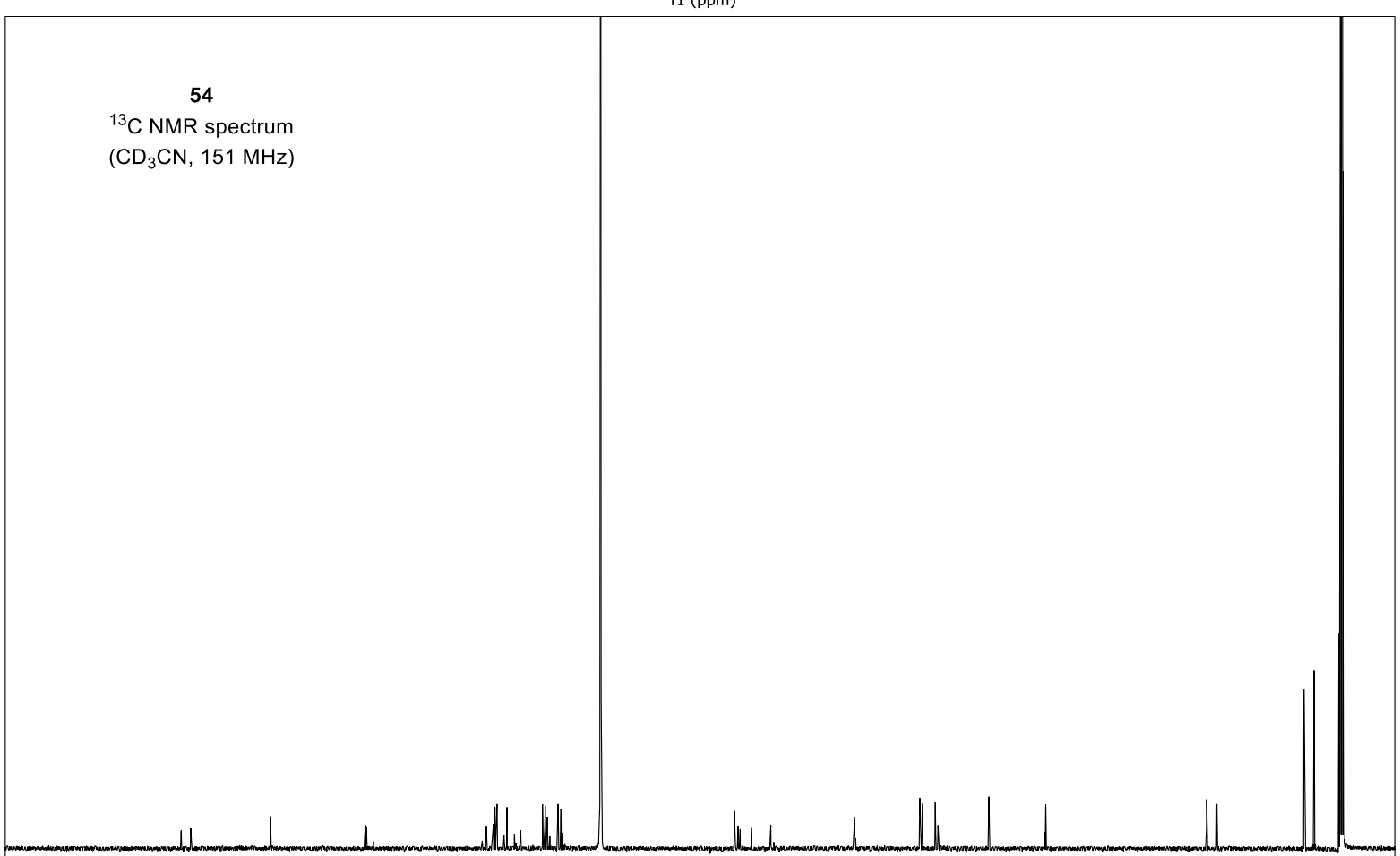

\begin{tabular}{lllllllllllllllllllllll}
\hline & 210 & 200 & 190 & 180 & 170 & 160 & 150 & 140 & 130 & 120 & 110 & 100 & 90 & 80 & 70 & 60 & 50 & 40 & 30 & 20 & 10 & 0
\end{tabular} 

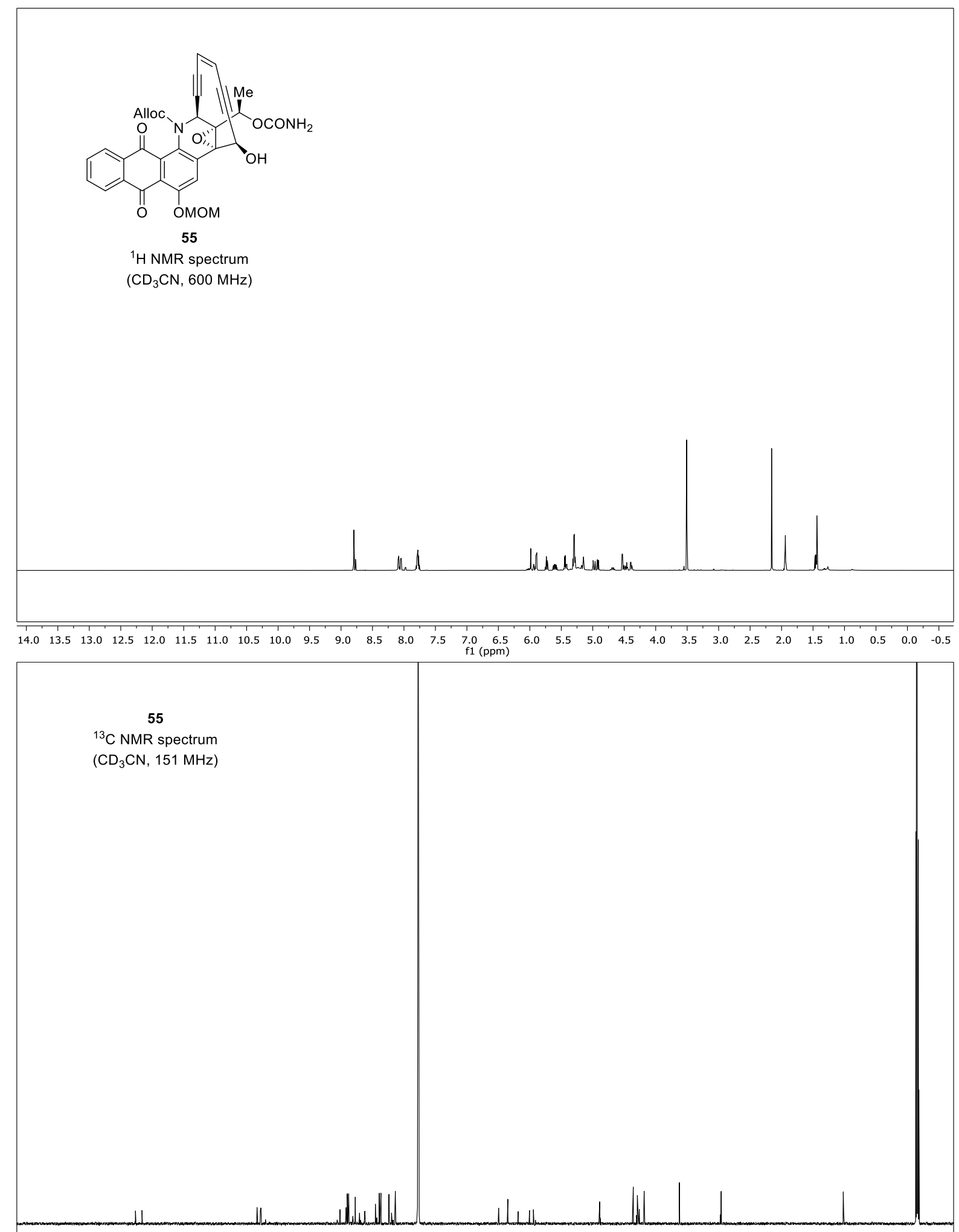

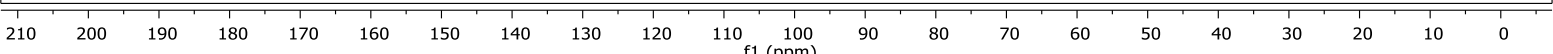




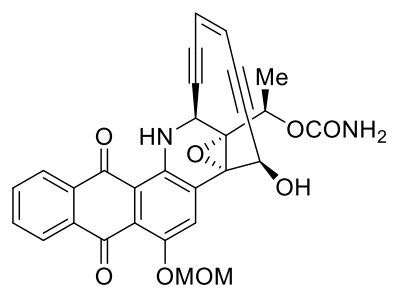

Alloc-deprotected derivative

${ }^{1} \mathrm{H}$ NMR spectrum

$\left(\mathrm{CD}_{3} \mathrm{CN}, 600 \mathrm{MHz}\right)$

1

4

\begin{tabular}{lllllllllllllllllllllllllllllllllllllllll}
\hline \hline 14.0 & 13.5 & 13.0 & 12.5 & 12.0 & 11.5 & 11.0 & 10.5 & 10.0 & 9.5 & 9.0 & 8.5 & 8.0 & 7.5 & 7.0 & 6.5 & 6.0 & 1.5 & 5.0 & 4.5 & 4.0 & 3.5 & 3.0 & 2.5 & 2.0 & 1.5 & 1.0 & 0.5 & 0.0 & -0.5 \\
\hline
\end{tabular}

Alloc-deprotected derivative

${ }^{13} \mathrm{C}$ NMR spectrum

$\left(\mathrm{CD}_{3} \mathrm{CN}, 151 \mathrm{MHz}\right)$

L

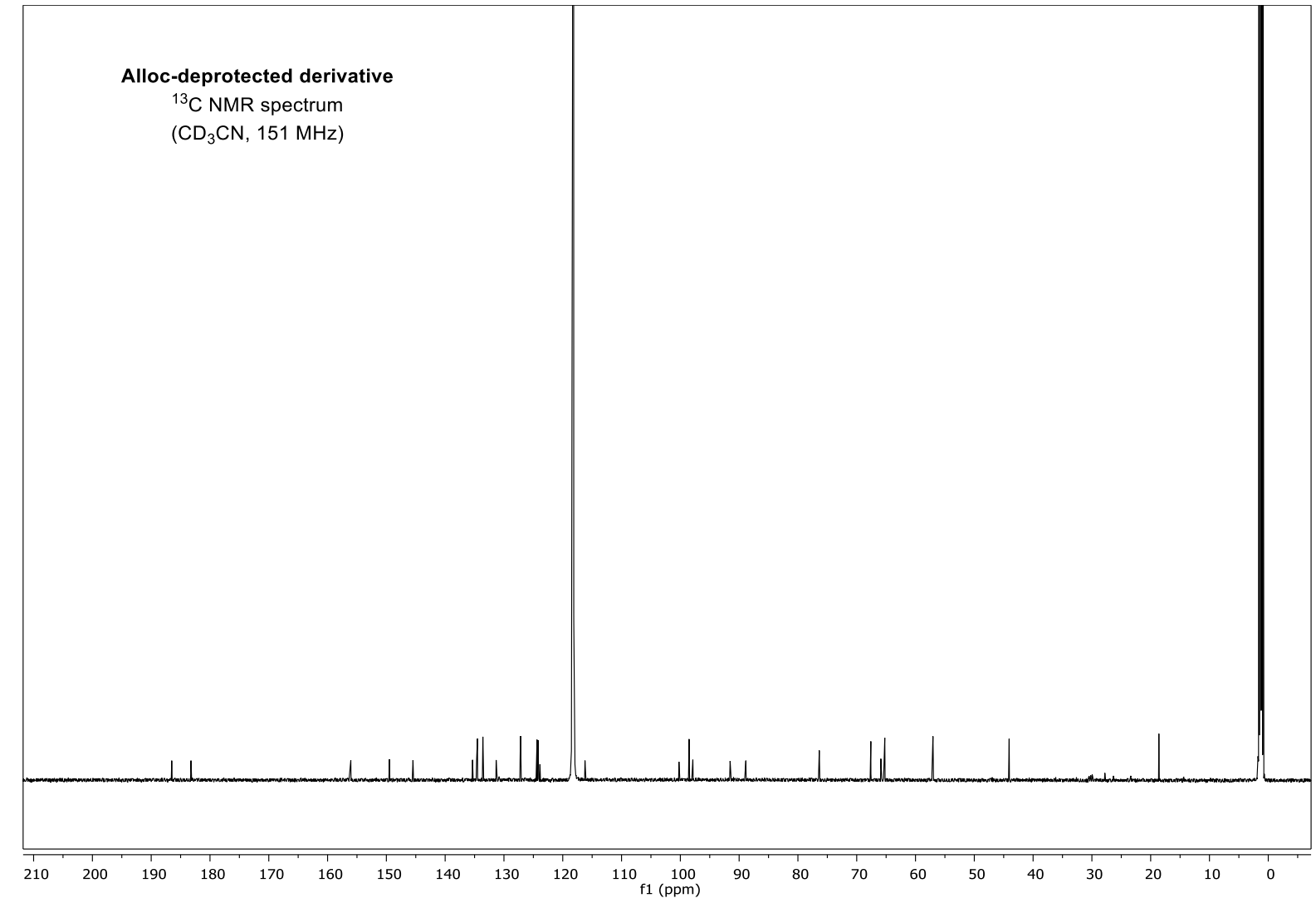




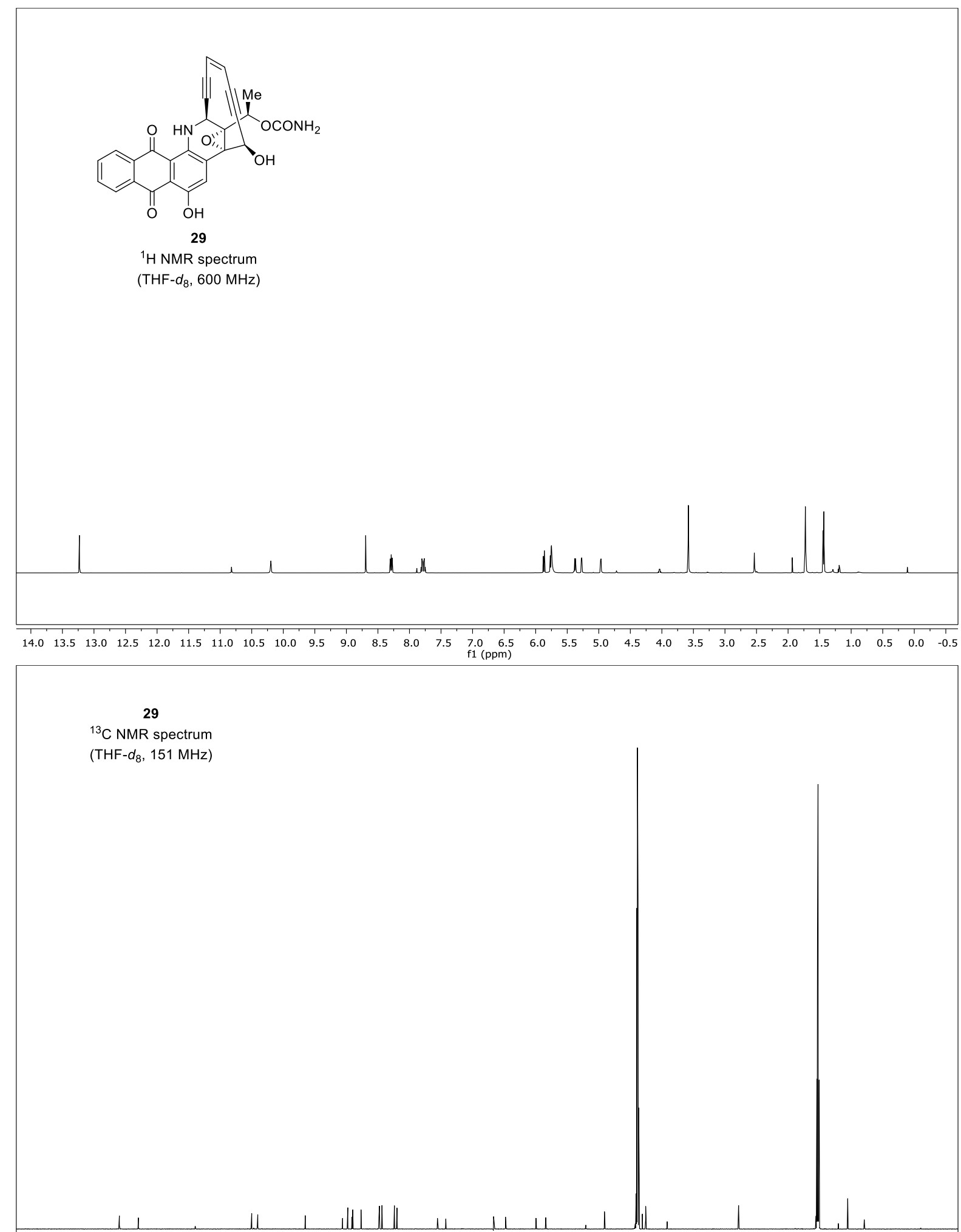

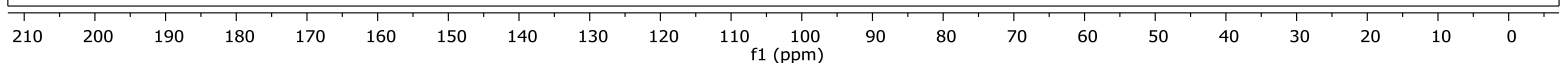




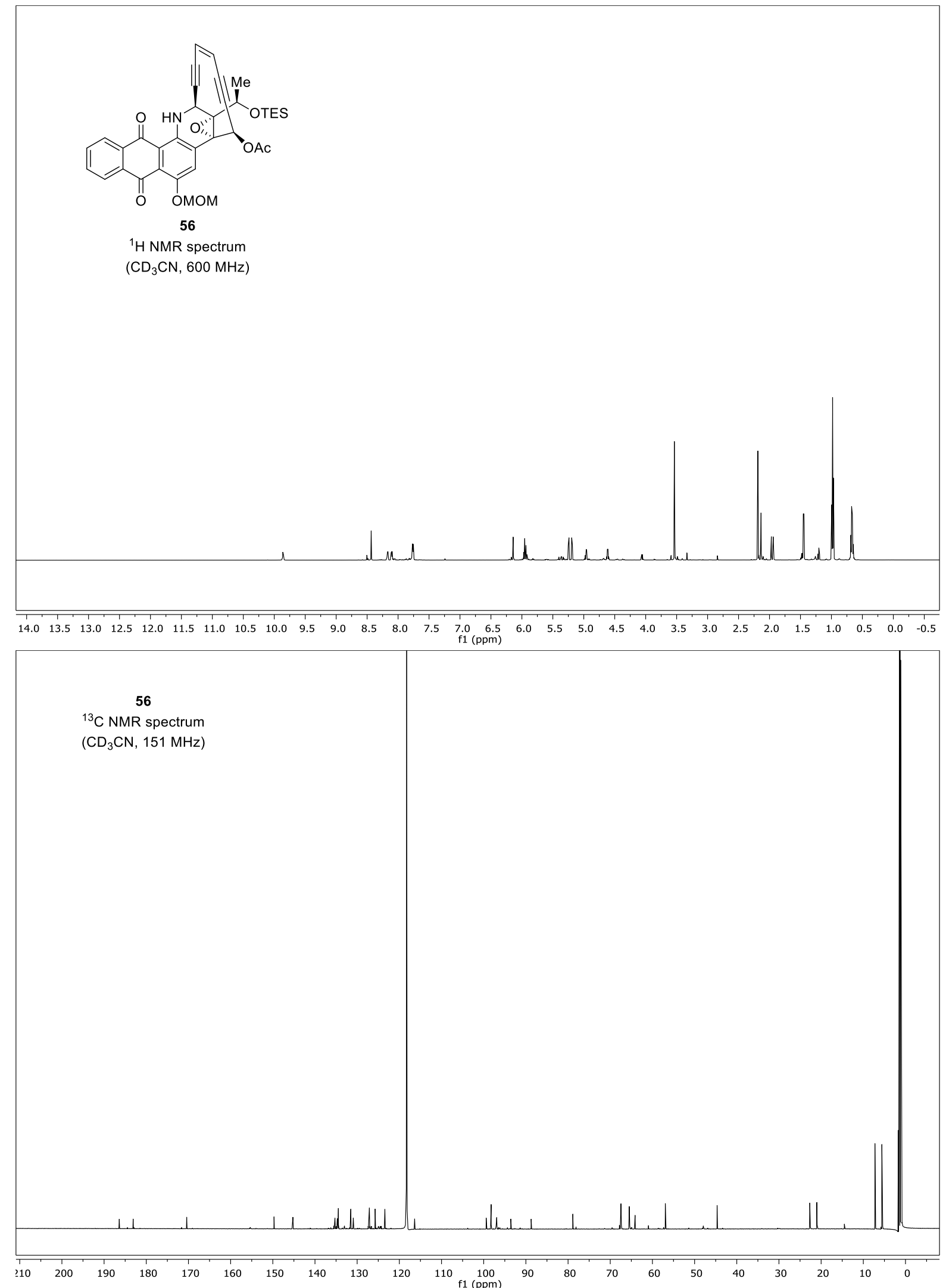




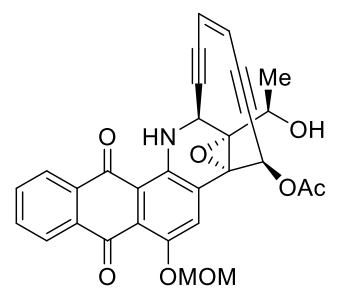

hydroxyl-ketone derivative

${ }^{1} \mathrm{H}$ NMR spectrum

$\left(\mathrm{CD}_{3} \mathrm{CN}, 600 \mathrm{MHz}\right)$

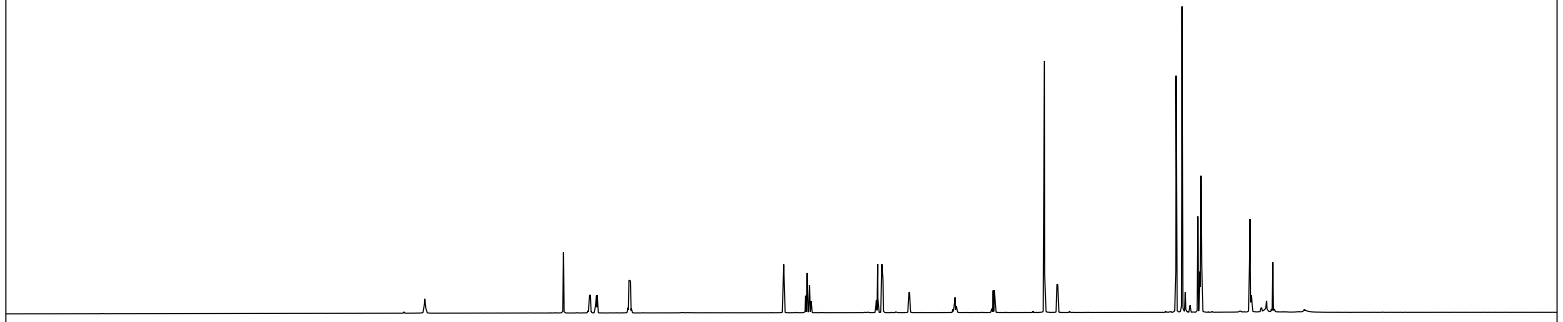

\begin{tabular}{|c|c|c|c|c|c|c|c|c|c|c|c|c|c|c|c|}
\hline 14 & 13 & 12 & 11 & 10 & 9 & 8 & 7 & $\begin{array}{c}6 \\
f 1(\mathrm{ppm})\end{array}$ & 5 & 4 & 3 & 2 & 1 & 0 & -1 \\
\hline
\end{tabular}

hydroxyl-ketone derivative

${ }^{13} \mathrm{C}$ NMR spectrum

$\left(\mathrm{CD}_{3} \mathrm{CN}, 151 \mathrm{MHz}\right)$
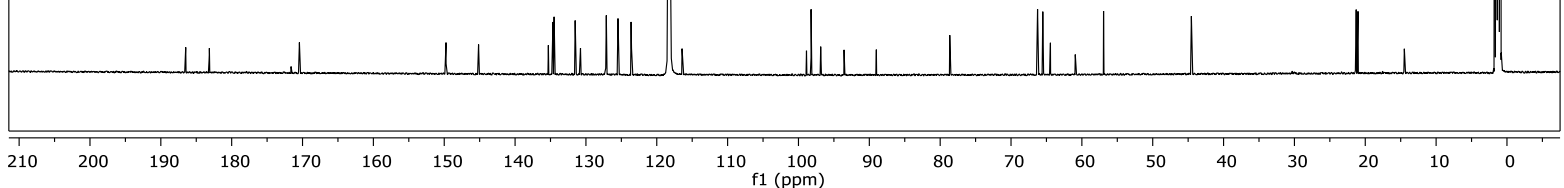

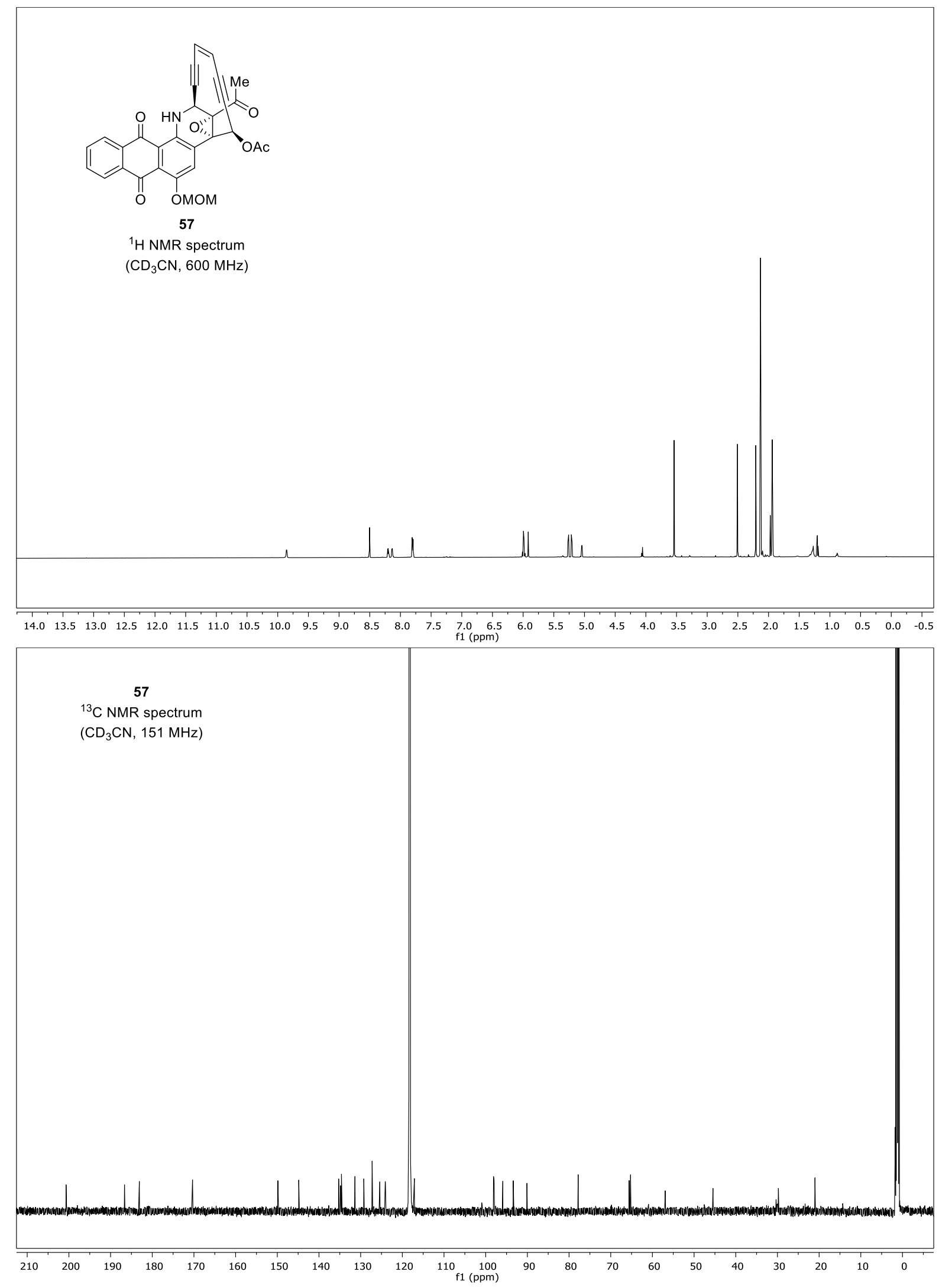

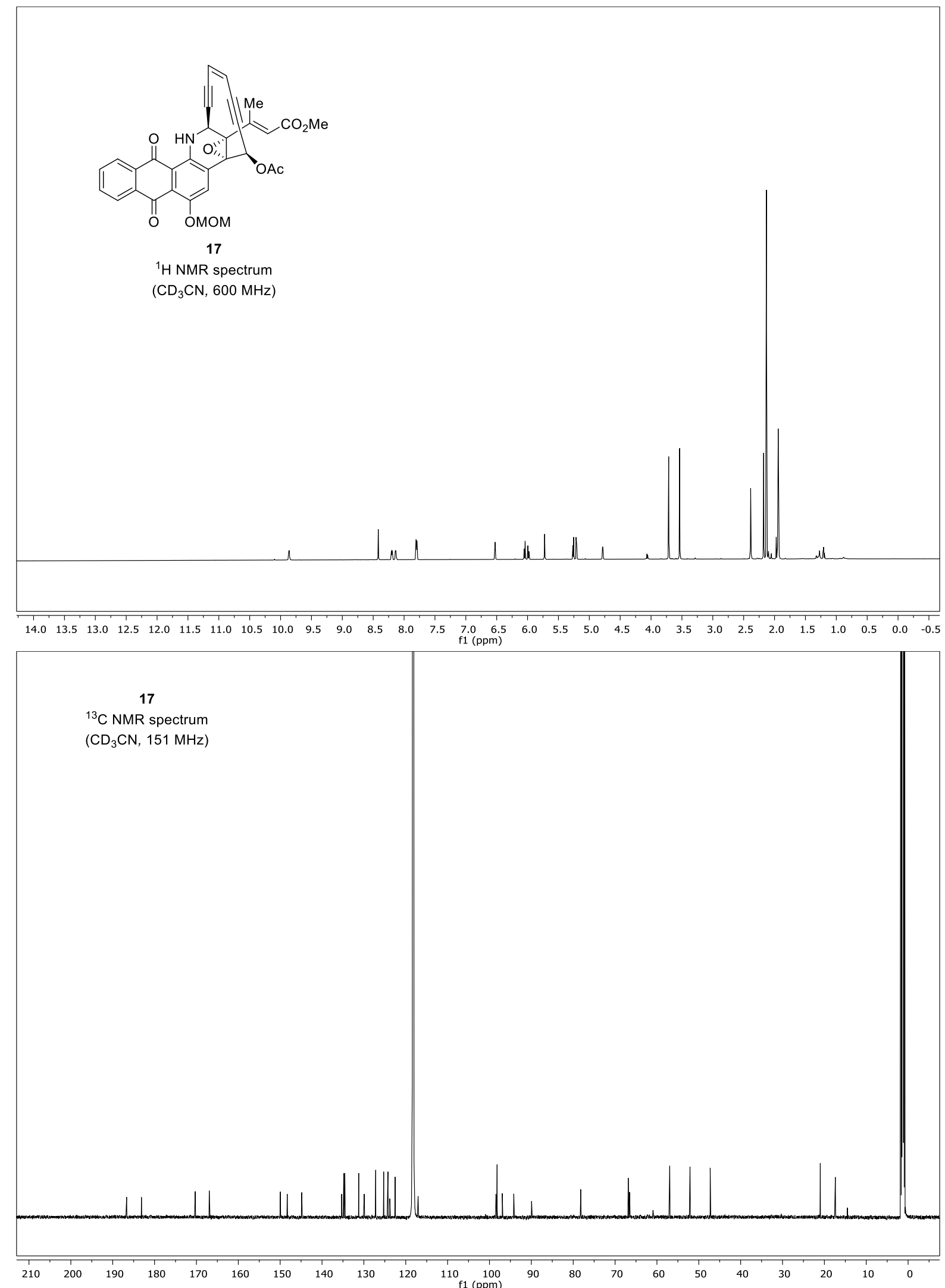


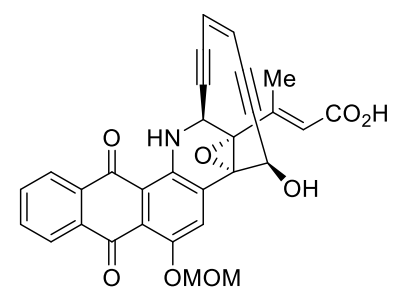

18

${ }^{1} \mathrm{H}$ NMR spectrum

$\left(\mathrm{CD}_{3} \mathrm{CN}, 600 \mathrm{MHz}\right)$

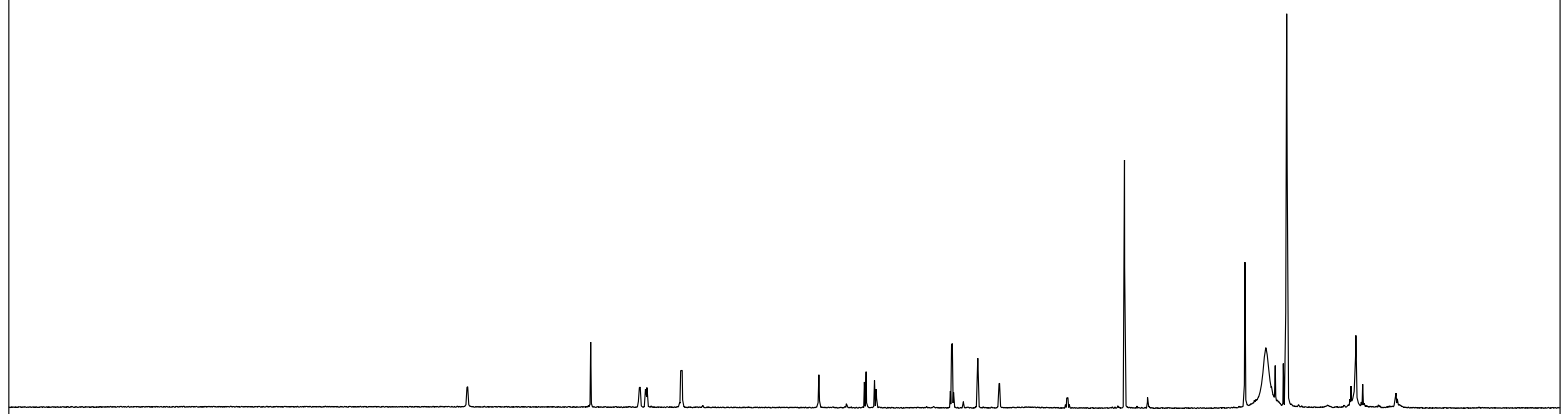

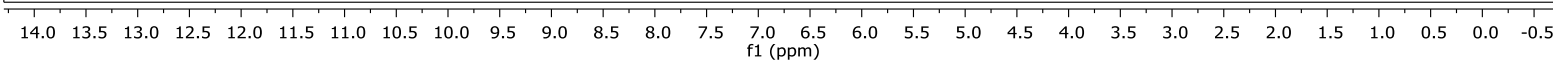

18

${ }^{13} \mathrm{C}$ NMR spectrum

$\left(\mathrm{CD}_{3} \mathrm{CN}, 151 \mathrm{MHz}\right)$

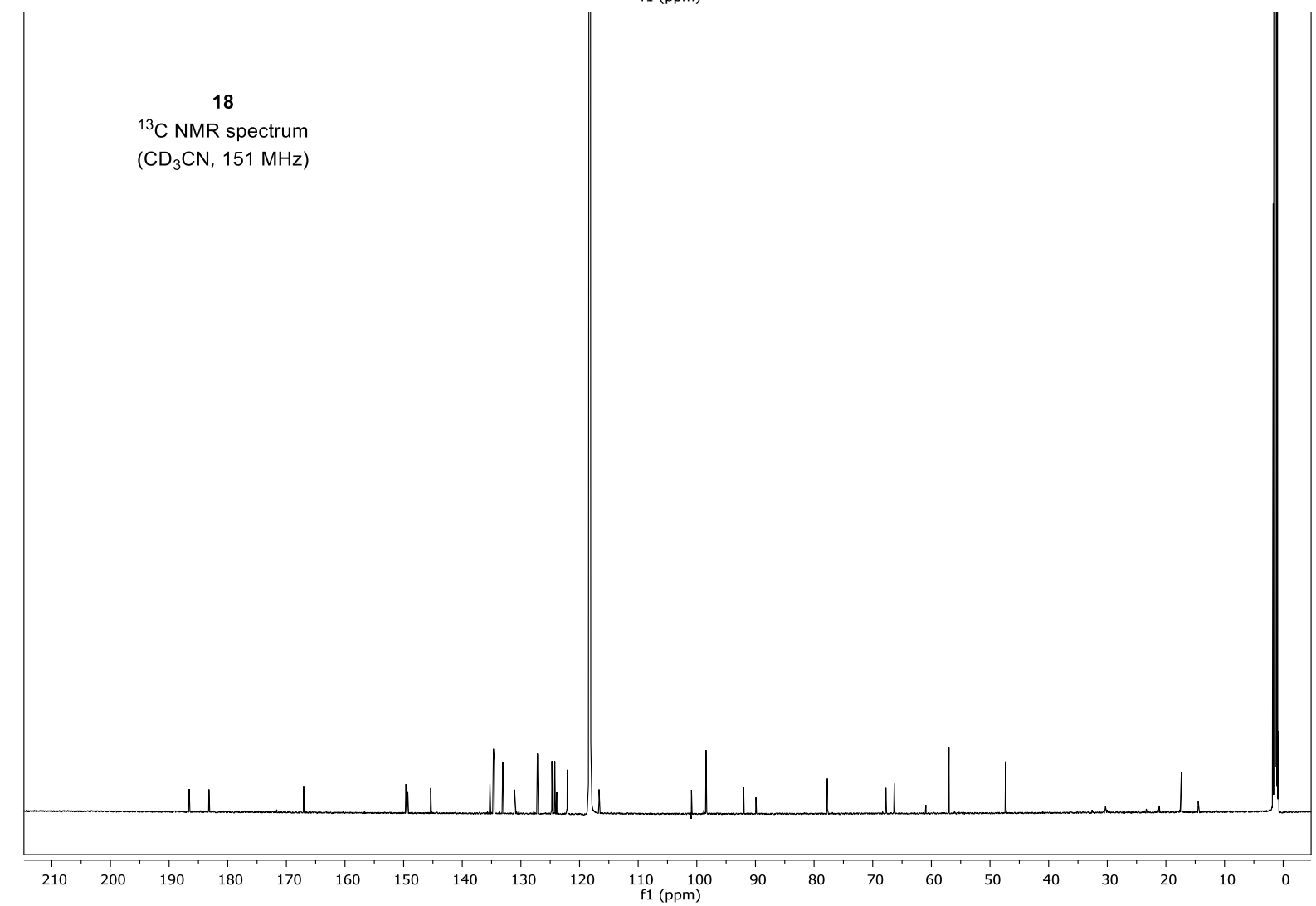

(




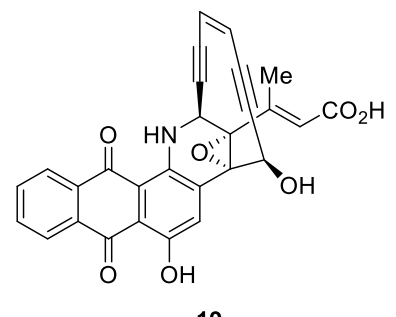

19

${ }^{1} \mathrm{H}$ NMR spectrum

$\left(\mathrm{CD}_{3} \mathrm{CN}, 600 \mathrm{MHz}\right)$

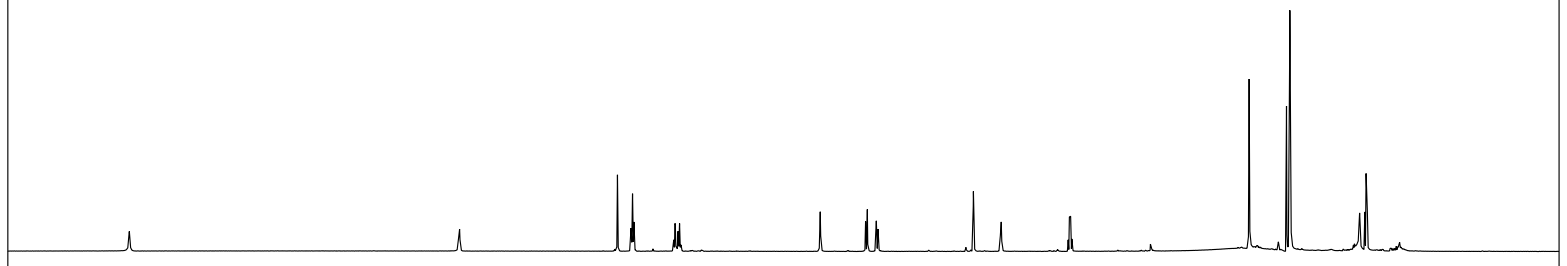

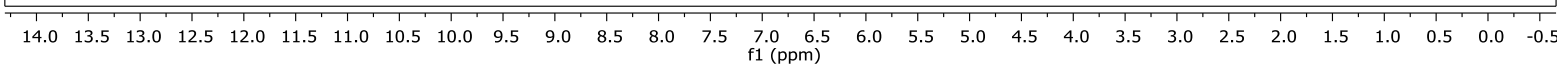

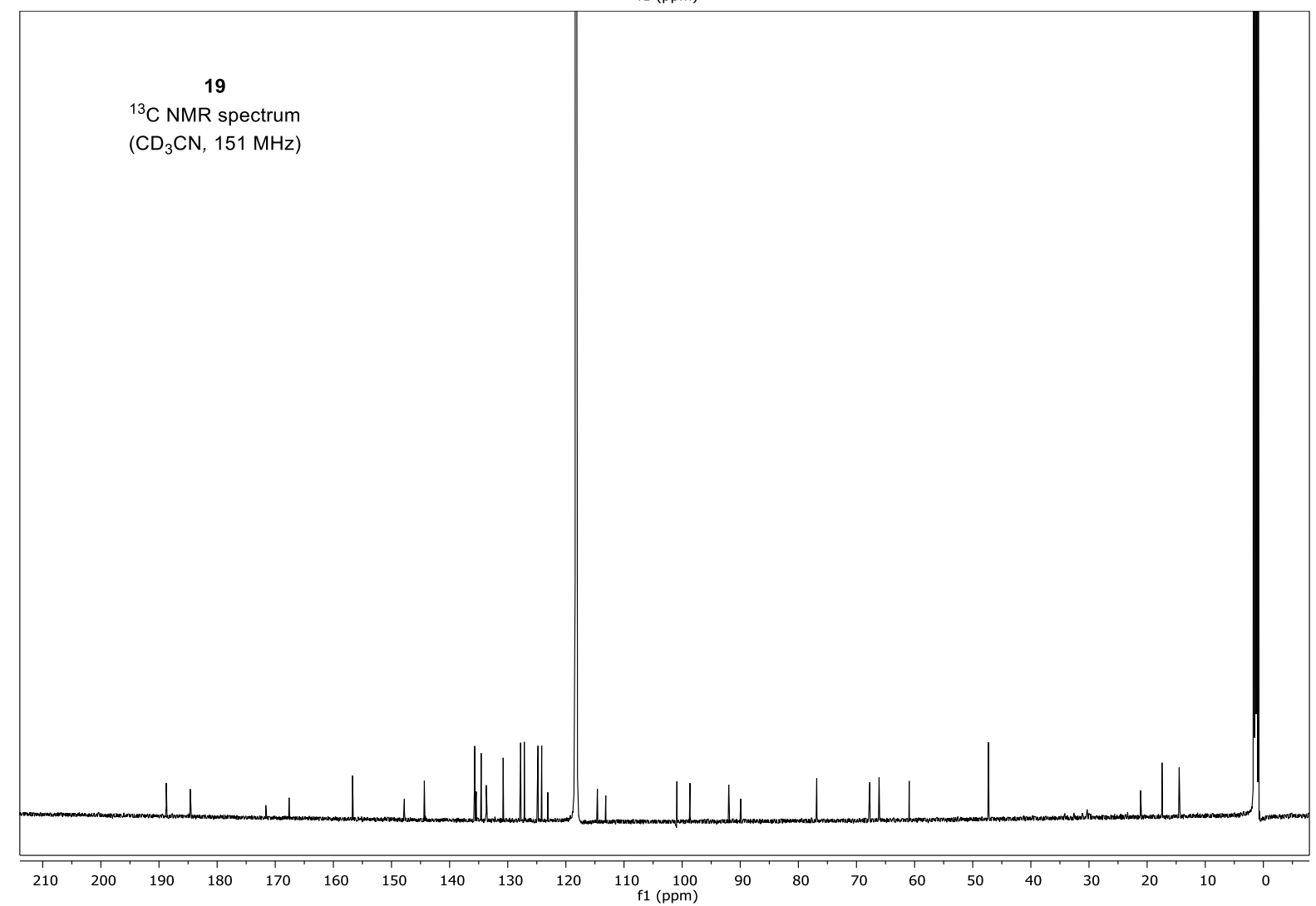



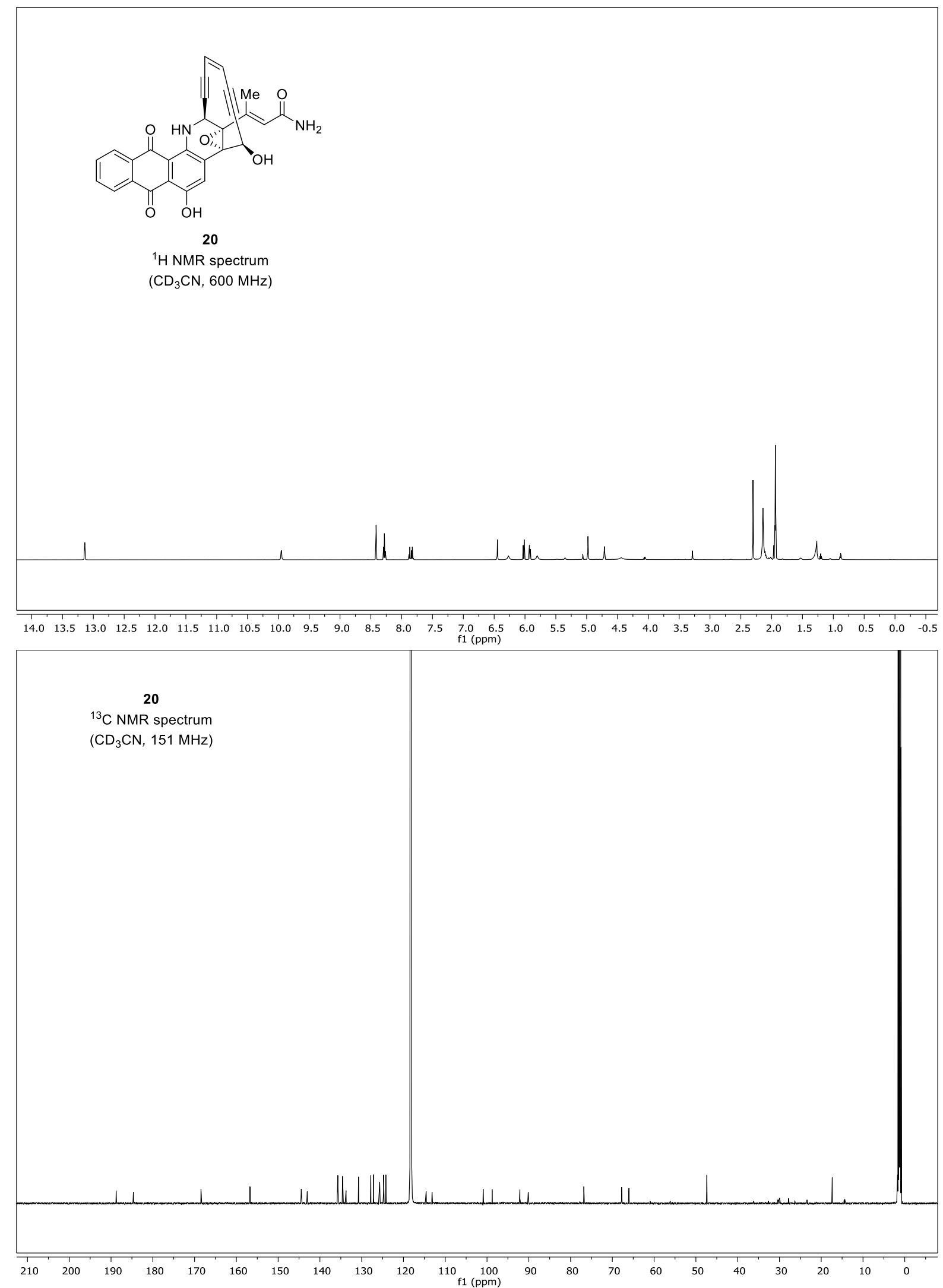

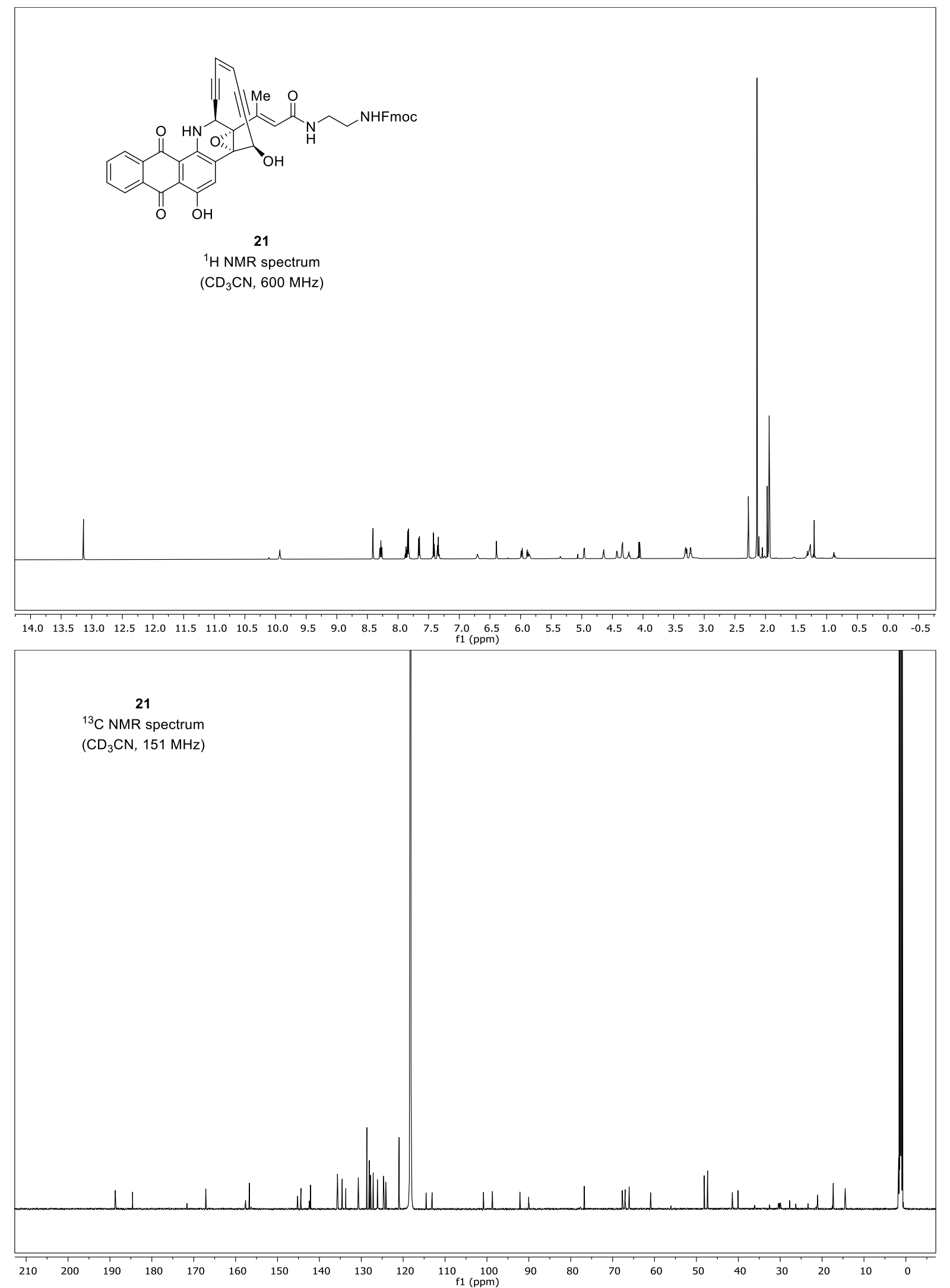

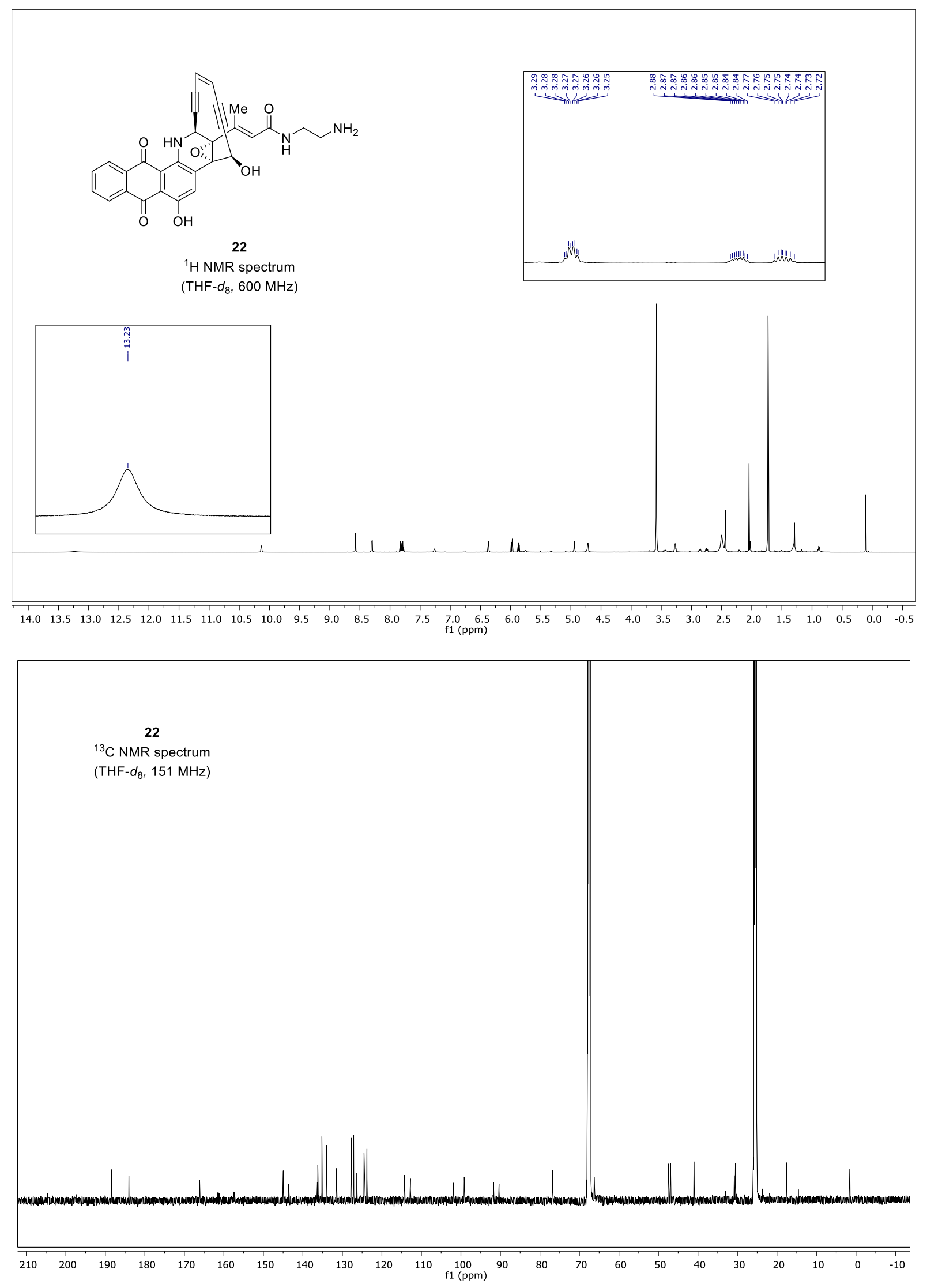


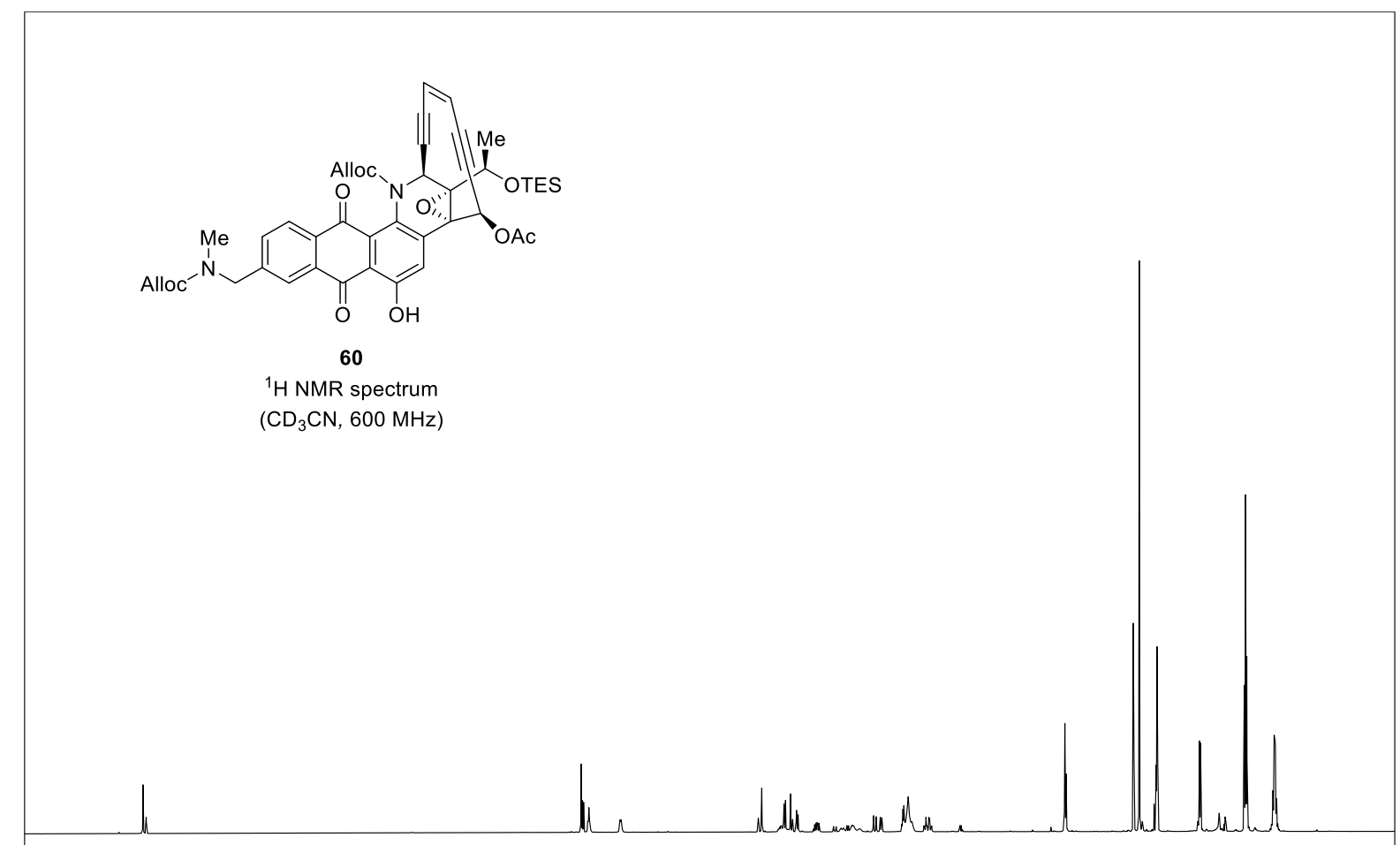

\begin{tabular}{llllllllllllllllllllllllllllllllllll}
\hline \hline 14.0 & 13.5 & 13.0 & 12.5 & 12.0 & 11.5 & 11.0 & 10.5 & 10.0 & 9.5 & 9.0 & 8.5 & 8.0 & 7.5 & 7.0 & 6.5 & 6.0 & 5.5 & 5.0 & 4.5 & 4.0 & 3.5 & 3.0 & 2.5 & 2.0 & 1.5 & 1.0 & 0.5 & 0.0 & -0.1
\end{tabular}

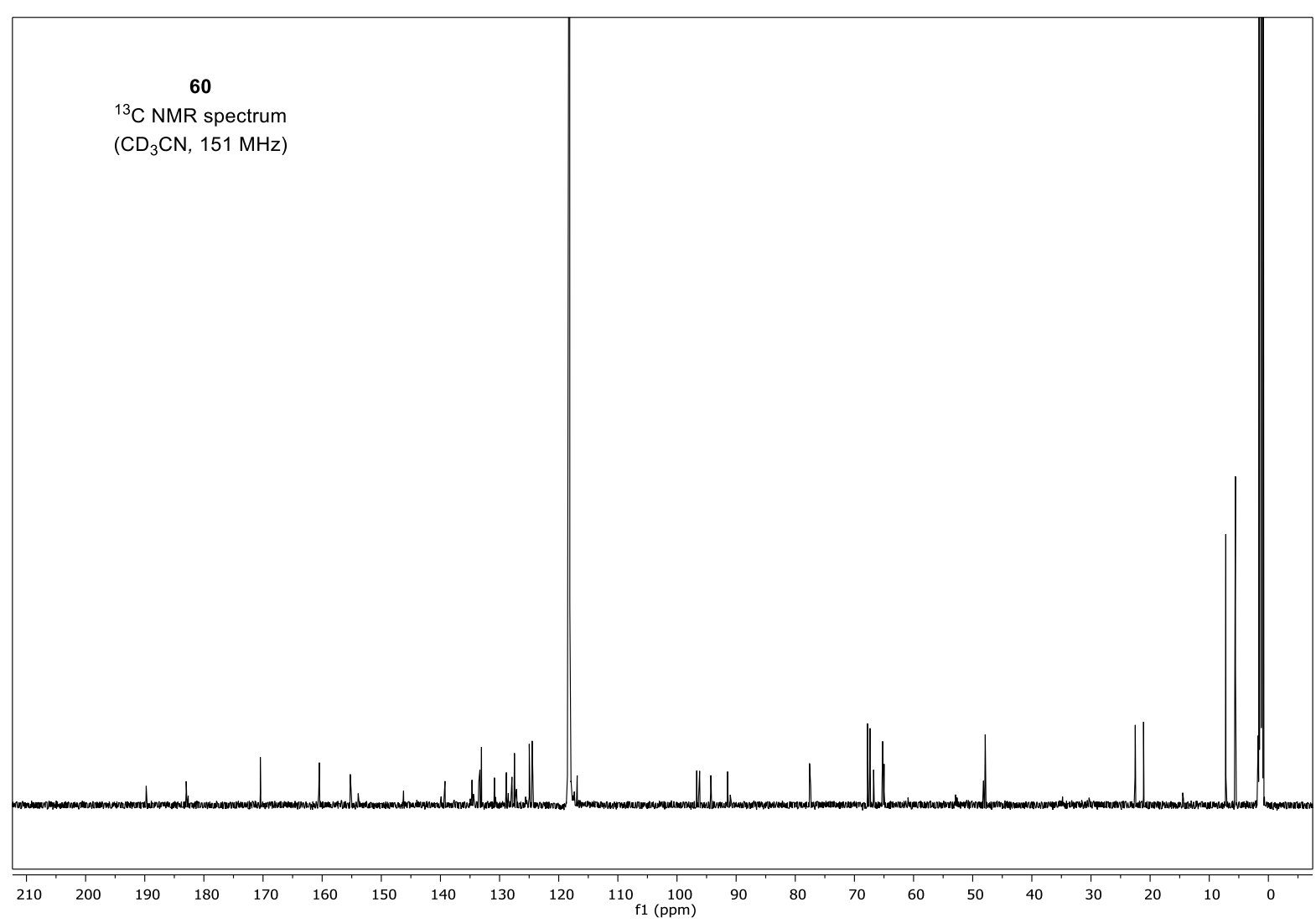




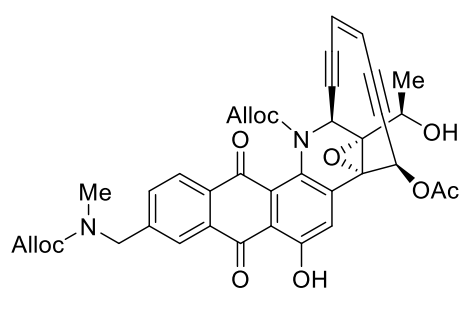

61

${ }^{1} \mathrm{H}$ NMR spectrum $\left(\mathrm{CD}_{3} \mathrm{CN}, 600 \mathrm{MHz}\right)$

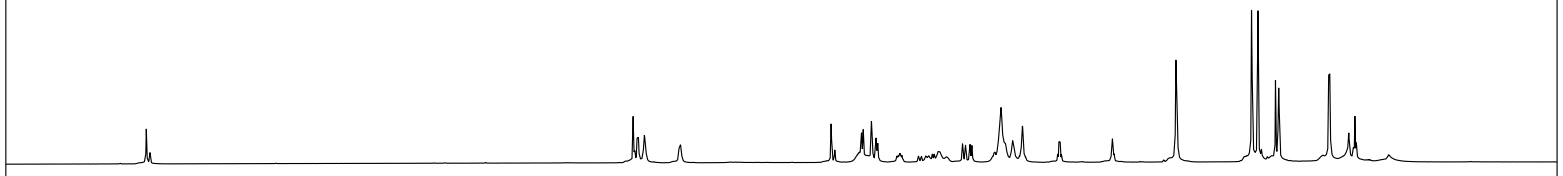
\begin{tabular}{lllllllllllllllllllllllllllllllllllll}
\hline \hline 14.0 & 13.5 & 13.0 & 12.5 & 12.0 & 11.5 & 11.0 & 10.5 & 10.0 & 9.5 & 9.0 & 8.5 & 8.0 & 7.5 & 7.0 & 6.5 & 6.0 & 5.5 & 5.0 & 4 & 4.5 & 4.0 & 3.5 & 3.0 & 2.5 & 2.0 & 1.5 & 1.0 & 0.5 & 0.0 & -0.5 \\
\hline
\end{tabular}

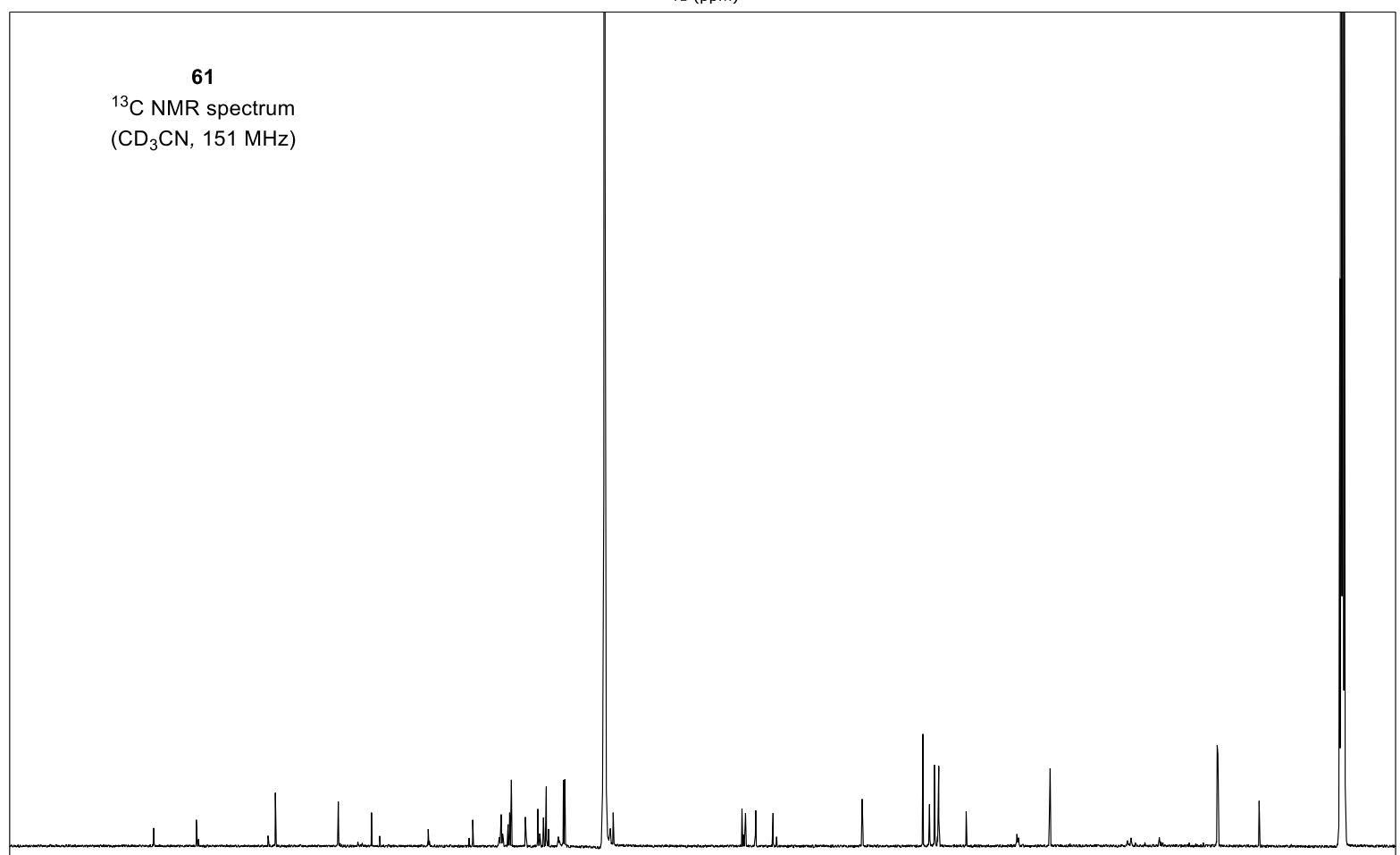

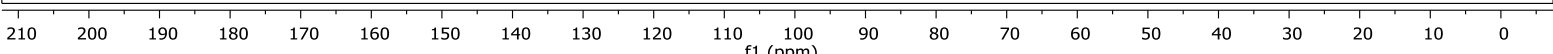




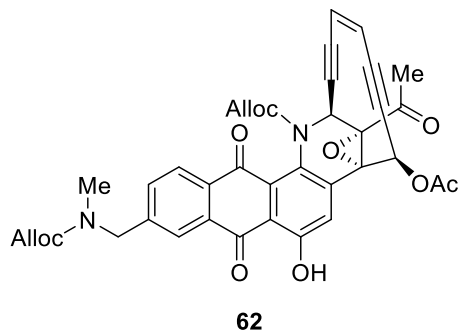

${ }^{1} \mathrm{H}$ NMR spectrum $\left(\mathrm{CD}_{3} \mathrm{CN}, 600 \mathrm{MHz}\right)$
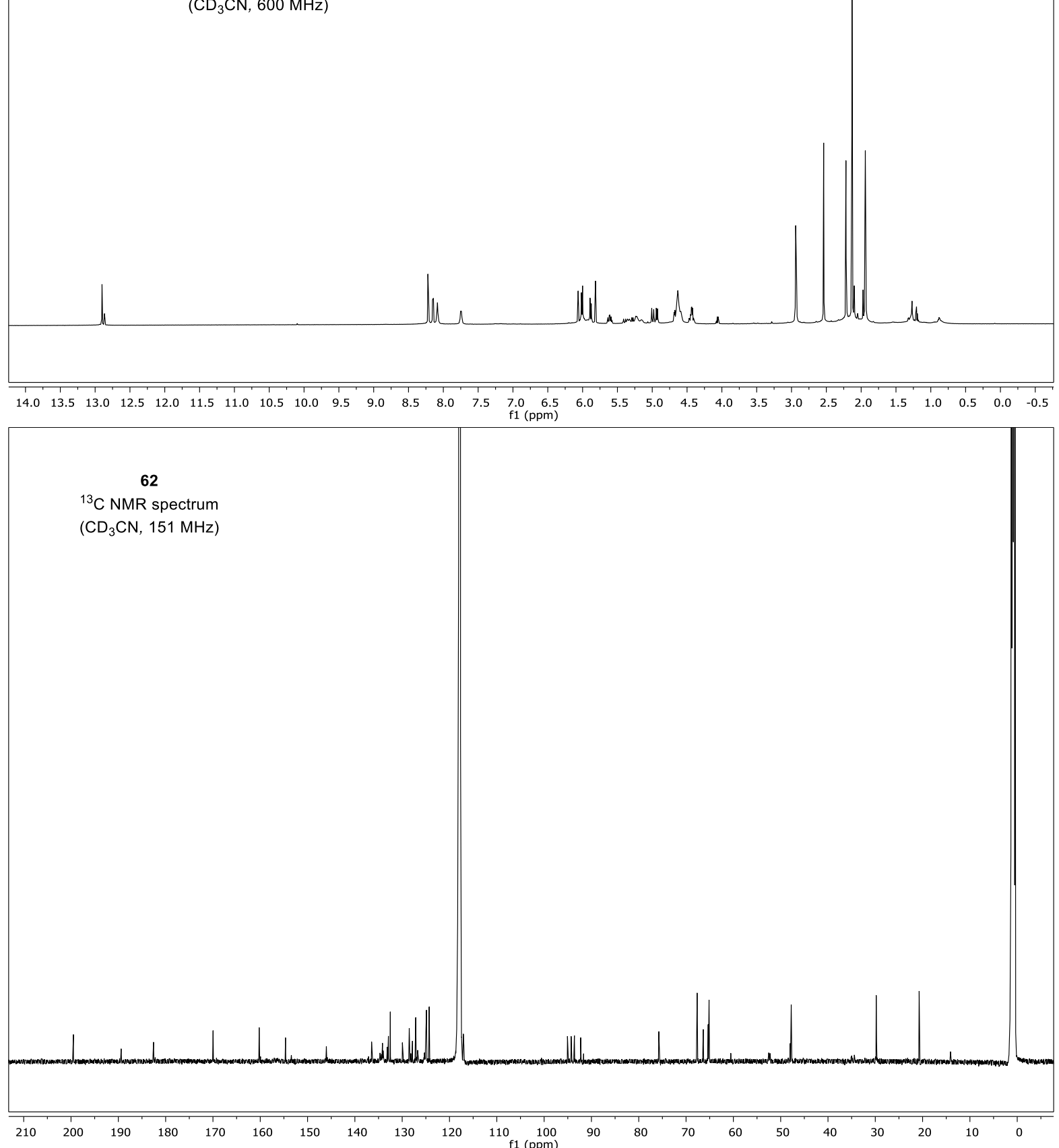

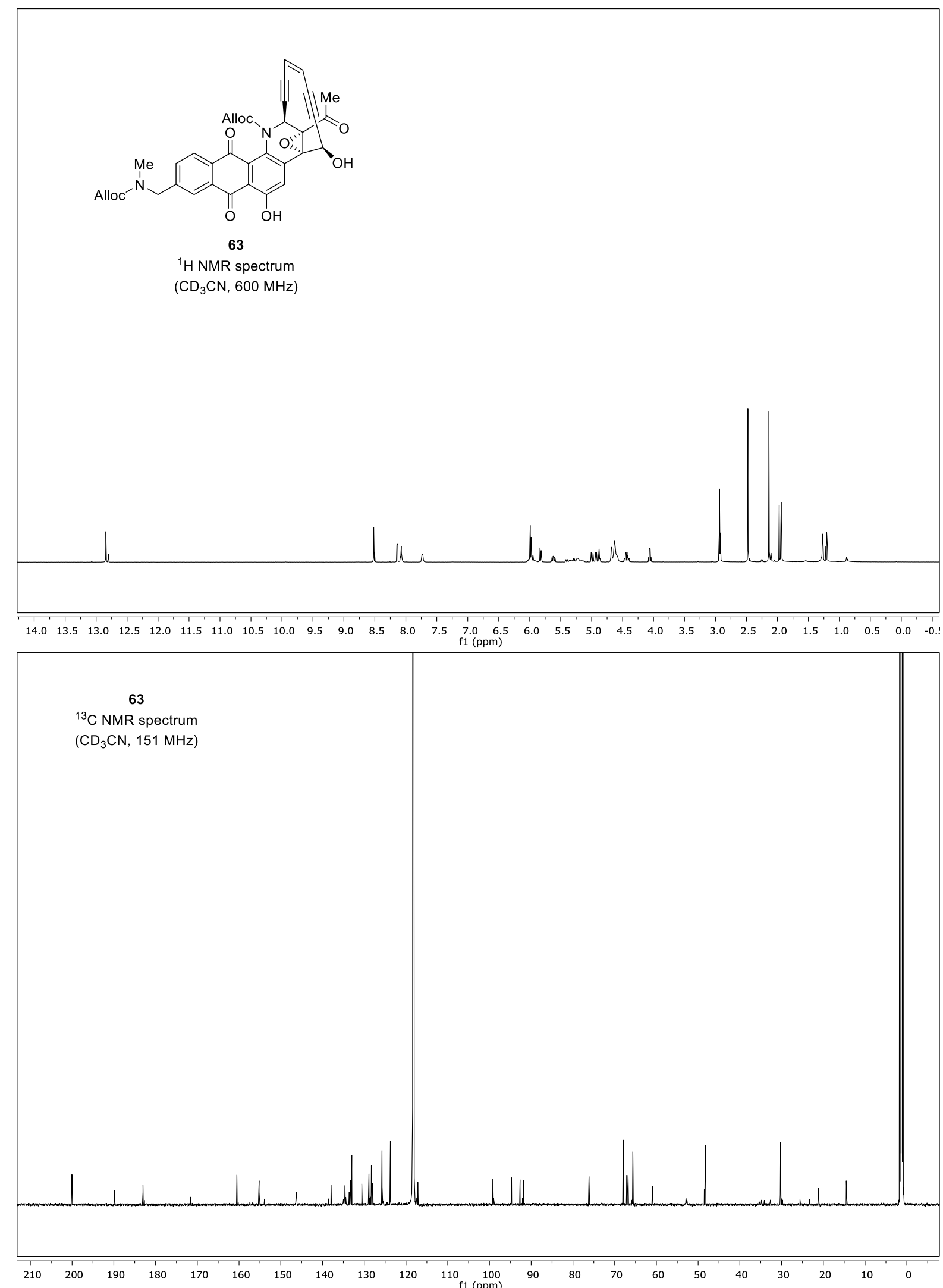


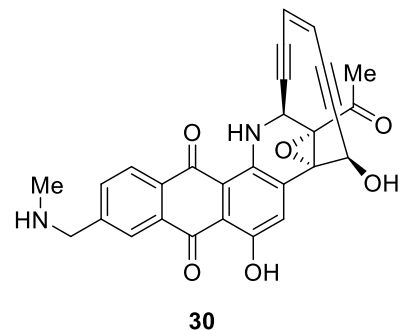

${ }^{1} \mathrm{H}$ NMR spectrum

$\left(\mathrm{CD}_{3} \mathrm{CN}, 600 \mathrm{MHz}\right)$

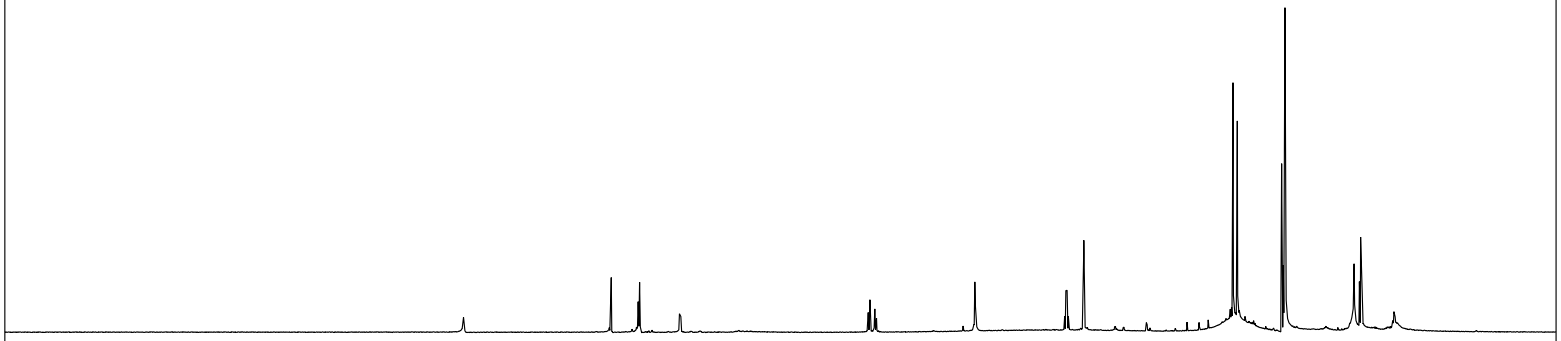

$\begin{array}{llllllllllllllllllllllllllllllll}14.0 & 13.5 & 13.0 & 12.5 & 12.0 & 11.5 & 11.0 & 10.5 & 10.0 & 9.5 & 9.0 & 8.5 & 8.0 & 7.5 & \begin{array}{c}7.0 \\ \mathrm{f}(\mathrm{ppm})\end{array} & 6.0 & 5.5 & 5.0 & 4.5 & 4.0 & 3.5 & 3.0 & 2.5 & 2.0 & 1.5 & 1.0 & 0.5 & 0.0 & -0.5\end{array}$

30

${ }^{13} \mathrm{C}$ NMR spectrum

$\left(\mathrm{CD}_{3} \mathrm{CN}, 151 \mathrm{MHz}\right)$
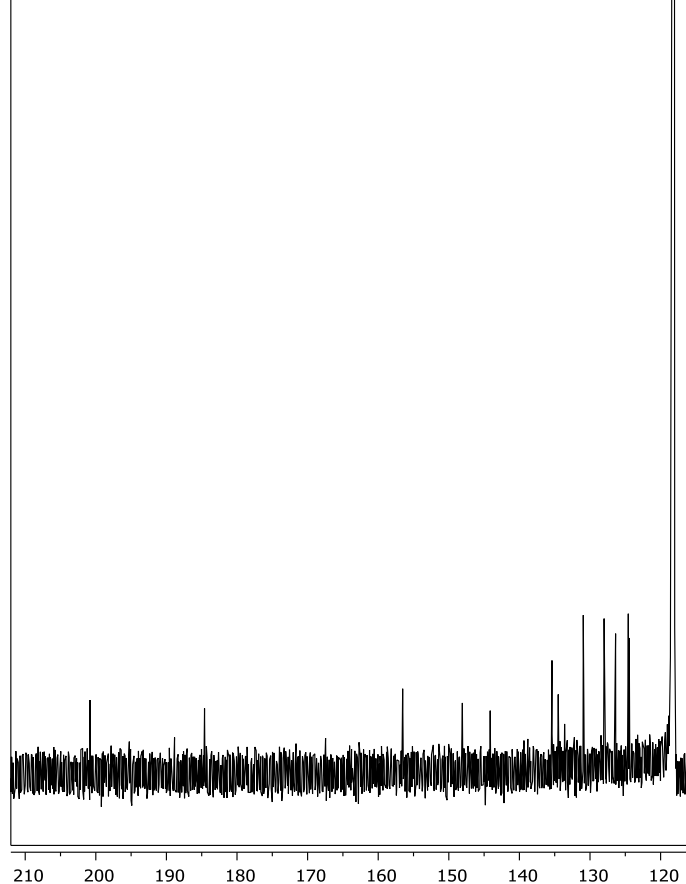

$110 \begin{array}{r}100 \\ \text { f1 }(\mathrm{ppm})\end{array}$ 


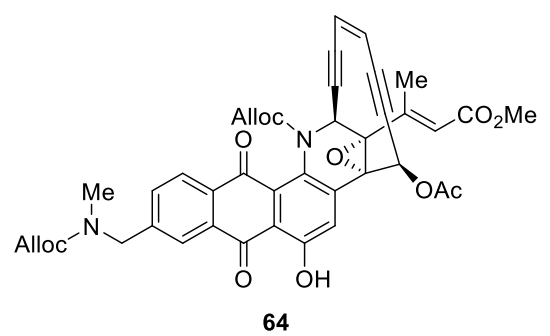

${ }^{1} \mathrm{H}$ NMR spectrum

$\left(\mathrm{CD}_{3} \mathrm{CN}, 600 \mathrm{MHz}\right)$

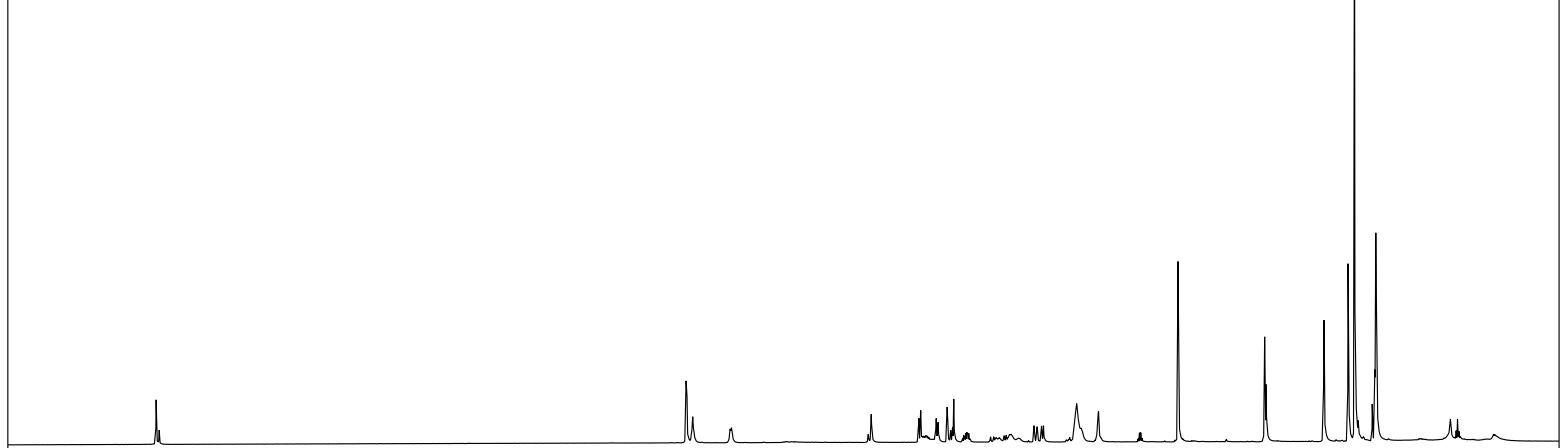

\begin{tabular}{lllllllllllllllllllllllllllllllllllllllllll}
\hline \hline & 14.0 & 13.5 & 13.0 & 12.5 & 12.0 & 11.5 & 11.0 & 10.5 & 10.0 & 9.5 & 9.0 & 8.5 & 8.0 & 7.5 & 7.0 & 6.5 & 6.0 & 5.5 & 5.0 & 4.5 & 4.0 & 3.5 & 3.0 & 2.5 & 2.0 & 1.5 & 1.0 & 0.5 \\
\hline
\end{tabular}

64

${ }^{13} \mathrm{C}$ NMR spectrum

$\left(\mathrm{CD}_{3} \mathrm{CN}, 151 \mathrm{MHz}\right)$

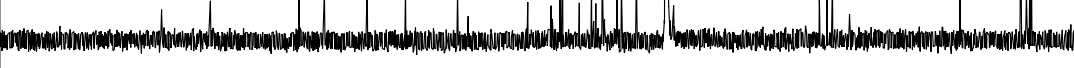

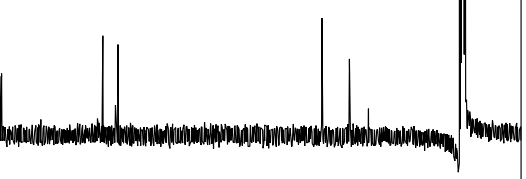

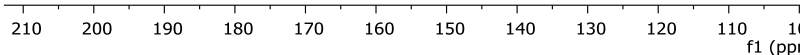




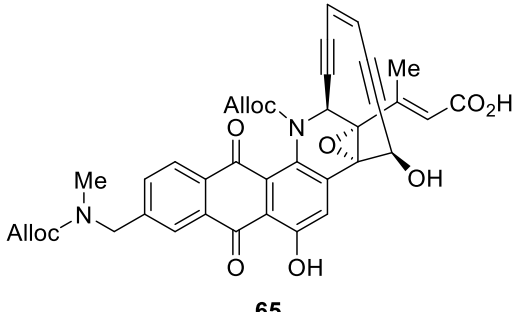

${ }^{1} \mathrm{H}$ NMR spectrum

$\left(\mathrm{CD}_{3} \mathrm{CN}, 600 \mathrm{MHz}\right)$

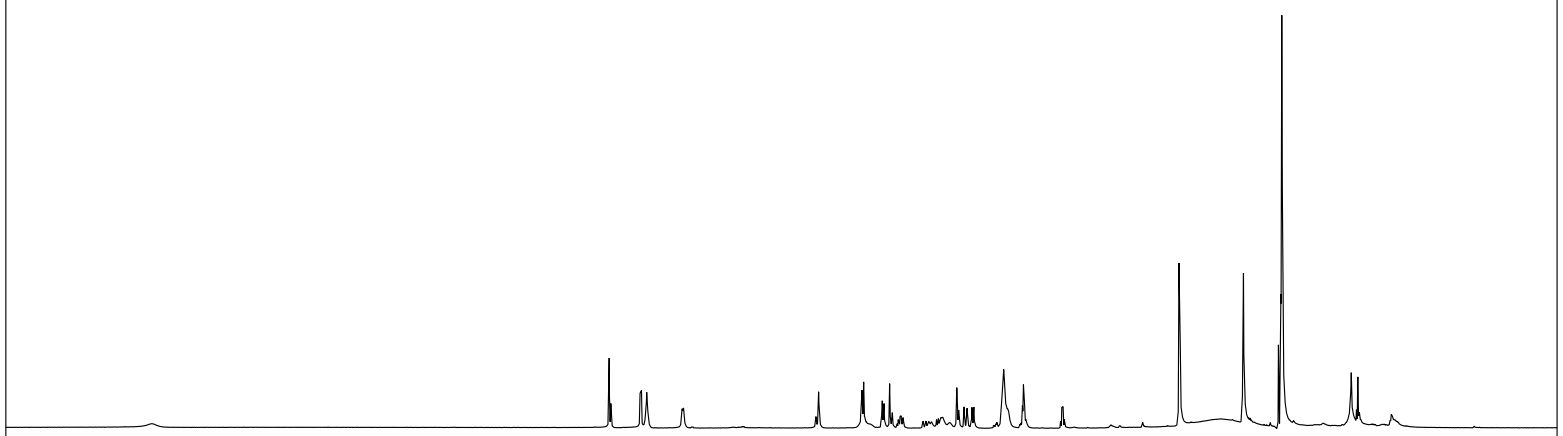

\begin{tabular}{llllllllllllllllllllllllllllllllllll}
\hline 14.0 & 13.5 & 13.0 & 12.5 & 12.0 & 11.5 & 11.0 & 10.5 & 10.0 & 9.5 & 9.0 & 8.5 & 8 & 7.0 & 7.5 & 7.0 & 6.5 & 6.0 & 5.5 & 5.0 & 4.5 & 4.0 & 3.5 & 3.0 & 2.5 & 2.0 & 1.5 & 1.0 & 0.5 & 0.0 & -0.5
\end{tabular}

65

${ }^{13} \mathrm{C}$ NMR spectrum $\left(\mathrm{CD}_{3} \mathrm{CN}, 151 \mathrm{MHz}\right)$

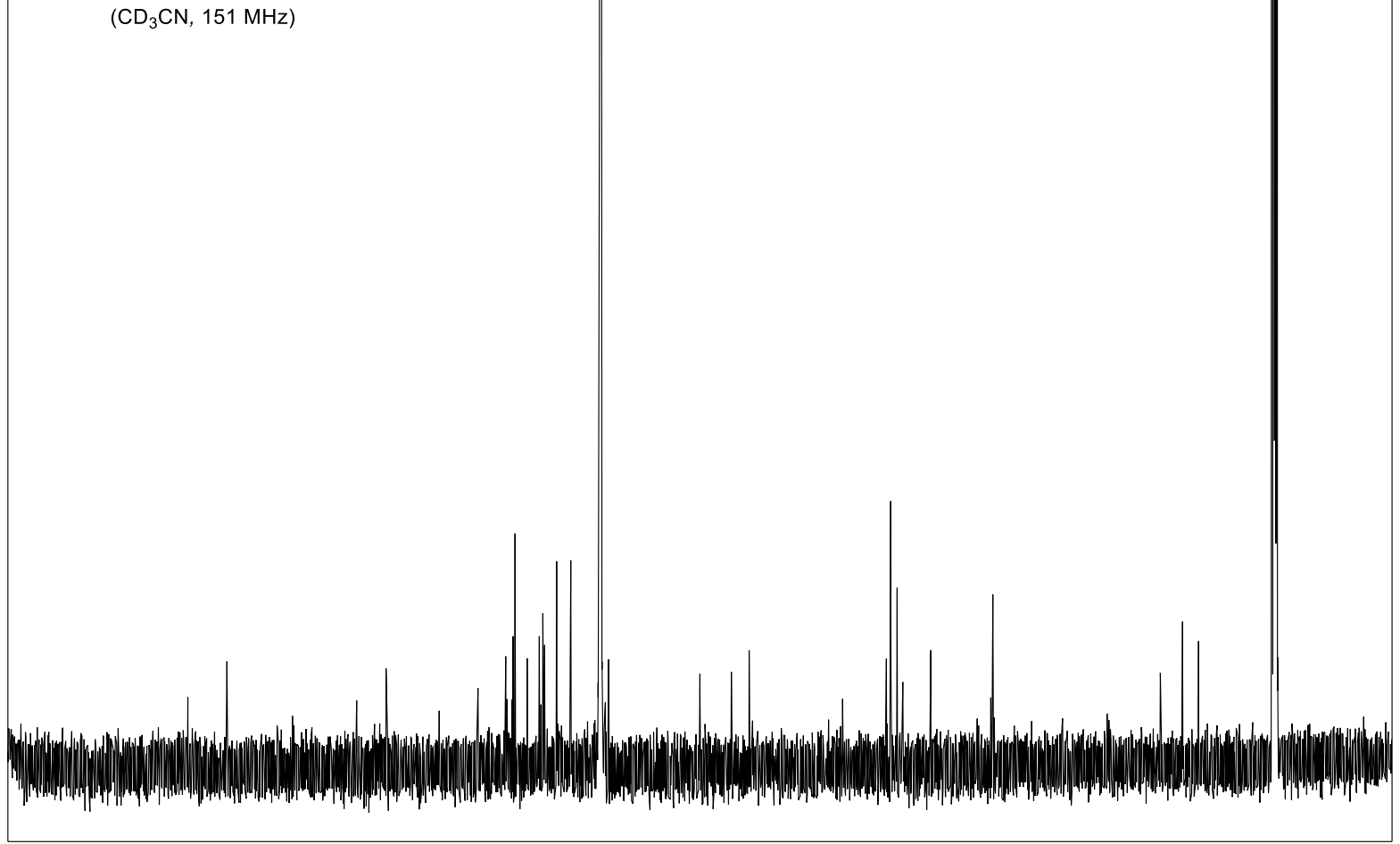




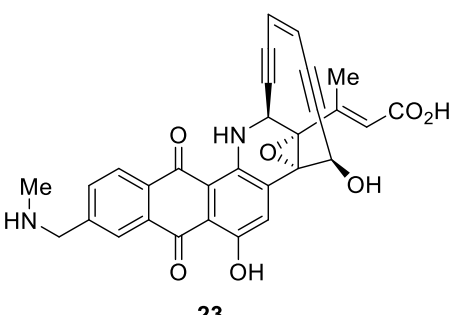

${ }^{1} \mathrm{H}$ NMR spectrum (DMSO-d 6 , $600 \mathrm{MHz}$ )

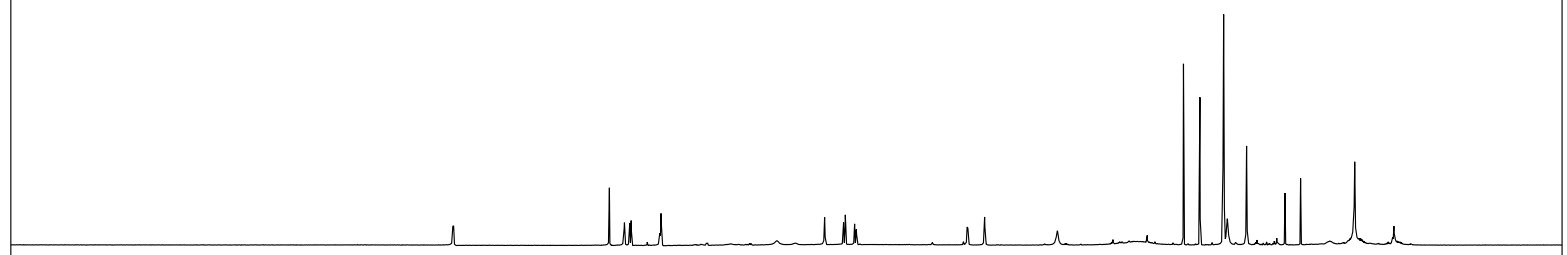

\begin{tabular}{rlllllllllllllllllllllllllllllllllll}
\hline 14.0 & 13.5 & 13.0 & 12.5 & 12.0 & 11.5 & 11.0 & 10.5 & 10.0 & 9.5 & 9.0 & 8.5 & 8.0 & 7.5 & 7.0 & 6.5 & 6.0 & 5.5 & 5.0 & 4.5 & 4.0 & 3.5 & 3.0 & 2.5 & 2.0 & 1.5 & 1.0 & 0.5 & 0.0 & -0.5
\end{tabular}

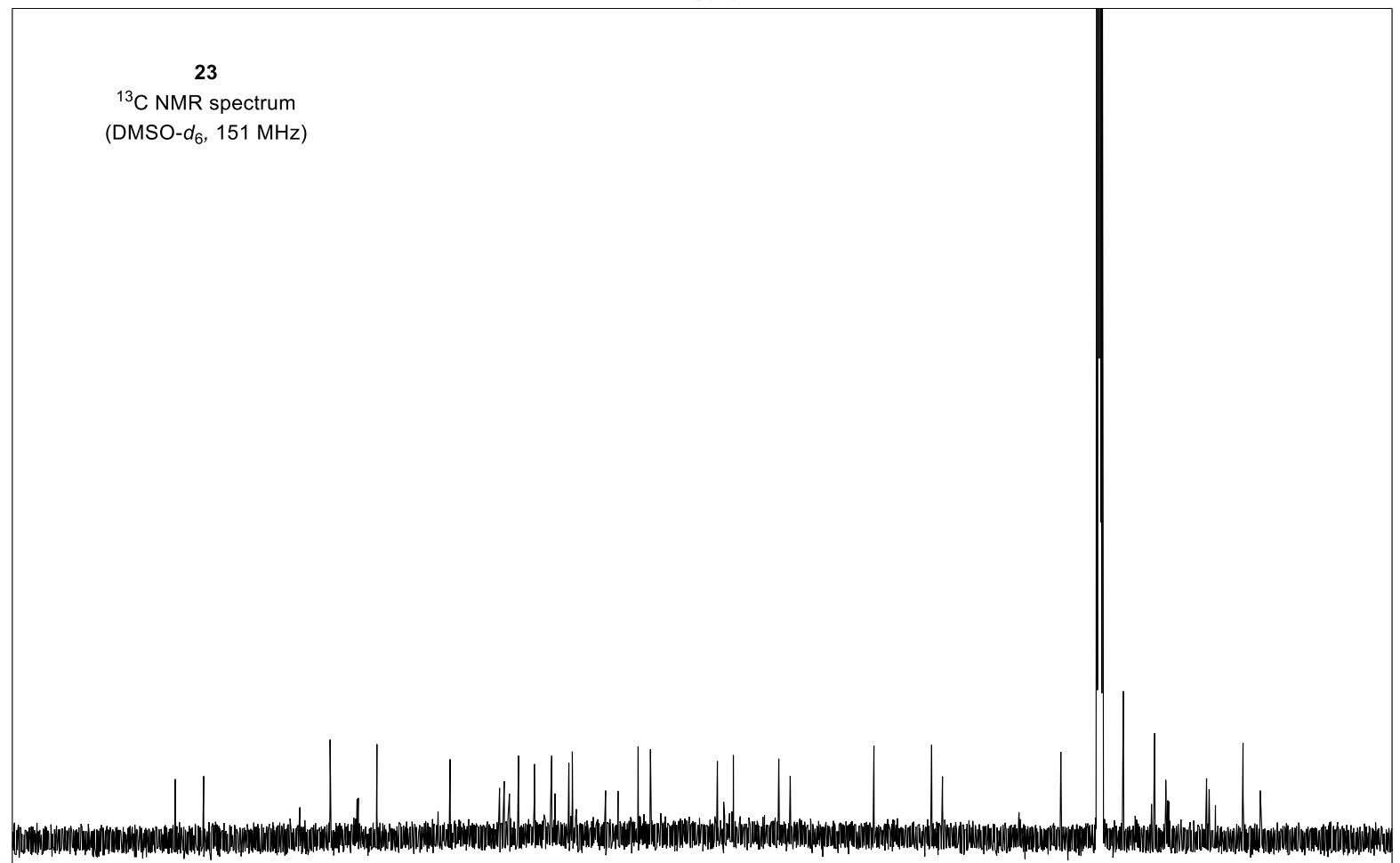

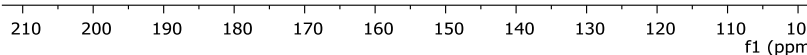



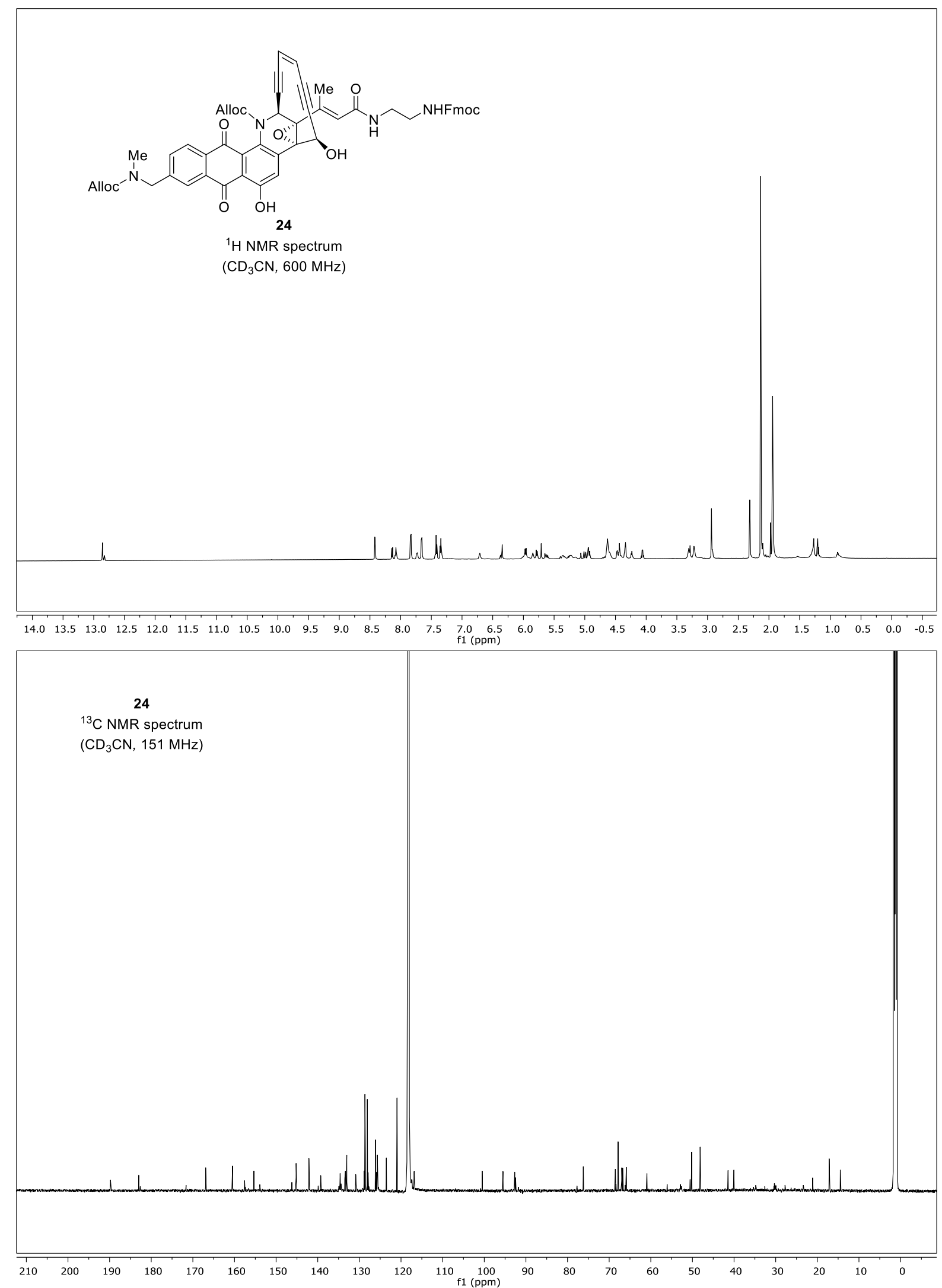

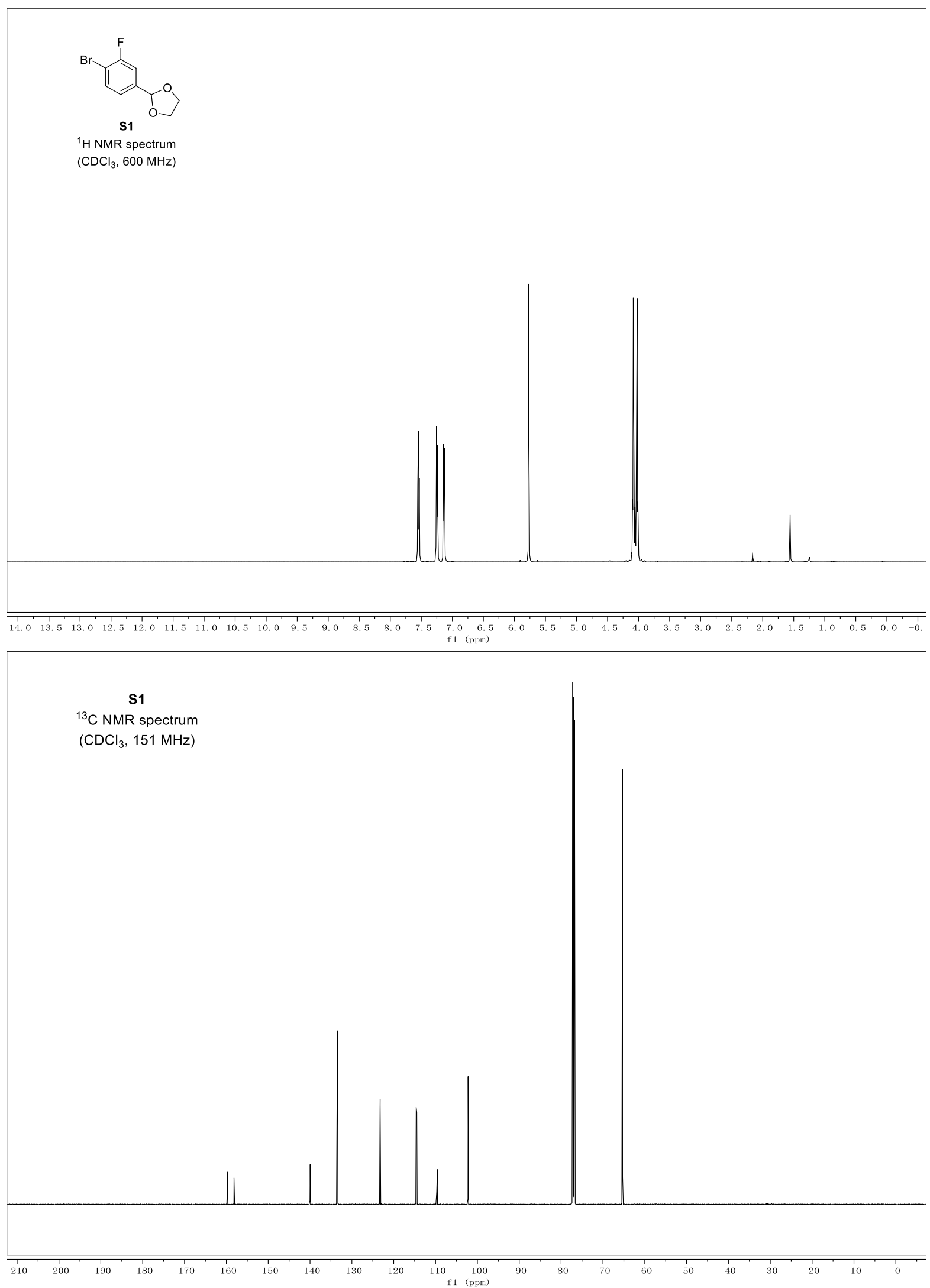


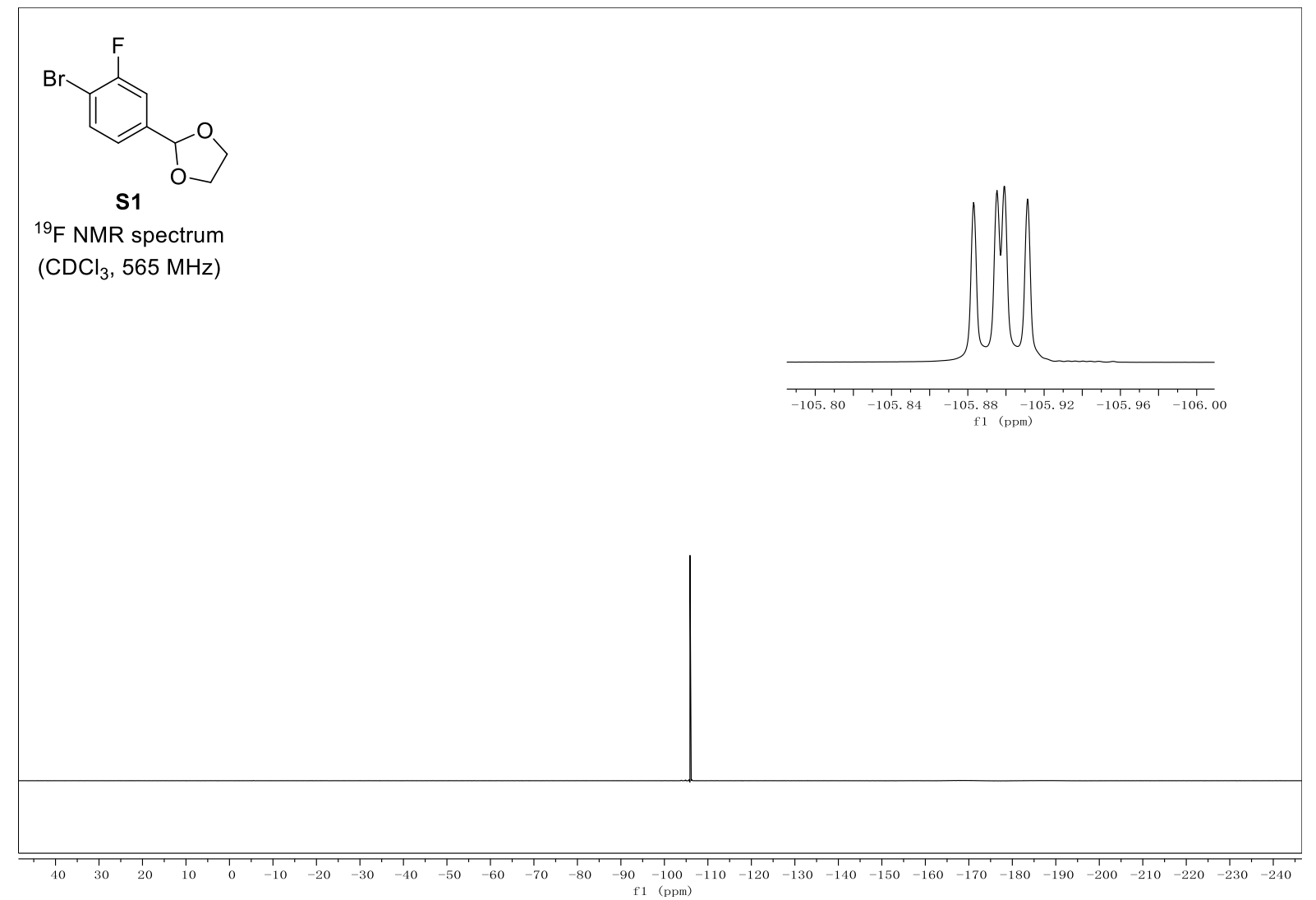




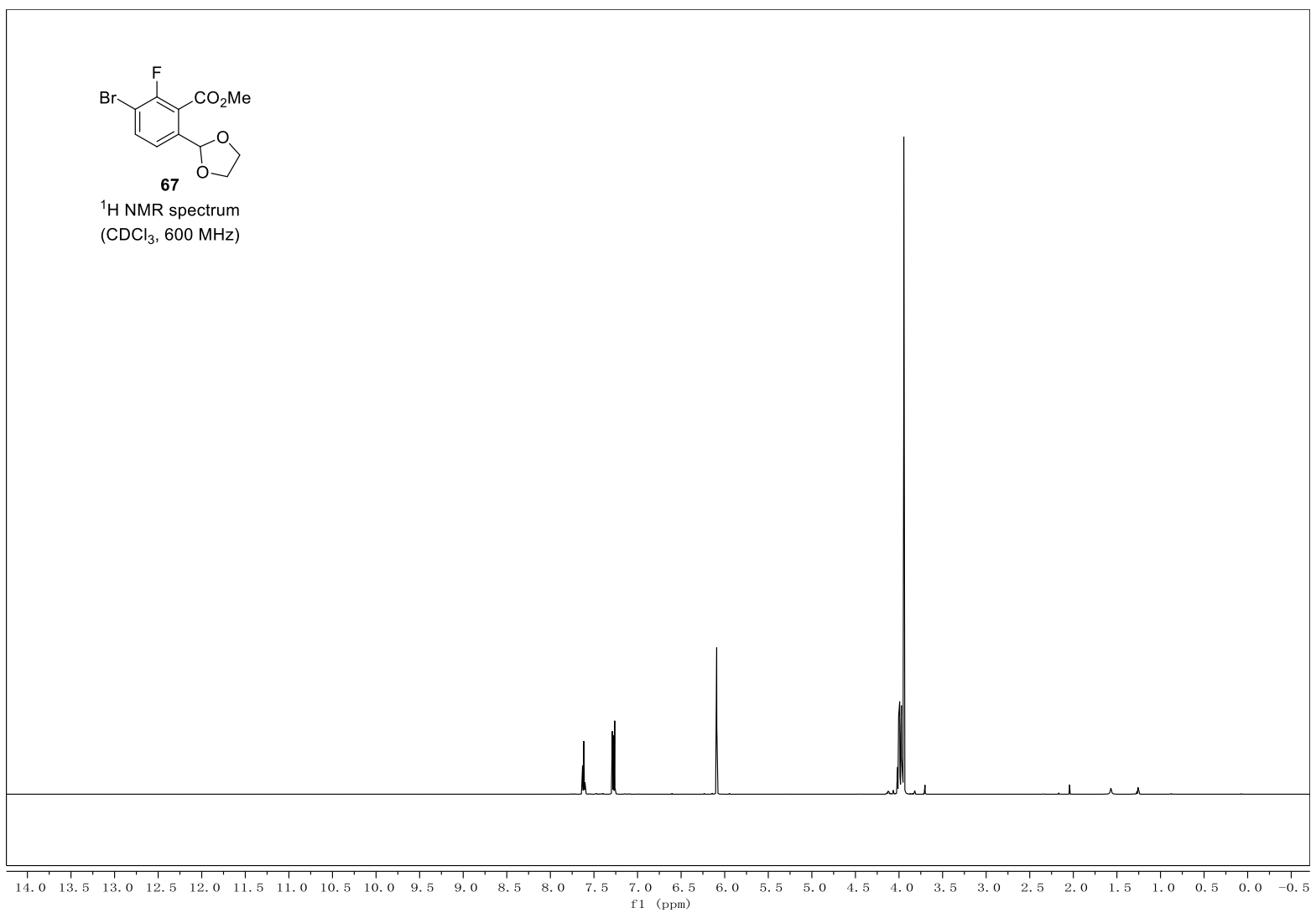

67

${ }^{13} \mathrm{C}$ NMR spectrum

$\left(\mathrm{CDCl}_{3}, 151 \mathrm{MHz}\right)$

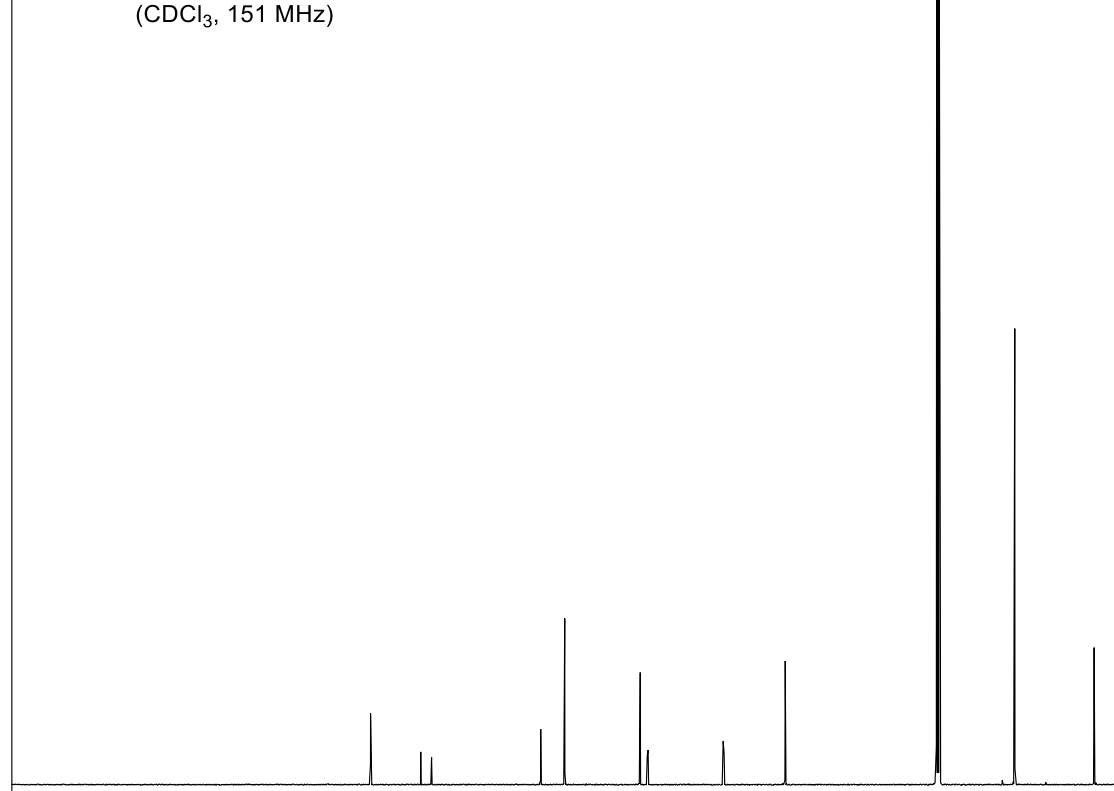

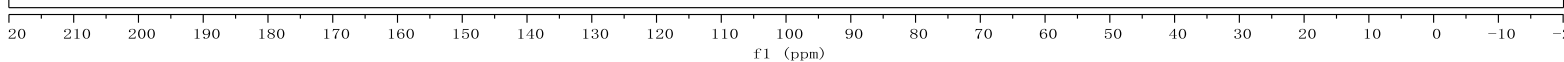




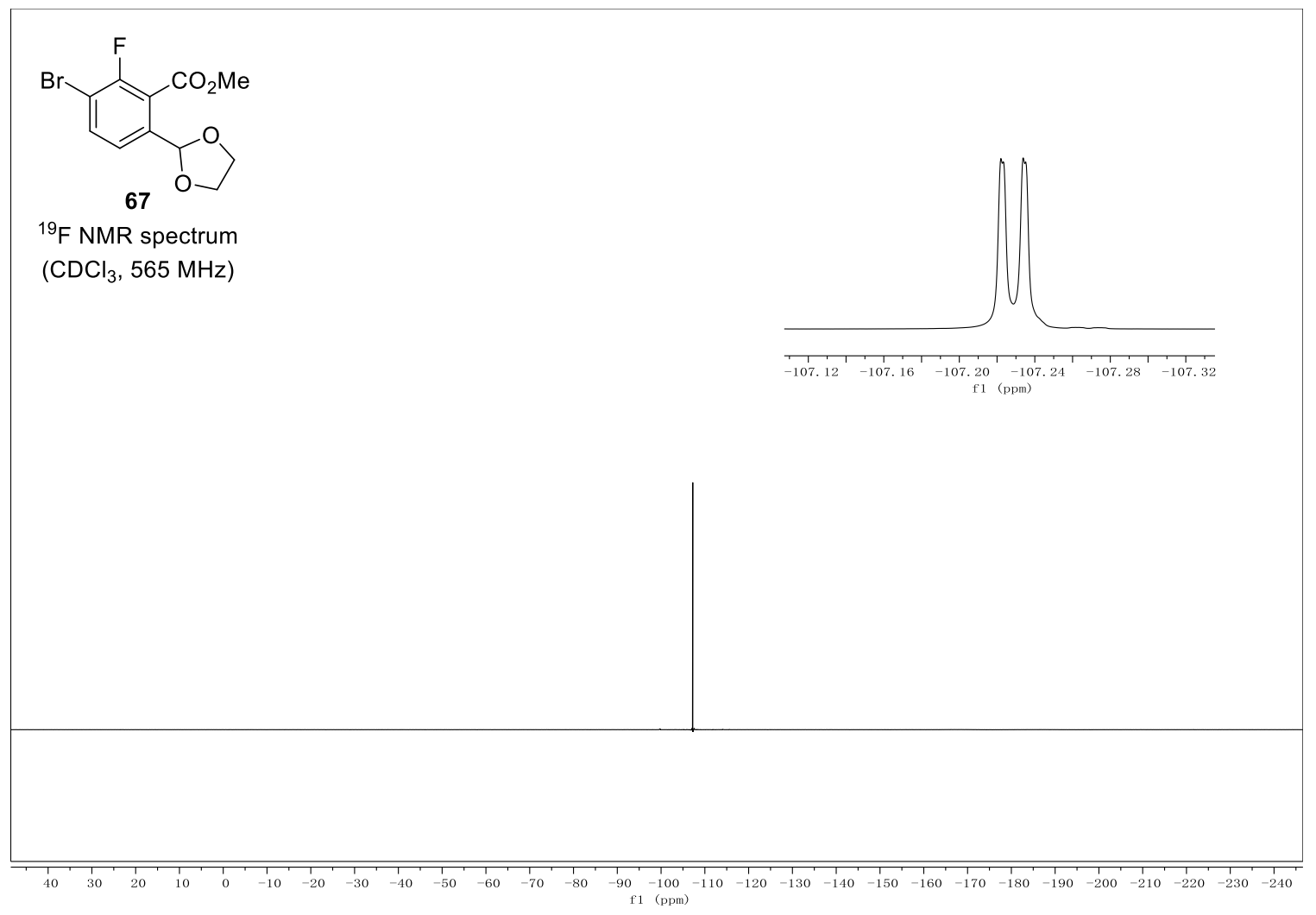



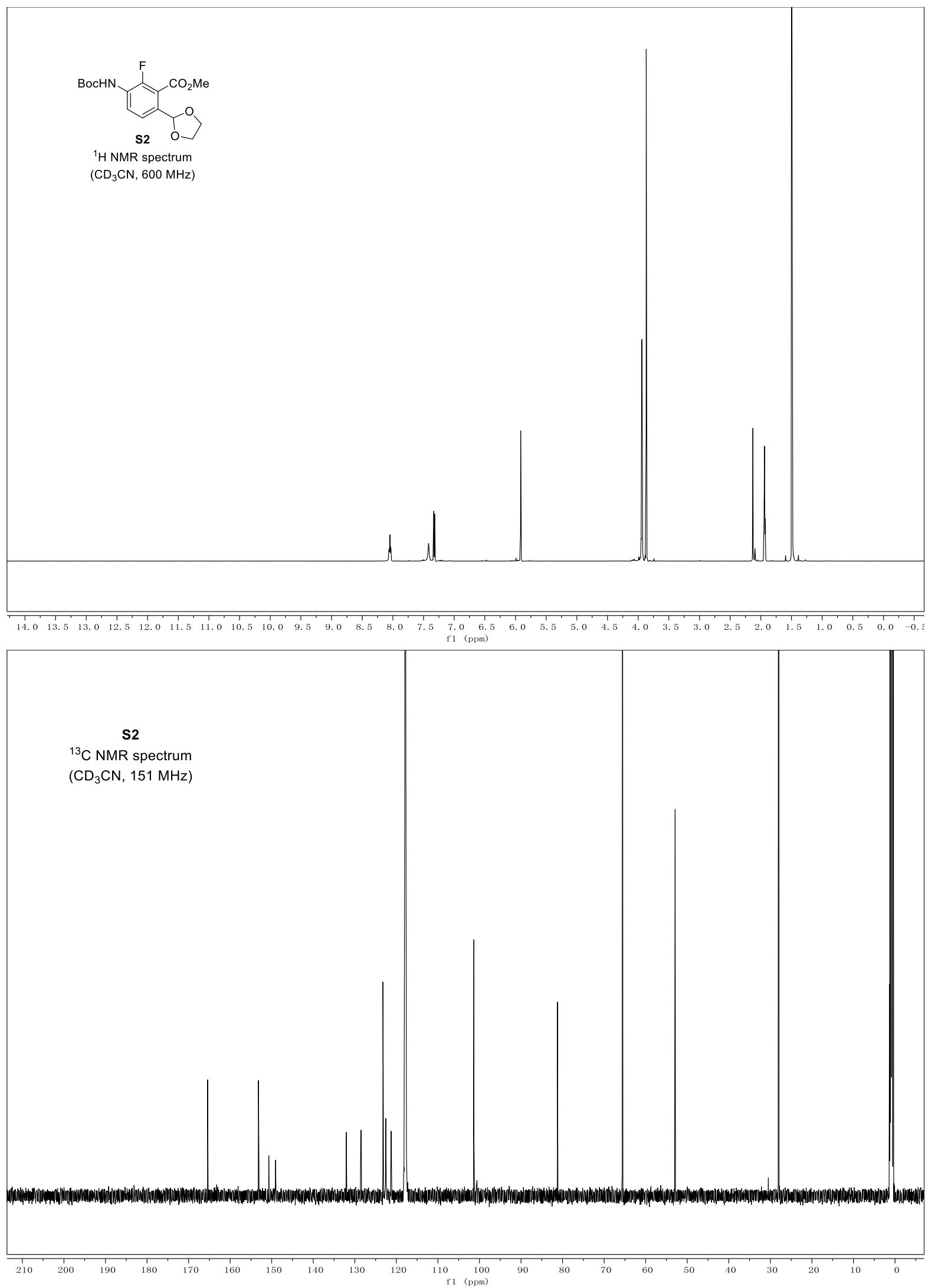


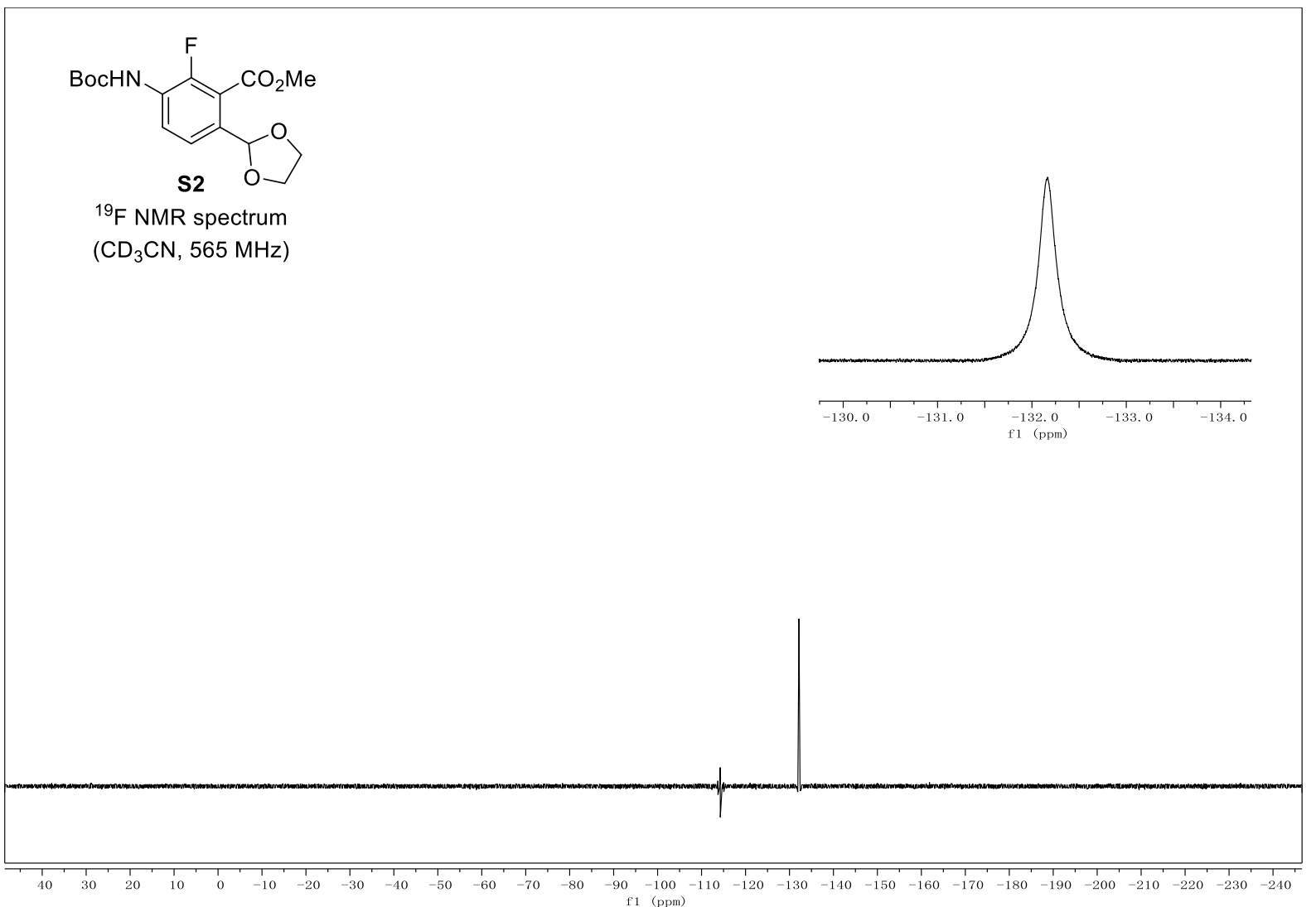




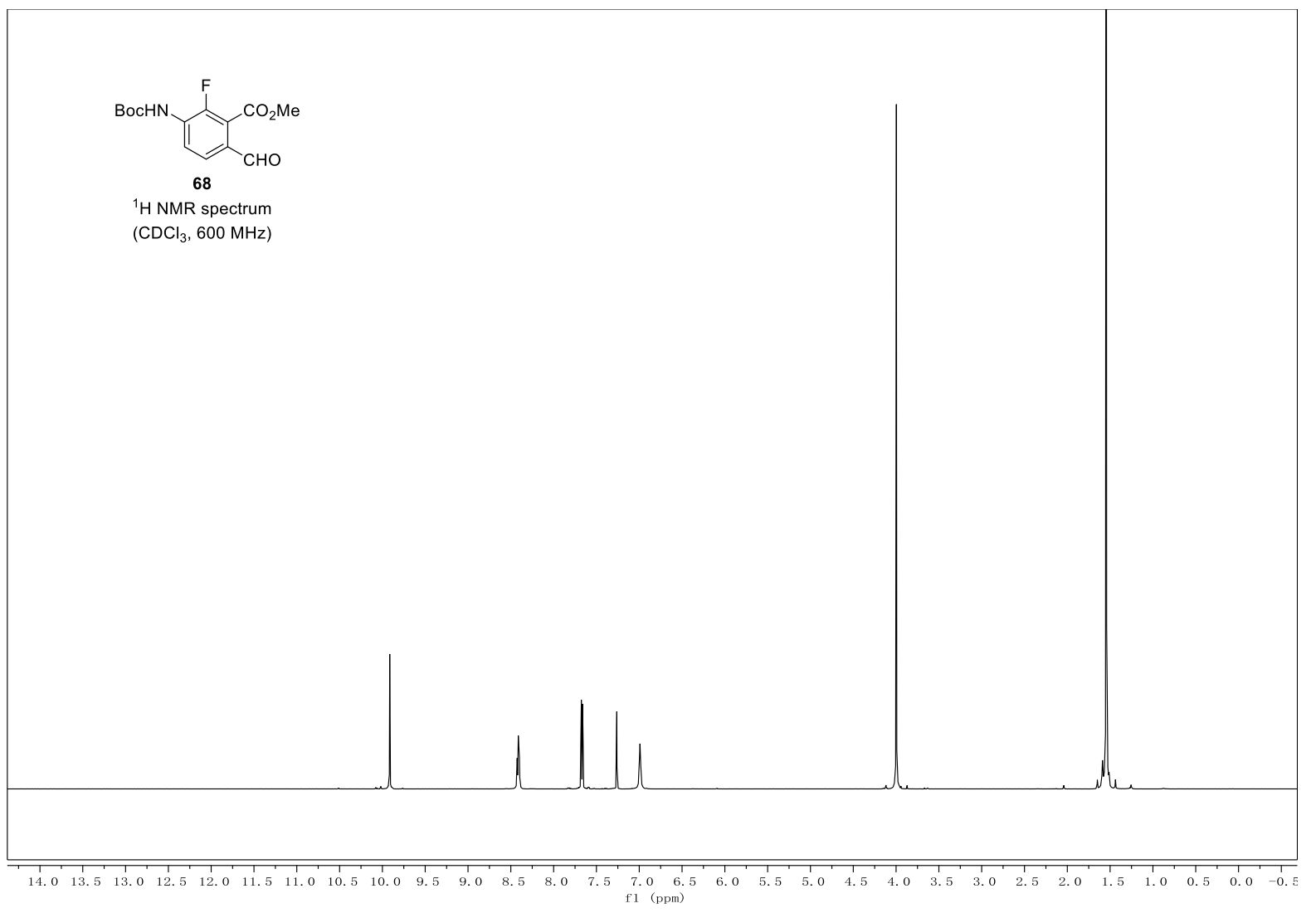

68

${ }^{13} \mathrm{C}$ NMR spectrum $\left(\mathrm{CDCl}_{3}, 151 \mathrm{MHz}\right)$
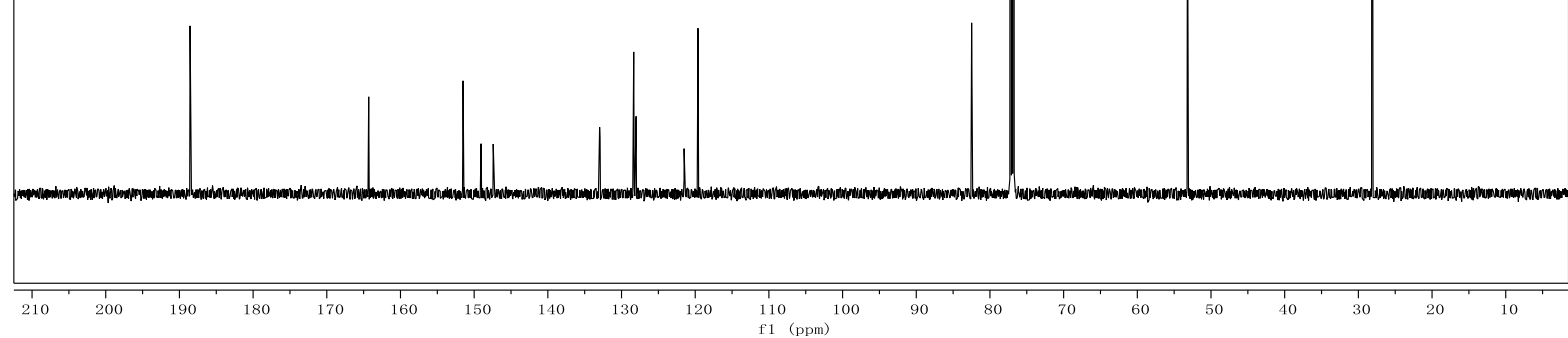


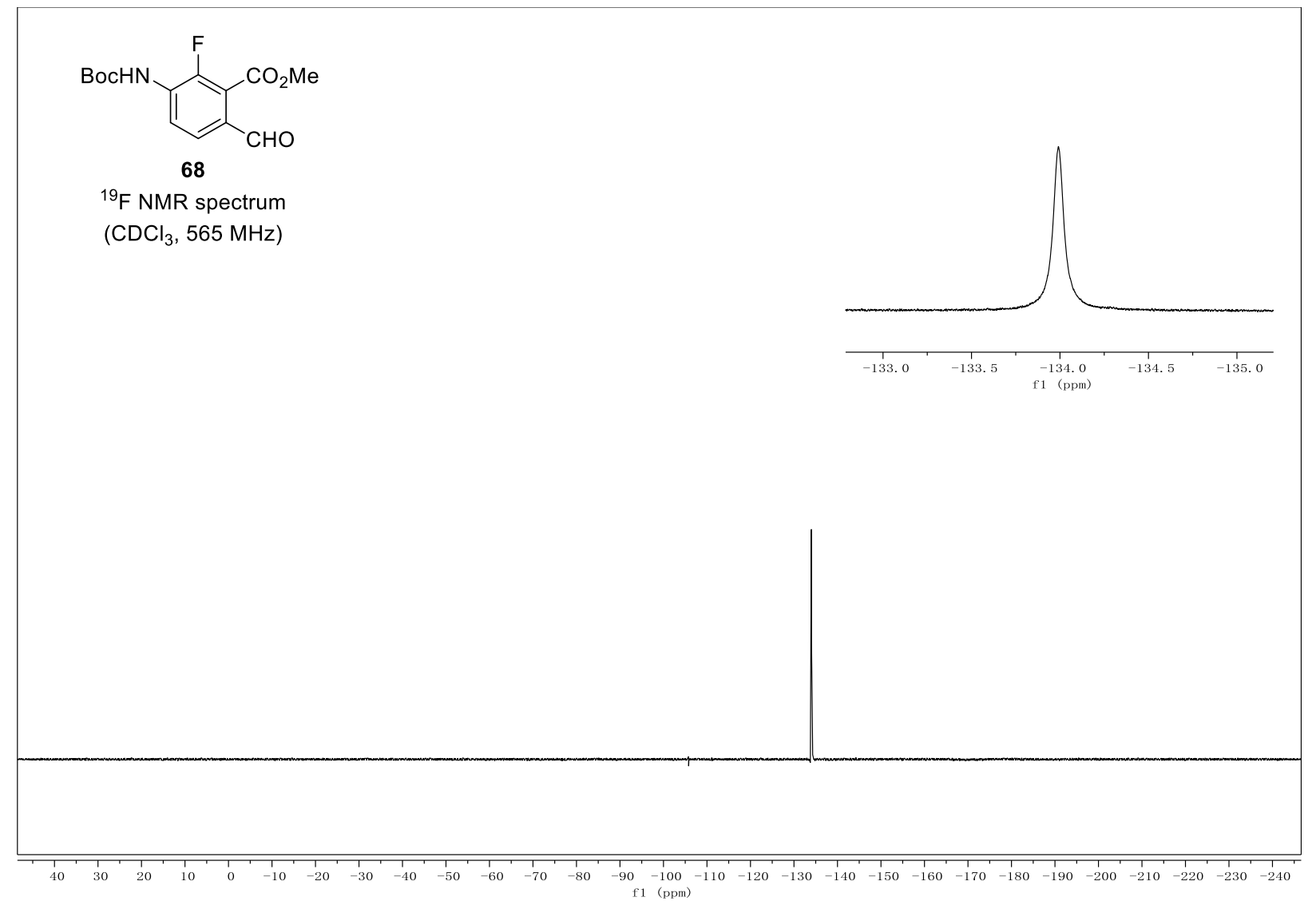




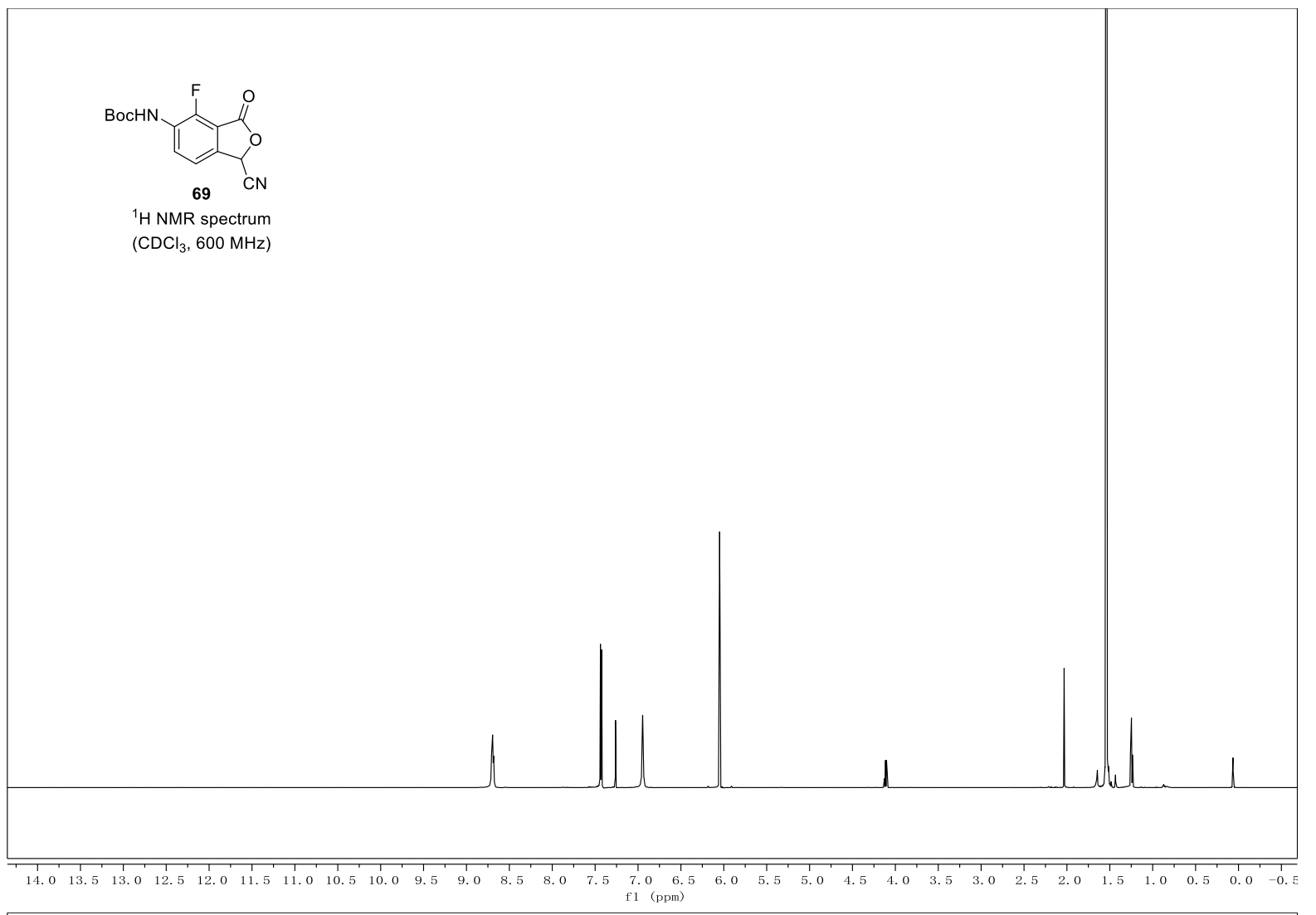

69

${ }^{13} \mathrm{C}$ NMR spectrum

$\left(\mathrm{CDCl}_{3}, 151 \mathrm{MHz}\right)$
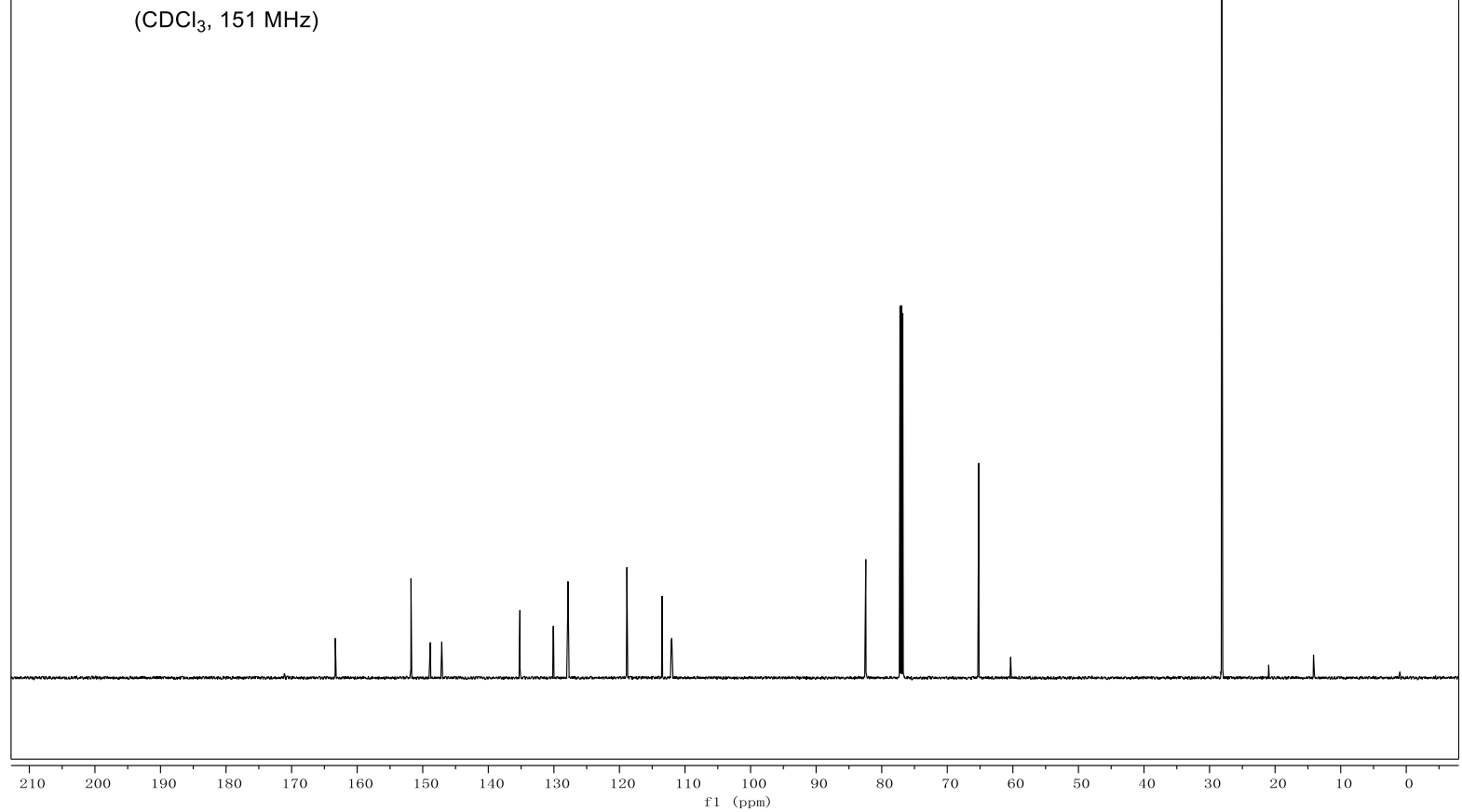


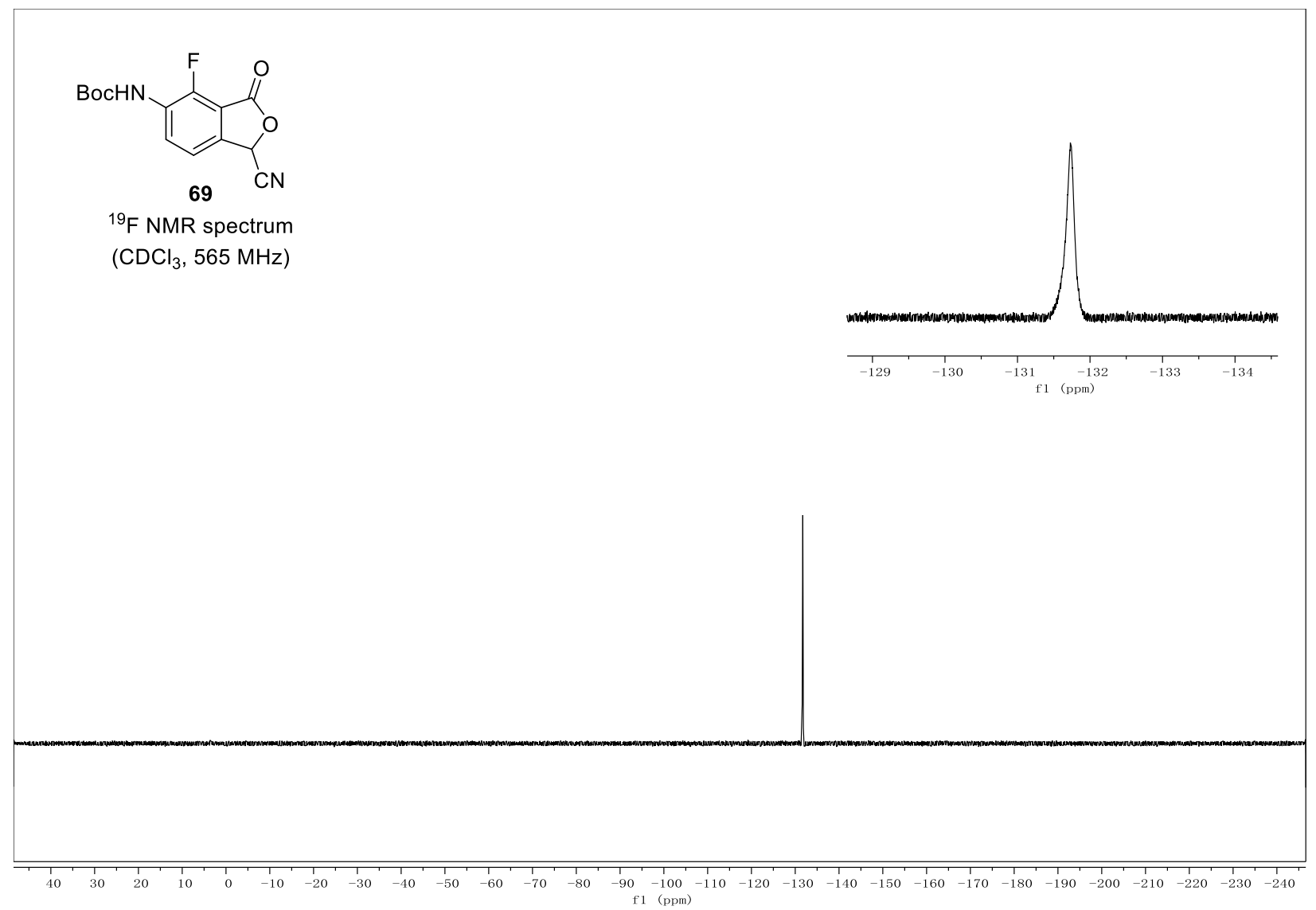




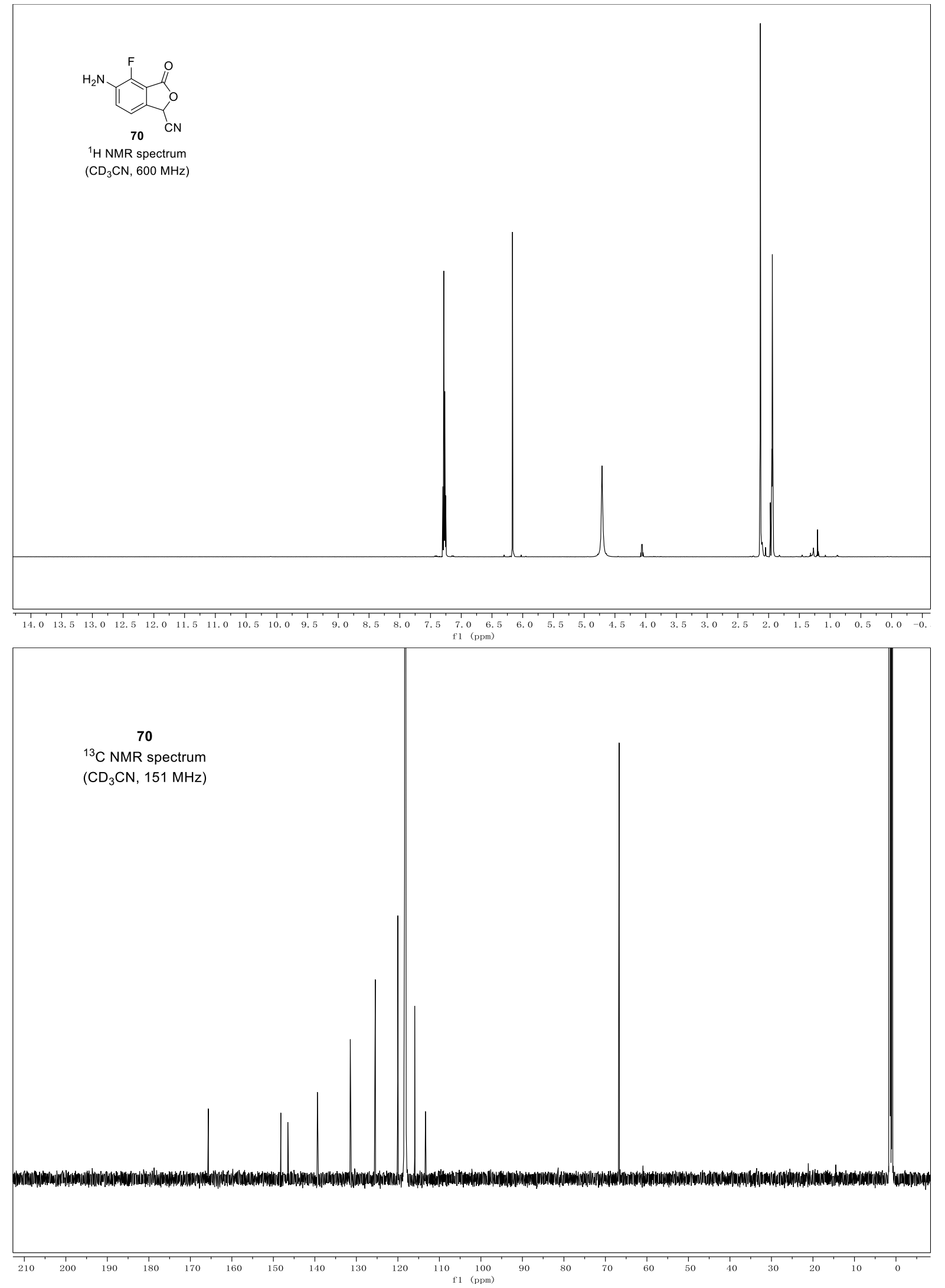




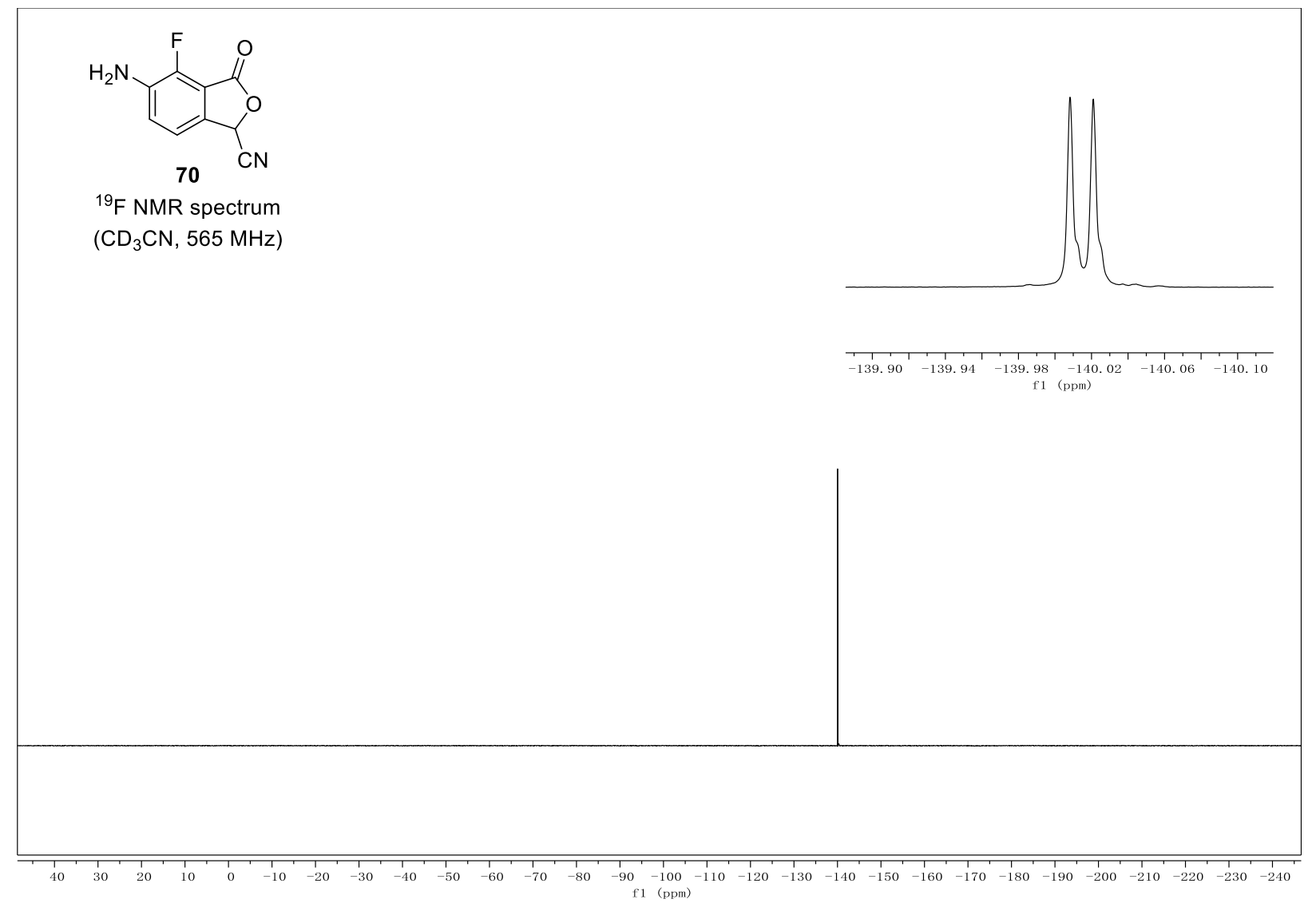



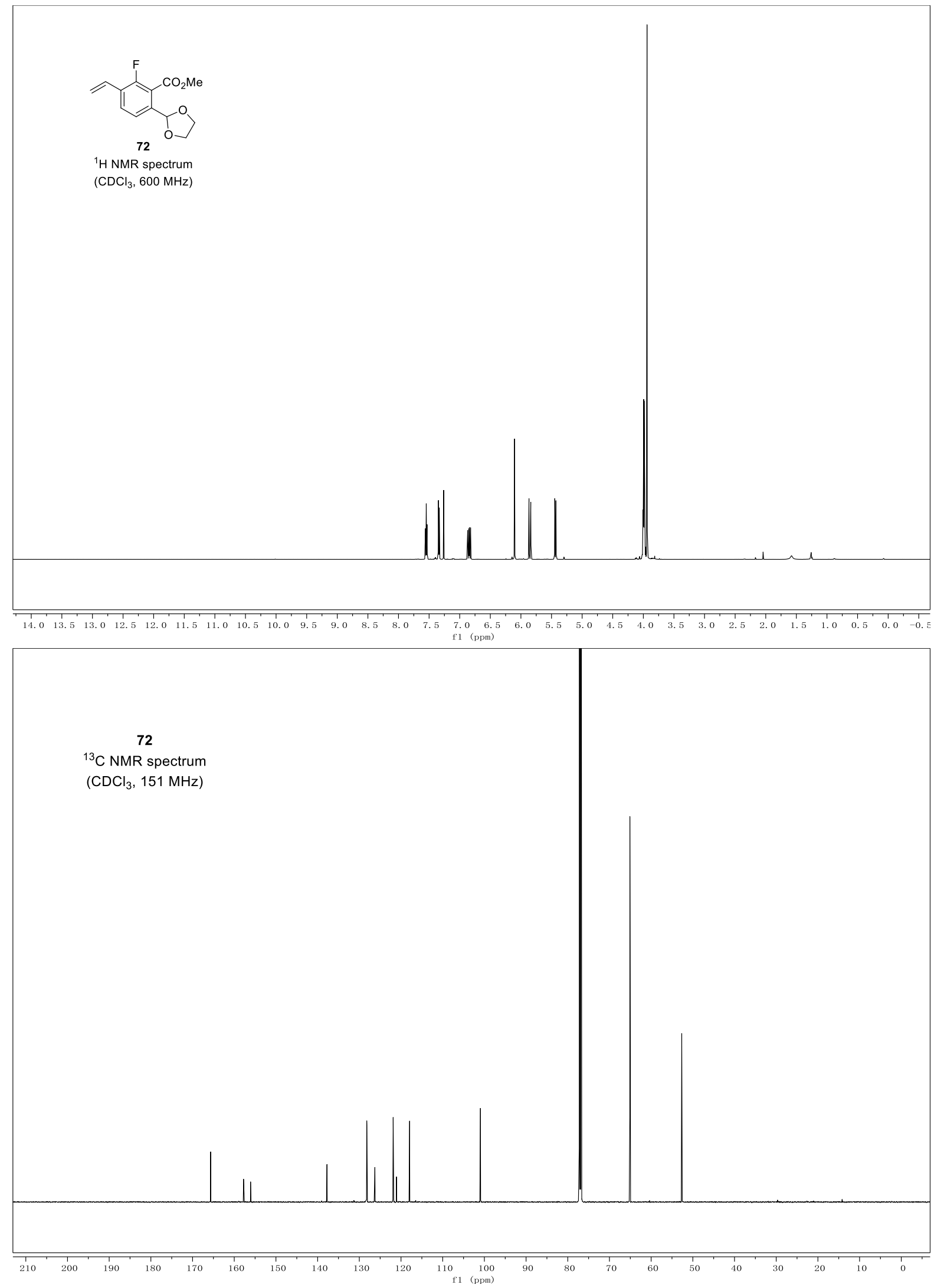


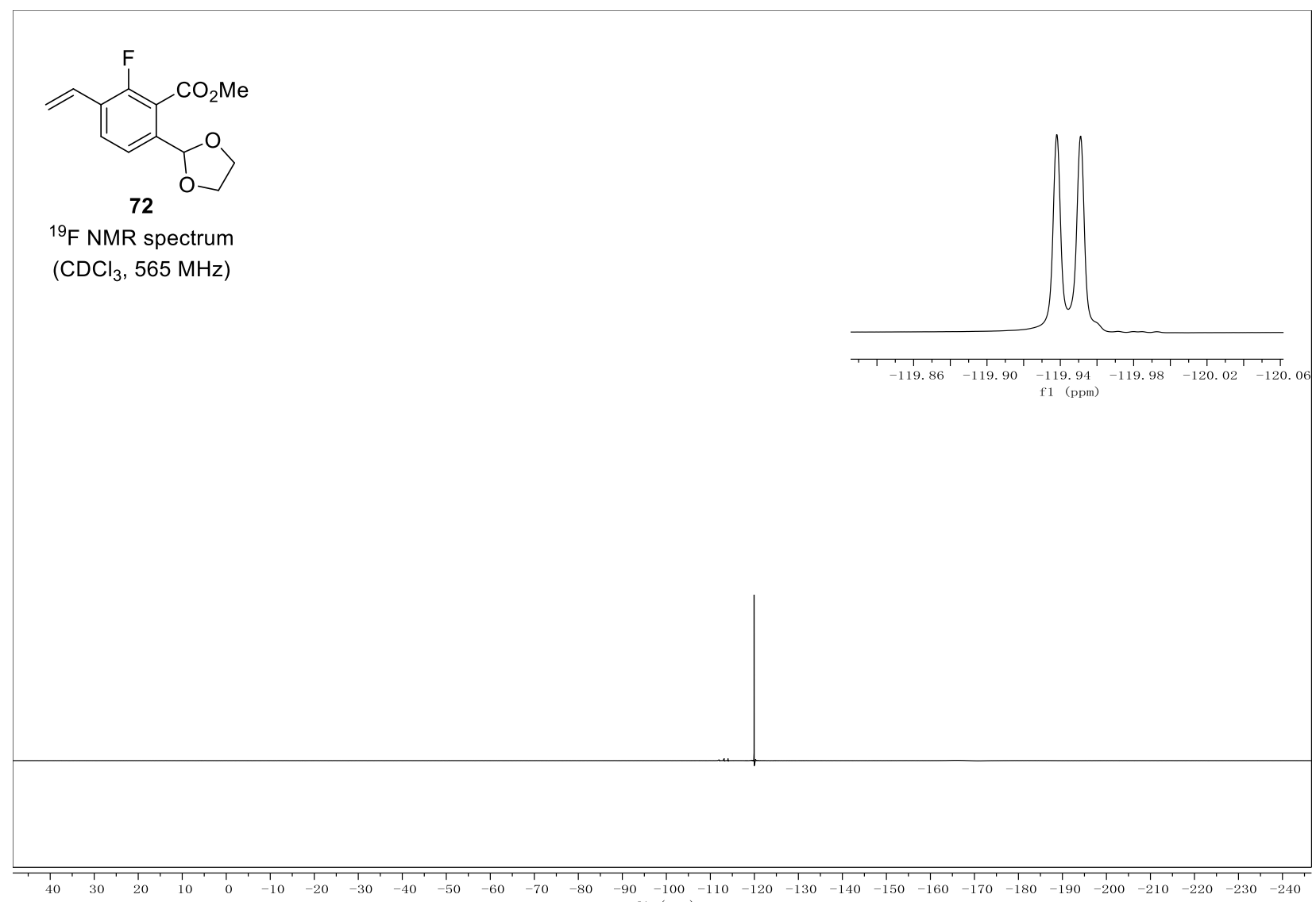



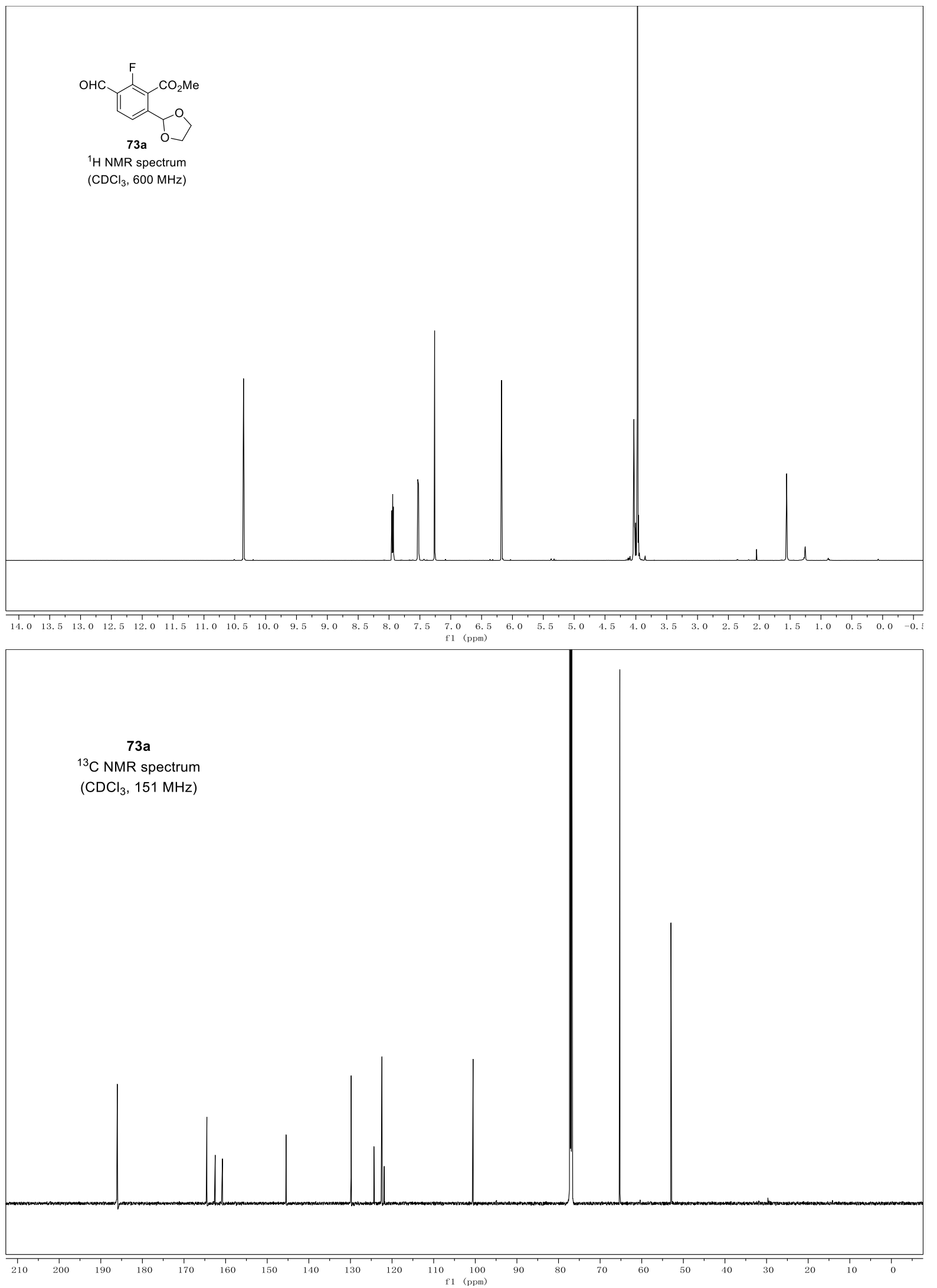


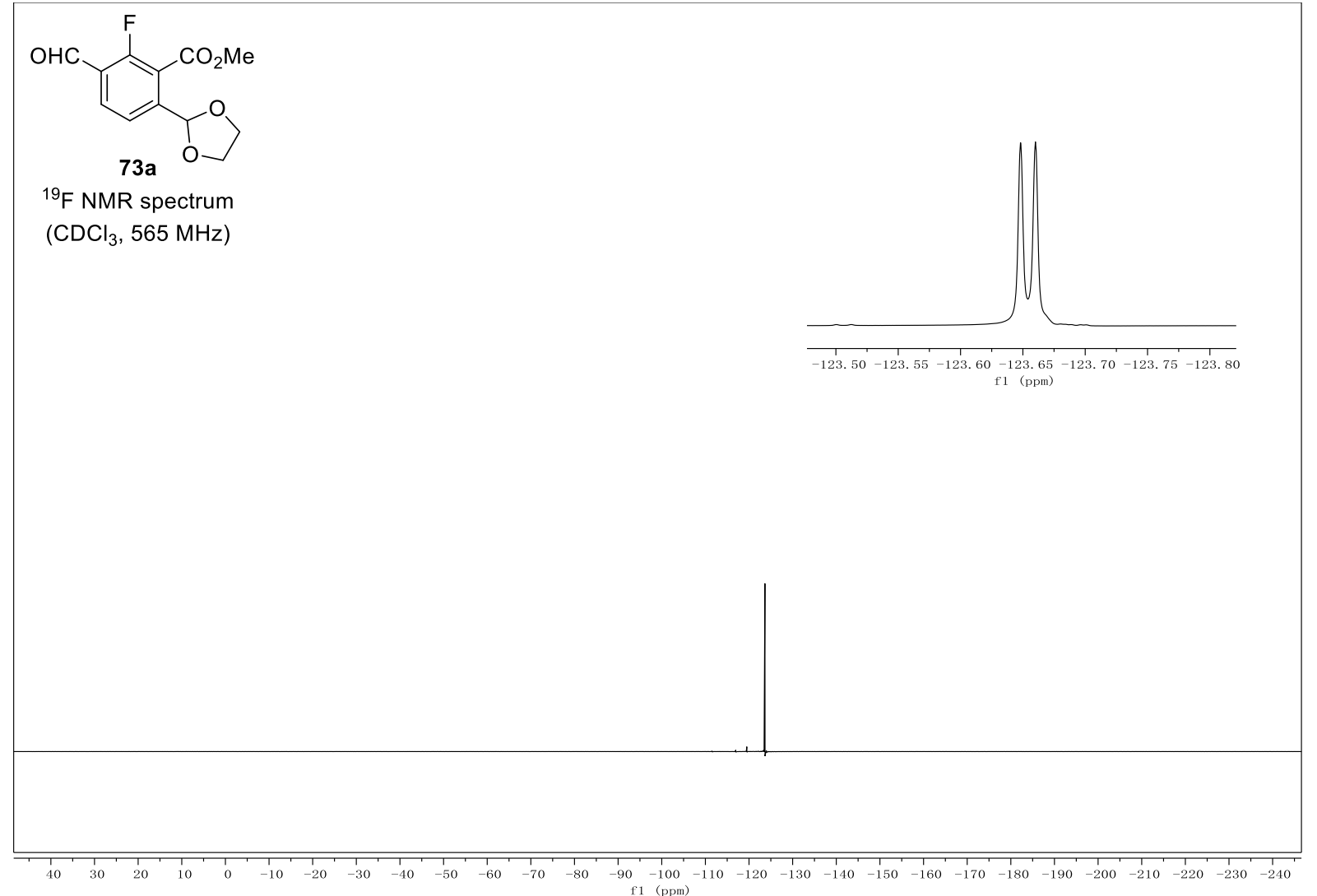




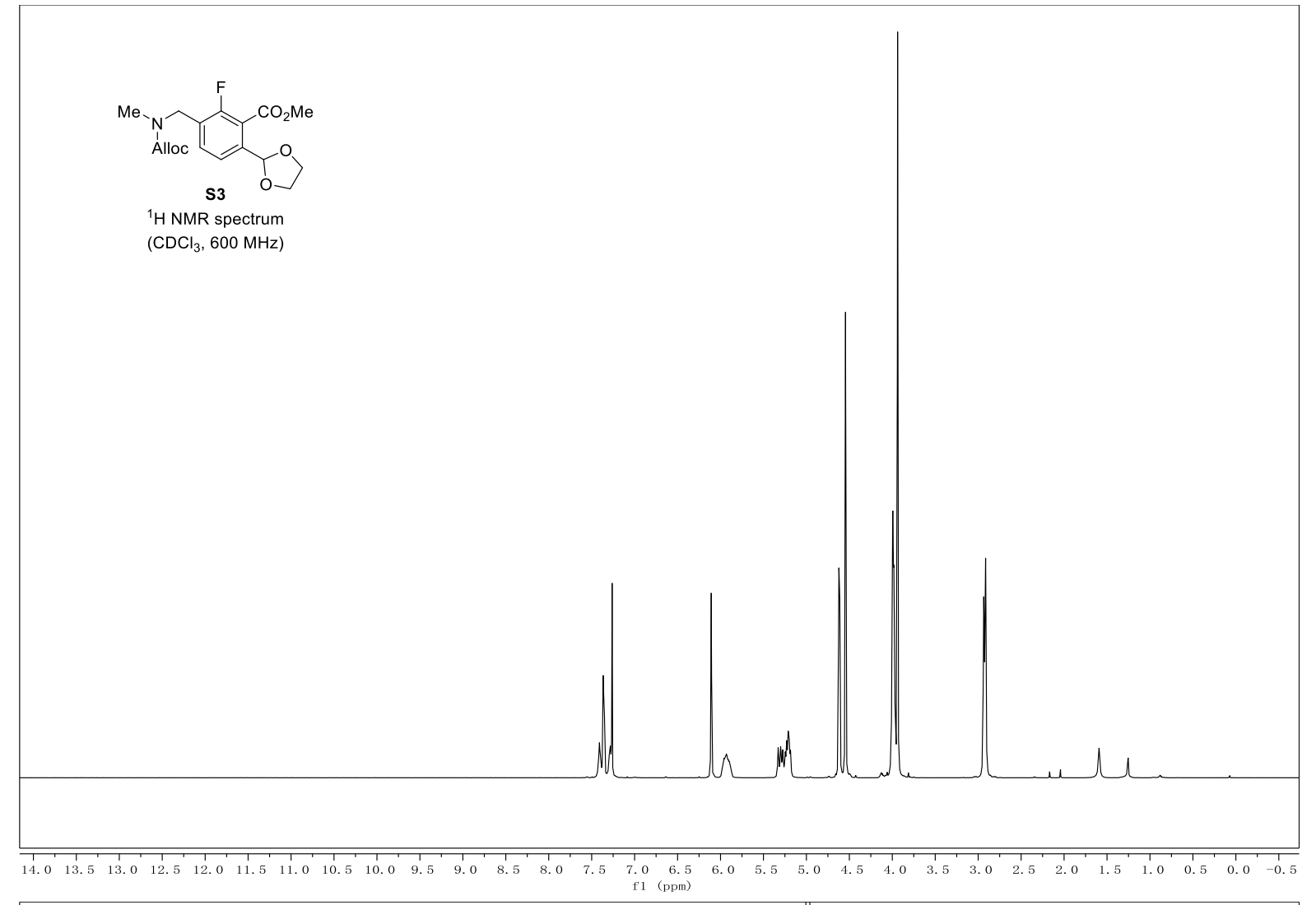

s3

${ }^{13} \mathrm{C}$ NMR spectrum ( $\mathrm{CDCl}_{3}, 151 \mathrm{MHz}$ )

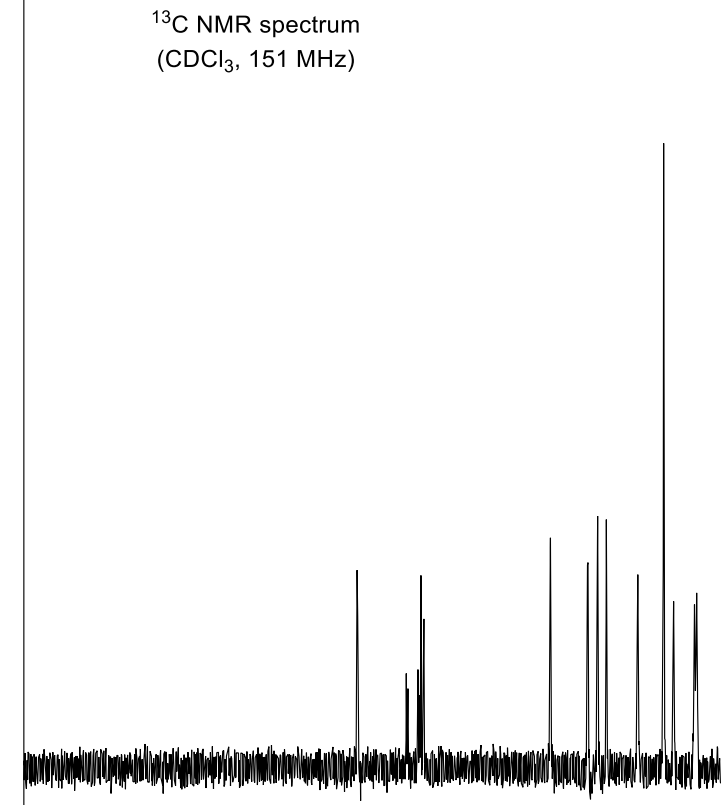

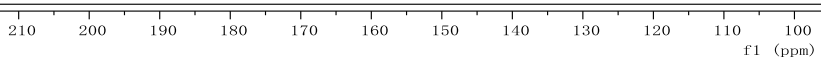




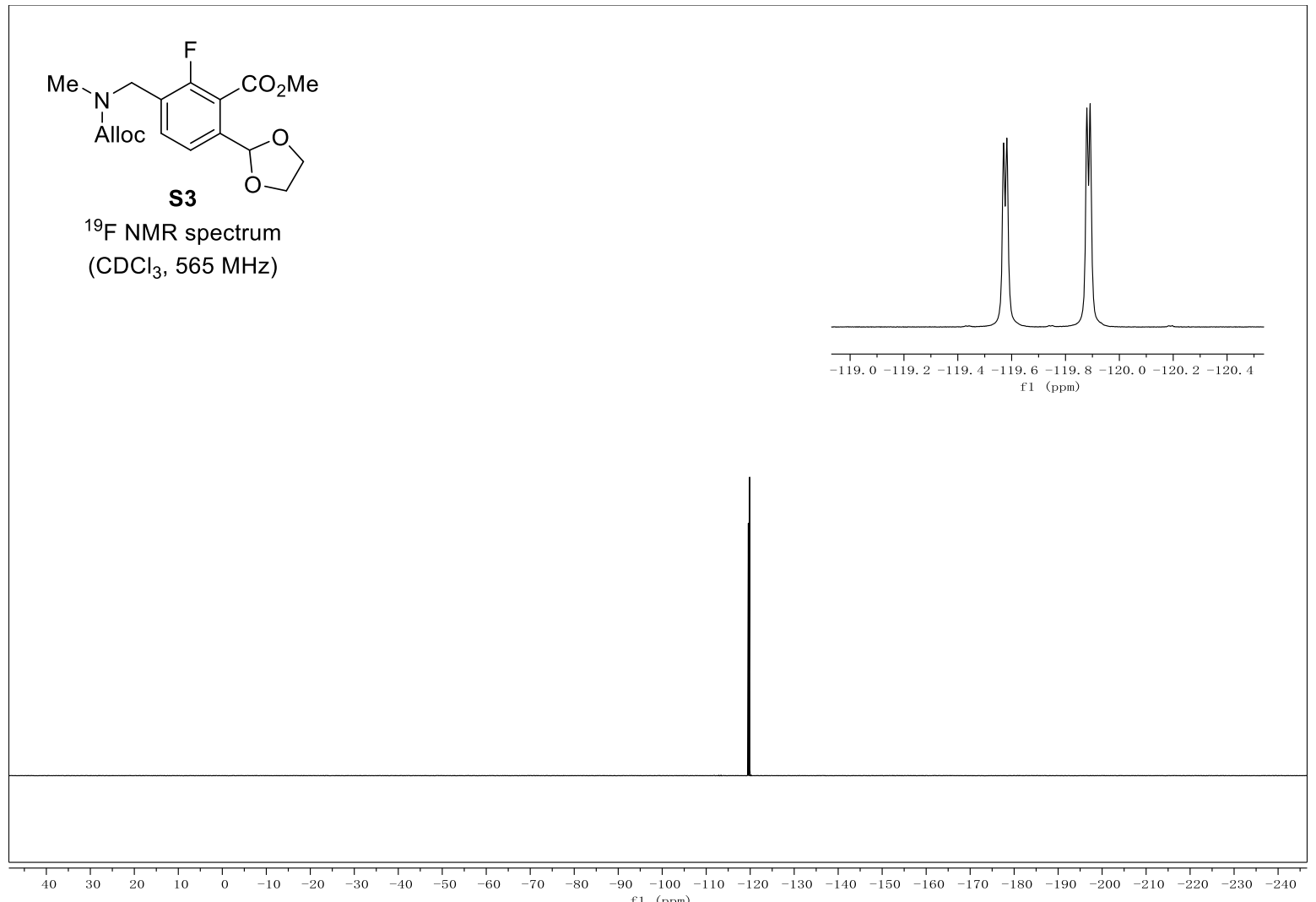



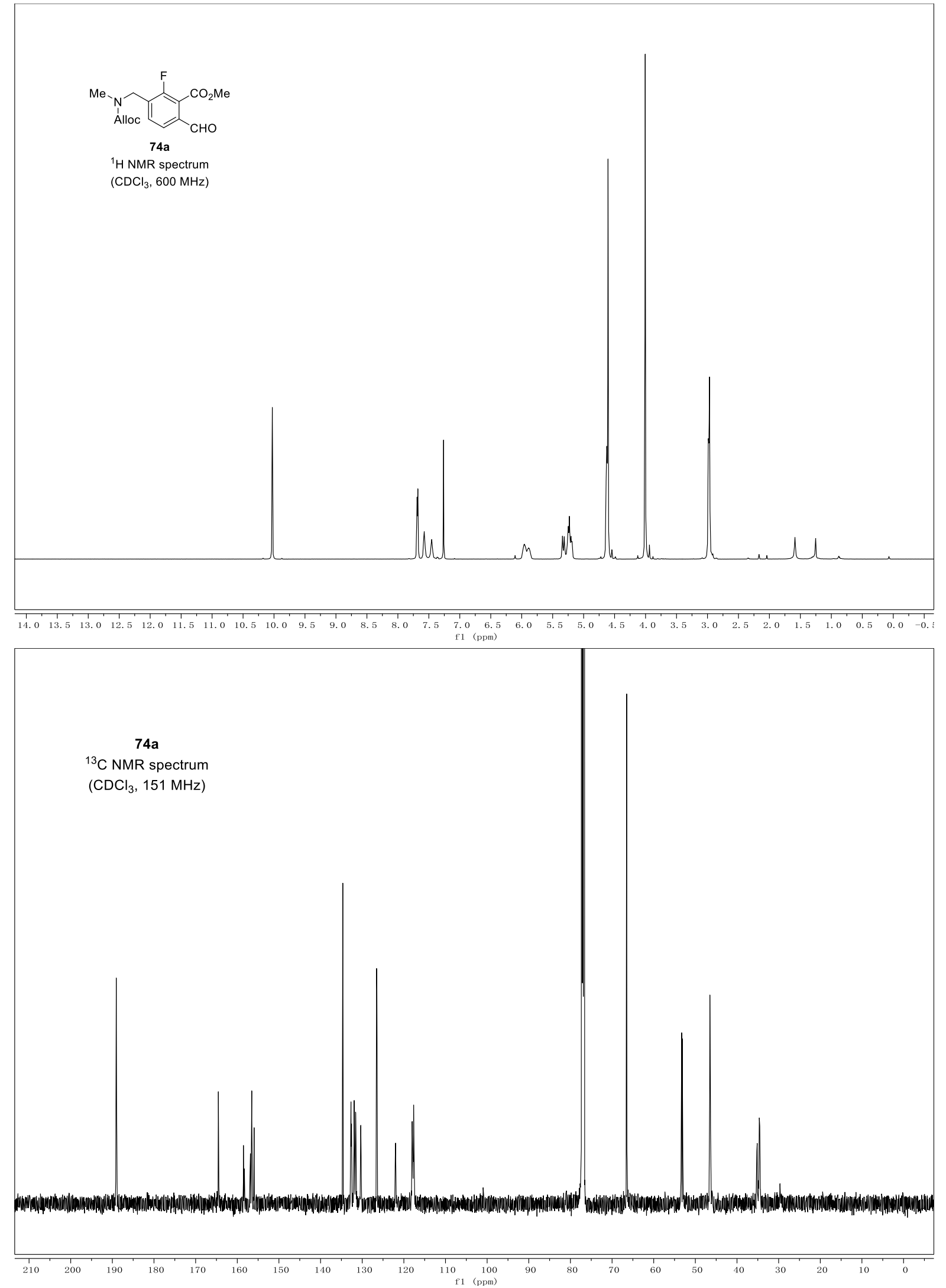


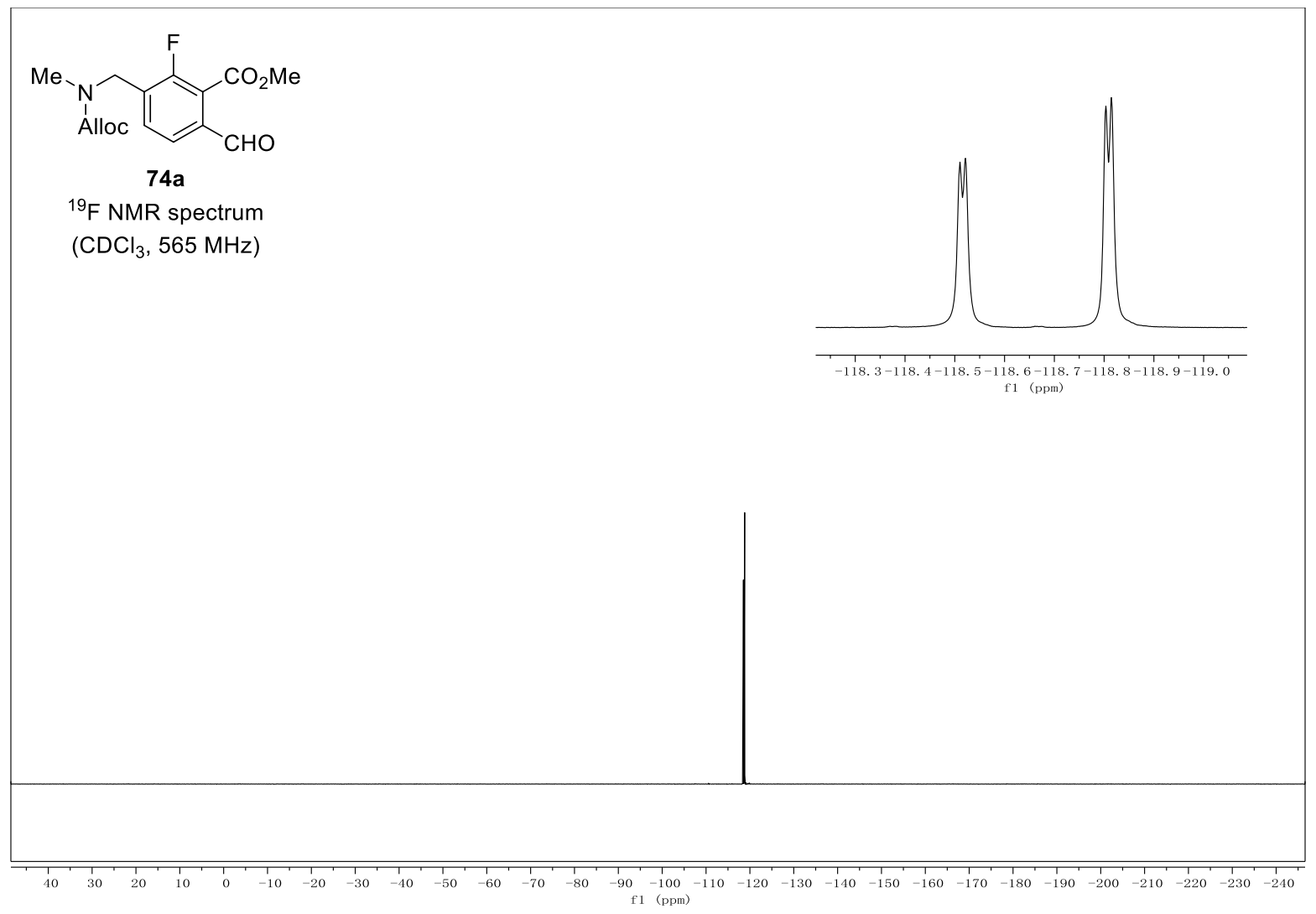



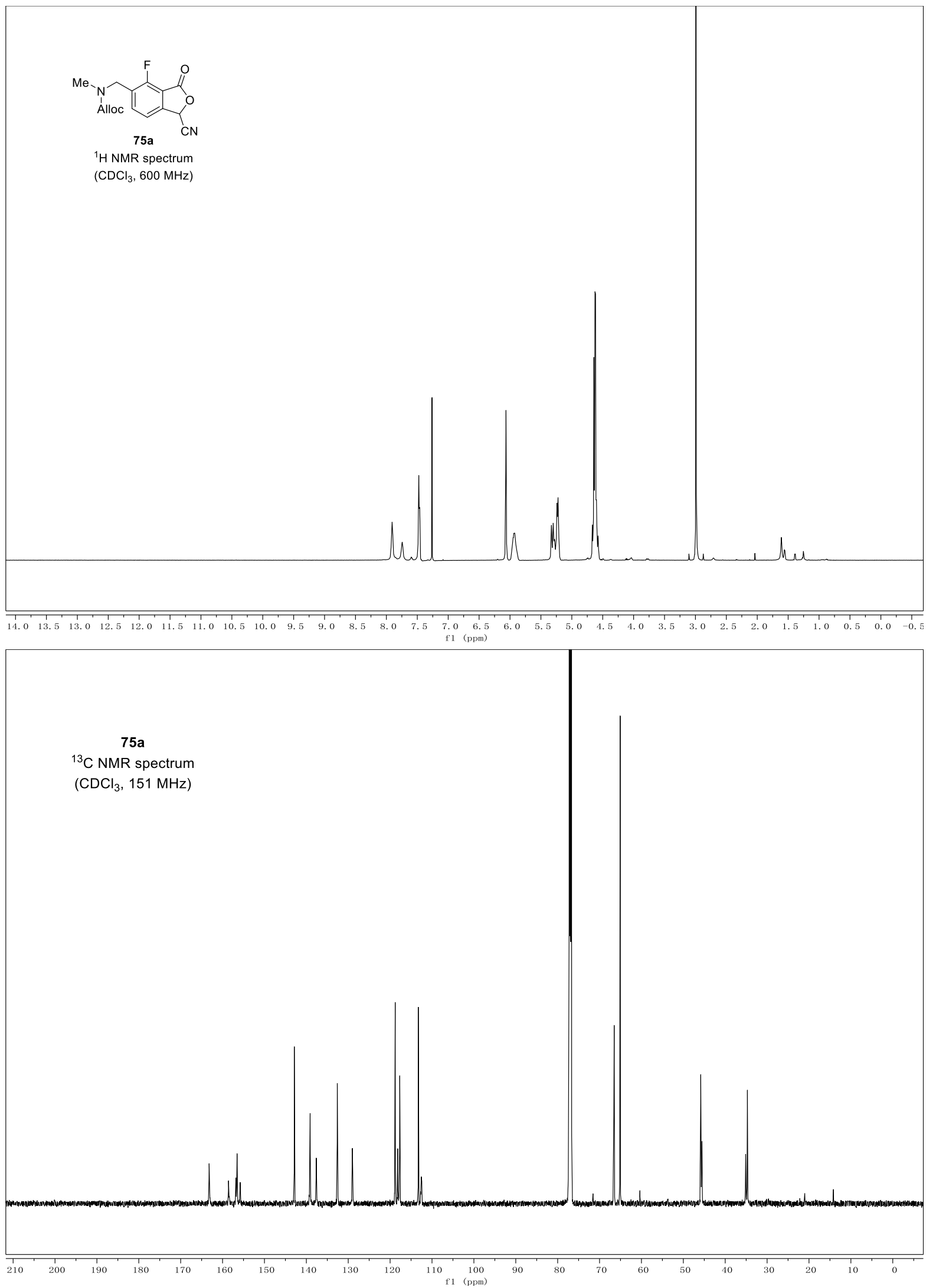


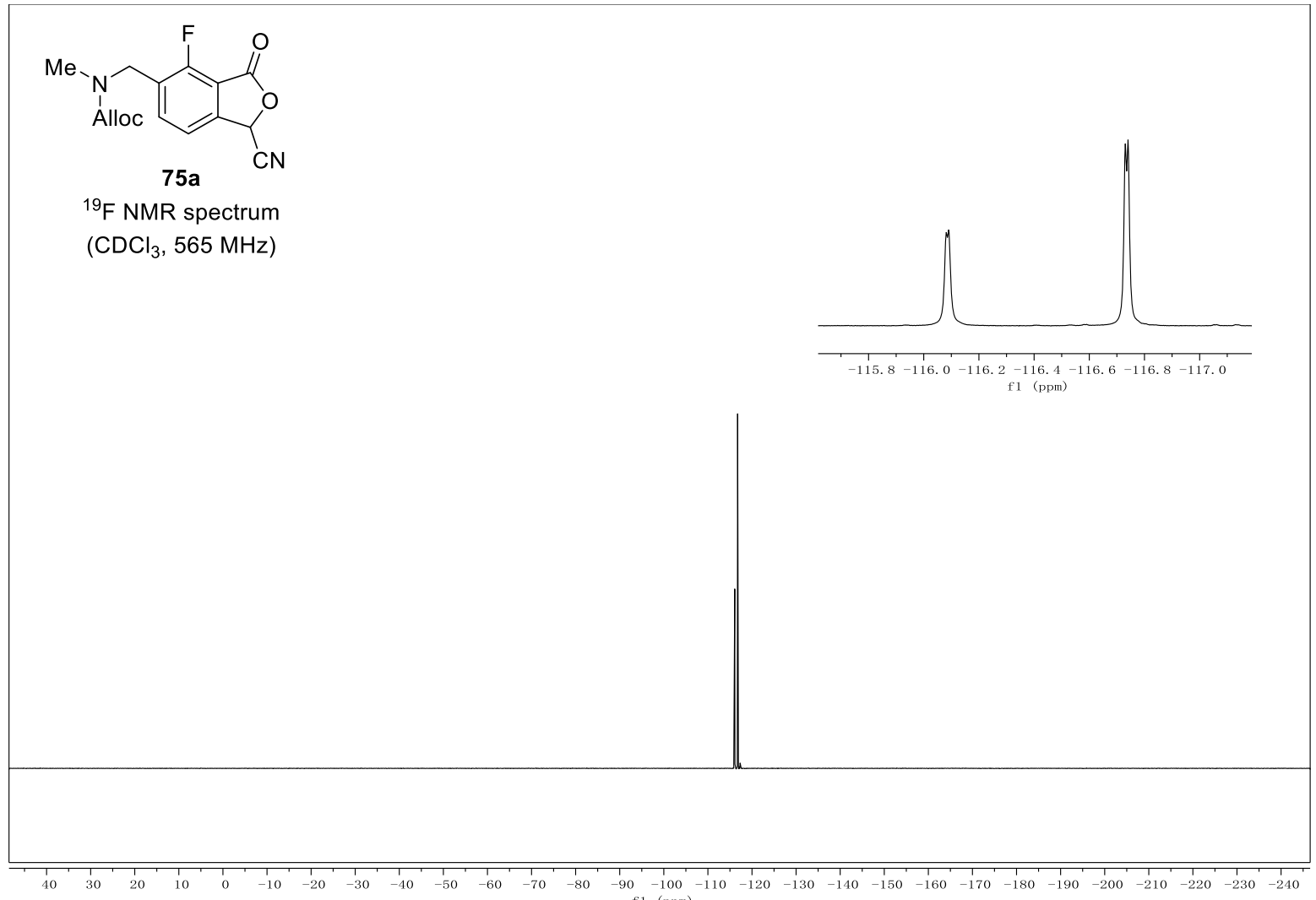



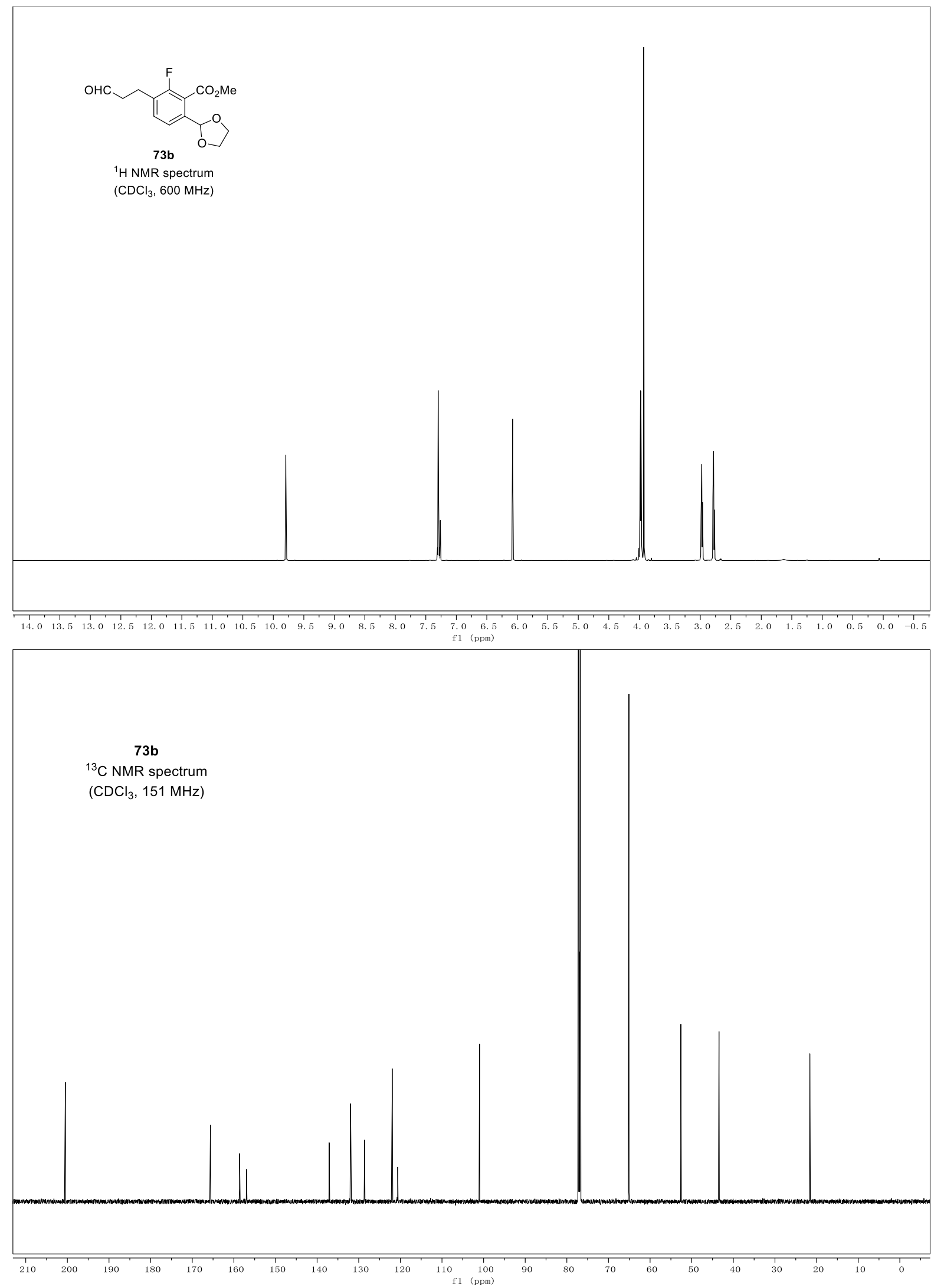


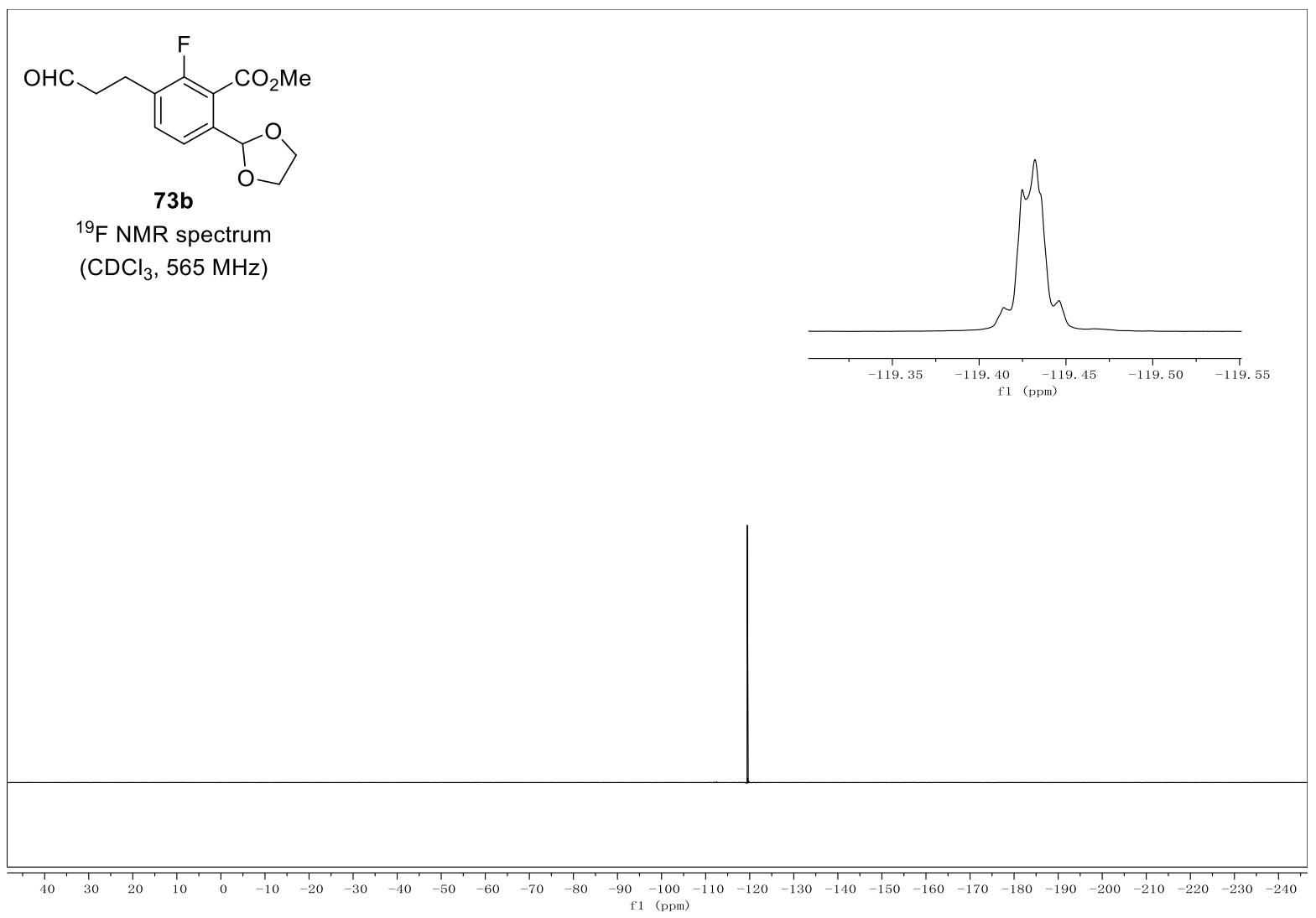



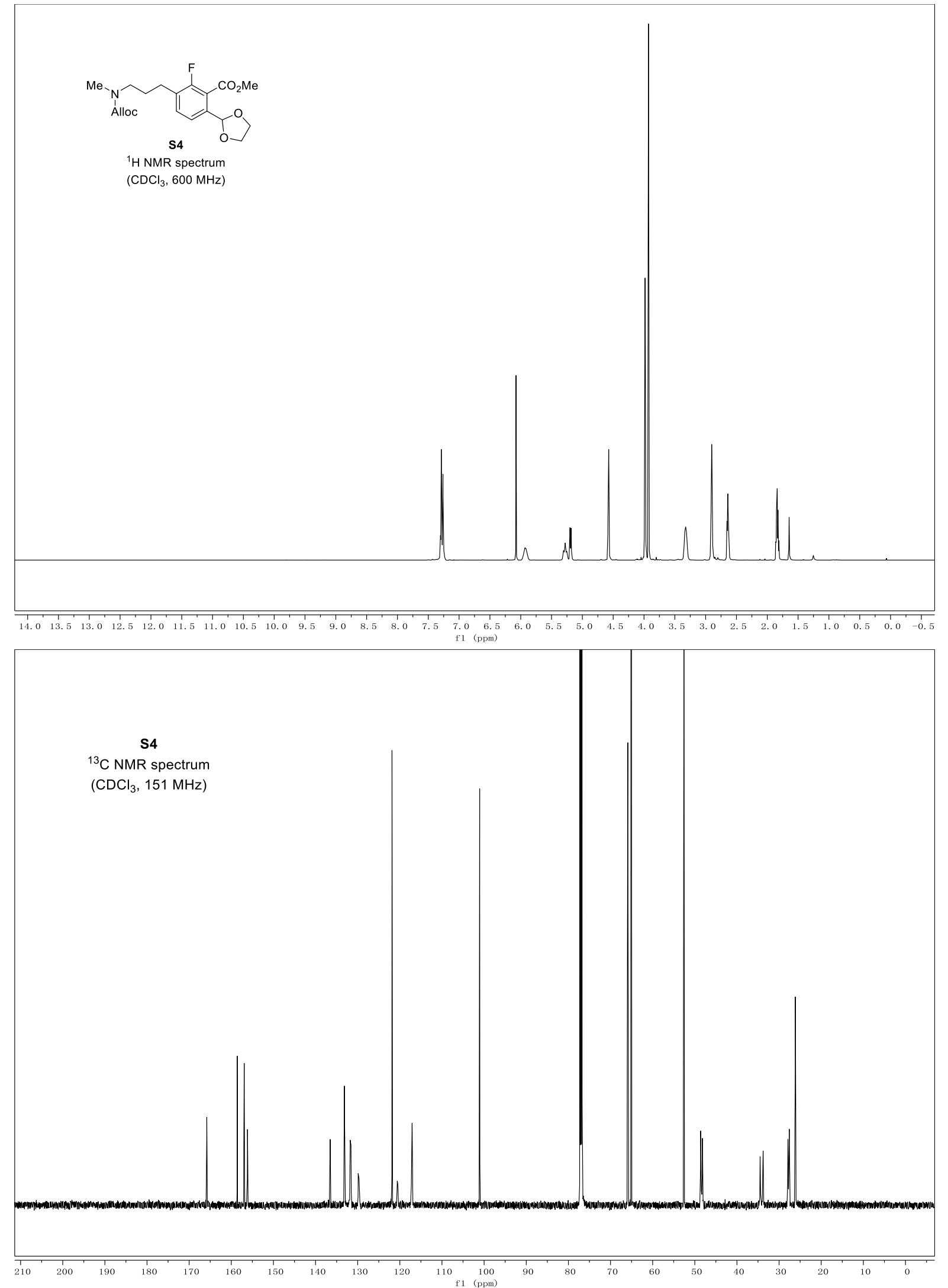


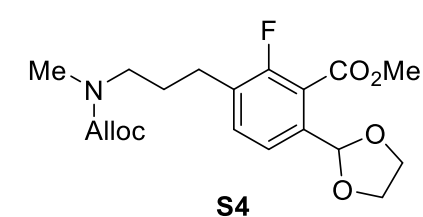

${ }^{19} \mathrm{~F}$ NMR spectrum $\left(\mathrm{CDCl}_{3}, 565 \mathrm{MHz}\right)$

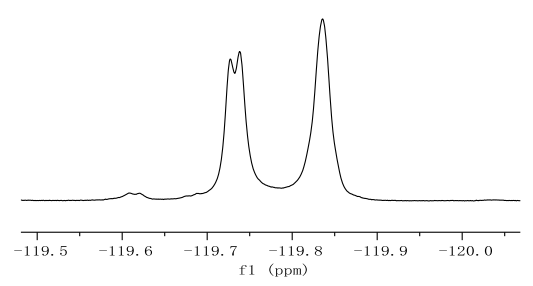

$\mathrm{f} 1$ (ppm)

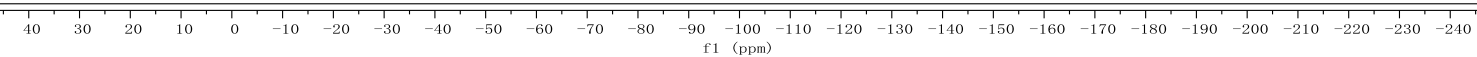



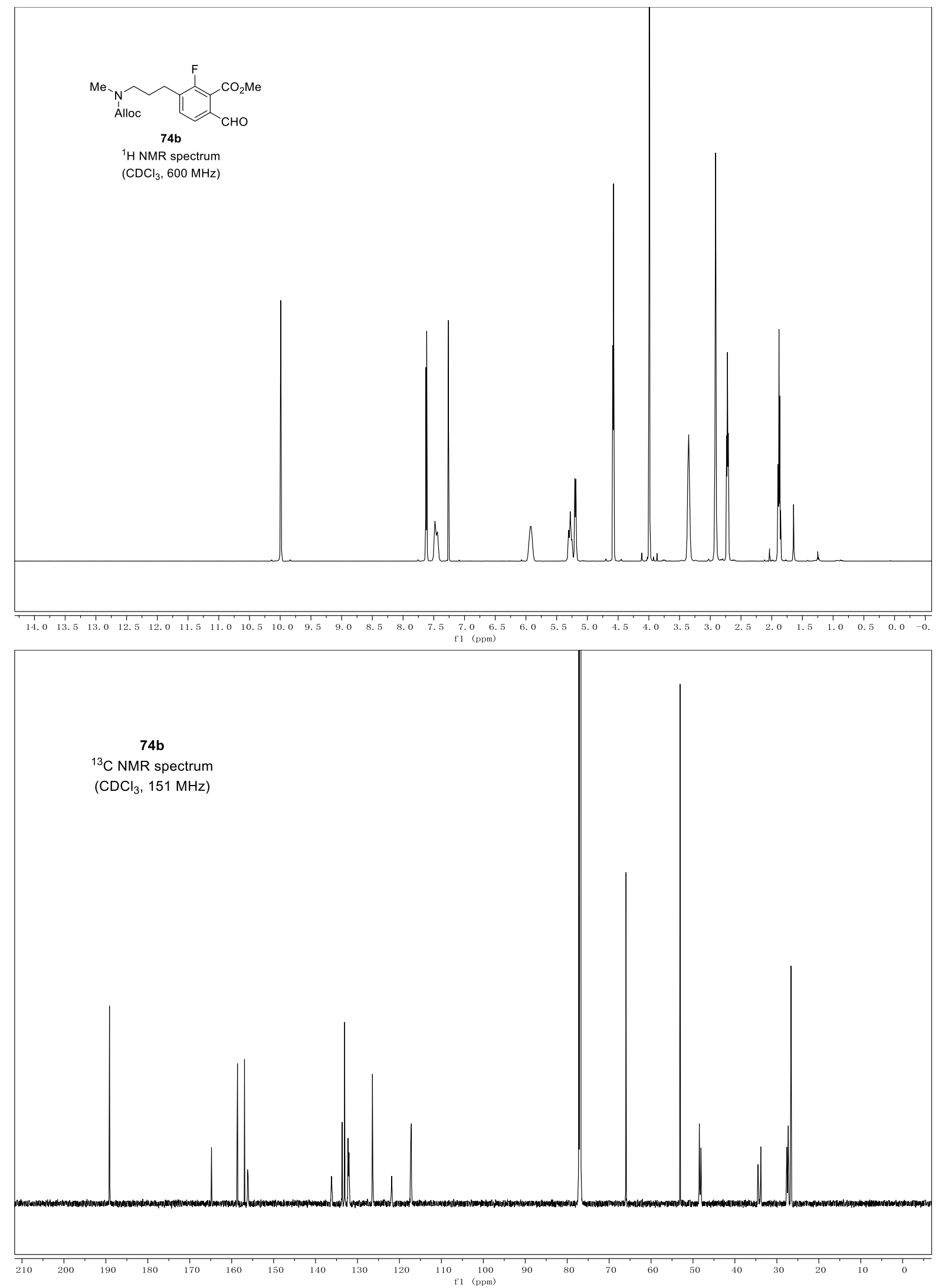


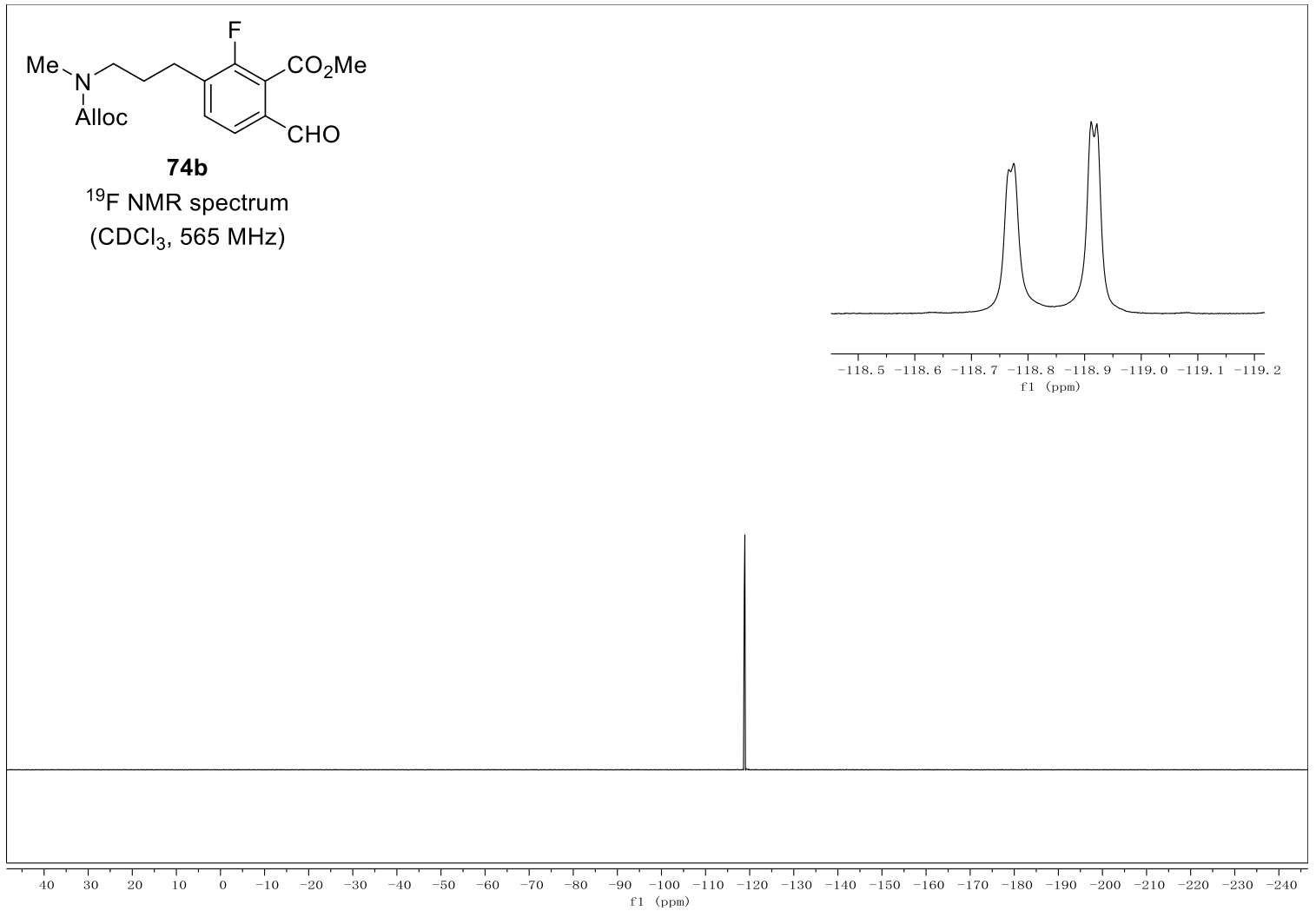



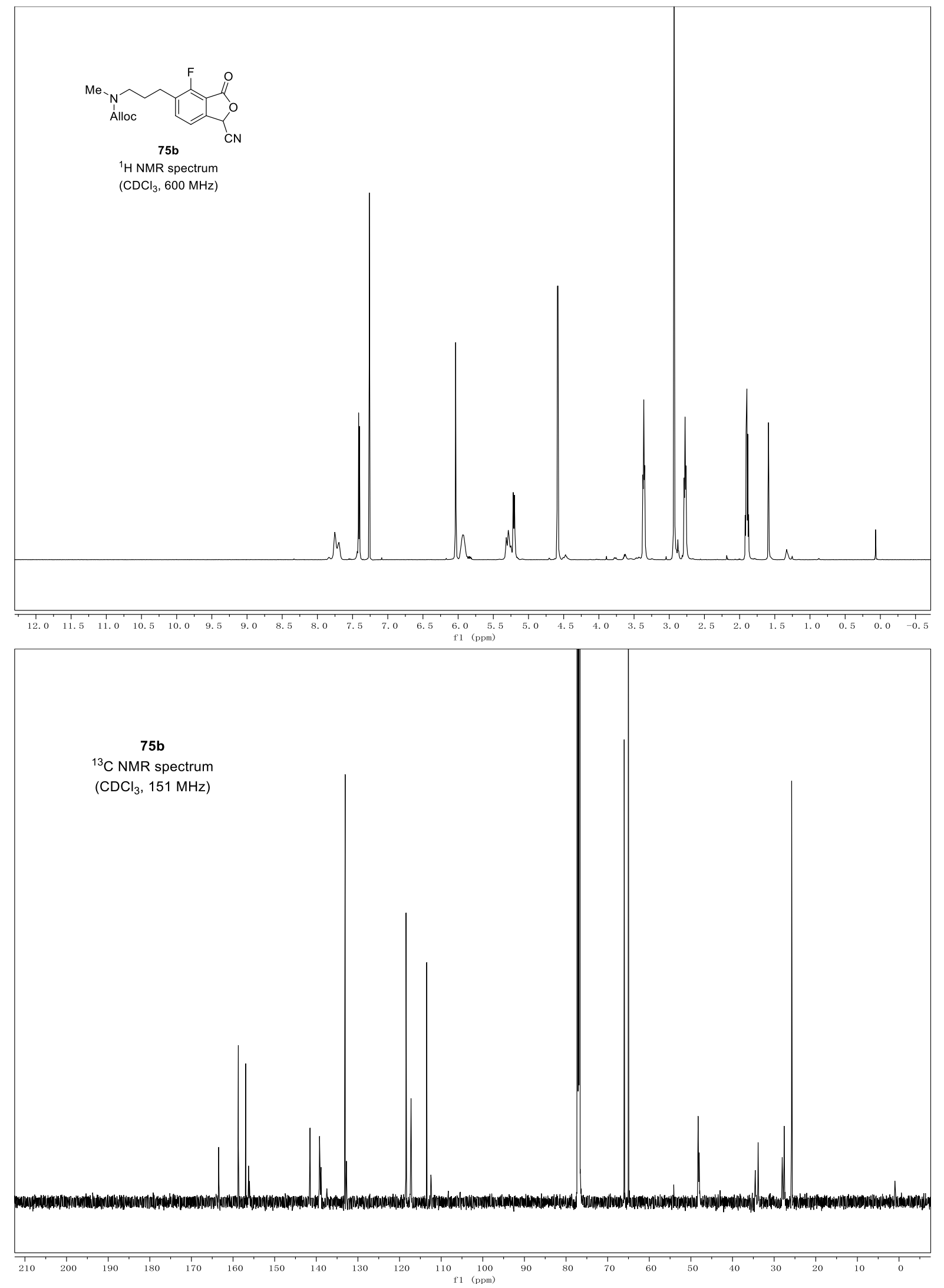


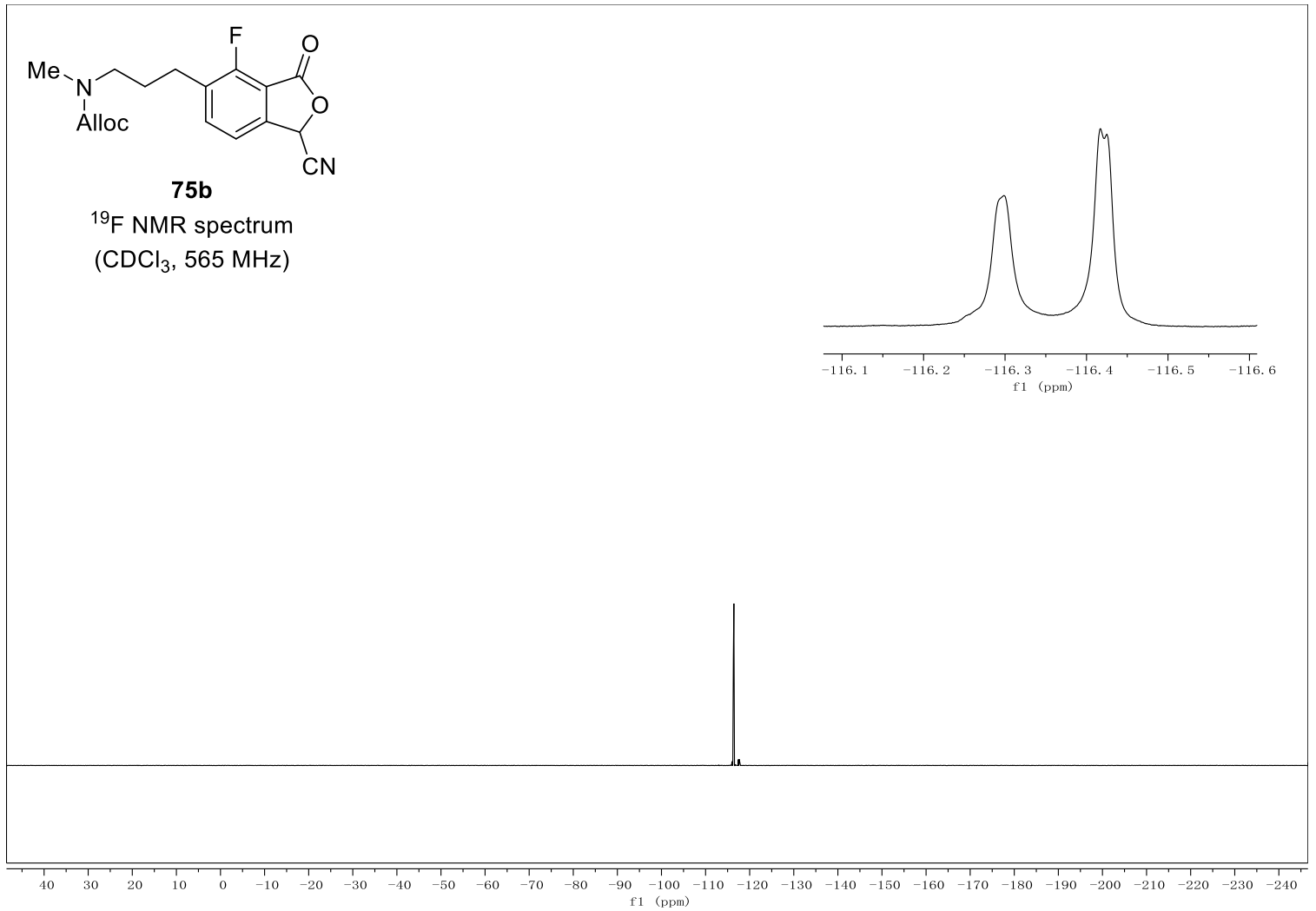



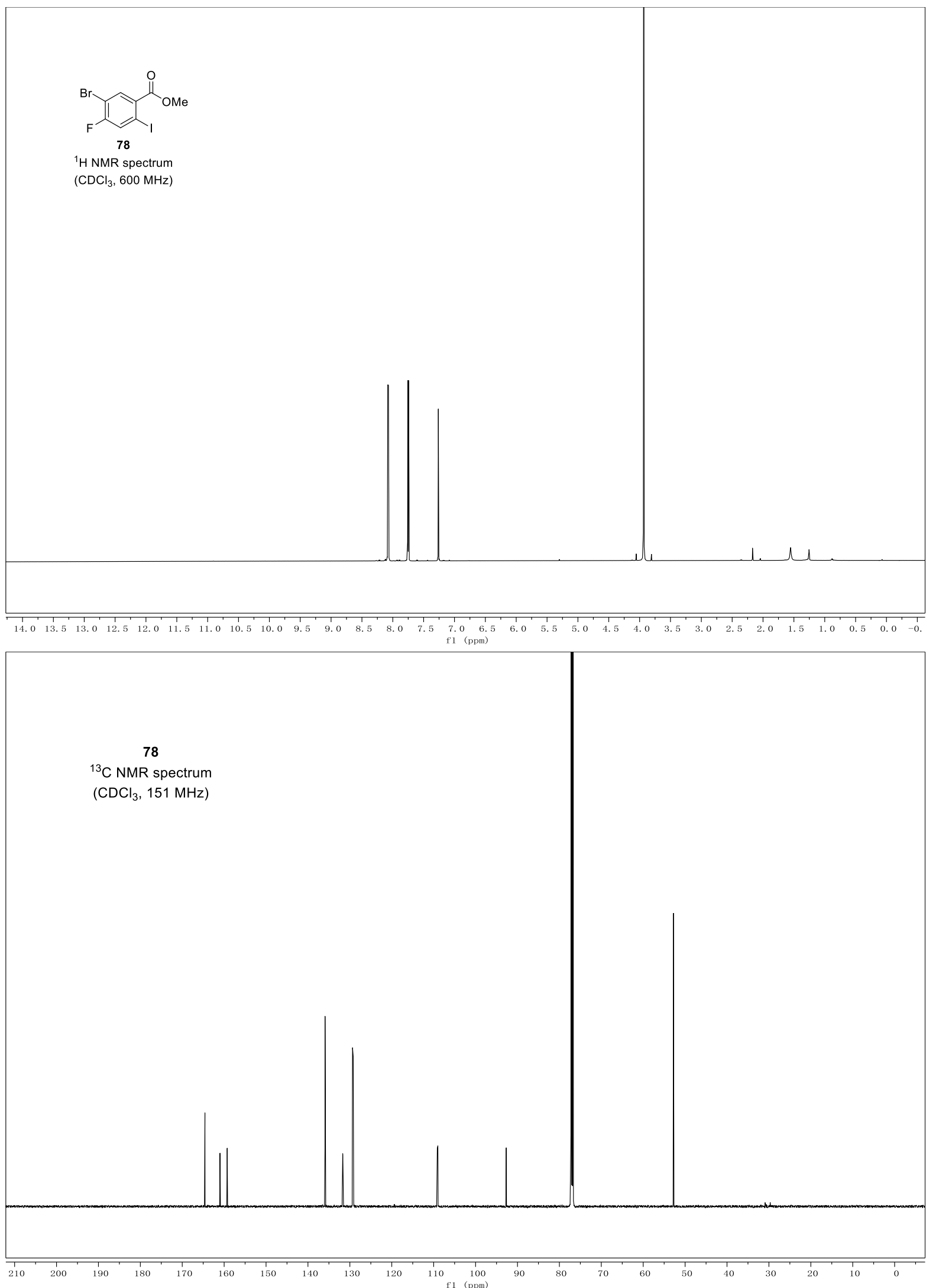


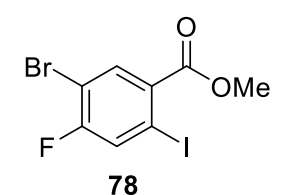

${ }^{19} \mathrm{~F}$ NMR spectrum $\left(\mathrm{CDCl}_{3}, 565 \mathrm{MHz}\right)$

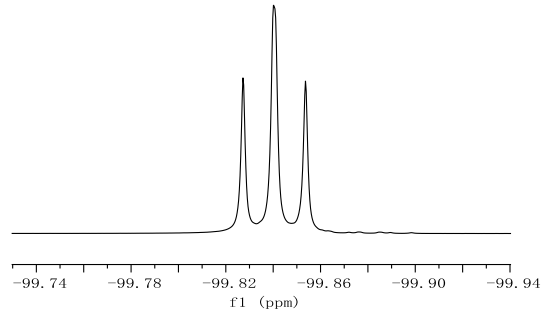

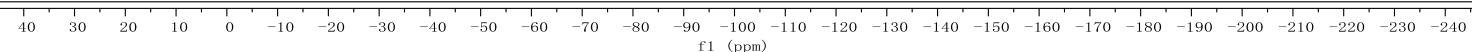



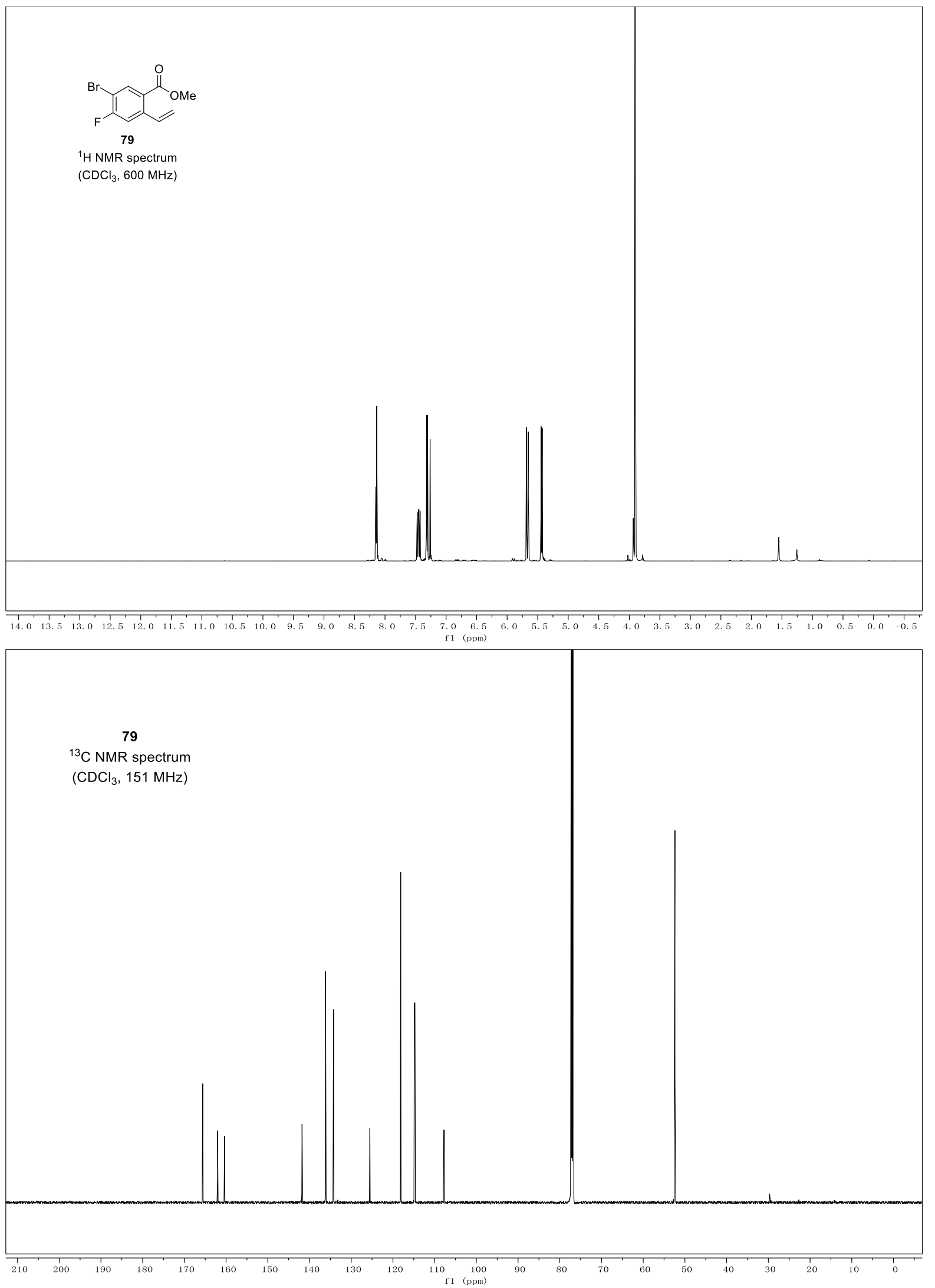


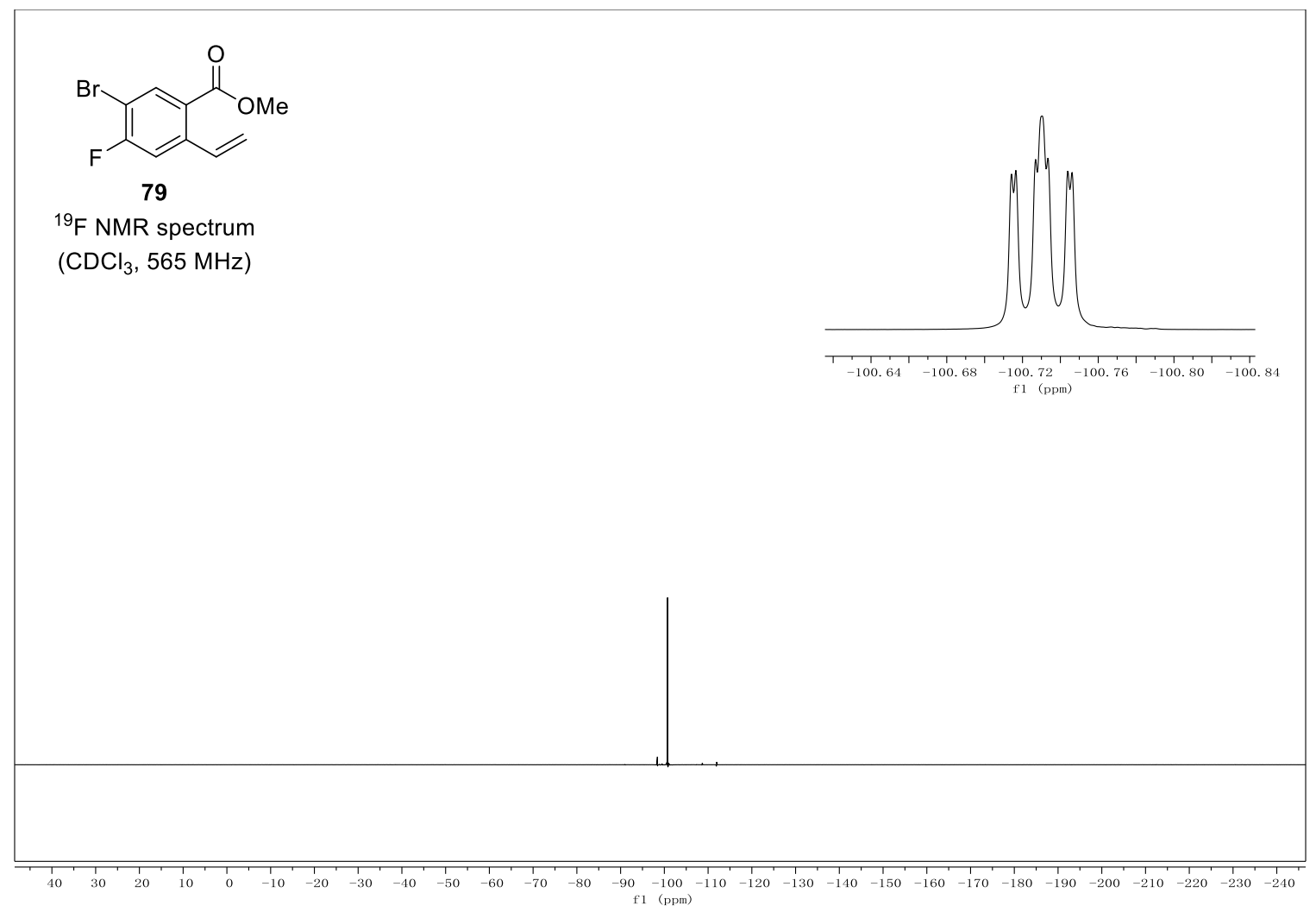



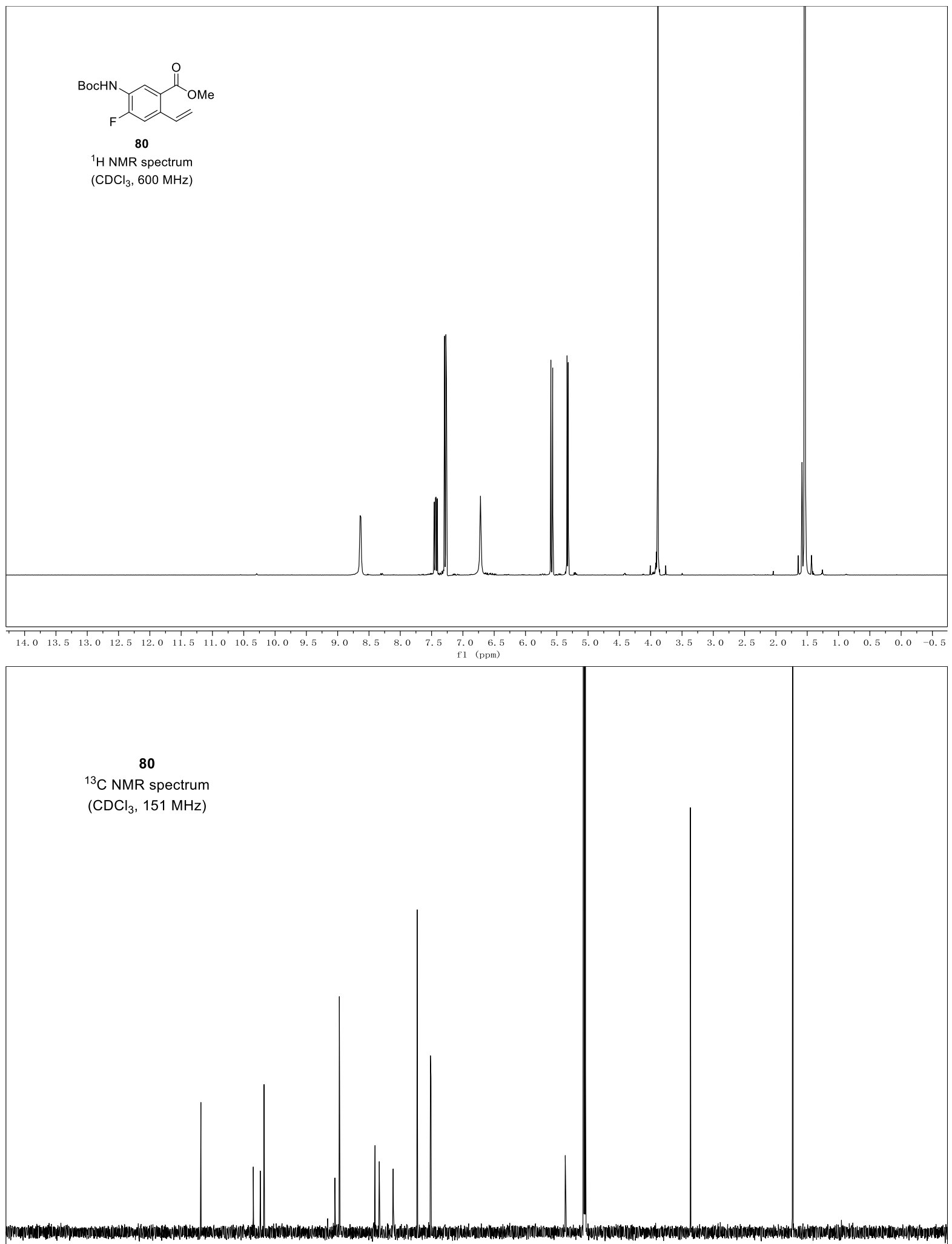

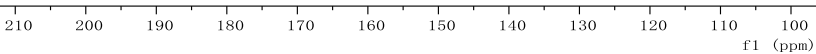




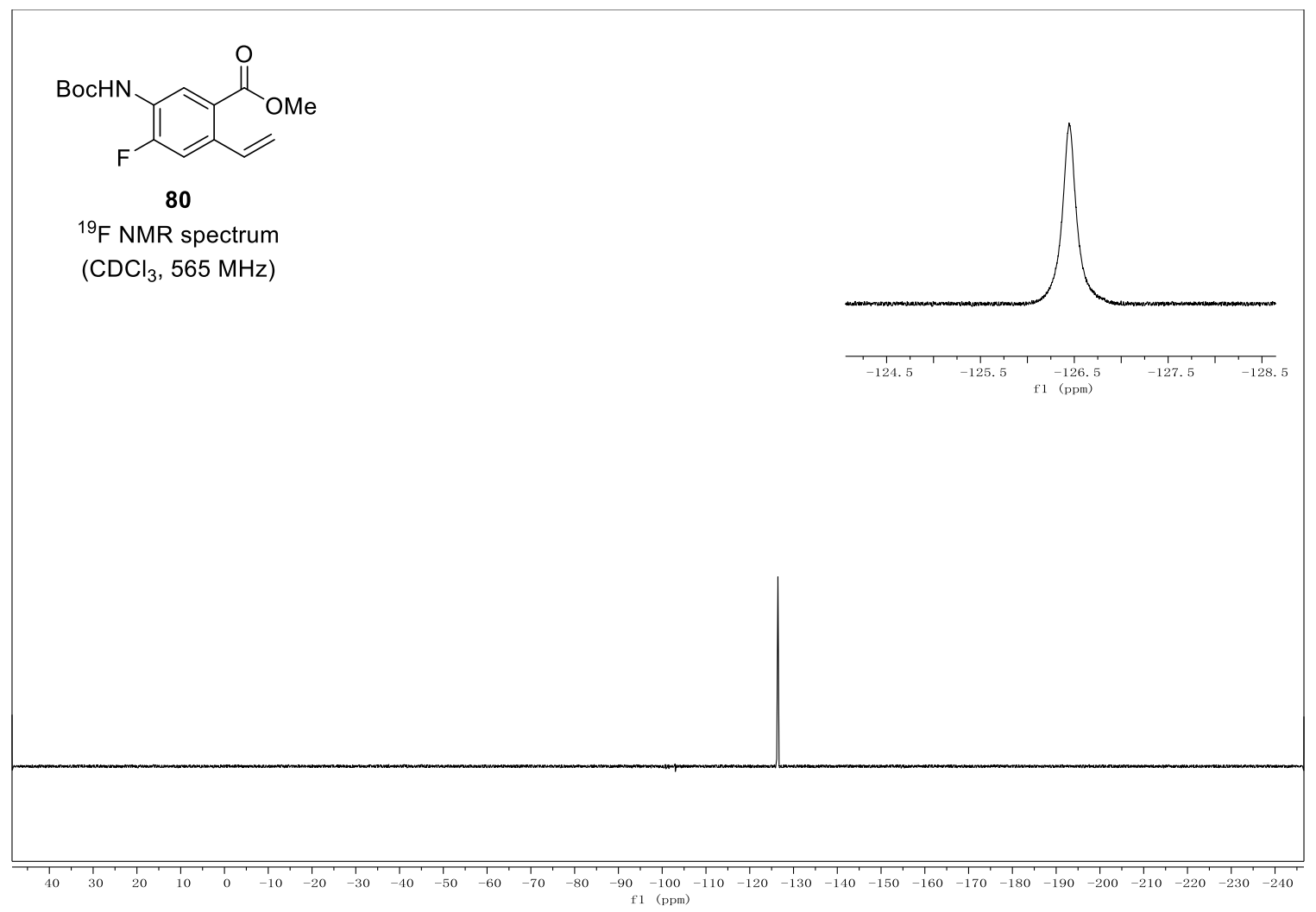




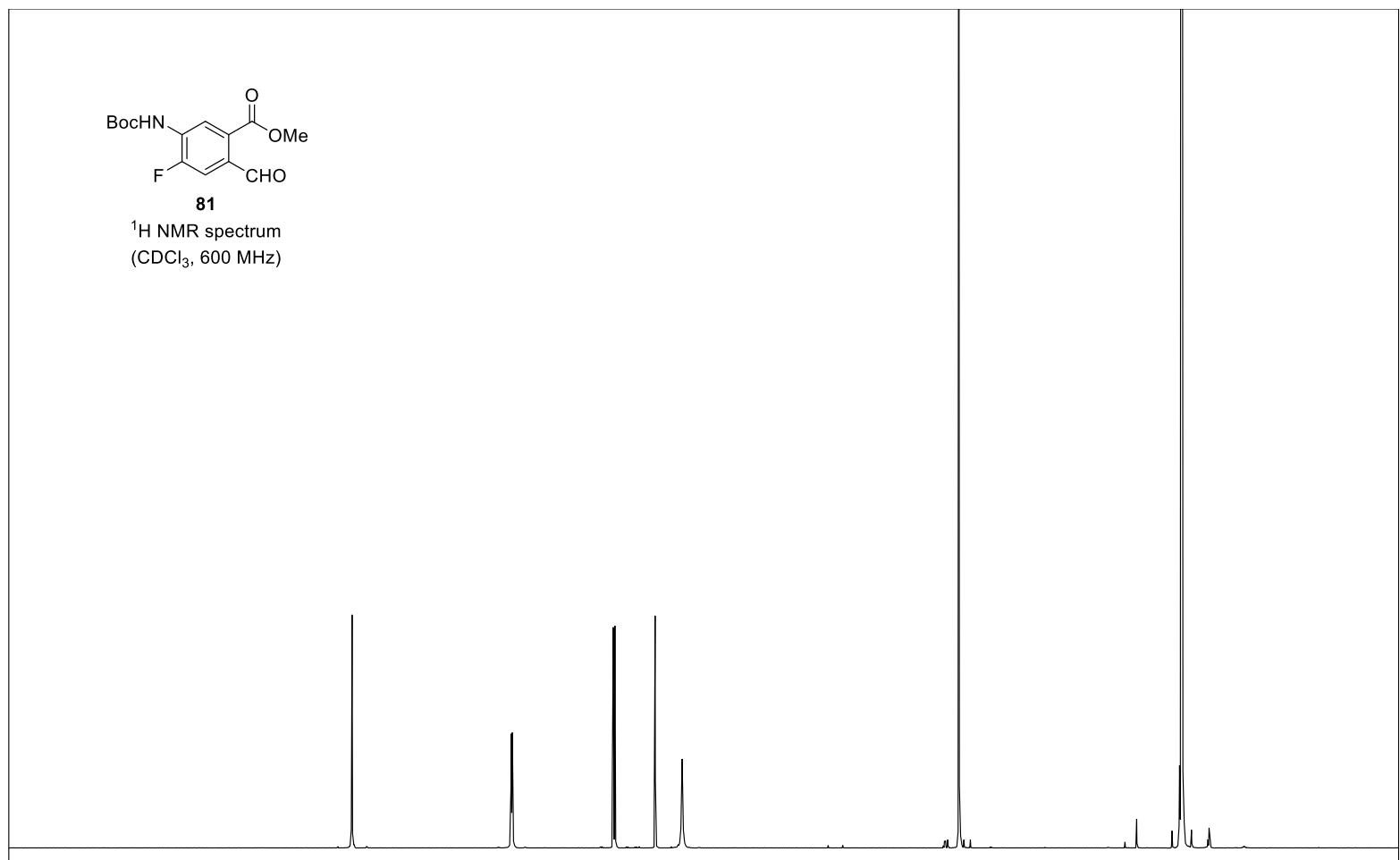

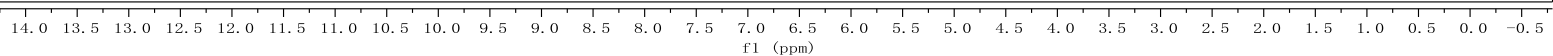

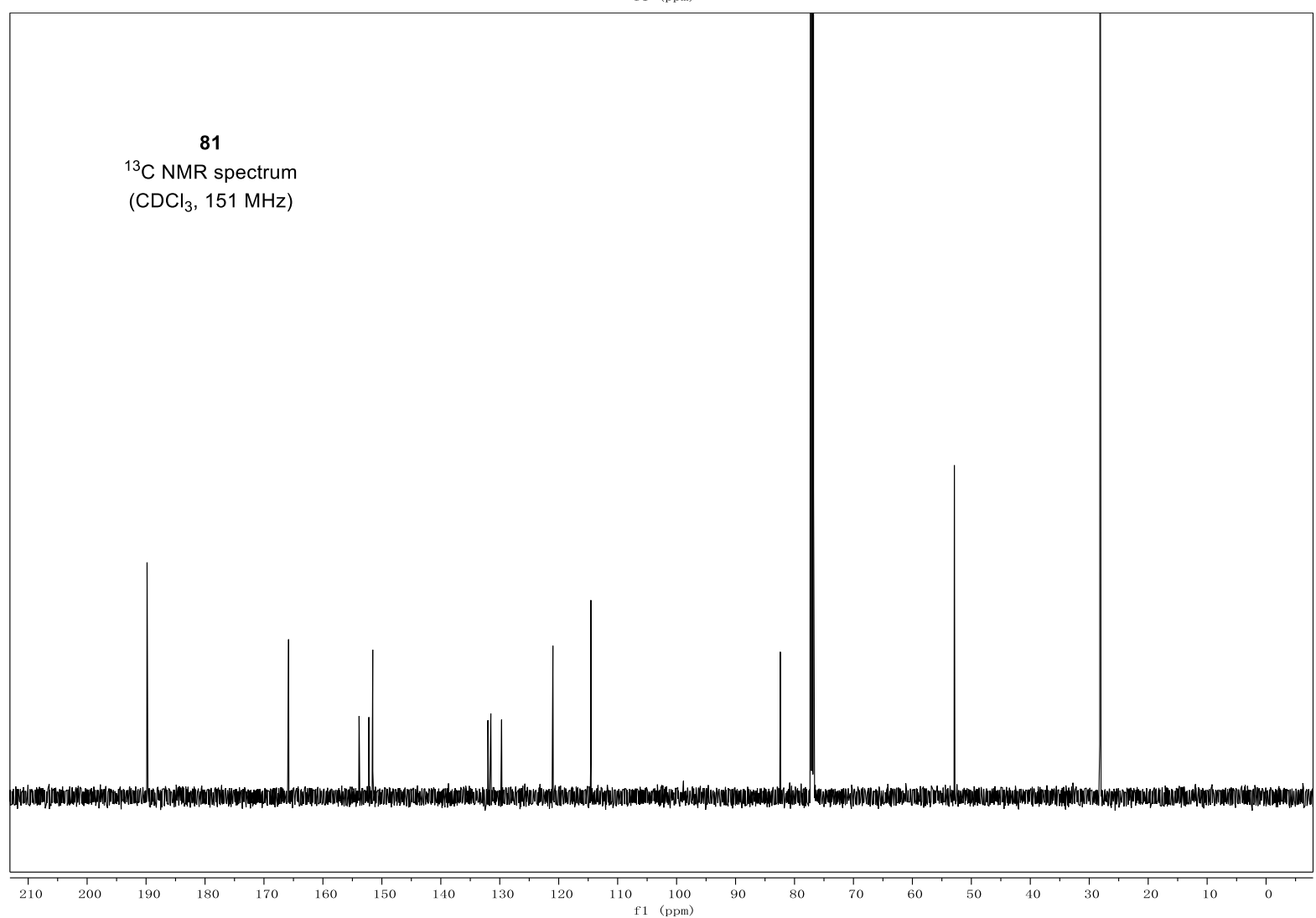




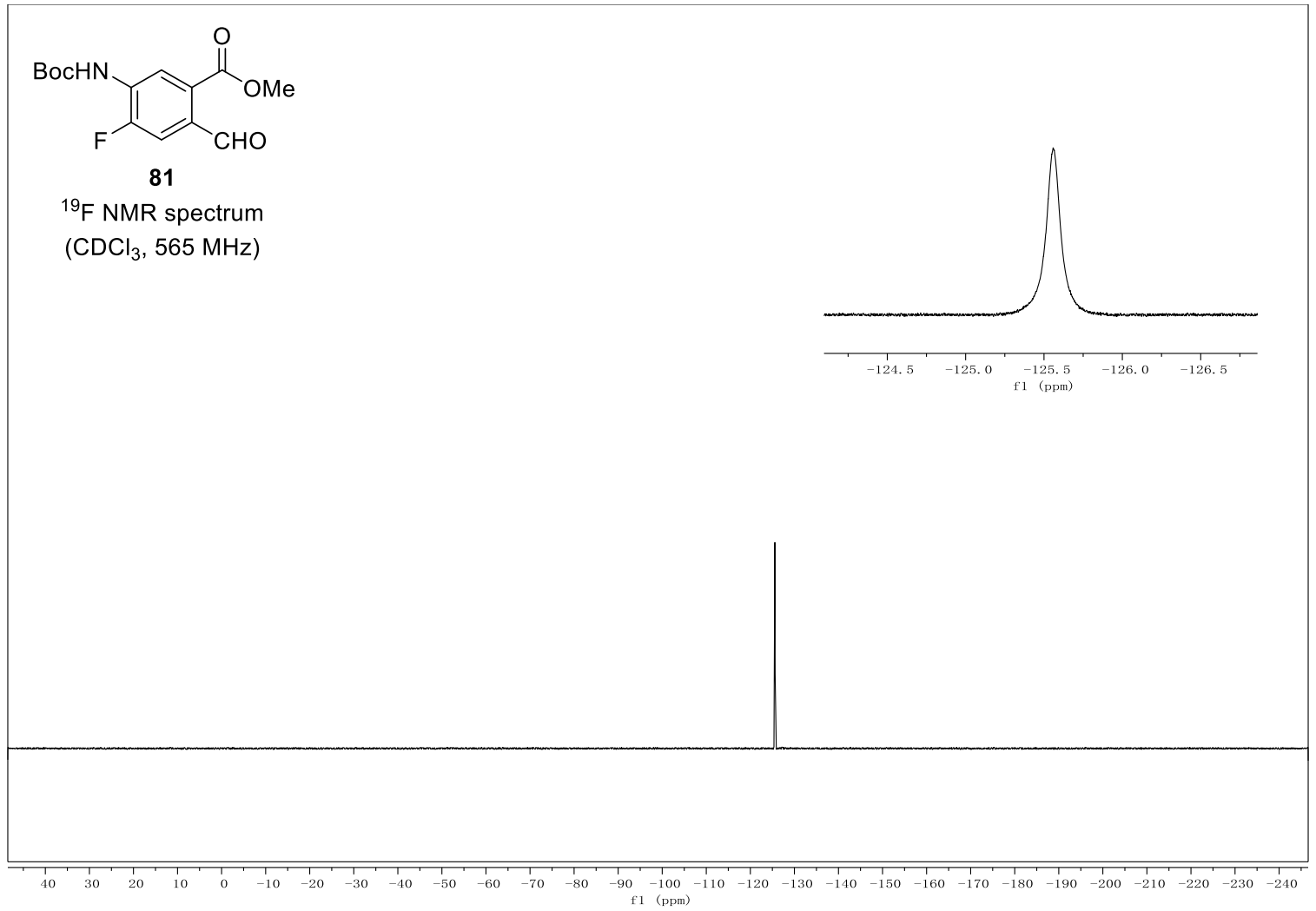




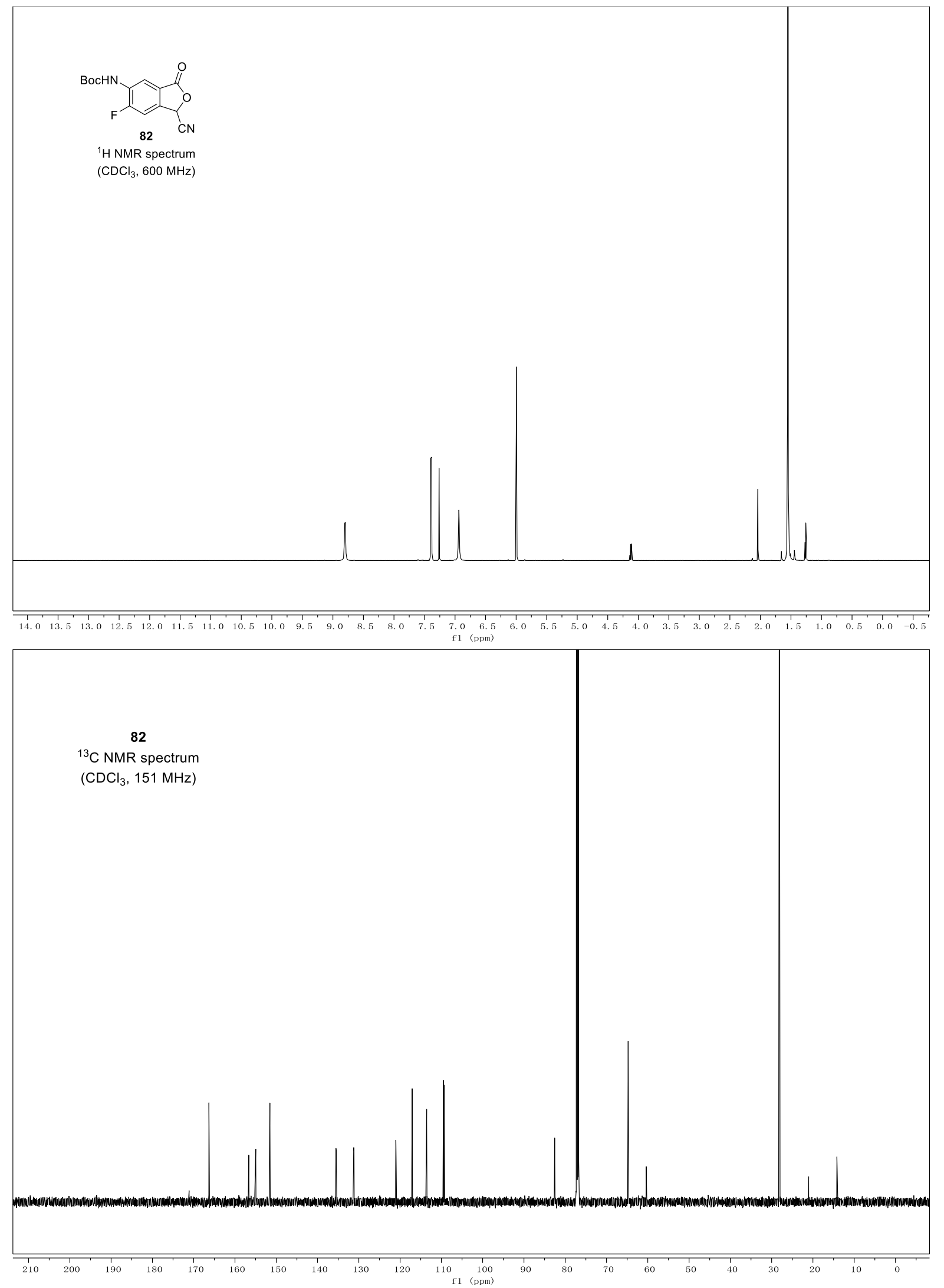




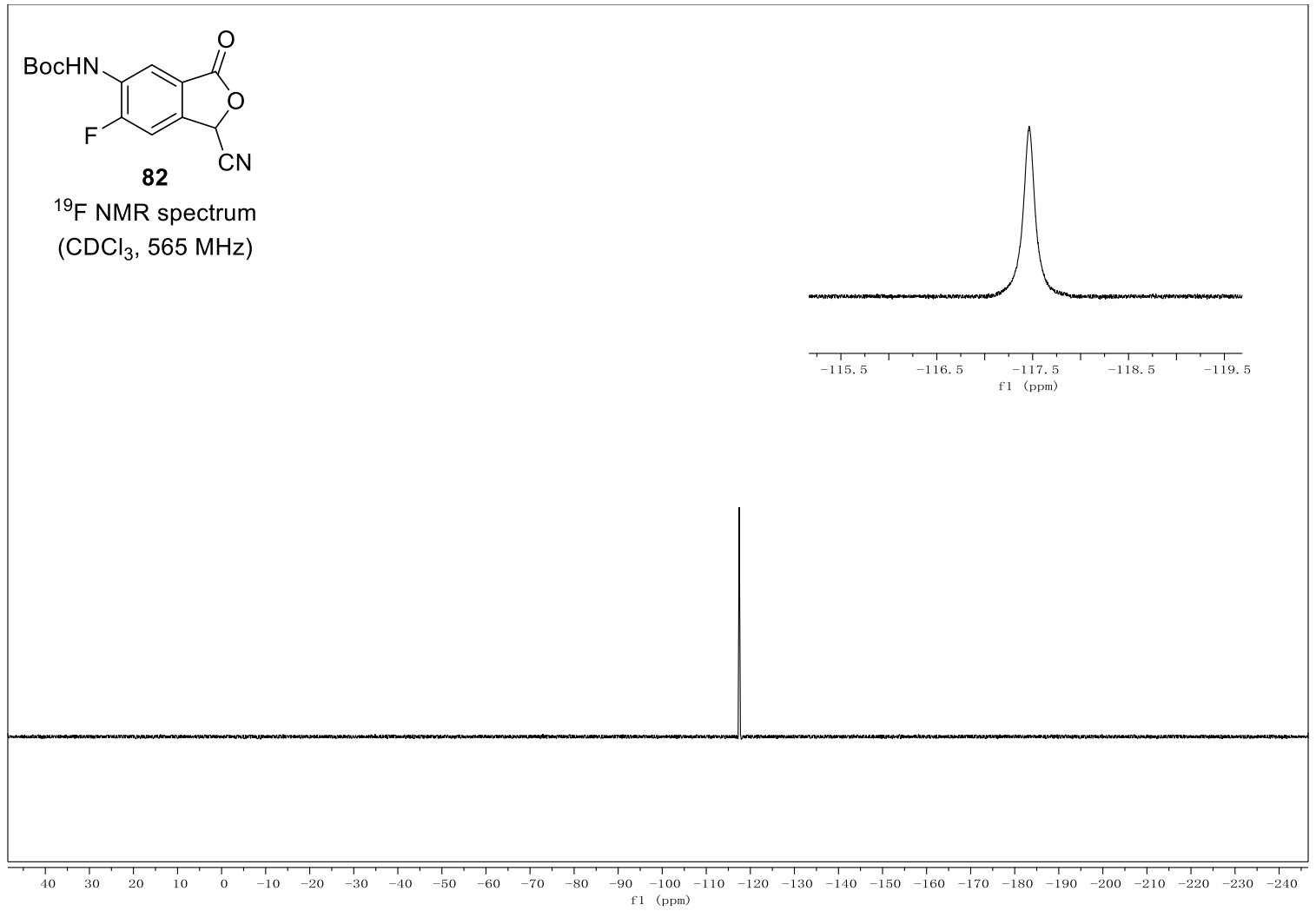




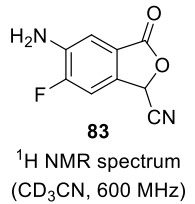

$\left(\mathrm{CD}_{3} \mathrm{CN}, 600 \mathrm{MHz}\right)$
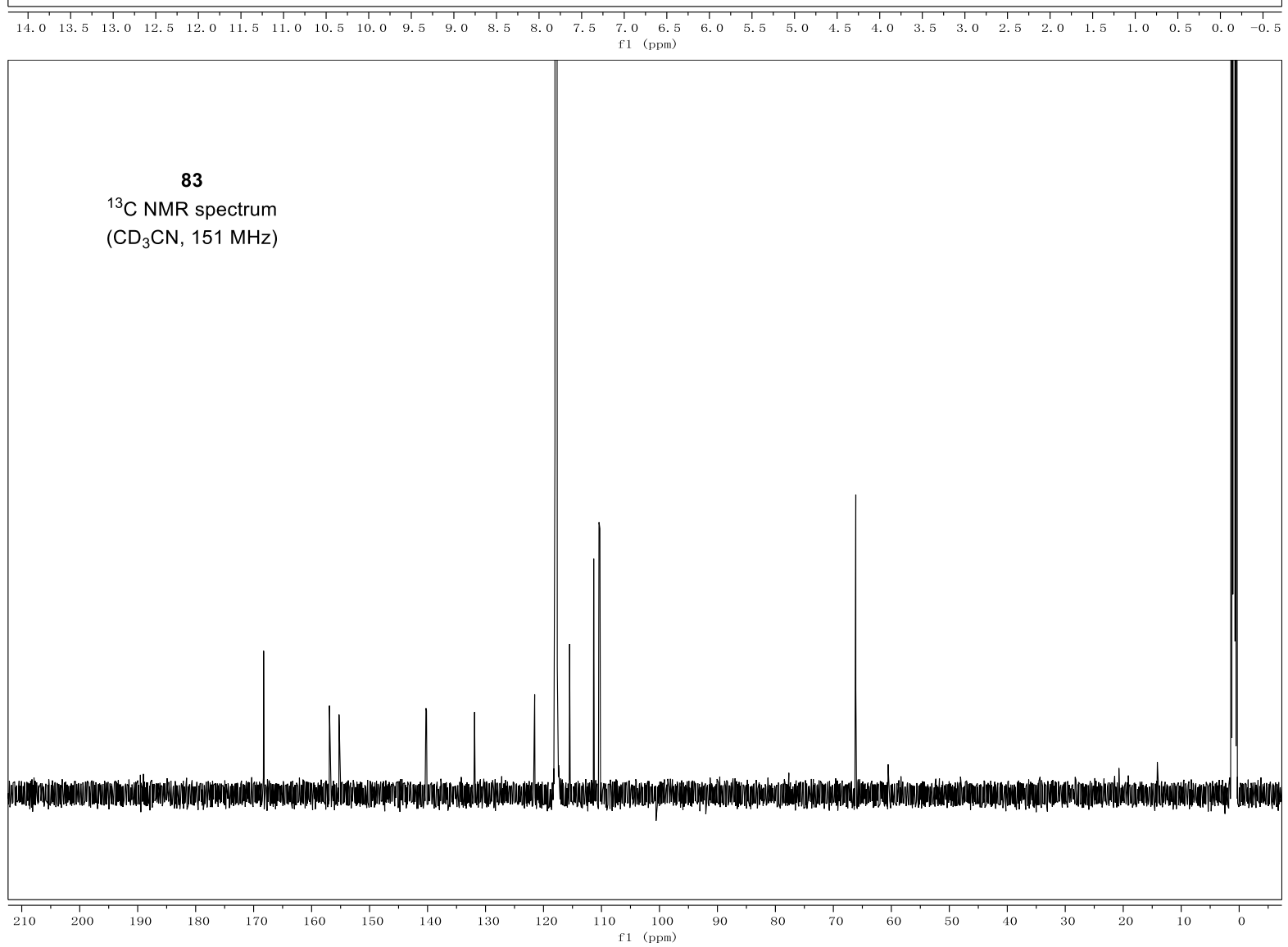


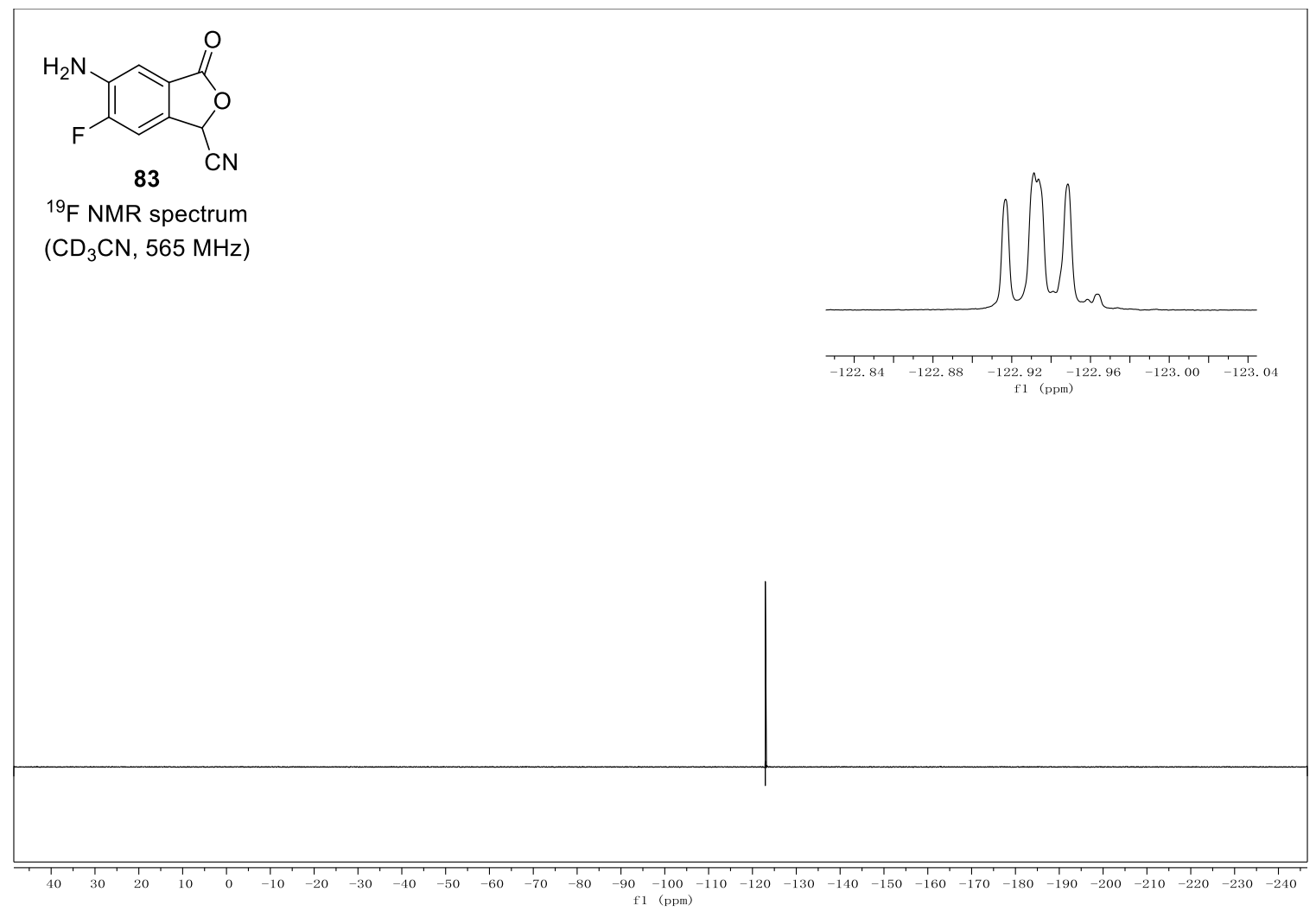



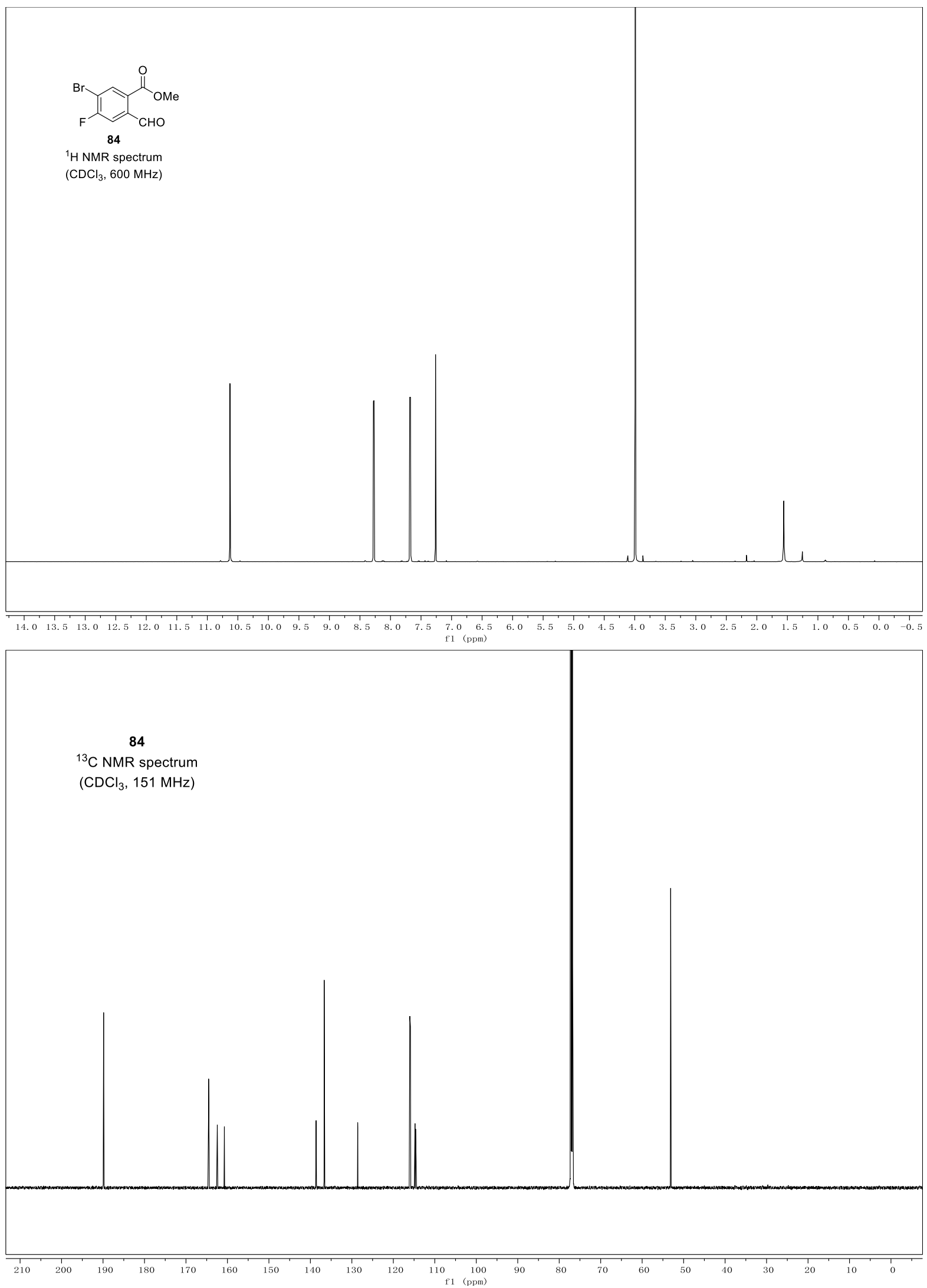


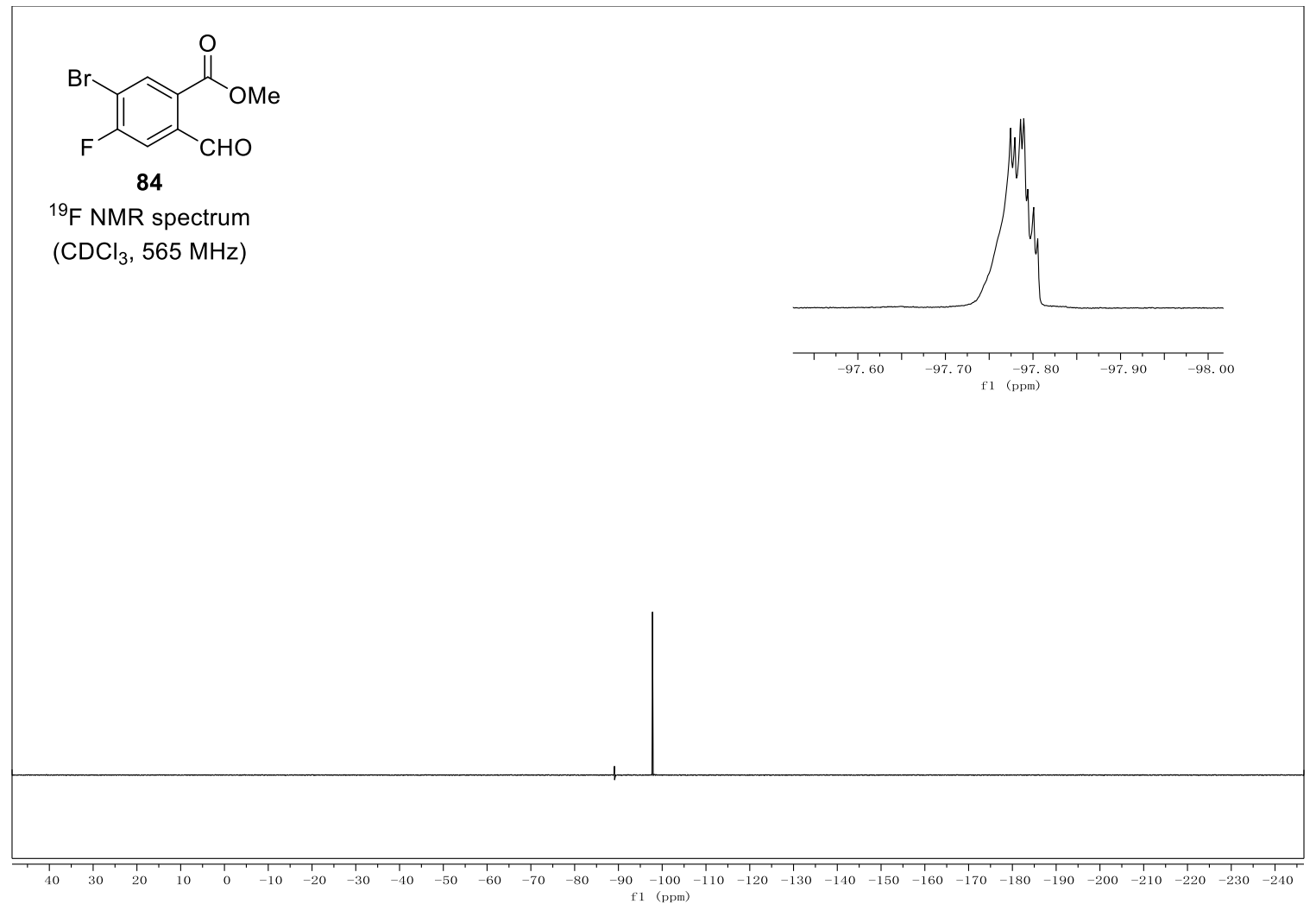



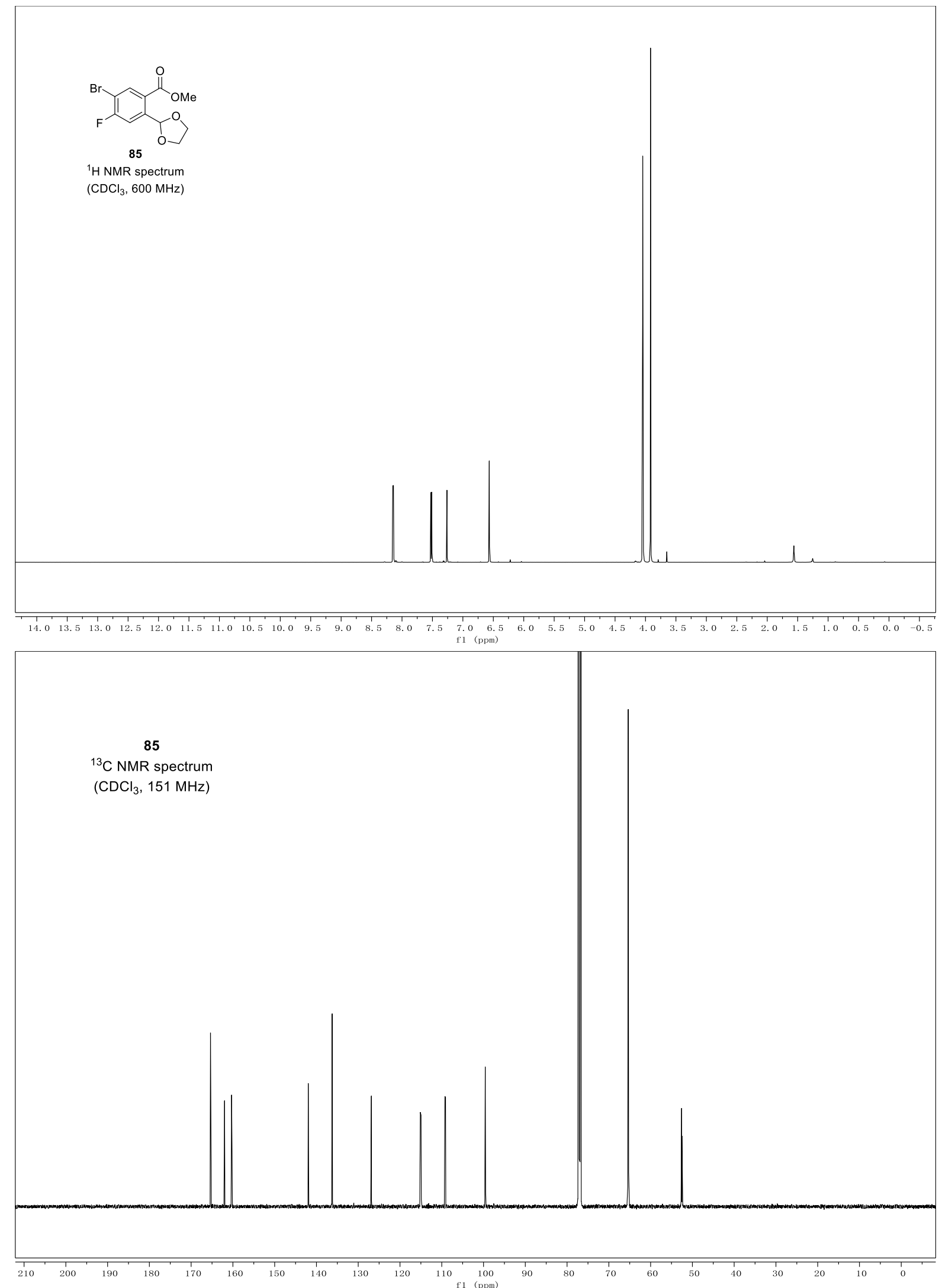


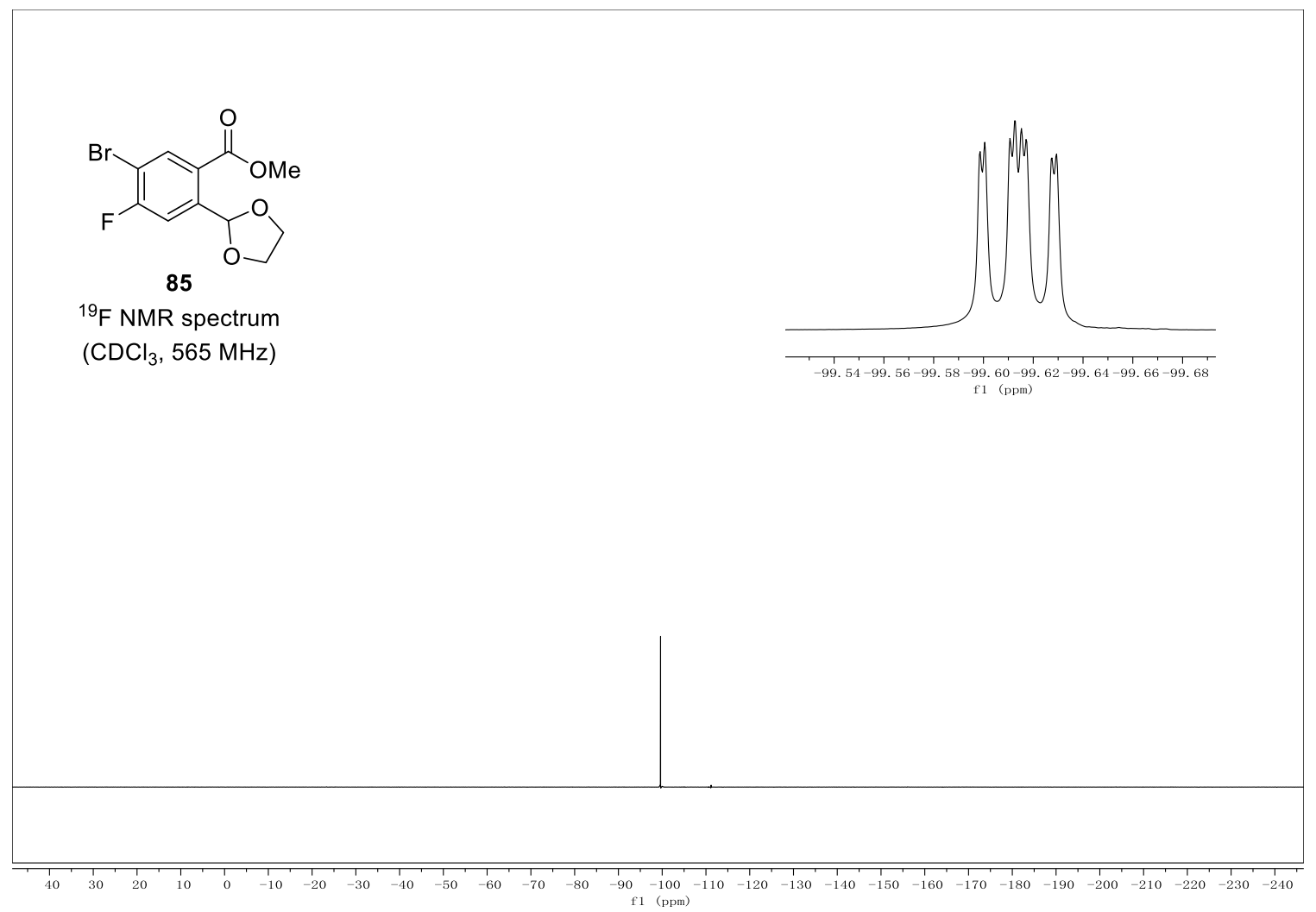



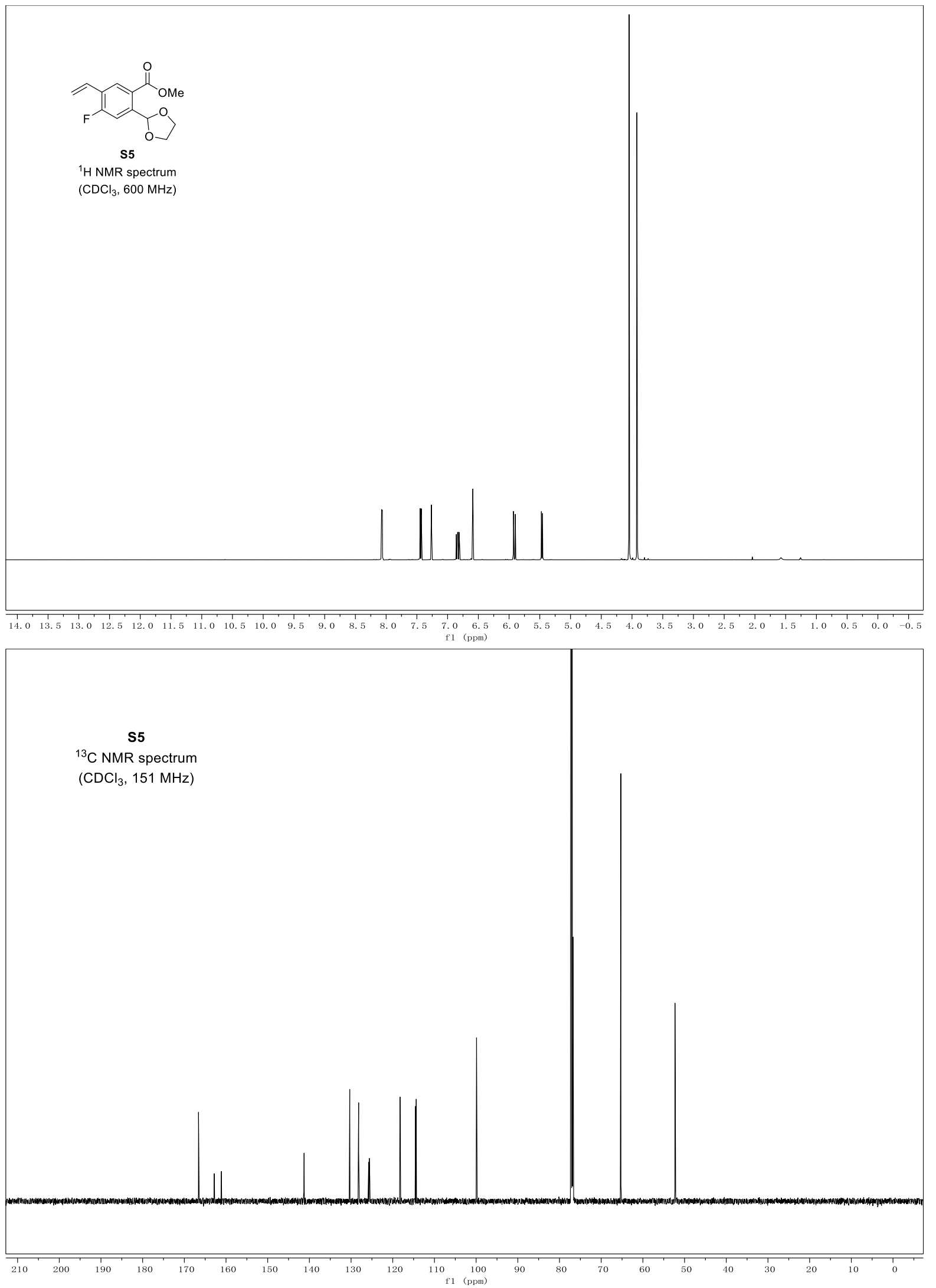


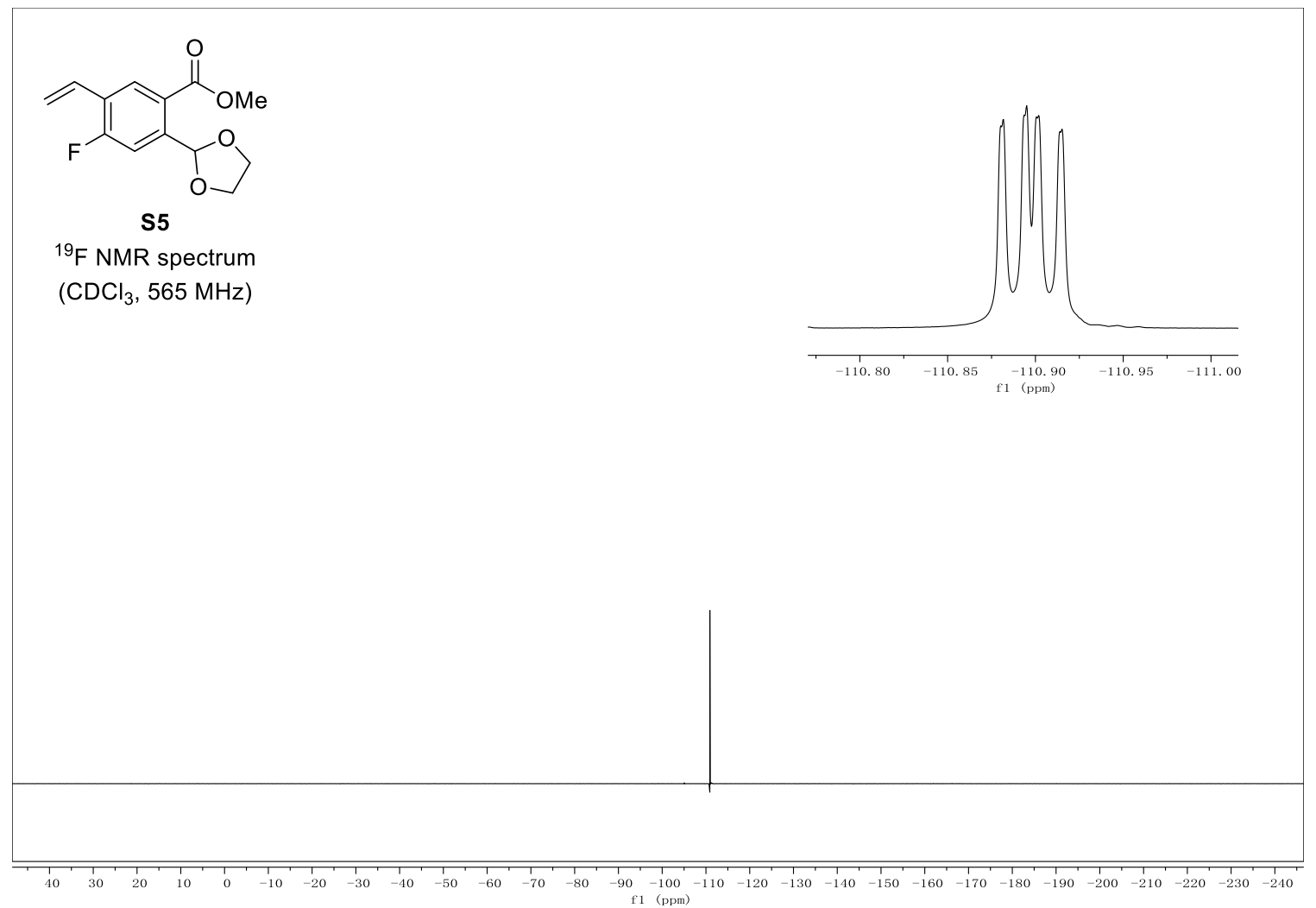




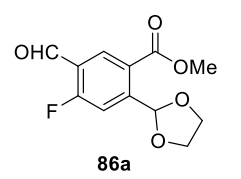

${ }^{1} \mathrm{H}$ NMR spectrum

$\left(\mathrm{CDCl}_{3}, 600 \mathrm{MHz}\right)$

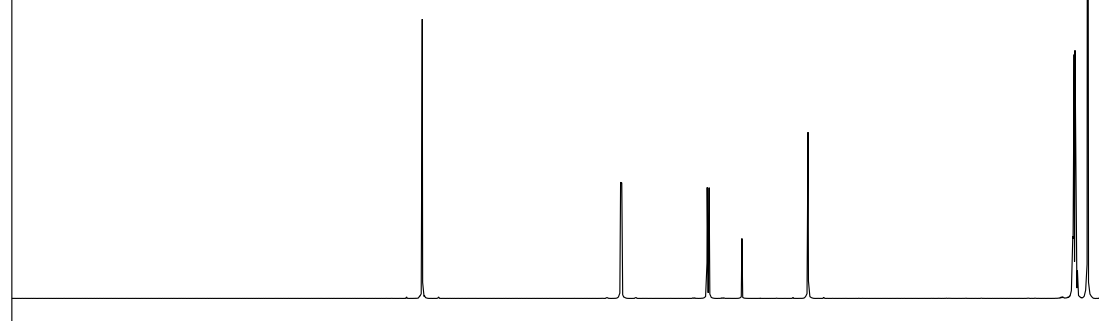

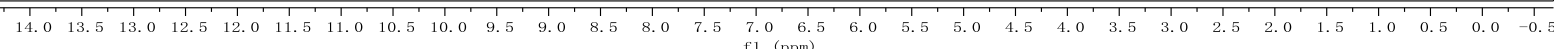
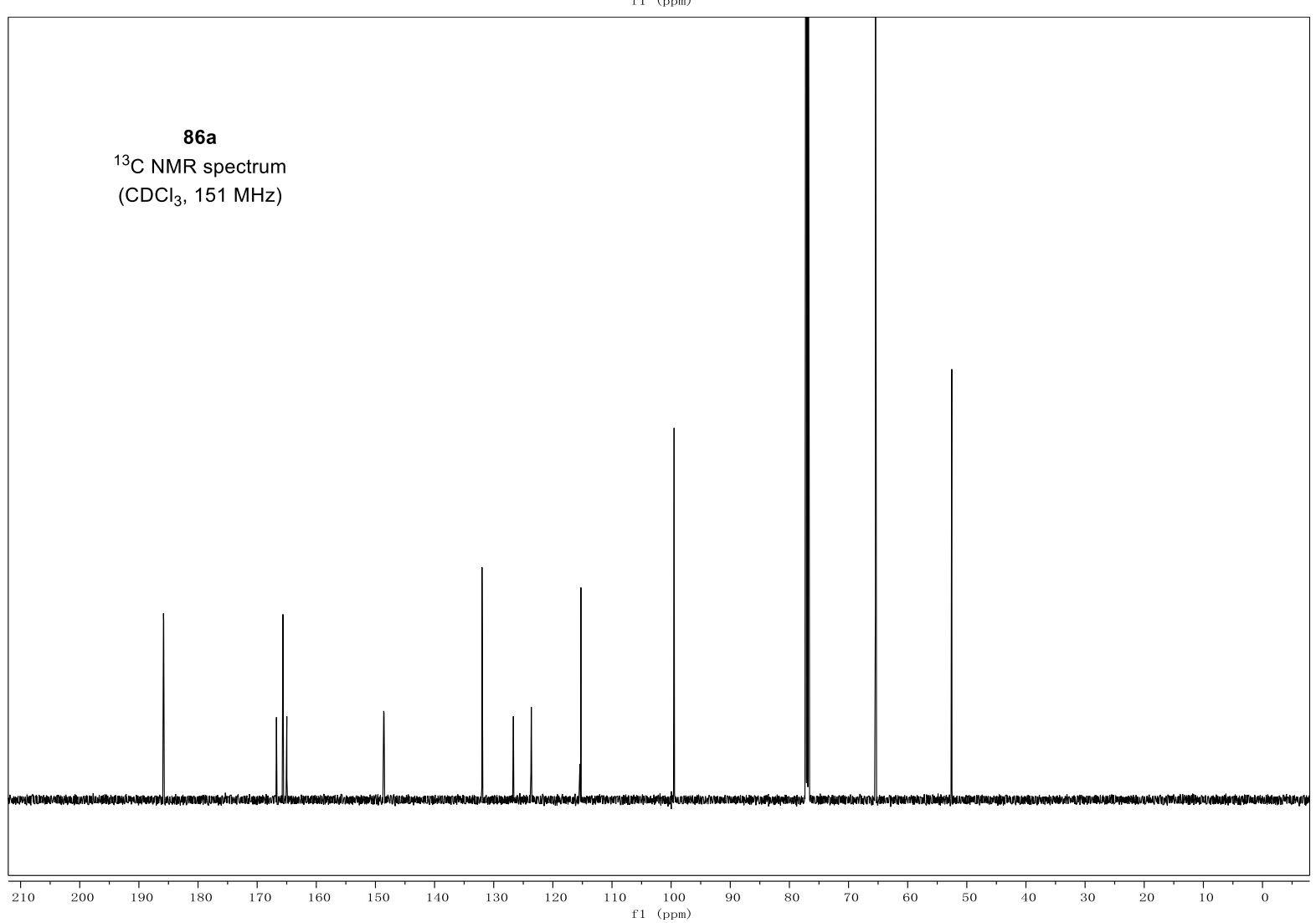


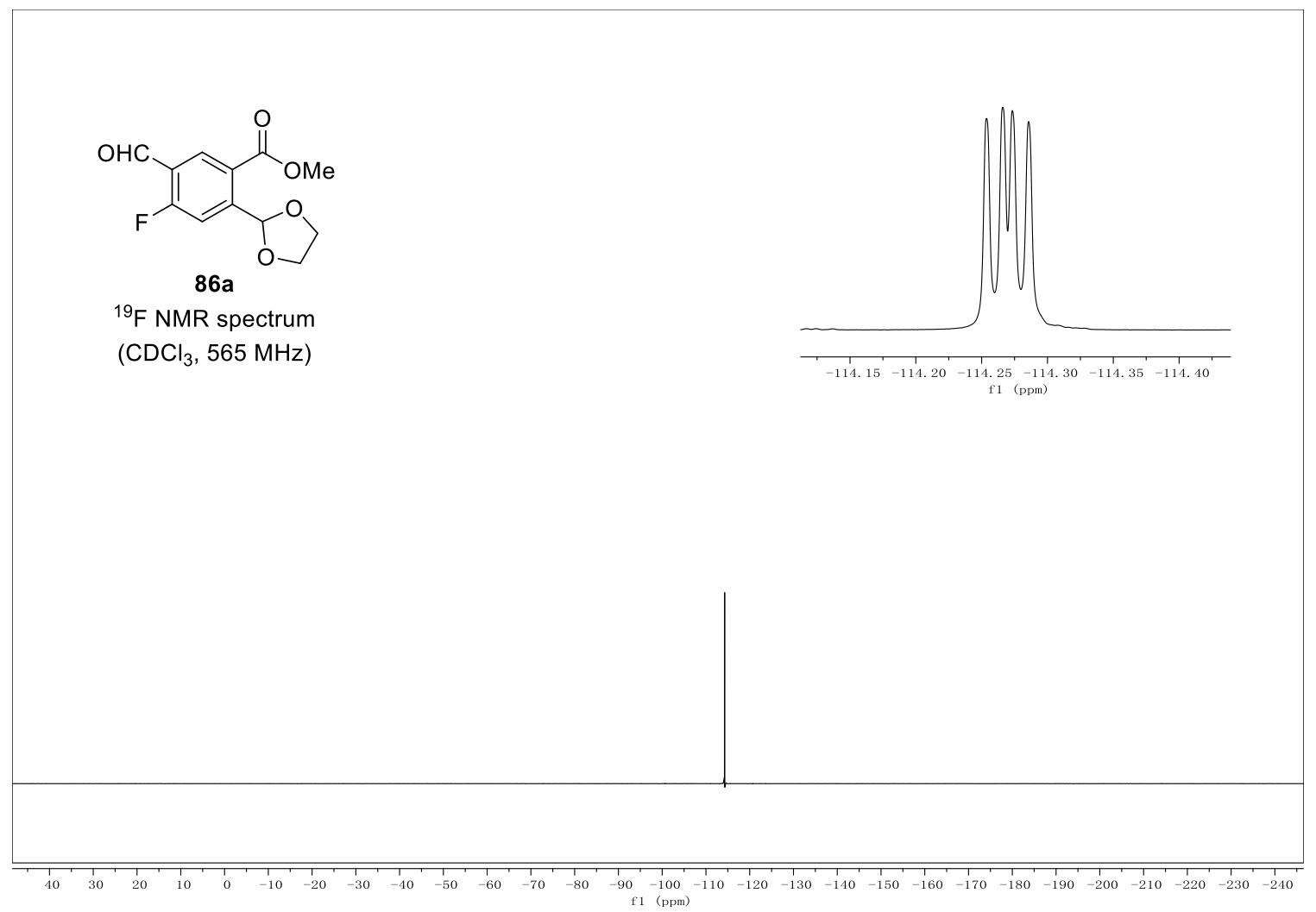




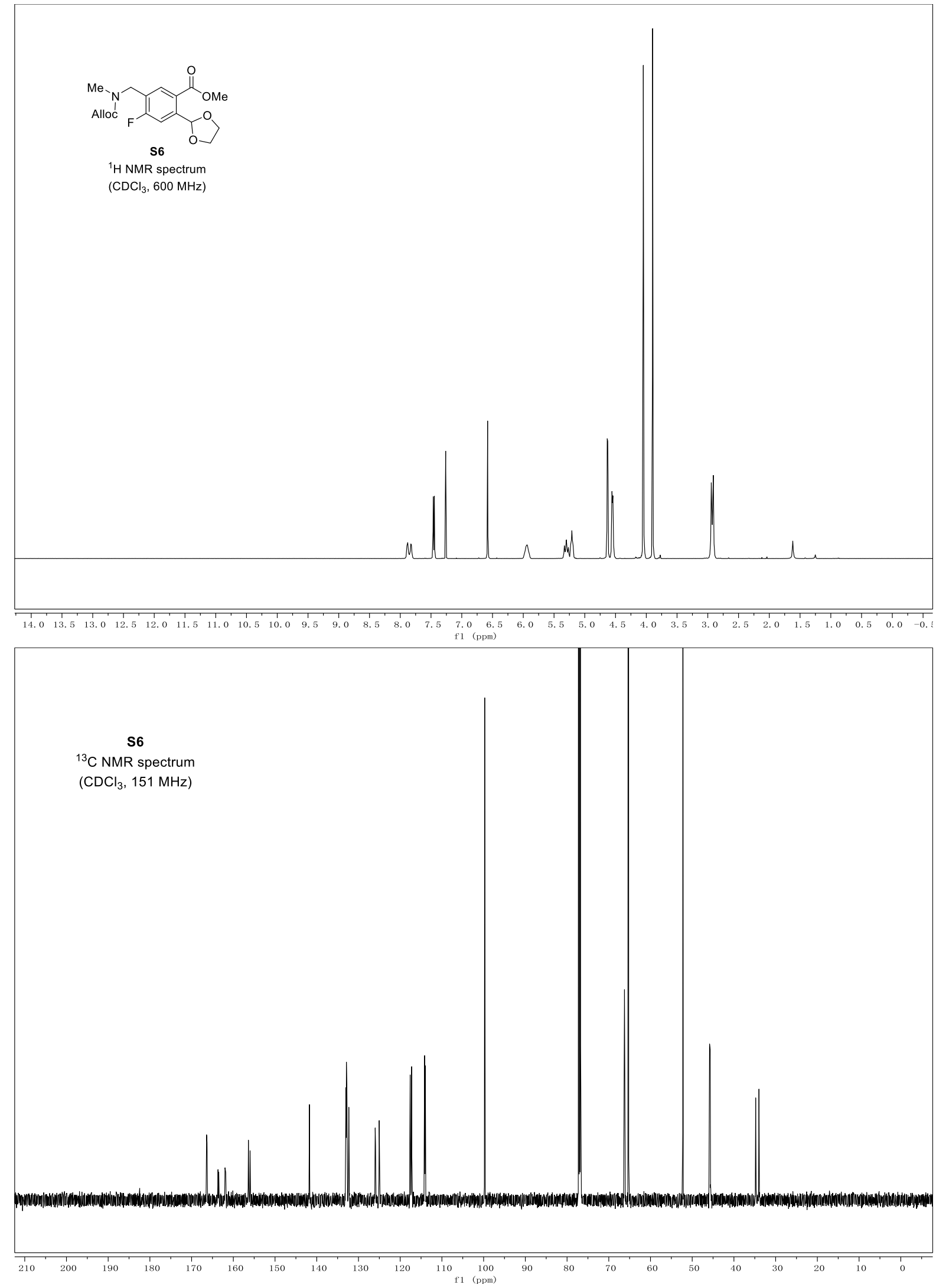




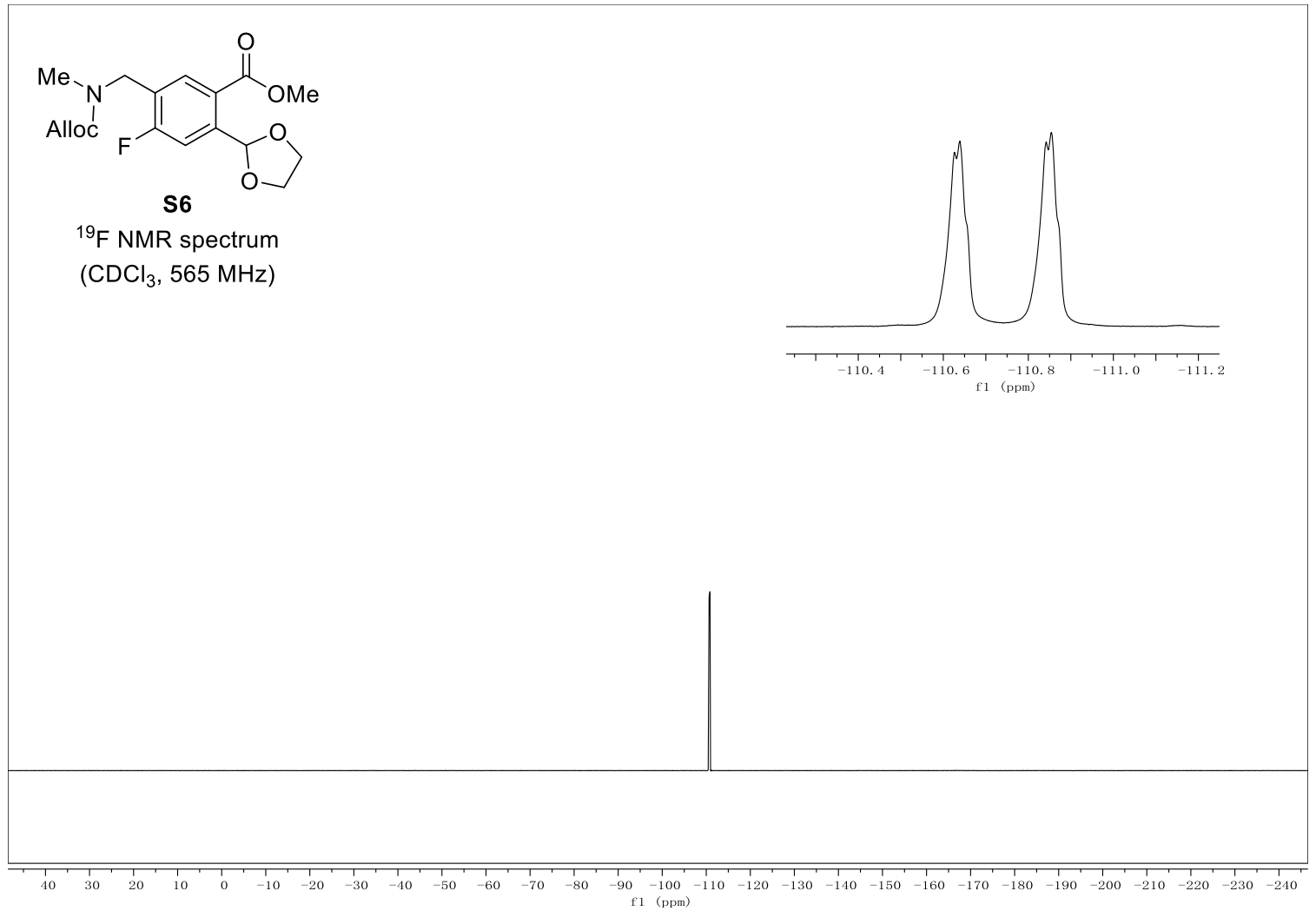



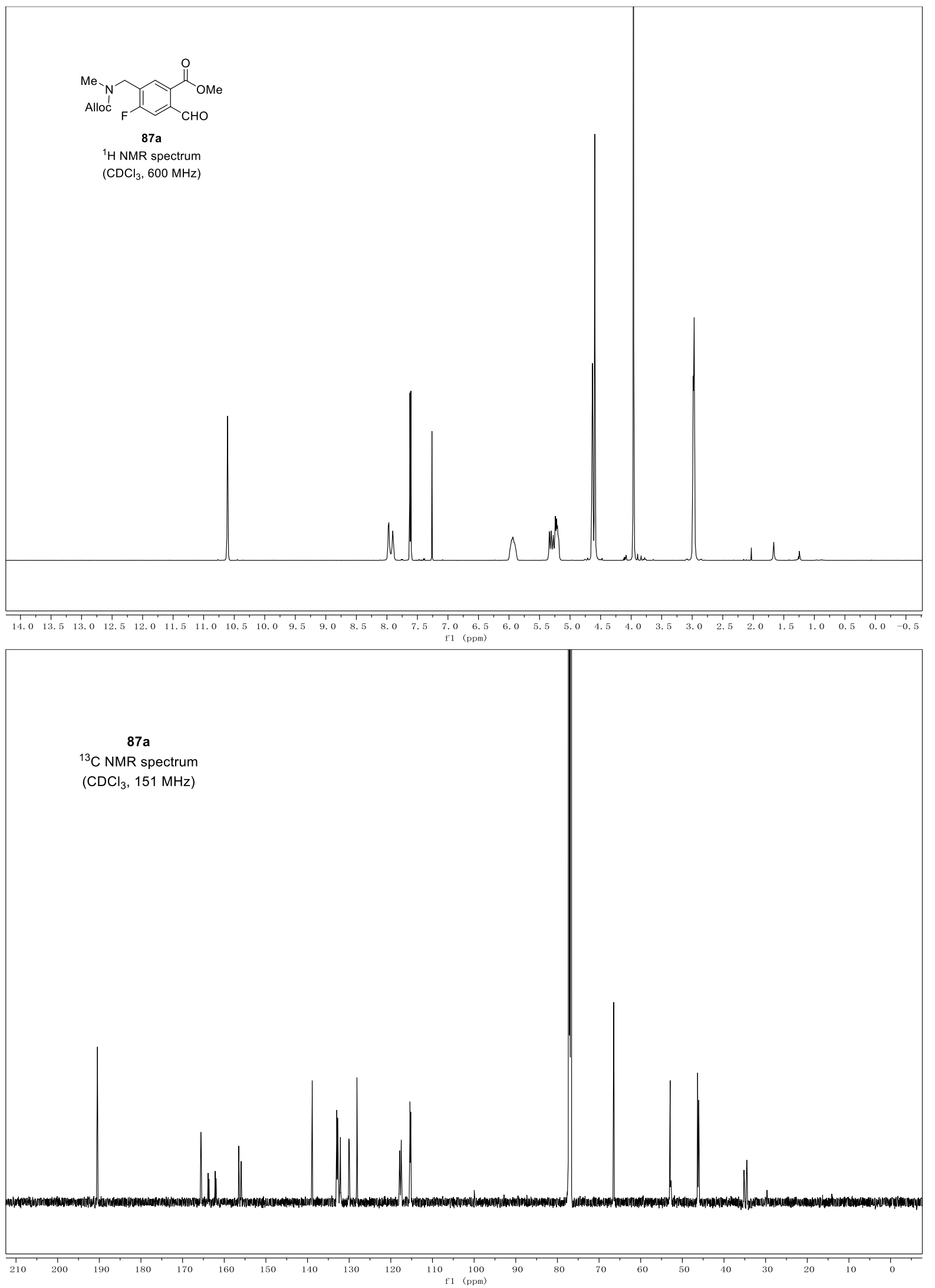


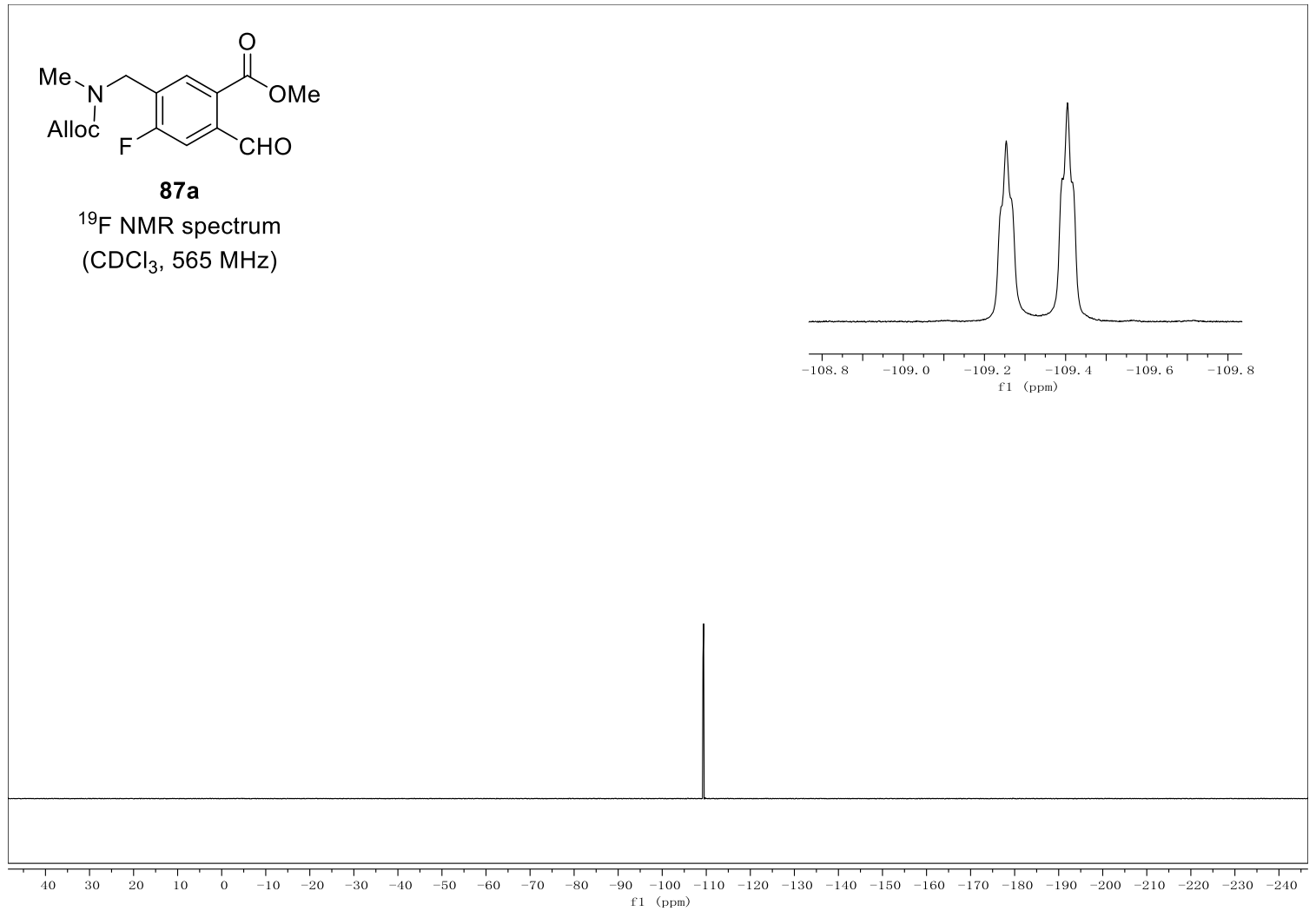



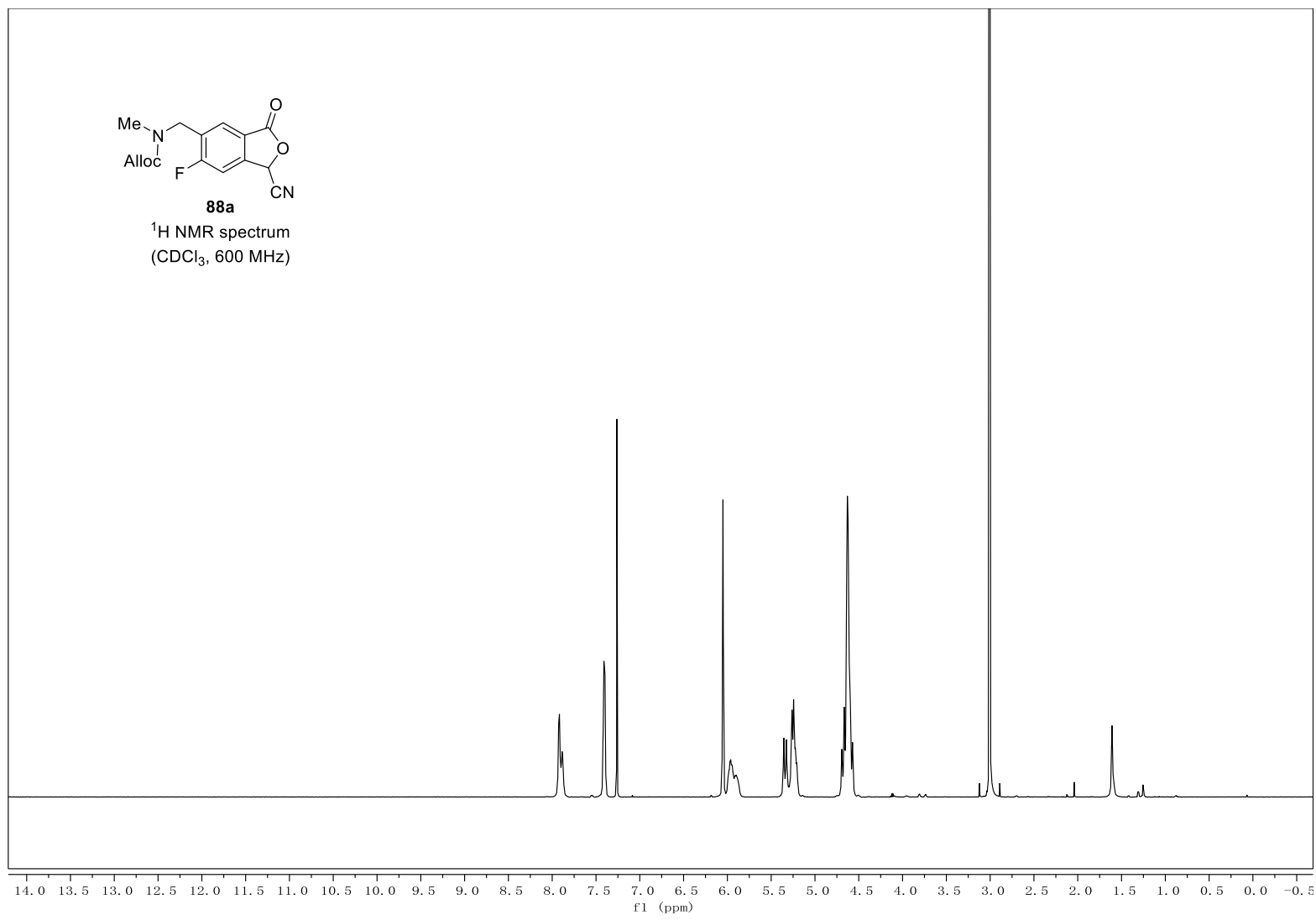

88a

${ }^{13} \mathrm{C}$ NMR spectrum $\left(\mathrm{CDCl}_{3}, 151 \mathrm{MHz}\right)$
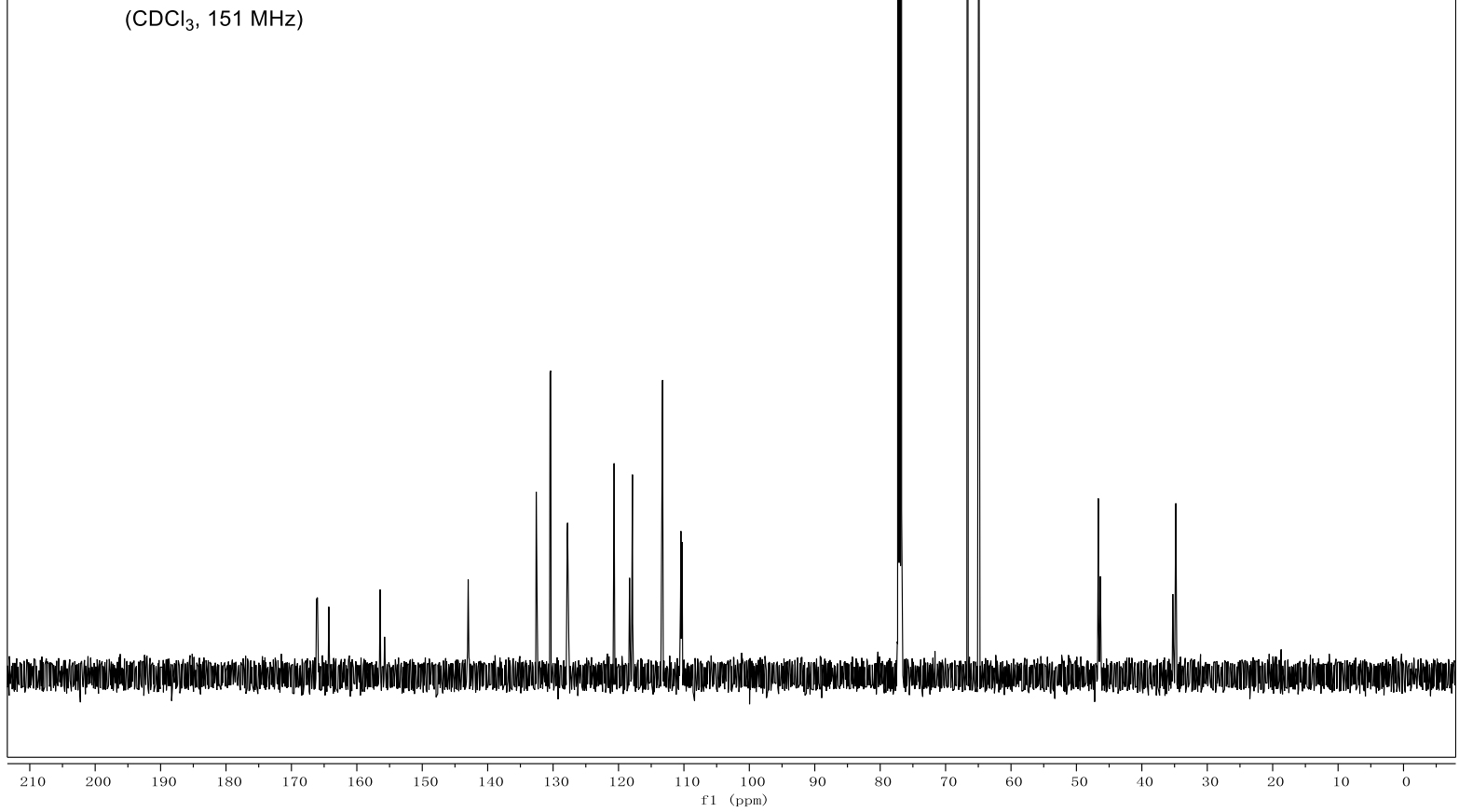


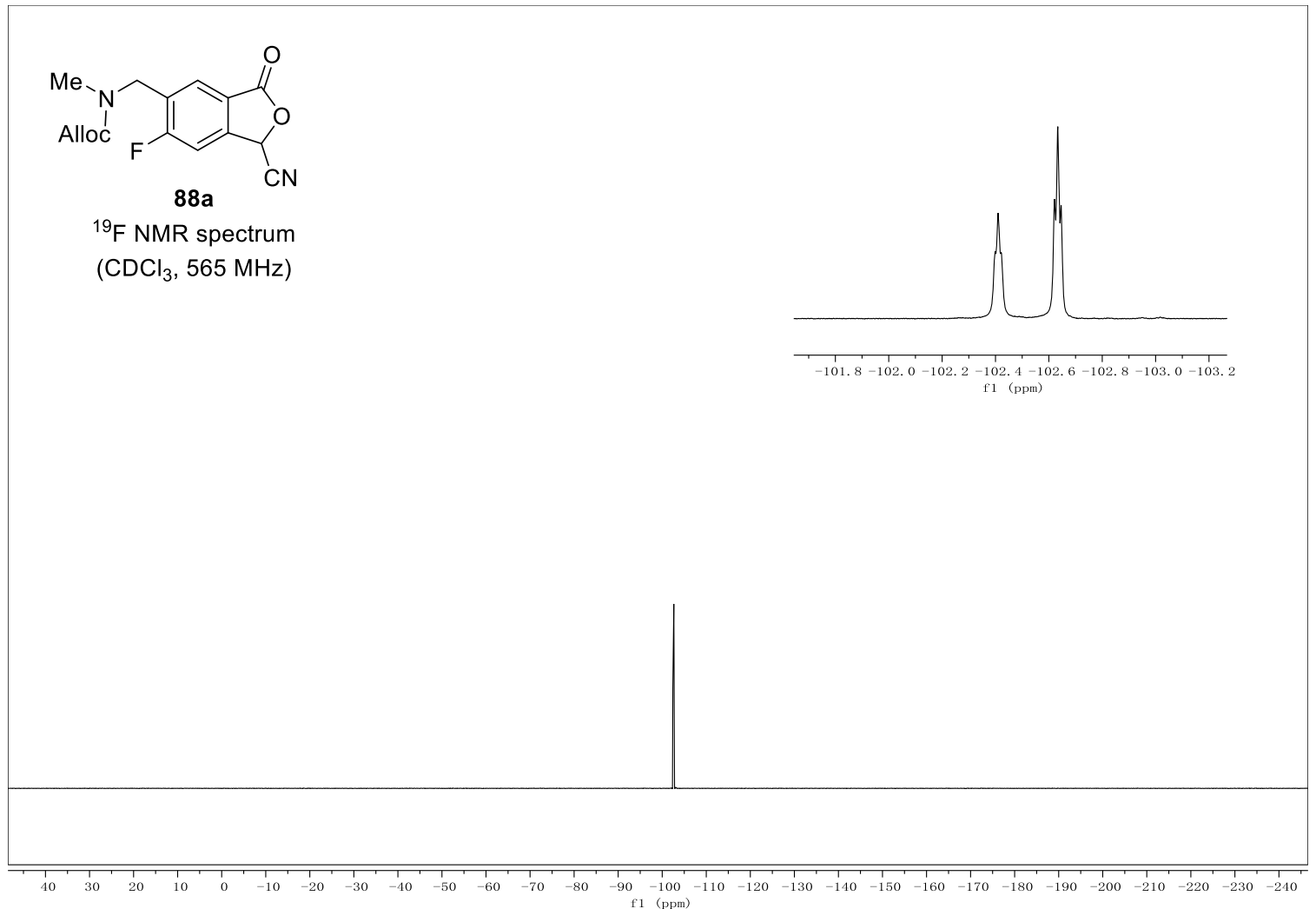



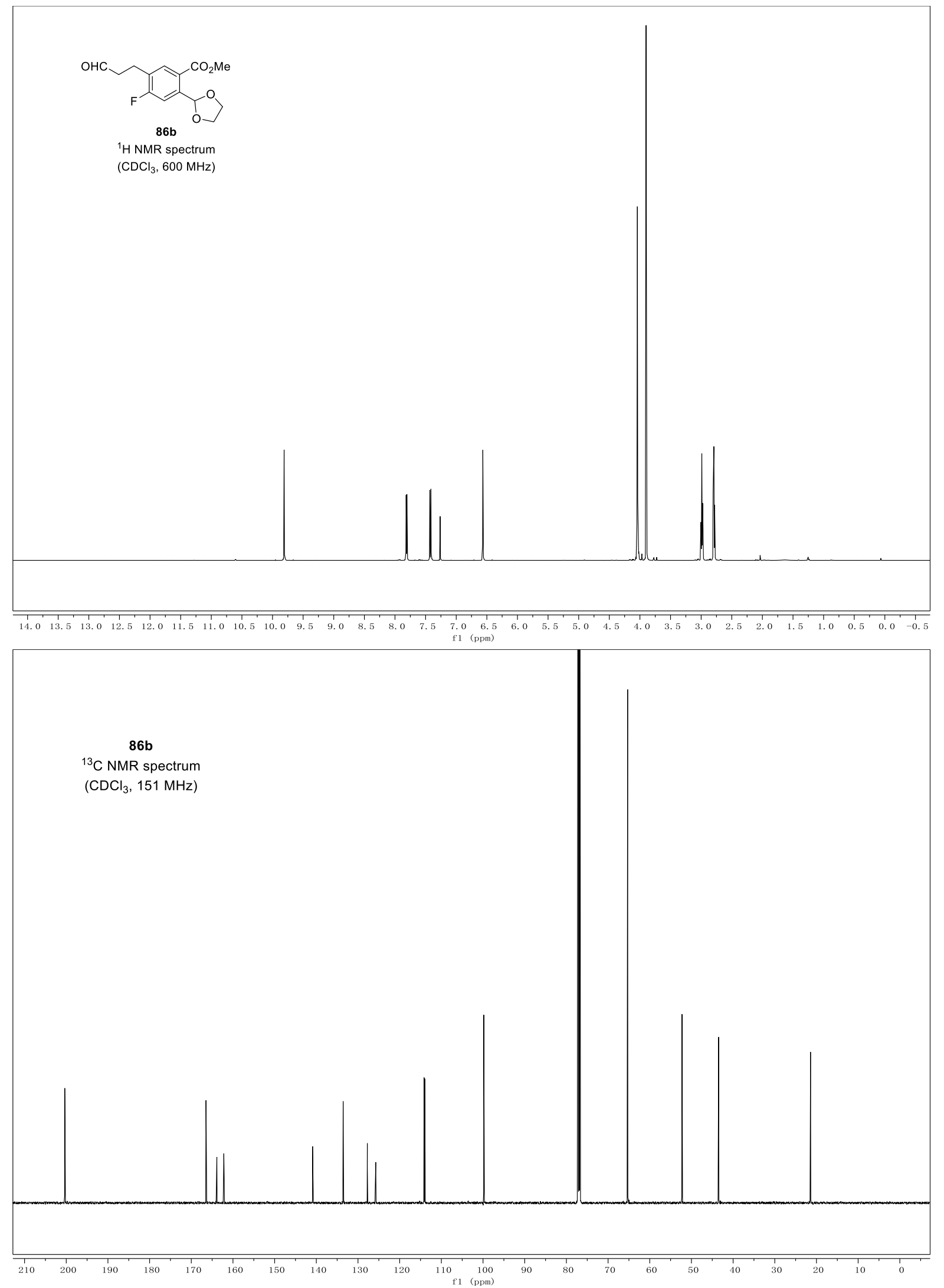


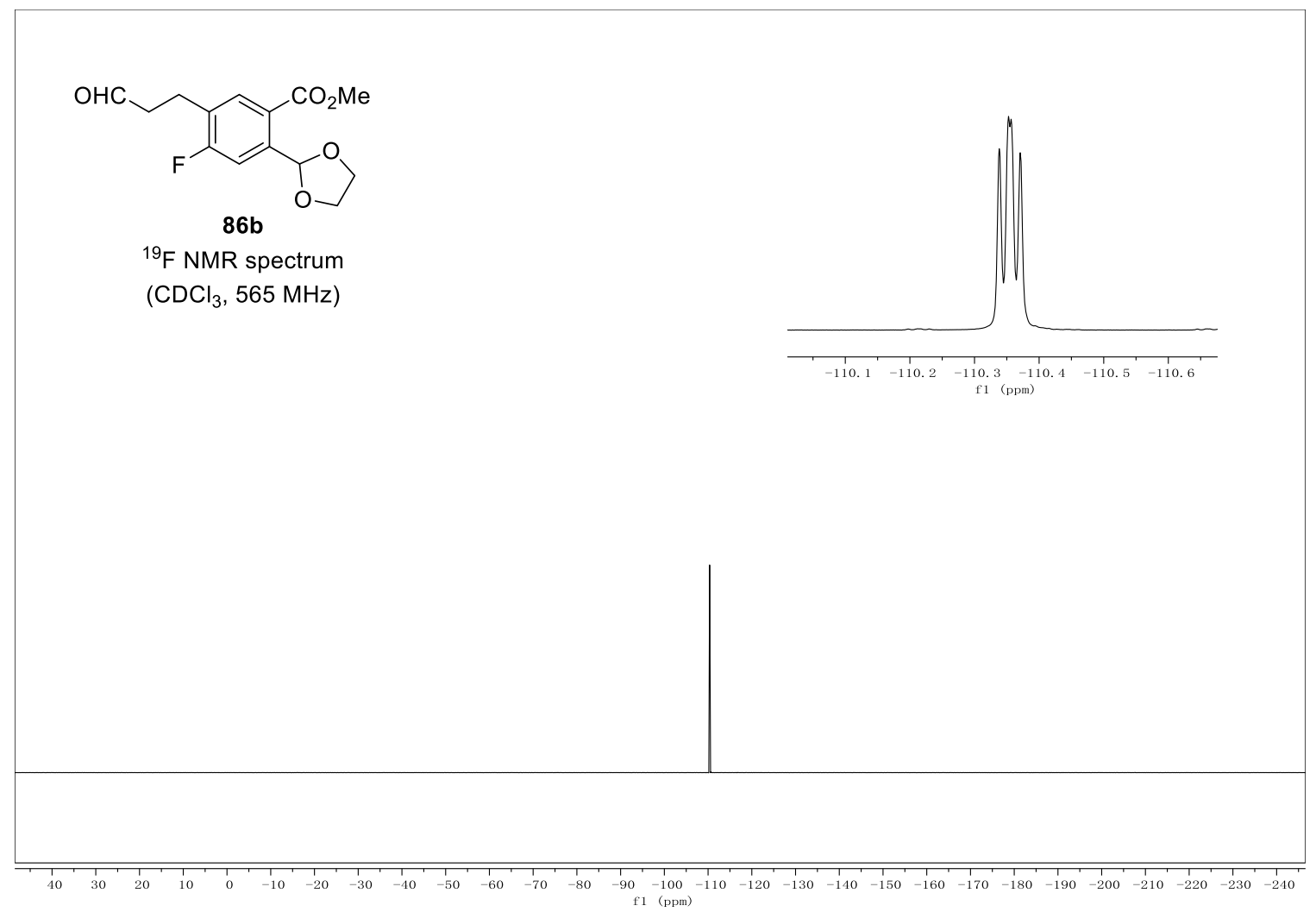



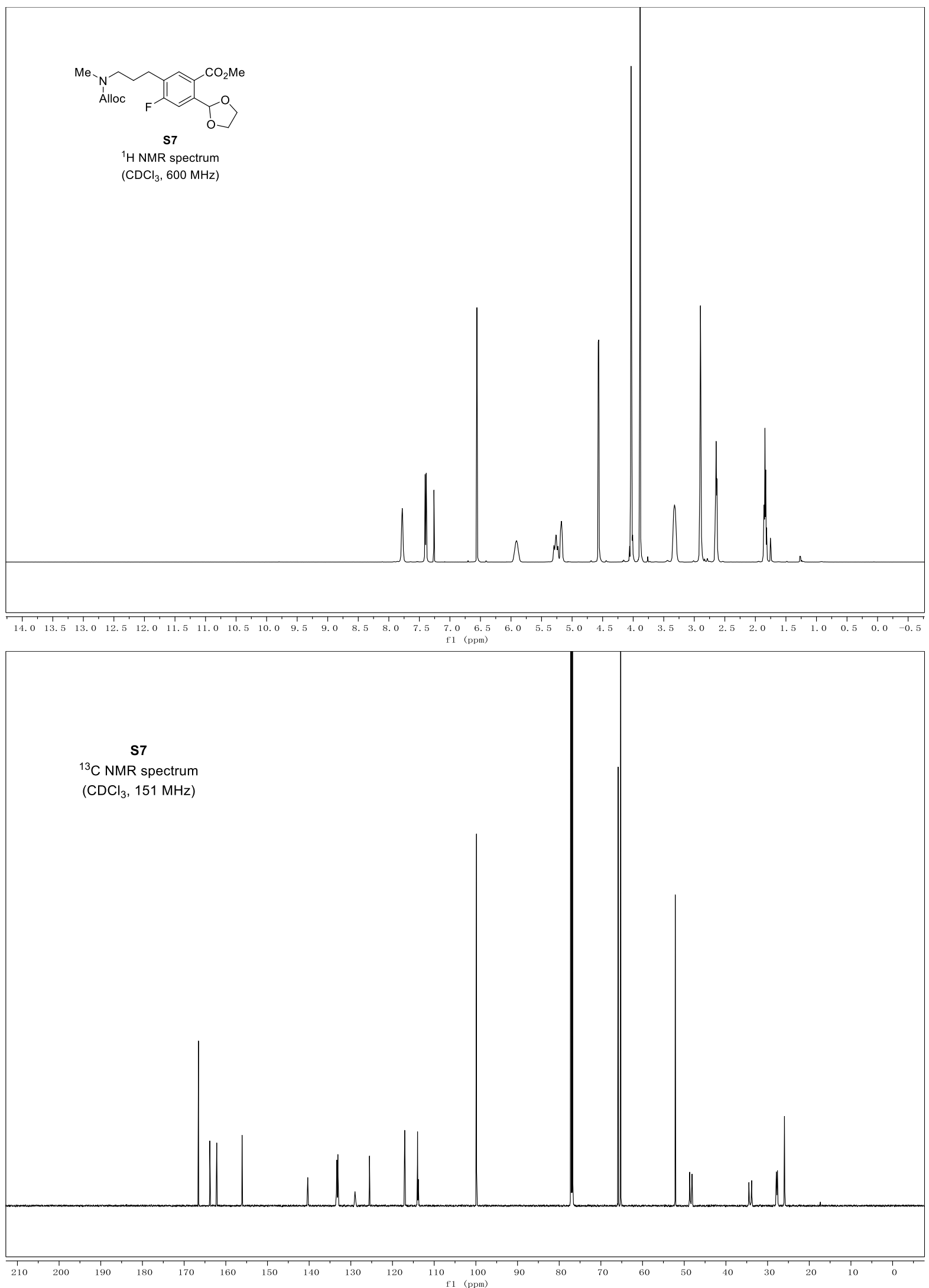


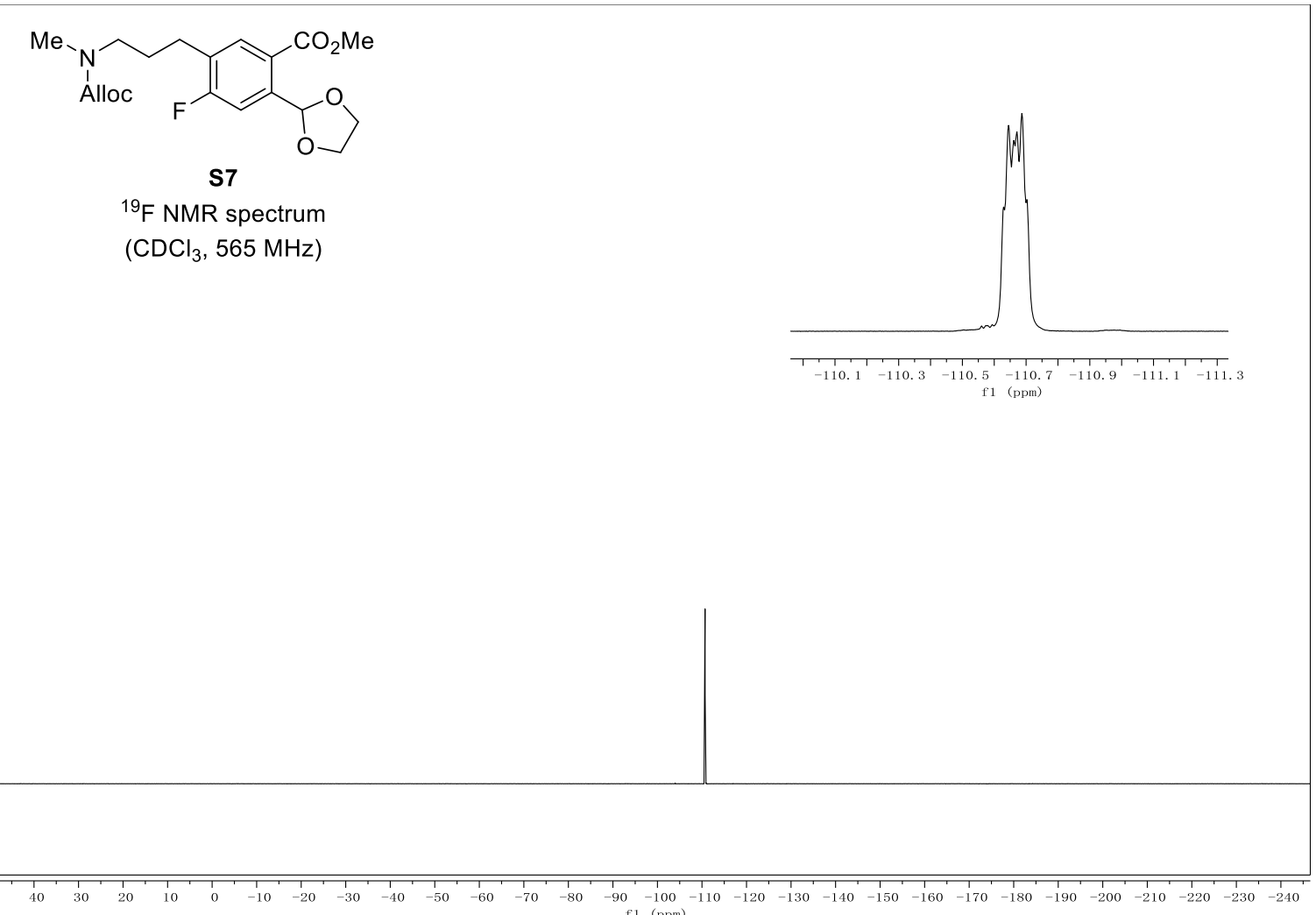




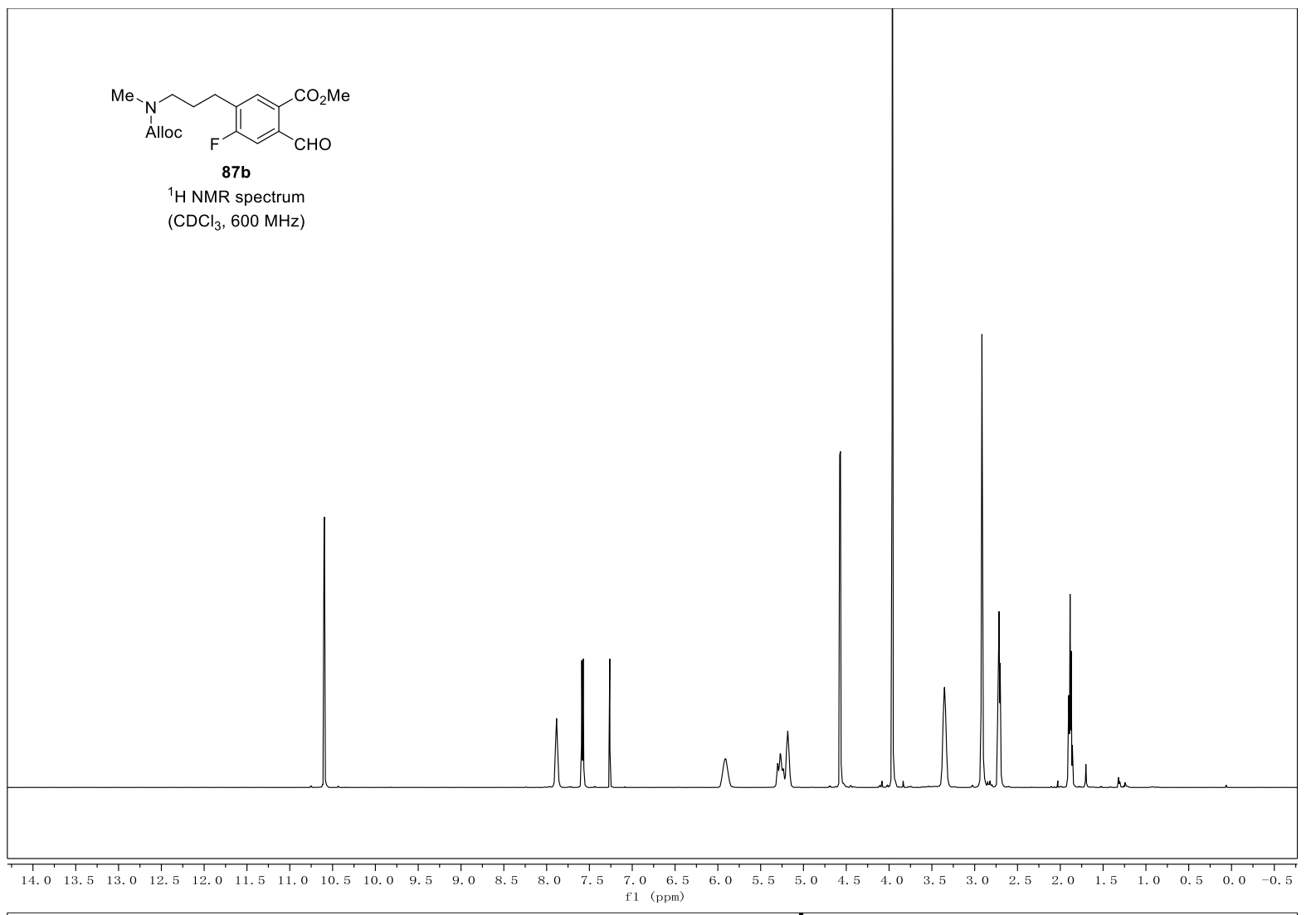

87b

${ }^{13} \mathrm{C}$ NMR spectrum $\left(\mathrm{CDCl}_{3}, 151 \mathrm{MHz}\right)$

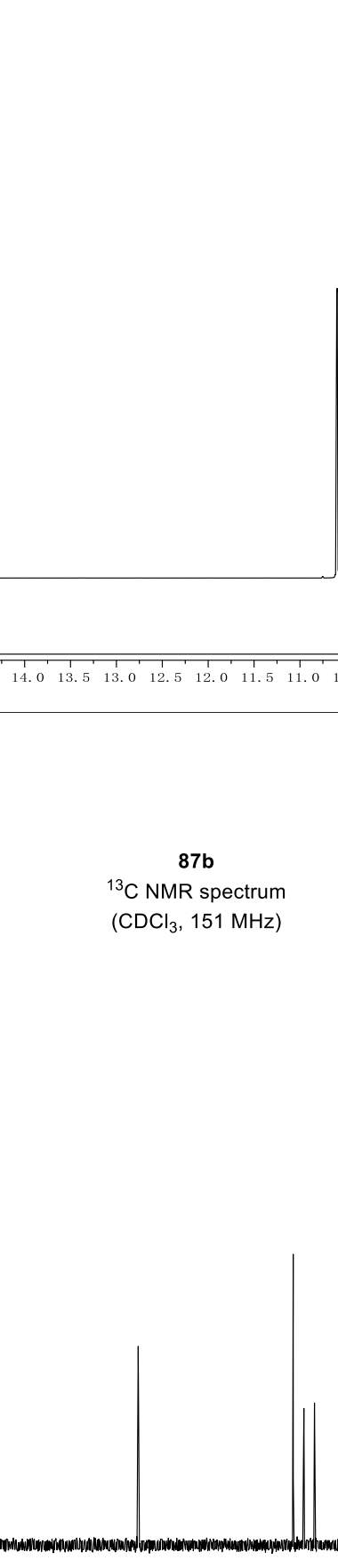

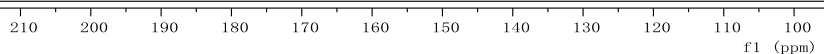




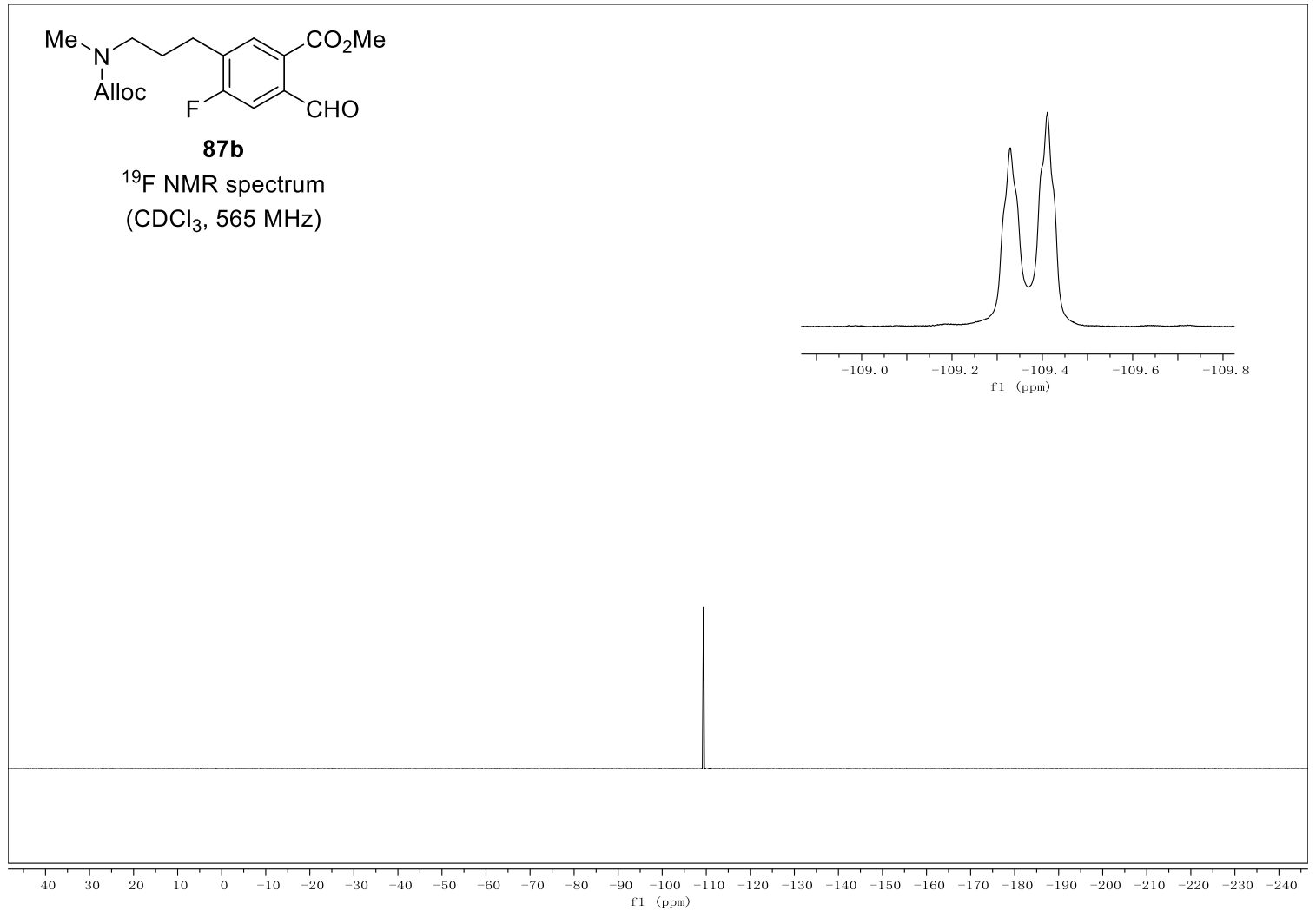



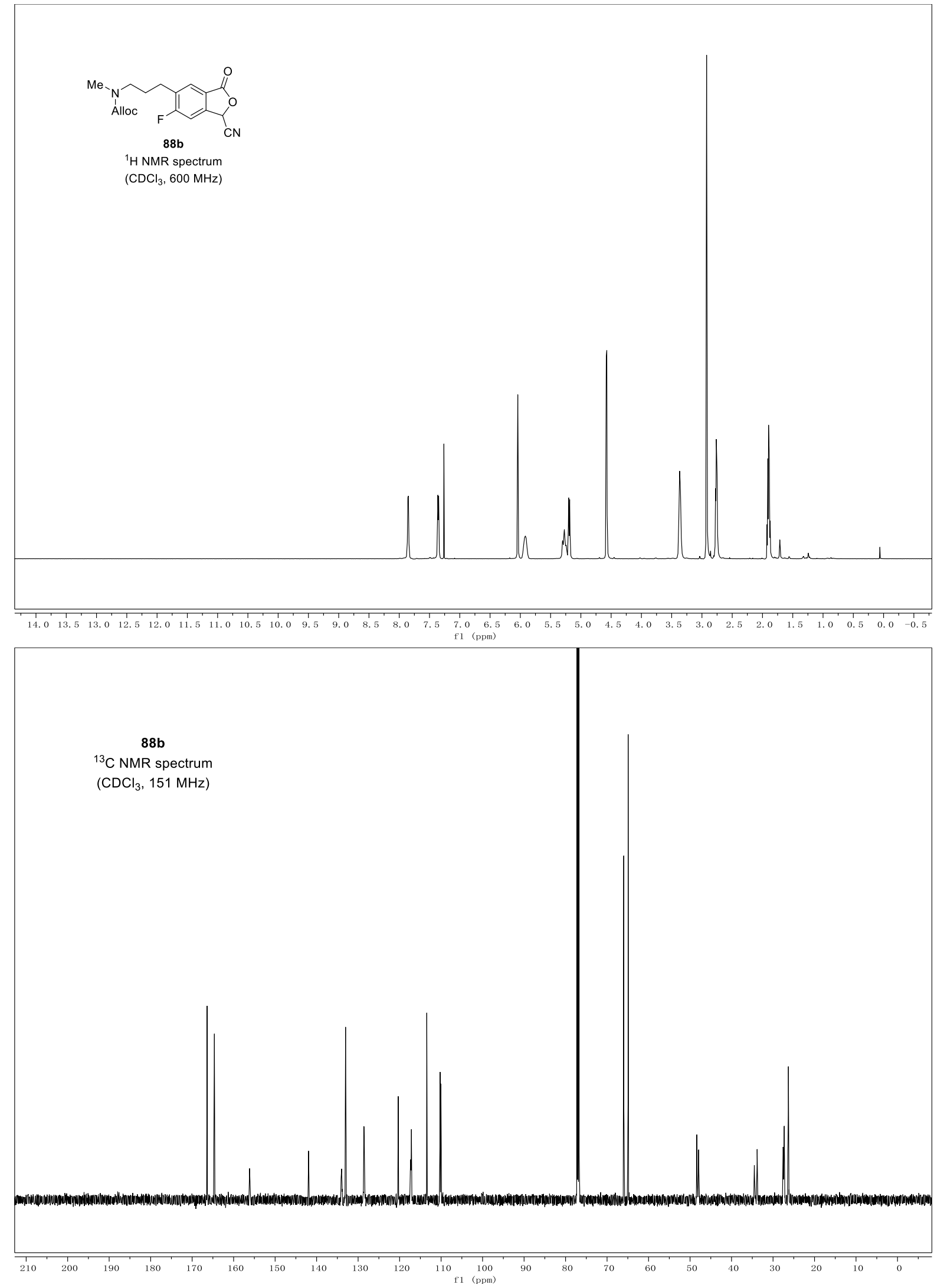


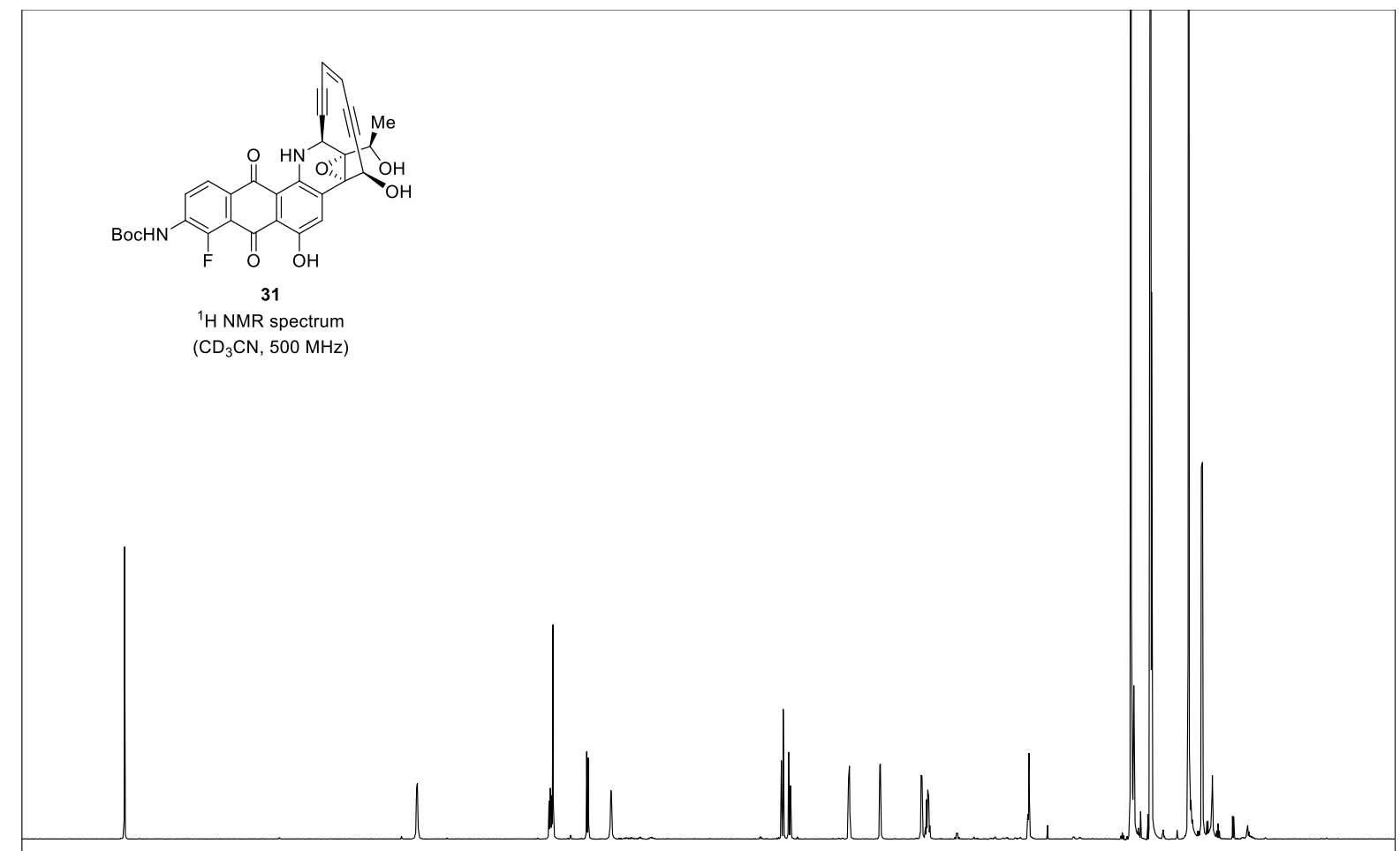

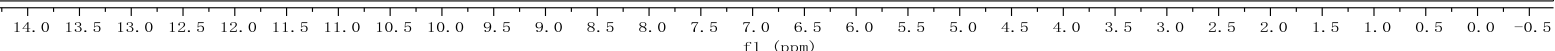

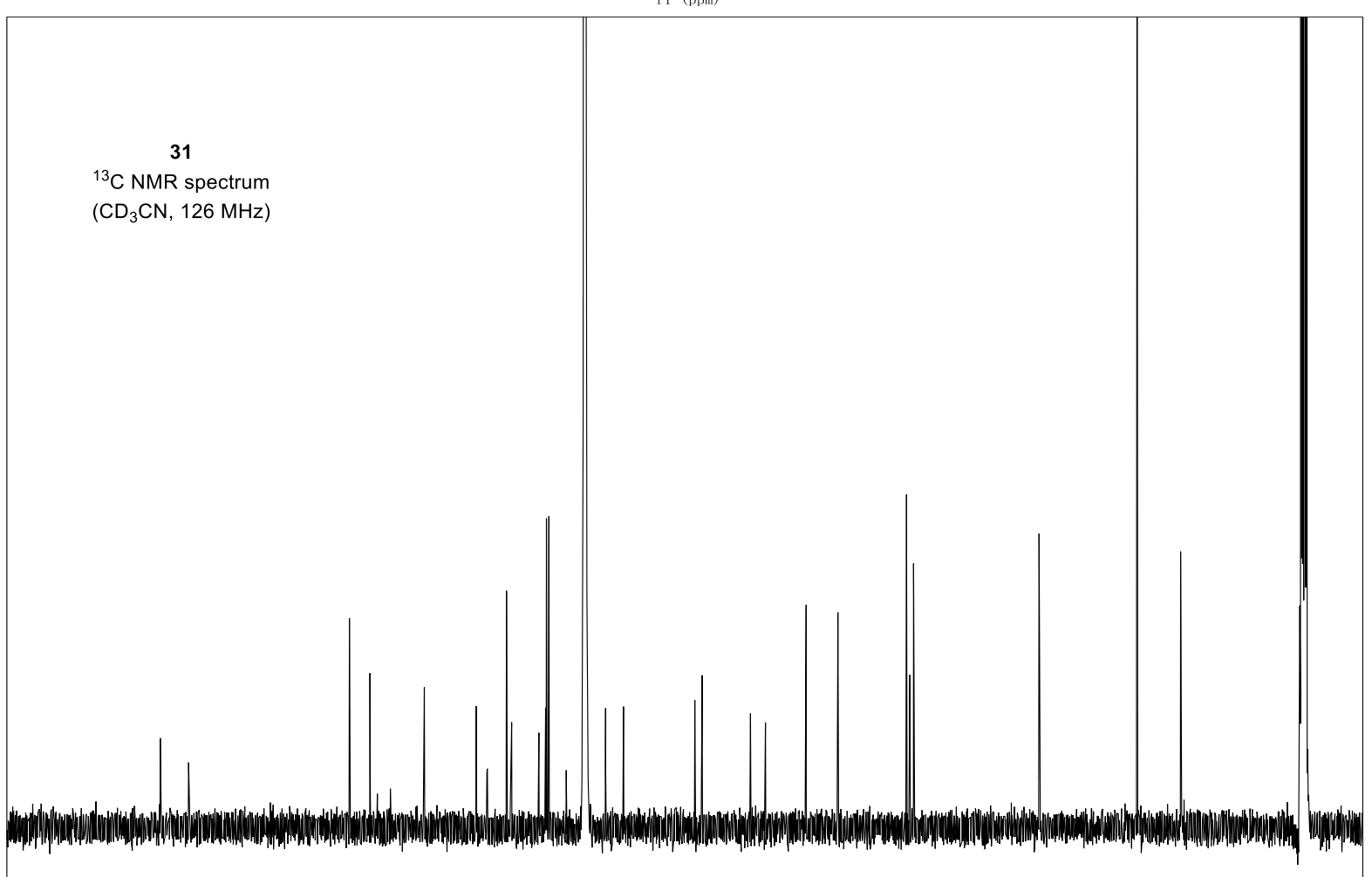

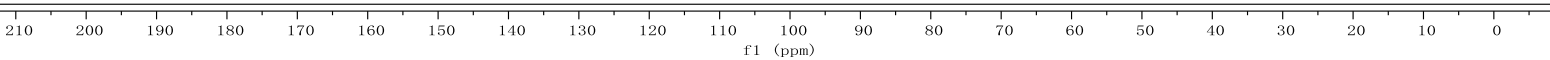




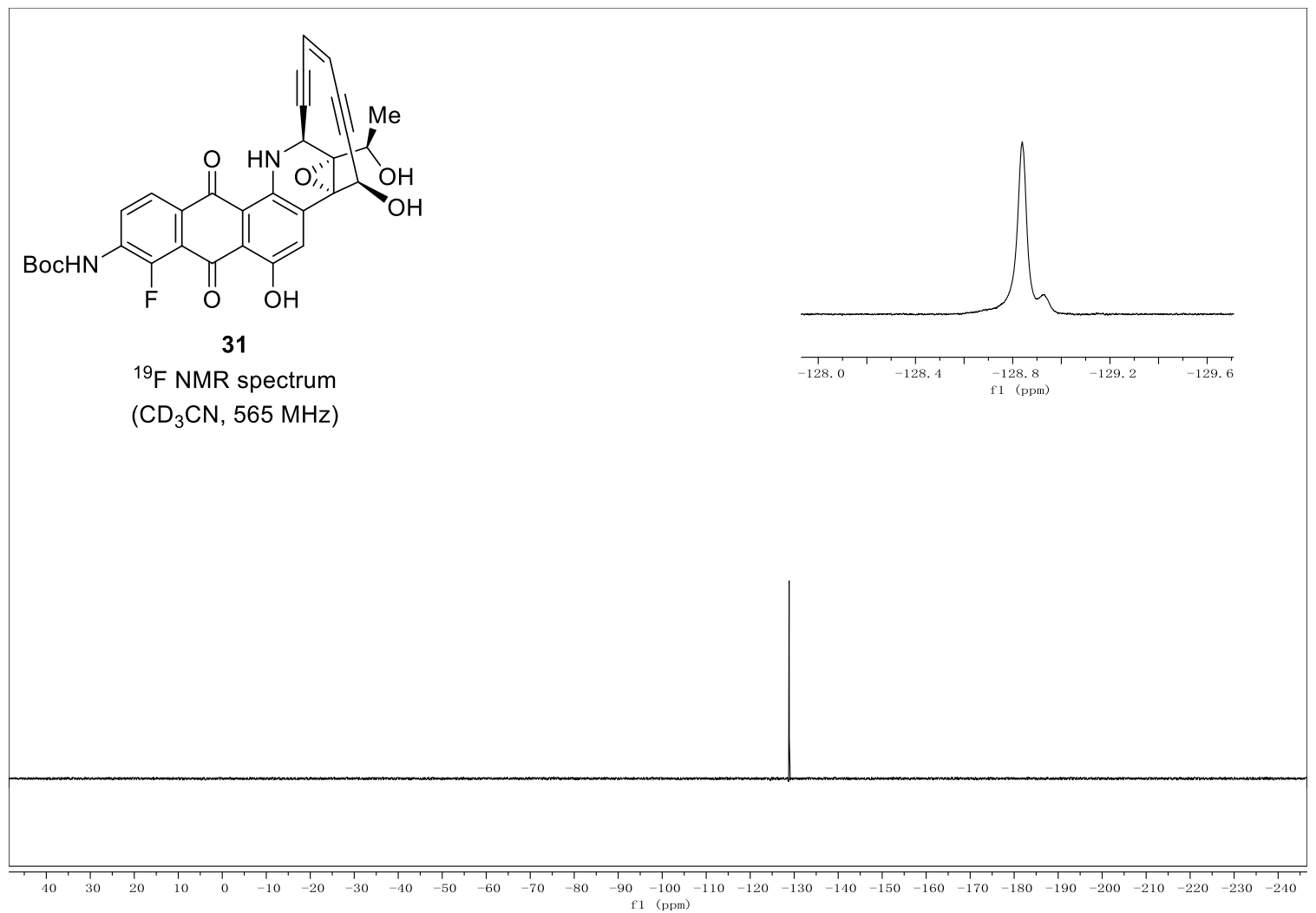




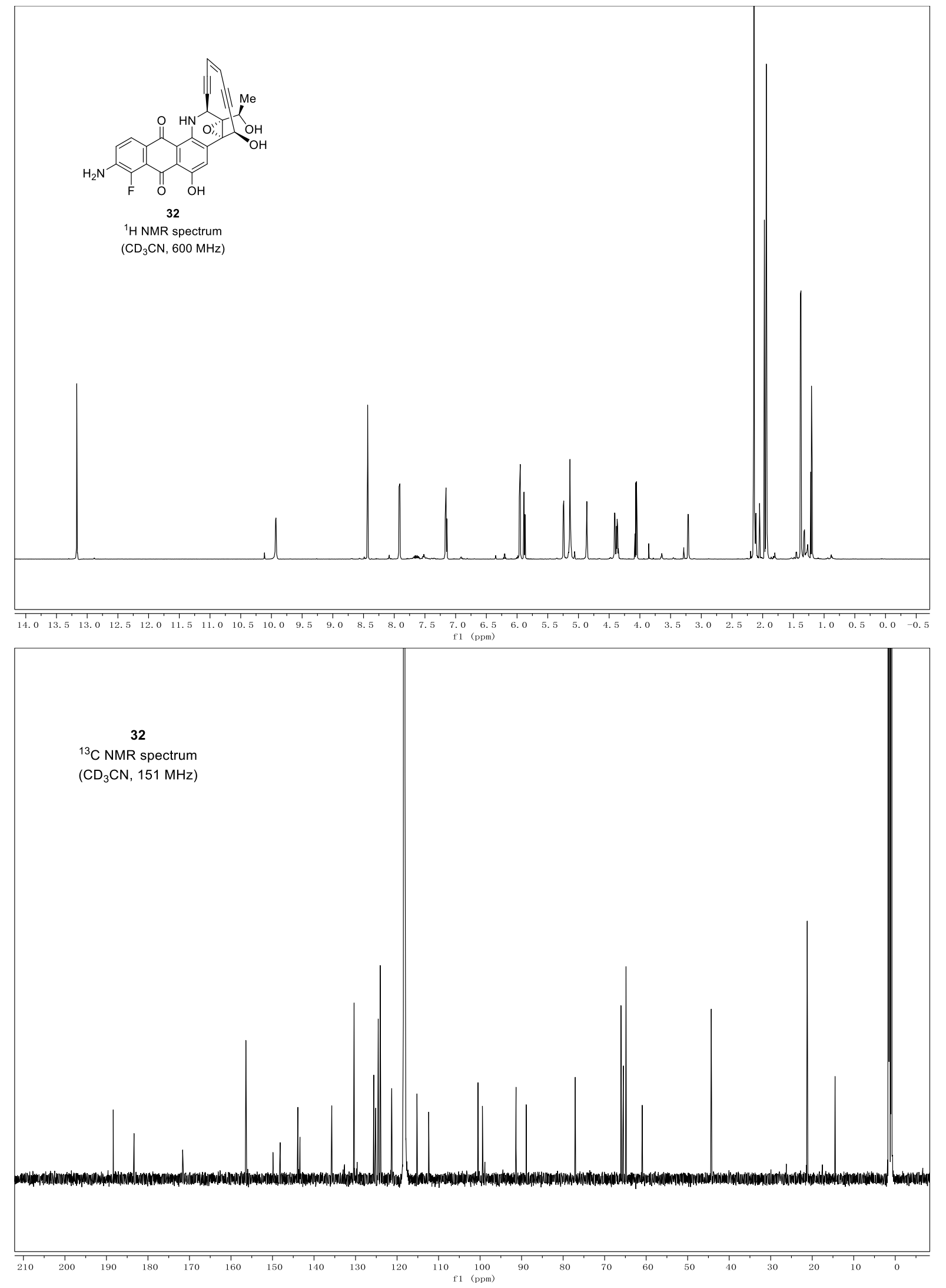




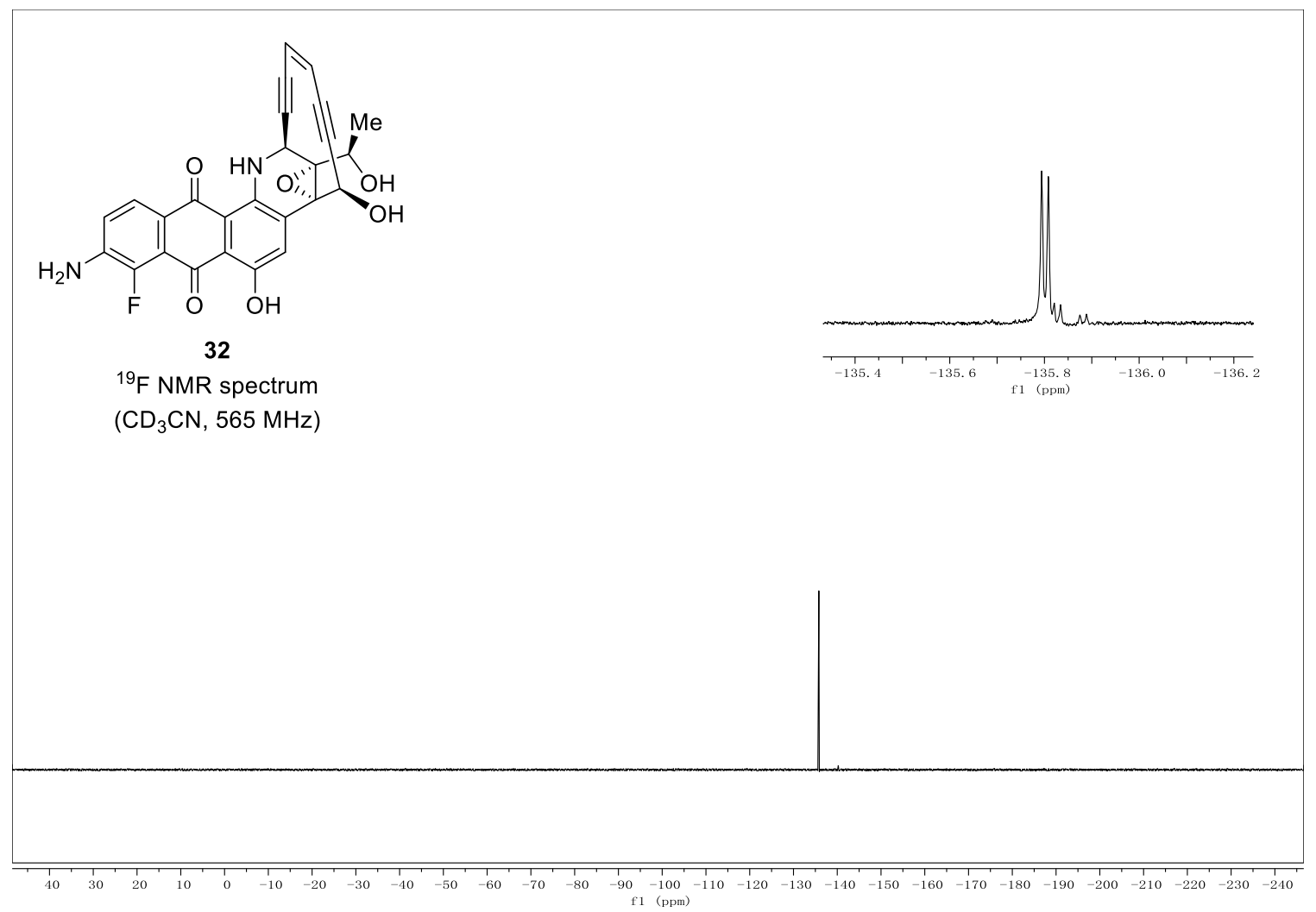




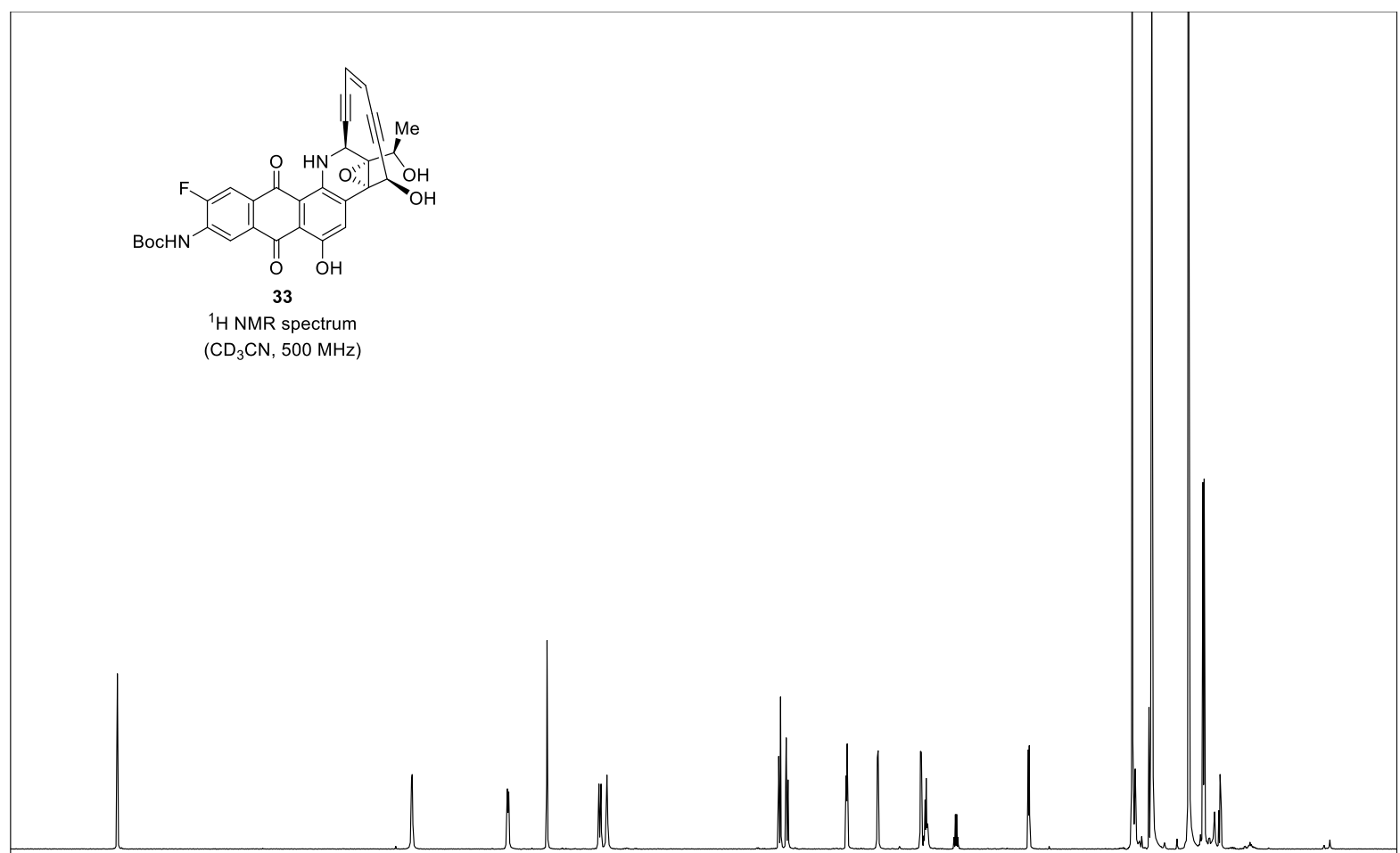

$\begin{array}{llllllllllllllllllllllllllllllllllllllllllllll}14.0 & 13.5 & 13.0 & 12.5 & 12.0 & 11.5 & 11.0 & 10.5 & 10.0 & 9.5 & 9.0 & 8.5 & 8.0 & 7.5 & 7.0 & 6.5 & 6.0 & 5.5 & 5.0 & 4.5 & 4.0 & 3.5 & 3.0 & 2.5 & 2.0 & 1.5 & 1.0 & 0.5 & 0.0 & -0.5\end{array}$

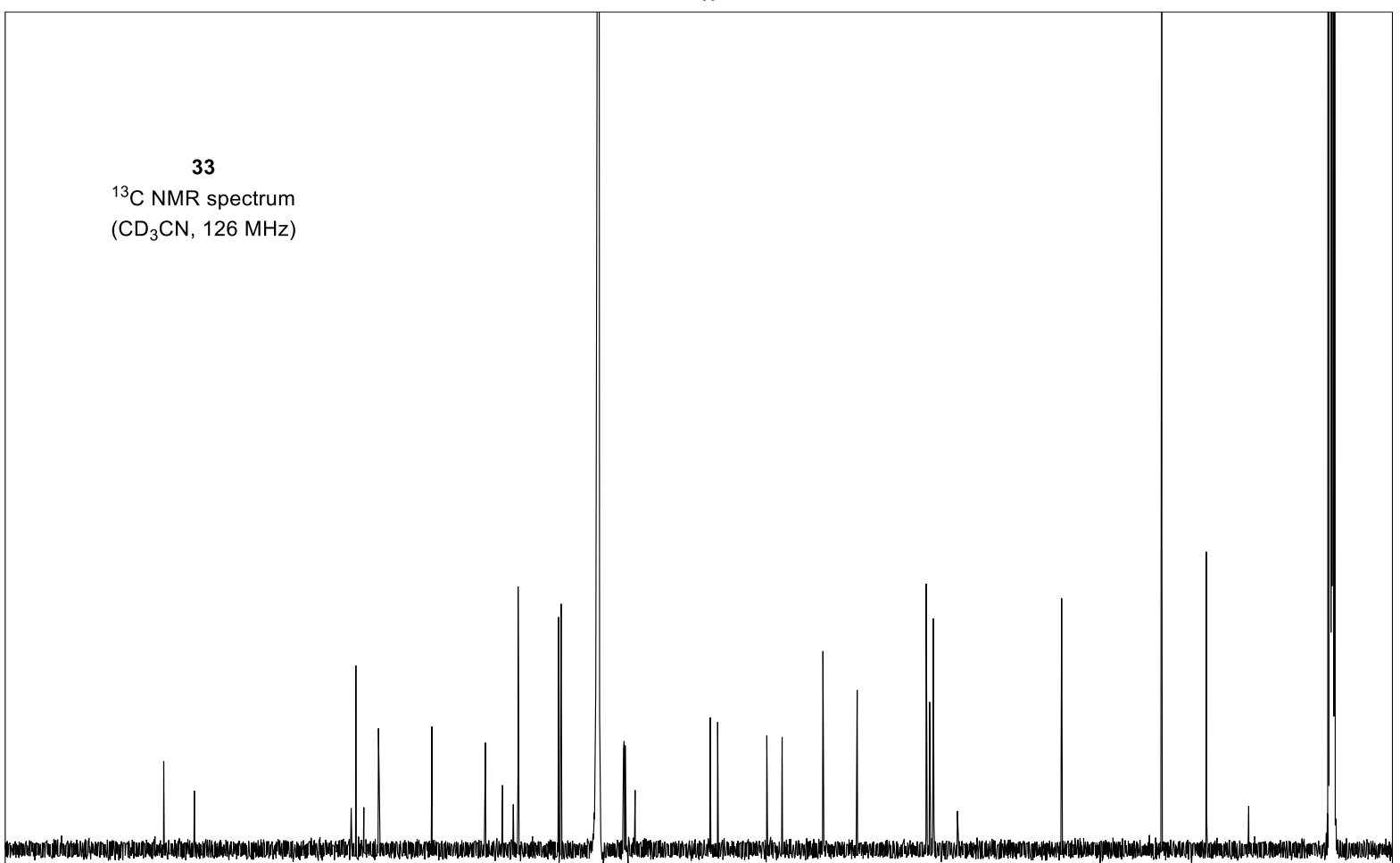

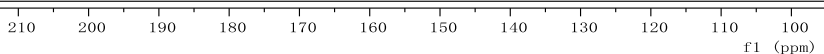




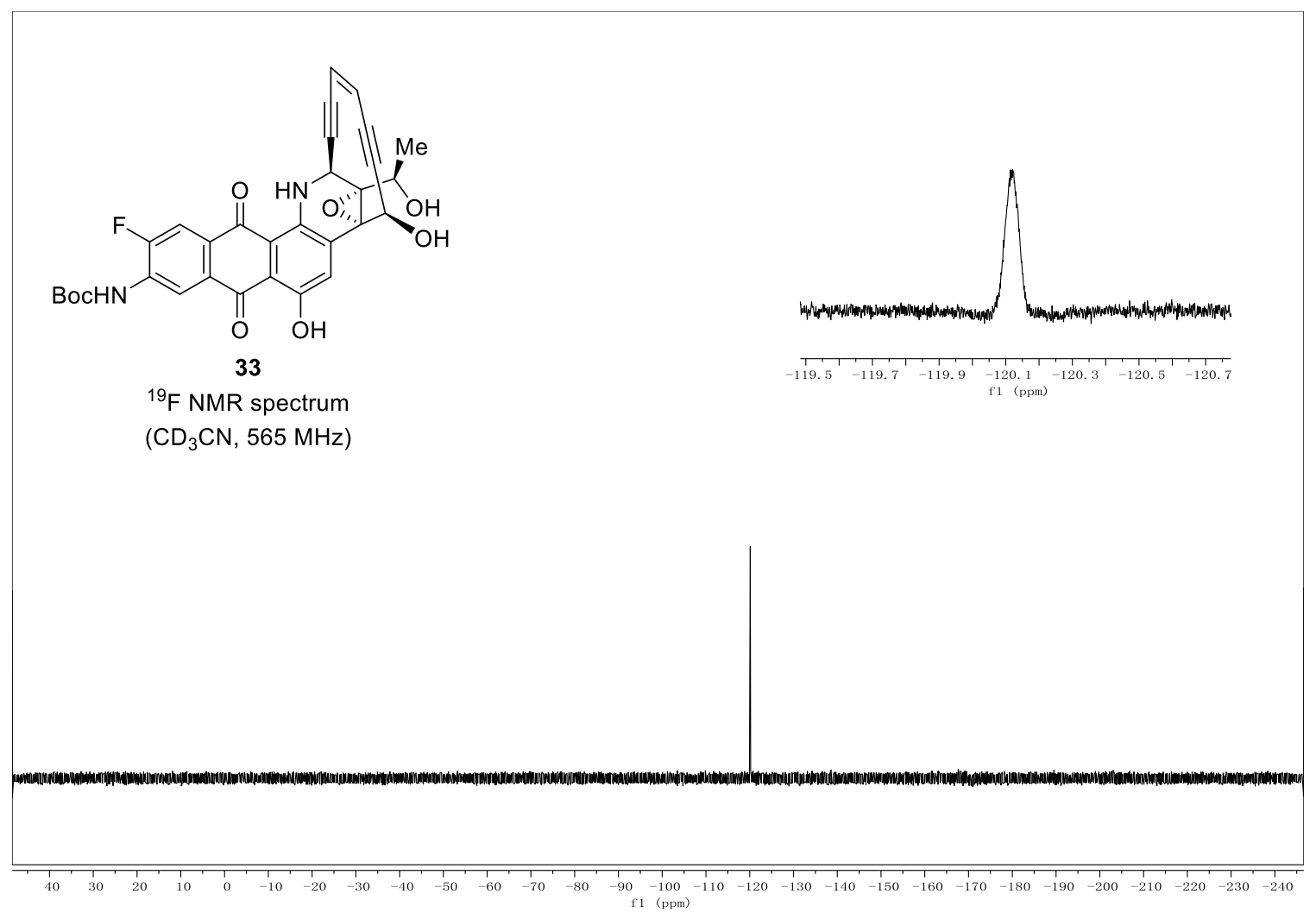



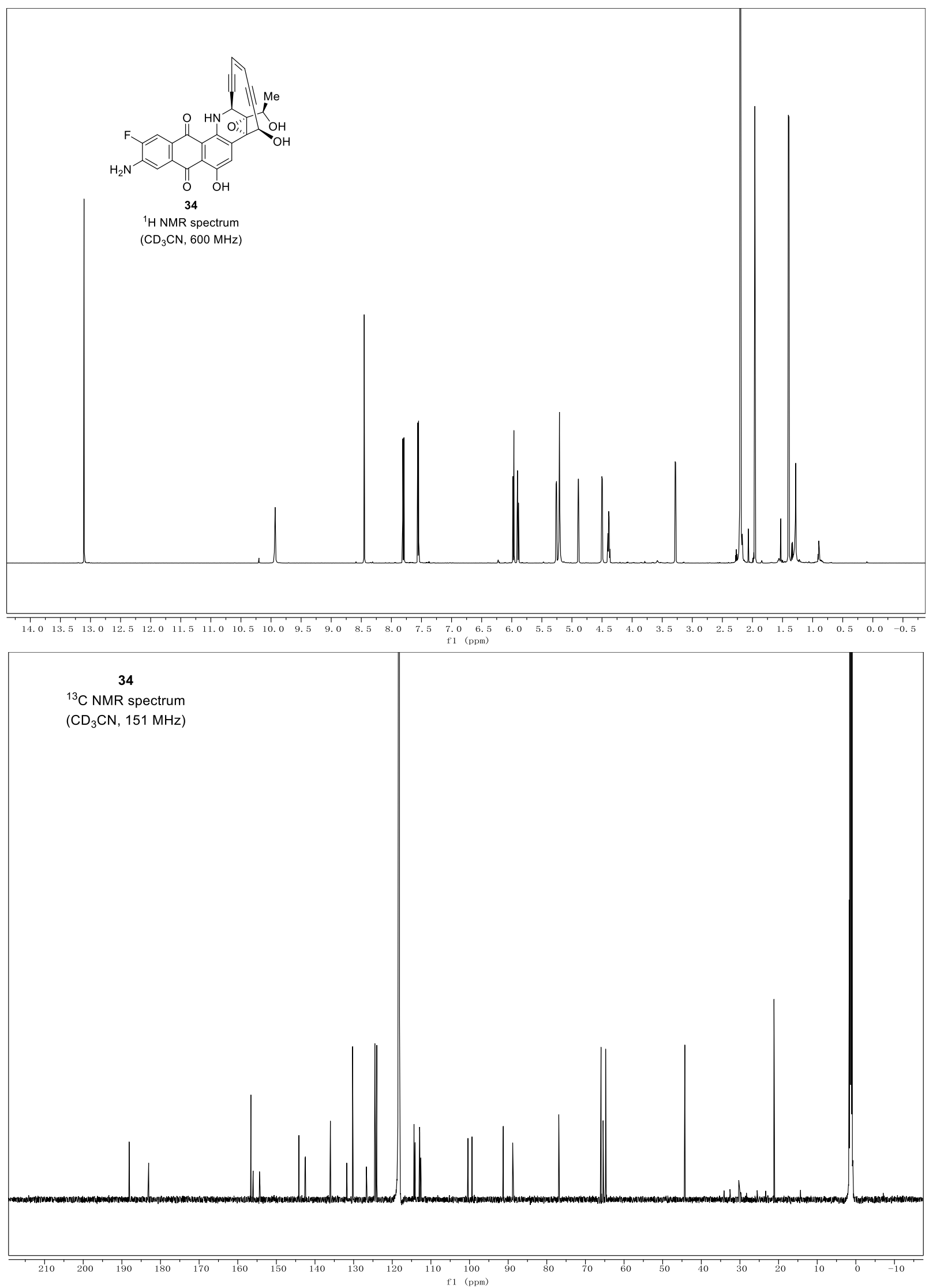


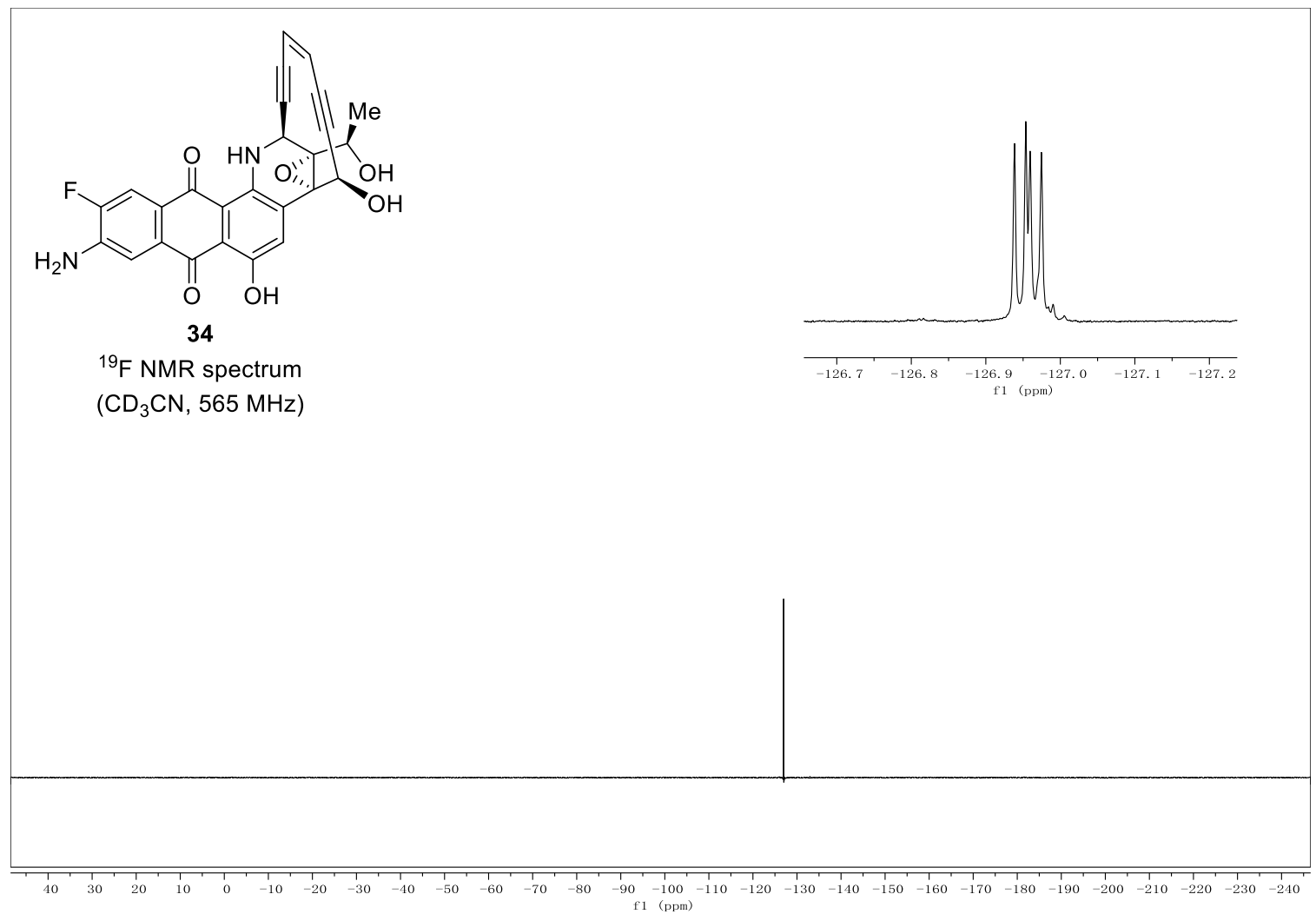




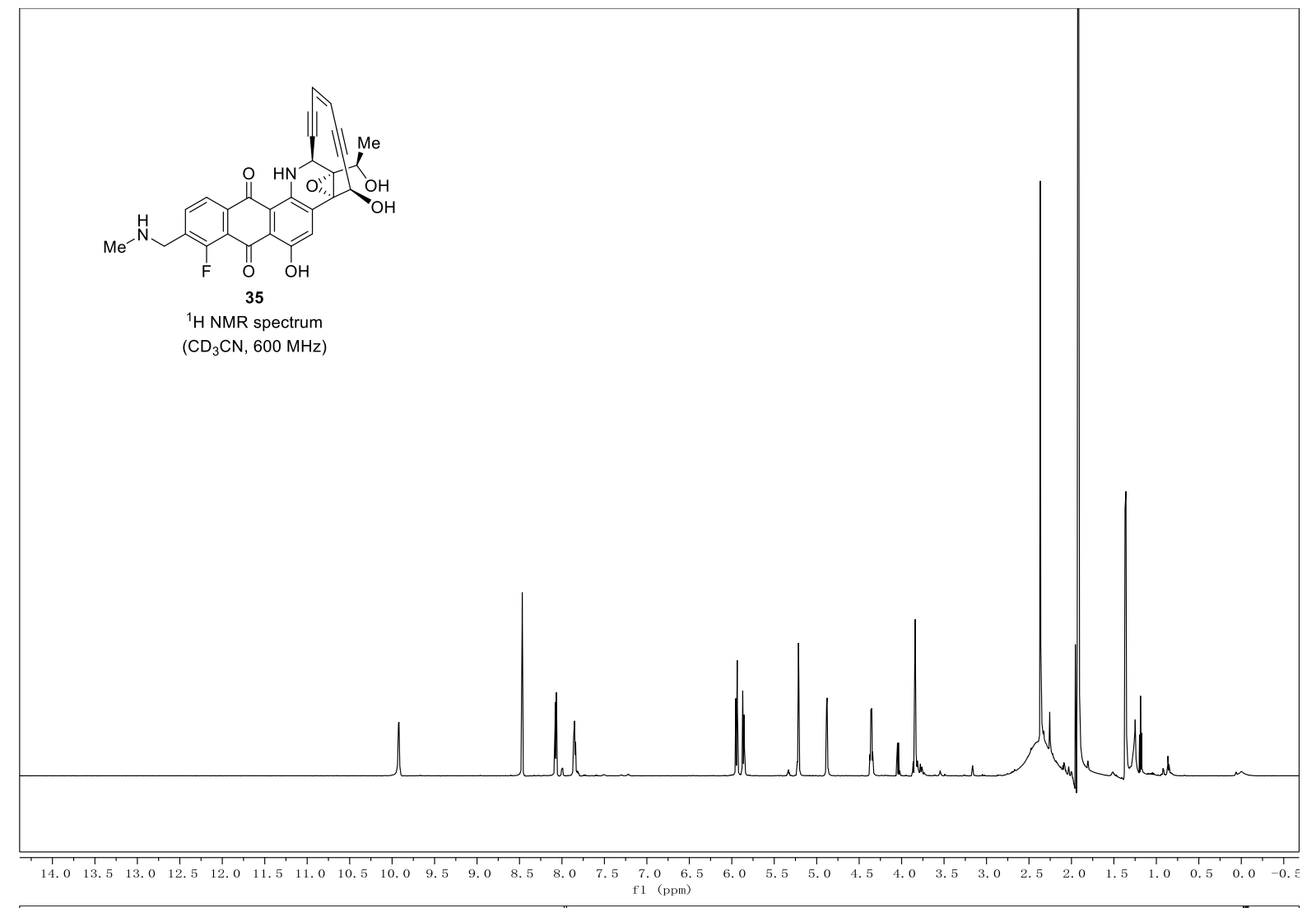

35

${ }^{13} \mathrm{C}$ NMR spectrum $\left(\mathrm{CD}_{3} \mathrm{CN}, 151 \mathrm{MHz}\right)$
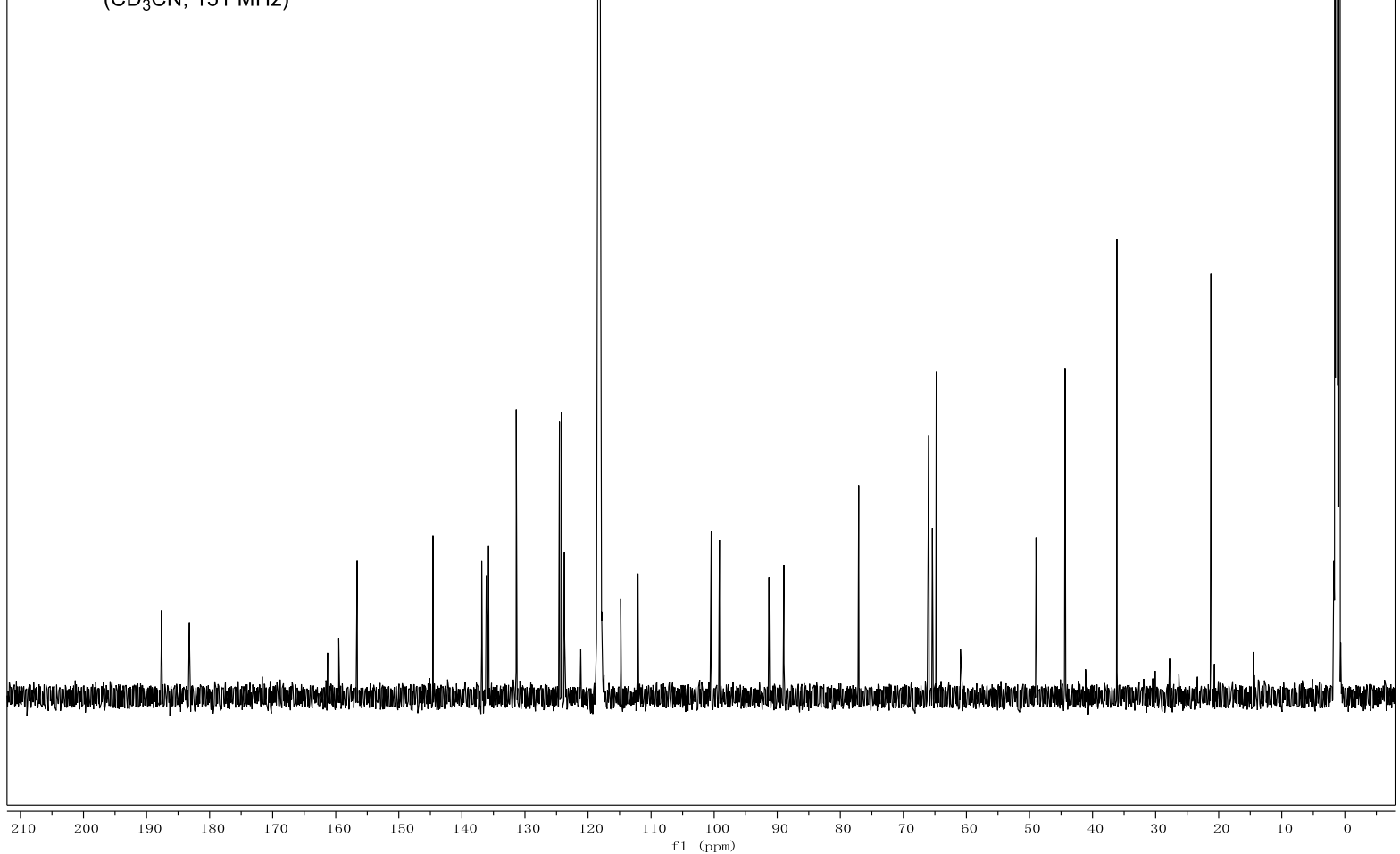


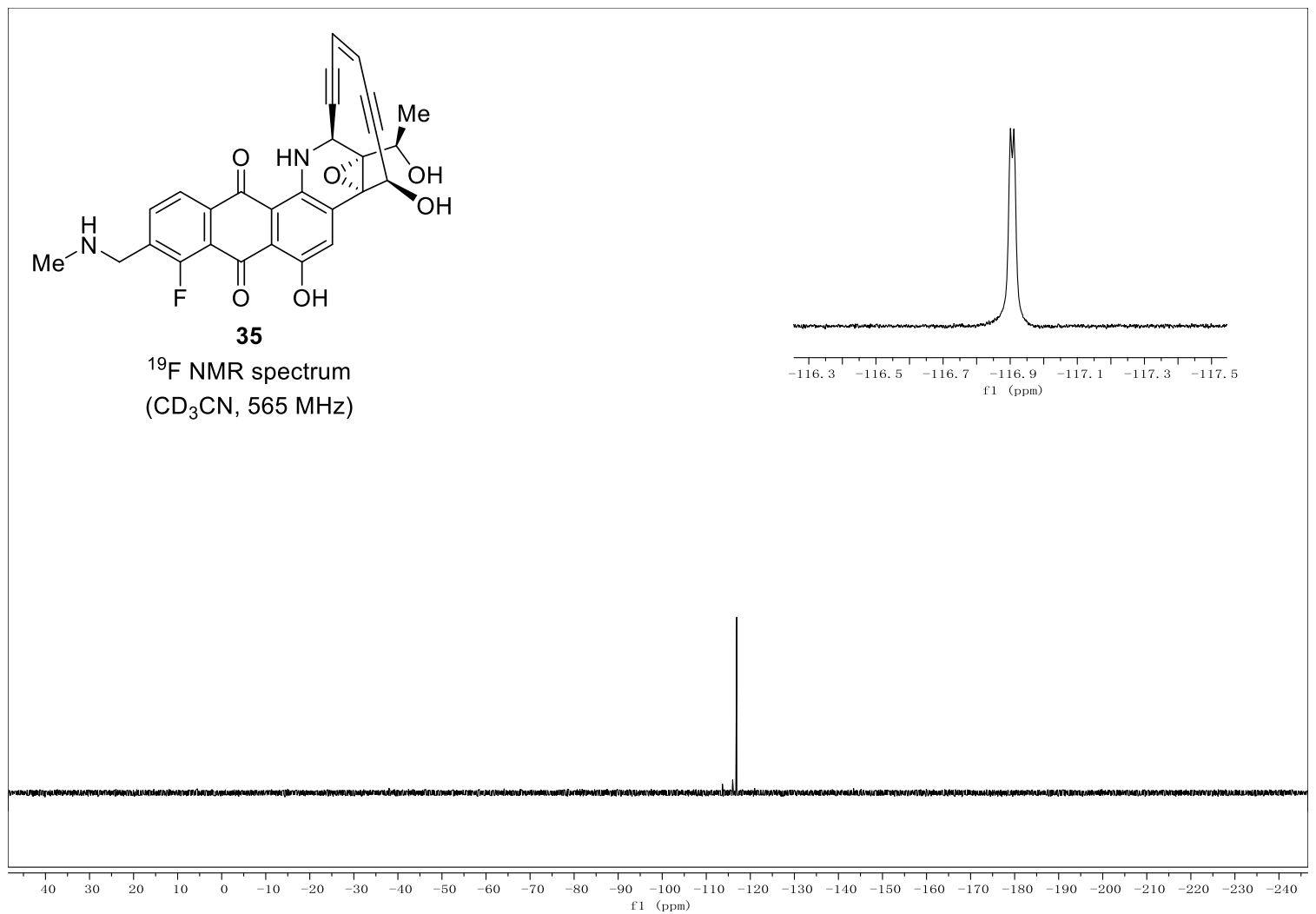




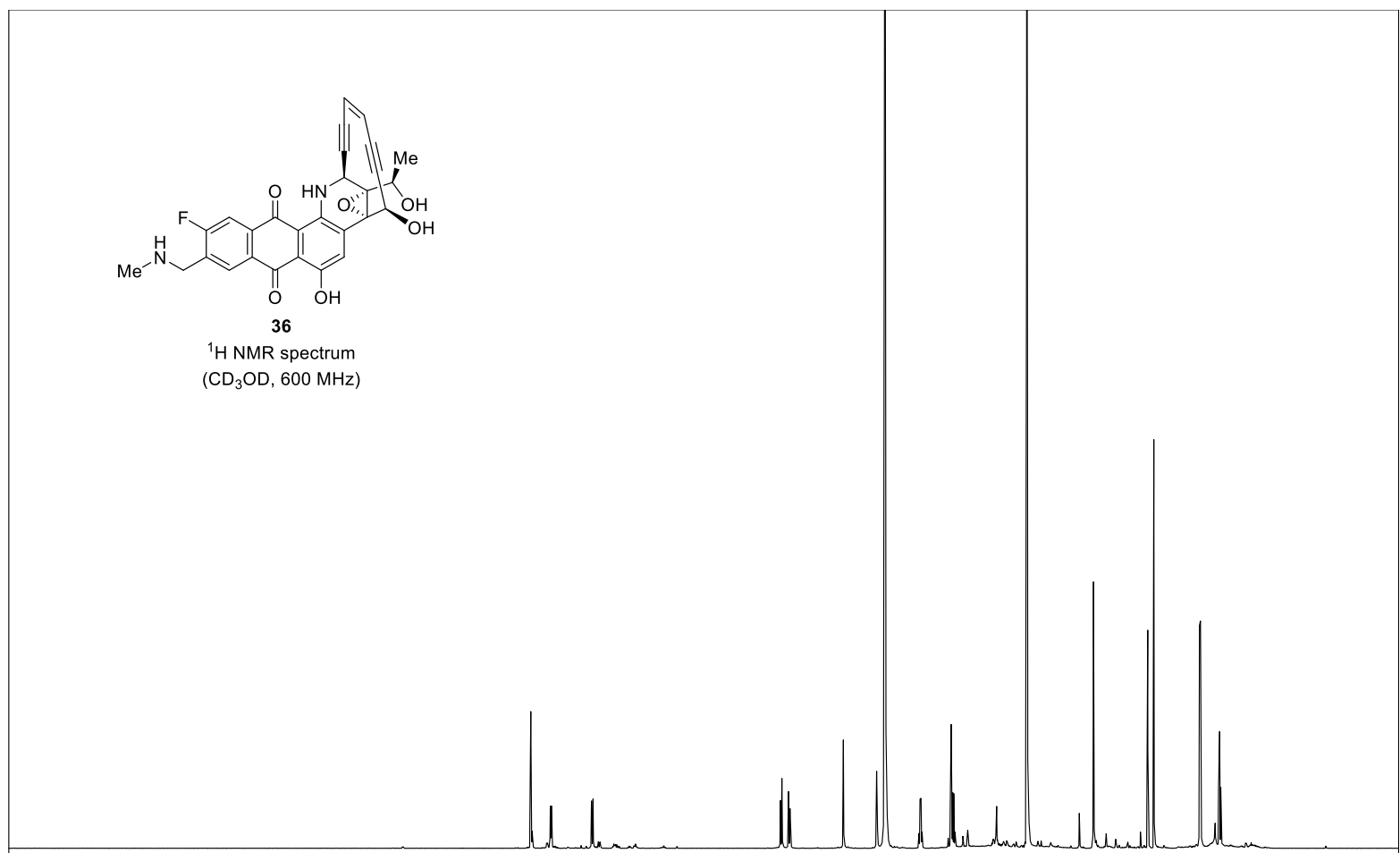

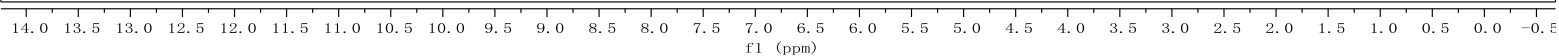

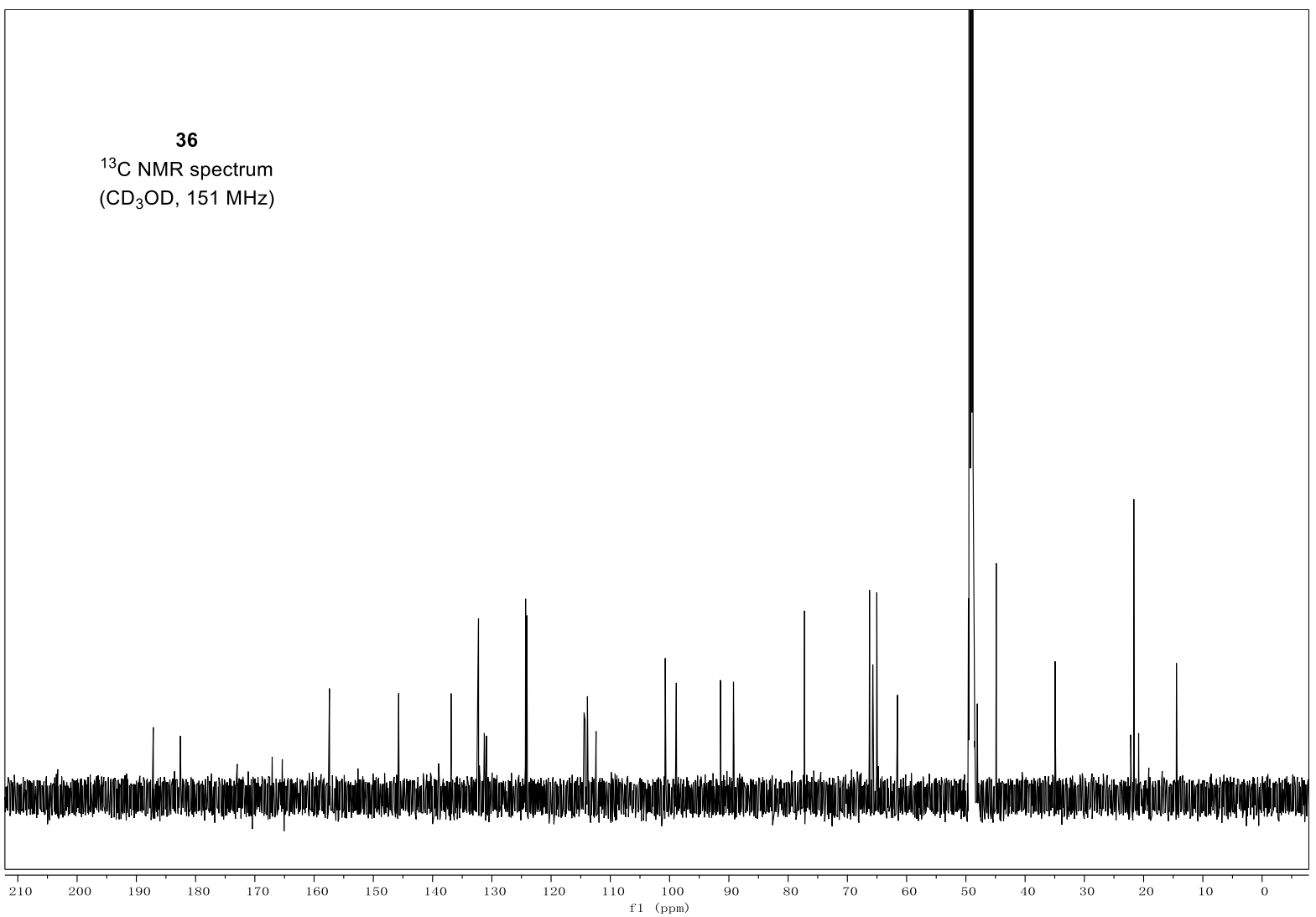




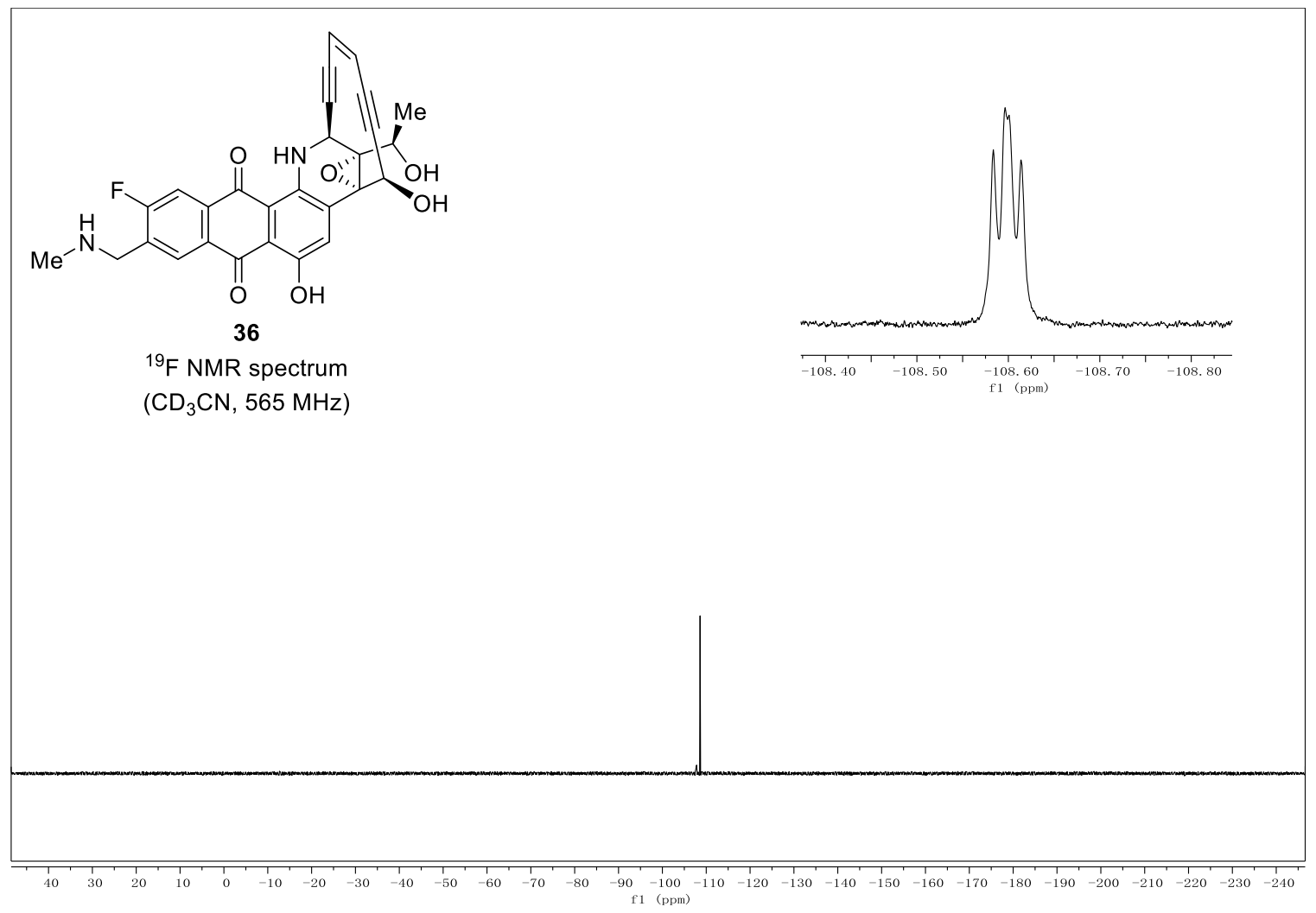




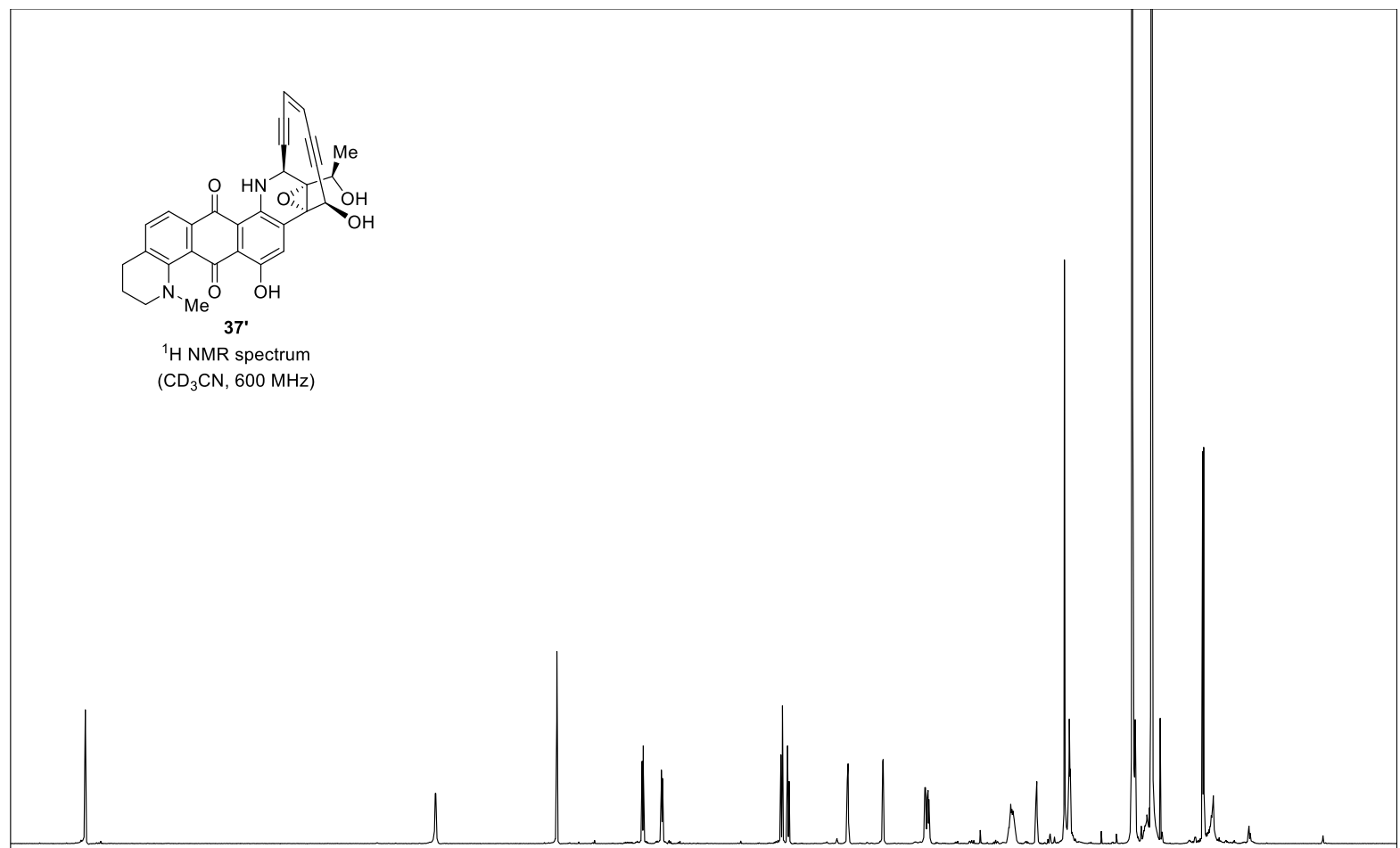

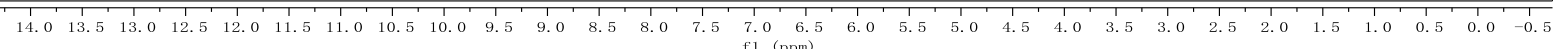

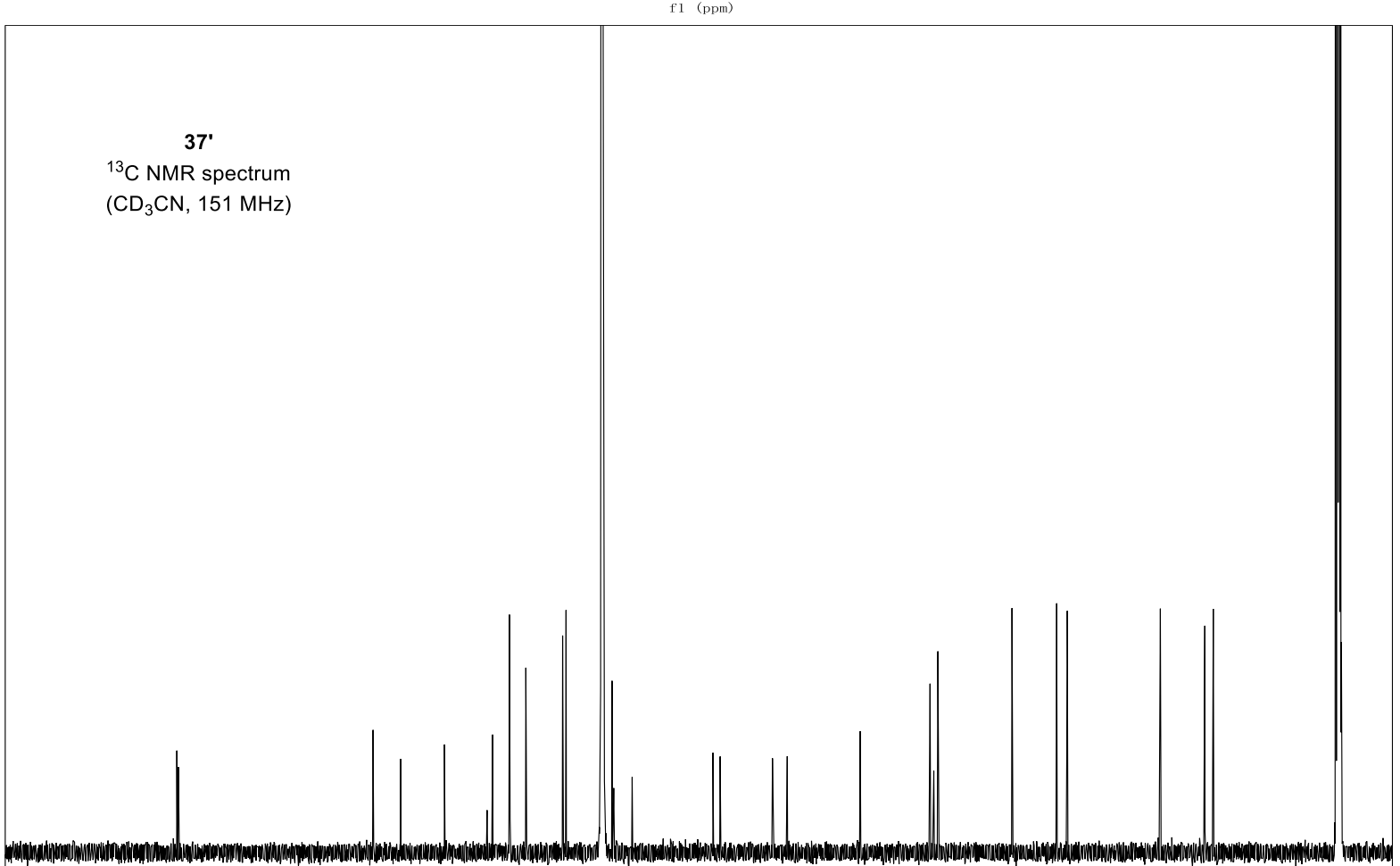

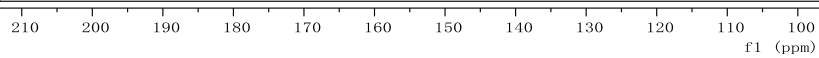



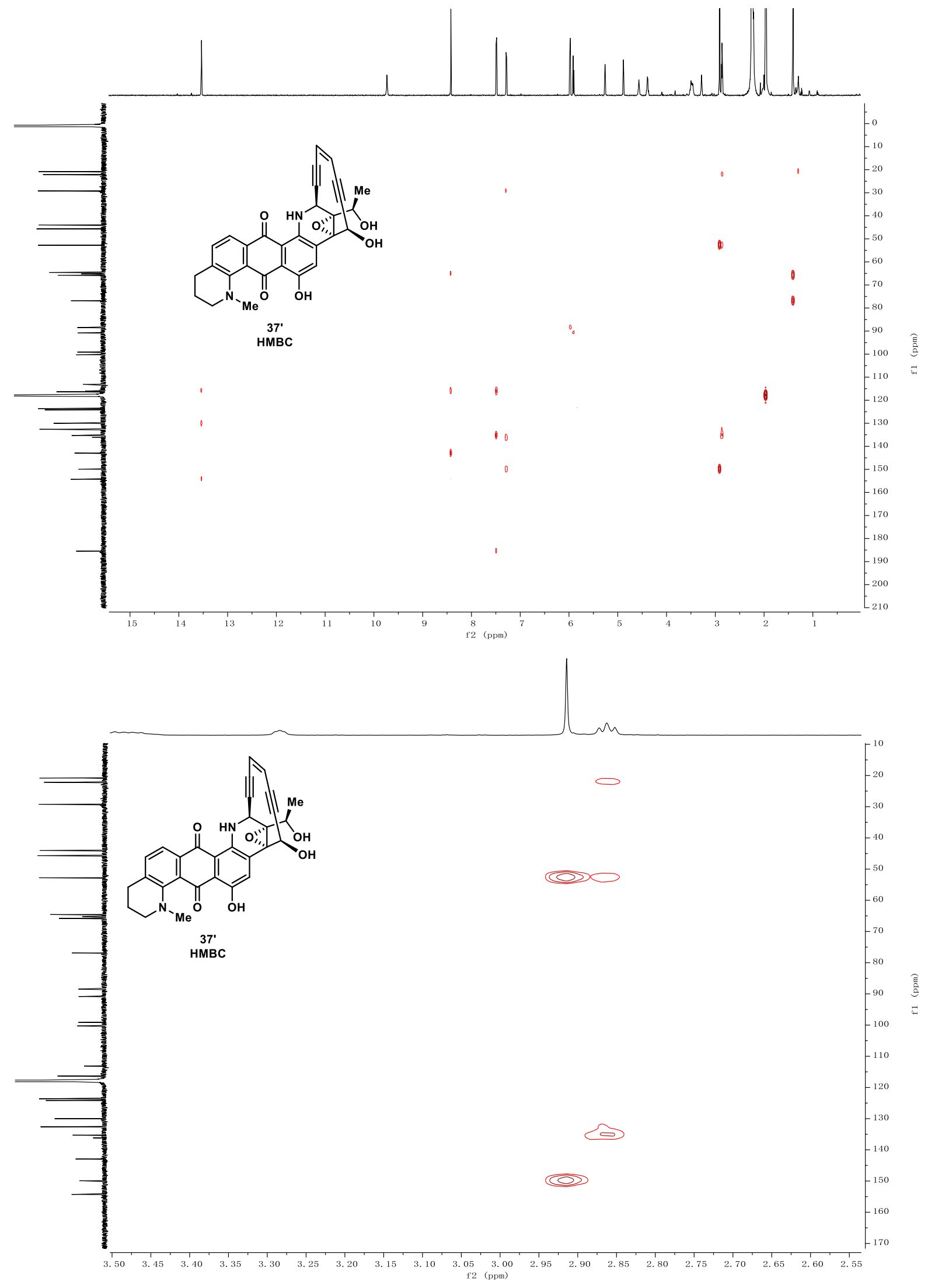


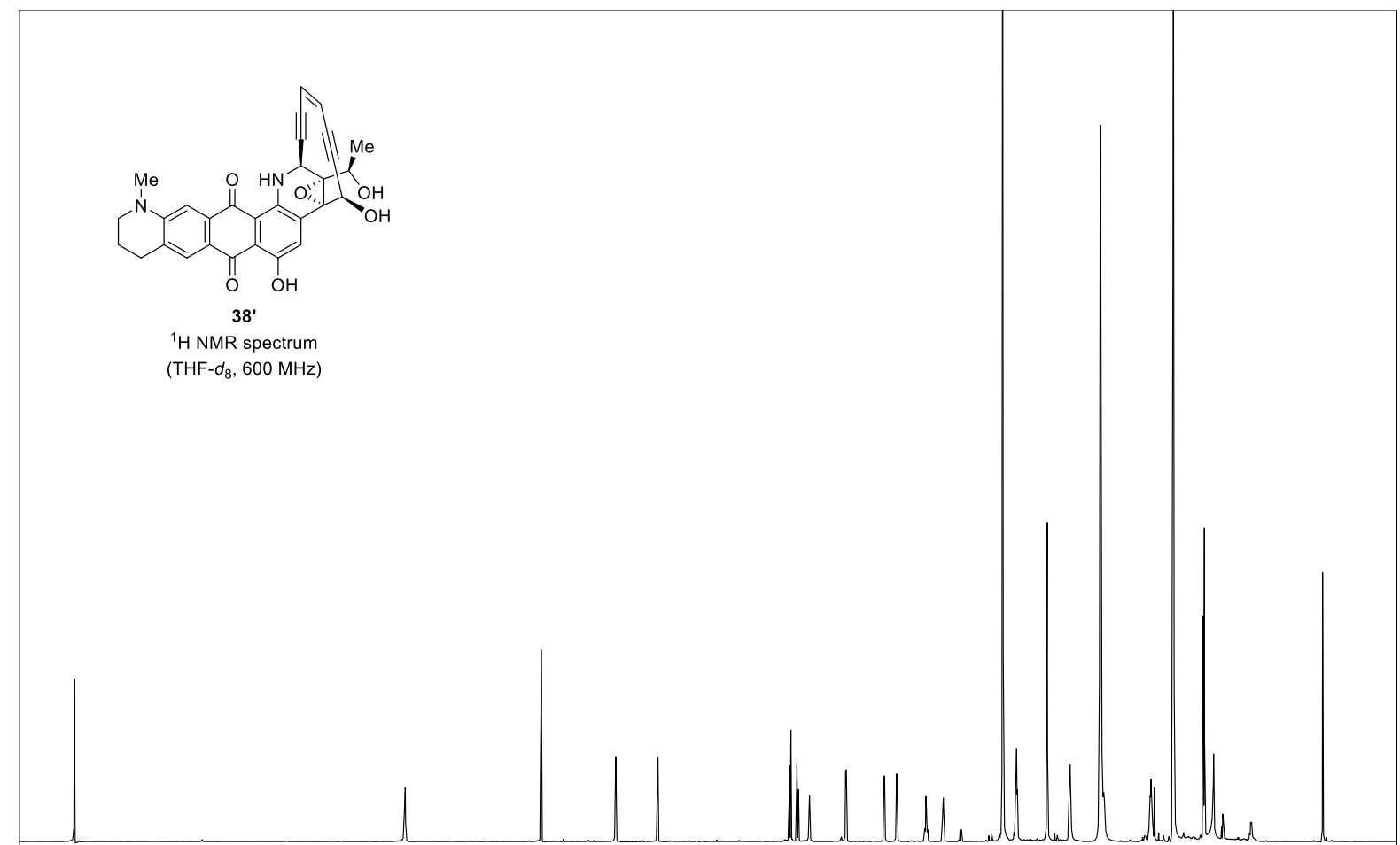

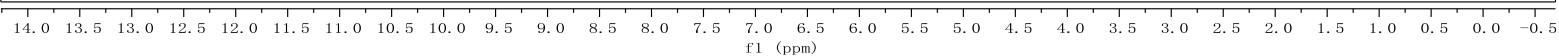

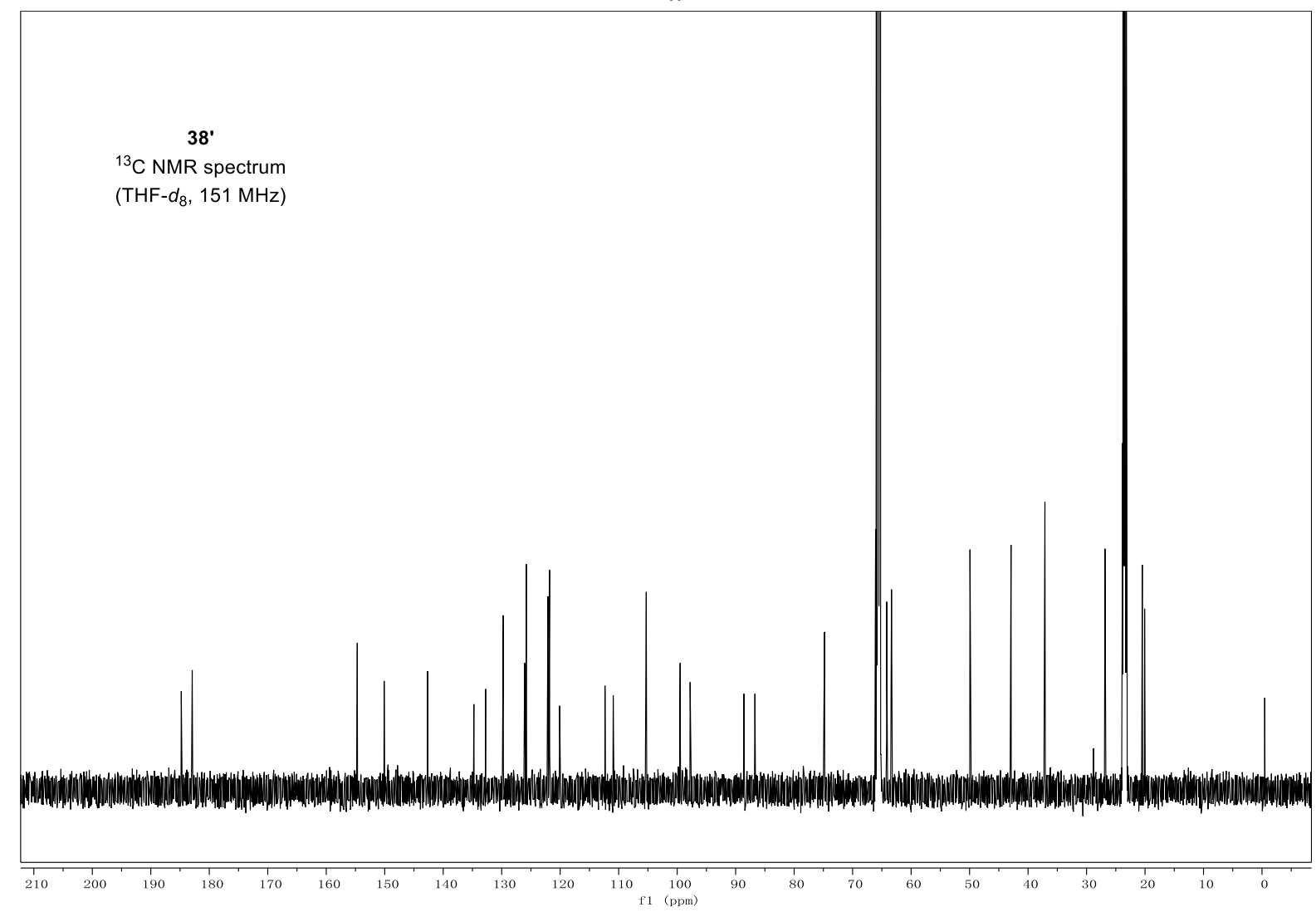




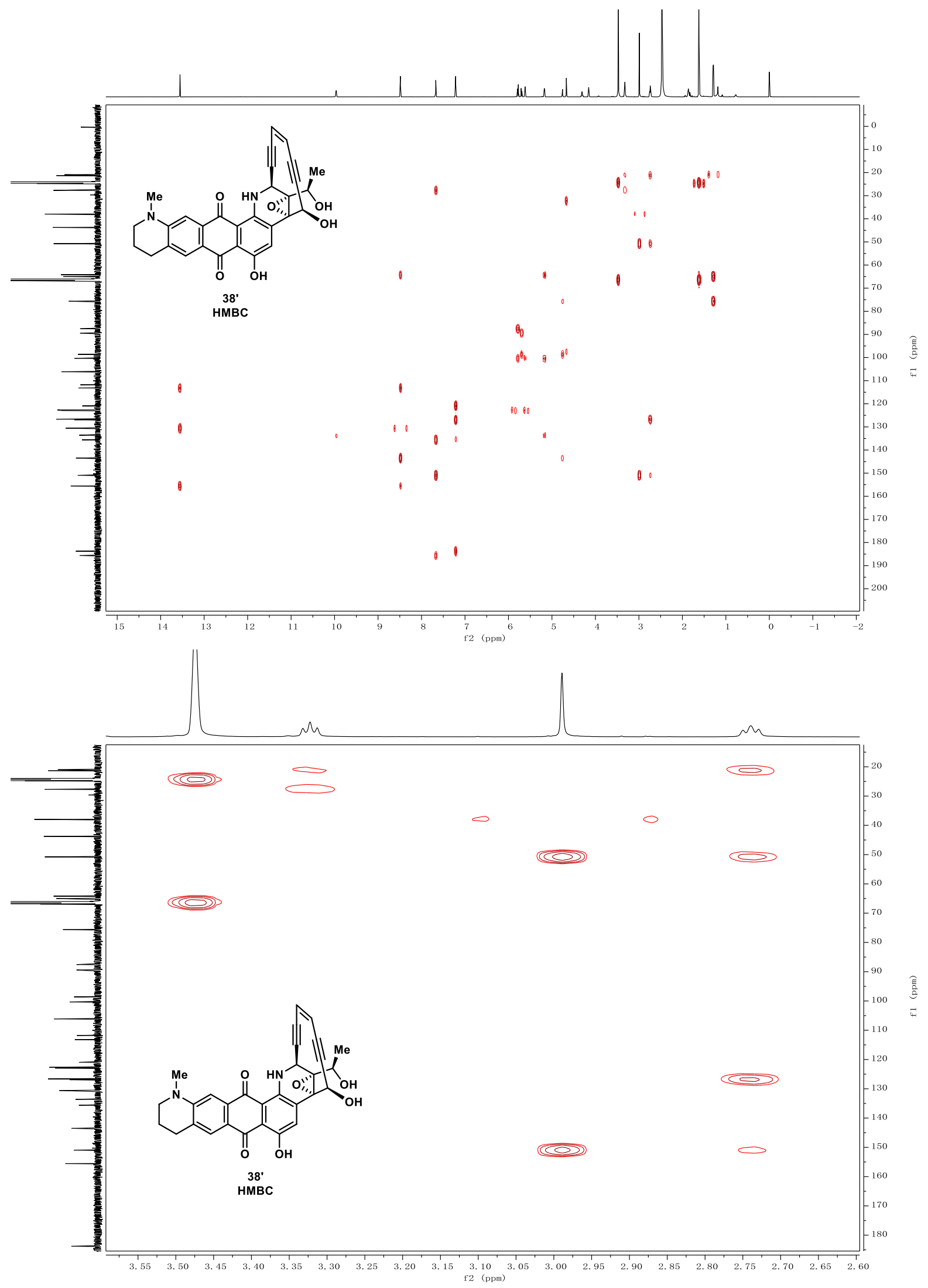




\section{References:}

${ }^{1}$ Fernández, D. F.; Gulías, M.; Mascareñas, J. L.; López, F. Iridium(I)-Catalyzed Intramolecular Hydrocarbonation of Alkenes: Efficient Access to Cyclic Systems Bearing Quaternary Stereocenters Angew. Chem., Int. Ed. 2017, 56, 9541-9545.

${ }^{2}$ Yan, X.; Chen, J.-J.; Adhikari, A.; Yang, D.; Crnovcic, I.; Wang, N.; Chang, C. Y.; Rader, C.; Shen, B. Genome Mining of Micromonospora yangpuensis DSM 45577 as a Producer of an Anthraquinone-Fused Enediyne Org. Lett. 2017, 19, 6192-6195.

${ }^{3}$ Nicolaou, K. C.; Wang, Y.; Lu, M.; Mandal, D.; Pattanayak, M. R.; Yu, R.; Shah, A. A.; Chen, J. S.; Zhang, H.; Crawford, J. J.; Pasunoori, L.; Poudel, Y. B.; Chowdari, N. S.; Pan, C.; Nazeer, A.; Gangwar, S.; Vite, G.; Pitsinos, E. N. Streamlined Total Synthesis of Uncialamycin and Its Application to the Synthesis of Designed Analogues for Biological Investigations J. Am. Chem. Soc. 2016, 138, 8235-8246.

${ }^{4}$ Yan, X.; Ge, H.; Huang, T.; Hindra; Yang, D.; Teng, Q.; Crnovčić, I.; Li, X.; Rudolf, J. D.; Lohman, J. R.; Gansemans, Y.; Zhu, X.; Huang, Y.; Zhao, L. X.; Jiang, Y.; van Nieuwerburgh, F.; Rader, C.; Duan, Y.; Shen, B. Strain Prioritization and Genome Mining for Enediyne Natural Products mBio 2016, 7, e02104-e02116.

${ }^{5}$ Yan, X.; Chen, J.-J.; Adhikari, A.; Teijaro, C. N.; Ge, H.; Crnovcic, I.; Chang, C.-Y.; Annaval, T.; Yang, D.; Rader, C.; Shen, B. Comparative Studies of the Biosynthetic Gene Clusters for Anthraquinone-Fused Enediynes Shedding Light into the Tailoring Steps of Tiancimycin Biosynthesis Org. Lett. 2018, 20, 5918-5921. 